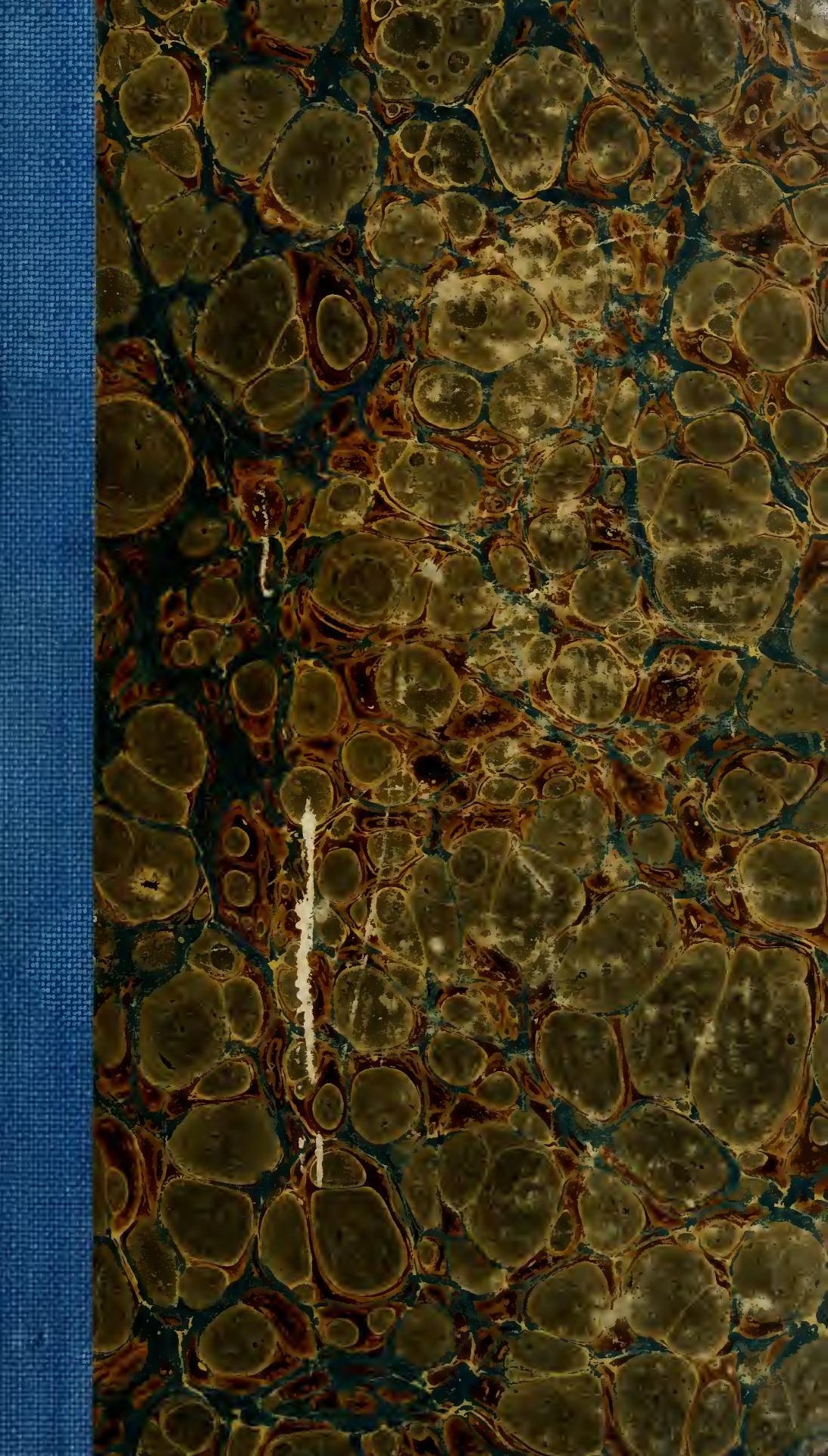




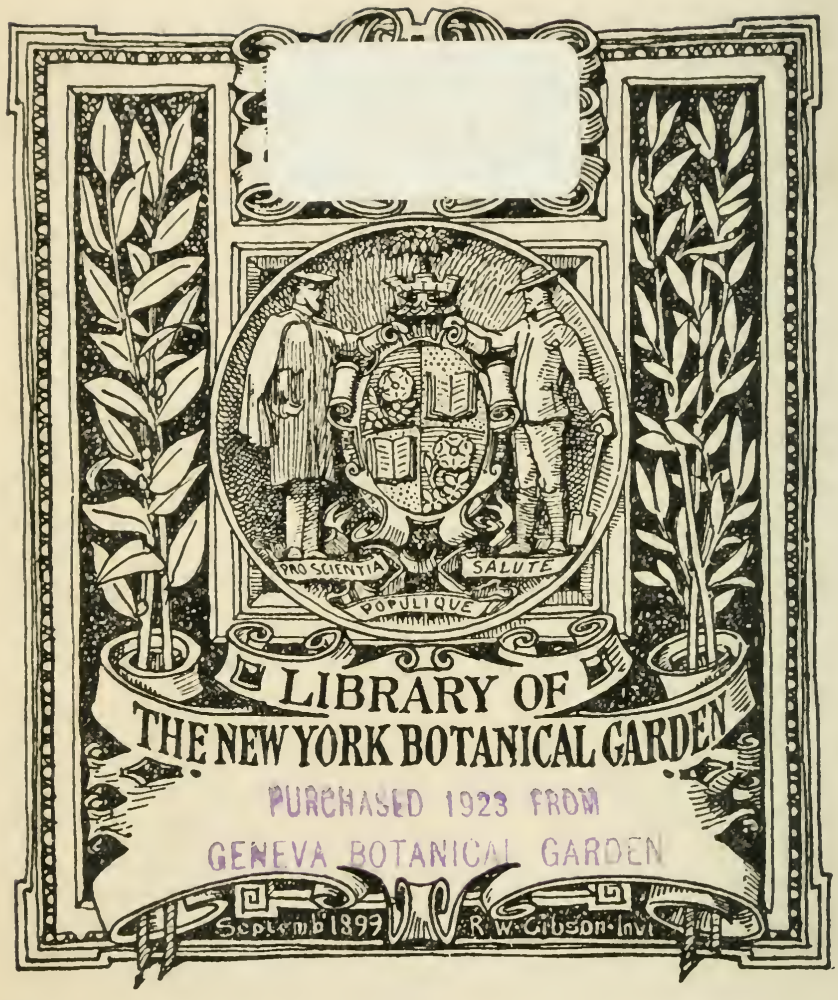


DUPLICATA DE LA BIBLIOTHÊQUE

DU CONSERVATOIRE BOTANIQUE DE GENEVE VENDU EN 1922 



\title{
FLORA BRITANNICA.
}

\author{
V O L. II.
}





\section{FLORA BRITANNICA,}

AUCTORE

JACOBO EDVARDO SMITH, M.D.

SOCIETATIS LINNAANEE PRESIDE,

IREIE LONDINENSIS, HOLA. UPSAL. TAURIN. OLYSSIP.

IHILADELPH.-PHYSIOGR. LUND. BEROLIN. PARIS.

ALIARUMQUE SOCIETATUM SOCIO.

" Nullius addictus jurare in rerba magiftri."

HOR.

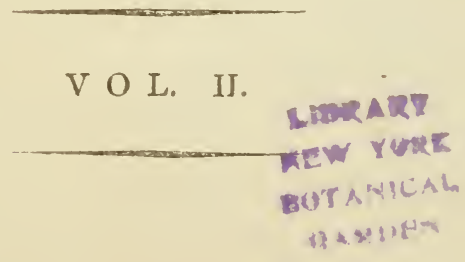

LONDINI:

TYPIS J. DAVIS, CHANCERY-LANE :

TENEUNT APUD J. WHITE, FLEET-STREET.

MDCCC.

1800 


$$
\begin{aligned}
& .5622 \\
& v .2
\end{aligned}
$$




\title{
Clafis $X$ : \\ DECANDRIA.
}

Stamina 10.

\section{MONOGYNIA.}

\author{
Stylus 1. \\ * Fl. polypetali.
}

20I. MONOTROPA. Pet. decem, quinque exteriora bafi gibba.

204. PYROLA. Pet. quinque. Antb. poris duobus.

* Fl. monopetali, rquales.

ऽ02. ANDROMEDA. Cor. ovata. Capf.quin. quelocularis.

203. ARBUTUS. Cor. ovata, bafi pellucida. Basca quinquelocularis.

Vaccinizum Myrtillus et uliginofun.

\section{DIGYNIA.}

Styli 2.

207. SCLERANTHUS. Cor. nulla. Cal. mo. nophyllus. Sem. duo.

205. CHRYSOSPLENIUM. Cor. nulla. Cal. coloratus. Caps. biroftris, polyfperma.

VoL, II.

B 206. SAXI- 


\section{$\left(43^{8}\right)$}

206. SAXIFraga. Pet.quinque. Call.quirs quepartitus. Caps. biroftris, polyfperma. 208. SAPONARIA. P'et. quinque. Cal. monophyllus, bafi nudus. Capf. oblonga.

209. DIANTHUS. Pet.quinque. Cal. monophyllus, bafi fquamofus. Cats. oblonga.

\section{TRIGYNIA.}

\section{Styli 3 .}

213. ARENARIA. Capf, unilocularis. Pet. integra, patentia.

212. STELlaria. Capf. uniloc. Pet. bipartita, patentia.

2i4. CHERLERIA. Capf. uniloc. Gland. nectarif. quinque ad bafin ftaminum. Pet. nulla ?

210. CUCUBALUS. Bacca uniloc. Pet. bifida, unguiculata.

21 I. SILENE. Capf. femitrilocularis. Pet. bifida, unguiculata. Cal. monophyllus.

\section{PENTAGYNIA.}

$$
\text { Styli } 5 .
$$

215. COTYLEDON. Capf. quinque, fquamá nectariferâ ad bafin. Cor. monopetala.

226. SEDUM. Capf. quinque, fquamâ nectariferâ ad bafin. Cor. pentapetala. 


\section{(439)}

25\%. OXALIS. Capf. quinquelocularis, angulata. Sem. bina, arillata. Pet. bafi connexa.

2rg. LYCHNIS. Capj. quinque- vel uni-locularis, polyfperma. Cal. tubulofus, membranaceus:

a r. AGROSTEMMA. Capif: unilocularis. Calo tubulofus, coriaceus.

220. CLRASTIUm. Capf: unilocularis. Pet. bifida. Cal. pentaphyllus.

2.r. SPERGULA. Capfounilocularis. Pet, in tegra. Cal. pentaphyllus. 


\section{DECANDRIA。}

\section{MONOGYNIA.}

201. MONOTROPA. G. Pl.214. Juf. 430 . Cal. nullus. Petala ro; horum quinque extcriora bafi excavata, mellifera. Capfula fupera, quinque-valvis. Quinta pars numeri quibufdam excluditur.

Hypopi- 1. MONOTROPA floribus lateralibus octandris: tys. terminali decandro.

Monotropa Hypopithys. Sp.Pl. 555. Hudf. I 75 . With. 398. Sibth. 136. Abbot. 92. Engl. Bot.t.69. Fl. Dan. t. 2:2.

Hypopitys lutea. Raii Syn 317.

Orobanche hypopytis lutea. Mentz. Pugill. t.3. Morif. Sect. I 2. t. I6. f. I 3 .

O. verbafculi odore. Phuk. Phyt.t. 209. f.5. Angl. Yellow Bird's-neft.

In fagetis vel pinetis, paratitica ad radices arborum. Frequent in the counties of Oxford, Bedford, Buckingham and Berks. Hudf. In Stoken-church woods. Ray. In Suffex, and near Tring, Hertfordhire. Dill. Near Uley, Gloucefterfhire. Rev. Mr. Baker. In a fir wood at Shottinam, near Stoke, Norfolk. Mr. Crowe.

Perennis. Fl. Junio.

Radix parafitica, carnofa, fquamofa, fibris tenuiffimis. Herba fucculenta, ftraminei coloris, marcefcens odorata, et demum nigricans. Caulis fimplex, teres, foliofus, apice racemofus. Folia fquamiformia, fparfa. Flores pedicellati ; laterales octofidi, fubinde fexfidi. Bractcæ folitariæ, foliis conformes. Pctala inæqualia, dccidua. Antheræ incumbentes. Stigma peltatum. 
202. ANDROMEDA. G. Pl. 2:9. JuJ. r60. Gartu. $t .63$ \&े 178 .

Cal. quinquepartitus. Cor ovata, ore quinquefido. Capfula fupera, quinquelocularis; diffepimentis e medio valvularum. Antbere poris duobus.

I. ANDROMEDA pedunculis aggregatis termi-polifolia. nalibus, foliis alternis lanceolatis revolutis fubtùs glaucis.

Andromeda polifolia. $S p . P l \cdot{ }_{564}$ Fl Lapp. t. 1. f. 2. Hudf. 176. With. 398. Dicks. H. Sici. fafc. 6. 4. Fl. Den. t. j4. Pallas. RoJ. t. 7 I.

Ledum paluftre noftras Arbuti flore. Raii Syn. 472.

Erica humilis rofmarinifolia, unedonis flore, capfulâ ciftoide. Pluk. Phyt.t. I75.f. I.

Angl. Marfh Andromeda, or Wild Rofemary.

In paludibus turfofis.

On moft peat bogs in the north of England and lowlands of Scotland.

Frutex. Fl. Junio.

Fruticulus humilis, ramofus, glaber. Folia fempervirentia, alterna, fubpetiolata, lanceolata, acuta, revoluta, venofa, latitudine varia, fubtùs glauca. Pedunculi terminales, aggregati, fubumbellati, bafi bracteati, uniflori. Flores nutantes, carnei. Calyx ruber. Antheræ fupernè biariftatæ. Capfula erecta, quinquefulcata. Semina plurima, exigua.

203. ARBUTUS. G. Pl. 220. Ju/. 160. Gartn. t. 59 .

Cal. quinquepartitus. Cor. ovata, ore quinquefido, bafi pellucida. Bacca fupera, quinquelocularis. Antbera poris duobus.
B 3
I. AR- 
Unedo. I. ARBUTUS caule arboreo, foliis glabris obtued ierratis, paniculâ terminali, baccis polyfipermis.

Arbutus Unedo. Sp. Pl. 566. Suppl. 238. Hudf. I77. With. 399. Disk. H. Sicc. fafi. 13. 16. Mhll. Ic, t. 48 .

Arbutus. Raii Syn. 46.4. Ger. em. 1 496. Camer. Epit. 168.

Angl. Strawberry tree, or Arbutus.

In rupibus calcareis Hibernia occidentalis. About the lake of Killarney pientifully. Mr. Crowe.

Fruter. Fl. Septembri.

Arbufcula formofa, fempervirens. Folia elliptico-lancenlata, obtufa, obtusè ferrata, glaberrima, petiolata, alterna. Paniculæ terminales, nutantes, multifloræ, bracteolatæ, glabræ. Calycis laciniæ obtufæ. Corolla albida, interdum rubicunda. Stamina fubulata, fubcomplanata, hirfuta. Antheræ rubræ, inflexo-pendulæ, obtufæ, bafi biariftatæ et poris duobus dehifcentes. Germen globofum, granulatum. Stylus cylindricus. Stigma peltatum. Bacca fragariæformis, tuberculata, rubra, fubdulcis, polyfperma.

alpira. 2. ARBUTUS caulibus procumbentibus, foliis rugofis ferratis.

Arbutus alpina. Sp. Pl. 566. Hudf. 177. With. 399. Ligbtf. 215. t, 11. fig. a. b. Fl. Dan. t. 73 .

Vaccinia pannonica five Vitis Idæa. Ger. em. 1416.

vitis Idæa. Clue. Hift. v. I. 6r. Angl. Blach-berried alpine Arbutus.

In petrofis aridis alpinis.

On mountains to the fouth of Little Loch Broom in Rois-thire, and between that lake and Loch Mari 
Mari abundantly, as well as on other highland mountains. Lighlff.

Frutex. Fl. Maio.

Caules lignofi, ramofi, proftrati, cortice deciduo. Folia alterna, obovata, acuta, ferrata, reticulato-venofa, rugofa, glabra; bafi in petiolum attenuata, et utrinque ciliata. Flores racemofi, terminales, albi ; pedunculi bafi bracteati, bracteis concavis, ciliatis. Baccæ globofæ, nigræ, umbilicatæ, pentafpermæ.

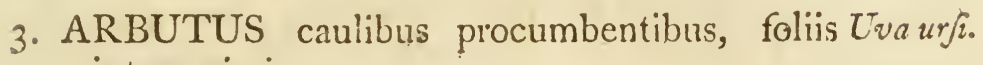
integerrimis.

Arbutus Uva urfi. S.p. Pl. 566, Fl. Lapp. t.6.f.3. Hiulf. 1 77. With. 399. Lightf. 216. t. II. fig. c. d. Fl. Dan. t. 33. Woodv. Med. Bot. t. 70.

Vaccinia rubra foliis myrtinis crifpis. Raii Syn. 457 .

V. urfi, five Uva urfi apud Clufium. Ger. em. 1416.

Uva urfi, folium. Pharmac. Lond. Angl. Red-berried trailing Arbutus,

In petrofis et ericetis aridis alpinis.

Common thraughout the highlands and weftern inles; alfo at the top of Eaft-Common-Waod, near Hexham, Northumbcrland, Ligbuf.

Frutex. Fl. Junio.

Caules lignofi, procumbentes, ramofi, cortice lævi. Folia alterna, petiolata, obovata, obtufa, integerrima, reticulato-venofa, glabra, fenspervirentia. Racemi terminales, breves, recurvi, fubpubefcentes, bractcolati. Flores incarnati. Baccæ depreffe, rubræ, pentafpermæ, aufterse.

\section{PYROLA. G. Pl. 221. Julf. I61. Gartn。 t. $\sigma_{3}$.}

Cal. quinquepartitus. Petala 5. Capsula firB 4 pera, 


\section{DECANDRIA-MONOGYNIA.}

pera, quinquelocularis, angulis dichifcens, polyfperma. Antbere poris duobus.

yotundi. I. PYROLA ftaminibus adfcendentibus, piftillo folia. declinato, racemo multifloro.

Pyrola rotundifolia. Sp. Pl. 567. Hud/. 175. With. 400. Engl. Bot. t. 213. Fl. Dan. t. 1 IO.

Pyrola. Raii Syn. 363. Ger. em. 408. Camer. Epit. 723. Bauh. Hift. v. 3. p. 2. 535. P. vulgatior. Cluf. Hift. v. 2. I16. Morif. sect. I . t. I . f. . .

Limonium. Fuchf. Hift. 467 .

L. fylveftre. Trag. Hift. 707 .

Angl. Round-leaved Winter-green.

In dumetis, præcipuè montofis, rariùs.

On a common at Bradivell, near Gorleftone, Suffolk. Mr. Wigg. In fome woods in Scotland. Mr. Donn.

Perennis. Fl. Julio.

Radix repens. Caules angulati, breves, foliofi. Folia alterna, petiolata, fubrotunda, obfoletè ferrata, glaberrima. Pedunculus terminalis, fpithamæus, bracteis fparfis veftitus. Racemus terminalis, erectiufculus, multiflorus. Pedicelii alterni, bafi bracteâ lanceolatâ. Flores nutantes, albi. Stamina adfcendentia ad latus floris fuperius. Antheræ inflexo-dependentes, quadrifulcatæ, muticæ, poris ad bafin duobus, fubtubulofis. Germen depreffum, quinquefulcatum. Stylus declinatus, apice recurvus, ftaminibus longior. Stigma rotatum, quinque-tuberculatum,

mincr. 2. PYROLA ftaminibus pifilloque rectis, floribus racemofis difperfis.

Pyrola minor. Sp. Pl. $56 \%$. Hzidf. 1 76. Whith. 401. Sibth. 136. Abbot. 92. Engl. Lot. t. 158. Fl. Dair. t. 55. Dill. in Raii syn. $3^{63}$. 


\section{Angl. Leffer Winter-green.}

In nemorofis montofis mufcofis.

In feveral parts of Scotland and the north of Yorkthire; alfo in Stoken-church woods, OxfordThire. This is the fuecies found in moft of the places of growth mentioned for the P. rotundifolia, as Hickfall woods, according to the obfervations of Mr. Dawfon Turner; Ray, Lightfoot, Curtis, Bobart and others having confounded it with that fpecies.

Perennis. Fl. Julio.

Habitus præcedentis, fed minor, Pedunculus ferè nudus, vel bracteà folitariâ tantùm munitus. Racemus erectus. Flores minores, frè rubicundi. Stamina undique patentia. Pori antherarum dilatati, nec tubulofi. Stylus breviffimus, rectus. Stigma peltatum.

3. PYROLA racemo unilaterali. Pyrola fecunda. Sp. Pl. 567. Hudf. I76. With. 40 r. Dickf. H. Sicc. fafc. 5. 8. Engl. Bot.1.517. Fl. Dan.t. 402.

P. folio mucronato ferrato. Raii Syn. 363 .

P. folio ferrato. Bank. Hift. v. 3. p. $2 \cdot 536$.

P. fecunda tenerior. Cluf. Hif. v. 2. I I 7. Ger. $\mathrm{em} .408$.

Ambrofia montana. Dalecb. Hift. ri 48 . Angl. Serrated Winter-green.

In fylvis alpinis mufcofis.

In fir or birch woods in the highlands of Scotland in inany places. Near Moffat. Rev. Dr. I alker. Foreft of Darnway on the hill of Dunnairn ncar Brodic-houfe. J. Brodie, Efq.

Perennis. Fl. Julio.

Caules ramofi, procumbentes, ramulis erectis, foliofis. Folia petiolata, ovata, acutiufcula, ferrulata, reticulatovenofa, 


\section{$\$ 46$ DECANDRIA-MONOGINIA.}

venofa, glabra. Pedunculi terminales, folitarii, palmares, bracteis paucis, fparfis, muniti. Racemi multiflori. Flores fecundi, virefcenti-albi, nutantes, pedicellis bafi bracteatis. Calyx parvus. Petala oblongi, concava. Antheræ ut in P. minore. Stylus longus, rectus, perfiftęus. Stigna peltatum, gibbofum.

wniffera. 4. PYROLA pedunculo unifloro.

Pyrola uniflora. Sp. Pl. 568. Engl. Bot. t. 146. With. 401. Fl. Dan.t.8.

P. quarta minima. Cluf. Hift. v. 2.118. Ger. em. 408.

P. minima alpina. Bauh. Hiff.v. 3.p.2.536. Aingl. Single-flowered Winter-grecn.

In fylvis alpinis, ræpiùs ad fontes mufcofos.

In fir woods near Brodie-houfe in Moray, Scotland. Mr. James Hoy. On the inlands of Harris and Bernera among the Hebrides, gathered there about the year $\mathrm{I}_{7} 8_{3}$ by Mr. Janies Hoggan. Ar. Gotobed.

Perennis. Fl. Julio.

Radix repens. Caules breves, finıplices, angulati, foliof. Folia obovata, obtufa, ferrulata, glabra, petiolata. Yedunculus folitarius, folia fuperans, ercetus, uniforus. Flos nutans, albus, in hoe genere maximus, fragrans, odore Convallarix majalis, fubinde rubro lineatus. Antherr tubis ad bafin binis, quibus pollen emittitur. Stylus rectus. Stignga quịnqueradiatum. 


\section{DIGYNIA.}

205. CHRYSOSPLENIUN. G. Pl. 222. Juff. 309. Gertn. t. 44.

Cal. quadrifidus feu quinquefidus, coloratus. Cor. nulla. Capfula biroftris, unilocularis, femiinferus, femibivalvis, polyiperma.

1. CHRYSOSPLENIUM foliis alternis.

Chryfofplenium alternifolium. Sp. Pl. 569. folium,

Hudf. I79. With. 401. Engl. Bot. t. 54.

Fl. Dan.t. 366. Dicks. H. Sicc. fafi. 3. 13 .

Saxifraga aurea, foliis pediculis oblongis infidentibus. Raii Syn. 158 .

S. aurea Dodonæi. Bauh. Hift. v. 3. p. 2. 70\%. Sedum rotundifolium paluttre, foliis pediculis longis infidentibus. Morif. fect. 12. t.8. f.8. Long Golden Saxifrage. Pet. H. Brit. t. 6. f. Io.

Angl. Alternate-leaved Golden Saxifrage.

Ad fcaturigines umbrofas, folo fpongiofo, rariùs.

On Poringland heath near Norwich. In feveral places in Yorkfhire, and other parts of the north of England. Below Polton-houfe oppofite to Laffivade, 5 mile; fouth of Edinburgh.

Perennis. Fl. Maio.

Radix fibrofa, repens. Herba fucculenta, fragilis. Cainlis triqueter, fimplex, bafi densè foliofus, medium verfus folio folitario. Folia alterna, petiolata, reniformia, suplicato-crenata, fubpilofa. Corymbus terminalis, dichotomus, foliofus. Flores aurei, plerumque quadrifidi, centralis tantum quinquefidus decandrus. 
oppofiti- 2. CHRYSOSPLENIUM folis oppofitis.

folium. Chryfofplenium oppofitifolium. Sp. Pl. 569. Hudf. 178. With. 402. Sibth. 137. $\Lambda b$ bot. 93. Curt. Lond. fufc. 2. t.27. Engl. Bot. t. 490. Fl. Dan. t. 365 .

Saxifraga aurea. Raii Syn. 158. Dod. Pempt. 3 г6. Ger. em. 341. Lob. Ic. 6 I 2.

Sedum paluftre rotundifolium, flore luteo. Mo. rif. fict. I 2. t. 8. f. 7 .

Golden Saxifrage. Pet. H. Brit.t.6. f. 9 . Angl. Oppofite-leaved Golden Saxifrage.

Ad fcaturigines umbrofas.

Perennis. Fl. Maio.

Habitus præcedentis, fed pallidior. Caulis fubinde ramofus. Folia oppofita, fubcordata, repanda, nec duplicato-crenata. Flores omnes fæpiùs quadrifidi, octandri.

206. SAXIFRAGA. G. Pl. 223. Juf. 309. Gertn. t. 36 .

Cal. quinquefidus, perfiftens. Cor. pentapetala. Capfula biroftris, unilocularis, polyfperma, inter roftra dehifcens.

* Foliis indivifis, caule fubrudo.

fellaris. I. SAXIFRAGA foliis ferratis, caule nudo ramofo, petalis acutis, capfulâ fuperâ.

Saxifraga ftellaris. Sp. Pl. 572 . Hudf. I 79. Wilb. 402. En?l. Bot. t. 167. Fl. Dan. t. 23. Jacq. Coll. v. 1. 202. t. I3. Scop. Carn. v. I. 292. t. 13 .

Geum paluftre rninus, foliis oblongis crenatis. Paii Syn. 354.

Sainiculæ alpinæ aliquatenùs affinis. Baub. Hift. ¿. 3. $.2 \cdot 708$. 


\section{Angl. Hairy Saxifrage.}

Ad rivulorum margines in umbrofis alpinis.

On the mountains of Wales, Scotland, and Weftmoreland abundantly.

Perennis. Fl. Junio, Julio.

Radix fibrofa, cæefpitofa. Caules bafi foliofi et fubradicantes, fupernè nudi, erecti, teretes, pilofi, apice paniculati. Folia congefta, obovato-cuneiformia, apice incifo-ferrata, margine præcipuè pilofa. Panicula pauciflora. Bracteæ lanceolatæ, feu trifidæ. Calyx reflexus. Petala ovata, unguiculata, trinervia, alba, maculis binis, tranfverfis, flavis. Stamina fubulata, bafi connexa. Germen omninò fuperum, ovatum. Capfula membranacea, nervofa, glabra. Semina lineis clevatis, tuberculatis, longitudinalibus, fcabra.

2. SAXIFRAGA foliis obovatis ferratis, caule nivalis. nudo, floribus congeftis, capfulâ femiinferâ. Saxifraga nivalis. Sp. Pl. 573. Fl. Lapp.t.2. f. 5. Hudlf. 180. With. 403. Lighlf. $22 \mathrm{1}$. t. 1 2. Engl. Bot. t. 440. Dickf. H. Sicc. fafc. 1. 7. Fl. Dan. t. 28.

S. foliis oblongo-rotundis dentatis, floribus compactis. Raii Syn. $35+$ t. 16. f.I. Angl. Cluftered Alpine Saxifrage.

In fummis alpibus Scoticis et Cambro-britannicis.

North Wales. Mr. Griffith. Clcfts of rocks on the top of Ben Lomond.

Perennis. Fl. Julio.

Habitus precedentis, fed folia latiora, magifque carnofa. Caulis nudus, apicem verfus pilofo-vifcidus. Flores congefti, bafi bracteâ lanceolatâ. Calyx femifuperus. Petala viridi maculata.

Variat caule fubinde uniforo, frequentiùs tamen ramofo, floribus paniculatis; at femper a præcedente certo certiùs diftinguenda germine femiinfero, nec fupero. 
umbrofa. 3. SAXIFRAGA foliis obovatis fubrctufis cartilagrinco-crenatis, caule nuclo paniculato, capiulâ luperâ.

Saxifraga umbrola. Sp. Pl.574. With. 403. Hull. 92. Engl. Bot. t.663.

Geum folio fubrotundo minori, piftillo floris rubro. Magnol. Hort. 88. 1 . 1t. (majori) Mill.Ic.t. 141. f. 2. Dill. in Raii Syn. 355 . Angl. London Pride. Nonc-fo-pretty.

In montibus.

On a mountain called the Mangerton, two miles from Killarney. Dr. Molyneux. Mountains rear Sligo. Mr. Lbreyd. On Croagh Patrick in the county of Mayo, 2666 feet above the level of the fea. A. B. Lambert, $E / q$. In Thorp Arch woods near Wetherby. Sir T. Frankland and Dr. White. Betwixt Arncliffe and Horton in Craven, York Thire. Mr. Bingley.

Perennis. Fl. Junio.

Folia plurima, aggregata, patentia, petiolata, obovata, obtufa, in petiolum decurrentia, cartilagineo-crenata vel ferrata, lævia, glaberrima. Scapus fpithamæus, erectus, ruber, pilofus, paniculatus. Flores erecti. Bracter parvæ, alternæ. Calyx demùm reflexus. Petala obovato-lanceolata, alba, fanguineo flavoque punctata. Germen omninò fuperum, rofeum. Capfula ventricofa, apice purpurea.

* Foliis indivifis, caule foliojo.

-ppofiti- 4. SAXIFRAGA foliis caulinis ovatis oppofitis imbricatis : fummis ciliatis.

Saxifraga oppofitifolia. Sp.Pl.575. Fl. Lapp. t. 2. f. 1. Hudf. 180. With. 404. Engl. Bot. t. 9. Dicks. H. Sicc. fafc. 2.6. Curt. Lond. fafc. 6. t. 27. Fl. Dan. t. 34.

S. alpina ericoides flore cæruleo. Raii Syn. 353. 
Sedum alpinum ericoides cæruleum. Bauh. Hift. v. 3. p. 2.694. Moris. Ject. I2. t. 10. $f \cdot 36$.

An $\%$. Purple Saxifrage.

In rupibus et petrofis alpinis.

On the weft fide of the fummit of Ingleborough hill, York?hire. Dr. Richardfon. On Snowdon plentifully. Mr. Lbrerd. On Ben Lomond, and other Scottifh mountains.

Perennis: Fl. Aprili.

Caules longiffimi, proftrati, cæfpitofi, vel e fcopulis pred ruptis penduli, ramofi, foliofi, ramulis floriferis erectis. Folia oppofita, imbricata, obtufa, carnofa, concava, carinata, ciliata; floralia remotiora. Flores terminales, folitarii, purpurei, formofi. Petala nervofa, obovata. Germen feminferum.

5. SAXIFRAGA foliis caulinis lanceolatis alternis Hircsinermibus, caule erecto, germine ovato fu-lus. pero.

Saxifraga Hirculus. Sp. Pl. 576. Hudf. I8I. With. 404. Curt. Lond. fajc. 6. t. 26. Fl. Dan. $t .200$.

S. n. 972. Hall. Hift. v. I. 417. t. II.

S. anguftifolia autumnalis, flore luteo guttato. Breyn. Cent. I. 48.

Geum anguftifolium autumnale, flore luteo guttato. Dill. in Raii Sym. 355 .

Sedum anguftifolium autumnale, flore luteo guttato. Morif. Sect. 1 2. t. 8. f. 6.

S. paluftre Nardi Celticæ foliis flore luteo. Ibid. $f \cdot 5$.

Chamæciftus Frificus. Ger.em. 1284: Angl. Yellow Marth Saxifrage.

In paludibus turfofis rariffimè. 
On Knutsford moor, Chefhire; Dr. Kingftone. Dill.

Perennis. Fl. Augufto.

Radix fibrofa. Caules ereeti, fpithamai, teretes, foliofi, pilofi, bafi ramofi, ramulis brevibus, decumbentibus. Folia alterna, lanceolata, obtufa, integerrima, utrinque glabra, margine fubinde pilis mollibus ciliata. Panicula fubtriflora, terminalis. Calyx reflexus. Petala obovata, nervofa, aurea, bafi appendiculata, ad medium ufque croceo maculata. Germen ovato-oblongum, omninò fuperum.

airoides. 6. SAXIFR AGA foliis caulinis lincaribus alternis dentato-ciliatis, caule bafi decur:bente, germine depreffo femiinfero.

Saxifraga aizoides. Sp. Pl. 576 . Hudf. ed. r. I 58. With. 404. Engl. Bot. t. 39.

S. autumnalis. Hudf. 180. Ligbtf. 222. Fl. Dan. t. 72. Scop. Carn. v. 1. 293. t. I4.

S. alpina angufto folio, flore luteo guttato. Raii Syn. 353 .

Scdum alpinum primum. Che. Pann. 485. Ger.em. 5 I 6.

S. alpinum flore pallido. Morif. Sect. I2. t. 6. $f \cdot 3$.

S. parvum montanum luteum. Baub. Hift.v.3. p. I. 693 .

Angl. Yellow Mountain Saxifrage.

Ad rivulos alpinos copiosè.

On moft of the Weftmoreland and Scottifh mountains.

Perennis. Fl. Julio, Augufto.

Caules aggregati, bafi decumbentes atque ramofi, foliofi, teretes, glabriufculi, apice crecti, paniculati. Folia alterna, teffilia, lineari-oblonga, obtufa, margine plerumque dentato-ciliata. Panicula vel fimplex pauciflora, vel ramofa multiflora, foliofa. Calyx, etiam in fructu, erecto- 
erecto-patens. Petala lingulata, enervia, aurea, rubro' punctata. Germen depreflum. Capfula ovata, femiinfera.

$$
\text { *** Foliis lobatis. }
$$

7. SAXIFRAGA foliis reniformibus lobatis, caule granula: paniculato, radice granulatâ, germine femi- $t a$. infero.

Saxifraga granulata. SP. Pl. $576 . H_{u d f .} 182$. With. 405. Relh. 166. Sibth. 137. Abbo6. 93. Curt. Lond. fafc. I. t. 30. Dickf. H. Sicc. fasc. 5. 5. Engl. Bot. t. 500. Freeman. Ic. t. I. Woodv. Suppl. t. 232.

S. rotundifolia alba. Raii Syn. 354.

S. alba. Ger. em. 84 i.

S. major feu alba. Fuchf. Hift. 747 . Saxifragia. Brunf. Herb. v. I. 185 . Angl. White Saxifrage.

In pratis et pafcuis, folo imprimis glareofo.

Perennis. Fl. Maio.

Radix granulata. Caulis erectus, teres, pubefcens, foliofus, fubvifcofus, paniculatus, rubicundus. Folia reniformia, fubcarnofa, lobata et incifa; caulina alterna, fubfeffilia; radicalia petiolata. Calyx erectus, pilofoglandulofus.. Petala obsvata, nervofa, nervis ramofis, alba, impunctata. Germen femiinferum.

Flore pleno in hortis vulgaris eft.

8. SAXIFRAGA foliis palmatis petiolatis, caule cerma. bulbifero, germine fupero, petalis retufis. Saxifraga cernua. Sp. Pl. 577 . Fl. Lapp.t.2. f. 4. Dickf. Tr. of Linn. Soc. v. 2. 290. With. 405. Hull. 93. Engl. Bot. t. 664. Saxifraga. Fl. Dan.t. 390. Angl. Drooping bulbous Saxifrage.

In rupibus irriguis alpinis.

On the fummit of Ben Lawers. Mr. Dickfon. VOL.II. C. Perennis. 
Perennis, Fl. Julio.

Radix fquamata. Caulis fpithamxus, ercetus, teres, folífus, glabriufculus, plerumque fimplex uniflorus, in. terdum ramofus. Folia petiolata, alterna, reniformia, palmato-lobata, fubcarnofa, glabriufcula ; fuperiora indivifa et feffilia, axillis gemmiparis. Flos terminalis, folitarius, nutans, albus. Calycis lacinire ellipticæ, crectx, pilofx. Petala unguiculata, retufa et fubemarginata, trinervia, nervis bafi connatis, fuperno ramofis et evanefcentibus. Germen omninò fuperum.

Talis eft planta noftra, quæ iconi et defcriptioni in Florâ Lapponicâ optimé refpondet. Fl. Dan. t. 22 alia fpecies videtur, cui petala acutiufcula funt, caulis nunquam non fimplex, uniflorus.

rivula- 9. SAXIFRAGA foliis palmatis petiolatis; fummo ris. fpatulato, caule paucifloro, radice fibrosâ, germine femiinfero.

Saxifraga rivularis. Sp. Pl. 577. Fl. Lapp. n. I74. t. 2. f. 7. ed.2. p. 142. Fl. Dan t. 1 i 8.

Angl. Alpine Brook Saxifrage.

In rivulis, et rupium fiffuris irriguis, alpinis.

On Ben Nevis, Scotland. Dr. Torinfon.

Perennis. Fl. Junio, Julio.

Radix fibrofa. Caulis plerumque folitarius, biuncialrs, erectus, fimplex, biflorus, interduin quinquetlorus. Folia longè petiolata, alterna, fubreniformia, palmata, tri-vel quinque-loba, glabra; fumma fpatulata, indivifa. Flores erecti, parvi, albi. Calyx bafi pilofo-vifcidus. Petala acuta, uninervia. Germen ovatum, feminferum.

tridacty - 10. SAXIFRAGA foliis cuneiformibus trifidis lites. quinquefidife alternis : fummis indivifis, caule paniculato, germine infero.

Saxifraga tridactylites. Sp. Pl.578. Itzidf. I82. With. 406. Rell. 166. Sibih. 138. Ligbtf. 224. Abbot. 93. Ciurt. Lond. fafi. 2. t. 28. Dickf. 
Dickf. H. Sicc. fafce. 8. ro. Engl. Bota t. $50 \mathrm{x}$.

S. verna annua humilior. Raii Syn. 354 .

Paronychia rutaceo folio. Ger. em. 624.

Angl. Rue-leaved Saxifrage.

In muris, tectis, et aridis incultis.

Annua. Fl. Maio.

Radix fibrofa. Herba fucculens, pubefcens, vif́cida, ru-

bicunda, magnitudine maximè varia. Folia palmata, bafi anguftata. Panicula erecta, foliolofa. Flores parvi, albi. Petala obovata, uninervia. Germen omnind inferum, urniforme.

II. SAXIFRAGA foliis radicalibus aggregatis ceppito. carnofis linearibus integris trifidifve fubtus $j a$. nervofis, caule nudiufculo fubbifloro.

Saxifraga cæfpitofa. Sp. Pl. 578. Scop. Carn.

v. 1.293. t. I 4 .

Angl. Tufted Alpine Saxifrage.

In rupibus alpinis.

On alpine rocks above lake Idwell in Carnarvonthire, rare. J, IE. Griffith, ESq. in Herb. Soc. Linn.

Perennis. Fl. Junio.

Radix cæfpitofa. Caulis biuncialis, erectus, parùm foliofus, teres, pilofus, fubbiflorus. Folia radicalia congefta, numerofa, carnofa, ciliata, linearia, obtufa, integra vel trifida, fubtus triplinervia; caulina alterna, fæpius indivifa, fubinde tripartita. Flores terminales, pedunculati, erecti, flavefcentes. Calyx hemifphæricus, pilofovifcidus, laciniis obtufis, denudatis. Petala obovata, integerrima, triplinervia. Capfula omninò ferè infera.

12. SAXIFRAGA foliis radicalibus aggregatis mo/chamembranaceis lineari-lanceolatis integris tri- ta.

$$
\text { C. } 2
$$

fidifve 
fidifve triplincrviis, caule nudiufculo fub. bifloro.

Saxifraga mofchata. Murr. in Linn. Syft. Veg. ed. 14. 414. Jaiq. Mifc. v. 2. 128. t. 21. f. 21 ? With. 406 .

S. cæefpitofa. Hudf. I $8 \mathrm{I}$ ?

S. n. 985 . Hall. Hift. v. I. 421 .

Saxifragia pyrenaica, foliis partim integris, partim trifidis. Hall. Opufc. It. Helvet. t. I. fingl. Mu1ky Alpine Saxifrage.

In rupibus alpinis.

Mountains above Amblefide, Weftmoreland ?

Perennis. Fl. Junio, Julio.

Habitus præcedentis, fed folia longè tenuiora, omnia ferè indivifa, ultra medium triplinervia. Petala flaveola, triplinervia. Germen inferum. Herba odorata, vifcida. Exemplaria fpontanea nunquam vidi. Locus in Flora Britannicâ e Cl. Witheringii auctoritate pendet. Figura apud Jacquinum minùs quam Halleriana placet, et mihi dubia videtur.

palmata. 13. SAXIFRAGA foliis pilofis palmatis quinque. fidis trifidifve, caule foliofo paniculato, petalis fubrotundis.

Saxifraga palmata. Engl. Bot. t. 455 .

S. petræa. With. 890.

S. Fl. Dan.t. 7 I.

Angl. Palmate Saxifrage.

In rupibus alpinis.

Rocks of Cwm idwell, Carnarvonnhire. J. W. Griffith, E/y.

Perennis. Fl. Máaio, Junio.

Radix cæfpitofa. Caulis palmaris, erectus, teres, pilofus, parum foliofus, paniculatus, ftolonibus ad bafin erectiufculis, foliolis. Folia palnata, bafi anguftata et elongata, pilofa; radicalia quinquefida, rariùs feptemfida, congefta ; 
congefta ; caulina alterna, trifida, laciniis omnibus fubellipticis, nec linearibus. Panicula eresta, terminalis, minus patula, 5-7-flora. Bractex trifidre, vel indivifa. Calyx pilofus, vifcidus. Petala flavefcenti-albida, fubrotunda, parùm acuta, triplinervia. Germen femiinferum.

14. SAXIFRAGA foliis linearibus integris tri-bynoifidifve, ftolonibus procumbentibus, caule nu- des. diufculo, petalis elliptico-oblongis.

Saxifraga hypnoides. Sp. Pl. 579. Hudf. 182. IVith. 407. Liglatf. 224. Fl. Dan. t. 348. Engl. Bot.t. 454. Freeman. Ic. t. 2.

S. mufcofa, trifido folio. Ruiii Syn. 354 .

Sedum alpinum trifido folio. Morif. Sect. I 2. t. 9. f. 26 .

Tridactylites alpina. Baub. Hift. v. 3. p. 2. Angl. Moffy Saxifrage, or Ladies' Culhion.

In rupibus alpinis.

On the mountains of Derbythire, Weftmoreland, Scotland and Wales in many places.

Perennis. Fl. Maio, Junio.

Radix fibrofa. Stolones cæfpitofæ, procumbentes, implexæ, foliofæ, pilofæ. Caulis folitarius, erectus, teres, nudinfculus, paniculatus. Folia alterna, linearia, acuta, fubciliata; inferiora femitrifida, laciniis divaricatis; caulina indivifa. Panicula laxa, paucifora, vifcida. Bracteæ lanceolatæ. Calycis laciniæ lanceolatæ, acutx. Petala alba, elliptico-oblonga, obtufa, triplinervia, nervo centrali fubinde ramofo. Germen femiinferum.

\section{0\%. SCLERANTHUS. G. Pl. 224. JuJ. 314. Gertu. t. 126 .}

Cal. monophyllus, inferus. Cor, nulla. Semina duo, calyce inclufa. 
annuus. 1. SCLERANTHUS calycibus fructûs patulis acutis, caulibus patentibus.

Scleranthus annums. Sp. Pl.580. Hudf. 178 . IIith. 407. Relh. 165. Sibth. 138. Engl. Bot.t.35r. Fl. Dan.t.504.

Polygonon, Germanis Knawel. 'Trag. Hift. 393. Polygonum felinoides, five Knawel. Ger. cm. 566. Knawel. Raii Syn. 159.

Upright Knawcil. P'et. H. Brit. t. 9. f. 6 . Angl. Annual Knawel.

In arvis arenofis frequens.

Annua. Fl. Julio.

Radix fibrofa, parva. Caules plurimi, patentiffimi, teretes, fubpubefcentes, foliofi, fupernè ramofi. Folia oppofita, comnata, linearia, acuta, bafi ciliata. Capitula terminalia, foliofa. Calyx decemcoftatus, femiquinquefidus, laciniis acutis, patentibus, margine fubmembranaceis. Stamina calyce breviora, inæqualia, quandoque numero incompleta. Gernien ovatum, fuperum. Styli patentes. Stigmata pubefcentia. Seminum rudimenta certè duo, quorum alterum fæpiùs abortit.

peremins. 2. SCLERANTHUS calycibus fructûs claufis obtufis, caulibus procumbentibus.

Scleranthus perennis. Sp. Pl. 580 . Hudf. I78. With. 407. Engl. Bot. t. 352 . H. Dan. t. $56_{3}$.

Knawel incanum flore majore, perenne. Raii Syn. I60. t. 5. f. I.

Alchimilla gramineo folio, fore majore. Vaill. Par.t. I. f. 5 .

Saxifraga anglicana alfinefolia. Ger. em. 567. Spreading Knawell. Pet. H. Brit. t. 9. f. 7 . Angl. Perennial Knawel.

In campis elatis arenofis. 
About Elden and Bury in Suffolk. Found near Snettifham in Norfolk by Mr. Crowe. W Vith.

Perennis. Fl. Oetobri, Novembri.

Habitus præcedentis, fed caules proftrati, color totius herbæ glaucus et fubmicans, demum rubicundus. Folia quandoque pubefcentia. Calyx margine dilatatus, albus, dentibus obtufis, incurvis. Stamina vix omnia perfecta.

208. SAPONARIA. G. Pl. 224. Julf.302. Gartn. t. I 30.

Cal. monophyllus, nudus. Petala quinque, unguiculata. Capfula fupera, oblonga, fubunilocularis.

I. SAPONARIA calycibus cylindricis, foliis el-oficina-
liptico-lanceolatis. Saponaria officinalis. Sp.Pl.584. Hudf. 18.3. With. 408. Relh. 167. Sibth. 138. Curt. Lond. fufc.2.t.29. Fl. Dan. t.543. Woodv. Suppl. t.25I.

Saponaria. Ger.em. 444.

Lychnis Saponaria dicta. Raii Syn. 339.

B. L. Saponaria dicta, folio convoluto. Raii Syn. 339.

Saponaria concava anglicana. Morif. Sect. 5 . t. 22. $f .53$.

Gentiana concava. Ger. em. 435 .

G. folio convoluto. Bauh. Hijt.v.3.52 r. Angl. Soapwort,

In pratis et ad fepes,

Perennis. Fl. Augufto, Septembri.

Radix longiffima, ramofa, ftolonibus repentibus. Caules fefquipedales, teretes, foliofi, glabri, apice paniculati. Folia oppofita, connata, elliptico-lanceolata, integerrima, trinervia, glabra. Panicula hemifphærica, multi$\mathrm{C}_{4}$ flora, 
flora, bractcolata. Flores rofei, fuaveolentes. Petala integra, fauce coronata.

Variat floribus plenis.

209. DIANTHUS. G. Pl. 225. Jug. 302. G.ertn. t. 129.

Cal. cylindricus, monophyllus, bafi fquamatus, Petala 5, unguiculata. Capfula cylindrica, fupera, unilocularis.

\section{* Flores aggregati.}

Armeria. I. DIANTHUS floribus aggregatis fafciculatis, fquamis calycinis lanceolatis villofis tubum xquantibus.

Dianthus Armeria. Sp. Pl. 586 . Hudf. 183 . With. 409. Sibth. I39. Engl. Bot. t. $31 \%$. Fl. Dan. t.230. DickJ. H. Sicc. frifc. 16.8.

Caryophyllus latifolius barbatus minor annuus, flore minore. Raii Syn. 337 .

C. pratenfis. Ger. em. 594 .

Viola barbata anguftifolia. Dalech. Hift. 8 1о. Bauh. Hift. v. 3.p.2.335.

Angl. Deptford Pink.

In pafcuis et ad fepes, folo glareofo.

Annua. Fl. Julio, Anguifo.

Radix parva, fufiformis. Caulis pedalis, teres, foliofus, pubefcens, fupernè ramofus, ramis ftrictis. Folia Ineari-lanceolata, carinata, integerrina, pubefcentia; infima fpatulata. Flores terminales, congefti, erect, inodori. Calyx gracilis, pubefcens, fquamis quaternis, longitudine tubi, apice fubpatentibus, bafi connatis. Petalorum limbus ellipticus, ferratus, ruber, albo punctatus.

scolifer. 2. DIANTHUS floribus aggregatis capitatis, irfuamis calycinis ovatis obtufis muticis fcariofis tubum fiperantibus. 
Diunthus prolifer. Sp. Pl. 587. IIudf. 184. With. 409. Fl. Dan. t.221.

Caryophyllus fylveftris prolifer. Dill. in Raï Sy.n. 337. Seguier. Veron. t. 7.f. 1 .

Armeria prolifera. Ger. en. 599. Lob. Ic。 p. I. 449 .

Betonica coronaria fquamofa fylveftris. Baub. IIff. v. 3. p. 2. $335^{\circ}$ Angl. Proliferous Pink.

In pafcuis glareofis rarius.

In Selfey ifland, Suffex; Mr. Manningham. Diit. In the borders of a field oppofite the mill out of St. Auftin's gates, Norwich. Mr. Humplarey. In a marle pit at Landridge hill, Hanley Caftle, Worcefterhire, Mr. Ballard, With.

Annua. Fl. Julio.

Radix parva, attenuata. Caulis erectus, frictus, vix ramofus, foliofus. Folia linearia, margine fcabra. $\mathrm{Ca}-$ pitulum terminale, multiflorum, fquamis calycinis communibus maximis, fcariofis, quaternis ; propriis binis, anguftioribus, compreffo-carinatis. Flores parvi, inodori, pallidè purpurei, ephemeri. Petala emarginata.

* Flares Solitarii, plures in eodem caule.

3. DIANTHUS floribus folitariis, fquamis caly-Caryvcinis fubrhombeis brevifimis, petalis crenatis pbyelluw. imberbibus.

Dianthus Caryophyllus. Sp. Pl. 587. Hudf. 184. With. 410. Tr. of Linn. Soc. v. 2. 299. Engl. Bot. t. 2 I 4.

Caryophyllus fimplex flore minore pallidè rubente. Raii Syn. 336.

C. fylveftris fimplex. Ger. em. 59 I.

3. Dianthus arenarius. Hudf. 185 , fynonymis erponeis, Conf. Tr. of Linn. Soc. v. 2. 296. 
Caryophyllum rubrum, flos. Pharmac. Lond. Angl. Clove Pink, or Carnation; $\beta$ Pheafant's eyc Pink.

In muris antiquis.

On Rochefter, Deal, Sandown and other caftles plentifully. Hudf. and Engl. Bot.

Perennis. Fl. Julio.

Radix fublignofa. Herba glauca. Caules erecti, ramofi, paniculato-multiflori. Folia linearia, canaliculat $x$; fupra bafin denticulata; apicen verfus integerrima, levia. Flores terminales, folitarii, ereeti, carnei, odorì. Calyx ftriatus, fquamis quaternis, tubo quadruplò brevioribus, rhombeis, mucronulatis, nervofis; interioribus latiffimis, et ferè cuneiformibus. Petala inæqualiter crenata, ore lævia.

Var. $\beta$ humilior eft, floribus albis, magis acute crenatis, ad os circulo atro-purpureo notatis.

dclicides.4. DIANTHUS floribus folitariis, fquamis calycinis ovato-lanccolatis acutis fubbinis, foliis obtufufculis fubpubefcentibus, petalis crenatis.

Dianthus deltoides. Sp. Pl. 588 . Hudf. 184 . With. 410. Relh. 167. Abbot. 94. Engl. Bot. t. 61. Tr. of Linn. Soc. v. 2. 300. Lightf. 225. Fl. Dan.t. 577.

Caryophyllus minor repens noftras, Roii Syn. 335 .

C. montanus purpureus. Ger. em. 593 .

B. Dianthus glaucus. Sp. Pl. 588. Lightf. 225. Tunica ramofior, flore candido cum corollà purpureâ. Dill. Elth. 1. 298. f. 384 . Angl. Maiden Pink.

In pafcuis et marginibus herbidis agrorum, folo glarcofo vel fabulofo.

B. In the King's Park at Edinburgh. Lightf. 
Ferennis. Fl. Julio ad Oetobrem ufque.

Radix fublignofa, cæepitofa. Caules plurimi, adfcenden. tes, fubramofi, foliofi, leviter pubefcentes. Folia lineari-lanceolata, fubpubefcentes, margine fcabra. Flores folitarii, parvi, rofei vel carnei, ore circulo purpureo. Calyx friatus, fubpubefcens, fquamis binis, ovato-lanceolatis, mucronatis, tubo duplò brevioribus. Petala inæqualiter crenala, fauce glabra.

$\checkmark$ ar. $\beta$ gaudet foliis magis glaucis, fquamis calycinis fæpiùs quaternis, petalis albis nec rofeis, circulo purpureo nihilominus notatis.

$$
\text { *** Caule unifloro, berbaceo. }
$$

5. DIANTHUS caulibus unifloris, fquarnis caly- cafus. cinis fubrotundis brevibus, petalis crenatis pubefcentibus, foliis margine fcabris.

Dianthus cæfius. Eingl. Bot. t. 62. Tr. of Linn. Soc. v. 2. 302. With. $41 \mathrm{I}$.

D. virgineus $\beta$. $S p . P l .590$.

D. glaucus. Hudf. I85. Hill. Fl. Brit. t. 26. f. I.

Armerix fpecies, flore in fummo caule fingulari. Rä̈i Syn. 336.

Tunica rupeftris, folio cæfio molli, flore carneo. Dill, Hort. Elth. 401. t. 298. f. $3^{8} 5$. Angl. Mountain Pink.

In rupibus ficcis rariffimè.

On Chedder rocks, Somerfet thire. Mr. Brewer.

perennis, Fl. Junio, Julio.

Radix lignofa. Herba glauca. Caules plures, fpithamæi, erecti, fimplices, glabri, fubquadranguli, foliofi, uniflori, vix unquam biflori. Folia lineari lanceolata, obtufiufcula, margine fcabra. Flores odoratifimi, carnei. Calyx fulcatus, fquamis quaternis, tubo triplò brevioribus, ovato-fubrotundis, obtusè mucronatis, ftriatis. Petala duplicato-crenata, ore lineata atque barbata, villis purpureis. 


\section{TRIGYNIA.}

210. CUCUBALUS. Gertn. $t .77$. Toumef. $t .176$.

Cal. monophyllus, inflatus. Petala 5, unguiculata. Bacca fupora, unilocularis, polyfperma.

bacifer. I. CUCUBALUS. Gertn. v. 1. 376. t. $7 \% \cdot f \cdot 7$. Cucubalus bacciferus. Sp. Pl. 591 . Hudf. I85. With. 411. Dickl. H. Sicc. fafc. 4. 9.

C. Plinii. Dalech. Hifl. I 429. Mill. Ic. t. I I2. Dill. in Raii Syn. 267. Toumef. Inft. 339.

Silene baccifera. With. ed. 2. 452 .

S. fiffa. Salifo. Prod. 302.

Lychnanthos volubilis. Gmel. in Act. Petrop. Ami I759. v. I 4. 22.5. t. I7. f. I. Linn. Mis. Vircago n. 9i2. Hall. Hift. v. 1. $39^{6}$.

Alfine baccifera. Ger. em. 614 . Angl. Berry-bearing Chickweed.

In umbrofis pinguioribus rariffimè.

Gathered in hedges in Anglefea, by Mr. Fowlkes of Llanbeder near Ruthin, and communicated to Dr. Richardfon. Dilt.

Perennis. Fl. Junio, Julio.

Radix repens. Caules debiles, tripedales; ranofiffimi, teretes, pubefcentes, foliofi; ramulis oppofitis, divaricatis, apice floriferis. Folia oppofita, petiolata, patentiffima, ovata, acuta, integrerrima, pubefcentia, pallidè viridia, margine fcabra. Flores terminales, folitarii, pedunculati, nutantes, albido-virentes, ebracteati. Calyx campanulatus, membranaceus, quinquefidus, pubefcens, perfiftens. Petala diftantia, limbo femibifida, incifa, fauce denticulis incifis, obfoletis, coronatâ. 
Stamina filiformia, petalis et receptaculo alternatim inferta. Germen pedicellatum, globofum, glabrum. Styli lineares, intùs longitudinaliter villofi. Bacca globofa, nigra, nitida, cortice pulpofo, unilocularis, non dehifcens, polyfperma. Semina reniformia, receptaculo centrali inferta.

2II. SILENE. G. Pl. 226. Juf. 302. Gertn. t. I 30.

Cucubalus. G.Pl.225. Juf. 302 .

Coll: monophyllus, ventricofus. Petala 5, unguiculata. Capfula fupcra, femitrilocularis, apice dehifcens, polyfperma.

I. SILENE hirfuta vifcofa, petalis emarginatis, anglscan floribus lateralibus erectis alternis, fructibus. inferioribus divaricato-reflexis. Silene anglica. Sp. Pl. 594. Hudf. 187. With. 4I3. Relh. I6g. Curt. Lond. fafc. 4. t. 30. Dick. H. Sicc. fafi. I3. I 8.

S. arvenfis. Salifb. Prod. 301.

Vifcago Cerattei foliis, vafculis pendulis, anglica. Dill. Hort. Elth. 417. t. 309. f. 398.'

Lychnis rylveftris, tlore albo minimo. Rais. Syn. 339.

Angl. Englith Catchity.

Ii arvis arenofis.

About Coombe in Surrey. Hudf. Curt. Cambridgethire. Ray. Relhun. Between Dundee and St. Andrews, and near Perth. Mr. Mackay. At Lakenham and Colley near Norwich.

Annua. Fl. Julio.

Radix fibrofa. Herba hirfuta, vifcofa. Caulis ramofus, patulus, flexuofus, teres, foliofus, ramis fubfpicatis, erectis. Folia lineari-lanceolata, acuta. Flores axillares, folitarii, pedunculati, ereeti, albi. Calyx nervofus, hirfutus, cylindricus, demum ventricofus. Pesalorum limbus ellipticus, emarginatus, fubinde macula carnet 
catneâ notatus. Capfula ovatx, rigidie; inferioreg divaricato-reflexæ, fuperiores plerumque erectx.

quinque- 2. SILENE hirfuta, petalis fubrotundis integervulno- rimis, floribus lateralibus alternis fructibufque ris. erectis.

Silene quinquevulnera. $S_{p} . P$. 595. Hudf. 188. With. 413. Engt. Bot. t.86.

Lychnis hirta minor, flore variegato. Dodart. Mem. 99, cunt icone.

Angl. Variegated Catchfly.

In arvis arenofis.

Near Wrotham in Kent. Hudf.

Annua. Fl. Junio, Julio.

Radix parva, fibrofa. Herba hirfuta, minùs vifcofa. Caulis ramofiffimus, patulus, fubdecumbens, debilis, foliofus. Folia elliptico-lanceolata, acuta. Flores ereeti. Petalorum limbus rotundatus, integerrimus, albus, maculâ centrali fanguineâ, pulcherrinîa, dentatâ. Capfinl $\boldsymbol{x}$ omnes plerumque erectæ, inferiores interdum reflex:.

mutans. 3. SILENE foribus paniculatis fecundis cernuis, petalis bipartitis: laciniis linearibus, foliis lanceolatis pubefcentibus.

Silene nutans. Sp. Pl. 596. Hudf. I 88. With. 413: Engl. Bot.t.465. Fl. Dan. t. 242. Iychnis fylveftris alba nona Clufii. Raii Syn. 340. Ger. em. 470. Deering. Nolt. 137. Angl. Nottingham Catchfly.

In rupibus calcareis.

On the walls of Nottingham caftle, and thereabout. Ray. On rocks in Dovedale. Mr. Woodward. Near North Queen's ferry, Scotland. Mr. Mackay. In Caernarvonthire. Mr. Pennant. On rocks about Knarefborough, York thire. Rer. sircledeacon Peirfon.

Perennis. 
2erennis. F1. Junio, Julio.

Radix fublignofa. Caules plures, fimplices, pedales, erecti, foliofi, teretes, pubefcentes, paniculati, bafi geniculati。 Folia lanceolata, acuta, integerrima, utrinque pubefcentia; radicalia ubovata, congefta. Panicula dichotoma, fecunda, nutans. Flores cernui, albi. Calyx decemcoftatus, femiuncialis, leviter pubefcens, quandoque purpurafcens. Petala vefperi expanfa, limbo ad bafin ferè bipartita, laciniis linearibus, obtufis. Corona bifida, acuta. Stamina quinque longiora, exferta; quinque breviora, petalis adnata. Styli pubefcentes, longitudine varii. Capfula ovata. Semina reniformia, rugofa.

4. SILENE floribus paniculatis fecundis cernuis, parapetalis obcordato emarginatis, foliis lineari- do.re lanceolatis glabris.

Silene paradoxa. Sp. Pl. 1673. Jacq. Hort. Vind. v. 3. t. 84 .

Cucubalus vifcofus. Hudf. 186.

Lychnis major noctiflora Dubrenfis perennis. Ruii Syn. 340.

L. vifcofa peregrina noctiflora odorata. Zanon. Hift. t. 109. Linn. Mrs.

Angl. Dover Catchfly.

In montofis cretaceis.

On Dover cliffs; Mr. Newton. Ray.

Perennis. Fl. Julio.

Habitus præcedentis, fed duplò triplòve major. Folia longe angultiora, lineari-lanceolata, glabra. Calyx uncialis, denfiùs pubefcens. Petalorum limbus obcordatus, haud femibifidus, laciniis dilatatis, rotundatis ; nequaquam ad bafin ufque in lacinias lineares divifus.

Quanta apud auctores de hâc plantâ confufio!

5. SILENE floribus paniculatis cernuis, petalis infata. femibifidis fubnudis, calycibus glabris reticulato-venofis, caule crecto.

Cucu- 
Cucubalus inflatus. Salifb. Prod. 302.

C. Behen. Sp. Pl.59 I. Mudf. 186. MiT.4I2. lith. 168. Silib. 139. Engl. Bot. t. I64. Fl. Dan. t. 914 . Dreves. Bilderb.t. 50.

Lychnis fylveltris, qua Ben album vulgo. Räi Syn. 337.

Behen album. Ger.em. 678.

Vilcago n. 913. Hull. Hijt. v. 1. 397. Angl. Bladder Campion, or Catchfly.

$\therefore$ In arvis, pafcuis, et ad vias vulgaris.

Perenis. Fl. Julio.

Radix cæefpitofa. Caules erecti, fefquipedales, ramofi, .... teretes, glabri, glauci. Folia ovato-lanceolata, acuta, integerrima, fubcarnofa, glauca, lævia, rariùs ciliata et fubhirfuta; radicalia aggregata, fpatulata. Panicula dichotoma. Flores nutantes, albi. Calyx albidus, purpureo viridique reticulatus. Petala femibifida, fauce omninò plerumque nuda, at ex obfervationibus nuperrime inftitutis, interdum coronatam inveni. Antheræ cinereo-virides. Germen violaceum. Capfula ovata, apice fexdentata.

sacriti- 6. SILENE floribus fubfolitariis terminalibus, pexha. talis bifidis coronatis, calycibus glabris reticulato-venofis, caule decumbente.

Silene maritima. With. 414.

S. amœna. Hudl. 188. Lightf. 22\%-

Cucubalus Bchen $\beta$. Sp. Pl. 591. Fl. Dan. t. $85 \%$.

Lychnis maritima repens. Bauh. Pin. 205. Rail Syn. 337 .

L. marina anglicana. Baub. Hift.v.3.p.2.357. Ger. em. 469. Lob. Ic. 337.

Angl. Sea Campion, or Catchily.

In maritimis areno.is vel petrofis haud infrequens; etiam ad fluvios alpinos.

Common 
Common on moft parts of the coaft. In the bed of the river at Hafod, Cardiganthire, near the kitchen gardens.

Perennis. Fl. Augufto, Septembri.

Facie precedenti proximè accedit, at plurimis notis difcrepat. Radix repens. Caules cæefpitofi, bafi decumbentes, quandoque omninò proftrati, ramofi, foliofi, pauciflori, vix paniculati. Folia anguftiora, linearilanceolata, fubinde anguftè fpatulata, glaberrima, margine denticulata. Flores terminales, folitarii vel terni, nutantes, albi. Petala ultra medium bifida, fauce femper coronata. Styli interdum quatuor vel quinque. Germen violaceum. Capfula fubrotunda, nec ovata.

7.S ILENE floribus paniculatis dioicis, petalis li-Otites. nearibus indivifis nudis.

Cucubalus Otites. Sf. Pl. 594. Hudf. I86. IIth. 412. Telh. 168. Engl. Bot. t. 85. H. Dan.t. $5 \geq 8$.

Lychnis vifcola flore mufcofo. Raii syn. 340. Sefamoides Salamanticum magnum. Ger. em. 493 .

Murcipula mufcofo flore, five Ocymoides belliforme. Banh. Hift. $\% 3 \cdot$ s.2.350.

Angl. Spanilh Catchfly.

In campis aridis fabulofis, vel glareofis, rariùs. Between Swatfham and Narford, Norfolk, on the grafly ridges of the road. Alfo about Thetford, Barton mills, and Bury.

Perennis. I1. Julio, Augufto.

Radix lignofa, flavicans. Canlis erectus, foliofus, fupernè vifcidus, paniculatus, multiflorus, pedunculis fubverticillatis, dichotomis. Folia petiolata, fpatulata, acuta, integerrima, pilis breviflimis, denfis, curvis, utrinque veftita, fubvifcida. Flores abortu dioici, luteo-rirides, parti, bracteolati. Petala linearia, indivifa, VOL. II. 
fauce nuda, aliquando abortiva. Calyx nervolus, pubefcens. Styli numero variant a duobus ad quinque.

corica. S. SILE,NE caule dichotomo, petalis bifidis coronatis, foliis mollibus, calycibus fructûs conicis ftriis triginta.

Silene conica. Sp.Pl.598. With.416. Jacq. Auftr.t. 253 .

S. conoidea. Hudf. 189 .

Lychnis fylveftris anguftifolia caliculis turgidis ftriatis. Dill. in Raii Syn. 341 .

L. fylveftris altera incana, cauliculis (caliculis) ftriatis. Lob. Ic. t. $33 \mathrm{~S}$.

I. rylveftris incana Lobelii. Ger. em. 470. Angl. Corn Catchfly.

In arvis arenofis.

A little to the north of Sandown caftle plentifully. Sberard and Rand. Oppofite the Warren houfe at New Romney, Kent. Rev. Mr. Stacey.

Annua. Fl. Julio.

Radix parva, fubramofa. Caulis erectus, teres, pubef cens, foliofus, dichotonus. Folia lineari-lanceolata, acuta, integerrima, utrinque mollifimè pubefcentia. Flores e dichotomiâ caulis, folitarii, pedunculati, erecti, rofei, fuaveolentes. Calyx conico-cylindricus, membranaceus, coftis triginta viridibus pubefcentibus, báf obtufus, apice dentibus 5, reetis, acuminatis. Petala bifida. Capfula ovata.

noziflo- 9. SILENE caule dichotomo, petalis bifidis obtusè ra. coronatis, calycibus decem-angularibus : dentibus tubum fubaquantibus.

Silene noctiflora. Sp. Pl. 599. Hudf: 189. ITith. 416. Relh. Suppl. I. I3. Sibth. 140. Albot. 9j. Engl. Bot.t. 291 . 
Ocymoides noctiflorum. Camer. Hort. Iog. t. 34 .

Lychnis noctiflora. Morif. Sect. 5. t.20.f. 12, Raii Syn. 340.

Angl: Night-fiowering Catchfly.

In arvis arenofis.

In Cambridgethire. Ray. Relh. Oxfordhire. Sibth. Very common about Wetherby. Sir T. Frankland. Not rare in Norfolk, efpecially on the weft fide of Norwich.

Annua. Fl. Julio.

Radix fibrofa, parva. Caulis erectus, ramofus, patens, foliofus; dichotomus, teres, pubefcens. Folia lanceolata, acuta, mollia et pilofa, faturate viridia; inferiora obovata. Flores e dichotomiâ caulis, pedunculati, erecti, carnei, nocte expanfi et odorati. Calyx pilofus, vifcidus; coltis decem, viridibus, ramofis; dentibus linearibus, longitudine ferè tubi. Petala femibifida, fauce denticulis obtufis coronata. Capfula ovata.

* $x$. SILENE paniculis dichotomis faftigiatis Armeria. multifloris, petalis emarginatis acutè coro- natis, foliis fuperioribus cordatis glabris. Silene Armeria. Sp. Pl. 601. Hudf. 189. Witb. 4I5. Fl. Dan.t.559.

Lychnis vifcofa purpurea latifolia lævis. Dill. in Räii Syn. 34I.

L. Yylveftris prima. Ches. Hift. p. I. 288.

Mufcipula Lobelii, Ger. em.60I.

Angl. Common, or Lobel's Catchfly.

In arvis, aggèribus, et muris antiquis, rariùs.

On the banks of the river half a mile below Cherter; Dr. Richardfon. Dill,

Annua. Fl. Julio, Augufto.

Radix parva. Caulis ramofus, foliofus, teres, glaber, fub geniculis vifcidus. Folia amplexicaulia, ovata, $\mathrm{D}_{2}$

glau. 
glaucefcentia, glabra; fuperiora cordata. Paniculac terminales, aphyllx, bracteolatx, multifloræ, dichotomx, faftigiate. Flores erecti, rofei. Calyx clavatolinearis, decem-angulatus, læviffmus, glaucus, dentibus parvis, rotundatis, purpurafcentibus. Petala rotundata, emarginata, acute coronata. Capfula elliptica, pedicellata.

accuits. II. SILENE acaulis, foliis linearibus bafi ciliatis, pedunculis folitariis unifloris, petalis coronatis. Silene acaulis. Sp. Pl. 603. Lightf. 227. t. 12. f. I. With. 416. H. Dan. t. 2 I. Dick. II. Sice. fofc. I. 8. Allion. Ped. t. 79. f. I. Cucubalus acaulis. Thudf. I 87 .

Lychnis alpina minima. Líaii Syn. $\hat{+}+1$.

L. alpina pumila, folio gramineo. Dill. Hort. I:tip. 206. cum tab.

Caryophyllus pumilio alpinus. Ger. em. 593 . Angl. Mofs Campion.

In alpibus.

On the higheft mountains of Walcs, Scotland and Devonfhire. Near the furmmit of Ben Lomond.

Perennis. Fl. Junio, Julio.

Radix caefpitofa, multiceps, longiffimè defcendens. Folia congefta, vaginantia, patentia, linearia, fubcarinata, fubciliata. Pedunculi terminales, folitarii, erecti, uniflori, nudi, obfoletè quadranguli, glabri, poft florefcentiam elongati. Flores erecti, rolei, pulchelli. Calyx campanulatus, feni-quinquefidus, quinquecoftatus, glaber. Petala fubemaroinata, fauce coronata. Capfula cylindrica, calyce duplò longior.

212. STELIAAR!A. G. Pl.226. JuJ. 30 I. Gertu. t. 130 .

Gal. pentaphyllus, patens. P'etala 5 , bipartita. Caplula tupera, unilocularis, polyfperma, apice iexclentata.

I. STEI. 
. . STELLARIA foliis inferioribus cordatis pe-nemotiolatis; fuperioribus ovatis feffilibus, pani- rum. culâ dichotơná.

Stellaria nemorum. Sp. Pl. 603. Hudf. 190. With. 417\%'Engl. Bot. t.92. II. Dan. t.271. Alfine montana, folio Smilacis inftar, flore laciniato. Dill. in Raii Syn. 347 .

A. montana latifolia, flore laciniato. Morif. Sect. 5. t. 23. f. 2 .

A. hedcracea montana maxima. Column. Ecphr. 290. f. 2 .

Angl. Wood Stitchwort.

In nemorofis humidis, ad fontium rivos umbrofos.

In the mountainous parts of the north of England, and the fouth of Scotland. By Cafterton mill near Kirkby Lonfdale, Weftmoreland, and in other parts of that county. Found by Mr. Rob. fon near Darlington.

Perennis. Fl. Maio, Junio.

Radix repens. Caules debiles, tripedales, ramofi, cavi, teretes, foliofi, undique fubpilofi. Folia oppofita, pallidè viridia, fragilia et fubfucculenta, integerrima, parúm pilofa; inferiora cordata, petiolata ; fuperiora ovata, feffilia. Panicula terminalis, dichotoma, multifora, foliolofa, divaricata, pubefcens. Flores erecti, albi. Calyx bafi hirfutus, foliolis margine fcariofo-albis. Petala patentifima, ad bafin ferè bipartita, laciniis lineariellipticis, divaricatis. Styli tres, nunquam plures. Pedunculi fructiferi reflexi. Capfula elliptica, ore fexdentato.

2. STELLARIA foliis ovatis, caulibus procum-media. bentibus lineâ laterali pilosâ alternâ.

Stellaria media. it ith. 418. Engl. Bot. t. 537. Alfine media, Sp.Pl.389. Hudf. 131. Relh. I28. Sibth. 105. Cart. Lond. fafe. I. t. 20. H. Dan. t. 438. et t. 525 .
D) 3
A. vulo 
A. vulgaris, feu Morfus gallinæ. Raii Syn. 34\%. A. minor five media. Ger. em. 6rI. A. major. Fuch.j. Hift. 2 r. Aingl. Common Chickweed.

In cultis et ruderatis ubique.

Annua. Fl. toto ferè anno.

Radix fibrofa, tenaciffina. Caules proftrati, ramofi, fragiles, foliofi, teretes, geniculati, lineâ pilosâ, longitu: dinali, ad genicula interruptâ, notabiles. Folia oppofita, petiolata, ovata, integerrina, glabra, petiolis ciliatis. Pedunculi axillares vel terminales, folitarii, uni= flori, lineâ laterali pilosâ. Flores albi, inconfpicui. Calyx pilofus, petalis longior. Petala ad bafin ufque bipartita. Stamina a decem ad quinque, rariùs tria, bafi glandulofa. Capfula ovata, ore fexdentato. Se= mina tuberculato-fcabra.

bolofica. 3. STELLARIA folịs lanceolatis ferrulatis, potalis bifidis, calyce enervi. Stellaria boloftea. Sp. Pl. 603. Hudf. 190. With. 4I7. Relh. I70. Sibib. 140. Curt. Lond. fafc. 2. t. 3०. Dicks. H. Sicc. fafc. 7.6. E gl. Bot.t. $5 \mathrm{II}$.

Caryophyllus holofteus arvenfis glaber, flore majore. Paii Syn. 346.

Gramen. Fuchj. Hijt. ${ }^{36 .}$

G. leucanthemum. Ger. em. 47 . Angl. Greater Stitchwort.

In nemorofis ficcis, et dumetis.

Perennis. Fl. Maio.

Radix repens. Caules bafi gracillimi, decumbentes, dein erecti, quadranguli, geniculati, foliofi, angulis fupernè fcabris. Folia feffilia, lanceolata, acuminata, margine fcabra, fubrevoluta, acutè carinata, glabra, glaucefcentia. Panicula dichotoma, foliolofa. Pedunculi longitimi, erecti, fcabri. Ilores formofi, nivei. Calycis foliola 
Foliola lanceolata, omninò enervia, margine alba. Petala obcordata. Capfula globofa.

4. STELLARIA foliis lineari-lanceolatis integer-gramirimis, paniculâ terminali divaricatâ, calyce $n e a$ 。 trinervi petalis fubæquali.

Stellaria graminea. Sp. Pl. 604. Hudf. I90. With. 419. Relh. I70. Sibth. 140.

Caryophyllus holofteus arvenfis glaber flore minore. Raii Syn. 346.

Gramini Fuchfii leucanthemo affinis et fimilis herba. Bauh. Hift. v. 3. p. 2.36r. Angl. Leffer Stitchwort.

In pafcuis et vepretis, præfertim folo arenofo, vel glareofo.

Perennis. Fl. Maio.

Præcedente minor. Folia margine integerrima, vix fcabra, minùfque glauca. Caulis omninò lævis, ut et pedunculi. Calycis foliola albida, membranacea, acutè trinervia, nervis viridibus. Petala bipartita, calyci æqualia, fubinde longiora.

5. STELLARIA foliis lineari-lanceolatis integer-glauca. rimis glaucis, pedunculis erectis, calyce trinervi petalis breviore.

Stellaria glauca. Irith. 420 .

S. media. Sibth. I41. Abbot. 96 .

S. graminea ß. Hudf. I 90.

Caryophyllus holofteus arvenfis medius. Raii $\operatorname{Syn} .347$.

Alfine floribus (foliis) gramineis, petalis bipartitis. Gmel. Sib. v. 4. 145. t.61. f. 2. Herb.

Linn.

Angl. Glaucous Marh Stitchwort.

In aggeribus foffarum pratifque humidis. 
In the Ine of Ely, and near Oxford. Raty. About Edinburgh. Mr. Mackay. On St. Faith's Newton bogs near Norwich.

Perennis. FI. Junio, Julio.

Pracedenti proximè affinis, fed folia gla!ıca, margine nmninò lævia. Caulis etiam lævis. Pedunculi erecti, axillares et terninales, alterni, fubinde paniculati. Flores precedente duplò ferè majores. Calyx acuninatus, minùs acutè trinervis. Petala obcordata, calyce dupló ferè longiora. Antheræ xeranpelinæ.

Fl. D.zn. t. $4 \mathrm{I} 4$, ab Iudfono citata, noftram minimè refert ftirpem.

uligino- 6. STELLARIA foliis elliptico-lanceolatis inteJa. gerrimis apicc callofis, floribus fubpaniculatis lateralibus, petalis calyce brevioribus.

Sicllaria uliginofa. Curt. Lond. frefc. 6. t. 28 . With. 420 . Sibth. $14 \mathrm{I}$.

S. graminea $\%$. Hudj. 19o. Limn. Fl. Suec. I 50. Relk. I 70. Fl. Dan. t. 415.

S. hypericifolia. Wiggers. Holfat. 34.

S. dilleniana. Leers. ro7.

S. aquatica. Pollich. v. I. 429.

S. fontana. Jacq. Coll. \%. I. 327.

Alfine fontana. Ger. em.6 i 3 .

A. longifolia, uliginofis proveniens locis. Baub. IIIfT. $\cdot 3 \cdot$. p.2.365. Raii Syn. 347 .

A. 11. 88 r. Hall. Hift. 2.1 .387$.

Angl. Bog Stitchwort.

In rivulis, folfis, inundatis, ct ad fontes.

Anmua. Fl. Junio.

Radix fibrofa, parva. Caules numernfi, debiles, ramofi, quadranguli, læves, folinfi. Folia elliptico-lanceolata, integerrima, multivenofa, pallidè glaucefcentia, mar-: gine fubundulata, levia, apice callofa. Pedunculi axillares et terminales, fxpiùs terni, quorum duo paniculato. 
riculato-triflori, tertius uniforus, ommes braiteolati, divaricati, glabriufculi. Flores parvi. Calyx trinervis, foliolis exterioribus ciliatis. Petala calyce breviora.

variat ftylis 4 vel 5 . Stokes.

\%. STHLLARIA foliis elliptico-oblongis obtufis, cerafoicaulibus fubbifloris, calycibus uninervibus des. pubercentibus.

Stellaria ceraftoides. Sp. Pl. 604. Sm. Pl. 1c. ex Herl. Linn. t. I 5. Dickf. in Tr. of Linn. Soc. v. 2. 290. H. Sicc. fafc. 2. I I. Wilb. 421. Fl. Dan. t. 92, Jacq. Coll. v. I. 254. t. I g. Retz. Olje. fafc. I. İ́.

S. n. 951. Gunn. Norv. p. 2. t. 6. f. 2 . Angl. Alpine Stitchwort.

In alpibus Scotix.

On Ben Nevis. Mr. Dickfon and Mr. Mackay.

Perennis. Fl. Junio.

Padix repens. Caules diffufi, bafi ramofi, fupernè foliofi, teretiufculi, glabri, apice uniflori vel biflori, rarius triflori, pubefcentes et vifcidi. Folia elliptico-oblonga, obtufa, integerrima, glabra, recurva, fubfecunda. Flores erecti, albi. Calycis foliola obtufa, uninervia, bafi pubcfcenti-vifcida, margine fcariofa. Petala calyce duplò ferè longiora, femibifida. Germen ovatum. Capfula oblonga, dentibus numero duplicato ftylorum.

Variat ftylis 4 vel 5. Wulfen apud Jacq. Quatuor etiam vidi.

\section{ARENARIA. G.Pl.226. Juff.30I. Gertn. t. I 30 .}

Cal. pentaphyllus, patens. Petala 5, integra. Capfula fupera, unilocularis, polyfperma.

1. ARENARIA foliis ovatis acutis carnofis, caly-peploides. cibus obtufis enervibus. Arrenaria peploides. Sp. Pl. 605. Hudl I9 I. 
With. 42r. Engl. Bot. t. 189. Fl. Dan. t. 624. Dickf. H. Sicc. fafc. Iо. 10.

Alfine marina, folis portulacæ. Loef. Pruf. rz.

t.2. Raii Syn. 35 I.

Anthyllis lentifolia, five Alfine cruciata marina.

Ger. em. 622.

Angl. Sea Chickweed or Sandwort.

In littoribus maritimis arenofis frequens.

Perennis. Fl. Junio, Julio.

Radix repens, longiffima, flagellifornis. Caules proftrati, ramofi, foliofi, angulati, glaberrimi. Folia oppofita, feffilia, ovata, acuta, recurva, integerrima, carnofa, glabra, carinata, avenia. Flores e dichotomiâ caulis, fubfeffiles, folitarii, parvi, albi. Calycis foliola elliptica, obtufa, carnofa, avenia. Petala obovata. Capfula fubrotunda, trivalvis. Semina magna, obovata, punctata, nigra.

triner- 2. ARENARIA foliis ovatis acutis petiolatis nerwis. vofis, calycibus carinâ fcabris obfoletè trinervibus.

Arenaria trinervis, Sp. Pl. 605. Hudf. IgI. With. 421. Relh. I I1. Sibth. 141. Abbot. 97. Curt. Lond. fafi. 4. t. 3I. Fl. Lan. t. 429 .

Alfine Plantaginis folio. Bauh. Hift. v. $3 \cdot p \cdot 2$. 363. Raii Syn. 349.

Angl. Plantain-leaved Chickweed or Sandwort.

In rylvis et nemorofis humidis.

Annua. Fl. Maio, Junio.

Radix fibrofa. Caulis debilis, erectus, fpithamæus, ramofus, teres, undique pilofus, foliofus. Folia petiolata, ovata, acuta, tri- vel quinque-nervia, ciliata. Pedunculi e dichotomiâ caulis, uniflori, elongati, demum dettexi. Flores albi, parvi. Calycis foliola lanceolata, acuta, carinate, obfolctè trinervia, margine membrana- 


\section{DECANDRIA-TRIGYNIA.}

cea, ciliatay dorfo fcabra. Petala longitudine vix calycis, obovata. Capfula ovata, are fexfido. Semina parva, glabra, nigra.

3. ARENARIA foliis ovatis fubfeffilibus fabris, ferpyltz= calycibus hirfutis fubquinquenervibus.

Arenaria ferpyllifolia. Sp. Pl. 606. Hudf. I9I.

With. 4.21. Relb. 171. Sibth. I42. Abbot.97. Curt. Lond, fafc. 4.t.32. Fl. Dan.

t. 977. Dickf. H. Sicc. fa/c. I6. 3 .

Alfine minor multicaulis. Raii Syn. 349.

A. petræa. Ger. em. 6I2.

Angl. Thyme-leaved Sandwort.

In aridis, arenofis, ct ad muros, vulgaris.

Annua. Fl. Junio, Julio.

Radix fibrofa, parva. Caules plurimi, palmares, patuli, adfcendentes, rigidi, ramofi, foliofi, teretes, pubefcentes, paniculato-dichotomi. Folia parva, ovata, integerrima, obfoletè nervofa, fcabra, fuperiora acutiora. Pedunculi femper erecti. Flores parvi, albi. Calycis foliola ovata, acuta, hirfuta, margine fcariofa ; tria exteriora quinquenervia, interiora trinervia. Petala calyce breviora. Capfula ovata, ore fexfida. Semina fulva, fubrugofa.

4. ARENARIA foliis linearibus mucronulatis, rubra. ftipulis fcariofis vaginantibus, feminibus compreffis angulatis fcabriufculis.

Arenaria rubra. Sp. Pl. 606. Hudf. 192. With. 422. Relh. I72. Sibth. 142. Abbot. 98 .

A. campeftris, Allion. Pedem.v.2. Ir 4.

Spergula purpurea. Raii Syn. 351. Baub. Hijt.

v. 2. p. 2. 7 I 9.2 . $f \cdot 3$.

folygonum foliis gramineis, Spergulæ capitibus.

Loes. Pruff. 203. t. 63. Angl. Purgle Sandwort. 
In arvis arenofis frequens.

Annura. Fl. Julio, Auguito.

Radix parva, fubfusfomis, ramofa. Caules proftrati, divaricati, ramofi, foliofi, teretes, glabri. Folia plana, lincaria, angufiffima, acuta, mucronulata, glanca, fubincana, longitudine ferè internodiorum. Stipulæe extrafoliaces, oppofita, amplexicaules, fcariolix, alba, acutx, lacerx. l'aniculæe terminales, foliofx, dichotomæ, racemofx, pubefcentes. Flores caruleo-incarnati. Calycis foliola lanceolata, hirfuta, enervia, margine fcariofi. Petala calyce breviora. Capfula longitudine calycis, orata, trivalvis. Semina plurima, fufca, angulata, fubcuneiformia, extús tuberculis acutis fcabriufcula.

marina. 5. ARENARIA foliis remicylindricis carnofis muticis, ftipulis fariofis vaginantibus, feminibus compreflis marginatis grlabris.

Arcnaria marina. F\%.Dan. t. 740.

A. rubra f. Sp. Pl.606. Lightf. 230. Huds. 193 (media).

A. media. Hth. 422 .

Spergula maritima flore parvo carulen, femine vario, Dill. in Raii Syn. 351. Dill. Criff. app. 30 .

f. Arenaria media. Sp. Pl. 606. exclufis fynonymis.

A. inarina. With. 422. Allion. Ped. : 2. I14. A. rubra g (marina). Hulf. 19.3.

Alfine Spergula facie media. Raii Syn. $35 \mathrm{I}$.

A. Spergula marina. Morif. fect. 5. \% $23 . f$. 15. Spergula marina. Dalech. Hift. $3_{3} 8$.

S. marina noftras. Bauh. Hijt. v. 3. p. 2. 720. Angl. Sea Spurrey-Sandwort.

In pafcuis et arenolis maritinis.

Annur. Fl. Junio, Julio.

Radix fufformis, Canles proftrati, glaberrini, Folia femi. 
femicylindrica, carnofa, mutica, glabra. Stipule ut in precedenti. Flores duplè majores, pallide incarnati, vel purpurafcentes. Capfula calyce longrior, trivalvis. Senina complanati, glabra, nıarginata; margine in $\beta$ dilatato, membranaceo, albo, ttriato.

Ambigunt ha: duse fpecies inter Arenariam et Spergulam.

6. ARENARIA foliis fubulatis acutis, caule pani-tenuifoculato, capfulis erectis trivalvibus, petalis lan- lia. ceolatis calyce brevioribus.

Arenaria tenuifolia. Sp. P\% 60\%. Hud/. 192. With. 423. Relb. 172. Silth. I 42 . Al一loot. 98. Engl. Bot.t.2 rg. Dick. H. Sicr. fali. I o. I I. H\%. D.an. t. 38 g.

Aline tenuifolia. Riaii Syn. 350 . Tiilt. Parts. t. 3. f. 1. Seguier. Feron. l. 6. f. . . Angl. Finc-leaved Sandwort.

In campis arenofis ficrilibus, et ad muros.

In corn-ficlds in feveral parts of Cambrirlgefhire. Ray and Rev. Mr. Hemfted. At Oxburgh, Norfolk. Nir. l'itchford. Worcelterthire. Mr. Bullart. Oxfordthire. Sibth.

Annuia. Fl. Tunio.

Radix fibrofa, parra. Caules erceti, teretes, foliofi, plerumque glabri, fupernè paniculati, dichotomi. Folia fubulati, trinervia, glabra, mutica, bafi connata et dilatata. Pedunculi capillares, erecti. Flores parvi, albi. Foliola calycina lanceolata, acuminati, trinervia, nıargine membranacea. Petala exigua, lanceolata, obtula, calyce duplò breviora. Stanina omminò decen, breviflima. Germen globofum. Styli tres. Capfula cylindrica, calyce longior, trivalvis. Semina minuta, re. niformi-fubrotunda, comprelia, ficabriufcula, figurá ferd. A. rubræ.

7. ARENARIA folis fubulatis obtufufculis, caule e'crna. paniculato, petalis obovatis calyce longroribus, calyce trinervi : nervis renotis equalibus. 
Arenaria verna. Mant. 72. Hudf. 191. With: 423. Lightf. 231. Engl. Bot. t. 512. Dickf。 Dr. Pl. 6. H. Sicc. fajc. I 3. I 7. Jacq. Auftr. t. 404 .

A. faxatilis. Hudf. ed. 1. 168. Pentr. Tour in Hiles. tat.

Alfine pufilla pulchro flore, folio tenuifimo nofiras. Raii Syn. 350 .

A. alpina glabra, tenuiffimis foliis, floribus albis。 Herm. Parad. I 2. t. I 2: malè; ob petala acuta: A. caryophylloides tenuifolia, flore albo punctato. Piuk. Phyt.t. $7 \cdot f \cdot 3$.

A. faxatilis et multifora, capillacec folio. Vailt. Paris. t. $2 . f \cdot 3$. opt.

3. A. juniperina. With. 424:

\%.A. Laricifolia. With. 424 . Angl. Vernal Sandwort.

In montibus quartzofis vel fpatofis:

About the mouths of lead mines in Derbythire: alfo on Arthur's feat near Edinburgh. On feveral mountains in the North, and in Wales.

Perenizis. Fl. Maio-Augufto.

Radix teres, longa, infernè rarnớlifima. Cáules numerofifimi, cæfpitofi, erectiufculi, palmares, foliofi, teretes, fubpubefcentes et aliquantulum vifcidi, bafi ramofi, fupernè paniculati. Folia erecto-patentia, fubulata, obtufuffcula, fubtùs trinervia, bafi dilatata et connata, fupernè canaliculata, plerumque glabra. Bracteæ ovatæa, trinerves, breves. Pedunculi erecti, pubefcentes. Foliola calycina ovata, acuta, pilofa, trinervia, nervis æqualibus et fubremotis, margine membranacea. $\mathrm{Pe}$ tala calyce longiora, obovata, obtufa. Antheræ carneæ: Capfula calyce longior, cylindrica, trivalvis. Semina fubreniformia, compreffa, fcabra, omninò ut in $\mathrm{A}$. rubra. 
214. CHERLERIA. G.Pl.22\%. Juf.301.

Cal. pentaphyllus. Petala nulla? Glandulce nectarifere 5 , bifide, ad ftaminum bafin. Capfula fupera, trivalvis, unilocularis, polyfperma.

s. CHERLERIA. Hall. Opref. 300.t. I. Segu. Sedoides Veron. Suppl. I 80. t. 6. f. 3 .

Cherleria redoides. Sp. Pl. 6os. Hudf. I93. With. 424. Lightf. 232. Dickf. H. Sicc. fafc. 1. 9. Jacq. Aluftr. t. 284 .

Cherleria, n. 859. Hall. Hift.v. 1. 381. t. 21. Lychnis alpina, mufcofis foliis denfiùs ttipatis, floribus parvis, calyce duriore. Pluk. Phyt. t. 42 . f. 8 .

Sedum montanum perpufillum luteolis floribus. Park. Theatr. 737. Morif. Sect. I2. t. 6. f. I4. Angl. Dwarf Cherleria. Molly Cyphel.

In fummis alpibus Scotix. Hope. Lightf.

Perennis. Fl. Julio.

Radix longa, fublignofa, multiceps. Caules cæefpitofi, unciales, densè foliofi. Folia triquetro-fubulata, obtufa, fubtùs trinervia. Pedunculus folitarius, axillaris, apicem versùs caulis, uniflorus, medio bracteis binis, connatis. Flores viridi-lutei, ereeti. Folia calycina obtufa, carinata. Stamina calyce breviora. Capfula ovata, calyce duplò longior, trivalvis, certè unilocularis, polyfperma. Semina angulata.—Petala 5, viridia, lingulata, invenit Seguier, nobis necdum obvia. 


\section{PENTAGYNIA.}

255. COTYLEDON. G. Pl. 229. Jiff. 30\%. Cul. quinquefidus. Cor. monopetala. Squame nectarifere 5 ad bafin germinis. Capfula 5, fupere.

Cimbili: I. COTYLEDON fuliis peltatis crenatis, caule sus. fpicato fubfimplici, floribus pendulis, radice tuberusâ.

Cotyledon Umbilicus. Hudf. 194. With. 425. Sibth. I 43. Eingl. Eot. t. 325 . Sp. Pl. 6 15 B.

C. rupeftris. Salifb. Prod. 307 .

C. vera, radice tuberosâ. Rucii Sym. 27 I.

C. Umbilicus Veneris. Cluf. Hift. v. 2.63.

Umbilicus Vencris. Ger. em. 528. Camers Efpit. 858 .

Angrl. Common Navclwort.

In rupibus umbrofis irriguis, murifque antiquis humidis.

Perennis. Tl. Junio, Julio.

Radix tuberofa. Herba fuccofa, fragilis, lrevis, pallide virens. Caulis fpithameus, teres, rubicundus, bafi foliofus, fupernè fpicatus, fubinde ramofus. Folia petiolata; inferiora umbilicato-peltata, crenato-repandla; fuperiora minora, vix peltata, dentato-crenata. Bracteæ lanceolatx, integræ. Flores congefti, pedicellati, cernui, tubulofi, flavefcentes, ore virides. Stamina breviffima, fauce inferta.

Lutea. 2. COTYLEDON foliis crenato-dentatis; infimis fubpeitatis, caule fpicato fubfimplici, floribus erectis, radice repente.

Cotyledon lutea. Hudj. 194. Whth. 426.

C. Un- 
C. Umbilicus. Sp. Pl. 6I $5 \alpha$.

C. flore luteo, radice tuberosâ repente. Dodart. Mem. 73, cum icone.

C. radice tuberosâ longâ repente. Raï Hijt. 1878 .

Sedum luteum umbilicatum fpicatum, radice repente majus. Morif. $v .3 .47 \mathrm{I}$.

Angl. Greater Yellow Navelwort.

In rupibus et muris humidis rariùs.

In the weft riding of Yorkfhire. Mr. Tofield. Somerfethire. Hudf. Cultivated in Cheliea garden.

Perennis. Fl. Junio.

Radix carnofa, repens. Caulis pedalis et alcior. Folia infima tantùm peltata ; cætera obovata, profundè dentata. Flores numerofiffimi, erecto-patentes, flavi. Bracteæ plerımque integræ.

\section{2r6. SEDUM. G. Pl. 230. Juf. 307. \\ Gurtn. $t .65$.}

Cal. quinquefidus. Cor. pentapetala. Squame nectarifere 5, ad bafin germinis. Capjule 5, fuperæ.

$$
\text { * Ptanifolia. }
$$

x. SEDUM foliis planiufculis ferratis, corymbo Teleptiz foliofo, caule erecto. Seduin Telephium. Sp. Pl.616. Hudf. I95. With. 42.6. Relb. 173. Sibit. 143. Abbot. 98. Cart. Lond. faijc. 3.t. 25 . Telephium purpurafcens. Fuch. Hift. 80 I. Anacampferos, vulgò Faba craffa. Raii Syn. 269. A. purpurea. Baulb. Hift. v. 3.682. Crafłula, five Faba inverfa. Ger. em. 518. B.'Telephium album. Fuchs. Hijt. 800 . Angl. Oruine or Live-long. 
In agris, dumetis, et ad fepes, folo glareofo vel calcareo.

Percnnis. Fl. Augufo.

Radix tuberofa, carnofa, alba. Caules bipedales, erecti, fimplices, foliofi, teretes, glabri, purpurafentes. Folia fparfa, feffilia, ovata, carnofa, plana, dentato-ferrata, glaucefcentia, lævia. Corymbi terminales, multiflori, congefti, foliofi. Illores purpurei, rariùs albi.

\section{* * Terelifolia.}

dafy- 2. SEDUM foliis oppofitis ovatis obtufis carnofis, phylcaule infirmo, paniculâ glutinosâ. Sedum dafyphyllum. Sp.Pl.618. Hudf. 197. With 428. Relh. 179. Sibth. 144. $A b$ bot. 98. Curt. Lond. fafc. 3. t. 26 . Jacq. Hort. Vind. v. 2. t. 153. Eingl. Bot. t. 656 .

S. minus circinato folio. Dill. in Raii Syn. $27 \mathrm{r}$. Morif. fect. I2. 1. $7 \cdot f \cdot 35$.

Aizoon Dafyphyllum. Dalech. Hift. I1 33. Angl. Thick-lcared Stone-crop.

In muris et petrofis.

Plentiful about London, as at Hammerfmith, Kew and Chelfea. On walls at Malton, Yorkfhire. Rer. Archdeacon Peirfon. At Clifton near Briftol. Mr.T. W. Dyer.

Perennis. Fl. Junio.

Radix perennis, fibrofa. Caules decumbentes, repentes, ramofi, cæefpitofi, debiles, tcretes, fubvifcidi, foliofi ; ramis floriferis erectis. Folia plerumque oppofita, imbricata, ovata, obtufa, gibbofa, valdè fuccofa, integerrima, glauca, rubicunda. Panicula terminalis, patens, pauciflora. Flores frepe fexfidi, dodecandri. Calyx pubefcens, vifcidus. Petala alba, carinâ purpureà. Anther: atro-fanguinere.

angli- 3. SEDUM foliis fubalternis ovatis carnofis gibbis čm. adnato-feffilibus, cymâ bifidâ lævi. 
Sedum anglicum. Hudf. 196. 'With. 428. Engl. Bot.t. I7I.

S. annuum. Hudr. ed. I. I72.

S. rubens. Lightf. 235. Fl. Dan. t. 82.

S. minimum non acre, flore albo. Raii Syn. 270. t. $12 . f .2$.

Mild White Stonecrop. Pet.H. Brit. t.42.f. 10. Angl. Englith Stonecrop.

In maritimis arenofis et fcopulofis; etiam in montibus.

On the fandy downs of the Norfolk and Suffolk coaft plentifully; as well as in Devonhire, Cornwall, Wales and Scotland. On the mountains of Weftmoreland.

Annua. Fl. Julio.

Radix fibrofa. Caules cæépitofi, bafi decumbentes, glabri, rubicundi, foliofi. Folia fæpius alterna, vel fuboppofita, carnofa, ovata, obtufiufcula, fubglauca, bafi producta ct libera. Cymæ terminales, folitariæ, bifidæ, ferè aphyllæ, racemofæ. Flores erecti, quinquefidi. Calyx obtufus, lævis. Petala acuminata, alba, carinâ rubrâ, fubinde apice rubro punctata. Capfulæ membranaceæ, læves.

4. SEDUM foliis alternis fubovatis carnofis gibbis acre. adnato-fefililibus, cymâ trifidâ foliosâ. Sedum acre. Sp.Pl.6rg. Hudf. 196. With. 427. Relb. I74. Sibth. 144. Curt. Lond. fafc. 1. t. 32. Wrodv. Suppl.t. 231.

S. parvum acre flore luteo. Buub. Hift. v. 3.694. Raii Syn. 270.

Vermicularis, five Illecebra minor acris. Ger. em. 517.

Scmpervivum minimum. Camer. Epit. 856. proculdubiò.

$$
\mathrm{E}_{2}
$$


Stonecrop, or Wall Pepper. Pet. H. Brit. t. 42. f. 9 .

Angl. Biting Stonecrop. Wall Pepper.

In muris, tectis, et aridis fabulofis vulgaris.

Perennis. Fl. Junio.

Radix fibrofa. Caules cæefpitofi, ramofi, decumbentes, glabri, teretes, foliofi. Folia alterna, imbricata, carnofa, ovata, obtufa, fubcomplanata, erecto-patentia, bafi gibbofa et libera. Cymæ terminales, folitariæ, fubtrifidæ, paucifloræ, foliofæ. Flores erecti, aurei. Calyx obtufufculus, lævis. Petala acuta. Capfulæ membranaccæ, læves. Herba acris.

jexangu- 5. SEDUM foliis fubternis teretiufculis obtufis lare. carnofis adnato-feffilibus patentibus, cym $\hat{\alpha}$ trifidâ foliosâ.

Scdum fexangulare. Sp. Pl. 620. Hudf. ed. r. I, With. 428. Relh. 175. Curt. Lond. fafc. 4. t. 33 .

S. acre $\beta$. Hudf. $19^{6 .}$

Sempervivum minimurn. Lob. Ic. 379 ? singl. Infipid Stonecrop.

In fabulofis aridis et ad muros, minùs frequens. Near Northflect, Sheemers, and in the Ifle of Shepey. Hudf. On Greenwich park wall near the weftern corner. Curt.

Perennis. Fl. Junio, Julio.

Habitus præcedentis, fed parùm major. Folia fubcylindrica, nec ovata, fubterna, duplici ordine digefta, hinc fexfariàm imbricata, patentiffima, bafi libera, vix gibbofa. Cyma foliofa. Flores aurei. Herba non acris.

vinfunfum. 6. SliDUM folis alternis linearibus planiufculis $\because$ pedunculifque fubpilofis, caule erecto. Sedum villofum. Sp. Pl. 620. Hudf. I97. 


\section{With. 426. Engl. Bot. t. 394. Fl. Dan. t. 24 .}

S. purpureum pratenfe. Bauh. Hift. v. 3.692. Raii Syn. 270.

S. minus paluftre. Ger. em. 5 I6. Angl. Hairy Stonecrop.

In pafcuis montofis irriguis, rupiumque fiffuris humidis.

In feveral rocky parts of the northern counties. In Scotland not uncommon. In a watery place. near Linlithgow.

Perennis. Fl. Junio, Julio.

Radix fibrofa, ex obfervationibus Nob. Marchionis de Blandford certè perennis. Caulis creêtus, foliofus, fupernè pubefcens, bafi ramofus. Folia alterna, linearia, obtufa, complanata, carnofa; fuperiora præcipuè pubefcentia. Panicula cymofa, terminalis, pubefcens, vifcida. Calyx etiam pilofo-vifcidus, obtufus. Petala albida, nervo purpureo. Capfulæ acuminatæ, fcabræ, purpurafcentes.

7. SEDUM foliis oblongis teretibus obtufis pa-album. tentibus glabris, paniculâ ramofrffimâ.

Sedum album. Sp. Pl. 619. Huds. ig6. With. 427. Relh. 174. Ablot. 99. Curt. Lond. fali. r. t. 31. F\%. Dan. t. 66.

S. minus teretifolium album. Dill. in Raii Syn. $27 \mathrm{I}$.

S. minus, folio longiufculo tereti, flore candido. Baub. Hift. v. 3. 690.

S. minus officinarum. Ger. em. 5 I 2.

Angl. White Stonecrop.

In rupibus, muris et tectis, rarius.

At Kentih-town and Bromley, Middlefex. Curt. On rocks above Great Malvern, Nath. With. Walls at Peterborough. Mr,Woodwark. 
Perennis. Fl. Julio.

Radix fibrofa. Caules fpithamæi, terctes, foliofi, ramofi, glabri, bafi decumbentes. Folia fparfa, horizontaliter patentia, cylinarica, obtufiffima, glabre fubolauca, carnofa. Panicula terminalis, alternatin ranofa, fubcymofa, mi:tiflora, glabra. Flores albi, vel rubicundi. Calyx obtufus, lævis.

reflexum 8. SEDUM foliis fubulatis fparfis bafi folutis: inferioribus recurvatis, floribus fubcymofis. Sedum reflexum. Sp. Pl. 618. Hudf. 195. With. 429. Relh. I73. Sibth. I 44 .

S. minus luteum ramulis reflexis. Raii Syn. 270. Bauh. Pin. 283.

Aizoon fcorpioides. Lob. Ic. 377. Ger. em.

Crooked Yellow Sengreen. Pet. H. Brit. t. 42. f. 6 .

B. Sedum minus hæmatoides. Ger.em.512. Raii Syn. 269.

S. minus flore luteo. Baub. Hift.v. 3.692.

S. minus mas. Fuchs. Hift. 33 .

Common Yellow Sengreen. Pel. H, Brit. 1. 42. $f \cdot 5$.

Angl. Yellow Stonecrop.

In muris et tectis vulgaris.

Perennis. Fl. Julio.

Præcedente duplò majus. Caules teretes, foliofi, bafi ramofi, fxpe dependentes, apice erecti. Folia fparfa, alterna, adnato-feffilia, bafi foluta et producta, fupernè erecta, fubulata, compreffa, acuminata, glaucefcentia; inferiora reflexa, decidua. Panicula fubcymofa, ramis multifloris, plerumque recurvatis. Flores erecti, anrei, fæpe fexfidi. C.alyx acutus, ad bafin ferè divifus, glaber:

rupefre. 9. SEDUM foliis fubulatis erectis quinquefariàm confertis bafi folutis, floribus fubcymofis.

Scdum 
Sedum rupettre. Sp. Pl. 6r8. Hudf. 195. With. 429. Engl. Bot. t. I 70.

S. rupeftre repens, toliis compretiis. Dill. Hort. Eltb. v. 2. $343 \cdot$ t. $256 . f \cdot 333$.

S. minus e rupe Sancti Vincentii. Raii Syn. 270. Angl. Rock Stonecrop.

In rupibus rariùs.

On St. Vincent's rocks, Briftol, alfo on Chedder rocks, Somerfetthire, and in Wales. Dill. On walls about Darlington. Mr. Robfon.

Perennis. Fl. Julio.

Præcedente parùm minus. Folia quinquefariàm vel fexfariàm densè imbricata, glauca, fubcomplanata, acuminata ; in caule florifero remotiufcula, ut in S. reflexo; omnia erecta, nec reflexa. Panicula fubcymofa, multiflora, ramulis vix reflexis. Flores aurei, fæpe fexfidi. Calyx obtufiufculus, glaucus, rubicundus, bafi monophyllus.

217. OXALIS. G. Pl.231. Ju/. 270. Gartn. t. II 3 .

Cal. pentaphyllus. Petala 5, unguibus connexa. Capfula fupera, quinquelocularis, angulis dehifcens, pentagona. Semina arillo elaftico tecta.

1. OXALIS fcapo unifloro, foliis ternatis obcor-Acetofel. datis pilofis, radice fquamofo-articulatâ.

Oxalis Acetofella. Sp. Pl. 620. Hudf. I 98. With. 430. Relh. I 76. Sibth. 144. Abbot. 100. Curt. Lond. fajc. 2. t. 3 I. Woodv. Med. Bot. t.20. Fl. Dan. t.980. Dick. H. Sicc. fafc. 1 7. 10.

Oxys alba. Raii Syn. ${ }^{2} 2$ I. Ger. em. I20I. Merr. Pin. 90.

B. Trifolium acetofum vulgare, flore purpureo. Dill. in Raii Syn. * $28 \mathrm{r}$.

$$
\text { F } 4
$$

Lujula, 
Lujula, folium. Pharmac. Lond. Angl. Common Wood-Sorrel.

In nemorofis vulgaris.

Perennis. Fl. Aprili, Maio.

Radix horizontalis, fquamofo-dentata, carnea. Folia radicalia, longiùs petiolata, ternata; foliolis fub-petiolatis, obcordatis, integerrimis, pilofis, fubtus purpurafcentibus. Scapi uniflori, ultra medium bracteati, folia fuperantes. Flores fubnutantes, tenelli, carnei, rubro. lineati. Capfula membranacea, loculis difpermis.

corniculatco.

2. OXALIS caule ramofo diffufo, pedunculis um:belliferis, petiolis bafi ftipulatis.

Oxalis corniculata. Sp.Pl. 623. Berk. Outl. v. 2. I 27. With. 430 . Jacq. Oxal. 10.t.5. O. pufilla. Salifb.Tr. of Limn. Soc. v. 2. 243. t. $23 \cdot f \cdot 5$.

Oxys flavo flore. Chuf. Hift. v.2.249.

O. lutea. Ger. em. I 202.

Angl. Yellow procumbent Wood-Sorrel.

In ruderatis umbrofis vel fubhumidis Devonix.

In feveral places about Exeter, Mr. J. Turner; Berk. At Dawlih, Devonfhire, and in feveral other places in the fame county, Mr. Martin. With.

Perennis. Fl. Maio-Oetobri.

Radix fibrofa. Caules procumbentes, radicantes, teretes, rubicundi, ramofi, foliofi, fubinde pilofi. Folia alterna, ternata, pilofa, ftipulis petiolo adnatis: Pedunculi axillares, folitarii, umbellati, pauciflori, Flores parvi, flavi. Capfularum loculis polyfipermis.

318. AGROSTEMMA. G. Pl. 231. Juf. 302. Gartn. t. I 30 .

Cal. monophyllus, coriaceus. Petala 5, unguiculata: 
culata; limbo obtufo indivifo. Casfula fupera, unilocularis, ore quinquedentata.

1. AGROSTEMMA hirfuta, calyce corollam Githage, fuperante, petalis integris nudis.

Agroftemma Githago. Sp. Pl.624. Hudf. 198. With. 431. Relh. 176. Sibth. 145. Curt. Lond. fafc. 3. t. 27. Mart. Ft. Ruft. t. 105. Fl. Dan. t. 576. Dreves. Bilderb. t.22, Lychnis fegetum major. Raii Syn. 338 . Pfeudomelanthium. Ger. em. 1087. Bawh. Hift. v. 3. 341. Camer. Epit. 554. Lolium. Fuchf. Hift. 127. Angl. Corn Cockle.

Inter fegetes vulgaris.

Annua. Fl. Junio, Julio.

Radix parva. Herba hirfuta, fetis erecto-adpreffis, canefcentibus. Caulis bipedalis, teres, ramofus, foliofus. Folia oppofita, lineari-lanceolata. Flores terninales, purpurei, fpeciofi. Calyx decemcoftatus, dentibus lineari-lanceolatis, foliaceis, patentibus, corollà duplò longioribus, demum deciduis. Petala fauce nuda, limbo obcordato. Capfula avata, rigida, polyfperma.

Genus vix diftinctum a Lychnide.

219. LYCHNIS. G. Pl.231. Juf. 302.

Gertn. t. I30,

Cal. monophyllus, oblongus. Petala quinque, unguiculatil; limbo fæpiùs divifo. Capjula fupera, ore quinquedentata, $\mathrm{I}-5$-locularis.

I. LYCHNIS petalis quadrifidis, fructu fubro Flostundo uniloculari.

Cuculi.

Lyychnis Flos-Cuculi. Sp. Pl.625. Hudf. I99. With. 432. Relh. 177. Sibth. 145. Curt. Lond. 
Lond. falc. 1. t. 33. Fl. Dan. t.590. Engl. Bot.t. 573 .

L. plumaria fylveftris fimplex. Raii Syn. 338 .

Armoraria pratenfis mas. Ger. em. 600. Angl. Ragged Robin. Mieadow Lychnis.

In pratis humidis.

Perennis. Fl. Junio.

Radix fibrofa. Caulis erectus, pedalis vel bipedalis, angulatus, foliofus, feris deflexis fcaber, fupernè vifcidus, bafi interdum ramofus, ramis decumbentibus, radicantibus. Folia connata, lanceolata, integerrima, lieviufcula. Panicula dichotoma, erecta, foliolofa. Calyx cylindraceus, coftis atropurpureis. Petala femiquadrifida, coronati, rofea, flaccida. Capfula fubrotundocylindracea, unilocularis. Semina pedicellata.

Variat flore pleno, fubinde albo.

$V_{2}$ caria. $_{\text {. }}$ LYCHNIS petalis indivifis, fructu quinqueloculari.

Lychnis Vifcaria. Sp. Pl. 625. Hudf. 199. With. 433. Lightf. 239. Fl. Dan.t.1032.

L. fylveftris vifcofa rubra anguftifolia. Raii Sy'n. 340 .

Mufcipula anguftifolia. Ger.em.60I.

Odontidi five flori cuculi affinis Lychnis fylvertris. Buut. Hift. v. 3. 348 .

Angl. Red German Catchily.

In fiffuris rupium rariùs.

On the rocks of Edinburgh park, T. Willifell; and on the fides of Craig Wreidhin hill in Montgomerythire, Mr. Lhwyd. Ray. On the rocks by the Hermitage, a mile fouth of Edinburgh, in tolerable plenty.

Peremis. Jl. Maio, Junio.

Radix lignola, cæfpitofa. Caulis pedalis, angulatus, fulcatus, foliofus, glaber, fub geniculis vifcidus. Tolia 
connata, lineari-lanceolata, glabra. Panicula fubfpicata, ramis dichotomis. Flores conferti. Calyx membranaceus, incarnatus, fubpilofus. Petala rofea, obfoletè emarginata, coronata. Capfula ovata, brevis, quinquelocularis, diffepimentis e medio valvularum. Semina plurima, reniformia, fcabra.

3. LYCHNIS floribus dioicis, fructu uniloculari. dicica.

Lychnis dioica. Sp. Pl. 626. Hudf. 199. With. 43 I. Abbot. IOI.

a. L. dioica. Curt. Lond. fafc. 2. t. 32 .

L. alurna. Sibth. I45. Sym. Syn. I 12.

L. Yylveftris rubello flore. Raii Syn. 339. Ger. em. 469 .

3. L. dioica. Fl. Dan. t. 792. Relb. 177.

L. vefpertina. Sibth. I46. Sym. Syz. I 12.

L. rylveftris albo fiore. Raabi Syn.339.

Angl. a Red Campion. $\beta$ Whitc Campion.

In nemorofis humidis, fepibufque, vulgaris. $\beta$ in fepibus et arvis frequens.

Perennis. Fl. Maio-Septembri.

Radix fufformis. Herba pilofa, fubvifcida. Caulis erectus, teres, foliofus, paniculatus, fubdichotonus. Folia integerrima, lanceolata vel ovata. Flores pediccllati, bracteati. Calyx decem-coftatus. Petala femibifida, coronata. Capfula ovata, unilocularis.

a fructu minore dignofcenda eft, caule infirmiore, foliis ovatis, mollioribus, floribus rofeis, inodoris, plerumque dioicis, rariflimè hermaphroditicis, calyce in utroque fexu decemcoftato, omninò ferè enervi.

\& gaudet fructu majore, caule firmo, altiore, foliis lanceolatis, floribus albis, nocte fuaveolentibus, dioicis, rariùs hermaphroditicis; calyce maribus elliptico-clavato, decemcoftato, enervi; foemineis ovato, nervis intercortalibus folitariis.

Differentiam fpecificam inter hafce varietates vix inveni, cum figura fructûs ne minimam præbet diftinctionem. Varietas carnea, fubindè hermaphreditica, quandoque invenitur.

220. CE- 
2.20. CERASTIUM. G. I\%. 232. Fill. 30 . Git's h. t. з 30 .

Cal. pentaphyllus. Petala bifida. Cappala fapera, appice dehifeens, ore decemblentata, unilocularis.

s'ulgaเนาน.

1. CERASTIUM hirfutum vifcidum cépitofum, foliis ovatis, petalis calyci xequalibus, floribus pedunculo longioribus.

Ceraftum vulgatum. Syt. Nat. ed. ro. v. 2. 1039 A, Ilerb. Limn. Fl. Stut. ed. 2. I 58. Sp. I\%. 627. lightf. 240.

C. vificofum. Hudf. 200. Hith. 433. Relh. 178. Sibtb. 147. Curt. Lond. fafi. 2. t. $35^{\circ}$

Alfine hirfuta major, foliis fubrotundis dilute virentibus. Arorif. v. 2. 551 . fect. 5. t. 23 . f. ro. Herb. Morif.

A. hirfuta Myofotis latifolia praecocior. Raii Syn. 348 .

Myofotis arvenfis hirfuta parro flore. Vaill. Par. t. zo. f. 3 .

Angl. Broad-leaved Moufe-car Chick-weed.

In pafcuis, ruderatic, muris, aggeribus, vulgaris.

Anná. Fl. Aprili, Maio.

Kadix fibrofa. Herba pallilè virens, hirfuta, vifcida.

Caules plurimi, fpithanæi, caepitof, teretes, foliofi, paniculato-dichotoni, multiflori; exteriores bafi diffuf, dein eresti. Folia latè ovata, vel elliptica, obtufa. Flores e dichotomiâ caulis, pedunculati, erecti, pedunculis calyce brevioribus, minus vifcidis, fuperiores conferti. Calycis foliola lanceolata, acuta; interiora margine fcariolo albo. Petala oblonga, emarginata, alba, calycem vix fuperantia. Stamina decem, omniza fertilia, bafi glandulofa. Germen ovatum. Capfula cylindracea, calyce duplò longior, parùm incurvała. Semina lineata, tuberculata, fulva. 
2. CERASTIUM hirfutum vifcidum diffufum, riffosum. foliis lanceolato-oblongis.

Ceraftium vifcofum. Sp. Pl. ed. I. 437. n. 2. Herb.Linn.-ed.2.627. Fl. Suec.ed.2. I 58. Lightf. 24 ○.

C. vulgatum. Hudf. 200. With. 433. Relh. 178. Curt. Lond. fafco. 2. t. 34. Wade Dubl. I 25.

Alfine hirfuta altera vifcofa, foliis longis faturatiùs virentibus. Morif. v. 2. $55 \mathrm{I}$. Sect. 5 . t. 23. f. I1. Herb. Morif.

A. hirfuta Myofotis. Rain Syn. 349 .

Myofotis hirfuta altcra vifcofa. Faill. Par. t. 3o. f. I.

Angl. Narrow-leaved Moufe-car Chick-weed.

In pratis, pafcuis, muris et ruderatis vulgaris.

Perennis. Fl. Miaio-Septembri.

Radix fibrofa, parra, perennis. Herba faturatè virens. hirfuta, magis vel minus vifcida. Caules plurimi, longitudine varii, diffuri, in pratis erecti, teretes, folliofi, paniculato-dichotomi. Folia lanceolato-oblonga, obtufiufcula. Flores e dichotoniâ caulis, pedunculis vifcidis, calyce duplù ferè longioribus. Calycis foliola omnia ferè margline fcariofa. Petala calyce plerumque longiora, obovata, apice bipartita. Stamina omnia fertilia. Capfula cylindracea, calyce duplo feré longior, parùm incurvata. Semina rugola.

3. CERASTIUM hirfutum vifcidum, floribus femipentandris, petalis emarginatis.

decans-

Ceraftum femidecandrum. Sp. Pl. 62\%. Hudf. drum。 200. With. 435. Relh. 179. Sibth. 147. Abbot. Iо . Curt. Lond. fafe. 2. t. 33. Dickf. H. Sicc. fafi. 8. I I.

C. hirutum minus, parvo flore. Dill. in Raii Syn. 348. t. I5. f. I.

Myofotis 
Myofotis arvenfis hirfuta minor. V'aill. Par. t. $30 . f .2$.

B. Ceraitium pumilum. Curt. Lond. fafc. 6. t. 30 . With. 435. Abbot. 102.

Angl. Little Moufe-car Chick-weed.

In ruderatis, arenofis, et ad muros, frequens.

6. On dry banks near Croydon, Surrey. Mr. Dirkfon.

Anmua. Fl. Martio, Aprili.

Radix fibrofa. Herba facie præcedentis, fed minor, fæep rubicunda. Caules erecti, bafi tantum decumbentes, hirfuti, fupernè vifcidi. Folia ovato-oblonga ; infina fæpiùs glabrata. Pedunculi calyce longiores, poft florefcentiam refracti, demùm erecti. Calyx vifcidus, margine dilatato, albo. Petala plerumque calyce breviora, emarginata. Stamina 5, rariùs plura. Capfula calyce duplò ferè longior, incurva. Semina fulva, granulata, compreffa.

B parùm difcrepat nifi petalis calyci æequalibus, profundius incifis, capfulis feminibufque aliquantulum majoribus; fed hæc omnia variabilia funt. Plantam $\mathrm{ex}$ amiciffimo Dickfono jamdudùm viventem habui. Structurâ partium, etian feminum, cun C. femidecandro vulgari tam arctè convenit, ut, me faltèm judice, feparari nequeunt.

4. CERASTIUM hirfutum fubvifcidum, floribus drum. quadrifidis tetrandris, petalis bifidis calyce brevioribus.

Ceraftium tetrandrum. Curt. Lond. fafc. 6. t. $3 \mathrm{I}$.

Sagina ceraftoides. Tranf. of Limn. Soc. v. 2. 343. Engl. Bot. t. I66. Dick. H. Sicc. fafc. ro. 4. Dryandr. Cat. $\approx$ 3. 244. Angl. Tetrandrous Moufe-ear Chick-wced.

In arenofis maritimis, muris et ruderatis Scotiæ. This I firft obferved on walls about Edinburgh, as 
well as on the Calton hill and Arthur's reat, in 1782 , and communicated it to Dr. Hope. It has fince been found by Mr. Dickfon on Inch Keith and Inch Combe in the Frith of Forth, and alfo on the beach below Prefton-pans.

Annua. Fl. Maio, Junio.

Radix fibrofa ramofa. Herba lætè virens, multicaulis, ramofa, hirfuta, fubvifcida. Caules diffufi, foliofi, dichotomi, vix paniculati. Folia elliptico-oblonga; fumma ovata. Pedunculi calyce triplò ferè longiores, erecti, demùm refracti. Calycis foliola hirfuta, acuminata, quaterna; quorum duo interiora anguftiora, margine fcariofa. Petala quatuor, calyce breviora, obcordata, alba. Stamina quatıor, rariùs quinque. Capfula cylindracea, calyce parùm longior, apice octodentata. Semina extùs fcabriufcula.

Flores in plantâ fpontaneâ femper quadrifidi tetrandri, in cultâ fubinde quinquefidi pentandri. C. pentandrum Linnæi habitu et calyce quam maximè refert, at differt partium numero, petalis majoribus, bifidis, pedunculifque fructiferis quintuplò longioribus.

5. CERASTIUM foliis lineari-lanccolatis obtufis arvenfi. bafi ciliatis, petalis calyce duplò longioribus. Ceraftium arvenfe. Sp. Pl. 628. Hudf. 201. With. 434. Relh. I 79. Sibth. 147. Ab. bot. 102. Curt. Lond. fafe. 6. t. 29. Engl. Bot.t.93. Fl. Dan. t. 626.

Caryophyllus arvenfis hirfutus flore majore. Raii Syn. 348 .

C. Holoftius. Ger. em. 595 .

Myofotis arvenfis hirfuta flore majore. Vaill. Par. t. 30. f. 4. ctiam M. polygoni foliò ranefcente. Ibid. f. 5. ni fallor, confirmante Hallero.

M. n. 889. Hall. Hift. $.3_{3}^{89 .}$ Angl. Field Chick-weer. 
In arvis, aggeribus, et montofis, folo glareofo vel cretaceo.

Perennis. H. Maio-Augufto.

Radix repens. Caules decumbentes, implexi, cæipitofi, pubefcentes. Folia lineari-lanceolata, plerumque dense pubefcentia, fubinde bafi tantùm ciliata. Panicula dichotoma, paucifora, pubefcens, fubvifcida. Flores magni, fpeciofi, nivei. Foliola calycina ovata, obtufa, margine fcariofa. Petala obcordata, calyce duplò longiora. Capfula cylindracea, recta, longitudine ealycis; ore decemdentato.

altinum. 6. CERASTIUM foliis ellipticis nudis pilofifve, paniculâ dichotomâ pauciflorâ bracteatâ, capfulâ oblongâ recurvâ.

Cerattium alpinum. Sp. Pl. 628. Hridf. 201. With. 434. Engl. Bot. t. 472. Fl. Dan. t.6:

C. latifolium. Lightf. 242.t. 10.

Alfines Myorotis facie, Lychnis Alpina, flore amplo niveo, repens. Raii Syn. 349. t. 15. f. 2 .

Angl. Alpinc Chick-weed.

In alpibus Scoticis et Cambro-britannicis, locis irriguis.

On the fides of Snowdon. Mr. Lbayd. On a mountain near Llariberris. Lighif. Herb. On Ben Lomond, near the top, in a dry fituation.

perennis. Fl. Junio, Julio.

Radix repens. Caules fubcæfpitofi, erecti, palmares, fimplices, teretes, foliofi, apice dichotomi, pauciflori, fubinde uniflori. Folia elliptica, obtufiufcula, latitudine varia; in aquofis ut videtur glabra; in apricis verò pilis longis, mollibus, articulatis, adfcendentibus, obfita. Pedunculi fubterni, uniriori. Bracteæ oppofitæ, lanceolatæ. Flores niägni, albi, formofi. Foliola calycina margine fcariofá. Petala obcordata, calyce fefuilongiora. Germen oratum. Capfula cylindracea, calyce longior, reenrva.

\%. $\mathrm{CE}$ - 
7. CERASTIUM foliis ellipticis feabris, pedun-latifos culis terminalibus fimplicibus fubfolitariis, Lium. capfulâ ovatâ.

Ceraftium latifolium. Sp. Pl. 629. Hudf. 202. With. 434. Jacq. Coll. v. I. 256. t.20. Engl. Bot. t. 473.

C. tomentofum. Hudf. ed. 1. I 6 .

Alfine Myofotis lanuginofa Alpina grandiflora. Ruiii Syn. 349.

Angl. Broad-leaved roitgh Chick-weed.

In alpibus Cambro-britannicis et Scoticis.

On Clogwyn y Garnedd, a very high mountain near Llanberris, Carnarvonthire. Dr. Ricbardfon. Mr. Grifith. On the Highland mountains. Mr. Mackay.

Perennis. Fl. Junio.

Caules cefpitofi, quam in precedente longè humiliores, densè foliofi, fcabri, unifori. Folia elliptica, vel fubovata, pilis brevibus, rigidis, porrectis, crebriùs articulatis, fcabra. Pedunculi terminales, folitarii, longitudine ferè caulis, ebracteati, fcabri, unifori. Flos ferè precedentis. Capfula ovata, brevis.

8. CERASTIUM foliis cordatis feffilibus, pedun-aquaticulis lateralibus folitariis: fructiferis reflexis, cum. capfulà ovatâ ore quinquedentato.

Ceraftum aquaticum. Sp.Pl. 620. Hudf.202. ITith. 436 . Relis. ISO. Sibth. 147. Abbot. 102. Curt. Lond. falfc. 1. t. 34. Engl. Bot. $t: 53^{8}$.

Alfine major repens perennis. Raii Syn. 347 . A. major. Ger. em. 6II. Camer. Lpit. 85 I. Dalech. Hift. 1232. Angl. Water Chick-weed.

Tn aquofis et ad ripas furrorum.
VOL. II. 
Perminis. Fl. Julio.

Radix repens. Caules bipedales, debiles, ramofi, foliof, tcretes, undique pilofi. Folia feffilia, cordata, acuminata, undulata, pilofa; infima fxpe petiolata. Pedunculi laterales, intrafoliacci, folitarii, unifori, erecti, demim refiacti. Calycis foliola ovata, pilofa, vifcida. Petala longitudine ferè calycis, fubindè longiora, profunde bipartita, alba; laciniis fublinearibus. Stamina femper ro. Styli 5. Capfula ovata, ad nedium ufgue quinqueficla, five quinque-dentata. Semina reniformia, ficabra.

\section{SIERGULA. G. Pl. 232. Juf. 30I. Giertn.t. 130 .}

Cat. pentaphyllus. Petula 5, integra. Capjula fupera, ovata, uniocularis, quinquevalvis.

arienfas. I. SPERGULA folitis verticillatis, pedunculis fructiferis reflexis, feminibus reniformibus.

Spergula arventis. Sf. Pl. 630. Hhulf. 202 : IVilb. 436. Reil. 181. Sibth. 149. Curt. Lond. falc. 5.t. 31. Fl. Dan. t. 1033. Spergula. Dod. Pempt. 537. Baub. Hift. v. 3 . $719,2$.

Aline Sperguia dicta major. Raii Syn. $35 \mathrm{I}$. Dubarnel Cult. 2.6 . I 49. t. I.

Sagina Spergula. Ger. em. II 25. Aingl. Corn Spurrey.

In arvis arenofis.

Anmua. Fl. Julio, Augurio.

Radix fibrofa, parva. Caules erecto-patentes, fubramofi, terctes, glabri, foliofi, geniculati, geniculis tumidis; fupernè pilofi, vifcidi, paniculati. Folia verticillata, linearia. obtufa, fubinde pilofa. Panicula dichotoma, divaricata, multiflora. P'edunculi uniflori, pubefcentes, rifcicli, bafi bractcati, poft florefcentiam refracti. Calycis foliola ovata, obtufa, concava, pilofa, margine fcariofa. Petala ovata, alba. Capfula calyce dupló lon- 


\section{DECANDRIA-PENTAGYNIA.}

gior. Semina reniformia, gibbofa, marginata, demùm tuberculato-fcabra.

Variat rariùs floribus pentandris.

†2. SPERGULA foliis verticillatis, floribus pen-pentan tandris, feminibus depreffis alatis. dra.

Spergula pentandra. Sp. Pl. 630 .

$\mathrm{S}$. annua, femine foliaceo nigro, circulo membranaceo albo cincto. Dill. in Raii Syn. $35 \mathrm{I}$. Gid. 46. Eph. Nat. Cur. Cent. 5 E5 6. 275 . t. $4 . f$. 1 .

Alfine Spergula dicta, femine membranaceo fufco. Raii Syn. ed. 2. 2 10. Conf. Morif.

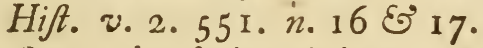

A. Spergulæ facie minima. Magn. Mon/p. I4. Angl. Little Corn Spurrey.

In arvis arenofis.

Obferved in Ireland by W. Sherard, M. D. Dill.

Annua. Fl. Junio.

Habitus præcedentis, fed minor. Folia pauciora, magifque carnofa. Calycis margo vix feariofus. Stamina 5. Semina complanata, lævia, margine dilatato, membranaceo, albo.

Hanc fpeciem nondum inveni, fed ex Dillenii fide admifi. E Loeflingio accepit Linnæus.

3. SPERGULA foliis oppofitis fubulatis lævibus : nodofa: fuperioribus fafciculatis, calyce enervi.

Spergula nodofa. Sp. Pl. 630. Hudf. 203. With. 437. Relb. 181. Sibth. 148. Abtiot. I03. Curt. Lond. fafc: 4. t. 34: Fl. Dan. t. 96.

Alfne palutiris foliis tenuiffimis, feu Saxifraga paluftris anglica. Raii Syn: 350 .

Saxifraga paluftris Alfinefolia. Goodyer in Ger: em. $5^{6} 7$.

Arenaria. Bank. Hif. ช. 3. ๆ20.

$$
\mathrm{F} \approx
$$

Poly- 
Polygonum foliis gramincis alterum. I:ver. 'inf: $204 \cdot t .64$.

Angl. Knotted Spurney.

In arenolis humidis.

Perennis. Fl. Julio, Augufto.

Radix fibrofia. Caules caefipitofi, patentes, palmares, fubramofi, foliofi, glabri, paucifori. Folia connata, fubulata, glabra, bafi fubinde obfuletè ciliata ; fuperiora in axillis fafciculata. Flores pedunculati, fubtcrminales, albi. Calycis foliola ovata, obtufa, carinata, enervia, glabra. Capfula calyce fefquilongior.

fagino:- 4. SPERGLLA foliis oppofitis fubulatis muticis nudis, pedunculis folitariis longiflimis glabris. Spergula faginoides. Sp. $P l . \sigma_{3} \mathrm{r}$. Swartz. A.r. Holin. Ann. 1-89. 4+. t. 1. f. 2 ?

Alfine floribus (foliis) gramineis, frepè fafciculatie, glabris, peduneulis longis nudis unifloTis. Gmet. Sit. 0.4. $15 \%$

Ang?. Smooth Awl-ihaped Spurrey.

In alpibus Scoticis.

On Ben Lawers, where it was difcovcred by Mr. J. Mackay in 1794 .

Perennis. Fl. Junio.

Siadix fibrofa. Herba omininù glabra. Caules decumbentes, fubramofi, fefquiunciales, foliofi, teretes, geniculati, apice erećti. Folia comnata, fubulata, acuta. Pedunculi plerumque terminales, foiltarii, erecti, uniflori, teretes, nudi, glaberrimi, longitudine ferè caulium. Flores cernui, albi. Calycis foliola ovata, obtafa, levia, ferè cnervia, bafi gibbofa. Petala fubrotunda, obtufa, integerrma, calyce breviora. Stamina decem, petalis vix longiora. Capfula ovata, calyce duplò longior, quinquevalvis. Semina reniformia, fufca, non marg:nata.

Stamina tantum gु in ienit Cel. Swartz. 5. SPER- 
5. SPERGULA foliis oppofitis fubulatis arifatis fubulata. ciliatis, pedunculis folitariis longifimis rubpilofis.

Spergula fubulata. With. 436 . Siurtz. Az. Holm. Arin. $1789 \cdot 45$. t. I. $f .3$.

S. laricina. Hudf. 203. Lightf. 244. Fi. D.m. t. 858 .

S. faginoides. Curt. Lond. fafc. 4.t.35.

Sagina procumbens $\beta$. ip. Pl. I 85 .

Saxifraga graminea pufilla, foliis brevioribus craffioribus et fueculentioribus. Raii Sy $\%$. 345 .

Angl. Ciliated Awl-fhaped Spurrey.

In ericetis arenofis.

Perennis. Fl. Julio, Augufto.

Radix fibrofa. Caules bafi procumbentes, radicantes, dein erecti, ramofi, foliofi, teretiufculi, glabri. Folia connata, fubulata, ariftata, ciliata pilis glandulofis. Pedunculi terminales et axillares, folitarii, unifori, magis vel minus pilofi. Flores fubcernui, albi. Calscis toliola ovata, obtufa, fubcarimata, pilofa, fubrificida. Petala obtufa, longitudine calycis. Stamina quinque, rarius decem. Capfula calyce parum longior, quinquevalvis. Semina reniformia, comprefra, pallidé fufca, lineầ nigrâ cincta, vix marginata.

Hauc cunı Saginâ procumbente proculdubiò confudit Linnæus. 



\section{Claffis $X I$. \\ DODECANDRIA,}

Stamina $12-20$.

\section{MONOGYNIA.}

\section{Stylus 1.}

222. ASARUM. Cor. nulla. Cal. trifidus, fuperus. Capf. iexlocularis.

223. Lythrum. P'et. fex, Cal. duodecimfidus, inferus.

\section{DIGYNIA.}

\section{Styli 2.}

224. AGRIMONIA. Pet. quinque, calyci inferta. Sim. in fundo calycis.

\section{TRIGYNIA.}

Styli 3 .

225. KESEDA. Pet. multifida. Capf. unilocularis, hians.

225. EUPHORBIA. Nectaria peltata. Caps. tricocca, pedicellata. 


$$
(508)
$$

\title{
TETRAGYNIA.
}

\author{
Styli 4 .
}

Tormentilla officinalis.

\section{DODECAGYNIA.}

$$
\text { Styli } 12 .
$$

22\%. SEMPERVIVUM. Pet. duodecim. C $u$ ? duodecimpartitus. Cap. duodecim. 


\title{
XI. DODECANDRIA.
}

\section{MONOGYNIA.}

222. ASARUM. G. Pl. 235. JuJf. 73.

\author{
Gertn. t. I4.
}

Cul. trifidus, germini infidens. Cor. nulla. Strmina 12. Capfula coriacea, fexlocularis, coronata. Stimma fexfidum.

7. ASARUM foliis reniformibus obtufis binis. europers Afarum europæum. Sp. Pl. 633. Hudf. 205. ums. With. 440. Woodv. Med. Bot. to 86. F\%. D..n. t. 633. Dick. Dr. Pl. 7.

Afarum. Raii Syn. 5 58. Ger. em. 836. Fuchl\% Hift. хо. Brunf. Herb. v. x. 7 т. Matth. Valgr. v. 1. 33. Cord. Hijt. II2. I. Afarum, folium. Pharrnac. Lond. Angl. Ararabacca.

In nemorofis Angliæ borcalis rariùs.

In feveral woods in Lancarhire. Ray. Near Kirkby Lonfdalc, Weftmoreland. Dr. Batty.

Perennis. Fl. Maio.

Radix repens. Caulis brevis, fimplex, uniflorus, et plerumque bifolius, teres, pubefcens. Folia oppoita, longiùs petiolata, reniformia, integerrima, fubpubefcentia. Flos pedunculatus, terminalis, urceolatus, atro-purpufeus, villofus.

223. LYTHRUM. G. Pl. 240. Jul. 332. Gartn. t. 62.

Cal duodecimfidus, inferus. Petalu fex, calyci inferta. Capfula bilocularis, polyfperma. 
Salica- I. LYTHRUM foliis oppofitis cordato-lanceoria. latis, floribus fuicatis dodecandris. Lythrum Salicaria. Sp. Pl. 640. IJudf. 205. Whth. 441. Relb. is2. Sibth. 149. Curt. Lond. faffe. 3. t. 28 . Fl. Dam. t. 6: I. Salicaria vulgaris purpurea foliis "blongis, Ruii Syn. 367 .

Lyfimachia purpurea fpicata. Ger. em. 476 . Angl. Purple Loofefirife.

In paluftribus, et ad ripas fluviorum.

Perennis. Fl. Julio, Augufto.

Formofa planta. Radix lignofa, ramofa, multiceps. Cau. les tripedales, erecti, virgati, quadranguli, fubinde hexagoni, foliofi. Folia oppofita, rarius terna, etiam quaterna, feffilia, lanceolata, bafi cordata ; fuprâ glabra; fubtùs margincque pubefcentia. Flores verticillatofpicati, purpurei, dodecandri. Calyx ruber. Petala oblonga, undulata. Stamina alterna longiora, inflexa. Capfula elliptica, parva.

by-fopifo-2. LYTHRUM foliis alternis lincari-lanccolatis, lium. floribus axillaribus folitariis hexandris.

Lythrum byfopifolium. Sibth. 149. Engl. Bot. t. 292. With. 4+1. Abbot. 104.

L. Hyfopifolia. Sp. Pl. 672. Hudf. 206. Relb. 183. Jacq. Auftr. t. 133. Dickf. H. Sicc. fafc. 16. 2 .

Salicaria Hyffopi folio latiore et anguftiore. Raii Syn. 367. Rupp. Jen. ed. Halleri 147. t. 6. f. 2 .

Gratiola anguftifolia. Ger.em. $58 \mathrm{I}$. Angl. Hyffop-lcaved Loofeftrife, or Grafs-poly.

In aquofis, et ubi aquæ per hyemem ftagnârunt, fed rariùs.

On Hounflow heath. Hudf. In Cambridgefhire and 
and Huntingdonthire. Reih. With. OxfordThire. Sibth. Near Bedford. Rev. Mr. Ab6ot.

Annua. Fl. Augufto.

Radix attenuata, fimplex. Caulis fpithamxus, bafi ramofus, erectus. Folia lineari-oblonga, glabra, latitudine varia; inferiora tantùm oppofita. Flores axillares, fubfeffiles, folitarii, parvi, purpurei, hexandri, reguslares, interdùm quinçuefidi pentandri.

\section{DIGYNIA.}

24. AGRIMONIA. G. Pl. 241. JufJ. 336 . Gertn. t. 73 .

Cal. quinquedentatus, calyculatus. Petala quinque, calyci inferta. Semina duo, in fundo calycis.

1. AGRIMONIA foliis caulinis pinnatis : impari Eupatopetiolato, fructibus hifpidis.

Agrimonia Eupatoria. Sp. Pl.643. Hudf. 206. With. 443. Relb. 183. Sibth. 150. Curt. Lond. fafs. 5. t. 32. Mart. F\% Ruft. t. 37 ; Fl. Dan.t.588. Moodv. Suppl. t. 253.

Agrimonia. Raii Sym.202. Ger. em. 7 I 2. Eupatorium. Matib. Valgr.v.2.362. Angl. Common Agrimony.

In dumetis et ad margines agrorum.

Perennis. Fl. Junio, Julio.

Radix ramofa, non repens. Caulis bipedalis, folinows, angulofus, 
angulofus, pilofus. Folia alterna, interruptè et impari pinnata, fublyrata, pilofa ; foliolis obovatis, acutis, incifo-ferratis; impari petiolato ; internedis minimis, integris trifidifie. Stipula lunatax, incifar. Spicaterminalis, multiflora, erecta, pilofa. Hlores brevius $p e-$ dicellati, aurei. Calyx perfiftens, induratus, fulcatus, futis uncinatis muricatus. Herba aromatica, tonica.

\section{II. TRIGYNIA.}

225. RESEDA. G. Pl. 242. Julf. $245^{\circ}$ Gartn. $t .76$.

Cal. monophyllus, partitus. Petala laciniata. Cap. fula fupera, apice hians, unilocularis, polyfperma.

Luiccla. I. RESEDA foliis lanceolatis integris planis, ca. lyce quadrifido.

Refeda Luteola. Sp. Pl. 643. Ifudf. $20 \%$ Wilb. 445. Relb. 184. Sibth. 150. Mart. Fl. Ruft. t. 40. Engl. Bot.t.320. Luteola. Raii Syn. 366. Ger. em. 494. B. L. minima Polygalix folio. Dill. in Raii Syn. 367 ?

Angl. Dyer's-weed, Yellow-weed, or Weld.

In ruderatis, arvis requictis, et ad muros.

Common about Norwich.

3. Corntields on Mount Ephraim, Tunbridge Wells Mr. Du Bois.

Annue. Fl. Julio. 
Radix fufformis. Caulis virgatus, ftrictus, bipedalis, ramofus, foliofus, ftriatus. Folia lineari-lanceolata, integerrima, plana, glabra, fixiùs denticulo utrinque ad bafin. Spicæ terminales, erectæ, mulifforæ, bracteolati. Flores ochroleuci. Calyx quadrifidus. Petalum fuperius impar, quadrifidum; lateralia trifida, fubinde linearia, indivila. Nectarium crenatum, ad bafin petali fuperioris. Stamina declinata.

2. RESEDA foliis omnibus trifidis: inferioribus lutea, pinnatis, calyce fexfido.

Rcreda lutea. Sp. Pl. 645. Hudf. 207. With. 446. Relh. I84. Sibth. 151. Engl. Bot.t.321. Dicks. H. Sicc. fajc. 8. I2. Jacq. Auftr. t. 353.

R. vulgaris. Raii Syn. 366.

Bafe Dyer's Weed. Pet. H. Brit. t.37.f. II.

3. Refeda crifpa galiica. Dill. in Paii Syn. 366. Boce. Sic. $76 . f \cdot 3$.

Angl. Wild Mignonettc, or Bare Rocket.

In arvis collibufre cretaceis.

Annuca, vel Pirennis. Fl. Julio, Augufto.

IRadix fublignofa. Caules plures, ramofi, foliofi, teretes, ftriati, glabri. Folia trifida vel pinnatifida, inferiora frope bipinnatifida, laciniis linearibus, canaliculatis, glabris, magis vel minus undulatis. Spica terminales, erectre, multiflore, bracteolatæ. Flores ochroleuci. Calyx fexfidus. Petala fex, variè lobata. Nectariumx finbriatum. Stamina declinata.

226. EUPHORBIA. G. Pl. 243. Jus. 385.

Cal. monophyllus, ventricofus, inferus. Nectaria 4 vel 5 , calyci infidentia. Capfuita pedicellata, tricocca.

* Disboiome (umbella bificla aut nullia).

t. ELPHORBIA foliis fubintegerrimis femicor- Feplis, datis, 
datis, floribus folitariis axillaribus, caulibus procumbentibus, capfulâ lixvi.

Euphorbia Peplis. Sp. Pl. 652. Hudf. 20\%. Ifith. 446.

Tithymalus maritimus fupinus annuus, Peplis dictus. Raiii Syn. 3 I 3 .

Peplis. Malth. Vulgr. v. 2.599. Camer. Epit. 970. Ger. em. 503 .

P. Matthioli, et Peplion. Dalech. Hifl. 1659. Angl. Purple Spurge.

In maritionis arenofs atufralioribus.

Between Penfans and Marketjeu in Cornwall plentifully. Ray. In the loofe fand near Exmouth, Deronthire. Hudf.

Anmua. Fl. Julio, Augufto.

Radix longiffina. Caules proftrati, divaricati, alterna* tim ramofi, foliofi, quadranguli, glabri, rubicundi. Folia oppofita, petiolata, femicorlata, obtufa, glabra, purpureo-glauca, uninervia, bafi apiceque fubinde denticulata. Stipulæ intrafoliacere, parvie, multifido-fetacex. Pedunculi axillares, folitarii, uniflori. Flores parvi, lutef́centes. Nectaria 4. Capfula deflexa, lævis.

\section{* * Unbella trifida.}

Pesplus. 2. EUPHORBIA umbellâ trifidâ : dichotomâ, involncellis ovatis, foliis integerrimis obovatis petiolatis.

Euphorbia Peplac. St. Pl. 653. Inudf. 208. With. 447. Relh. $18_{5}$. Sibth. 15s. Curt. Lond. fu/ce. $3 . t .35$.

Tithymalus parves annums, folis fubrotundis non crenatis. Pephu diclus. Ruii Syn 313. Peplus, five Efula rotunda. Ger. em. 503 . P. Matthioli. Daleib. Hif. $: 558$.

Peplus. Camer. Epit. gog. Airigl. l'etty Spurges. 
In cultis pafim.

Annua. Fl. Julio, Augufto.

Radix parva, fibrofa. Herba læte virens, glabra. Caulis erectus, ramofus, teres, foliofus, trifidus, ramis dichotomis. Folia caulina fparfa, petiolata, obovata, integerrima. Involucella, feu folia ramea, oppofita, fubleffilia, ovata, bafi inæqualia. Flores parvi, lutei, nectariis 4 , bicornibus. Capfula glabra. Semina angulata, excavato-punctata.

3. EUPHORBIA umbellâ trifidâ: dichotomâ, exigư⿱ involucellis lanccolatis, foliis linearibus.

Euphorbia cxigua. SP. Pl. 654. Hudf. 208. With. 447. Relh. 185. Sibth. I5 I. Curt. Lond. fafc. 4. t. 36 . Dickf. H. Sicc. fafc. 9.6. F.. Dan. t. 592.

Tithymalus leptophyllos. Raii Syn. 3I3. $C_{a z}$ mer. Epit. 966.

Efula exigua Tragi. Ger. em. 503 .

Peplis minor. Dalech. Hi/t. I 659 .

B. Tithymalus iegetum longifolius. Raii Syn. 3 r2? Angl. Dwarf Şpurge.

Inter fegetes.

Annua. Fl. Julio.

Herba fpithamza, glabra. Folia feflilia, linearia, acuta. integerrima. Flores exigui, flavi. Nectaria 4, bicornia. Capfula lievis. Semina quadrangula, corrugata. Variat umbellâ quadrifidâ, fubinde quinquefidâ. Curtis, Relban.

$$
\text { * * Umbella quinquefida. }
$$

4. EUPHORBIA umbellâ quinquefidâ : dicho- Fortlar tomâ, involucellis fubcordatis concavis, foliis disa. lineari-obovatis acutis glabris patentibus. Euphorbia Portlandica. Sp. Pl.656. Hudf. 208. With. 448. Enjl. Bot. t. 4 II.

Iithy- 


\section{5l. DODECANDRIA-TRIGINIA.}

Tithvmalus maritimus minor, Portlandicus Dill. in Raii Sy.n. $313 \cdot t \cdot 24 \cdot f \cdot 6$. Angl. Portland Spurge.

In maritimis auteralioribus.

On Portland ifland, and on the coafts of Devonfhire and Cornwall. Near Caernarvon, Wales. Hudf. On the warren near Exmouth, plentifully. Rev. Dr. Goodenongh.

Perennis: FI. Augufto.

Rudix ramofa, longa. Herba glauca. Caulis ferè pedalis. Folia obovato-linearia, mucronulata. Umbella quinquefida, pedunculis aliquot fparfis ex axillis foliorum fuperiorum. Involucrum follis conforme, pentaphyllum. Involucella fub-rhombea, vix cordata, acuminata. Ncetaria quatuor, flava, lunata. Capfula angulis fcabra.

peralia. 5. EUPHORBIA umbellâ fubquinquefidâ : bifidâ, involuccil is corclato-reniformibus, foliis fursùm imbricatis concavis.

Euphorbia paralia. Engl. Bot. t. 195.

E. Daralias. Sp.Pl.657. Hudf. 209. With. 448. Jacq. Hort. Vind. t. Iis.

Tithymaius paralius, Raii Syz.312. Ger. em. 498. Cumer. Epit. 962. Dulech. Hijt. $16+7$. Angl. Sea Spurçe;

In moritimis arenofie, havd vulgaris.

Percnnis. Fi. Augufto, Septembrí.

P.adix fublignofia. Herba cefia, levifima. Caules erecti, pedales: Folit imbricata, obnvata, concava. Umbella niagis vel mints ordinatim quinquefidta, ramulis bifidis, vix dichotonis. Involucella reniforma, concava. Neetaria 5, lunatia, fulva. Capfula lectiniviata.

3.Tigen- 6. FUPHCRBLA umblî̀ quinquefidâ: trifidâ : p.s. dichotomâ, 
dichotomâ, involucellis obovatis, foliis cuneiformibus ferratis.

Euphorbia heliofcopia. Sp. Pl. 658. Hudf. 209. With. 449. Relh. 185. Sibth. 152. Curt. Lond. fafc. 1. t. 36 .

Tithymalus heliofcopius. Raï Syn. 31 3. Ger. em. 498. Camer. Epit. 963. Dalech. Hifl. I648. Fuchj. Hift. $8 \mathrm{I}$ I.

Angl. Sun Spurge, or Wart-wort.

In cultis paffim.

Annua. Fl. Julio, Augufto.

Radix fufformis. Caulis fæpiùs bafi ramofus. Folia cuneiformia, vel obovata, apicem verfus ferrata, glabra. Umbella quinquefida, ramis bafi patentibus, trifidis et dichotomis. Involucra, ut et involucella, foliis ferè conformia. Flores lutei. Nectaria 4, integra. Capfula omninò lævis, glabra.

7. EUPHORBIA umbellâ fubquinquefidâ : tri-platytrifidâ : dichotomâ, involucellis ovato-rhom. plyylla. beis carinâ pilofis, foliis ferrulatis, capfulis verrucofis.

Euphorbia platyphylla. Sp. Pl. 660. Hudf. 209. With. 449. Abbot. 106.

Tithymalus platyphyllos. Raii Syn. 3 12. Fuchj. Hift. 8 г 3. Banb. Hift. v. 3. 670 .

T. arvenfis annuus latifolius Germanicus. Morif. fect. Iо. t. $3 \cdot f$. I.

Pityufa five Efula minor. Dalech. Hift. ${ }^{6}{ }_{53}$.

B. Euphorbia ftricta. Sy/t. Nat. ed. 10. 1049. Engl. Bot. t. 333. With. v. 4. 404.

E. verrucofa. Hhidf. 209. With. 449. Relb. 186.

Tithymalus verrucofus. Raii Syn. 312, nec Bauhini.

Angl. Warty Spurge.

VOL. II. 
In arvis.

At Black Notley, Effex. Kay. Near Harefield. Blackftone, and Rerv. Mr. Ligbtfoot. Near Northfleet, Kent. Hudf.

B. On the north fide of Everfden wood, Cambridgefhire. Rer. Mr. Relban. Near Ripton, Huntingdonthire. Mr. IVodward.

Annua. Fl. Julio, Augufto.

Radix fibrofa, parva. Caulis erectus, teres, glaber. Folia feffilia, obovato-lanceolata, acuta, glaucefcentia, fubpilofa; bafi cordata, integerrima; e medio ad apicem ferrulata: inferiora fubpetiolata. Umbella plerumque quinquefida, radiis trifidis, dichotomis; ramis axillaribus pluribus, per caulem fparfis, dichotomis. Involucella ovato-rhombea, acuta, ferrulata, flavefcentia, fubundulata, carinâ pilis albis ciliatâ, fubinde undique pilofa. Calyx interdum apice pilofus. Nectaria fubrotunda, mutica, flava. Capfula taberculato-fcabra, angulis rariùs lineâ lævi notatis. Semina lenticularia, læviffima.

a nullo difcrimine dignofcenda, nifi quod minor et tenuior eft, umbellâ fæpe quadrifidâ, fubinde trifidâ. Pubefcentia in utrâque varietate variat, at carinæ involucellorum pilis nunquam planè deftituuntur.

\section{**** Umbella multifida.}

Efula. 8. EUPHORBIA umbellâ multifidâ : bifidâ, involucellis fubcordatis, nectariis bicornibus, ramis fierilibus foliis uniformibus.

Euphorbia Efula. Sp. Pl. 660.

Efula. Rivin. Tetrapet. irreg. t. I $16 . f$. I.

E. minor. Dodon. Pempt. 374. Dalech. Hifo. 1653 .

Tithymalus pineus. Ger. $\mathrm{em}$. 499. Lob. Ic. 35\%. Angl. Leafy-branched Spurge.

In nemorofis Scoticis. 
In a wood near a rivulet at Abercorn, I3 miles weft of Edinburgh, I792. Mr. J. Mackay.

Perennis. Fl. Julio.

Radix lignofa. Caules pedales, vel fefquipedales, ereeti, glabri; ramis axillaribus inferioribus foliofis, fterilibus, plurimis. Folia lineari-obovata, integerrima, lætè viridia, glabra, omnia uniformia. Umbella 6-8-fida, fubdichotoma, ramis axillaribus paucioribus, caulis apicem versùs, fubunifloris. Involucella cordata, integerrima, glabra. Nectaria lunata, bicornia, fulva. Capfula lævis.

9. EUPHORBIA umbellâ multifidâ : dichoto-Cyparifmâ, involucellis fubcordatis, ramis fterilibus fias. foliis fetaceis, caulinis lanceolatis.

Euphorbia Cypariffias. Sp. Pl.66r. With. 45ז. Jacq. Auftr. t. 435 .

Tithymalus cupreffinus, five humi pinus. Lob. 1c. 35 6. Ger. em. 499 .

T. cypariffias. Mattb.Valgr.v. 2.592. Dalech. Hift. 1644. Bauh. Pin. 291.

T. cyparifias repens. Morif. Ject. Io. t.2.f.29. Angl. Cyprefs Spurge.

In nemorofis et campis fterilibus.

Woods at the Earl of Stamford's at Enville, Staf. fordhire. With.

Perennis. Fl. Maio, Junio.

Radix repens. Caules pedales; ramis inferioribus foliofis, fterilibus; fuperioribus floriferis, ut in præcedente. Folia integerrima, lineari-lanceolata, acuta; ramea anguftiffima, et ferè fetacea. Umbella 7-15-fida, dichotoma, ramis umbellæ fubjectis etiam dichotomis. Involucella cordato-reniformia, integerrima, glabra, luteo-viridia, demùm miniata. Nectaria lunata, bicornia, fulva. Capfula lævis.

Io. EUPHORBIA umbellâ fexfidâ: dichotomâ, byberna, 
involucellis ovalibus, foliis obtufis integerri$\mathrm{mis}$, ramis nullis, capfulis verrucofis.

Euphorbia hyberna. Sp. Pl. 662. Hudf. 210. With. 450.

Tithymalus bybernicus. How. Pbyt.121. Raii Sin. 312.

T. hibernicus, vafculis muricatis erectis. Dill. Hort. Elth. 387 . t. 290.

T. platyphyllos. Chuf. Hift. v. 2. 190. Dalech. Hift. I649. Ger. em. 500.

Angl. Irith Spurge. Makiuboy.

In arvis.

In Ireland. Ray. About Twickenham. Doody. Between Feverfham and Sittingbourn in Kent. Hudf.

Perennis. Fl. Junio.

Radix fufformis. Caulis fimplex, bipedalis, bafi fubinde ramofus. Folia uniformia, obovata, vel fubelliptica, obtufa, integerrima, glabra. Umbella fæpius fexfida, radiis dichotomis, paucifloris. Involucella elliptica, integerrima, flava. Nectaria reniformia, fulva. Capfula erecta, breviùs pedicellata, fubrotunda, muricata.

*mygda- I1. EUPHORBIA umbellâ multifidâ: dichotoloides. rnấ, involucellis perfoliatis, foliis obtufis pilofis, capfiılâ glabrâ.

Euphorbia amygdaloides. Sp. Pl. 662. Hudf. 2 10. With. 452. Relh. 186. Sibtb. I52. Engl. Bot. t. 256.

Tithymalus characias amygdaloides. Raii Syn. Angl. Wood Spurge.

In nemorofis et dumetis, vulgaris.

Perennis. Fl. Martio, Aprili.

- Caules fimplices, rubicundi, pilofi, inferne nudi, fuffruticofi. 
ticofi. Folia obovato-lanceolata, integerrima, pilofa, ferè fempervirentia. Umbella 5-8-fida, dichotoma, ramulis fubjectis axillaribus, dichotomis. Involucella connato-perfoliata, reniformia, obtufa, pallida, fubpilofa. Nectaria lunata, acuminata, citrina. Capfula giabra.

Euphorbia fylvatica Linnæi, fpecies reverà diftineta, difcrepat foliis lanceolatis, mucronulatis, glabris, neetariis bicornibus. Icones antiquiores hanc fpeciem potius quam E. amygdaloidem referunt.

12. EUPHORBIA umbellâ multifidâ : dichoto-Charamâ, involucellis perfoliatis, foliis lanceolatis cias. mollifimè pubefcentibus, capfulâ pilosâ.

Euphorbia Characias. Sp. Pl. 662. Hulf. 211. With. 451. Engl. Bot. t. 442. Jacq. Ic. rar. v. 1. t. 89 .

Tithymalus Characias. Mattb. Valyr. v. 2. 588. T. Characias Monfpelienfium. Raii Syn. 312. Ger. em. 499 .

Angl. Red Spurge.

In montofis et dumetis rariùs.

In the foreft of Needwood, Staffordhire, in great plenty, undoubtedly wild. Mr. Whately.

Frutex. Fl. Martio, Aprili.

Caules fruticofi, fimplices, tripedales, pubefcentes. Folia lanceolata, integerrima, utrinque molliffimè pubefcentia, fubtus pallida, fempervirentia. Umbella multifida, dichotoma, ramulis fubjectis axillaribus, fubdichotomis, villofis. Involucella connato-perfoliata, reniformia, acutiufcula, pallida, villofa. Nectaria lunata, mutica, atro-purpurea. Capfula pilofa. 


\section{DODECANDRIA-DODECAGYNIA.}

\section{DODECAGYNIA.}

227. SEMPERVIVUM. G.Pl. 244. Jilf.30\%. Gertn. $t .65$.

Cal. inferus, duodecim-partitus. Petala i 2. Capfulce i2, polyfpermæ.

teclorum. I. SEMPERVIVUM foliis ciliatis, propaginibus patentibus.

Sempcrvivum tectorum. Sp.Pl.664. Hudf. 2 I I. With. 452. Relh. 187. Sicth. 153. Abbot. 106. Curt. Lond. fajc. 3. t. 29. Fl. Dan.t.60r.

S. majus. Raii Syn.269. Ger.em.510. Camer. Epit. 854.

Sedum majus. Fuchs. Hift. 32.

singl. Common Houfeleek.

In tectis et ad muros vulgaris.

Perennis. Fl. Julio.

Radix fibrofa, propaginibus foliofis, rofaceis, plurimis.

Caulis erectus, pedalis, teres, carnofus, pubefcens, foliofus, apice corymbofus, multiflorus. Folia maximè carnofa, carinata, acuta, ciliata; radicalia obovata; caulina alterna, lanceolata, tenuiora, rubicunda. Flores pallidè carnei, pubefcentes. Petala lanceolata, bafi connata. Stamina petalis breviora. Partium numeFus maximè vạiat. 


\section{Clafis XII. ICOSANDRIA.}

Stamina plura, calyci inferta.

\section{MONOGYNIA.}

Stylus I.

228. PRUNUS. Cal. inferus, quinquefidus. Pet. quinque. Drupa nucleo integro.

Mespilus Oxyacantba.

\section{(DIGYNIA.)}

Styli 2.

Meppilus Oxyacantba. Pyrus torminalis, bybrida, et Aria.

\section{(TRIGYNIA.)}

Styli 3.

Mespilus Oxyacantha. Pyrus torminalis, allfuparia, bybrida, et Aria. 


\section{(TETRAGYNIA.)}

Styli 4.

Pyrus torminalis, aucuparia et Aria.

\section{(PENTAGYNIA.) \\ Styli 2 ad 5 .}

299. MESPILUS. Cal. fuperus, quinquefidus. Pet. quinque. Drupa nucibus 2 ad 5, diSpermis.

230. PYRUS. Cal. fuperus, quinquefidus. Pet. quinque. Pomm loculamentis 2 ad 5 , difpermis.

23I. SPIRÆA. Cal. inferus, quinquefidus, Pet。 quinque. Capf. bivalves, polyfpermæ.

\section{POLYGYNIA.}

\section{Styli plures.}

232. ROSA. Cal. quinquefidus, urceolatus, demùm baccatus, polyfpermus.

233. RUBUS. Cal. quinquefidus. Bacca fupera, compofita, acinis monofpermis.

236. TORMENTILla. Cal. octofidus. Pet. quatuor. Sem. nuda, mutica.

238. DRYAS. Cal. octo- vel decem-fidus, Pet. quinque vel octo. Sem, caudata, plumora. 


\section{( 525$)$}

234. FRAGARIA. Cal. decemfidus. Sem. nuda, lævia, receptaculo deciduo, baccato, affixa.

235. POTENTILla. Cal. decemfidus. Sem。 nuda, rugofa, mutica.

237. GEUM. Cal. decemfidus. Sem. arifta geniculata. Recept. columnare.

239. COMARUM. Cal. decemfidus. Sem. nuda, lævia, receptaculo ovato, fpongiofo, villofo, perfiftenti, affixa.

Spirea Filipendula et Ulmaria. 


\section{ICOSANDRIA.}

\section{MONOGYNIA.}

228. PRUNUS. G.Pl.249. Ju/. 341. Giertn. $t .93$.

Ccrafus. JufJ. 340.

Cal. quinquefidus, inferus. Petala 5. Drupa mux fiaturis prominulis.

Fadus. 1. PRUNUS floribus racemofis: racemis pendulis, foliis deciduis bafi fubtùs biglandulofis. Prunus Padus. Sp.Pl.67\%. Hudf. 213. With. 455. Fl. Dan. t. 205.

Ccrafus Avium nigra et raccmofa. Raii Syn. 463 . Ger. em. 1504. Angl. Bird Cherry.

In fylvis et fepibus.

Common in the north of England, and in fome parts of Norfolk, as about Watton and Dereham. Arbufcula. Fl. Maio.

Rami teretes, læres. Folia alterna, petiolata, obovata, acuminata, ferrata, ferraturis inflexis, venofa, glabra, fubglaucefcentia, odore acri rutaceo. Stipulæ intrafoliaceæ, binæ, lineares, fubciliatæ, deciduæ. Racemi e bafi ramorum novellorum, folitarii, fimplices, nutantes, multiflori, glabri, bafi foliofi. Flores albi. Petala ferrulata. Fructus niger, naufeofus.

Cerafus. 2. PRUNUS umbellis fubfeffilibus, foliis ovatolanceolatis conduplicatis.

Prunus Ccrafus. Sp. Pl. 679. Hudf. 213. IVith. 455. Relh. 189. Sibth. 155. Abbot. 107 .

Cerafus fylveftris fructu rubro, Räi Syn. 463 .

C. vul- 
C. vulgaris. Ger. em. 1502 .

C. fativa, fructu rotundo rubro et aeido. $D_{u}$ bamel. Arb. v. I. I48. t. 56 .

3. C. fylveftris, fructu minimo cordiformi. Raii Syn. 463 .

$\%$. C. fylveltris feptentrionalis, fruciu parvo ferotino. Raii Syn. 463.

\&. Prunus avium. Sp. Pl. 680? With. 456. Sibtb. I 54. Abbo6. 107.

P. Cerafus $\gamma$. Hudf. 213 .

Cerafus fylveftris, fructu nigro. Paii Syn. $46_{3}$. C. nigra. Ger. em. I 505 .

Ł. Corone or Coroun Cherry. Mill. Dizt. slingl. Cherry-tree.

In fylvis et fepibus.

B. In Lancathire, Chefhirc and Weltmoreland. Ray.

$\gamma$. On the banks of the Tees near Barnard-cafile plentifully. Ray.

$\delta$. In the midland and eaftern counties.

\&. About Bergh.Apton in Norfolk, and in Hertfordhire.

Arbor. Fl. Maio.

Rami cinerei, nitidi, teretiufculi. Folia petiolata, ovata vel ovato-lanceolata, acuminata, inæqualiter ferrata, venofa; juniora conduplicata, fubtùs magis vel minùs pubefcentia. Stipulæ dentatæ, glandulofæ. Umbellæ aphyllæ, paucifloræ, nutantes. Calyx reflexus. Petala alba. Drupa rubra, acida, in $\delta \& \varepsilon$ nigra, fubdulcis, in $\varepsilon$ major.

*. PRUNUS pedunculis fubfolitariis, foliis lan-domefticeolato-ovatis convolutis, ramis muticis. ca.

Prunus domeftica. Sp. Pl. 68o. With. 456.

Ger. em. 1497. Woodv. Med. Bot. t. 85.

P. communis $\delta$. Hudf. 212.

P. fativa. 


\section{ICOSANDRIA-MONOGYNIA.}

P. fativa. Fuchf. Hift. 403 .

Prunus gallica, fructus. Ploarmac. Lond.

Angl. Plum-tree.

In fepibus, vix indigena.

Arbor. Fl. Aprili.

Arbor mediocris. Rami mutici. Folia breviùs petiola-

ta, ovata, ferrata, glabra ; juniora convoluta et fubtùs pubefcentia. Pedunculi breves, plerumque folitarii.

Calyx erectus. Petala alba, obovata. Drupa elliptica.

injetitia. 4. PRUNUS pedunculis geminis, foliis lanccolatoovatis convolutis fubtus villofis, ramis fpinercentibus.

Prunus infititia. Sp. Pl. 68o. Witio. 456 . Relb. 188. Sibth. I54.

P. fylveftris major. Racii Syn. 462.

B. P. fylveftris, fructu majore albo. Raii Syn. 462 . \%.P. 1ylveftris, fructu rubro accrbo et ingrato. Raii Syn. I 63 .

Angl. Bullace-tree.

In fepibus et nemorofis.

Arbor. Fl. Aprili.

Arbor humilis. Rami plerumque fpinâ terminati. Folia breviùs petiolata, ovata, bafi attenuata, ferrata, fubtùs villofa. Pedunculi gemini. Calyx erectiufculus. Petala alba, obovata. Drupa fubrotunda.

jpinefa. 5. PRUNUS pedunculis folitariis, foliis lanceo. latis glabris, ramis fpinofis.

Prunus fpinofa. Sp. Pl. 68 1. Hudf. zir2. With. 457. Relh. 189. Sibth. 155. Fl. Dan. t. 926. Woodv. Med. Bot. t. $8_{4}$.

P. fylveftris. Raii Syn. 462. Ger. em. 1497. Trag. Hift. го 6. Fucl. . Hijt. 404. Prunus fylveftris, fructus. Pbarmac. Lond. Angl. Sloe-tree. Black thorn. 
In repibus et dumetis vulgaris.

Frutex. Fl. Martio, Aprili.

Rami divaricati, fpinis terminati. Folia petiolata, obovato-lanceolata, ferrata, glabra. Flores ante folia enata expanfi, nivei, pedunculati, folitarii. Calyx patens. Drupa nigra, fubrotunda, valdè auftera.

\section{PENTAGYNIA.}

$$
\text { (Styli } 2 \text { ad 5). }
$$

229. MESPILUS. G. Pl.25 I. Juf. $335^{\circ}$

$$
\text { Gartn. t. } 87 .
$$

Cratægus. G. Pl. 250. Ju/f.335.

Cal. quinquefidus. Petala 5. Drupa infera. Nuces 2 ad 5, difpermæ.

I. MESPILUS fpinofa, foliis obtufis fubtrifidis Oxyaferratis glabris, floribus fubdigynis.

Mefpilus Oxyacantha. Grertn. v. 2. 43. t. 87. M. Apii folio fylveftris fpinofa, five Oxyacantha. Raii Syn. 453 .

Cratægus Oxyacantha. Sp. Pl. 683. Hudf. 2 I 4 . With. 459. Relb. 189. Fl. Dan. t. 634.

C. munogyna. Sibth. ${ }_{5} 6$. Abbot. ro8. Jacq. Auftr. t. 292.

Oxyacanthus. Ger.em. 1327.

B. Merpilus Apii folio fylveftris fpinofa, folio et fructu majore. Dill, in Raii Syn. 454. 
$\%$ Glaftenbury Thorn. With. 459 . Angl. Hawthorn. White-thorn. May.

In campis elatis, fylvis et fepibus.

Arbufcula. Fl. Maio, Junio.

Lignum durum. Rami glabri, rigidi, fpinofi. Folia pe* tiolata, alterna, trifida, incifa, apice ferrata, glabra, ftipulis lunatis, dentatis, magnitudine variis, "in $\gamma$ maximis," Withering. Corymbi terminales, glabri. Flores albi, quandoque rofei, fuaveolentes. Styli 1 ad 3. Drupa fanguinea, pulpâ farinosâ. Nuces I ad 3, offex, fæpiùs monofpermæ. Variat fructu luteo, vẹl albido. Frutex ad fepes vivas preftantiffimus.

sermani-* 2. MESPILUS incrmis, foliis lanceolatis fub$c a$. tomentofis, floribus folitariis feffilibus term:nalibus pentagynis.

Mefpilus germanica. Sp. Pl. 684. Hudf. $21 \%$. With. 46r. G.crtn. v. 2. 43. t. 87 .

Mefpilus. Dill. in Raii Syn. 453 .

M. fativa. Ger. em. 5453 .

M. vulgaris. Camer. Epir. I54.

M. altera. Matth. Valgr. :.1.230.

Angl. Common Medlar.

In fepibus.

In all the hedges about Minfhull, Cherhire. Du Bois.

Arbor. Fl. Maio.

Rami patentes. Folia oblonga, apice ferrulata, fubtùs precipuè tomentofa. Flores terminales, fubfeffiles, folitarii. Calycis dentes longiffimi, perfiftentes. Petala alba. Styli 5. Drupa pubefcens, apice concava. Nuces 5, offex, compreffæ, angulatæ. E fpecimine hortenfi hanc defcriptionem confeci. 
230. PYRUS. G.Pl.251. Juf. 335. Garin.t.8\%

Sorbus. G. Pl. 250 . Juef. 335 .

Cratægus. G. Pl. 250. JufJ.335.

Malus. Juff. 334 .

Cal. quinquefidus. Petala 5. Pomm inferum, 2 ad 5-loculare. Semina bina.

1. PYRUS foliis fimplicibus ferratis, pedunculis commit* corymbofis.

Pyrus communis. Sp. Pl. 686. Hudf. 216.

IVith. 462. Relh. I9I. Sibth. I56.

P. Achras. Gartn. v. 2. 44. t. 87.

P. fylveftris. Ger. em. 1458.

Pyratter, feu Pyrus fylveftris. Raii Syn. 452.

Angl. Pear-tree. Iron Pear-tree.

In fylvis et fepibus.

Arbor. Fl. Aprili.

Arbor excelfa, ramis erectis, ramulis dependentibus. Folia elliptica, obtufa, ferrata; juniora fubtùs margineque tomento deciduo veftita. Stipulæ lineares. Corymbi terminales, villofi. Flores nivei, pentagyni. Pomum bafi productum, durum, acerbum. Loculamenta quinque, fingula bivalvia, difperma.

2. PYRUS foliis fimplicibus ferratis, umbellis Malus, fimplicibus feffilibus.

Pyrus Malus. Sp. Pl. 686. Hudf. 2:6. With. 462. Relh. 191. Sibth. 157. Engl. Bot. t. I 79 .

Malus fylveftris. Raii Syn. 452. Ger.em. I46. Angl. Apple-tree. Crab-tree.

In fylvis et fepibus.

Arbor. Fl. Maio.

Arbor patula, ramis ramulifque tortuofis, magis quam in priore horizontalibus. Folia ovata, ferrata; juniora fubtùs pubefcentia. Stipulæ lineares. Umbellæ terminales, fefiles, villofæ. Flores albi, extùs rofei, pen-
tagyni. 


\section{ICOSANDRIA-PENTAGYNIA.}

tagyni. Pomum fubrotundum, bafi umbilicatum, acidum. Loculamenta ut in præcedente.

tormine- 3. PYRUS foliis fimplicitus fubcordatis ferratis lis. feptemlobatis: lobis infimis clivaricatis.

Cratægus torminalis. Sp.Pl.68r. Hudf. 2 I 4 . With. 458. Sibth. 156. Engl. Bot. t.,298. Fl. Dan. t. 798. Jacq. Auftr. t. 443 .

Mefpilus Apii folio fylveftris non fpinofa, feu Sorbus torminalis. Raii Syn. 453 .

Sorbus torminalis. Ger. em. I47I. Camer. Epit. 162. Trag. Hift. гого. Matth. Valgr. v. 1. 239. Cord. Hift. I76. I. Angl. Wild Service Pear-tree.

In fylvis et fepibus.

Arbor. FI. Aprili, Maio.

Arbor mediocris, ligno duro, cortice lævi. Folia longiủs petiolata, fubcordata, inæqualiter feptemloba, acuminata, ferrata, glabra, exftipulata. Corymbi terminales, ramofi, tomentofi, multiflori. Flores albi. Styli 2 ad 5 . Pomum punctatum, fufcum, aufterum, demum, pruinâ emollitum, gratè acefcens et pulpofum.

domefi- 4. PYRUS foliis pinnatis; foliolis æqualibus fub$\epsilon a$. tùs villofis anticè ferratis, foribus paniculatis. Pyrus domeftica. Engl. Bot. t. 350 . P. forbus. Grertn. v. 2. 45. t. 87 .

Sorbus domeftica. Sp. Pl. 684. Hudf. 215. With. 46o. Crantz. Stirp. fafc. 2. 48. t.2. f. 3. Matth. Valgr.v. 1. 237. Jacq. Ahetr. t. 447 .

Sorbus. Raii Syn. 452. Ger.em. I47 I. Angl. True Service-tree.

In fylvis montofis rariùs.

In the mountainous parts of Cornwall and StaffordThire. Ray. In the middle of Wire foreft near Bewdley, 
Bewdley, Worcefterthire. Mr. Pitts. Lord Vifcount Valentia.

Arbor. Fl. Maio.

Arbor mediocris, tardè crefcens, nec nifi grandæra fructiferd. Folia impari-pinnata, 6-9-juga, foliolis feffilibus, oblongis, æqualibus, a medio ad apicem ferratis, fubtùs villofis, autumno cienudatis. Paniculæ terminales, fubcorymbofæ, tomentofæ. Flores albi. Styli 5 . Pomum obovatum, rubicundum, quinqueloculare, loculamentis bivalvibus monofpermis, demùm pulpofum et edule. "Seminum rudimenta in germine conftantèr bina." Gertn.

5. PYRUS foliis pinnatis; foliolis æqualibus fer-ancuparatis glabriufculis, floribus corymbofis fubtri- ria. gynis.

Pyrus aucuparia. Germ. v.2.45. t. 87. Sorbus aucuparia. Sp. Pl. 683. Hudf. 2i工5. With. 460. Relh. Igo. Abbot. I09. Engl. Bot. t. 33\%. Fl. Dan. t. I034.

S. fylveftris, foliis domefticæ fimilis. Rä̈ Syn. 452.

S. fylveftris, five Fraxinus bubula. Ger. em. I 473 .

S. fylveftris. Camer. Epit. I6I. Matth. Valgr. v. I. 238.

Angl. Mountain Afh. Quicken-tree.

In fylvis montofis, fepibufque.

Arbor. Fl. Maio.

Formofa arbor, lentè crefcens, ligno teriaci. Folia impari-pinnata, ferrata, glabra; juniora fubtùs pubefcentia. Corymbi terminales, pubefcentes, ramofiffimi, multiflori. Flores albi. : Styli 3 vel 4. Pomum magnitudine pif majoris, coccineum, acidum, amaricans, loculamentis fubdifpermis. 
bybrida. +6. P'YRUS foliis femipinnatis fubtus tomentofis, floribus corymbolis fubtrigynis.

Sorbus hybrida. Sp. Pl. 684. Hudf. 216.

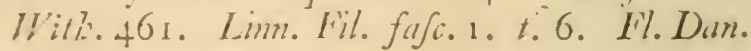

t. 302 .

Angl. Baftard Mountain A h.

In montofis.

Unt the walls of Caftel Dinas brân, Denbighthire.

Mr. Waring. Huelf. Mr. Griffils. A fpecimen gatheral there by Dr. Prattinton is moft certainly only P. Aria.

Arbor. I1. Nlaio.

Arbor mediocris. Folia anticè lobata, bafi pinnata, ferrata, exfipulata ; fuprà orlabra ; fubtùs tomentofo-alba. Corm mi terminales, tonientofi, multiflori. Flores albi. Styli tres, fuhinde tantum bini. Pomum ut in precedente fed paulo majus. Seminibus propagatur, quamins cx monte Linnei hybrida fit, matre Pyro aucupariat, paté P. Ariâ. Ex horto.

s

4ria. 7. PIRUS foliis fimplicibus ovatis incifis ferratis lincal is fubtùs tomentofis, floribus corymbofis rubdigynis.

Cratrogus Aria. Sp. Fl. 681. Hulf. 214. With. 458 . Silth. I55. Fl. Dan.t. 302 .

Mefpilus Alni folio fubtù incano, Aria Theophratí dicta. Raii Syn. 453 .

Aria Theophrafti. Ger. em. 1 $32 \%$.

Sorbus alpina. Baut. Hijl. $\%$. . 65 .

1ngl. White Bcam-trce. White Wild Pear-tree,

In montofis folo calcareo, vel fiffuris rupium. stris. Fl. Maio.

Arbor mediocris, ramis junioribus tomentofis. Folia fimplicia, fubovata, duplicato-ferrata, fubinde incifa; fuprà glabra, venis parallelis lineata; fubtùs tomentolo-alba. Corymbi terminales, tomentofi, multiflori. Flores albi. Styli 2 ad 4 . Pomum coccineum, par- 
vim, farinofum, aftringens. Loculamenta coriacea, 2 ad 4 , difperma.

\section{SPIR AEA. G. Pl.253. Juf. 339. \\ Gertn. $t$ 69.}

Cal. quinquefidus. Petala 5. Capfule fuperæ, bivalves, polyfpermæ.

x. SPIRAA foliis lanceolatis obtufis ferratis gla-Salicifobris, racemis terminalibus compofitis.

Spiræa falicifolia. Sp. Pl. 700. With. 463. Pallas. Rof. t. $2 \mathrm{I}$.

Spiræa. Gmel. Sib. v. 3. 1\$3. t. 39.

S. Theophrafti forte. Chus. Hift. p. I. 84. Ger. em. I60 I.

Angl. Willow-leaved Spiræa.

In nemorofis humidis fubalpinis rariùs.

In moift hedges in Weftmoreland, and on the borders of Winandermere. Mr. Gough. By the road between Pool bridge and Colthoufe, near Hawkrhead, Cumberland. Mr. Dalton. With. In a wood at Hafod, Cardiganthire, near a gate in the eaftern approach to the houfe; but it fcarcely appears to be wild.

Frutex. FI. Julio.

Frutex quadripedalis, virgatus, glaber, ramis lutefcentibus. Folia alterna, fubfefflia, lato-lanceolata, inæqualiter ferrata, utrinque glabra. Racemi terminales, folitarii, erecti, decompofiti, obtufi, multiflori, bracteati, bracteis linearibus, folitariis. Flores rofei.

2. SPIR FA foliis interruptè pinnatis; foliolis Filipenuniformibus ferratis glabris, caule herbaceo, dula. floribus cymofis polygynis.

Spiræa Filipendula. Sp. Pl. 702. Hudf. 2 I 7. With. 403. Relh. 191. Sibth. 157. Ab$\mathrm{H} 2$ 
hot. т 1о. 1\%. Dan. 1. 635. Engl. Bot. t. 284 .

Filipendula. Raii Syn. 259. Ger. em. 1058. Camer. Epit. 608. Matth. Iulgr. v. 2.217. Angl. Common Dropwort.

In pafcuis elatis, folo calcareo vel glarcofo.

Perennis. Fl. Julio.

Radix lignofa, tuberibus ellipticis. Caulis pedalis, vel fefquipedalis, angulatus, glaber, foliofus, fupernè parùm ramofus. Folia alterna, interruptè pinnata, ferrata et incifa, glabra, multijuga, foliolo terminali trilobo, haftato. Stipulæ adnati, dentatæ, rotundatæ. Panicula cymofa, erecta, multiflora. Flores lactei vel rubicundi. Styli 8 ad 12. Variat flore pleno.

Ulmaria.3. SPIR ÆA foliis interruptè pinnatis fubtùs tomentofis ; impari majori lobato, floribus cymofis polygynis.

Spirac Ulmaria. Sp. Pl. $702 . \quad H u d j .217$. Wilt. 464. Relb. 192. Sibth. I57. Ab. bot. I Iо. Fl. Dan.t.547. Curt. Lond. fafc. 5 . t. 33 .

Ulmaria. Raii Syn. 259.

Regina prati. Ger. em. I043.

Angl. Meadow-fwcet.

In pratis humidis, et ad ripas fluviorum vulgaris.

Perennis. Fl. Junio, Julio.

Radix fibrofa. Caules $3-4$ pedales, fulcati, foliofi. Folia interruptè pinnata, foliolis maximè inæqualibus, lobatis, ferratis, fubtùs tomentofo-albis, venofis; impari tripartito. Stipulæ fubrotundæ, diftinctæ, venofie, dentatæ. Cyma ramofiffima, multiflora. Flores albi, parvi, fuaveolentes. Styli 6 ad 8. Capfulæ contortæ. 


\section{POLYGYNIA.}

232. ROSA. G. Pl. 254. Jue. $335^{\circ}$ Gertn. 1.73 .

Cal. urceolatus, quinquefidus; carnofus, collo coarctatus. Petala 5. Semina plurima, hifpida, calycis lateri interiori affixa.

\section{* Fructibus fubglobofis.}

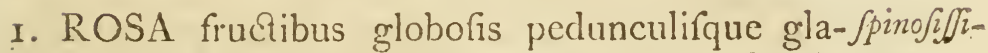
bris, aculeis caulinis numerofiffimis rectis fe- $m a$. taceis, foliolis fubrotundis glabris.

Rofa Ppinofiffima. Sp. Pl. 705. Hudf. 2 I8. With. 465. Lightf. 260. Fl. Dan. t. 398. Engl. Bot. t. 187 .

R. pimpincllifolia. Sy/t. Nat. ed. ro. ro62.

R. pumila fpinofifima, foliis Pimpinellæ glabris, flore albo. Raii Syn. 455. Baub. Hift. v. 2. 40.

R. campeftris odorato flore. Chus. Hift. p. I. I 6 .

G. R. Ciphiana, feu R. pimpinellæ foliis minor noftras, flore elegantèr variegato. Sibb. Scot. p. 2. 46. t. 2 .

$\%$ Pedunculis aculeatis. With. 465 . Angl. Burnet Rofe.

In ericetis, dumetis, vel ad agrorum margines, folo arenofo.

Frutex. Fl. Julio.

Caules vix bipedales, aculeatiffimi, ramofi, erecti; aculeis rectis, gracillimis, inæqualibus. Foliola 7 vel 9 , fubrotunda, obtufa, ferrata, glabra, parva. Petioli fubinde aculeati. Pedunculi terminales, folitarii, uniflori, glabri, rarius aculeati. Germen fere hemifphxricum, 
lære. Petala alba, bafi Jutea. Fructus atro-purpureus, demùm niger, globofus, interdùm fubfpinofus.

arvenfis. 2. ROSA fructibus globofis pedunculifque inermibus, aculcis caulinis petiolorumque aduncis, floribus fubcymofis.

Rofa arvenfis. Mant. 2. 245. Hudf. 2 I 9. Irith. 464. Relb. 193. Sibth. 159. Enjl. Bet.t. I88. Abbot. III.

R. fylveftris altera minor, flore albo noftras. Raii Syn. 455 .

R. fylvectris folio glabro, flore planè albo. Baub. Hift. v. 2. 44.

Angl. White Dog-rofe.

In fepibus et dumetis.

Frutex. Fl. Junio, Julio.

Rami flagelliformes, longifimi, arcuati, implexi, rubicundi, aculeis fparfis, aduncis. Foliola 5 vel 7 , ovata, acuta, glabra, fubtùs glaucefcentia. Petioli aculeati. Pedunculi terminales, 3 ad 5 , fubcymofi, rariùs folitarii, glandulofo-fcabri, inermes, uniflori. Germen oblongum, læve. Petala nivea. Styli bafi in columnam fimplicem coaliti. Fructus globofus, atro-fanguineus, glaber.

villoja. 3. ROSA fructibus globofis pedunculifque hifpidis, aculeis caulinis rectiufculis, foliolis ellipticis utrinque tomentofis.

Rofa villofa. Sp. Pl. 704. Ifudf.2r9. With. 466. Lighif. 261. Engl. Bot. t. 583 .

R. fylveftris pomifera major noftras. Raii Syn.

R. poino fpinofo, folio hirfuto. Baub. Hif. v. 2. 38 .

R. pomifera major. Park. Parad. $418 . f \cdot 7 \cdot$ B. R. Fylveftris folio molliter hirfuto, fructu ro- 
tundo glabro, calyce et pediculo hifpiclis. Dill. in Raii $S_{3} n \cdot 47 \mathrm{~S}$ ?

Angl: Apple Roic.

In uemorofis et dumetis montofis.

Plentifully in Weftmoreland, Cumberland and the north of Yorkfhirc. Ray. Hudf. Witb. In the way from Edinburgh to Raveliton wood.

Frutex. Fl. Junio.

Frutex quadripedalis, erectus, ramofus, ramis erectis, - brevibus. Aculei caulini rariufculi, parvi, fubulati, ferè. recti. Foliola feptena, elliptica, obtufufcula, utrinque mollifimè villofa, ferraturis glandulofo-ciliatis. Petioli tomentofi, aculeati, glandulofi. Pedunculi terminales, plerumque folitarii, uniflori, fetis rigidis, apice glandulofis, muricati. Germen globofum, muricatum. Calycis laciniæ elongatæ, tomentofæ, dorfo muricatæ. Pctala faturatè rubentia. Fructus globofus, maximus in hoc genere, calyce coronatus, fanguineus, muricatus, rarius inermis.

\section{* Fructibus ovalis.}

4. ROSA fruetibus ovatis pedunculifque hifpidis, tomento- . aculeis caulinis aduncis, foliolis ovatis utrin. $f a$. que tomentofis.

Rofa villora f. Hudf. 2 I9. Witb. 466.

R. villofa. Relh. I94? Sibth. 159?

R. fylvestris fructu majore hifpido. Raii Syn. 454 .

R. fyluefiris alba, cum aliquo rubore, folio hirfuto. Bauh. Hift. v. 2. 44.

Angl. Downy-leared Dog-rofe.

In fepibus et dumetis haud infreguens.

A bout London. Hudf. At St. Faith's, Catton, and other places near Norwich. Common in Shropfhire and Wales.

Prutex. Fl. Junio, Julio.

Precedente omnibus partibus minor eft, et habitn cum $\mathrm{H}_{4}$. R. caninâ 
R. caninâ convenit, nifi quòd folia undique pubefcunt, et fubcinerea videntur. Rami erecto-patentes, fubAesuofi. Aculei canlini adunci, bafi dilatati, Foliola 5 vel 7 , fuaveolentia, elliptico-ovata, utrinque molliffimè tomentofa, ferraturis glandulosé ciliatis. Petioli. tomentofi, muricati. Peclunculi terminales, fubfolitarii, fetis rigidis glandulofis muricati. Germen etiam muricatum, ellipticum. Calyx glandulofo-hifpidus. Petala bafi albida, fupernè pulcherrimè rofea. Fructus ovatus, coccineus, muricatus, magnitudine et formâ, R. caninæ proximus.

rubiginoja.

5. ROSA fructibus ovatis pedunculifque hifpidis, aculeis caulinis aduncis, foliolis ellipticis fubtìs glandulofo-rubiginofis.

Rofa rubiginofa. Mant. 2. 564. With. 466. Relh. 193. Sibth. 158. Abbot. I Io. Jacq. Auftr. t. 50. Web. Gott. I5.

R. eglanteria. Hudf. 2 I 8.

R. ruavifolia. Ligbif. 262. Fl. Dan. t. 870.

R. Sylveftris odora. Raii Syn. 454. Ger. em. I $269 \cdot f_{0}$ I.

Angl. Sweet-briar. Eglantine.

In ericctis et montofis folo glareofo.

Frutex. Fl. Junio, Julio.

Habitus præcedentis. Aculei caulini adunci, flavi. Foliola feptem, valdè fragrantia, elliptica vel fubovata; fuprà glabra, rugofa; fubtùs atomis refinofis rubiginofa; ferraturis glandulofis. Petioli glandulofi, aculeati. Pedunculi terminales, corymbofi, muricati. Germen ovatum, muricatum. Calyx glandulofus. Petala rofea, bafi alba. Fructus ovatus, miniatus, muricatus, interdùm glaber, farinofus, infipidus.

cantin. 6. ROSA fructibus ovatis pedunculifque glabris, aculeis caulinis aduncis, foliolis ovatis acuminatis glaberrimis.

Rofa canina. Sp.Pl.jo4. Hudf. 218 . With. 467. 
467. Relb. i94. Sibtb. I58. Abbot. III. Curt. Lnnd. fafi. 5. t. 34. Fl. Dan. t. 555 .

R. fylveftris inorlora, feu canina. Raii Syn. 454 . R. fylveftris alba cum rubore, folio glabro. Baub. Hift. v. 2. 43 .

R. fylveftris prima. Camer. Epit. 99.

Cynofbatus, fruitus. Pbarmac. Lond.

Angl. Common Dog-rofe, Wild-briar, or Heptree.

In fepibus et dumetis pafim.

Frutex. Fl. Junio.

Rami elongati, erecto-patentes. Aculei caulini conicoadunci, comprefli, rubicundi. Foliola feptem, inodora, ovata, acuminata, utrinque nuda et glaberrima. Petioli aculeati. Pedunculi fubcorymbofi, fubinde folitarii, laves. Germen ovatum, glabrum. Calyx intus margineque pubefcens. Petala dilutè carnea, odorata, fxpè alba. Fructus ovatus, coccineus, glaber, gratè acefcens.

«s Variat fructu hifpido." D. C. Sutton.

233. RUBUS. G. Pl. 254. Juf. $33^{8 .}$ Gortn. t. 73 .

Cal. quinquefidus. Petala 5. Bacca fupera, compofita acinis monofpermis.

I. RUBUS foliis quinato-pinnatis ternatifque fub-idaus. tus tomentolis, petiolis canaliculatis, caule aculeato.

Rubus idæus. Sp.Pl. 706. Hudf. 220. With. 468. Sibth. I59. Abbot. r i r. Fl. Dan. t. $78 \mathrm{~S}$. Woodv. Med. Bot. t. I38. Ger. em. 1272. Matth. Valgr. v. 2. 357 .

R. Idxus fpinofus fructu rubro. Raii Syn. 467. Baub. Hift. v. 2. 59.

Rubus idaus, fructus. Plommac. Lond. 


\section{Angl. Rafp-berry.}

In fylvis montofis et dumetis.

Plentiful in Walea and the north of Fingland. On hills between Norwich and Thorpe.

Fratix. Fl. Maio, Junio.

Caules fuffinticofi, biennes, erecti, terctes, actleato-hifpidi. Folia pinnata ; fuperiora ternata; foliolis rhombeo-ovatis, acutis, lineatis, inæqualiter forratis, fubtùs tomentofo-albis. Petioli pubefcentes, aculeati, fuprà canaliculáti. Flores paniculati, albidi. Calyx patens, tomentofus, acuminatus, perfiftens. Petala parva, ob. tufa, plana. Fructus fanguineus, odoratus, gratifimus, deciduus, ftylis perfiftentibus fetofus.

cafuss. 2. RUBUS foliis ternatis fubtùs pilofis : lateralibus bilobis, caule aculeato proftrato glauco. Rubus cafius. Sp. Pl. 7o6. Hudf. 220 . Hilb. 468. Relh. I94. Sibtb. I6o. Abbot. II . R. minor fructu cæaruleo. Raii Syn. 467. Bauk. Hijt. ข. 2. 59 .

R. minor. Dud. l'empl. 742. Angl. Dew-berry.

In nemorofis, fepibus ct ad margines agrorum.

Frutex. Fl. Junio, Julin.

Caules proftrati, flagclliformes, radicantes, terctes, aculeati, rore crefio glauci. Folia ternata, incifa et ferrata, fubius pilofa, nec incana; foliolis lateralibus feffilibus, extus fæpiùs lobatis, figurâ variss. Stipulæ lanceolatæ. Petioli pubefcentes, aculcati, fuprà obfoletè canaliculati. Paniculie terminales, paucifloræ; tomentofax, fubaculcatie. Calyx fericeus, longè acuminatus, patens. Petala alba, undulofa. Fructus niger, rore cæfin, gratè acefcens, ex acinis paucioribus, majufculis, compotitus.

corylifo- 3. RUBUS foliis fubquinatis fubtis pilofis: latelisis。 ralibus feffilibus, aculeis rectiufculis, caijcibus fructûs inflcxis, 
Rubus fruticofus major. With. 469 .

R. major fructu nigro. Scbmidel. Ic.t. 2. Angl. Hazcl-leaved Bramble.

In fepibus frequens.

Frutex. 'Fl. Julio.

Caules flagelliformes, fragiliores, longiffimi, arcuatopatentes, rubri, teretiufculi, aculeis rectiufculis. Folia quinata, vel ternata, inæqualitèr ferrata et incifa ; fuprà læetè viridia, glabriufcula; fubtùs pilofa, nequaquam incana; foliolis lateralibus feffilibus; in folio ternato extùs lobatis. Stipulæ formâ variæ, fetaceæ vel lanceolatr. Petioli pilofi, aculeati. Panicula multiflora. Calyx villofus, patens, maturefcente fructu inflexus, monente acutiffimo viro D. WVigg. Petala alba. Fructus fufco-fanguinems, rore cefiu, acidus, acinis rarioribus.

Hanc fpeciem indicare voluit, ut videtur, Dillenius in Raii $\$ y n .467$. Perfuafu et inductu amiciffimi D. Jacobi Crowe, obfervationibus iteratis confirmati, a fequente feparavi. Foliola folia Coryli interdùm tam exactè referunt ut vix diftinguenda.

4. RUBUS foliis fubquinatis fubtùs tomentolis : fruticos foliolis petiolatis, aculeis aduncis, caule angu- fus. lato, calyce reflexo.

Rubus fruticofus. Sp. Pl. 707. Hudf. 220. With. 469. Relh. 195. Sibth. 160. Ab. bot. 1 i2. Mill. Illuftr. t. 45 .

R. major fructu nigro. Raii Sym. 467. Bauh. Hijt. v. 2. 57.

Rubus. Ger. em. 1272. Camer. Epit. 751. Blackw. Herb. t. 45 .

B. R. vulgaris major fructu albo. Raii $S_{y} n \cdot 467$. Angl. Common Bramble.

In fepibus, dumetis, et fylvis vulgaris,

Frutex. Fl. Julio, Augufto.

Caules ut in præcedente, fed magis angulati, tenaciffimi, aculeis 
aculeis omninó aduncis. Folia quinata, fubindé ternata, duplicato-ferrata, acuta; fuprà faturatè viridia, nitidiufcula; fultús tomentofo-alba, rariùs pilofa tantùm et pallidè virentia. Foliola ommia petiolata, petiolis aculeatis. Stipula fetaceæ. Panicula multifora, fubracemofa, tomentofa. Calyx brevis, reflexus, concavus, tomentofus. Petala dilutè purpurea, vel alba. Fructus violaceus, fubdulcis, acinis numerofis.

faxarizis. 5. RUBUS foliis termatis glabriufculis, flagellis reptantibus herbaceis, paniculâ pauciflorâ. Rubus faxatilis. SP. Pl. 708. Hudf. 221. With. 470. Fl. Dan. t. I34. Ger. em. 1273. R. alpinus humilis. Baub. Hift. v.2.61.

Chamarubus faxatilis. Raii Syn. $2 G_{1}$. Angl. Stone Bramble.

In petrofis umbrofis fubalpinis.

In Scotland, Wales, and the north of England, but not very common.

Ferennis. Fl. Junio.

Radix fibrofa, flagellis longiffimis, proftratis, reptantibus, nudis vel foliofis, fterilibus. Caules erecti, fimplices, fpithamæi, fubangulati, villofi, foliofi, inermes. Folia temata, inferiora raiùs quinata, pallidè viridia, tenuia, duplicato-ferrata, acuta, fubtùs fubpilofa'; foliolis lateralibus feffilibus. Panicula terminalis, pauçifora, pubefcens. Calycis laciniæ lanccolatæ, planæ, fubpubefcentes. Petala alba, lanceolata, ereeta. Fructus suberrimus, acidus, ex acinis pancis, plerumque tribus vel quatuor, majufculis.

cactious. 6. RUBUS foliis ternatis glabris, caule inermi uniforo.

Rubus areticus. Sp.Pl. 708. Fl. Lapp.n. 207. t. 5. f. 2. Fl. Dan. 1. 488 . Curt. Mag. t. I32.

Angl. Dwarf Crimfon Bramble. 
In petrofis alpinis.

In the Ine of Mull. Rev. Dr. Walker.

Perennis. Fl. Maio, Junio.

Radix repens, flagellis nullis. Caules palmares, erecti, fimplices, angulati. Folia ternata, inæqualitèr ferrata, omninò ferè glabra. Flos folitarius, pedunculatus, terminalis, faturatè rofeus, petalis interdùm laciniatis. Calyx pilofus. Fructus purpurafcens, dulcis et fragrans, gratifimus, guftu Rubum idæum atque Fragariam referens.

7. RUBUS foliis fimplicibus lobatis, caule inermi Chameunifloro, laciniis calycinis ovatis.

Rubus Chamæmorus. Sp. Pl. 708. Fl. Lapp. n. 208. t. 5.f. I. Hudf. 221. Witb. 47 I. Ligbtf.266. t. 13.f.2. Fl. Dan. t. 1. Dicks. H. Sicc. fafc. 2. 8.

Chamæmortus. Raii Syn. 260. Ger. em. 1273. Morus Norvagica. Tillands. Ic. I 59. Angl. Mountain Bramble, or Cloud-berry.

In paludibus turfofis aipinis.

On the higheft mountains of Scotland, Wales, and the north of England. On Axedge near Buxton. A. B. Lambert, Efq. Between Patterdale and Kefwick, Cumberland: Mr. Salt.

Perennis. Fl. Junio.

Radix repens. Caules erecti, fpithamæi, fimplices, unifori. Folia petiolata, cordata, quinqueloba, plicata, rugofa, inæqualitèr ferrata, glabra. Flos terminalis, pedunculatus, albus. Calyx extùs pilofus. Stamina in flore fœmineo abbreviata, abortiva, ficut piftilla in mafculino; at plantam fomineam cum mafculinâ radicibus connexam invenit Cel. Solander. Fructus fulvus, acidus, mucilaginofus, nee ingratus, ex plurimis acinis compofitus. 


\section{$54^{6}$ ICOSANDRIA-POLYGYNIA.}

234. FRAGARIA. G. Pl. 255. Ju/. 338 .

$$
\text { Gertn. } t .73 \text {. }
$$

Cal. decemfichs, inferus. Petala 5. Recoptaculum reminum ovatum, baccatum, deciduum. Semina levia.

vefca. I. FRAGARIA flagellis reptantibus.

Fragaria vefca. Sp.Pl. 708. Hudf.221. With. 47 1. Relh. 195. Sibth. 160.

Fragaria. Raii Syn. 254. Ger. em. 997. Camer. Epit. 765. Brunf. Herb. v. 2.35.

Common Strawberry. Pet. H. Bril. t. 40.f. 7 . B. Fragaria fructu hifpido. Raii Syn.254. Ger. em. 998 .

Angl. Wood Strawberry.

In nemorofis et ad fepes frequens.

Perennis. Fl. Maio, Junio:

Radix fibrofa, flagellis longiffimis, radicantibus. Canles breves, erecti, fubfimplices. Folia longiùs petiolata, ternata, obtufa, lineata, æqualitèr ferrata, pubefcentia. Flores erecti, fubcymofi, albi. Petala fubrotunda, calyce breviora. Fructus nutans, ovatus, carnofus, odoratus, gratifimus, faturatè ruber, feminibus denudatis granulatus.

ferilis. 2. FRAGARIA caule decumbente, ramis floriferis laxis fubbifloris.

Fragaria fterilis. Sp. Pl. 709. Hildf. 222. With. 472. Relh. 196. Sibth. 160. Curt. Lond. fafc. 3. t. 30. Raii Syn. 254.

F. minimè vefica. Ger. em. 998.

Angl. Barren Strawberry. Pet. H. Brit. t. 40. f. 8 .

In pafcuis fterilibus paffim.

Perennis. Fl. Martio, Aprili.

Radix fublignofa. Caules diffufi, nee repentes. Folia fubtùs 
fubtus fericea. Rami floriferi erecto-patentes, fubdiphylli, fæpiùs biflori. Flores tongiùs pedunculati, albi. Calyx villofus, longitudine petalorum. Fructus parvus, exfuccus, vix deciduus. Semina læria, nec rugofa.

Planta habitu, potiùs quam ftructurâ fructûs, Fragarixe congener; ambigit inter Fragariam, et Comarum. A Potentillâ difcrepat feminibus lævibus.

235. POTENTILLA. G. Pl. 255. Juf. 338. Pentaphyllum. Gortn.t.73.

Cal. decemfidus, inferus. Petala 5. Semina fubrotunda, nuda, fxpiùs rugofa, receptackio parvo, exfucco, affixa.

\section{* Foliis pinnatis.}

I. POTENTILLA foliis pinnatis, caule fruticofo. frutico $\{a$. Potentilla fruticofa. Sp. Pl. 7०9. Hludf. 222. With. 472. Engl. Bot. t.88. Dickf. H. Sice. fafc. 6. I 2 .

Pentaphylloides fruticofa. Räii Syn.256. Cat. ed. 2. 228. t. I.

P. fruticofa clatior, minùs hirluta. Amman. Puth. 89. t. 17.

Angl. Shrubby Cinquefoil.

In montofis dumofis, fed rarius.

About the river Tees plentifully, as mentioned by Ray. Mír. Robjon.

Fruiex. Fl: Junio.

Caulis fruticofus, erectus, ramofifimus, tripedalis. Folia alterna, petiolata, quinato-pinnata, fubreroluta, integerrima, fubtùs pilofa, fuperiora temata. Stipulæ amplexicaules. Flores terminales, folitarii, pedunculati, aurei, formofi. Calycis lacinic quinque exteriores foliacea, patentes. Pétala fubrotunda, iel cibcordata.

2. POTENTILLA foliis interuptè pinnatis fer-anferina. ratis fubtùs fericcis, caule repenie, pedunculis unifloris. 
Potentilla anferina. Sp. Pl. 7 ro. Hutlf. 222. With. 473. Relh. 196. Sibth. 161. Curt. Lond. fafs. 3. t. 31. Fl. Dan. t. 544.

Potentilla. Matth. Valgr. v. 2.364. Camer. Epit. 758 .

Pentaphylloides Argentina dicta. Raii Syn. 256. Argentina. Ger. em. 993 .

Angl. Silver-weed. Wild Tanfey.

In pratis humidis fpongiofis, vel falicetis, frequens.

Perennis. Fl. Junio, Julio.

Formofa planta. Caules proftrati, flagelliformes, repentes, foliofi, pilofi, rubicundi, Folia interruptè pinnata, fublyrata, foliolis obtufis, incifo-ferratis, fubtùs argenteonitidiffimis. Pedunculi folitarii, axillares, unifori. $\mathrm{Ca}-$ lyx fericeus, incifas. Petala aurea. Variat foliis nus dis; at frequentiùs verò utrinque fericeis.

rupeftis. 3. POTENTILLA foliis lyrato-pinnatis feptenatis quinatis ternatifque : foliolis ovatis ferratis pilofis, caule crecto.

Potentilla rupeftris. Sp. Pl. 7 I r. Hudf. 223. With. 473. Jacq. Auftr. t. I I 4.

Pentaphylloides erectum. Raii Syn. 255. Morif. ject. 2. t. 20. f. I. Baub. Hift. ข. 2. 398. d.

Pentaphyllum fragiferum. Ger. em. 99 r.

Upright Welch Cinquefoil. Pet.H. Brit.t. $4 \mathrm{I}$. f. 6 .

Angl. Strawberry-flowered Cinquefoil.

In rupibus umbrofis alpinis.

On the fides of Craig Wreidhin in MontgomeryThire. Mr. Lhwyd. Ray.

Perennis. Fl. Junio, Julio.

Caulis ferè pedalis, erectus, ramofus, foliofus, ftriatus, pubefcens. Folia lyrato-pinnata; foliolis fubovatis, obtufis, incifo-ferratis, venofis, pilofis, nec incanis, in 
radicalibus et caulinis inferioribus 5 vel 7 , in fuperioribus 3. Stipulæ radicales lineares, ácutæ; caulinæ rhombeo-fubrotundæ. Pedunculi fubpaniculati, uniflori, villofi. Calyx bafi villofus. Petala obcordata, àlba. Styli rubicundi. Semina lævia, nec rugofa, hinc forfitan ad Fragariam amandanda, cui facie affinis elt.

$$
\text { * * Foliis digitatis. }
$$

4. POTENTILLA foliis quinatis cunciformibus argentea. incifis fubtus tomentofis, caule erecto.

Potentilla argentea. Sp.Pl. 7I 2. Hudf. 223. With. 474. Relb. 197. Sibth. I61. Abbot. I I3. Engl. Bot. t. 89. Fl. Dan. t. 865.

Pentaphyllum erectum, foliis profundè fectis fubtùs argenteis, flore luteo. Raii Syn. 255. Baub. Hift. v. 2. 398. c.

P. album. Mattb. Valgr. v. 2.367.

Quinquefolium Tormentillx facie. Ger. em. 983. Angl. Hoary Cinquefuil.

In pafcuis folo glareofo.

Perennis. Fl. Junio.

Caules patentes, fpithamæi, lanati. Folia petiolata, quinata, incifa ; fupra viridia, glabra ; fubtùs niveo-tomentofa, ficut pedunculi et calyces. Flores numerofi, parvi, aurei. Semina læviufcula.

5. POTENTILLA foliis radicalibus quinatis ob-aurea. ovatis incifo-ferratis pilofis fubmembranaceis; caulinis ternatis, caule erectiufculo.

Potentilla aurca. Sp. Pl. 712. With. 475. Fl. Dan.t. I14. Engl. Bot.t. 56 I.

Fragaria n. II22. Hail. Hijt. 0.2 . 49, t. 21 . f. 4 .

Pentaphyllum alpinum fplendens aureo flore. Baub. Hif. v. 2. 398.

Quinque. 
Quinquefolium minus flore aureo. Ger. ent. 990.

Angl. Golden Cinquefoil.

In alpibus Scoticis.

On Ben Lawers and other mountains in Bredalbanc. Mr. J. Mackay.

Perennis. Fl. Julio.

Caules fpithamæi, ferè crecti, ramofi, foliofi, pilofi. Folia tenuia et quafi membranacea, nitidiufcula, parùn pilofa, incifo-ferrata, fubtus pallidiora; radicalia longiffimè petiolata, quinata, foliolis obovatis, obtufis; caulina fubfeffilia, ternata; fumma frepiùs oppofita. Pedunculi axillares et terminales, folitarii, longiffimi, uniffori, pilofi, erecti. Calyx pilofus, laciniis omnibus longitudine fubæqualibus, alternis anguftioribus. Petala obcordata, calyce longiora, faturatè aurea et ferè aurantiaca. Semina longitudinaliter corrugata.

verna. 6. POTENTILLA foliis radicalibus quinatis cuneatis ferratis lineatis ciliat is fubcoriaceis ; cau. linis ternatis, caule declinato.

Potentilla verna. Sp. Pl. 7 12. Hudf. 224. With. 475. Relh. 197. Engl. Bot. t. 37. Lightf. 270. Dickf. H. Sicc. fafc. 13. 19. Fragaria verna. Crants. fafe. 2. 12. t. I. f. I. Pentaphyllum parvum hirfutum. Racii Sjn. 255. Angl. Spring Cinquefoil.

In pafcuis elatis fierilioribus.

In Yorkthire and Lancafhire. Ray. Hudf. With. Near Kippax. Rev. Mr. Wood. About Bury. Sir T. G. Cullum, Bart. In the King's Park, Edinburgh.

Perennis. Fl. Aprili, Maio.

Canles palmares, ferè proftrati, divaricati, ramofi, foliofi, pubefcentes. Folia rigida, fubcoriacea, glabriufcula, lineata, 
lineata, margine carinâque ciliata; radicalia longiùs petiolata, quinata, foliolis cuneiformibus, fubretufis; caulina fubfeffilia, ternata, trifida; fumma fimplicia, et fæpiùs integra. Pedunculi fubterminales, uniflori, pubefcentes, erecti. Calyx tomentofus et pilofus, laciniis fubæqualibus. Petala emarginata, aurea. Semina minùs quam in præcedente rugofa.

7. POTENTILLA foliis quinatis fubtùs fericcis alba. apice conniventi-ferratis, caulibus filiformibus procumbentibus, receptaculis hirfutiffimis.

Potentilla alba. Sp. Pl. 7I3. Hudf. 224. With. 474. Jacq. Auftr. t. I I5.

Quinquefolium fylvaticum majus fiore albo. Ger. em. $9^{89}$.

Q. majus candidum. Fuch.. Hift.623. Ic. $35 \%$.

Q. Tragi. 'Trag. Hift. 507 .

Q. album. Camer. Epit. $76 \mathrm{r}$.

Pentaphyllum album. Baub. Hift.v.2.598. d. Angl. White Cinquefoil.

In alpibus.

In Wales, Mr. Haviland. Hudf. I know of no other authority.

Perennis. Fl. Julio, Augufto.

Caules procumbentes, filiformes, ramofi. Folia radicalia longè petiolata, quinata, foliolis lanceolatis, obtufurfculis, fubtùs fericeo-villofis, apicem versùs conniventiferratis; caulina ternata, parva. Pedunculi longiffimi, filiformes. Calycis laciniæ acuminatæ, fericeæ. Petala alba. Receptaculum fetis longis, denfis, villofum. Semina obfoletè rugofa.

8. POTENTILLA foliis quinatis obovatis ferratis, replans. caule repente, pedunculis unifloris.

Potentilla reptans. Sp. Pl. 714. Hudf. 224. With. 474. Relh. 19S. Sibth. 16r. Curt. Lond. fufe. 1. t. 37. Woodv. Med. Bot. t. 59 . 
Pentaphyllum vulgatiflimum. Raï Syn. 255.

Quinquefolium. Matth. Falgr.v. 2.365.

Q. majus. Ger.em. 987 .

Q. majus luteum. Fuch. Hift. 624 .

E. Pentaphyilum aureum minus, fylvaticum, noftras, folis tripartito-divifis, ex cauliculorum geniculis radicefcens. Dill. in Raii Syn. 255? Pentaphyllum, radix. Pbarmac. Lond. Angrl. Common creeping Cinquefoil.

In pratis pafeuis ct ad femitas paffim. Perennis. Fl. Junio-Augufto.

Radix fibrofa. Caules proftrati, flagelliformes, repentes, foliofi. Folia petiolata, crecta, quinata, foliolis obovatocuncatis, ferratis, pilofis. Pedunculi folitarii, foliis longiores, uniffori. Calyx pilofus. Petala aurea.

236. TORMENTILLA. G. Pl.256. Juf.337. Cal. oetofidus, inferus. Petala 4. Semina fubrotunda, nuda, rugofa, receptaculo parvo, exfucco, affixa.

aficina- I. TORMEN TILLA caule erectiufculo ramofo, lis. foliis feffilibus.

Toumentilla officinalis. Curt. Lond. fafe. 5 . t. $35 . W i t h .476$.

T. erecta. Sp.Pi.716. Hudf. 225 . Relh. I98. Woodv. Med. Bot. t. 9. H. Dan.t. 589.

Tormentilla. Raii Syn. 257. Ger. em. 992.

Camer. Epit. 685. Matth. Valgr. v. 2. 297. Brunf. Herl. v. 1. $8_{5}$.

Potentilla Tormentilla. Sibth. 162. Ablot. I 14. Tormentilla, radix. Pbarmac. Lond. Angl. Common Tormentil, or Septfoil.

In parcuis ferilibus, ericetis et dumofis.

Peremis. Fl. Junio, Julio.

Radix 
Radix lignofa. Caules, ramofi, erecti, diffufi, vel procumbentes, teretes, foliofi. Folia ferè feffilia, ternata, lanceolata, lineata, incifo-ferrata, pilofa. Stipulæ incifæ. Pedunculi oppofitifolii, folitarii, capillares, uniflori. Calycis laciniæ ovatæ, pilofæe. Petala aurea, obcordata. Semina rugofa, pauca.

Variat rariùs floribus quinquefidis. Interdum flore pleno gaudet. Mifs Jobnes.

2. TORMENTISLA caule proftrato fimpici, reptans. foliis petiolatis.

Tormentilla reptans. Sp. Pl. ๆ 6.6 Wits. 476. Raii Syn. 257 .

Potentilla procumbens. Silth. I62.

Pentaphyllum reptans alatum, folits profundius ferratis. Plot. Oxf.t. 9. f. 5 .

Plot's Tormentil. Pet. H. Brit. t. 41.f. 10. Angl. Trailing 'lormentil.

Ad repes, vel margines agrorum.

In feveral places in Oxfordhire. Ray. Lakenham near Norwich. Mr. Crowe. Hcrtfordthire. Mr. Woodward. Surrey. Herb. Lightf. At Brighoufe near Halifax, Yorkfhire.

Perennis. Fl. Junio, Julio.

Caules pauci, proftrati, fimplices, bipedales, flagelliformes, pubefcentes, foliofi, non radicanțes. Folia longiùs petiolata, ternata, foliolis obovatis, incifo-ferratis, pilofis. Stipulæ lanceolatæ, frepius indivifæ. Pedunculi folitarii, foliis longiores. Calycis laciniæ ovato-lanceolatx, inaquales, pilofæ. Petala obcordato-fubrotunda, aurca. Semina rugofa.

Variat floribus inferioribus fubinde quinquefidis. Diftinctiffima fpecies a præcedente, ut et ab omnibus $\mathrm{Po}$ tentillis Linnæanis. 


\section{GLUM. G. Pl.256. Jlif. 338. Gartu. t. 74 .}

Cal. Accemfidus, inferus. Petala 5. Seminum arifta geniculata. Receptaculum columnare.

urba-

num.

I. GEUM folis ternatis, fipulis rorundatis incifis, foribus erectis, ariftis uncinat is nudis.

Geum urbanium. Sp. Pl. 716. Hudf. 226. With. 477. Relb. I99. Sibth. 162. Curt. Iond. fafc.2. t. 36. Fl. Dan. t. 6\%2. Woodv. Suppl.t. 259 .

Caryoplyyliata. Raii Syn. 253. Ger. em. 994. Camer. Epit. 725. Malth. Valgr. ข. 2. 333. Brunf. Herb. v. 2. 22.

C. hortenfis. Fuch\%. ITift. 384 .

E. C. vulgaris majore flore. Baub. Pin. 32 I. Raii Syn. 253 .

C. fylveftris. Fucbs Hift. 385 .

Great-flowered Aveus. Pet. H. Brit.t. 40.f.2. Angl. Common Avens. Herb Bennet.

In fylvis et ad fepes frequens.

Percniss. Fl. Main-Augufto.

Radix fibrofa. Caulis bipedalis, teretiufculus, pilofus, foliofus, fupernè ramofus, erectus. Folia petiolata, ternata, foliolis fubcuneatis, incifis et ferratis, pilofis; fumma fimplicia, trifida, acuminata. Stipulæ maximæ, rotundatæ, lobatæ, ferratæ. Flores terminales, folitarii, crecti. Petala plcrumque calyce breviora, lutea, patentia. Semina fubpilofa, ariftis purpureis, nudis, apice uncinatis et geniculatis.

4ivale. 2. GEUM foliis radicalibus lyratis, ftipulis ovatis acutis incifis, floribus nutantibus, ariftis plumofis tortis.

Geum rivale. $S p . P l .717$. Hudf.226. With. 478 . 6 
Relh. I99. Siblh. 163. Abbot. I I4. Engl. Bot. t. ro6. H. Din. t.722.

Caryophyllata montana purpurea. Raii Syn. 253. Ger. em. 994.

C. aquatica. Comer. Epit. 726 .

3. Var. 2. With. 478 . floribus Ravis.

. Var. 3. With. 478 . floribus plenis, interdum proliferis.

Childing Avens. Pet. H. Brit. t. $40 \mathrm{f} .4$. Angl. Water Avens.

In pratis et nemorofis humidis, præcipuè fubmontofis.

Not rare in the north of England, Scotland, Wales, nor cren Norfolk. Sec Engrl. Bot.

Perennis. Fl. Junio, Tulio.

Radix horizontalis, fublignofa. Caulis pedalis, erectus, fubfoliofus, apice ramolus, nutans. Folia radicalia lyrata, interruptè pimnata, plicata, incifa, ferrata, pilofa ; caulina ternata, vel frimplicia. Stipulæ ovatre, acutæ, integra vel incifie. Flores cernui. Calyx extùs fufcopupureus, campanulatus. I'etala erecta, cuneiformiobcordata, luteo-purpurafcentia. Ariftæ medio geniculato-flexuofæe, pilofæe, apice uncinatæe.

B videtur hybrida, patre G. urbano, cui habitu fimilis éft. $y$ folo ficco fterili originem fuam debet.

\section{DRYAS. G. Tl. 256 . Juf. 338 . \\ Gartn. t. 74,}

Cul. 8-vel ro-fidus, inferus. Petala 5 vel 8. Semimum cauda plumofa. Recestaculum depreflim.

I. DRYAS octopetala, foliis fimplicibus ferratis. octopetaDiyas octopetala. $S_{p} . \mathrm{Pl}$. 717 . Hudf. 226. With. 478, Lighlf. 274. Engl. Bot, t. 45 I. Fl. D.w. t. 31 . 
Caryophyllata alpina, Chamædryos folio. Raii Syn. 253.

Chamxdrys montana. Dalech. Hift. I 64 .

C. montana durior. Lob. Ic. 495.

Tcucrium alpinum Cifti flore. Ger. em. 659. Angl. Mountain Avens.

In campis petrofis alpinis.

In the highlands of Scotland, the north-weft part of Yorkfhire, and in Ireland.

Perennis. Fl. Julio, Augufto.

Radix lignofa. Caules decumbentes, implexi, lignofi; ramulis foliofis, erectis. Folia petiolata, ovata, fubrevoluta, ferrata ; fupra glabra, rugofa, nitida ; fubtùs tomentofo-nivea. Pedunculi folitarii, erecti, longiffimi, unifori, tomentofi, apice glandulofo-hifpidi. Flore erecti, formofi, albi. Calyx glandulofus, pilofus, laciniis octo, fubrqualibus. Petala octo, patentia, fubelliptica. Semina pilofa, ariftis fefquiuncialibus, rectis, plumofis.

\section{COMARUM. G.Pl. 257. Juf: 338. Gartn. t. 73.}

Cal. decemfidus, inferus. Petala 5, calyce minora. Receptaculum feminum ovatum, fpongiofum, villofum, perfiltens. Semina lævia.

palufire. I. COMARUM.

Comarum paluftre. Sp. Pl. 718. Hudj. 227. With. 479. Relh. 200. Dickf. H. Sicc. fafc. 2. I6. Engl. Bot. t. I 72. Fl. Dan. t. 636 Albot. I I 5 .

Pentaphylloides paluftre rubrum. Raii Syn. 256. Pentaphyllum rubrum paluftre. Ger. em. 987 . P. paluftre. Cord. Hift. 96. I.

Quinquefolium paluftre. Camer. Epit. 762. P. Pentaphyllum paluftre rubrum, craffis et villofis foliis, 
foliis, Suecicum et Hibernicum. Räii $S_{j} z_{2}$ 256. Pluk. Phyt. t. 2I2. f. 2. Angl. Marhh Cinquefoil.

In paluftribus fpongiofis et cœnofis.

Perennis. Fl. Junio, Julio.

Radix repens. Caules bafi decumbentes, teretes, foliof glabri. Folia longiùs petiolata, quinato-pinnata, oblonga, ferrata, fubtùs incana; in $\beta$ utrinque villofa. Flores fubpaniculati, atro-purpurei. Calycis laciniz alternæ valdè inæquales, acutæ. Petala parva, acuta. Fructus ovato-conicus, feminibus numerofis, lævibus, fragariæformis. 



\section{Clafis XIII. POLYANDRIA.}

Stamina plura, receptaculo inferta.

\section{MONOGYNIA.}

Stylus 1.

* Tetrapetali.

243. PAPAVER. Cal. diphyllus. Caps. unilo. cularis, poris fub ftigmate dehifcens.

241. CHELIDONIUM. Cal. diphyllus. Sillqua unilocularis. Sem. criftata.

242. GLAUCIUM. Cal. diphyllus. Siliqua bilocularis. Sem. punctata.

240. ACT无A. Cal. tetraphyllus. Bacca unilocularis. Semina plana, bifaria.

Ciftus marifolius.

* Pentapetali.

246. CISTUS. Capf. trivalvis, apice dehifcens. $\mathrm{Cal}$. pentaphyllus; foliolis duobus minoribus.

245. TILIA. Capf. quinquevalvis, bafi dehifcens, coriacea. Cal. quinquepartitus, deciduus.

Delphinium Confolida.

$$
\text { * * Polypetali. }
$$

244. NYMPHÆA. Bacca multilocularis, corticofa. Cal. petalis major. 


\section{$(560)$ \\ TRIGYNIA. \\ Styli 3 .}

247. DeLPhiniUm. Cal. nullus. Pet. quinque ; fupremo cornuto. Necl. bifidum, feffile.

Refeda Luteola, Helleborus.

\section{PENTAGYNIA.}

\section{Styli 5 .}

248. AQUILEgIA. Cal. nullus. Pet. quinque, Nect. quinque, infernè cornuta.

\section{HEXAGYNIA. Styli 6.}

249. STRATIOTES. Spatha diphylia. Perianthium fuperum, trifidum. Pet. tria. Bacca fexlocularis.

\section{POLYGYNIA. \\ Styli plures.}

252. THALICTRUM. Cal. nullus. Pet.4-5. Sem. ecaudata. 


\section{( 56 I )}

25I. Clematis. Cal. nullus. Pet.4-6. Sen. caudata. Recept. capitatum.

250. ANEMONE. Cal. nullus. Pet.5-9. Sem. plurima.

256. HELLEBORUS. Cal. nullus. Pet. quinque, perfiftentia. Nect. tubulata, bilabiata.

257. CALTHA. Cal. nullus. $P$ et. quinque. Nect. nulla.

255. TROLliUS. Cal. nullus. Pet. quatuordecim. Nect. complanata.

254. RanUnCULUS. Cal. pentaphyllus. Pet. quinque, unguibus nectariferis. Sem. plurima, nuda.

253. ADONIS. Cal. pentaphyllus. Pet.5-io, nectario deftituta. Sem. plurima, nuda. 


\section{POLYANDRIA。 \\ I. MONOGYNIA.}

240. ACTEA. G. Pl. 26 I. Ju开. $235^{\circ}$ Gerin. t. 1 I 4.

Cal. tetraphyllus. P'etala 4. Bacca fupera, unilocularis, polyfperma. Semina plana.

fpicala. I. ACT EEA racemo ovato.

Actra fpicata. Sp.Pl. 722. Hudf. 228. With. 483. Fl. Dan.t. 498.

Chriftophoriana. Raii Syn. 262. Ger. em.979. Cluf. Hift. v. 2. 86. 'Tillandf. Ic. I 48.

Napellus racemofus. Dalech. Hift. I 747 . Angl. Herb Chritopher. Bane-berries.

In nemorofis fubalpinis rariùs.

In the north-weft corner of Yorkhire, as about Malham Cove, Clapham, Afkrig, and upon the lower part of Ingleborough hill. Ray. Hudf. Curt. and Woodward. About Thorpe Arch. Rev. Mr. Wood.

Perennis. Fl. Maio, Junio.

Herba fefquipedalis, glabra, foliis triternatis, acuminatis, incifo-ferratis. Racemi terminales, folitarii, ovati, obtufi, pedicellis unifloris, pubefcentibus, bafi bracteatis. Bracteæ oblongæ, concavæ. Calyx deciduus. Petala alba. Stamina filiformia, longitudine petalorum. Germen ovatum, glabrum. Stigma capitatum, feffile. Bacca purpureo-nigra, fuccofa, venenata.

241. CHELIDONIUM. G. Pl. 262. Juf. 236. Gertn. t. I I 5 .

Cal. diphyllus. Petala 4. Siliqua fupera, bivalvis, unilocularis, lincaris. Semina plurima, criflatя. 
I. CHELIDONIUM.

Chelidonium majus. Sp. Pl. 723. Hudf. 228 . majus. With. 483. Relh. 201. Sibth. 16.4. Fl. Dan. t. 542. Woodv. Suppl.t.263. Ger. enr. 1069. Fuch. Hift. 865. Trag. Hift. 107.

C. majus vulgare. Mill. Ic. t.92. f. I.

Papaver corniculatum luteum, Chelidonia dictum. Raii Syn. 309.

8. Chelidonium inajus foliis quernis. Dill. in Raik Syn. 309. Mill. Ic. t. 92. f. 2. Fl. Dan. t. 676 .

C. majus, folio magìs diffećto. Ger. em. 106g. Angl. Celandine.

In ruderatis, rel umbrofis folo calcareo.

Perennis. N. Maio, Junio.

Radix fufformis. Caulis bipedalis, ramofus. Folia pinnata, lobata, levia, fubglauca, lobis rotundatis, crenatis. Umbellæ axillares, pedunculatæ, folitariæ. $\mathrm{Ca}$ lyx fubpilofus, deciduus. Petala aurea. Siliqua torulofa. Semina nigra, nitida, criftâ albâ.

Herba tota fucco croceo fcatet. Folia et petala in $\beta$ laciniata funt.

242. GLAUCIUM. Toumef. t. г 30. Ju囚. 236. Gertn.t.II5.

Chelidonium. G. Pl.262.

Cul. diphyllus. Petala 4. Siliqua fupera, bilocularis, lincaris, bi- rel tri-valvis. Semtina plurima, punctata.

I. GLAUCIUM caule glabro, foliis caulinis re- Zuteum. pandis, filiquâ tuberculato. f́cabriufculâ.

Glancium luteum. Gertn.v.2. I66. Scop.Carn. ข. I. 369 .

Chelidonium glaucium. Sp. Pl. 724. Indf. 229 . With. 484. Engl. Boi.t.8. H\%. Darr. t. 585 . Papaver 
Papaver corniculatum. Fucb. IIif. 52c.

P. corniculatum luteum. Raii Syn. 309. Paub. Hift. v. 3. $39^{9}$.

P. cornutum flore luteo. Ger. em. $3^{67}$. Angl. Yellow Horned-Poppy.

In arenofis maritimis.

Annua. Fl. Julio, Augufto.

Herba glauca. Caulis ramofus, patens, lævis. Folia radicalia lyrato-pinnatifida, fcabra ; caulina alterna, amplexicaulia, rotundata, repanda vel finuata. Pedunculi axillares et terminales, uniflori. Calyx hifpidus, deciduus. Petala rotundata, magna, aurea. Siliqua Iongiffima, ferè pedalis, curva, fæpiùs tuberculato-fcabra. fubinde lævis, bilocularis, diffepimento fpongiofo. Semina numerofa, excavato-punctata.

phenici † 2. GLAUCIUM caule hifpido, foliis caulinis snt. pinnatifidis incifis, filiquâ fetosâ.

Glaucium phœnicium. Gerln.v.2.165.t. I I5. Allion. Ped. v. I. 290.

G. corniculatum. Curt. Lond. fafc. 6. t.32.

Cheliclonium corniculatum. Sp.Pl. 724. Hudf. 229. With. 484 .

Papaver corniculatum phœnicium, folio hirfuto. Bants. Hift. v: 3. 399 .

P. cornutum phænicco forc. Cluf. Hift. v.2.91.

P. cornutum flore rubro. Ger. em. 367 .

Angl. Red Horned.Poppy.

In arvis arenofis; dubia civis.

Sent from Norfolk by Mir. Stillingfleet. Hudf. It has never been found by any perfon fince.

Annua. Fl. Junis, Julio.

Radix fuffiformis. Folia pilofo-hifpida, glauca; radicalia lyrato-pinnatifida; caulina pimnatifida, dentato-incifa, amplexicaulia. Petala phœenicea, fugacia, præcedente duplò minora. Siliqua fetis adpreffis feabra. Semina excavato-punctata. 
In hortis tantum vidi, neque fpontaneum habuit Curtifius dum in Florâ Londinenfi defcriberet.

3. GLAUCIUM foliis bipinnatifidis linearibus violace glabris, caule lævi, filiquis trivalvibus.

Glaucium violaceum. Juf. Gen. 236.

Chelidonium violaceum. Lamark. Franc. $\vartheta 3$. r6g.

C. hybridum. Sp. Pl. 724. Hudf. 229. With. 485. Relh.201. Engl. Bot.t. 201.

Papaver corniculatum violaceum. Raii Syn. 309. Bauh. Hiß. v. 3. 399.

P. cornutum flore violacco. Ger, em. 367 . Angl. Violet Horned-Poppy.

Inter fegetes rariùs.

Between Swaffham and Burwell, Cambridgehhire.

Ray. About four miles from Aylham towards

Cromer, Norfolk. Mr. Rofs.

Annua. Fl. Maio, Junio.

Caulis lævis, ramofus, viridis. Folia bipinnatifida; linearia, faturate viridia, glabra, interdum tripinnatifida. Petala pulcherrimè violacea, caduca. Stigma trifidum. Siliqua apicem versùs fubaculeatum, trivalvis, unilocularis ; receptaculis tribus, valvulis affixis. Semina excavato-punctata.

Omnibus his fpeciebus nomina fpecifica antiqua reftitui, prout optima, et Linnæanis longè præeferenda.

243. PAPAVER. G.Pl. 263. JuJ.236. Gertn. t. 60.

Cal. diphyllus. Petala 4. Stigma radiatum. Capfula fupera, fub ftigmate perfiftente poris dehifeens.

* Capfulis bijpidis.

I. PAPAVER capfulis fubglobofis torolis hifpidis, bybricaule foliofo multifloro.

VOL. II. $\quad \mathrm{K}$ Papaver dum. 
Papaver hybridum. Sp, Pl. 725. Hudf. 230. With. 485. Relh. 202. Silth. 165. Ab. bot. II6. Engl. Bot. t. 43 .

Papaver laciniato folio, capitulo hifpido rotundiore. Raii Syn. 308.

Argemone capitulo torulo. Ger. em. 373.

A. capitulo breviore hifpido. Bauß. Hif. ข. 3. 396.

Angl. Mongrel Poppy.

In arvis rariùs.

At Wells, Norfolk. Mr. Crowe. Out of St. Benedict's gates, Norwich. Mr. Pitchford. About Durbam. Mr. Robjon. At Darent near Dartford. Mr. Lewin.

\section{Annua, Fl. Julio.}

Caulis gracilis, ramofus, foliofus, hifpidus, fetis adpreffis. Folia tripartita, pinnatifida, laciniis linearibus, ariftatis, hifpidis. Rami unifori, nudi. Calyx fetis fulvis muricatus. Petala punicea, bafi frepiùs violacea. Stamina lineari-lanceolata, violacca. Pollen cyaneum. Stigma 6-8-radiatum. Capfula obovata, fulcato-torofa, aculcis arcuato-adfcendentibus muricata.

Argemo-2. PAPAVER capfulis clavatis hifpicis, caule fore liofo multifloro.

Papaver Argemone. Sp. Pl. 725. Hudf. 230. Witb. 486. Relh. 202. Sibth. 165. Curt.

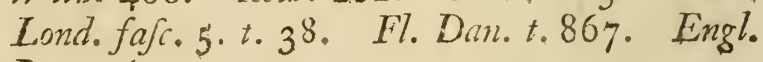
Bot.t. 643 .

P. laciniato folio, capitulo hifpido longiorc, Rai Syn. 308.

Argemone capitulo longiore. Ger. $\mathrm{cm} .373$.

B. Papaver maritimum. With. 486. caule unifloro.

Angl. Long-rough-headed Poppy.

In arvis, 
Annua. Fl. Junio, Julio.

Habitus prioris, fed foliorum laciniis plerumque latioribus.

Setæ caulinæ minùs aretè adpreffæe. Petala pallidè coccinea, fugacia. Stamina apicem versus latiffima. Antheræ pedicellatæ. Stigma quadri-vel quinque-radiatum. Capfula lineari-clavata, fubpentagona, minimè torofa, apice præcipuè fetofa.

Variat rariùs flore pleno.

$$
\text { * Capjulis glabris. }
$$

3. PAPAVER capfulis glabris oblongis, caule dubium. multifloro pilofo, fetis pedunculorum adpreffis, foliis bipinnatifidis.

Papaver dubium. Sp. Pl. 726. Hudf. 230. With. 487. Relh. 203. Sibth. 165. Curt. Lond. fafc. 5. t. 37. Fl. Dan. t. 902. Engl. Bot. t. 644 .

P. łaciniato folio, capitulo longiore glabro. Räi Syn. 309 .

Argemone capitulis longioribus glabris. Morij: ject. 3. t. I $4 . f . \mathrm{II}$.

Angl. Long-fimooth-headed Poppy.

In arvis, imprimis folo fabulofo.

Annua. Fl. Junio, Julio.

Caulis bipedalis, pilofus, pilis patulis. Foliorum lacinix latiores quam in præcedentibus. Pedunculi elongati, hifpidi, fetis aretè adpreffis. Petala pallidè coccineà. Stamina linearia. Pollen flavum. Stigma 6-8-radiatum. Capfula glaberrima, clavato-oblonga, fulcata, fubinde oborata.

4. PAPAVER capfulis glabris rubglobofis, caule Rócas. multifloro hifpido: pilis omnibus patentibus, foliis pinnatifidis incifis.

Papaver Rhœas. Sp. Pl. 726. Huals. 230. Hith. 486. Rell. 203 . Sibth. 165. Curt. $\mathrm{K} 2$ Lond. 
Lond. fafc. 3. t. 32. Woodv. Med. Bot.

t. 186. Ger. em. 37 I. Engl. Bot. t. 645.

P. laciniato folio, capitulo breviore glabro, annuum, Rhoas dictum. Raii Syn. 308.

P. crraticum primum. Fuchs. Hift. 5 I5

P. erraticum. Matth. Valgr.v.2. 404.

Papaver erraticum, flos. Pbarmac. Lond. Angl. Common Red Poppy. Corn Rofe.

Inter fegetes vulgaris.

Annua. Fl. Junio, Julio.

Caulis et pedunculi undique pilofi, fetis horizontaliter patentibus. Folia pinnatifida, ferrata, vel incifa, fæpe bipinnatifida, pilofa, fubinde glabra. Petala faturatè punicea, magna, fpeciofa. Stigma multiradiatum. Capfula ovata, truncata, glaberrima.

fomnifo- * 5. PAPAVER calycibus capfulifque glabris, forum. liis amplexicaulibus incifis glaucis.

Papaver fomniferum. Sp.Pl. 726. Hullf.23 1. With. 487. Relh. 204. Sibth. 166. Woodv. Med. Bot. t. I 85 .

P. fylveftre. Raii Syn. 303. Ger. em. 370.

P. album. Bauh. Hift. v. 3. 390.

Papaver album, capfula. Plarmac. Lond. Angl. White Poppy.

In arris et ruderatis, vix indigena.

By the Roman road from Cambridge to Ely. Rer. Arcbdeacon Peirfon.

Annua. Fl. Julio.

Iierba glauca. Caulis tripedalis, infernè lævis, fuperne hifpidus, pilis patentibus. Folia fimplicia, amplexicaulia, obtufa, lobata et crenata. Calyx glaber. Petala alba. Stigma multiradiatum. Capfula fubrotun, da, glaberrima.

cambri- 6. PAPAVER capfulis glabris oblongis roftratis, cum. caule 


\section{PÓLYANDRIA-MONOGYNLA.}

caule multiforo læviufculo, foliis pinnatis incifis.

Papaver cambricum. Sp.Pl. 727. Huds.23I. With. 488. Engl. Bot.t. 66.

P. luteum perenne, laciniato folio, Cambro-britannicum. Raii Syn. 309 .

P. Cambricum perenne, flore fulphureo. Dill. Elth. v. 2.300. t. 223.

Argemone lutea Cambro-britannica. Park. Theatr.369. Morif. Sect. 3. t. I4. f. 12.

Angl. Yellow Poppy.

In montofis umbrofis petrofis.

In feveral places in North Wales. Ray. About Kendal, Weftmoreland, plentifully. Hudf. Near Kirkby-Lonfdale.

Perennis. Fl. Junio.'

Caulis pedalis, fubpilofus, nec omninò lævis, pilis erectiufculis. Folia pinnata, rachi alatâ, foliolis fubovatis, acutis, incifis, glabris, teneris, fubtus glaucis. Flores fuaveolentes. Calyx pilofus. Petala amœene citrina. Stigma fubquinque-radiatum, ftylo brevi elevatum. Capfula glabra, clavato-oblonga, coftata, ftylo perfiftente roftrata. Herba fucco luteo fcatet more Chelidonii majoris, cui habitı quodammodò affinis eft. .

244. NYMPH层A. G. Pl. 264. JuJ. 68. G.ertn.t. Ig.

Cal. 4-5-phyllus. Cor. polypetala. Stigma radiatum, feffilc. Bacia fupera, multilocularis, polyfperma.

I. NYMPH无A foliis cordatis integerrimis, calyce lutea. pentaphyllo petalis majore, ftigmate integerrimo.

Nymphæi lutea. Sp. Pl. 729. Hudf. 234. With. 488. Relh. 205. Sibth. 167. Engl. K 3 Bot, 
Bot.t. 159. Fl. Dan.t.603. Raii Syn. 368. Ger. em. 819. Camer. Epit. 635. Fuchs. Hil. 536 . Matth. Valgr.v.2. 246. Angl. Yellow Watcr-Lily.

In furiis et ftagnis frequens.

Perennis. Fl. Julio.

Kadix fublignofa. Folia radicalia, longè petiolata, natantia, cordata, obtufa, integerrima, levia. Scapi teretes, uniflori. Flores lutei, odore vinofo aquæ vitæ vulgò dietre. Calycis foliola quinque, rotundata, conca$\because$ a, colorata. Petala calyce triplò breviora, obtufa, caruolia, fulva. Stamina lincaria, recurva, ferè uniformia, receptaculo inferta. Fructus ovatus, fubroftratus, levis. Semina luteo-margaritacea.

albas.

2. NYMPHALA foliis cordatis integerrimis, calyce tetraphyllo, ftaminibus germini infertis, ftigmate lobato.

Nymphixa alba. Sp. Pl. 729. Hudf. 234. 167h. 489. Relh. 206. Sibth. 167. Engl. Bot.t. 160. Fl. Dan.t.602. Raii Syn. 368. Ger. en. 819. Camer. Eipit. 63t. Mattho Talgr. 2. 2. 245 .

N. candicla. Fuch. Hijf. 535.

Angl. White Water-Lily.

In furvils et fagnis purioribus.

Perennis. Fl. Julio.

Præcedente major. Flores formofi, albi, fubinde rubicundi, foli meridiano expanfi. Calycis foliola quatuor, oblonga; fupra colorata, complanata. Petala lanceolata, fenfim dininuta, et in ftamina mutata, interiora cerminis bafi inferta. Stamina exteriora dilatata, petalis fenfim affimilata, omnia germini inferta, flava. Stigma margine multifidum. Fruetus cicatricofus, obtufus. Semina precedentis minora. 
245. TILIA. G. Pl. 267. Jus].292:

Gertn. i. II3.

Cal. quinquepartitus: Petala 5. Capfula fupera, coriacea, obovata, angulata, quinquelocularis, quinquevalvis, bafi dehifcens.

I. TILIA floribus nectario deftitutis, foliis cor-europass. datis; ramificationibus venarum fubtùs villofis.

Tilia europæa. Sp. Pl. 733: Hudf. 23 I. With. 490. Relh. 204. Sibth. I66. F\%. Dan. t. 553. Engl. Bot.t.6ro.

T. vulgaris platyphyllos. Kaii Syn. 473. Baub. Hift. $v .1:$ p. 2.133 .

T. fnmina. Ger. em. 1483. Fuich. Hift.862. Tilia. Trag. Hift. I 10.

Lime Tree. Hunt. Evel. Syli. tab. ad p. 201.

B. T. folio minore. Raï Syn. 473. Baub. Hif. v. I. p. 2. I 37 .

$\gamma$.T. foliis molliter hirfutis, viminibus rubris; fructu tetragono. Raii Syn. 473 .

\$. T. ulnifolia, femine hexagono. Dill. in Rait Syn. 473:

Angl. Lime-tree. Linden-trec. $\gamma$ Fed Lime. trec.

In fylvis et fépibus.

if frequent in Effex, Suffex and Lincolnfhire. Ray.

$\gamma$ in Stoken-church woods. Ray. Sibth.

$\delta$ in Surrey. Merret.

Arbor. Fl. Julio.

Kami læves. Folia alterna, petiolata, cordata, acuminata, ferrata, vix lobata, venofa, glabra, bafi obliqua, fubtue ad venarum origines villofa. Pedunculi axillares, folitarii, corymbofi vel umbellati. Bractea oblonga, obtufa, membranacea, pallida, integerrima, pedunculo adnata, Flores fuaveolentes, luteo-albidi. Calyx mar$\mathrm{K}+$

gine 
'gine lanatus. Petala obtufa, concava. Stamina filiformia. Stignia quinquefidum. Germen villofum, depreffum. Capfula glabra, angulis 4 ad 8, inæequalibus, feepiùs unilocularis, monofperma, intùs fpongiofa, loculamentis pluribus abortientibus. Semen fubrotundum.

246. CISTUS. G. Pl. $x 71$.

Helianthemum. Juff. 294. Gertn.t. 76.

Cal. pentaphyllus: foliolis inæequalibus. Petals 5. Capfula fupera, angulata, trivalvis, polyfperma.

* Exftipulati, Juffruticoj.

marifo- 1. CISTUS fuffruticofus exftipulatus, foliis oppofitis petiolatis oblongis planis fubtùs tomentofis.

Ciftus marifolius. Sp. Pl. 741. Berk. Otcsl. ed. 1. v. 2. 150. Engl. Bot. t. 396. Sym. Syiz. 126.

C. hirfutus. Hudf. 232 .

C. anglicus. Linn. Mant. 245. With. 490.

C. canus. Jacq. Auftr. t. 277 .

Helianthemum alpinum, folio Pilofellæ minoris Fuchfii. Raii Syn. 342. Bauh. Hif. v. 2. I9. H. ferpilli folio incano, flore minore luteo, inodoro. Dill. Elth. v. I. I.77. t. I 45. f. 173 . Chamæciftus luteus, Thymi durioris folio. $B a=$ rel. Jc. 44I.

Angl. Hoary Dwarf Ciftus.

In rupibus alpinis rariùs.

On fome rocks in Weftmoreland and Lancafhire. Ray. Gloddath near Conway, Carnarvonfhire. Herb. Lightf.

Fruiculits. FI. Maio, Junia。

Radits 
Radix lignofa. Caules lignofi, palmares, teretes, foliofi, ramofi, bafi decumbentes. Folia oppofita, petiolata, patentia, ovato-oblong̣a vel lanceolaia, plana; fupra viridia, fetis depreffis hifpida; fubtus tomentofo-incana. Stipulæ nullæ. Racemi terminales, pauciflori, pubefcentes, bracteolati. Flores aurei, parvi, inodori. Calyx villofus. Petala 4 vel 5 , obovata, integerrima. Germen glabrum, lineis pilofis. Stylus geniculatus.

\section{* Exftipulati berbacei.}

2. CISTUS herbaceus exftipulatus, foliis oppo-guttatws. fitis lanceolatis trinervibus, racemis fubnudis.

Ciftus guttatus. Sp. Pl. 741. Hudf. 232. Witb. 49 I. Curt. Lond. fafc. 6. t.33. Dicks. H. Sicc. fafc. 9. 7. Engl. Bot. t. 544.

C. flore pallido, punicante maculâ infignito. Raii Syn. 342.

C. annuus, flore maculato. Ger. em. I28r.

C. annuus, flore guttato. Banb. Fijt. ข. 2. p.I. It.

Helianthemon flore maculofo. Column. Ecppr. p. 2.78.t.77.f. I.

Angl. Spotted-flowered Cifus.

In pafcuis arenofis rariùs.

In Jerfey. Sberard. In the Ifle of Man, Mr.Brewer. Huld.

Annua. Fl, Junio, Julio.

Radix parva, fibrofa. Caulis ferè pedalis, erectus, finıplex vel ramofus, foliofus, tetragonus, pilofus, pilis dbis, patulis. Folia oppofita, exftipulata, lanccolata, obtufiufcula, integerrima, fubtrinervia, utrinque pilofa, fubvifcida. Racemi terminales, fimplices, fecundi, pilofi, fæpius ebracteati; interdum bracteis lanceolatis, folitariis, ad bafin pedicellorum. Calyx giandulofus, hirtus. Petala inæqualiter crenata, flava, maculâ fanguineâ ad bafin. Stigma feffle. Capfula ovata, trilocularis, 
locularis, diffepimentis e medio valvularum, feminía feris.

$$
\text { * * : Stipulati berbacei. }
$$

delifoli- 3. CISTUS herbaceus exftipulatus pubefens, foss. liis lanccolatis, pedunculis erectis calyce brevioribus.

Ciftus ledifolius. SP. Pl. 742 .

C. Aalicifolius. Hulf. 233. Hith. $49 \mathrm{I}$.

C. anntus. Ger. em. 1 280 . Chus. Hift. v. г. 76 .

C. annuus longifolius Lobelii. Ger.em.1280.

C. humilis annuus, folio Salicis humilis. Lob. Ol. . 552. Ic. p. 2. II 8: f. I.

C. annuus folio Ledi. Lob. Obf. 552. Ic.p.36 $118 . f$. 2 . foliis nimis acutis.

C. annuus I Clufio, folio rotundiore. Buth. Hift. ¿. 2. p. i. 13 .

C. annuus folio Ledi flore itutco. Ibid. I f. Angl. Ledum-leaved Ciftus.

In pafcuis arenofis rarì̀s.

Oi Brent downs, Somerictihire. Hudf.

Annua. Fl, Junio, Julio.

Radix parsa, parùm ramofa. Caulis fuberectus, fimplexi

"bafi intercum ramofus, teres, hirfutus, foliofus, paucifiorus. Folia oppofita, lanceolata, obtufa, integerrima; bafi anguftata, utrinque pubefcentia. Stipulic binæ; lanceolatæ, acutæ, folio tripló breviores. Flores oppofitifolii, folitarii, erecti, breviùs pedunculati. Calycis foliola acuminata, nervofa, hirfuta. Petala lutea, calyce breviora, fugaciffma. Capfula longitudine ferè calycis, glabrata, unilocularis.

Hanc ftirpem ad C. ledifolium Linnæi retuli, ex exemplario hortenfi e feminibus indigenis enato. C. falicifolius diferepat magnitudine duplò ninore, caule ramofiore, pedunculis horizontalibus, calyce fefquilongioribus. Confer 'segu. Veron. Suppl. t. 6.f. 3 ; et etian Ciftum mainisumi fulio fubrotundo. Basth. Hif: 8. 2. I4. 
**** Stipulati Juffruticofi.

4. CISTUS fuffruticofus procumbens ftipulatus, furrejafoliis ovato-oblongis fubtùs pilofis punctatis, mus. petalis lanceolatis.

Ciftus furrcjanus. Sp. Pl. 743. With. 492. Hill. Fl. Brit. t. $27 \cdot f$. I.

C. Helianthemum $\delta$. Hud 5.233 .

Helianthemum vulgare, petalis florum peranguftis. Dill. in Raii Syn. 341. Hort. Elth. I $77 . t .145 \cdot f \cdot 174$.

Angl. Dotted-leaved Ciftus.

In montofis calcareis rariùs.

Near Croydon in Surrey. Mr. Edward Du Bois.

Fruticulus. Fl. Jullio, Augufto.

Caules proftrati, fimplices, foliofi, teretes, hirti, pilis de. preffis, implexis. Folia petiolata, ovato-oblonga, vel lanceolata, obtufa, plana, integerrima; fupra nudiufcula; fubtùs pilofa et excavato-punctata ; utrinque viridia, nec incana. Stipulæ binæ, lanceolatæ, ciliatæ. Racemi terminales, folitarii, fimplices, multiflori, recurvati, pubefcentes, bracteati. Flores erecti. Calyr. pilofus, nervis rubicundis. Petala lanceolata, angufia, àcuta, flava, calyce longiora, interdun breviora. Stamina breviffima, vix germen fuperantia. Capfula unilocularis, vel obfoletè trilocularis.

Foliorum puncta optimè notavit D. Lightfoot in Herbario fuo.

5. CISTUS fuffruticofus procumbens fipulatus, Helianfoliis elliptico-oblongis fubtùs tomentofo-in-tbemzum. canis.

Ciftus Helianthemuin. Sp. Pl. 744. Hudf. 233. livith. 492. Reih. 205. Sibth. 167. Curt. Lond. fafc. 5. t. 36 . Fl. Dan. t. I о I.

Helianthemum anglicum luteum vel album. Ger. em. 1282 .

Chamx- 
Chamæciftus vulgaris flore luteo. Loes. Pruf. 43. t. 8.

Panax Chironium, five flos Solis. Camer. Epit. $50 \mathrm{I}$.

Angl. Common dwarf Cifus.

In pafcuis montofis, folo calcareo, vel glareofo.

Fruticulus. Fl. Julio, Augufto.

Caules procumbentes, fubfimplices, teretes, foliofi, hirti ut in præcedente。 Folia minora, elliptica, obtufa, magnitudine varia, fubrevoluta; fupra pilofa; fubtùs tomentofo-alba. Stipulr lanceolatre, ciliatæe, utrinque virides. Racemi pauciflori. Calyx ad nervos præcipuè pilofus. Petala aurea, fubrotunda, interdum crenata. Stamina longitudine fryli, erecta, tactu ftatim decumbentia. Capfula obfoletè trilocularis.

Variat rariffimè floribus albis. Raius.

polifuli- 6. CISTUS fuffruticofus procumbens ftipulatus, us. pubefcentiâ ftellari, foliis oblongis revolutis fubtùs tomentofo-incanis.

Ciftus polifolins. Sp. Pl. 745. Hudf. 234. With. 492 .

C. humilis alpinus durior, Polii noftratis folio candicante. Pluk. Phyt. t. 23. f. 6.

Helianthemum montanum, polii folio incano, flore candido. Dill. Elth. I 75. t. I45. f.: I 72 . Chamæciftus montanus Polii folio. Raii Syn. 342. Hill. Fl. Brit. 274. t. 27. f. 2. Angl. White mountain Ciftus.

In collibus faxofis, auræ marinæ expofitis, rariưs. On Brent downs, Somerfetthire. Pluk. Dill.

Fruticulus. Fl. Junio, Julio.

Habitus præcedentis, at plurimis notis differt. Caules tomentufi, pilis arcè adpreffis. Folia oblonga, tevoluta; fupra viridia, pilis ftellatis fparfis tecta; fubtùs alba, densè tomentofa, tomento etiam fiellato, nervo maxime 
maximè prominente. Calyx ad nervos præcipuè hirtus, pilis fafciculatis vel ftellatis. Petala alba, fæpius crenulata. Capfula obfoletè trilocularis.

Cum C. marifolio in Mant. 245 fub C. anglico confundit Linnæus. A C. apennino, pubefcentiâ foliorum et calycum ftellari, præcipuè difcrepat.

\section{TRIGYNIA.}

247. DELPHINIUM. G. Pl. 274. Juf. 234. Gartn. t. 65 .

Cal. nullus. Petala 5, fuprema calcarata. Nectarium bifidum, poftice calcaratum.

r. DELPHINIUM capfulâ folitariâ, nectario mo- Confolz. nophyllo, caule fubdivifo.

Delphinium Confolida. S . Pl. 748. Hudf. 235. With. 494. Relh. 206. Ablat. II8. H\% Dan. $t .683$.

D. fegetum, flore cæruleo. Dill. in Raii Syn. 273 .

Confolida regalis fativa. Ger. em. 1082.

C. regia. Trag. Hift. 569 .

Chamemælum eranthemon. Fuch. Hift. 27.

Cuminum fylveftre fecundum. Malth. Valgr. v. 2. 118 .

Angl. Field Larkfpur,

In arvis folo arenofo.

In feveral places in Cambridgefhire. Relh. Swaffham field, Cambridgethire. Sberard. Fields between Blackheath and Eltham. Dill. About Feltwell 
Feltwell near Brandon. Mr. Francis Smith. Near Bury. Rev. Dr. Gocidenough.

Annua. Fl. Junio, Julio.

Radix fibrofa. Herba fubpubefcens. Caulis creetus, bipedalis, alternatim ramofus, foliofus. Folia linearimultipartita. Racemi terminales. Flores violacei, cal. cari adfcendente, fubincano.

\section{PENTAGYNIA.}

248. AQUILEGIA. G. Pl. 275. JuJ. 234, Gartn. $t$. I I 8 .

Cal. nullus. Petala 5. Nectaria 5, corniculata, inter petala. Capfule 5, difinct $x$.

vulgaris.

I. AQUILEGIA nectariis incurvis vix petalis æqualibus, caule foliifque glabris.

Aquilegia vulgaris. Sp. Pl. 752. Hudf. 235 . With. 495. Relh. 207. Sibth. 169. Abbot. I I 8. Engl. Bot. t.297. Ft. Dan. t.695. A. flore fimplici. Raii Syn. 273. Bauh. Hijt. v. 3.484 .

Aquilegia. Fuchf. Hift. 102.

A. cærulea. Ger. em. I093.

R. A. alpina. Hudf. 235 .

Angl. Common Columbine.

In pratis pafcuis et dumetis, præcipuè montofis. Perennis. Fl. Julio.

Radix tuberofa. Herba glabra, lavis. Caulis erectus, 
bi- vel tripedalis, parùm ramofus, foliofus, teres. Folia radicalia longius petiolata, biternata, foliolis petiolatis, fubcuneatis, lobatis, crenatis, fubtus glaucic; catilina ternata, fumma foliolis integerrimis. Flores terminales, fubpaniculati, cernui, pallidè violacci. Nectaria obtufa, adunca.

Ferba in $\beta$ minùs luxuriat, nectariis attenuatis, parim incurvis. Omıninò dịtincta ab $\mathrm{A}$, alpinâ Limnei.

\section{HEXAGYNIA.}

249. STRATIOTES. G. Pl. 277. Juff.6\%. Gertn. t. 14 .

Spatba diphylla. Periantbium fuperum, trificum. Petala 3. Bacca fexlocularis.

7. STRATIOTES foliis enfiformi-triangulis acu-alocile. leato-ferratis.

Stratiotes aloides. Sp, Pl. 754. Hudf. 236. IVith. 496. Relh. 207. Fl. Dian. t. 337 . Engl. Bot.. 1. 379. Mill. Illuftr. t. 50. Dick.j. H. Sice. fafc. I7. 11 .

S. foliis Alocs, femine longo. Raii Syn. 290.

Militaris aizoides. Ger. Em. 825. Lob. 16. v. I. 375 .

Angl. Water Aloe. Water Soldier.

In foffis et ftagnis.

Plentiful in the Inc of Ely, and in the marfhy parta of Lincolnfhire and Norfolk. In Chenire and Yorkfhire. With. 
Perennis. Fl. Julio.

Radix fibrofa. Herba fobolifera, natans. Folia conferta, enfiformia, acutè carinata, nervofa, aculeato-ferrata, glabra, vafculofa, fracgilia, atro-viridia. Pedunculi foliis breviores, ereeti, ancipites, aculcato-ferrati, uniflori. Flores albi, abortu plerumque dioici.

Genus Hydrocharidi quam maximè affine.

\section{POLYGYNIA.}

250. ANEMONE. G. Pl. 279. Juf. 232, Gartn. t. 74.

Cal. nullus. Petala 5-9. Seminia plura.

Pulfatil- 1. ANEMONE fcapo involucrato unifloro, petalis

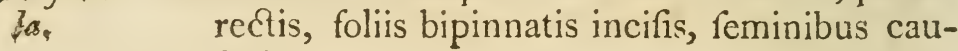
datis.

Anemone Pulfatilla. Sp. Pl. 759 . Hudf. 237: With. 498. Relb. 208. t.3. Fl. Dan.t. 153. Engl. Bot.t.5I. Abbot. I I8.

A. pratenfis. Sibth. 169. With. 498.

Pulfatilla folio craftiore et majore flore. Raii Syn. 260.

P. vulgaris. Ger. em. 385 .

Pulfatilla. IVath.Valgr. $\%$. 568.

Angl. Pafque Flower. Pel. H. Brit. 1. 40. f. I Q.

In pafcuis elatis calcareis.

Perennis. Fl. Aprili, Maio.

Thadix fublignofa. Folia omnia radicalia, bipinnata, vel potitis bipinnatifida, incifa, pilofa, laciniis ferè lineari- 
bus, acutis, fulco exaratis. Scapus fpithamæus, crectus, uniflorus, teres, pilofus, apicem versùs involucratus, involucro multifido. Petala fex, violacea, lanceolata, recta, patentiufcula, extùs fericea. Semina caudata, plumofa.

A. pratenfem Sibthorpii ex anctoritate Amiciffimi D. Williams, Bot. Prof. Reg. Oxonienfis, ad A. Pulfatillam revocavi.

2. ANEMONE fcapo involucrato unifloro, inro-nemorolucro triphyllo petiolato foliaceo, feminibus $\int a$. ecaudatis, foliolis incifis.

Anemone nemorofa. Sp.Pl. 762. Hudf. 236. With. 499. Relh. 209. Sibth. 170. Curt. Lond. fafc.2. t. $3^{8}$. Fl. Dan. t.549. Engl. Bot.t. 35 5.

A. nemorum alba. Raii Syn. 259. Ger. em. 383 . Ranunculi quarta fpccies lactea. Fuchj. Hift. I 6 I.

Herba fylveftris ignoti nominis. Brunf. Hift. ข. 2. 80.

Angl. Wood Anemone.

In nemorofis, dumetis et ericetis frequens.

Perennis. Fl. Aprili.

Radix tuberofa, horizontalis. Folia petiolata, ternata, foliolis fubtripartitis, lobatis et incifis, fubpilofis. Scapus foliis longior, omninò uniflorus, erectus. Involucrum foliis conforme, triphyllum, petiolatum, ternatum, incifum, patens. Petala frepiùs fex, elliptica, alba, fubinde extùs purpurea. Semina mucronata, ecaudata.

3. ANEMONE fcapo involucrato unifloro, invo-apenni. lacro triphyllo petiolato foliaceo, feminibus na. ecaudatis, petalis lanceolatis numerofis.

Anemone apennina.' Sp. Pl. 762. Hudf. 237. VOL. II. With. 500. Curt. Lond. fafc. 6.t.35. 
A. geranifolia. Ger.em. 377 .

Ranunculus nemorofus, flore purpuro-cæruleo. Dill. in Riciii Syn. 259.

R. nemorofus flore ceruleo, duplex, Apennini montis. Ments. Pugill.t. 8.

A.ngyl. Bhue Mountain Anemone.

In nemorofis rariùs.

In Wimbleton woods. Rancl. Near Harrow. Dhe Bsis. Near Luton-hoe, Bedfordhire. Know 1on. Near Berkhanftead, Herts, Mr. Goodall: lith.

Percnnis. Fl. Aprili.

Radix quam in precedente craffior. Foliola latisudine varia. Fetala $\mathrm{I} 2$ ad 16 , lanceolata, obtufifufcula, $\mathrm{cy}$ : anen. Diffinctiffima fpecies, in Italiâ vulgaris, uti apud nos A. nemorofa. Conf. Tour on the Ciontinent, $\because 2.145$.

Tamzan-4. ANEMYNE fapo involucrato fubbifloro, inbidis. volucro triphyllo fubferile foliaceo, feminibus ecaudatis, petalis ellipticis quinis.

Anemone ranunculoides. Sp.Pl. qóz. IHudf. 237. With. 499. Fl. Darr. 1.40.

A. ncmorum lutea. Ger. em. 383 .

Ranunculi quarta fpecies lutea. Fucbs. Hift. 162 .

Angl. Yellow Wood Anemone.

In nemorotile.

Near Kings Langley, Irerts, and Wrotham in Kent. Hudif.

Perennis. Fl. Aprili.

Radix ut in A. nemorosâ. Folia pauca, fubinde quinata. Involucra ferè feffilia, foliolis lanceolatis, incifis. Scapus infia involucrum glaberrimus. Pedicelli pilofi, fxpius binati, foliolis binis, ninutis, integris, fubinde interfinctis. Y'tala aurea, late elliptica, quina ut in Ilorâ 
Flor Suecicâ defcripfit Linnæus, nec fena ut apud Cl. Witheringium.

A Cl. Hudfono exemplaria fpontanea accepi.

25I. CLEMATIS. G. Pl. 280. FuJ. 232. Gertn. t. 74.

Cal. nullus. Petala 4-6. Semina caudata. Receptaculum capitatum.

1. CLEMATIS foliis pinnatis: foliolis cordatis : Titalל̌a。 petiolis ficandentibus.

Clematis Vitalba. Sp. Pl. 766. Hudf. 238. With. 500. Relh. 209. Sibth. 170. Curt. Lond. fufc. 4. t. 37. Jacq. Auftr. t. 308. Engl. Bot.t.6r2.

C. Iatifolia feu Atragene quibufdam. Raii Syr. 258.

C. tertia. Camer. Epit. 697.

Viorna. Ger. em. 886.

Vitis nigra. Fuchs. Hift. 97. Ic. 53.

Angl. 'Traveller's Joy. Pet. H. Brit. t. 40. f. I I, I 2 .

In fepibus, imprimis folo calcareo.

Frutex. FI. Julio.

Caules perennes, fiagelliformes, ramofi, foliofi, fulcati, petiolis contortis fcandentes. Folia oppofita, imparipinnata, foliolis quinis, petiolatis, ovatis, acutis, irregulariter incifis integrifve, glabriufculis. Paniculæaxillares, dichotomx, foliololie, pubefcentes. Flores albi, odorati. Petala 4 , coriacea, utrinque villofa. Semimum caudæe plumofæe, fericeæ.

252. THALICTRUM. G. Pl. 280. JuJf. 232. Gartn. t. 74 .

Cal. nullus. Petala 4-5. Semina ecaudata.

$$
\text { I. I. THA. }
$$




\section{4}

alpinun. x. THALICTRUM caule fimpliciffimo fubnudo, raceno fimplici terminali.

Thalictrum alpinum. Sp.Pl. $76 \%$. Hudf. 238 . Will. 500. Lightf. 286. t. 13.f. I. Fl. Dan. t. II. Engl. Bot.t. 262.

T. minimum montanum atro-rubens, foliis fplendentibus. Raii Syn. 204. Boerb. Ind. Alt. r. I. 44. t. I.

T. minimum precox, foliis fplendentibus. Morif. Sect. 9. t. 20. f. 14 .

Angl. Alpine Mcadow-ruc.

In turfofis irriguis alpinis.

On moft of the higheft mountains in Wales and Scotland.

$p_{\text {erennis. }}$ Fl. Junio.

Padix e fibris fimplicibus. Folia radicalia longius petiolata, bitcmata, fubpinnata, foliolis fubrotundis, crenatoincifis, glaberrimis, nitidis, fubtùs glaucis. Caulis nudus vel monophyllus, fpithamæus, erectus, fimplex. Racemus terminalis, fimplex, bracteatus, nutans. Flores pedicellati. Petala 4, acuta, aibida. Stamina 8-10, capillaria. Antheræ verticales, oblongæ, flavæ. Germina vix ultra 4. Stigmata feffilia, lanceolata, divaricata, pubefcentia. Semina læviufcula.

minns. 2. THALICTRUM foliis tripinnatis: foliolis trificlis glaucis, floribus paniculatis cernuis. Thalictrum minus. Sp. Pl. 769. Hudf. 238. With. 501. Relh. 210. Lightf. 285. F\% Dan. t. 732. Engl. Bot. t. I I. Raii Syn. 203. Morif. Sect. 9. t. 20. f. 12. Ger. em. 1251. f. T. montanum minus, foliis latioribus. Raii Syn. 204 .

Anjl. Leffer Meadow-rue.

In pafcuis calcareis, præcipuè fubmontofis.

Perennis. Fl. Junio, Julio. 
Radix fibrofa. Caulis ercetiufculus, pedalis, flexuofas, fulcatus, rore cæfio glaucus, foliofus, paniculatus. Folia inferiora maxima, patula, e bafi ferè tripimnata, foliolis cordatis vel cuncatis, trifidis, fubinde incifis, glibris, glaucis. Panicula patens, compofita. Flores pedicellati, cernui. Petala 4, elliptica, purpureo-glauca. Semina fulcata.

3. THALICTRUM foliis tripinnatis : foliolis lo majus. batis, paniculæ ramis confertis fubumbellatis, floribus cernuis.

Thalictrum majus. Jacq. Auftr. t. 420, Murr. Syft. Veg. Limn. ed. I4. 513. With. 502. Engl. Bot. t. 6I I.

Angl. Greater Meadow-rue.

In dumetis fubmontofis.

On a buhy hill at Baydales near Darlington; alfo on the margin of Ulls-water, Cumberland. $M r$. Riclifon.

Perennis. Fl. Junio, Julio.

Præcedente duplò vel triplò majtis. Folia atro-viriclia, fubtùs glauca. Caulis purpurafcens. Lobi foliorum inferiorum rotundati, fuperiorum acuti. Paniculæ rami inferiores axillares, binati vel ternati; ramuli umbellati, vel alterni. Flores longius pedicellati, cernui. Petala 4, viridi-purpurea. Antheræ luteo-virefcentes, pendulæ.

Icon apud Dodonæum $5^{8} \mathrm{f}$. I, et Ger. cm. I25I. $f$. I. huic potiùs quam $T$. flavo refpondet.

4. THALICTRUM foliis bipinnatis: foliolis tri-flavum. fidis, caule fulcato, paniculâ ramofifinimâ coarctatâ, floribus erectis.

Thalictrum flavum. Sp. Pl. 770. Hudf. 239. With. 501. Relh. 210. Sibth. 171. Engl. Bot. t.367. Fl. Dan. t. 939.

T. nigricans. Jacq. Auftr. t. $42 \mathrm{r}$.

$$
\text { I. } 3 \text { T. fel }
$$


T. feu Thalietrum majus. Raiii Syn. 367. viọ Gerardi.

T. nigrius, caule et femine ftriato. Baub. Hift. v. 3.486.

E. T. majus, foliis rugofis trifidis. Morif. Sect: 9 . t. $20 \mathrm{f} \cdot 3$.

Angrl. Common Meadow-rue.

In pratis humidis, et ad ripas fluviorum.

Perennis. Fl. Julio.

Radix flava. Caules tripedales, crecti, foliofi, angulatofulcati, parùn ramofi, apice paniculati. Folia bipinnata, vix tripinnata, foliolis fubcuneatis, frepiùs trifidis, Jatitudine variis, fubtús glaucis. Panicula erecta, ranofiffima, coarctata, parùm foliofa. Flores erecti, 'och. soleuci. Petala 4. Stigmata cordata, brevia.

\section{ADONIS. G. Pl. $28 \mathrm{I}$. JuJ. 232: Gertn. $t .74$.}

Cal. pentaphyllus. Petala $5-8$, vel plura, nectario deftituta. Semina nuda.

cusum- I. ADONIS petalis fuboctonis concavis emargiralis. natis, fructu ovato.

Adonis autumnalis. Sp. Pl. $77 \mathrm{I}$. Hudf. 239. IVith. 503. Sibth. 17x. Curt. Lond. fafc. 2. t. 37. Engl. Bot. t. 308. Wade Dubl. I 47 : Flos Adonis. Raii Syn. 25x. Park. Parad. 293. f. 5. Ger. em. 387. Pet. H. Bril. t. 39. f. 8.

Angl. Corn Adonis. Pheafant's-cye.

Inter fegetes rariùs.

A bout London. Hudf. Curt. Near Denver fluice, Norfolk. Mrs. Pleftorv. Gloucefterhire. Mifs Lyfons. About Dublin. Dr. Wade. Annua: Fl. Maio-Oetobri. 
Radix fubfufiformis. Caulis erectus, ramofus, foliofus, teres, ftriatus, fulbinde pubefcens. Folia alterna, feffi. lia, tripinnatifida, laciniis linearibus, acutis. Flores terminales, folitarii, erecti, nitidi, faturatè phonicei, inodori. Calycis foliola decidua, frepe purpurafcentia, concava, glabriufcula, interdum pubetcentia. Petala 6-10, fxpius 8, latè obovata vel obcordata, concava, nervofa, emarginata vel crofa, calyce parum longiora. Stamina violacea, petalis duplò breviora. Fructus aggregatus, fubovatus, vix uncialis. Semina corrigatofcrobiculata.

A. æftivalis Linnæi, (fammea fortè Jacquini, difcrepat petalis anguftioribus, miniato-fulvis, parum concaris, numcro quidem variis at ficpiris quinis; fructu duplò longiore, omninù cylindrico; calyce interdum bafí villofu. Hæc Italix, vix Anglix, indigena eft.

254. RANUNCULUS. G. Pl. 28 I. JufJ:233. Gertn. t. 74.

Cal. pentaphyllus. Petala 5-8, intra ungues poro mellifero. Semina nuda.

* Foliis fimplicilus.

х. RANUNCULUS foliis ovato-lanceolatis obtu. Flam. furculis petiolatis, caule declinato.

Ranunculus Flammula. Sp.Pl. 772. Hudf.239. With. 504. Rell. 211. Sibth. 171. Alibot. I20. Curt, Lond. fafc. 6.t. 37. Engl. Bot.t.387. Fl. Dan. t. 575 .

R. flammeus minor. liaii Syn. 250. Ger, em. $96 \mathrm{r}$.

6. R. flammeus ferratus, Ger. em. 962. Small Spear-wort. Iet. I. Brit. t. 39.f.6. $\gamma \cdot$ R. flammeus, latiori plantaginis folio, marginibus pilofis. Dill. in Raii $S_{y} n .25 \mathrm{I}$. non vidi. ¿. R. reptans. Sp. Pl. 773. Lightf $28 \mathrm{~g}$. With. 505. Dick. II. Sice. fafa. 6. I0. Fl. Dan, t. 108.

$$
\text { I } 4 \text { Anglo }
$$


fingl. Leffer Spear-wort.

In paludolis vulgaris. $\delta$ ad margines lacuum alpinortum.

Pcronis. Fl. Junio-Septembri.

Radix e fibris fimplicibus, longiffimis. Caules patuli, fubdecumbentes, ramofi, foliofi, teretes, læves. Folia alterna, lanceolata, acuta, nervofa, glabra, integerrima vel ferrata, inferiora longiùs petiolata, petiolis canaliculatis, bafi dilatatis. Flores terminales, folitarii, pedunculati, erecti, aurei, nitidi. Pedunculi teretes. $\mathrm{Ca}$ lyx rcflexus, glabriufculus. Nectarium minutum. Semina lævia.

$\delta$ magnitudine minori, cauleque radicante differt.

Iingua. 2. RANUNCUI.US foliis lanceolatis acuminatis, caule erecto multifloro.

Ranunculus Lingua. Sp. Pl. 773. Hudf. 240. With. 504. Relh. 211. Sibth. 172. Abbot. I20. Engl. Bot. t. Iо0. Fl. Dan. t. 755 .

R. flammeus major. Raii Syn. 250. Ger. em. $96 \mathrm{I}$.

Angl. Great Spear-wort. Pet. H. Brit. t. 39 . f. 5 .

In paludofis et forlis minùs frequens.

In the Inle of Ely, Norfolk, and feveral parts of the north of England. In Duddington Loch near Edinburgh.

Perennis. Fl. Julio.

Habitus præcedentis, fed triplò major. Caulis erectus, quadripedalis. Folia minús petiolata, acuminata, nec cbtufiufcula. Calyx pilofus. Pili totius ferè herbæ adprefli, ut etiam in præcedente. 
tinervofis feffilibus, caule erecto paucifloro glaberrimo.

Ranunculus gramineus. Sp.Pl. 773. Witb.505. R. anguftifolius bulbofus. Baub. Hift. v. 3. 850. R. phneniceus Myconi, Dalech. Hijt. I036. Angl. Graffy Crowfoot.

In pratis aridis alpinis.

Brought from North Wales by Mr. Pritchard. With.

Perennis. Fl. Maio, Junio.

Radix bulbofa, tuberofa, cylindracea, apice fibrofa, fibras radiatim exferens. Caulis pedalis, erectus, teres, glaber, pauciflorus, parùm foliofus. Folia petiolis vaginantibus, lanceolata, integerrima, multinervofa, glauca. Flores terminales, magnitudine ferè præcedentis, aurei. Calyx glaberrimus, patens, nec deflexus.

Phœniceum dicitur e foliis palmæ (Phœnici) fimilibus. Dalech.

4. RANUNCULUS foliis cordatis angulatis peti- Ficarizu olatis, petalis numerofis.

Ranunculus Ficaria. Sp. Pl. 7-4. With. 503. Relb. 21 r. Sibth. I72. Abbot. r21. Curt. Lond. fafe. 2. t. 39. Mart. Fl. Ruft. t. 2I. Fl. Dan. t. 499. Engl. Bot. t. 584.

Ficaria. Brunf. Herb. v. I. 2 I5.

F. verna. Hudf. 244.

Chelidonium minus. Raii Syn. 246. Ger. err. 8г6. Fuchf. Hift. 867.

Angl. Pilewort. Leffer Celandine.

In pratis, nemorolis, et ad fepes vulgaris.

Perennis. FI. Aprili.

Kadix tuberofa, tuberibus pyriformibus, carnofis, annuis. Caules erectiufculi, paimares, foliofi, fubuniflori, slabri. Folia longè petiolata, cordata; angulata, nitida, glabra. Flores pedunculati, erecti, folitarii, aurei, lu- 
cidi, fupra demùm dealbati. Foliola calycina fxpitua tria, interdum quinque. Petala $8-10$, elliptico-lan. ceolata.

\section{* Foliis diffectis et divifis.}

guterico- 5. RANUNCULUS foliis radicalibus reniformimes. bus tripartitis crenatis; caulinis digitatis linearibus, caule multifloro, calyce colorato.

Ranunculus auricomus. $S p . P l .775$. Hudif. 242. With. 505. Relh. 212. Sibth. 172. Abbot. 12 1. Curt. Lond. fajo. 2. t. 41. Engl. Bot.t.624. Fl. Dan. t.665. Ger.em. 954: $R$. nemorofus dulcis, fecundus Tragi. Kaik Syn. 248.

R. prima fpecies fylveftris. Fuch.j. Hif. I56. Dalech. Hift. I 029 . Angl, Wood Crowfoot. Goldilocks.

In nemorofis, et ad fepes umbrofas; "rariùs in paluftribus." Curt.

Perennis. Fl. Aprili, Maio.

Radix fibrofa. Caules pedales, ramofi, foliofi, fupernd villofufculi. Folia fubpubelcentia; radicalia longits petiolata, reniformia, fæepiùs tripartita, incifo-crenata, fubinde quinquepartita; caulina feffilia, ad bafin ufque multifida, laciniis linearibus, plerumque integerrimis et indivifis. Flores terminales, folitarii, aurei. Calyx villofus, luteus, haud reflexus. Nectaria nuda. Herba non acris.

Variat floribus apetalis, calyce dilatato, margine petaliformi.

freicta- 6. RANUNCULUS foliis inferioribus palmatis; ins. fummis digitatis, fructibus oblongis. Ranunculus fceleratus. Sp. Pl. 776. Hudf. 241: With. 505. Relb. 212. Sibth. 173. Curt. Iond. fajc. 2. t. 42 . Fl. Dan. t. 57 I. R. paluftris. Raii Sym. 249 .

R. pa- 
R. paluftris rotundifolius. Ger. em. 962.

R. iecundi fpecies. Fuch. Hifl. I59.

R. primus. Camer. Epit. 80.

Angl. Water Crowfoot. Celery-leaved Crowfoot.

In aquofis vulgaris.

Annua. Fl. Junio-Angufto.

Radix fibrofa. Herba pallida, lævis. Caulis rectus, craffus, ramofus, fuccofus, foliofus. Folia inferiora petiolata, minùs profundè incifa; fuperiora lêtilia, ad bafin ufque diffecta. Flores numeroti, pedunculati, exigui, lutei. Calyx villofus. Fructus ovato-oblongus, feminibus, numerofiffimis.

7. RANUNCULUS calycibus retroflexis, pedun- $b u l b 0 / 245$, culis fulcatis, caule erecto multifloro, foliis compofitis, radicc bulbosâ.

Ranunculus bulbofus. Sp.Pl. 778 . Hudf.241. With. 508. Rell. 213. Sithth. 173. Curt. Lond. fafc. I. t. $3^{8 .}$ Mart. Fl. Ruft. t. 28. Engl. Bot. t. 515. Fl. Dam. t. 551. Mitl. Illugtt. t. 51. Raiii Syn.247. Ger. em. 953. Lob. Ic. 666.

R. tertia fpecies. Fuch.j. Hift. 160. Angl. Bulbous Crowfoot. Butter-cups,

In pratis et pafcuis ubique.

Perennis. Fl. Main.

Radix bulbofa, folida, fupernè prolifera. Caules erecti, pedales, ramofi, foliofi, teretes, pilofi, multiflori, farmentis deftituti. Folia petiolata, ternata, trifida, varia incifa, magis vel minus pilofa. Flores terminales, folitarii, pedunculati, aurei, nitidi. Pedunculus fulcatus, angulatus, pilofus. Calyx ad pedunculum reflexus, extùs hirfutus. Nectarium fquamâ emarginatâ operculatum. 
- his futws. 8. RANUNCULUS calycibus retroflexis acuminatis, caule crceto multifloro hirfuto, foliis ternatis, radice fibrosâ.

Ranunculus hirfutus. Curt. Lond. fafc. 2. t. 40. With. 508. Relh. 213. Sibth. 173. Albos. 122 .

R. bulbofus $\beta$. Hudf. $24 \mathrm{I}$.

R. rectus, foliis pallidioribus, hirfutis. Baub. Hif. v. 3. 417 . Raii Syn. 247. Angl. Paic hairy Crowfoot.

In cultis, ruderatis ct ad vias, locifque inundatis. Annua. Fl. Junio-Octobri.

Radix fibrofa. Caulis erectus, fefquipedalis, ramofus, foliofus, hirfutus, pilis patentiflimis. Folia ternata, hirfuta, pallida; fuperiora incifa, laciniis fæpe linearibus. Pedunculi fulcati, hirfuti. Calyx acuminatus, hirtus, pilis bafi glandulofis, demùm retroflexus. Petala aurea. Nectarium fquamâ operculatum.

qapens. 9. RANUNCULUS calycibus patulis, pedunculis fulcatis, furmentis repentibus, foliis compofitis.

Ranunculus repens. Sp. Pl. 779. ITudf. 240. IFith. 509. Relh. 214. Sibth. I73. Curt. Lond. fifc. 4. t. 38 . Mart. F'. Rujt. t. 29. Engl. Bot. 1. 5 r6. Fl. Dan. . . 795 .

R. pratenfis repens. Raii Syn. $2 \div 7$.

R. pratenfis etiamque hortenfis. Ger. em. 95 I. Anr!. Crecping Crowfoot. Pet. II. Brit. t. $3^{8}$. f. 7,8 .

In pratis, pafcuis, et umbrofis humidiufculis.

Perenis. Fl. Jinio-A ngufo.

Radix fibrofa. Citulis ut in præcedentibus, fed farmentis radicantibus, foliofis, diverfus. Folia ternata, trifida et incifa; fumms integerrima. Calyx hirfutus, patens, 
nec retrofiexus. Petala aurea, fæpiùs emarginata. Nec. tarium fquamâ obcordatâ operculatum.

5o. RANUNCULUS calycibus patulis, pedun-acris. culis teretibus, foliis tripartito-multifidis : fummis linearibus.

Ranunculus acris. Sp. Pl. 779. Hudf. 241. With. 506. Relh.214. Sibth. 174. Curt. Lont. fajc. 1. t. 39. Mart. Fl. Ruft. t. 30. IVoodv. Suppl.t. 246. Engl. Bot. t. 652.

R. pratenfis erectus acris. Raii Syn. 248 .

R. furrectis cauliculis. Ger. em. 95 I. Angl. Upright Meadow Crowfoot. Pet. $H_{\text {n }}$ Brit. t. $38 . f .3$.

in pratis ct pafcuis vulgaris.

Perennis. Fl. Junio, Julio.

Radix tuberofa, fibris longis, fimplicibus. Caulis erectus, bipedalis, teres, pilofus, pilis adpreffis, parum foliofus, fupernè ramofus. Folia tripartita et quinquepartita, multifida; radicalia longiùs petiolata; fumma fubfeffilia, linearia. Pedunculi teretes, nec fulcati, pilofi. Calyx patens, hirfutus. Petala aurea. Nectarium fq̣iamâ emarginatâ operculatum.

In hortis flore pleno frequens eft.

II. RANUNCULUS feminibus tuberculatis, fo- parvuliis hirfutis trilobis incifis, caule crecto pauci- lus. floro.

Ranunculus parvulus. Linn. Mant. 79.

R. parviflorus. Gouan. Fl. MLons 270. ex Herb. Gouan.

R. arvenfis parvus folio trifido. Magnol. Monfp. 217.

R. minimus faxatilis hirfutus. Baub.Prod. 96 .

R. minimus Apulus. Column. Ecpbr. 3 I4.t. 3 I6. f. I.

Angl. Little upright Crowfoot. 
In pratis uliginofis.

In a low mearlow on the banks of the Avora below Briftol Hot-wells plentifully. Mr.T.W. Djer.

Annze. Fl. Julio, Augufto.

Radix parva, fibris longis, fimplicibus. Caulis erektus, vix fpithanæus, fubranofus, foliofus, pauciflorus, hirfutus, pilis erecto-patentibus. Folia inferiora petiolata, tripartita, incifa, utrinque pilofa; fuperiora trifida, ve! indivifa. Stipulæ membranaceæ, pilofæe, petiolis adnatæ. Flores terminales, folitarii, erecti, præcedentibus minores. Calyx reflexus, pilofus, foliolis margine fcariofis. Petala rotundata; fuprà aurea, nitida ; fubtùs pallidiora, opaca. Nectarium fquamâ cuneatâ, retusâ, operculatum. Semina lenticulata, compreffa, marginata, punctata, utrinque muricata tuberculis irregulazibus, acutis.

arcenfss. I2. RANUNCULUS feminibus aculeatis, foliis trifido-decompofitis : laciniis linearibus.

Ranunculus arvenfis. Sp. Pl. $780^{\circ}$. Hudf. 242. With. 509. Relh. 215. Sibth. 174. Engl. Bot. t. 135. Curt. Lond. fafc. 6. t. 36. Mart. Fl. Ruft. t. 56. Fl. Dan. t. 219. Brignon。 Mem. de l' Acad de Turin, v. 4. 108. t. 3. R. arvorum. Laii Sym. 248. Ger. em.95x. singl. Com Crowtoot. Pet. H. Brit. t. $38 . f$. 10. Inter fegetce.

Anmur. Tl. Junio.

Radix fibrofa. Caulis erectus, ramoffnimus, teres, ferés glaber. folia tripartita, laciniis linearibus; inferiora decompofita. Flores orpofitifolii, pedunculati, parvi, citrini. Calyr patens, hirtus. Petala oborata. Semina maxima, compreffa, aculeis numerotis, rigidis, lateralibus, uirinque muricata.

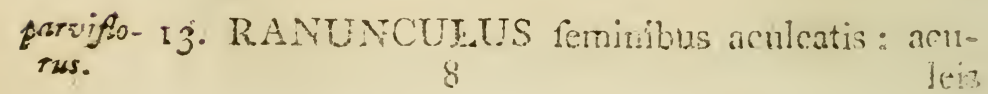


leis aduncis, foliis fimplicibus laciniatis acutis hirfutis, caule diffufo.

Ranunculus parviflorus. Sp. Pl. 780. Hudf. 242. IVith. 506. Relh. 215. Sibth. 174. Engl. Bot. t. I 20.

R. hirfutus annuus flore minimo. Raii $S_{y} n$. 248. t. 12. f. I. Pluk. Plbyt.t.55.f. I.

R. hirfutus flore omnium minimo luteo. Moo rif. fect. 4. t. 28.f. 21 .

Ray's hairy Crowfoot. Pet. H. Brit. t. $38 . f .9$. Angl. Small-flowered Crowfoot.

In arvis et ad fepes folo glareofo.

In feveral places about London. On Malvern hill, Worcefterhire, Mr. Ballard; and in the fouth-weft part of England. With. Near Norwich. Mr. Pitchford.

Annua. Fl. Maio, Junio.

Radix fibrofa. Caules proftrati, ramofi, foliofi, teretes, pilofi. Folia longius petiolata, pilofa, reniformia, incifo-crenata; fuperiora triloba : fumma lanceolata, integerrima. Flores oppofitifolii, pedunculati, exigui, favi. Calyx patens. Petala oblonga, frepe imperfecta. Stamina pauca. Semina compreffa, aculeis denfis, uncinatis, lateralibus, muricata.

14. RANUNCULUS foliis reniformi-fubrotundis bederatrilobis quinquelobifive integerrimis lævibus, ceus. caule repente.

Ranunculus hederaceus. Sp.Pl. $78 \mathrm{r}$. Hulfs. 243. With. 507. Relh. 2I5. Sibth. I75. Albot. I23. Curt. Lond. fafc. 4. t. 39. F\%. Dan. t.32I. Dalech. Hift. 103 I.

R. aquatilis hederaceus aibus. Raii Syn. 249. Angl. Ivy Crowfoot. Pet. H. Brit. t. 38 .f. I2.

In aquis vadofis, ct locis inundatis; ad foaturigines et ad forfas. 
Perennis. Fl. Main-Augufto.

Radix fibrofa. Caules proftrati vel natantes, radicantes, ramofi, divaricati, glabri. Folia longè petiolata, reniformia, obfoletè triloba rel quinqueloba, integerrima, fubcarnofi, levia. Flores parvi, albi, oppofitifolii. Stamina 5-io. Semina fubrotundi, corrugata.

aquati- 15. RANUNCULUS foliis fubmerfis capillaccis; cmarfis fubpeltatis.

Ranunculus aquatilis. Sp. Pl. 73 r. Hudf. 24.3. With. 507. Relh. 216. Engr. Bot. t. Iо . Ger. em. 829. Raï Syn. 249.

R. aquatilis albus. Bauh. Hift. v. 3. 773.

R. hetcrophyllus. Wigg. Holfal. 42. Sibth. 175 . Abbot. 123 .

B. R. aquatilis omninò tenuifolius. Raii $S, n .249$. Bauh. Hift. $.3 \cdot 773$.

R. aquatilis. Sibth. I75.

Millefolium five Maratriphyilon, flore ct femine Ranunculi aquatici hepaticæ facic. Ger. em. $82 \%$.

$\gamma$. Ranunculus aquaticus aỉns, circinatis tenuiffince divifis foliis, fribus ex alis longis pediculis innixis. Räi Sjn. 249. Pluk. Pbyt.t. 55 . f. 2 .

R. circinatus. Sibth. 175 .

\&. Ranunculo five Polyanthemo aquatili albo affine; Millefolium Maratriphyllum fluitans.

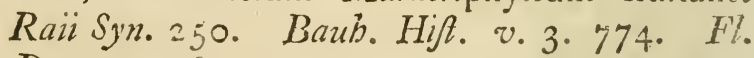
Din. $t .376$.

R. Aluviatilis. Higg. Holfat. 42. Sibth. IT, $^{6}$ Abbot. I23.

Angl. Water Crowfoot.

In foffis et ftagnis vulgaris; $\delta$ in fluviis.

Perennis. Fl. Maio, Junio.

Radix fibrofa. Caules natantes, fubmerfi, elongati, tere- 
tes, foliofi. Folia petiolata, glabra; fuperiora plerumque fubpeltata, triloba, incifa, natantia; inferiora tripartito-multifida, fupradecompofita, laciniis linearibus, anguftiffimis, acutis : in var. $\delta$ folia aquæ impetu elongantur. Flores pedunculati, oppofitifolii, natantes, albi, medio lutei. Stamina numerofa. Semina corrugata.

255. TROLLIUS. G. Pl. 282. Juff. 233 . Garlin. t. I 18 .

Cal. nullus. Petala circiter i4. Neczaria circiter 9, complanata. Capfula plurimæ, oblongæ, polyfpermæ.

I. TROLLIUS corollis conniventibus, nectariis europese longitudine ftaminum.

Trollius curopæus. Sp. Pl. 782. Hudf. 244. With.510. Ligbtf. 295. "Engl. Bot. t. 28. Fl. Dan. t. 133.

Ranunculus globofus. Raii Syn. 272. Ger。 em. 955 .

R. rextus. Camer. Epit. 385 .

Globe Crowfoot. Pet. H. Brit. t. 43. f. 2. Angl. Globe-flower.

In umbrofis montofis fubhumidis.

Not rare in Weftmoreland, Cumberiand, Durham,

Wales, and the lowlands of Scotland.

Perennis. Fl. Maio, Junio.

Radix fibrofa. Caulis erectus, bipedalis, teres, glaber, fupernè ramofus. Folia multipartita, pinnatifida, incifa, glabra; radicalia longiùs petiolata; caulina fuhfeffilia, alterna. Flores terminales, folitarii, formofi, globofi, aurei. Petala concava, ferè claufa. Nectaria lineari-fpatulata, faminibus vix æqualia, petalis duplò breviora. Stamina linearia. Antheræ incurvæ. Capfulæ plurimæ, fubcylindricæ. Semina numerofa, nigra, nitida.

Vor. II. 
256. HELLEBORUS. G. Pl. 282. Ju/. 233. Germ. t. 65 .

Cal. nullus. Petala 5, five plura. Nectaria tubulata, bilabiata. Capfulce compreffe, erectiufcule, polyfpermæ.

viridis. I. HELLEBORUS caule multifloro foliofo, foliis digitatis, petalis patentibus.

Helleborus viridis. Sp. Pl. 784. Hudf. 245. With. 510. Relh. 217. Sibth. 176. Abbot. I 24. Engl. Bot. t. 200. Curt. Lond. fafc. 6. t. 34. Jacq. Auftr. t. 106.

H. niger hortenfis, flore viridi. Raii Syn. 271. Helleboraftrum. Ger. em. 976.

Elleborus niger adulterinus hortenfis. Fuchf. Hift. 274.

Elleborum nigrum alterum. Matth. Valgr. v. 2. 951. Camer. Epit. 941. Angl. Green Hellebore.

In fylvis et dumetis, folo cretaceo.

In Oxfordhire, Cambridgehire, Suffex, and other chalk countries, but not common. Near Harefield, Middlefex. Mifs Jane Baynes.

Perennis. Fl. Aprili.

Radix carnofa, nigra, fibris longis, plurimis. Caulis ereetus, fefquipedalis, apice dichotomus, foliofus, glaberrimus. Folia glaberrima, nitida, digitata, incifoferrata; foliolis exterioribus fæpiùs ad medium ufque connatis; radicalia petiolata; caulina feffilia. Flores pauci, terminales et axillares, folitarii, pedunculati, cernui, virides. Petala patula, perfiftentia. Nectaria et ftamina decidua. Germina, et capfula, 3 vel 4, vix plura.

fretidus. 2. HELLEBORUS canle multifloro foliofo, foliis pedatis, petalis conniventibus. 
Helleborus fœtidus. Sp. Pl. 784. Hudf. 245. With.510. Relh.218. Sibth. 177. Woodv. Med. Bot. t. 19. Engl. Bot.t.613.

Helleborafter maximus. Raii Syn.271. Ger. em. 976 .

Elleborus niger adulterinus fylveftris. Fucbs. Hift. 275 .

Helleborafter, folizm. Pharmac. Lond. Angl. Stinking Hellebore. Bear's-foot. Setterwort.

In pafcuis et dumetis, folo cretaceo.

In chalk countries more common than the laft. On the caltle hill at Caftle-Acre, Norfolk.

Perennis. Fl. Martio, Aprili.

Præcedente altior et ramofior. Caulis multiflorus, paniculatus. Folia pedata, æqualiter ferrata, atro-viridia; floralia integra, pallida. Flores cernui. Petala erectoconniventia, viridia, margine atro-purpurea, perfiftentia. Capfulæ 3 vel 4.

257. CALTHA. G. Pl. 283. JuJ.234. Gertn. t. I I 8 .

Cal. nullus. Petala 5. Nectaria nulla. Cupfulce plurimx, polyfpermx.

x. CALTHA.

Caltha paluftris. Sp. Pl. 784. Huds. 245 . With.511. Relb.217. Sibth. 176. Curt. Lond. fafc. I. t. 40. Engl. Bot. t.506. Fl. Dan. t. 668.

C. paluftris major. Ger.em. 817 .

Populago. Raii Syn. 272.

Tufilago altera five Farfugium. Matth. Valgr。

$\because$ 2. 200. Camer. Epit. 594. Angl. Marh Marigold. 
In paluftribus et ad rivos paftim.

\section{Percnnis. Fl. Maio.}

Caules fefquipedales, erecti, parùm ramofi, fulcati, glabri. Folia cordata, venofa, glaberrima, acute crenata. Flores pedunculati, erecti, magni, fpeciofi, aurei. 


\section{Clafis $X I V$. DIDYNAMIA.}

Stamina 4 , quorum 2 longiora.

\section{GYMNOSPERMIA.}

\section{Semina nuda.}

* Calyces fubquinquefidi.

271. LEONURUS, Antbere punctis ofleis adfperfæ.

263. GLECHOMA. Anth. per paria cruciatx.

26\%. MEN THA. Filamenta diftantia, recta. Cor. fubæqualis.

259. TEUCRIUM. Cor. labium fuperius ultra bafin bipartitum.

258. A JUGA. Cor. lab. fuperius minimum. 267. BETONICA. Cor. lab. fuperius planum, adfcendens, tubo cylindrico. Stam. longitudine faucis.

264. LAMIUM. Cor. faux utrinque dentata. 265. GALEOPSIS. Cor. lab. inferius fupra bidentatum.

266. GALEOBDOLON. Cor. lab. inferius trifidum, laciniis acutis.

268. STACHYS. Cor. lab. inferius lateribus reflexum. Stam. deflorata ad latera reflexa. 260. NEPETA. Cor. lab. inferius crenatum; faux margine reflexo.

$$
M_{3}^{269 . ~ B A L-~}
$$




\section{$(602)$}

269. BALLOTA. Cal. decemftriatus. Cor. lab. fuperius fornicatum.

270. MARRUBIUM. Cal. decemftriatus. Cor. lab. fuperius rectum, bifidum.

261, VERBENA. Cal. unicu dente truncato. Cor. fubæqualis, curva.

$$
\text { * Calyces bilabiati. }
$$

276. SCUTELLARIA. Cal. fructiferus operculatus.

274. THYMUS. Cal. fauce villis claufus.

277. PRUNELLA. Filamenta omnia apice bi= furca.

273. ORIGANUM. Strobilus calyces colligens.

272. CLINOPODIUM: Involucrum multifetum calyces colligens.

275. MELITTIS. Cal. tubo corollæ amplior. Cor. lab. fuperius planum. Antb. cru. ciatæ.

\section{ANGIOSPERMIA.}

Semina pericarpio inclufa.

* Calyces quadrifidi.

232. LATHR王A. Capf. unilocularis. Glanx dula fub germine.

273. BARTSIA. Caps. bilocularis. Sem, angulata.

279. RHINANTHUS. Cap. bilocularis. Sem. compreffo-plana, imbricata.

28I. MELAMPYRUM. Caps. bilocularis. Sem. bina, gibba, lævigata. 


\section{$(603)$}

280. EUPHRASIA. Capf. bilocularis. Sem. ftriata. Anth. fpinofx.

* Calyces quinquefidi.

289. LIMOSELLA. Cap $\int$. femibilocularis. Cor. campanulata, fubæqualis.

285. SCROPHULARIA. Capf. bilocularis. Cor. refupinata. Lab. fegmento intermedio interno.

288. SIBTHORPIA. Caps. bilocularis, diffepimentis tranfverfis. Cor. fubrotata. Stan. per paria approximata.

286. DigitaLIS. Capf. bilocularis. Cor. campanulata, fubtùs ventricofa.

284. ANTIRRHINUM. Capf. bilocularis. Cor. perfonata, fubtùs nectario prominente.

283. PEDICULARIS. Capf. bilocularis. Sem. mucronata. Cor. perionata; galea compreffic.

287. LINNEA. Bacca trilocularis, ficca. Cor. campanulata. Cal. fuperus.

*** Calyces fubdipbylli.

290. OROBANCHE. Cal. foliola lateralia, tobata. Capf. unilocularis. 


\section{DIDYNAMIA.}

\section{GYMNOSPERMIA.}

\section{* Calyces fubregulares.}

258. AIUGA. G. Pl. 287.

Bugula. Juf. iा 2 .

Corolle labium fuperius minimum, emarginatum. Stamina labio fuperiore longiora.

retants. I. AJUGA glabra, canle folitario, folonibus reptantibus.

Ajuga reptans. Sp. Pl. 785 . Hudf. 248. With. 517. Relb. 220. Sibib 180. Curt. Lond. fajc. 2. t. 43. Engl. Bot. to 489. Fl. Dan. t. 925 .

Bugula. Raii Syn. 245. Ger.em.631.

Confolida media. Fuchs, Hift. 39 I. Angl. Common Bugle.

In nemorofis, et pafcuis humidis.

Perennis. Fl. Maio.

Radix fibrofa. Caulis folitarius, erectus, pedalis, quadrangulus, foliofus, purpurafcens, fubpilofus, bafi ftolonibus flagelliformibus, proftratis, reptantibus, foliofis. Folia oppofita, elliptica vel obovata, abtufa, crenatorepanda, in petiola lata decurrentia, ferè glabra, lícida. Verticilli multiflori, denfi, foliolofi. Calyx pilofus. Corolla cærulea, fauce albo picta. Labium inferius quadrilobum.

Variat in montofis aridis caule rotundiore, ftolonibus ab. breviatis, herbâ totâ hirfutâ; monente D. Gough.

alpina. 2. AJUGA caule fimplici, foliis glabriufculis inæqualiter dentatis fubuniformibus, verticillis remotiufculis multifloris.

Ajuga 
Ajuga alpina. Mant. 8o. Engl. Bot. t. 477 . A. pyramidalis. Hudf. 2.18. Liybtf. 302 ?

A. geneven'is. With. 5 I6. Scboll. Barb. I35. Bugula cærulea alpina. Pluk. Ployt.t. 18.f. 3 . Raii Syn. 245.

Mountain Bugle. Pet. H. Brit. t.34. f. 4 . Aingl. Alpine Bugle.

In montofis.

In Carnarvonfhire. Ray. Durham. Mr. Rob,fon. On the fummit of a mountain near Caftleton, Derhythire. Mr. Darefon Turner.

Perennis. Fl. Julio.

Caules plures, ftolonibus deftituti, erecti, ferè pedales, fimplices, fubhirfuti, foliofi. Folia fubranalia, obovata, inxqualiter dentata, pilofiufcula: floralia incifa; fuperiora integra, colorata. Verticilli multiflori. Calyx dentibus præcipue pilofus. Flores cærulei, lineis faturatioribus, labio inferiore trifido.

3. AJUGA caule diffuro ramofo, foliis trifidis Chamalinearibus integerrimis, floribus axillaribus pitys. folitariis.

Ajuga Chamæpitys. Engl. Bot. t. 77 . With.

$$
5 \text { I } 7 \text {. }
$$

A. five Chamæpitys. Camer. Epit. 679.

Teucrium Chamepitys. Sp. I'. 787. Hudf. 247. Relh. 220. Dick. Dr.Pl. 9 .

Chamæpitys vulgaris. Raii Syn. 244 .

C. mas. Ger. em. 525 .

Bugula n. 284. Hall. Hift. v. I. I24. Angl. Ground Pine.

In arvis arenofis.

In Cambridgefhire and Kent. Ray.

Annua. N. Aprili, Maio.

Radix fibrofa, parra. Herba pilofa, vifcida, aromatica, 
amara. Caulis ramofus, quadrangulus, foliofus, rubicundus. Folia ad medium ufque trifida, lincaria, integerrima, fubrevoluta; infima indivifa. Flores axillares, folitarii, oppofiti, fubfeffiles, flavi, rubro punctati. Labium inferius trifidum, lobo centrali maximo, obcordato.

\section{TEUCRIUM. G.Pl. 28\%. JuJ. I I 2.}

Corolla labium fuperius (nullum) ultra bafin bipartitum, divaricatum. Stanma exierta.

Sorack- I. TEUCRIUM foliis cordatis ferratis petiolatis, ria.

racemis lateralibus fecundis, caule erecto. Teucrium Scorodonia. Sp.Pl. 789. Hudf. 248. H'ith. 518. Relh. 220. Sibth. 180. Curt. Lond. fafc. 5. t. 40. Fl. Dan. t. 485 .

Scorodonia. Cord. Hifl.9 I. I. Rivin. Irr. Mon. t. 12.

S. feu Salvia agreftis. Raii Syn. 245. Ger. em. 662.

Scordion alterum Plinii. Lob. Ic. 497.

Salvia fylvefiris. Trag. Hif. I5.

Angl. Wood Germander. Wood Sage.

In fylvis, dumctis, et ericetis.

Perennis. Fl. Julio.

Radix repens. Caules fefquipedales, tetragoni, pilofi, foliofi, paniculato-racemofi. Folia oppofita, rugofa, ferrata, pilofa, fubglutinofa, graveolentia, amara. Flores pedicellati, fecundi, flavi, ftaminibus violaceis.

Scordi- 2. 'TEUCRIUM foliis oblongis feffilibus dentato$2 \iota \mathrm{m}$. ferratis, floribus axillaribus geminis pedunculatis, caule diffuro.

Teucrium Scordium. Sp. Pl. 790. Hudf. 247. With. 519. Relh.219. Siblh. 180. Woorlv. Mec. Bot. t. 57. F\%. Dan.t. 593 .

Scordium, 
Scordium. Raii Syn. 246. Ger.em.661. Fuch. Hift. 776 . Rivin. Irr. Mon. t. I I. Scordium, berba. Pbarmac. Lond. Angl. Water Germander.

In paluftribus.

In the Ine of Ely plentifully. Ray. In feveral places about Cambridge. Relb.

Perennis. Fl. Julio, Augufto.

Radix fibrnfa. Caules procumbentes, parum ramofi, quadranguli, fulcati, pilofi, foliofi. Folia fefilia, elliptico-oblonga, dentato-ferrata, fubvillofa. Flores axillares, utrinque fæepiùs gemini, purpurei, calyce villofo.

3. TEUCRIUM foliis fubovatis petiolatis incifo-Cbamacrenatis, floribus axillaribus pedunculatis ter- drys. nis, caule tereti pilofo.

Teucrium Chamædrys. Sp. Pl. 790. Hudf.247. With. 518. Sibth. 179. Abbot. 1 25. Woodv. Suppl. t. 243 .

Chamædrys. Tourn. Inft. t. 97. Rivin. Irr. Mon. t. го. f. 2. Cord. Hift. I 26.

C. vera mas. Fuchf. Hift. 869.

C. major latifolia. Ger. em. 656 .

C. vulgaris feu fativa. Raii Syn. $23 \mathrm{I}$. Angl. Wall Germander.

In muris antiquis.

On the ruins of Winchelfea caftle. Sherard. On the walls of Norwich near Magdalen gates.

Perennis. Fl. Julio.

Radix repens. Caules erectiufculi, ramofi, teretes, foliofi, pilofi. Folia fubovata, incifa, crenata, pilofa, bafi attenuata. Flores axillares, utrinque fubterni, purpurei, calyce pilofo. 


\section{NEPETA. G. Pl. 289. Juf. I1 3 .}

Corolle labium inferius lacinulâ intermedı̂̉ crenatâ: faux margine reflexo. Stum nu approximata.

pataria. I. NEPETA floribus fpicatis, verticillis fubpedicellatis, foliis petiolatis curdatis dentatorerratis.

Nepeta cataria. Sp.Pl. 796. Hudf. 249. With. 519. Relh. 221. Sibth. 181. Engl. Bot. t. 137. Fl. Dan. t. 580.

N. major vulgaris. Raii Syn. 237 .

Nepeta. Rivin. Irr. Mon. t. 52.

Mentha felina, feu Cattaria. Ger.em. 682.

Herba Gattaria. Math. Valgr.v. 2. 79.

Angl. Nep, or Cat-mint.

In aggeribus ferium, imprimis folo calcareo.

Perennis. Fl. .ulio.

Lerba mollifimè tomentofa, incana, odore aromatico, pungente, felibus gratiffimo. Caulis tripedalis, erectus, tetragonus. Folia petiolata, deflexo-patentia, cordata, acuta, æqualiter ferrata, rugofa. Spica obtufa, verticillata, multifora; forum fafciculis inferioribus pedunculatis, foliolofis. Calyx nervofus, dentibus fetaceis, fubæqualibus. Corolla alba, labio rubicundo, punćtato.

26r. VERBENA. G.Pl. I4. JuJ. Iog. Gertn. t. 66.

Cor. infundibuliformis, fubæqualis, curva. Colycis unico dente truncato. Stamina 2 five 4. Semina 2 five 4 , tenuiflimè arillata.

-ficina- I. VERBENA tetrandra, fpicis filiformibus panilis. culatis, foliis multifido-laciniatis, caule fubfolitario. 
Verbena officinalis. Sp. Pl. 29. Hudf. 249. With. 520. Relh. 22 t. Sibth. IBI. Almbot. 127. Curt. Lond. fafc. I. t. 41. Fl. Dan. t. 628. Woodv. Suppl. t. 213. Dieves. Bilderb.t. 45 .

V. vulgaris. Raii Syn.236.

V. communis. Ger. em. 7 I 8.

V. mafcula. Brunf. Hift. ข. I. I I9.

Verbena. Rivin. Irr. Mon. $t .56$.

Verbenaca. Matth. Valgr.v.2.399.

Angl. Common Vervain.

In pafcuis, ruderatis, et ad vias.

Perennis. Fl. Julio.

hadix lignofa, ramofa. Caules fparf, fæpe folitarii, erecti, aculeis fparfis fcabri, bafi curvati. Folia petiolata, lyrato-pinnatifida, incifa, crenata, fcabriufcula. Spicæ terminales, paniculatx, filiformes, multifloræ. Flores parvi, pallidé purpurei. Corolla fance coarctatâ. Stamina breviflima, tubo inferta, inclufa, quorum duo fuperiora.

262. MENTHA. G. Pl. 29I. Juff. II3.

Cor. fubæqualis, quadrifida; lacinia latiore emarginatâ. Cal. quinquefidus. Stam. erecta, diftantia.

x. MENTHA fpicis villofis fubcontinuis, foliis $f_{j} l v e f-$ dentato-ferratis fubtùs præcipuè tomentofis, tris. bracteis fubulatis.

Mentha fylveftris. Tr. of Lim. Soc. v. 5. I79. Witb. 521. Rell.222.

$z$, foliis lanceolatis, acutis.

M. fylveftris. Sf. Pl. 804. Hudf. 250, a. Hull. 125 .

M. fpicata $\beta$, longifolia. Sp. Pl. ed. I. 576 .

M. Spicata $\alpha$, longifolia. Gouan. Hort. 279. 
M. longifolia. Hudf. ed. I. 22 I. Herb. Rofé,

M. villofa prima. Sole Menth. 3. $t$. I.

M. n. 227. Hall. Hift. $v .1 .99$.

M. n. I. Hort. Cliff: 306 . Herb. Cliff.

M. fylvefiris, longiore folio. Bant. Pin. 227.

Menthafirum. 1Dod. Pempt. 96. Ger. em.684.

M. fpicatum, folio longiore candicante. Raii Syn. 234. Baub. Hif.v. 3. p. 2. 221. 2 , foliis ovatis, acutis.

Mentha fylueftris. Fl. Dan. t. 484.

M. villofa fccunda. Sole Menth. 5. t. 2.

M. villofa. Hull. 26.

Menthaftrum. Riv. Monop. Iir. t. 5 r. f. 1. Fuchf. Hift. 292. Camer. Epit. 479.

$\gamma$, foliis brevioribus, fpicis obtufioribus.

Mentba candicans, foliis fpicis ct odore vulgari fative fimilis. Doody in Raii Syn.ed. 2.34t. Herb. Bobart.

$\&$, foliis ellipticis, latis, obiufis.

M. rotundifolia. Sole Menth. 9. t. 4 .

M. alopecuroides. Hull. r 26.

M. fylveftris, rotundiore folio. Bauh. Pin. 227. ex fule Herb. Baub. Haller.

M. hortenfis fecunda. Fuchs. Hifl.289.

Menthaftrum fylveftre foliis latis. Hort. Eysto Ejft. ord. $7 \cdot t \cdot 3 \cdot f \cdot 2$.

Angl. Horfe Mint.

In rudcratis humidiufculis.

$\%$. Plentiful in Kent. Rand. Buddle. $\delta$. In Kent and Fffex, but rarc. Sole. Eleven miles from Norwich in the road to Hingham. Mr. Crowe. At Thorpe near Norwich, and in other parts of Norfolk.

Perennis. Fl. Augufto, Septembri.

Radix repens, ut in omnibus hujus generis. Caules fubtripedales, 
tripedales, erecti, foliofi, quadranguli, villofi, pilis deflexis. Folia oppofita, feffilia, dentato-ferrata, venofa, fuprà incana, fubtùs villofa, figurâ et latitudine varia. Spicæ terminales, paniculatæ, acutiufculæ, villofæ, denfæ, multifloræ. Pedicelli verticillati, fafciculati, hirti, pilis arctè deflexis; verticillis inferioribus remotiufculis. Bractex fubulatæ, villofæ, floribus duplò longiores; inferiores látiores. Calyx parvus, undique hirtus, dentibus fetaceis, tubo longioribus. Corolla calyce duplò longior, incarnato-purpurea, extùs hirfuta. Stamina plerumque inclufa. Odor totius herba aromaticus, acris, parùm gratus.

2. MENTHA fpicis fubhirfutis interruptis, foliis rotundiellipticis obtufis rugofis crenatis fubtùs villo- folia. fis, bracteis lanceolatis.

Mentha rotundifolia. Sp. Pl. So5. Tr. of Linn. Soc. v. 5. 183. Hudf. 251. Hith. 522. Hull. 126. Engl. Bot. t. 446.

M. crifpa. Sp.Pl.ed. I. 576 .

M. Sylveftris. Sole Menth. 7.t.3.

M. n. 226. Häll. Hift. v. I. 99 .

Menthaftrum anglicum. Riv. Monop. Irt. t. 5 s. f. 2 .

M. folio rugofo rotundiore, fpontancum, fore fpicato, odore gravi. Raii Syn. 234. Hert. Buddle. Bauh. Hift. v. 3. p.2.219.

Mentaftrum. Tabern. Krauterb. 729.

8. Menthaftrum nivcum Anglicum. Ger. em. 684 . M. Spicatum, folio crifpo rotundiore, colore partim albo, partim cinereo vel virente. Baub. Hift. v. 3. p. 2. 219.

M. cinereum vel niveum Anglicum, variegatis foliis. Hort. Eyft. Asfl. ord. 7. t. 3. f. 2. Angl. Round--leaved Mint.

In ruderatis humidis et paludofis, rariùs. By the river fide at Lydbrook near Rofis, Herefordhire, 
fordhirc, alfo in Eflex. Ray. Near Hally, Kent, plentifully. Doody'. On the erlge of an old moat at Shingham, Norfolk. Pev. Mr. Forby.

Perennis. Fl. Augufto, Septembri.

Caulis 2-3-pedales, erecti, pilof fou villofi, pilis fubdeflexis. Folia feffilia, elliptico fubrotunda, acutè crenata, rugofa, fuprà fubpilofa, fubtus villofa; inferiora elliptico-oblonga ; fuperiora minora, incifo-ferrata. Spicæ paniculatæ, obtufufculæ, hirfutæ, interruptæ, verticillis ferè omnibus remotiufculis. Bracteæ lanceolatæ, hirfutæ, floribus dupló longiores, fæpiùs deflexæ; inferiores ovatæ. P'ili pedicellorum deflexi. Calyx parvus, campanulatus, undiaue hirtus, dentibus lanceolatis longitudine tubi. Corolla ferè prioris. Stamina exferta. Odor acris, peculiaris, et ingratus. Herba fubvifcida, minùs incana.

viridis. 3. MENTHA fpicis interruptis, foliis feffilibus lanceolatis acutis nudis, bracteis fetaceis dentibuique caly inis rubhirfutis.

Mentha viridis. Sp. Pl. 804. Tr. of Linn. Soc. v. 5. 185. Hudf. 250. With. 52 1. Hull. I 26. IVoodr. Med. Bot. t. I jo. Sole Menth. II. t. 5 .

M. ppicata $\alpha$, viridis. $s p . P l . e d$. I. 576 .

M. n. 229: Iall. Hift. v. I. 100.

Mentha. Camer. Fpit. 477.

M. romana officinarum, five præltantior anguftifolia. Lob. Ic. 507. Herb. Buddl.

M. romana. Ger. em. 680.

M. hortenfis tería. Fuch. Hift. 290.

B. N. anguftifolia picata. Raii Syn. ed. I. 79.

M. anguftifolia fpi ata glal, a, tolio rugotiore, odore graviore. Raii is. ed. 2. 123. ed. 3. 233. Hurb. Stberard.

M. Pricala rutras, cardiacæ fativæ formâ et odore æmula, folio rugatiore. Plick. Mant. 129. $\gamma$. M. fpi- 
6. M. Spicata anguftifolia glabril, fpicâ latiore. Dill. in Raii Syn. 233. Dale in Herl. Sherara.

M. fylveftris, longioribus, nigrioribus, et minus incanis foliis. Bauk. Pin. 227 . Sherard.

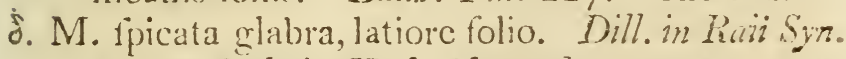
23+. Dale in Herb. Sherar?.

Mentha fativa, berba. Pharmac. Lon:d.

Angl. Spear Mint.

In palufribus.

Near Exmouth, Deronfhirc, and on the banks of the Thames. Hiadf. Someriethire. Sole.

B. By the river fide at Bocking, Efiex. Dale. Ori the river Medway near Maidftone, Kent. Plukinet. At Babcrgh near Norwich. Mr. Pitchfort.

$\%$ In a meadow at Bocking, Effex. Dill. and Date.

8. In a mcadow by Manwood bridge, on the right hand of the road from Merfey-ifland to Colchefter. Dill. and Dale.

Prennis. Fl. Angufto.

Caules 2-3-pedales, erecti, glabri, acutanguli, ramofi, frepè purpurafcentes. Folia feffilia, lanceolata, acuta, ferrata, glabra, quandoque fubtus fubhirfuta; in $\beta, \gamma$ et $\delta$ latiora et breviora, magifque aliquantulum rugofa. Spicæ paniculatæ, elongatæe, acutre, verticillis ferè omnibus remotiufculis. Bractere fetacere, floribus duplo longiores, magis vel minus ciliatx; inferiores fubinde lanceolatre. l'edicelli omninú glabri. Calyx gracilis, fulcatus, in $\alpha$ glaber, in $\beta, \gamma$ et $\delta$ dentibus ciliatis, pilis longitudine variis. Corolla gracilis, purpirea, glabra. Stamina longitudine varia، Herba aronatica, acris et calicla, nec ingrata.

IIec fpecies dlignofcitur pedicellis femper glaberrimis. Dentium calycinorum atque bractcarum cilix in $\beta$ et $\delta$ breviores, in y longiores et copiofiores funt.

4. MENTHA fpicis obtufis infernè interruptis, fiperitas, foliis petiolatis fubovatis glabriufeulis, calyce bafi glaberrimo.

YoL. ii. 
Mentha piperita. Tr. of Lim. Soc. v. 5. I89, nec Linn.

a, foliis ovato-lanccolatis, fpicis elongatis.

M. piperita. Iludf. $25 \mathrm{I}$. Wilb. 523, var. 2. IIoodv. Med. Bot. t. I69.

M. pipcrita officinalis. Sole Menth. I5. t. 7 .

M. officinalis. Itull. 127 .

M. aquatica nigricans, fervido fapore. Herb. Buddl.

Eales' Pepper-mint. Pet. H. Brit.t. 31. f. Io. Mentha piperitis, berbu. Pharmac. Lond. $\beta$, foliis ovatis, fpicis abbreviatis, ferè capitatis.

M. piperita. Hull. I 27 .

M. piperita vulgaris. Sole Men/h. 19. t.8.

M. fpicis brevioribus ct habitioribus, foliis Menthre fufcx, fapore fervido Piperis. Riaii Syn. cd. 2. 124 . ed. 3. 234. t. 10. f. 2 .

N. fervida nigricans, breviore folio et f́picá. Herb. Sberard.

M. aquatica five Sifymbrium. Baub. Hifl. $: 3$. p. 2. 223 ?

$\gamma$, foliis cordato-ovatis, fpicis acutioribus.

M. piperita fylueftris. Sole Menth. 53.t. 24 .

M. hircina. Hull. 12\%.

Angl. Pepper Mint.

In aquofis.

a. In Hertfordnirc. Dr. Ealles. In a fwampy place on Lanfdown, near Bath, called the Wells; alfo by the fide of the Aven in Newton mead. Mr. Sole. In a rivulet in Bonfall dale near Matlock.

B. In Effcx. Dale. By Wandfworth river. Herb. Sberard. About Bath, and betwcen Wells and Glaftenbury; alfo in Chiltern-bottom, Wilts. Mr. Sole. 
$\gamma$. At Lyncomb Spa, and various other wet places about Bath. Mr. Sole. In a little peninfula at the fouth-weft corner of Saham meer near Watton, Norfolk.

Perennis. Fl. Augufto, Septembri.

Caules erectiufculi, 2-3-pedales, in y 4-pedales, ramofi, purpurafcentes, fublirfuti, pilis recurvis. Folia oinnia petiolata, ovata, acutiufcula, ferrata, atro-viridia; fuprà glabriufcula; fubtùs pallidiora et hirfutiora, renis albidis vel purpurafcentibus: in a anguftiora, et fere lanceolata; in \& breviora et fubelliptica; in y latiora, cordato-ovata, frjiùs glabra. Spiçe terminales, folitariæ, obtufufculæe, infernè interruptæ, verticillo infimo, in $\alpha$ et $\gamma$, remotiflimo, pedunculato; in $\beta$ abbreviatæ, obtufiores et fcrè capitatæ. Bracteæ lanceolatæ, ciliatæ. Pedicelli vel omninò glabri, vel fupernè hirfuti, pilis raris, recurvis. Calyx gracilis, fulcatus, glandulofopunctatus; bafi omnino denudatus, nitidus, et glaberrimus; dentibus atro-purpureis, ciliatis; quandoque in $\gamma$ apicem verfus undique hirfutus, pilis adfcendentibus. Corolla purpurafcens. Stamina inclufa.

Odor pungens, fubcamphoratus, gratifimus. Sapor aromaticus, fervidus, demùm refrigerans, amaricans; in $\gamma$ virofus et ingratus.

5. MENTHA ficis capitatis obtufiffimis, foliis odorata. petiolatis cordatis utrinque nudis, calyce pedicellifque undique glaberrimis.

Mentha odorata. Sole Menth.2 r.t.9. Tr. of Linn. Soc. v. 5. I 92.

M. rubra. Mill. Dia. ed.8. n. 9. defer. crroneâ.

M. rotundifolia rubra, aurantii odore, (rotundifolia fpicata altera C. B.) Morif. v. 3. 369. fect. I . t. 6. $f .3$, glabra.

Angl. Bergamot Mint.

In aquofis rariùs.

Very common by the fides of rivers and brooks in $\mathrm{N}_{2}$ Chethire, 


\section{G15 DIDYNAMIA-GYMINOSPERMIA.}

Chefhire, efpecially about Afion houfe; Mrs. Walmfley : alio in a finall brook or ditch ncar Capel-Carcy, between Llanrooft and Llanberris, North Walcs. Mr. Sole.

Perennis. Fl. Julin, Augufto.

1 Jerba undique glaberrima, rubicunda, odore fuavi, anrantinco, ferc Monardex didvmx. Caules bipedales, eresti, ramofiffimi, patuli. Fólia petiolata, late cordata, obtufuferta, ferrata. Spica terminales, breviffima, fere hemifpherica, denfre, verticillo infino remoto, axillari, fubpedunculato. Bractex fetacex, omninc Glabre. Pedicelli terctes, glaberrimi, atro-purpuri. Calyx gracilis, fulcatus, glandulofo-punctatus, atropurpurcus, tubo dentibufque onminu glaberrimis. Stamina inclufa.

Diftinctiflina a MI. aquatica Linnxi, quæ fequentis va. bietas elt.

60 ut. 6. MENTHA floribus capitatis verticillatife, foJis petiolatis ovatis, callyce undique hirfuto, pedicellis retrorsim hifpilis.

Nentha hirtuta. Tr. of Jivin. Soc. $: 5.193$.

M. fativa. Ti. of Limn. Soc. v. 5. 199 .

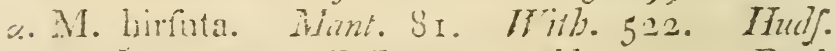
ch. 1. 223. Hull. 127. Ablot. 127. Engl. Bot. t. $44 \%$.

M. aqquatica. Hudf. 252, of ct 3 . Tinll. I27. Relh.223. Siblik. 182. Ablot. 12\%.

M. aquatica major. Sole Nonth. 25.t. Ir.

M. aquatica minor. Sole Menth. $23 . t$. 10.

M. acuatica five Sifymbrium. Hoa: Plyt. 74Merr. Pin. 76. licuii Sin.233. Ge\% em.684. M. aquatica five Sifymbrim hirfutius. Baub. Iifft. $\because 3 \cdot$. f. 2. 224 .

M. rotundifolia paluerris. Norif feet. Ix. t. 7 . f. 6.

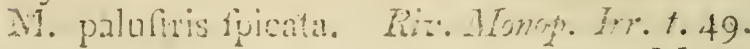


M. n. 4. Hort. Cliff. 306 .

Sifymbrium hirfutum. Raii Syn. 233 .

S. hirfutum, folio anguftiore et acutiore, minimes ramofum; 13. Rand. Herb. Busddl.

S. fylveftre. Dalech. IIift. 677.

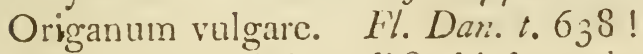

f. Mentha Sifymbrium dicta hirrita, glomerulis ac foliis minoribus ac rotundioribus. Dill. in Iiciii S S:n.233.t. IO. f. I.

\%. piperita. Sp. Il. \&oj. Berg. Mat. Med. 5 I6.

\$. M. paluftris. Sule Menth. I3.t.6.

N. aquatica. Mill. Dict. ed. 8. n.5.

M. aquatica, folio oblongo viridi glabro, faporis fervidiflini. Hert. Buddl. et Herl. Bobart.

Menthaftri aquatici genus hirfutum, fpica latiore.

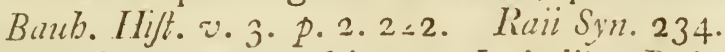

Menthaftrum minus fpicatum Lobclii. Dalech. Ijift. 674. How. Plyt. 74 .

M. minus. Ger. em. 68j.

Calanintha tertia Diofcoriclis, menthaftrifolia aquatica hirfuta. Lob. Ic. 5 I 0 . Dill. in Herb. sberard.

E. Mentha paludofa. Sole Menth. 49. t. 22.

$\$$ M. fativa. Sp. Pl. 805 , cxclutis fynonymis. Hudf. 253. Engl. Bot. t. 448 .

M. verticillata. Syjt. Nat. ed. I o. Iо39. ILudf. $e d, x .222$.

M. rivalis $\beta, \gamma$ et $\delta$, nec a. Sole Menth. 45 .

M. verticillata varietas, hirfutie foliorum difcrepans. Raï Sym.ed. 2, 124. 6. et. 3. 23z. Hert. Bobart.

NI. Sifymbria facic et odore, hirfuta ct verticillata; D. Rand. Herl. Buddl.

Calamenthe arventi verticillate- finilis, fod inultì elatior. Herb. Buddl. 
$\eta$. Mentha aquatica verticillata glabra, rotundiore folio. Dill. in Herb. Sberard.

9. M. verticillata minima, odore fragrantifimo. Herb. Bliddl. Sub M. aquaticâ exiguâ, Dill. in Paii Syn. 232. Angl. Hairy Mint.

In aquofis vulgaris.

G. In the parith of Eant Borne, Sufex, in the road to Pevenfey. Lill.

\%. A native of England. Herb. Banks.

o. Ner. B cking. Dulte. Somerfethire. Mr. Sole. Un the couth-wett fhore of Saham meer, Norfolk.

$\varepsilon$. In Holt fen at Streatham near Ely; alfo in a rivulet by the fide of Awdry caufeway, ncar $\mathrm{Ha}$ dingham in the lne of Ely. Mr. Sole.

3. About rivulets on the fide of Shotover hill near Oxford; Mr. Tilleman Bobart. Herb. Bobar:t. On the banks of the river Lea near Hackney. Mr. E. Forfter. At Saham and Athill in Norfolk; allo eleven miles from Norwich in the Hinghan road, and in many other places.

$\eta$ In a ditch on the left hand of Chalk's green, going from Braintree to Leez houfe. Dill.

$\therefore$ Found by Mr. Buddle and Mr. F. X)ale fen. by the fide of the new-river near the upper end of Stuke Newington. Herb. Sherarl. On Skoulton common near Hingham, Norfolk, but with only the urual finell of the fpecies.

Perennis. Fl. Augufo, Septembri.

Planta polymorpha, magis vel minùs hirfuta, fæpè purpurafcens, odore variabili, plerumque acri et aromatico, fubindè camphorato, interdùm fuavi. Caules erecti, fæi pius ramofi. Folia petiolata, ovata, ferrata, magnitudire varia. Flores in $\alpha, \beta$, ct $\gamma$ capitati; in $\delta$ fpicati vel capitati; in $\varepsilon$ picato-verticillati; in reliquis verticillati, 
cillati, axillares. Bracteæ fæpiùs lanceolatæ, hivfutæ. Pedicelli undique hirfutiffimi, pilis reflexis, albis, fubindè arctè depreffis. Calyx tubulofus, fulcatus, purpurafcens, glandulofo-punctatus, undique hirfutus, pilis fursùm curvatis, longitudine variis. Corolla dilutè purpurafcens, extùs hirfuta. Stamina longitudine varia. Verticilli inferiores fæpiùs pedunculati.

7. MENTHA floribus verticillatis, foliis ovato-acutifolanceolatis utrinque acutis, calyce undique lia. hirfuto, pilis pedicellorum patentibus.

Mentha acutifolia. Tr. of Limn. Soc. v. 5. 203. M. verticillata. Mill. Dict.ed. 8. n. I7. Herb. Miller.

M. verticillata aromatica, folio longiore et acutiore. Kand. MJs.

M. aquaticil verticillata odoris grati. Herl. Buddle.

Angl. Fragrant Sharp-lcaved Mint.

Ad fluviorum margines rariùs.

On the river Medway, Kent. Rand. Between Rochetter and Chatham. Miller.

Perennis. Fl. Septembri?

Herba hirfuta, odore fuavi, aromatico. Caules erecti, bipedales, fubfimplices, pilis aretè deflexis. Folia breviùs petiolata, patentia, ovato-lancenlata, utrinque acuta, iñequalitèr et acutè ferrata, bafi apiceque integrerrima. Verticilli numerofi, omnes feffiles, denfi, petiolis ferè æquales, multiflori. Bractex lineari-lanceolatæ, vel fubulatæ. Pedicelli hifpidi, pilis horizontalitèr patentibus, longitudine variis, fubinde recurvatis. Calyx tubulofus, undique hirfutus, imprimis ad bafin, pilis adfcendentibus. Corolla extùs fauceque pilofa. Stamina inclufa.

Præcedenti valdè affinis,

3. MENTHA floribus verticillatis, foliis ovatis, rubra $\mathrm{N}_{4} \quad$ cau'e 
caule crecto flexuofo, pedicellis calycibufque glaberrimis: dentibus hirfutis.

Mcntha rubra. Tr. of Limn. Soc. $\%$ 5. 205.

M. fativa. Snle Menth. 47. t. 24.

M. verticillata. Rerii Syn. 232. Riv. Monop. Irr. t. 4 S. f. I ?

M. crifpa. Hort. Ey t. Aft. ord. 7.t.5. f. I.

Mi. crifpa verticillata. Baiub. P'in, 227. Morif. jęt. II. t. 7. f. 2. Herú. Bolrart.

M. crifpa verticillata, folio rotundiore. Banb: Ilif: $v .3 \cdot p \cdot 2.21 \%$ Raii Syn. ed. 2.124, Herb. Buddl. et Herb. Sherard.

M. prima. Dod. Pempi. 95.

M. fitiva rubra. Ger. em. $68 \mathrm{a}$.

M. cruciata. Lob. Ic. 507 .

Mienta. Brunf. Herl. v. 2. 76. Ang. Tall Red Mint.

In forfis et ad fluviorum margines.

By Hackney river at the ferry-houfe. Herb. Shen rard. Peckham fiekls. Dill. North Wales and Shrophire. 31r. Sole. By the road fide between Edmonton and Enficld; alfo near Walthamfiow. Mr. E. Forfter. Under a wet hedge in the road from Watton to Saham church, Norfolk.

Perentis. Fl. Septembri.

IIerba glabriufcula, oilore forti congenerum. Caulis 4-6-pedalis, esectus, flexuofus, parim ramofus, rubicundus, glaber. Folia petiolata, latè ovata, incifo-ferrata, faturatè viridia, lucida; fubtus palididiora, venis fubhirfutis: fuperiora nimora, breviora et fubrotunda, interdim crifpa. Verticilli numerof, pedunculati, multiflori. Bractex lineari-lanceolatæ, apice fubciliatæ; interiores fetacex. Pedicelli teretes, purpurci, lucidi, glaberrimi, Calyx tubulofo-campanulatus, refinofopunctisus, glabcrimus, dentilus ciliatis, quandoque dorfe 
dorfo hirfutis. Corolla majufcula, purpurea, glabra, refinofo-punetata. Stamina longitudine varia.

9. MENTHA floribus verticillatis, foliis ovatis, gentilis, caule ramofifimo patulo, calycibus bafi pedicellifque glabris.

Mentha gentilis. Sp. Pl. So5. Tr. of Limo Soc. 2.5 .208$.

M. rubra. Sole Menth. 4r. t. is.

F. M. rivalis $\alpha$. Sole Menth. 45. t. 20.

\%.M. variegata. Sole Mentb. 43. t. I9.

M. arventis verticillata verficolor. MLris. feck I I. $t .7 \cdot f \cdot 5 \cdot$ Herl. Budal.

M. crifpa verticillata. Herl. Cliffort. Angl. Buthy Red Mint.

In aquofis et ruderatis rariìs.

\%. In pools and brooks between Mole and Llanrooit, North Wales. Mr. Sole.

B. In Lock's brook between Wefton and Twerton, Someriet hire. Mr. Sole.

$\%$ About towns, but fearcely to be found truly wild.

Perennis. Tl. Augufto.

Hcrba fubhirfuta, in folo ficciore gratè aromatica. Caulis erectus, pedalis, in $\beta$ tripedalis, fcaber, ramofiffinus, ramis clongatis, patentibus. Folia petiolata, ovata, obtufufcula. ferrata, lete viridia, utrinque fubhirfuta, pilis fparfs, brevibus, venis fubtùs albidis, omnia fere conformia; in $\beta$ longiora et fubelliptica; in $\%$ luteo variata. Verticilli fublefiles, multiflori; in $\gamma$ interdum longius pedunculati. Bractere lanceolatre, magnitudine varix. Pedicelli teretes, purpurci, frepius glaberrimi; in \% interdim, fed rariffimè, parum hirfuti, pilis deflexis. Calyx tubulofo-campanulatus, fupernè hirfutus, pilis adfendentibus; bafi glaber; undique 8 refinofo: 
refinofo-punctatus. Corolla pallidè purpurafcens. Stamina inclufa.

gracilis. IO. MENTHA floribus verticillatis, folis lanceolatis fubfefilibus, caule ramofifimo erecto, calycibus bafi pedicellifque glaberrimis.

Mentha gracilis. Tr. of Lim. Soc. v. 5. 2 Io. a. M. gracilis. Sole Menth. 37. t. 16. Hull. x 29. M. gentilis. Engl. Bot. t. 449. With. 52t. M. rubra. Hudf. 252.

M. furca five vulgaris. Paii Syn. 232. Herb. Bliddl.

M. verticillata glabra, odore $M$. fativa (viridis). Herb. Sherard.

Balfamita officinarum. Hort. Eyf. Ajf. ord. 7 . t. $3 \cdot f \cdot 3$.

B. Mentha pratenfis. Sole Menib. 39. t. I 7. Hull. I 29.

* $\%$. gentilis. Sole Menl\%. 35. t. I5.

M. hortenfis verticillata, Ocymi odore. Morij. Sect. I I. t. 7. f. I. Herb. Buddl.

M. verticillata minor, acuta, non cripa, odore Dcymi. Baub. Hift. ข. 3. p. 2. 216 , ex defer.

M. cardiaca. Ger. em. 68o, ex iconc. Angi. Narrow-leaved Mint.

In aquofis, pratifve humidis.

a. At Bocking and Stoke Newington. Herb. Sberard. Near Walthamftow. Mr. E. M. Forfter. Near Bradford, Wilts. Mr. Sıle. At Saham and Oxborough, Norfolk.

6. In the New Foreft, Hants. Mr. Sole.

$\%$. Frequent in ditches and wafte places near towns and villages, but farcely wild. Mr. Sole. 
Perennis. Fl. Augufto.

Herba fubhirfuta. Caulis erectus, pedalis ant fefquipedalis, fcaber, rubicundus, medio præcipuè ramofiflimus. Folia fubfethilia, uniformia, lanccolata, acuta, ferrata, bafi anguftata, lætè viridia, utrinque pilis brevibus fubhirfuta; in $\beta$ deflexa. Verticilli multiflori, fæpiùs feffiles, interdùm pedunculati. Bracteie lanceolatæ, hurfutx. Pedicelli teretes, purpurei, omninò glaberrimi. Calyx tubulofo-campanulatus, purpureus, refinofo-punctatus; bafi glabcrrimus; apice dentibufque hirfutus, pilis albis, erectis. Corolia purpurea, apice barbita. Stamina inclufa.

$\approx$ gaudet odore M. viridis, $\beta$ M. piperita ; $\gamma$ Ocymum redolet.

I. MENTHA floribus verticillatis, foliis ovatis, aryentis. caule ramofifimo, calycibus campanulatis undique hirfutis pilis horizontalibus.

Mentha arvenfis. Sp. Pl. 306. Tr. of Linn. Soc. v. 5. 2I3. Huds. 253. Wilh. 524. Hull. I28. Relh. 224. Sibth. 182. Abbot. 127. Sole Mentb. 29. I. I2. Fl. Dan. t. 5 I 2. M. n. 5. Hort. Cliff. 307. Herb. Cliff.

M. verticillata hortenfis, orlore Ocymi C.B. Pin. Herb. Cliff. nec Baubini.

M. aquatica. Raii Syn. ed. 1. 78 .

M. feu Calamintha aquatica. Kaii Syn. ed. 2 . $12.3 \cdot \mathrm{ed} \cdot 3 \cdot 232$.

M. arvenfis verticillata procumbens. Morif. Sect. I I. t. $7 \cdot f \cdot 5 \cdot$

Calamintha aquatica. Ger. em. 684. How. Phyt. I8. Nerr. Pin. 18.

6. Mentha arvenfis major, verticillis et floribus amplis, fuliis latioribus, ftaminibus corollâ longioribus, odore grato. Sole Menth. 29, $\gamma$. y.M. pracox. Sole Mentb 3. t. I3. Hull. I28. ¿. M. gentilis. Mill. Di九t. ed. 8. n. 15. Herb. Mill. 


\section{DIDYNAMTA-GLMNOSPERIIA.}

M. rerticillata, rotundiore folio, odorc Ocymi, S. Dale MIs.

M. verticillata glabra, foliis ex rotunditate acuminatis, Buddle. Herb. Buddl. et Herb. Bo. bart.

M. arvenfis verticillata, folio rotundiore, odore aromatico. Raii syn.ed.2. 123 ? ed. 3. 232?

s. M. agrefiis. Sole Mentb. 33. t.:4. ingl. Corn Mint.

In arris inundatis, præcipuè arenofis, frequens, $\gamma$. In moift meadows. $M r$. Sole.

¿. On the right hand of the road from Bocking to Gofsfield, Eflex. Dale. At Shelford, CambridgePhire; Mr. Wigmores. Ray ?

ع. Common in corn-fields and neglected gardens abont Mendip hills, Shepton-Mallet, and Frome, Somerfetihire. Mr. Sole.

Perennis. Fl. Junio-Septembri.

Herba magis vel minùs pilofa, pallida, odore forti, fapiùs peculiari et ingrato. Caulis ramofiffimus, plerunque diffufus; in $\gamma$ et $\varepsilon$ crectus. Folia petiola a, ovata, feu elliptico-ovata, obtufufcula, varie ferrata; in $\varepsilon$ rugofa, et ferè cordata. Verticilii nultifiori, fubfefliles. Ĺractc: lanccolatæ, fubtus hirfutæ. Pedicelli terctrs, apice purpurafcentes, fæpè glaberrimi, interdùm plùs minùs hirfuti, pilis fparfis, fubreflexis, pedicelli apicinn versùs numerofioribus. Calyx brevis, campanulattes, obfoletiùs fulcatus, refinofo-punctatus, undique pilofis, pilis horizontaliter patentibus. Corolla purpurco-cerulefcens, cxtis pilofa. Stamina in $\alpha$ et $\beta$ exferia, in $\gamma, \delta$, et $\varepsilon$, inclufa.

Dignofcitur calyce brevi, campanulato, pilis horizontalitòr patentibus.

Puts- 12. MENTHA foribus verticillatis, foliis ovatis, caule proftrato, pedicellis calycibuique undique tomcontofio: dentibur ciliatis. 
Mentha Pulegium. Sp. Pl. So7. Tr. of Linn. Soc.v.5.216. Hudf.254. With.525. Hull. I 30. Relb. 224. Sibth. 182. Woodr. Med. Bot. t. I7 . Sole Menth. 51. t. 23.

Pulegium. Raii Sym. 235. How. Phyt. 99. Merr. Pin. 99. Baub. Hif. v.3. p.2.256. Fuchs. Hift. 198. Riv. Monop. Irr. t. 23.f. ז. Brunf. Herb. $\because .227$.

P. regium. Ger. em.67I.

Pulegium, berba, flos. Pharmac. Lond.

Angl. Penny-royal.

In ericetis inundatis et pafcuis irriguis.

Pcronnis. Fl. Septembri.

Herba præcedentibus longè minor, odore acri, aromatico. Caules proftrati, ramoliffimi, repentes, pilofi, angulis obtufufcellis. Folia parra, petiolata, ovata, obtufa, crenato-ferrata, fubtùs precipuè fubhirfuta. Verticilli fefiles, pro foliorum ratione magni, numeroli, multifori. Bractere nullie. Pedicelli tomentofo-incani, feu pilis brevifimis, denfifimis, undique tecti. Calyx tubulofus, gracilis, fulcatus, refinofo-punctatus, pilis denfis, brevibus, porrectis, undique veftitus, dentibus ciliatis, acutis, inæqualibus, fauce villis albis, conniventibus, clausî, ut in Thymo. Corolla calyce duplò longior, purpurca, bafi alba, extis villofiflina. Stamina exferta.

Variat flore albo.

263. GLECHOMA. G. Pl. 29I. JuJ. II 3 .

Cal. quinquefidus. Antber.e per paria in crucein conniventes.

I. GLECHOMA folis reniformibus crenatis.

bcderas

Glechoma bederacen. Sp.Pl.80\%. Iults.254. cca. IVith. 526. Relk. 225. Wiluth. I83. Curt. Lond. Forfe. 2. t. 44. Mart. F\%. Puift. t. 6r.

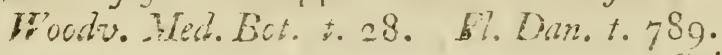


Calamintha humilior, folio rotundiore. Raii Sirn. 243 .

Ifedera icretìis. Ger. em. 856. Brunf. Hift. v. I. 167.

Chamacillos. Fuch.j. Itif?. 876. 'Trag. Ilift. 799. singl. Groundlyy. Gill. Alc-hoof.

In nemorofis et ad fepes ubique.

Peremis. I'l. Aprili, Maio.

Herba pubefcens, grate aromatica. Caules repentes, ramis foriferis ercetis. Folia petiolata, cordato-reniformia, crenata, patentifima. Flores verticillati, utrinque fub-terni, cærulei. Calyx ftriatus. Anther:e albæ.

\section{LAMIUM. G. Pl. 292. Jug. I13.}

Cal. quinquefidus, dentibus fetaccis patentibus. Cor. labium fuperius intcgrum, fornicatum; inferius bilobum; faux inflata, utrinque inargine dentata.

album. I. LAMIUM foliis cordatis acuminatis petiolatis, verticillis vigintifloris.

Lamium album. SP. Pl. Sog. Hudf. $255^{\circ}$ With. 526. Relh. 226. Sibth. 183. Curt. Lond. juf c. 2. t. 45. Mart. T. Rinft. t. 26. Fl. Dan. t. 594. Raii Syn. 240. Ger. em. 702. Angl. White Archangel. White Dead-nettle.

In ruderatis et ad vias paffim.

Perennis. Fl. Míaio, Junio; etiam Septcmbri.

Radix repens. Caules erecti. Folia fubhirfuta, cordatoelongata, profundè ferrata. Flores verticillati, utrinque fub-deni, crecti, albi, galeâ villosâ, fauce utrinque bidentatâ. Antheræ nigra. Calyx campanulatus, lævis, dentibus fetaceis, ciliatis.

purpure-2. LANIUM foliis cordatis obtufis petiolatis: $u m$. juperioribus confertis.

Lamium 
Lamium purpureum. Sp. Pl. 809. Hudf. 255. IVith. 527. Relh. 226. Sibth. 183. Curt. Lond. fujc. I. t. 42 . Mart. Fl. Riuft. t. 25. Fl. Dan. t. 523. Dickf. H. Sicc. fafc. 16. 20.

L. rubrum. Raii Syn. 240. Ger. em. 703.

B. L. rubrum minus, foliis profundè incifis. Raï Syn. 240. Pluk. Pbyt.t.4I.f.3.

I. diffectum. With. $52 \%$.

Red cut-leaved Archangel. Pet. H. Brit. t. 33 . $f \cdot 3$.

$\%$ Lamium rubrum, foliis per ambitum nec ferratis nec crenatis, flore minore. Prof. Mart. MJs. Angl. Red Archangel.

In ruderatis et cultis ubique.

$\%$ Near Sudbury. Mr. Jofeph And́rews. Martyn.

Annue. Fl. Maio.

Radix fibrofa, tenax. Caules glabri, bafi ramofi, medio nudiufculi, apice densè foliofi. Folia cordata, fubreniformia, obtufa, inæqualiter crenata; in $\beta$ laciniata; in y integerrima. Flores purpurei, interdum albi. Antheræ rubræ. Calvcis dentes ciliati.

Varietas y Lamio molli Ait. H. Kerv. maximè affinis eft, fed differt foliis omnibus cordatis, nequaquam dentatis.

3. LAMIUM foliis foralibus feffilibus amplexi-amplexicaulibus obtufis.

Lamium amplexicaulc. Sp. Pl. 809. Hudf. 255 . With. 527. Relh. 226. Sibth. 184. Curt. Lond. fafc. 2. t. 46 . Fl. Dan. t. $75^{2}$.

L. folio caulem ambiente majus et minus. Raiz Syn. 240.

Alfine Hedernla altera. Ger. em. 6 I6. Angl. Henbit Archangel. Great Henbit,

In arvis fibulofis.

Annua. Fl. Februario-Junio. 


\section{G28 DIDYNAMIA-GYMNOSPERIIA.}

Ilabitus pracedentis, fed folia fuperiora feffilia, amplexicaulia, rotundata, incila et crenata, bafi pallida Hores pulcherrimè rofei; primordiales corollâ ạbortivâ. Cay.: densì villofus.

\section{GALEOPSIS. G. Pl. 292. Juf. I If.}

Cal. quinquefidus, arifatus. Cor. labium fuperius crenatum, fornicatum; inferius fupra bidentatuin.

Lrata- 1. GALEOPSIS internodiis caulinis aqualibus, num. folis lanceolatis fubferratis hirtis, corolla galeâ obfolctè crenatâ.

Galcopfis Ladanum. Sp. Pl. S ro. Hudf. 256. With. 523. Tielh. 227. Sibth. 184.

Ladanum fegetum. Ríc. Minnp. Irr. t.24.f. I. L. fegetum flore rubro. Bant. Hijt. $\cdot 3 \cdot 8$;9. Sideritis arvenfis rubia. Raii Syn. 242.

Narrow lion-Wort. Pet. H. Brit.t. 33 .f. II. E. Var. 2. With. 528 , calycc lanato. Angl. Red Hemp-Nictle.

In arvis ficcioribus, prifertion folo calcarco.

Annua. Fl. Augufto, Septembri.

Radix tortuofa. Caulis perlalis, brachiatus, ramofirimus, hirfutus, pilis deflexis, geniculis fupernè vix incraflatis. Folia petiolata, patentia, lancenlata rel ovato-lanceolata, fubferata, interdum integerima, lineata; fupra hirfuta, pilis adpreflis; fubtus villofa. Ilores rerticillati, rofei, albo purpureoque pifti. Calyx campasulatus, hirfutus, dentibus erectiufculis, mucronate-pungentibus. Corolla labium fupcrius obfolsti at obtusè erenatum.

Exemplaria Limnanan a nofratibus panlholum diforepane folis latioribus, ommibus equaliter forratis, ferte ut in fequerite; dentibus calycinis brevioribus; at nullam differentiam fpecificam inveni.

Tariat flore teminali hypocatenformi ut in G. Tetrahi. D. lorliy. 
2. GALEOPSIS internodiis caulinis equalibus, sillça. foliis ovato-ianccolatis ferratis villofis, corollix galcâ crenato-incisâ.

Galcopfis villofa. Hudf. 256. Relh. 227. Dich. H. Sice. fafc. 10. I 5 .

G. grandifiora. Gimel. Syft. 905. With. 528 .

Petonica hirta. Hudf. ed. i. 22c. nec Lim.

Sideritis arvenfis latifolia hirfuta lutea. Raib Syn. $2+2$.

Ladanum fegetum folio iatiorc. Riv: Iínonop. I.r. t. $24 . f .2$.

Yellow lron-Wort. Pet. H. Brit. t.33. f. Io.

6. Cannabis fpuria, flore albo magno, 1taminibus luteis. Merr. Pin. 19 .

Angl. Downy Hemp-IVettle:

In arvis arenofis.

- Frequent in YorkThire and Lancathire; near Nerark, Nottinghamfhire; and about Bangor in Wales. Hiidf.

Annua. Fl. Julio, Augifto.

Eræcedente major. Internodii caulini omninò æquales. Folia ovata, vel ovato-lanceolata, omnia xqualiter et regulariter ferrata, lineata, fericea, fubtùs præcipue densè villofa. Calyx villofus, dentibus rectis, pungrntibus. Corolla calyce quadruplò longior, lutea, paIato faturatiore, labio fuperiore recto, acutè crenato vel incifo. Stamina flava.

3. GALEOPSIS caule hifpido: internodiis fu-Tetrabit, pernè incraffatis, corollâ calyce duplò longiore, galeâ rectiufculâ.

Galcopfis Tetrahit. Sp.P?. 310. Huilf. $257^{\circ}$ With. 529. Relh. 228. Sibth. 184. Engl. Bot.t. $20 \%$.

Lamium cannabino folio vulgare, $P$ atii $S_{y} n .2+10$. FoL. II, 


\section{DIDYNAMIA-GYMNOSPERMIA.}

Cannabis fpuria. Ger. em. 7og. Riv. Monop. lir.t. $3 \mathrm{I}$.

Angl. Common Hemp-Nettle.

In arvis frequens.

Annuia. Fl. Julis, Angufto.

Caulis undique hifpidus, fetis pungentibus, fubdeflexis, geniculis precipuc inferioribus fupernè gibbofis. Folia ovata, acutil, ferrata, utrinque hifpida. Calyx hifpidus, dentibus aculeato-pungentibus. Corolla calyce duplò circitcr longior, tubo attenuato, albido; galeâ porrectà, convexiufculâ, crenatâ, purpureâ; labio inferiore trifido, albo purpureoque variato. Interdun corolla tota alba eft.

V'ariat flore terminali reçulari, quadrifido, hypocrateriformi, ftaminibus xqualibus; confer F\%. Lapp. ed. 2. 201 .

verfico- 4. GALEOPSIS caulc hifpicio: internodiis fupernè incraffatis, corollâ calyce triplò longiore: galê̂́ ventricosâ.

Galeopfis verficolor. Curt. Lond. fafc. 6.t.38. Engl. Bot. t. 667.

G. camnabina. With. 529. Pollich. v. 2. 148. Fl. Dan. 1. 929 .

G. Tetrahit F. Sp. Pl. 8 ro. Lightf. 3 го.

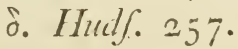

Lamium cannabino folio, flore amplo luteo, labio purpureo. Raii Syn.24I.

L. cannabinum aculeatum, flore fpeciofo luteo, labiis purpureis. Pluk. Pbyt. t. $4 \mathrm{I} . f \cdot 4$.

Cannabis fpuria flore majore. Riv. Mronop. Irr. t. 32 .

B. Lamium cannabinum floribus albis, verticillis purpurafecntibus. Iáii Syn.241.

$\%$ Cannabis fpuria flore albo magno eleganti. Merr. Pin. 19. Dill. in Rüii Syn. 240. 
Angl. Large-flowered Hemp-Nettlc. Bec Nettlc.

In arvis arenofis:

Not rare in the north of England. Plentiful near

Norwich and at Watlington, Norfolk; alfo about

Moffat and near Edinburgh. Obferved by Sir

T. G. Cullum at Gretna green very abundantly. At Afhill, Norfolk. Revo.Mr. Watis.

Anmua. Fl. Julio, Auguito.

Habitus omnino precedentis, fed foliis pallidioribus, littioribus. Corolla maxima, calyce triplò vel quadrupló iongior, lutea, labio inferiore lineis fulvis picto, maculäque centrali violaceo; galeà dilatatî, ventricosà, incifo-crenatå.

Varietates ex defcriptionibus in Raii Syn. huc retuli, necdum mihi obviæ funt.

266. GALEOBDOLON. Hudf. 257.

Galeopfis. G. Pl.292. Julf. I I 4 .

Cal. quinquefidus, inæequalis, ariftatus. Cor. labium fuperius integerrimum, fornicatum; inferius trifidum, laciniis omnibus acutis.

I. GALEOBDOLON.

Galeobdolon luteum. Hudf: 258. With. 530 . Abbot. I29.

G. Galcopfis. Curt. Lond. fafc. 4: t. 40. Relb. 228. Sibth. 185 .

Galeopfis Galcobdolon. Sp. Fl. 8 го. Dreves. Bilderb. t. 20.

Lamium luteum. Puiii Syn. 24.0. Gur. em.702. Riv. Monop. Irr. t. 20.f. 2.

Yellow Archangel. Pet. H. Brit. t. 33.f. 6. Angl. Yellow Dead-Nettle. Weafel-fnout.

In umbrofis humidiuferlis. 
63: DIDTXAMI-GMMNOSPERMA.

l'cremis. Fl. Maio.

Trabitu et formâ omnino Lamium eft, fed corollâ fauce inteçerimâ, nec dentatâ, calyceque ariftato, fpinofo, difcrepat. Radix fubrepens. Caules erecti, fimplices, foliof, pilof, pilis deflexis. Folia petiolata, ovata, fubpilofa, incifo-ferrata, latitudine varia. Verticilli numeroti, multifori, bracteis linearibus, acutis. Calyx bati tubulofus, lexvigatus ; dentibus incequalibus, patulis, pilofis. Corolla crectal, lutea, fauce rubro maculata.

267. BETONICA. G. Pl. 293. Juf. II4.

Cal. quinquefidus, ariftatus. Cor. labium fuperius adfecndens, planiufeulum, inferius trifidum : tubus cylindricus.

offinabes.

I. BETONICA fpicâ interruptâ, corollarum lacíniâ labii intermediâ cmarginatâ. Betonica officinalis. Sf. Pl. 8 I0. Inulf. 258. With. 530. Rels. 229. Siblh. 185. Curt. Lont. fifc. 3. t.33. H. Dan. t. 726 . Woodv. Suppl. 1.2+1.

Betonica. Thiil Sm. 238 . Ger.em.714. Brunf, Herl. .. . S8. Hubbf. Hift. 350. Angl. Wood Betony.

In fylvis et dumctis.

f'rennis. Fl. Juiio, Augute.

Herba tota fetis rigidis, adprefis, fcabra. Caules frmplices. Folia cordaro-oblonga, obtufa, latè ferrata; inferiora longé petiolata. Spica terminalis, obtufa, intermpta, foliolold, bracteolata. Calyx levis, margine fetofus. Corolla purpurea, extus villofa, rarius aliva.

368. STACHIS. G. Pl. 293. JuR. II4.

Cal. quinquefidus; arifatus. Cor. labium fuperias forncatum; inferius lateribus reffexum; 
laciniâ intermediâ majore, emarginatâ. Siamina deflorata verius latera reflexa.

7. STACIIYS verticillis fexforis, foliis cordativelectio petiolatis.

Stachys fylvatica. Sp. Pl. 81 i. Hudf. 259. With. 531. Relh. 229. Sibth. 186. Curt. Lond. fafc. 3. t. 34. Engl. Dot. t. 4 I6. Riv. Monop. Im. t. 26. $f .2$.

Galeopfis legitima Diofcoridis. Raii Syn. 23\%.

G. vera. Ger. em. 704.

B. Lamium fylvaticum ficatum foctidum, folio $a n$ guloro, minus. Dill. in Raii Syn. 237. Angl. Hedge IToundwort.

In fepibus ct nemorofis.

Perennis. Fl. Julio, Augufo.

Radix fubrepens. Herba pilofa, føetida, faturatè virens.

Caules fimplices, bipedales. Folia cordato-ovata, ferrata. Spica interrupta, bafi foliofi, fupcric bracteata, Calyx hifpidus. Corolla fufco-fanguinca, labio inferiore albo purpureoque picto, tubo bafin verfus infra giblbo.

2. STACHYS verticillis fexforis, foliis lincari-palufris. lanccolatis femiamplexicaulibus.

Stachys paluftris. Sp. Pl. 8I I. Hudf. 259. With.532. Reih. 230. Sibth. 186. Curt. Lond. falc. $3 . \% 35$. Riv. Mmop. Mrr.t. $26 . f .1$. Dickl. H. Sicc. faice. 15.8.

Sideritis anglica firumosât radice. Ra ï s, sy. 242 , Panax Coloni. Ger. em. 1005. Angl. Marfh Woundwort.

In paluftribus, et ad ripas fluvioum.

Percmnis. Fl. Auguito.

Radix repens, folonibus demum tuberofis. Caules bipedaleş, ftriati, fcabri, fetis defexis, Fulia ineari-lan$\mathrm{O}_{3}$ ccolata, 


\section{3:t DIDYNAMA-GYMNOSPCRMIA.}

ceolata, acuta, ferrulata; fupra fericen-pilnfa; fubtus lanata, reticulato-venofil; hafi dilatata, amplexicaulia: inferiora fubpetiolata. Spica longa, denfa ; bafi interrupta, foliofa. Calyx villofus. Corobla purpurea, labio inferione variegato.

sermani- 3. STACHYS rerticillis multilloris, foliis crenatis, $i a$.

calule lanito.

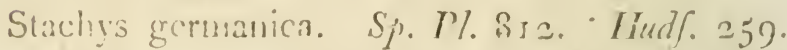
li ill. 532. Silm. 186. Fi. Dan. t. 684. Jurq. Aly 1 tr. 1.319.

Stachys. Fuclig. Hijt. 766.

S. Fuchlie. Rüii syn. 239. Ger.em.695.

S. montana Rir. Vimon. Jir. 1.27.f. I.

S. altua latifolia mior. Barrel. Ic. t. 297.

Ángl. Downy Woundwort.

In arvic, fepibus, et ad vias, folo calcarco.

In feveral parts of Oxfordfhire, efpecially towards Woodfinck and Witney. In the corn-fields at Brizenorton, Oxfordthire, plentifuily: Rev. Dr. Grodenough.

Parennis. Fl. Julio.

Caules densè lanati, mollifimi. Folia ovata, crenata, reticulato-renofa; fuprà fericea: fubtus lanata. Verticilli multiflori, fuperiores feri in fpicam foliofam approximati. Bractex et calyces denfifmè villofi. Flores purpurafcentes, labii inferioris laciniâ centrali maximâ, galeầ extùs villofifimâ.

arvenfos. 4. STACHYS verticillis fexfloris, caule dcbili, foliis cordatis obtufis crenatio fubpilofis. Stachys arventis. Sp. I\%. \& I 4. Hudf. $\approx 60$. IIilb. 532. Relh. 230. Sibib. 187. Curt. Lond. fufi.4. t. 4 I. Fl. Dan. t. 587. D:ckj. H. Sice firfic. I 5.7 .

S. arvenfis minima. Riv. Monop. Irr.t.27.f.2. Sidcrit is humilis lato obtufo folio. Räi Syn. 242 . kourd hou W ort. I't. H. Lit. t. 33.f. 12. 


\section{Angl. Corn Woundwort.}

In arvis glareofis vel calcareis vulgaris.

Annua. Fl. Julio, Augufto.

Radix parva. Caulis erectiufculus, ramofus, fubpilofus. Folia petiolata, baî trinervia, cordata, obtufa, latè crenata, utrinque fubpilofa. Flores omnes verticillati. Calyx pilofus, dentibus ciliatis. Corolla vix calycem excèdens, dilutè purpurafcens.

269. BALLOTA. G. Pl. 294. Juf. II4.

Cal. hypocrateriformis, decemftriatus, quinqủedentatus, Cor. labium fuperius crenatum, concarum.

1. BALLOTA foliis ovatis indivifis ferratis, caly-nigra cibus fupernè dilatatis fubtruncatis : dentibus patentibus.

Ballota nigra. Sp.Pl. ed. r. 582. Hudf. 260. With. 533. Leth. 231. Sibth. 187. Eingl. Bot. t. 46 .

Mentha aquatica. Fl. Dan. $t .673$ !

Ballotte. Raii Syn. 24.. Fuch. Hifl. 154. Matth. Fulgr. v. 2. 180. 'Tourn. Int. IS5. t.85.f.3. Vaill. Pall. 20.

Marrubium nigrum. Ger. en. 70 г.

M. vulgare. Chu. Hift. v. I. 34.

Stinking Horehound. I'et. H. Brit. t. 32 . f. 4. B. Ballota alba. Sp.Pl.ed.2.8I 4. Fl. Suec. 206. B. nigra $\beta$. Hudf. 260 . With. 533. Relb.231. B. flore albo, Tuun. Inft. I85. Taill. Par. 20. Ballote. Camer. Epit. 572 . Angl. Black or Stinking Horehound.

Ad fepes et in ruderatis vulgaris.

3. Near Hammerfmith. Mr. Woodzeart. Stafford. Dr. Slokes. Wefton fupra inare, Somer$\mathrm{O}_{4}$ fethire. 
fethire. Herb. Lightf. Between Norwich and Hellecilon.

Perennis. Fl. Julio, Augufto.

Herba tota pubefcens, odore acri, pungente. Caulis bivel tri-pedalis, ereetus, ramofus, pilis recurvis. Folia petiolata, orata vel fubcordata, æequaliter ferrata. Verticilli omnes axillares, multifori, pedunculati, foliolofi, bracteati. Bractex fetacex, ciliatre, calyce duplò breviorcs. Calyx tubulofus, hirfutus, deceincoftatus, plicato-fulcatus, margine dilatato, infundibuliformi, obtusè quinquelobo, venis reticulato, dentibus breviflimè ariftatis, patentibus. Corolla obfcurè purpurafcens, (in $\beta$ alba); labio fupcriore emarginato, fornicato, extuis pilofo, pilis magis vel minùs fursùm conniventibus; inferiore trilobo, venis albis, lobo centrali obcordato.

Cum hâc, qua B. nigra Sp. Pl. ci. x omniumque auctorum eft, aliam fpeciem, Suecix indigenam, qux B. nigra Sp. Pl. ed. 2 et Fl. Suecica, furfitan Marrubiaítrum Rivini t. $65 . f$. r, poftmodò confudit Linnæus; hine in errorem, aped Engl. Bot. 46, de B. albâ incidi?

2\%.. MARRUBIUM. G. Pl. 294. JuJ. II4.

Cal. hypocratcriformis, rigidus, decemftriatus. Cor. labium fuperius bifidum, lineare, rectum.

w? ?re. I. NARRUBIUM dentibus calycinis decem fetaceis uncinatis.

Marrubium vulgare. Sp. Pl.816. Hudf. $26 \mathrm{r}$. 泣ith. 533. Relh. 232. Sibih. 197. Wrody. Med. Bot.t.97. Engl. Bot.t.410. Fl. Daln. $\therefore 1036$.

M. album. Raii Syn. 239. Riv. Monop: Irr: t. 66. $f .1$.

Marmbium. Fuch. Hit. 590.

Marubium album, berba. Pbarnac. Lond. Angl. White Horchound.

In ruderatis et ad rias. 
Derennis. Fl. Julio.

Herba aromatica, amara. Caules fefquipedales, densd lanati. Folia petiolata, rotundata, crenata, rugofa, albida, fubtùs precipuè lanata. Y'rticilli multifori, feffiles, villofiffmi. Bractere fetacex, ariftatr, adunce. Calyx fuicatus, dentibus deccm, fetaceis, apice reuncjnatis. Corolla alba.

\section{7r. LEONURUS. G.P7.295. Juff. II4.}

Cal. pentagonus, quinquedentatus. Cor. labium fuperius concavum, villofim, integrum. Anthere punctis nitidis adperfo.

3. LEONURUS foliis fuperioribus lanceolatis Cardiat

trilobis integrific.

Lconurus Cardiaca. Sp. Pl.8 i 7. Hudf. 26 т. With. 534. liell. 232. Abbot. 131. Engl. Bot.1.286. Fl.Dan.t. 727 .

Cardiaca. Pali Sy. 239. Ger. em. 705. Dorfo. But.65. Riv. Nonof. Irr. t. 2o.f. r. Fubl. Tiift. 395. Camer. Entit. 864. Angl. Motherwort.

Ad fepes folo glarcofo vel calcareo.

Near Chichefter; and between Tickhill and Workfop. Ihudf. Nonmouththire. Fierb. Lightf. In a lane near Combe wood, Surrey. Mr. Suverly. In fereral parts of Norfolk and Sufolk, efpecially about Bungay.

Perennis. Fi. Julio, Augufto.

Ilerba amara, odore pungente, ingrato. Caulis triped.sili, purpureus, pubefeens, villis brevifimis, deflexis. Folia numerofa, petiolata, patentia, acuta, fubtùs tomentofa, venofa; inferiora palmato-incifa; fuperiora trifida, fubdentata; fumma plerumque integra. Verticilli multiflori. Calyx rigidus, dentibus patulis, pungentibus. Corolla exús lanata, alba; intus fanguineo-variegrata. Semina 
Semina tetragona. Anthere punctis alhis, nitidis, prominentibus adfperfa, quibus a l'hlomide, dignofcitur.

$$
\text { * Calyces lilaliari. }
$$

2\%2. CLINOPOBIUM. G. Pl. 296. Juf: I I5.

Cal. bilabiatus. Involucrum multifetum verticiilo fubjectum.

vulgare. I. CLINOPODIUM verticillis hifpidis, bracteis fetaceis, pedicellis ramofis, foliis obfoletè ferratis.

Clinopodium vulgare. Sp. P\%. $\delta_{21}$. Hudf. 26 I . Wib.535. Ralh. 233. Silu. r88. Fl. Dan. t. 930 .

C. origano fimile. Rani Syn. 239 .

Clinopodium. Riv. Minns. Irr. t. 43. f. I. Camer. Ejit. 503 .

C. vulgare. Maith. Valgr. 2. 2.169.

Acynos. Ger. em. 675 .

Angl. Vild Bafil.

In dumetis et ad fepes, praferim folo calcarco vel glareuto.

Peremis. Fl. Augufto.

Caules fape fubflexuofi, pilofi, anguiis obtufis. Folia ovata, obtufufcula, obfoleté ferrata, hirfutiufcula, renis fubtis fubpectinato-pilofis. Verticilli terminales et axillares, pauci, multitiori. Pedicelli ramofi, pilofi. linvolucia anguftiflima, pilofa, calyce breviora. Calyx multinervolus, hirfutus, dentibus duobus infimis porrectis. Corolla calyce duplú longior, purpuren-rofea, fauce hirfutâ, laciniis rotundatis. Herba aromatica،

273. ORIGANUM. G. Pl. 297. Jul. I I 5 . Sirvtilis tctragonus, fpicatus, calyces colligens. 
Y. ORIGANUM pipiris fubotunlis paniculatis vulgare. conglomeratis glabris, in olacris ovatis calyce longioribus.

Origanum vulgare. Sp. Pl. 83t. Hulds. 2 '́2. Itith. 535. Relh. 234. Sibth. 188. Curt. Lond. fafie. 5. t. 39. Woodv. Med. Bot. t. 164. Matth. Valgr. v. 2.62. Camer. Epit. 469.

O. vulgare fpontancum. Raii Syn. 236 .

O. anglicum. Ger. em. 666.

O. fylveftre feu vulgare. Fuch. Hift. 552.

Origanum, berba. Pbarmac. Lond.

ingl. Common Marjoram.

In dumetis et ad fepes, folo calcareo, vel glareofo.

Perennis. Fl. Julio, Augufto.

Radix repens. Caules concinnè tetragoni, hirfuti, purpurafcentes, paniculati. Folia ovata, integerrima, fubpilofa, ciliata, pellucido-punctata. Spicæ terminales, congeftr, erectre, ovatæ, multiflore. Involucra ovata, glabra, purpurea. Calyx fubrqualis, lævis, fauce ciliatus. Corolla rofea. Herba aromatica, fragrans, pungens et calida.

Origanum Onites Linn. nequaquam in Britanniâ nafcitur. O. Onites Dill. in Raii Syn. videtur vulgaris varietas, et fortè in loco indicato non fpontanea.

\section{THYMUS. G. Pl.297. Juff. II5.}

Cal. bilabiatus, faux viliis claufa. Cor. labium fuperius planum, emarginatum.

I. THY MUS floribus capitatis, caulibus decum-Serpylbentibus, foliis planis ovatis obtufis bafi cili- lum. atis.

Thymus Serpyllum. S. . Pl. S25. Hudf. 262. Hith. 536. Relh. 234. Silith. 188. Curt. Lon!. fajc. 2. t. $4 \%$.

Serpyllum 
Scrpyllum vulgare. Raii Syn. 230. Ger. em. 570.
B. Hhudf. 262 .

570. Vaill. Par. t. 32. f. 9. etiam $f \cdot 7$.

S. vulgare flore albo. Tourn. Inft. 197.

$\gamma$. S. vulgare flore amplo. Raii Syn. 230 . Vaill. Par.t. 32. f. 8.

Large-flowered Mother of Thyme. Pet. H. Brit.t. $31 . f .2$.

๙. Serpyllum valgare majus. Dill. in Raii Sym. $23 \mathrm{I}$. Upright Broad Thyme. Pet. H. Brit. t. $3^{1}$. $f \cdot 3$.

ع. Serpyllum citratum. Raii Syn. 23I. Ger. em. $57 \mathrm{I}$.

Lemon Thyme. Pet. H. Brit.t. 31. f. 4 .

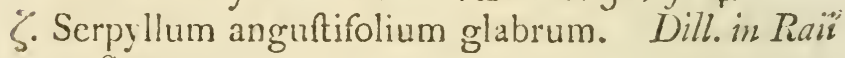
Syn. 23I.

Thymus Serpyllum. Woodr. Med. Bot. t. I Io? \%. Serpyllum vulgare hirfutum. Traii Syn. $23 \mathrm{I}$.

9. S. hirfutum minus, repens, inodorum. Dill. in Raii Syn. 231.

4. S. villofum fruticofius, floribus dilutè rubentibus. Raii Syn.231.

Angl. Wild Thyme. Mother of Thyme. $\varepsilon$ Lex mon Thyme.

In ericetis et montofis ubique.

\$. In Okey ho'e, Somerfethire. Petiver. E. In Kent, but rarely. Ray. At Downton caftle, Shrophire, in a wood on the north bank of the river. 2. In Ireland. Pluk. 6. On the Welch mountains. Lbroyd. Sherard.

Perennis. Fl. Julio, Auguto.

Caules fuffruticofi, procumbentes, ramofi, foliofi, pubefcentes, frepius rubicundi. Folia petiolata, elliptica vel ovata, obtufa, integerrima, pellucido-punctata, bafi ciliata, fubinde undigue hirfuta. Capitula terninalia, foliolofa. 
foliolofa. Flores pedicellati. Calyx coftatus, punctatus; dentibus duobus infimis profundè incifis, anguftioribus, acutis, ciliatis; fauce villis albis, conniventibus, clausâ. Corolla purpurea; labio fuperiore erecto, fubreflexo; inferiore tripartito. Stamina divaricata.

Varietates $\beta, \gamma$ et $n$ haud raræ funt: $\delta$ ex anctoritate Petiveri pendet; figura ejus plantam a Serpyllo vulgari longè alienam facie refert: $\varepsilon$ odore citreo omnibus familiaris eft : cæteras ex auctoribus citatis inferui.

₹. THYMUS verticillis fexfloris, pedunculis fim-Asinos. plicibus, caule adfcendente ramofo, foliis acutis ferratis, calyce gibbofo.

Thymus Acinos. Sp. Pl. 826. Hudf. 263. With. 537. Relh. 235. Silbth. 189. Abbot. 132. Cart. Lond. fafc. 1. t. 43. Dicks. H. Sicc. fafc. II. 8. Eiggl. But. t. 4 I I. Acinos. Riv. Monop. Irr. t. 43.f.2.

A. multis. Raii Syn. 238.

Ocymum fylveftre. Ger. em. 675.

Ocimaftrum. Fucbs. Hif. 396.

Small Wild Bafil. Pet.H. Brit.t.32.f. Io, Angl. Bafil Thyme.

In arvis, præfertim arenofis vel cretaceis.

Anmua. Fl. Julio, Augufto.

Radix parva. Caules villofi, ramofi. Folia ovata, acuta, plerumque ferrata, fubrevoluta, fcabra. Flores verticillati. Calyx hifpidus, fubtus gibbofus. Corolla dilutè violacea, labio inferiore alho nigroque vario. Herba longè minùs quam præcedens aromatica.

3. THYMUS verticillis pedunculatis multiforis Caliadichotomis, foliis fubferratis, villis calycinis mintba, inclufis.

Melifia Calamintba. Sp. Pl. 827. Fiulf. $26_{3}$. IVith. 538. Relh. 235. Sibth. I89. Abbot. 133 . 
Calamintha. Mutth. Ialgr. v. 2. 76. Kiv. Monop. Jir. H. 46. f. 2.

C. vulgaris, Raii Sinn. 243 .

C. vulgaris officinarum. Ger. $\mathrm{cm} .68 \%$.

C. montana. Dod. Pempt. 98 . Lob. Jc. 5 I3. - f. $\mathrm{x}$.

Angl. Common Calamint. I'et. H. Brit.t. วł. f. $\mathrm{I}$.

In agrorum marginibus, agecribus, ct ad vias, imprimis folo giarcofo, iparfim.

Perennis. Fl. Julio, Augufto.

Caules erecti, ramofi, villofi. Folia petiolata, ovata, abfolctè fersata, venofa, utrinque fubhirfuta, pellucidopunctata, fubtùs pallidiora. Pedunculi axillares, oppofiti, folitarii, multiflori, fubdichotomi, pubefcentes; pedicelli longitudine varii, crecti, uniflori, foliis inferioribus breviorcs, fuperioribus (fenfim diminutis) longiores. Bracter fetaccæ, ciliatæ, ad bafin pedicellorum. Calyx fulcatus, fubpubefcens, refinofo-punctatus, coftis hirfutis; fubtùs ventricofus; fauce pilis albis, inclufis, nec prominentibus; dentibus ciliatis; durbus inferioribus duplò longioribus porrectis ; tribus fuperioribus erectis, fubdivaricatis, minimè faftigiatis. Corolla calyce duplò longior, dilutè violacea, pilofa; galeâ fubfornicatil, margine erecto, fubreflexo, ennarginato. Herba gratè aromatica, odore fuavi.

Nepeta. 4. THYMUS verticillis pedunculatis multiforis dichotomis folio longioribus, foliis ferratis, villis calycinis prominentibus.

Meliffa Nepeta. Sp. Pl. 828. Hudf. 263. With. 538. Relh. 235. Siblh. I90. Curt. Lond. fajc. 6. t. 40 .

Calamintha odore Pulcgii. Raii Syn. 243. Ger. em. 687 .

Angl. Lefier Calamint.

In collibus, et ad margines viarum, folo calcareo, copiosè.

Pcrennis. 
Perennis. Fl. Augufto.

Habitus pracedentis, fed diftincta fpecies, charactere licet difficili. Differt odore fortiori, acri, quo Pulegium recolet; caulibus minùs erectis; foliis minoribus, latè ferratis; pedunculis omnibus folio proximo longioribus, fæpe repetito-dichotomis; dentibus calycinis longitudine minus inæqualibus, fuperioribus recurvis; pilis e fauce prominentibus, confpicuis, albis.

Synonyma cautè citavi, cum fpecies extraneas plures, hifce affines, haud fatis inveftigavi.

De harum genere ne minimus quidem mihi fcrupulus reftat; villi enim coaretati in calycis fauce, dentefque fuperiores haud fafiigiati, Thymo proprii funt, nec in Melifsât verâ (officinali) inveniuntur.

275. MELITTIS. G. Pl. 299. Juff. I16.

Call. inæqualis, tubo corollæa amplior. Cor. litbium fupcrius planum; inferius trilobum, crenatum. Anibere cruciatic.

I. MELIT'Tís calyce trilobo.

Melittis Mclifiophyllum. Sp. Pl. 832. Hudf. Mrifo264. With. 539. Jacq. Auftr. t. 26. Engl. lum. Bot.t. 577 .

Melifophyllum. Ria. Monop. Irr.t. 2 r. $f \cdot 2$.

Melifla Fuchtii. Ruii Sym. 242. Lob. Ic. 515. Cumer. Hort. 99. t. 30. benè.

M. Fuchfii flore purpureo. Ger.em. 590.

Lamium Pannouicum primum, verficolore flore. Cluf. Hift. v. 2. 37 .

Angl. Reddih Baftard-Balm.

In fylvis et fepibus Anglix occidentalis.

About Totnefs in Devonthire, and Haverfordwet in Pembrokenhire. Ray. New Foreft, Hampfhire. Hudf. Specimens in the Phyfic-garden, Chelfea, brought from Devonthire by Mr. Hudfon. Mr. Fairbaim. St. Leonard's Foreft, Su1- 


\section{DIDYNAMIA-GMANOSPETIM.}

fex ; and near Netley Abbey, Hamphine. Herb. lightf.

Perennis. Fl. Main, Junio.

Radix fibrofa. Caules erecti, fefquipectales, fimplices, foliofi, quadrifulcati, pilofi. Folia petiolata, ovata, ferrata, pilofa. J'lores axillares, pedunculati, fecundi, utrinque fubtemi. Calyx campanulatus, pilofns, tubo corollie multo amplior, coloratus, margine trilobus; lobo fuperiore impari, longiore, acuto, thinque fæpins unidentato; lateralibus rqualibus, rel acutis rel eniarginatis. Corolla calyce duplò vel triplò lorgior, pubefcens, camea, labio inferiore maculâ fangunineâ bifidâ. Herba exfiecata odore Afperulæ vel Anthoxanthi gaudet.

spandi- 2. MELITTIS calyce quadrilobo.

fiura. Melittis grandiffora. Engl. Bot. t. 636.

M. Meliffophyllum. Curt. Lond. fafc. 6. t. 39. Mill. Illugh. $t .52$.

Melifophyllum. Riv. Monop. Irr. t. 2I. f. I. Fucbl. Hift. t. 498 .

Melifla Fuchnii flore albo. Ger. em. $6 g \circ$.

Lamium Pannonicum primum albo flore. Clufs Hift. v. 2. 37.

Angl. Purple and White Baflard Balm.

In fylvis et fepibus Anglix occidentalis.

By the roarl fide at Hall near Barnftaple, Deronfhire. Curt. A mile from Affuburton in the road to Plymouth, in great plenty; alfo at Lefkards; Comwal! Mir. D. Tumer' and Mr. Sowerby, I799.

Pereninis. Ni. Maio.

Habitus et folia ferè precedentis, at floribus abund differt. Calyx quadrilobus, lobis utrinque duobus hateralibus, fubequalibus, interdum erofis. Corolla quams in preccedente major, luteo-alka, labii inferioris lacina mellit volaccù, margine albu; galeü futemarginati. 
э76. SCUTELLARIA. G. Pl. 30I. Jiij. I 7 .

$C a$. ore fubintegro: poft florefcentiam claufo operculato. 1. SCUTELLARIA foliis cordato-lanceolatis galericte
crenatis rugolis, floribus axillaribus.

Scutellaria galericulata. So. Pl. 835. Hudf. 265 . With. 540. Relh.23 h. Sibth. 190. Curt. Lond. falc.3. t. 36. Fl. Dan. t. 637. Engl. Bot. t. 523 .

Scutellaria. Riv. Monop. Irr. t.77.f. r. Calfida paluftris vulgatior, flore cxrulco. Raii Syn. 244.

Iyfimachia galericulata. Ger. em. 477 . Hood-mint. Pet. H. Brit.t. 34. f. Io. Angl. Common Skull-cap.

In aquofis, foffis, et ad ripas fluviorum.

Perennis. Fl. Julio, Augufto.

Radix repens. Caulis erectus, pedalis vel bipedalis, niedio ramofus, foliofus, acutè quadrangulus, fcabriufculus. Folia breviffimè petiolata, patentia, cordato-lanceolata, a bafi ad apicem ferè xqualiter crenata, rugofa, venofa, pilis breviffimis pubefcentia, fubt is pallidiora. Flores axillares, utrinque folitarii, fubfeffiles, per paria fecundi, fubnutantes, cærulci. Calyx pilofus, emarginatus, fupra fquamâ fornicatâ munitus, delapsâ corolliân claufus, et fquamâ (demùm auctii) operculatus. Corolla infundibuliformis, ringens, claufd. Stigma finplex.

¿. SCUTELLARIA folis cordato-ovatis fubinte- minos, gerrimis, floribus axillaribus.

Scutcllaria minor. Sp. Pl. 835. Huds: 265. With. 540. Curt. Lond. fufc. 4. t. 43. Dicks. H. Sicl. falc. 5. 6. Engl. Bot. t. 527 .

Caffida paluftris minima, flore purpurafente. Raii Syn. 244. Iind. Alfat. 2 16. t.9.

Tos. II. 
Gratiola latifolia. Ger. em. 581 . Sinall Hood-mint. Pet. H. Brit. 6. 34. f. 1 I. fingl. Leffer Skull-cap.

In ericetis humidiufculis, folo glarcoro.

Perennis. Fl. Augufto.

Præcedente quadruplò minor. Caulis bafi ramofus. Folia latiora, minùs rugofa, plerumque integerrima, interdum bafi dentata, et fubinde haftata. Flores rubicundi, vel purpureo-incarnati; labio albo, punctis fanguineis.

277. PRUNELLA. G.Pl. 301. Juf. I 6.

Filamenta bifurca, altero apice antherifera. Stigma bifidum.

valgaris. I. PRUNELLA foliis omnibus ovato-oblongis petiolatis.

Prunella vulgaris. Sp. Pl. 837. Hudf. 264. With. 541. Relb. 236. Sibth. I 90. Curs. Lond. fisf. 4. t. 42. Mart. Fl. Ruft. t. I37. Fl. Dan. t. 910.

Prunella. Raii Syn. 238. Ger. em. 632. Fuchj. Hift. 62 I.

Confolida minor. Camer. Epit. 703. Angl. Self-heal.

In pratis et pafcuis vulgaris.

Perennis. Fl. Julio, Auguftn.

Radix fibrofa. Caulis fæpiùs ramofus, pilofus, pilis erectis, albis. Folia ovato-oblonga, obtufiufcula, pilofa, fubdentata vel repanda. Spicæ terminales, folitariæ, obtufa, bafi diphyllæ. Practeæ reniformes, acuminatæ, ciliatæ, nervofæ. Calycis labium fuperius dilatatum, tridentatum; inferius bifidum, mucronatum. Corolla violacea; galea concava; labii lacinia media dentata. 


\section{ANGIOSPERMIA.}

* Calyces quadrifidi.

278. BARTSIA. G. Pl. 303. JuJ. 100.

Cal. quadrilobus, fubcoloratus. Cor. ringens, fauce clausâ: labium fuperius concavum, longius; inferiıs æqualiter trifidum, reflexum. Capfula ovata, compreffa, bilocularis. Semina plurima, angulata.

I. BARTSIA foliis oppofitis cordato-ovatis obtusè alpina. ferratis, antheris hirfutis.

Bartfia alpina. Sp. Pl. 839. Hudf. 267. With. 542. Dick. H. Sicc. fafc. 10. 14. Engl. Bot. t. 36 r. Tl. Dan. t. 43 .

Euphrafia rubra Weftmorelandica, foliis brevibus obtufis. Raii Syn.*285.

Clinopodium alpinum. Ger. em. 676. Pon。 Bald. 207.

C. alpinum hirfutum. Pluk. Plyyt.t. I6 $3 \cdot f \cdot 5$. Red Eye-bright. Pet. H. Brit. t. $36 . f .8$. Angl. Alpine Bartfia.

Ad rivulos alpinos rariùs.

Near Orton, Wentmoreland. Ray. Hudf. Near

Middleton in Teefdalc, Durham. Rev. Mr.Harriman and $M r$. Oliver. Among rocks to the eaft of Malghyrdy in the highlands of Scotland. Dick. Tr. of Linn. Soc. v. 2. 290.

Perennis. Fl. Julio.

Radix repens. Caules fpithamæi, erecti, fimplices, foliofi, fub-quadranguli, pilofi. Folia oppofita, feffilia, ovata vel cordata, ferrata, rugofa, fubtùs pilofa; fumma colorata. Spica terminalis, purpurea, foliofa. $\mathrm{Ca}-$ lyx vifcidus, pilofus, purpureus, laciniis ferè æqualibus, 
acutis. Corolla purpuren-violacea, galeá vix emarçinatî; labii lacinis xqualibus, integerrinis. Antherce lirfutx, biloba, fubtus acuninata. Stylus' hirfutus. Capfula orata, pubefcens, diflepimentis e medio valvularum. Semina numerofa, angulata, angulis membranaceis, ftriatis.

rifiofa.

2. BARTSIA foliis ferratis : fuperioribus alternis, floribus lateralibus diliantibus, an theris hirfutis. Bartia vifcofa. Sp. Pl. 839. Hudf. 267 . Wilb. 54. Lightf. 32 1. t. 14. Dick. Dr. Pl. 72. Euphrafia inajor lutca latifolia paluftris. Raii Syn. $2_{2} S_{5}$. Pluk. Pbyt. t. 27.f.5. peffimè.

Alectorolophos Italica luteo pallida. Barrel. If. t. 665 . benè.

Angl. Yellow Vifcid Bartfia.

In palufiribus, imprimis Auglix occidentalis. In feveral parts of Cornwall and Devonfhire. Hudfs F. Borone. Plentiful near Ormfkirk, LancaThire. Hudf. In Argylihire. Lightf. Mr.J. Mackay. Annua. FI. Julio, Augufto.

Kadix fibrofa. Caulis plerumque fimplex, nec, nifi yalde luxurians, ramofus, altitudine varius, erectus, teres, pubefcens, foliofus. Folia feffilia, ovato-lanceolata, ferrata, nervofa, feabra; inferiora tantum oppofita. Flores axillares, fubfefiles, folitarii. Calyx tubulofus, pilofus, regularis, bafi albidus. Corolla calyce dupiò longior, flava, galeâ integrấ; labii laciniiis obtufis, fubxqualibus. Anthere hirfutre, fubtus acuminatx. Stylus hirfutus. Capfula ovata, teretiufcula, apice hifpida, diffepimentis e medio valvularum. Semina numerofifima, parva, fubangulata, nec marginata.

Odonti- 3. BARTSIA foliis lanceolatis ferratis: fuperiies. oribus alternis, floribus racemofis fecundis, antheris glabris.

Bartfia Odontites. Mudf. 268.

Euphrafia Odontites. St. Pl. 841. With. $5+3$. 
Relh. 239. Silth. 192. Curt. Lond. fafc. 1. t. 44. Mlart. Fl. Ruft. t. 42. Fl. Dan. t.625. E. pratenfis rubra. Raii Syn。 *284.

Odontitcs. Riv. Monop. Irr. t. 90.f. 2. Cratæogonon Euphrofine, Ger.em.9 I, Angl. Red Bartfia.

In pratis et pafcuis.

Annua. Fl, Julio, Augufto,

Radix fibrofa, Caulis ramofus, quadrangulus. Folia feffilia, lanceolata, ferrata, fcabra ; inferiora oppofita. Racemi terminales, multiflori, foliofi. Flores fecundi. Calyx purpurcus, hirfutus, interdum quinguefidus. Corolla rofea, galeâ integrâ; labii laciniis obtufis, æqualibus. Antheræ glabræ, fubtus acuminatx, neque longius ariftatæ. Stylus plerumque hirfutus. Capfula fubcomprefia, pilofa. Semina numerofa, parva, ftriata.

279. RHINANTHUS, G. Pl. 304. JIID. IоI. Garln. t. 54.

Cal. ventricofus, quadridentatus. Cor. galca compreffa. Capj. bilocularis, obtufa, compreffa. Semina imbricata, compreffo-plana.

I. RHINANTHUS corollæ labio fupcriore for-Criftanicato, calyce glabro, foliis lanceolatis ferratis. galli. Rhinanthus Crititi-galli. Sp. Pl. 840. Hudf. 268. With. 542. Reth. 238. Sibth. 192. Curt. lond. faff. 5. t. 43. Nart. Fl. Rufl. t. I 48. Fi. Dan. t. $9^{\text {S r. Engl. Bot. t. } 657 .}$

Pedicularis, feu Crifta galli lutea. Ruii $S_{y} n$. $*_{2} 84$.

Crifta galli. Ger.em. 1071. Lob.16.529.

P. Pedicularis major anguftifolia ramofiflima, flore minore lutco, labello purpureo. Pill. in fitcli $S_{Y} n_{0} * 284$.

$$
\text { P. } 3 \quad \text { Angl. }
$$


Angl. Yellow Rattle. Pet. H. Brit.t. $36 . f .2$,

In pratis et pafcuis.

Annus. Fl. Junio.

Radix fibrofa. Caulis ramofus, lavis, fæe maculatus. Folia feffilia, oppofita, lanceolata, acutè ferrata, fcabra, bafi cordata. Spica terminalis, foliacea. Flores fubalterni, brevius pedicellati, lutei. Calyx inflatus, compreflus, nervofus, reticulatus, coloratus, glaber, perfiftens, ore quadridentato, contracto. Corolla calyce dupló longior; labio fuperiore arcuato, compreffo; inferiore trifido, laciniis æqualibus. Antheræ muticæ, valdè hirfutæ. Capfula fcariofa. Semina membranaceo-alata.

280. EUPHRASIA. G. Pl. 304. Julf. 100. Gertn. $t .54$.

Cal. cylindricus, quadridentatus, æqualis. Cor: labium fuperius bificum; inferius trilobum, laciniis bifidis. Anthere fpinis inæqualibus ariftatæ. Capf. ovato oblonga. Semina ftriata.

officinalis.

I. EUPHRASIA foliis ovatis lineatis argutè dentatis.

Euphrafia officinalis. Sp.Pl. 841. Hudf.269. With. 543. Relh. 238. Sibth. 192. Curt. Lond. fafc. 5. t. 42. Fl. Dan. t. 1037. Wuodo. Suppl.t. 220.

Euphrafia. Riaii Syn. 284 , Riv. Monop. Irr. t. 9o.f. I. Ger. em. 663. Fucbs. Hift. 246. Angl. Eye-bright.

In ericetis et pafcuis.

Annua. Fl. Julio-Septembri.

Radix parva, fibrofa. Caulis palmaris, ramofus, hirtus, purpurafcens. Rami erećti, fubfaftigiati, racemofi, folinfi. Flores alterni, axillares, felliles, pulcherrimi, albi, purpureo lineati, palato flavo. Antherarum lobi omnes 
omnes fubtùs frinâ armati, infimâ longiore. Capfula obovata, emarginata. Semina panca, fubangulata, ftriata, parva.

281. MELAMPYRUM. G. Pl. 305. Jild. ior. G.ertn. t. 53 .

Cal. tubulofus, quadrifidus. Cor. labium fuperius compreffum, margine replicato. Capf. bilocularis, obliqua, hinc dehifcens. Semina bina, gibba.

I. MELAMPYRUM fpicis quadrangularibus : criffabracteis cordatis imbricatis compactis denti- tum. culatis.

Melampyrum criftatum. Sp. Pl. 842. Hudf. 269. With. 54t. Relh. 240. Engl: Bot. t. 41. Riv. Monop. Irr.t.81.f.2. Ablot. I 35 .

M. criftatum, flore albo et purpureo. Raii $S_{y} n$. *286.

M. villofum, fpicâ purpurcâ quadratâ. Morif: fect. I I. t. 23. f. 2.

Angl. Crefted Cow-wheat. Pet. H. Brit. t. $3^{6}$. f. Iо.

In nemorofis, interdùm et inter fegetes.

Plentiful in Cambridgenhire and Bedfordhire. Huds.

Annua. Fl. Julio.

Caulis fcaber, quadrangulus, ramofus, brachiatus. Folia linearia, integerrima, fcabra. Spicæ terminales, folitariæ, tetragonæ, imbricatæ, multitloræ. Bracteæ cordatæ, compreffe, coloratæ, pectinato-dentatæ; inferiores apice foliaceo, reflexo. Calyx inæ jualıs, bracteis brevior. Corolla lutea, galeâ purpuraicente, palato fulvo. Antheræ atro-purpureæ, fubtùs acuminatie. Capfula lunata, comprefla, fcaroola, diflepi$\mathrm{P}_{4}$ mentis 
mentis tranfverfis. Semina in utroque loculaments certè duo, elliptica, obtufa, lævigata.

2. MELAMPYRUM fpicis conicis laxis : bractcis lanceolatis pinnato dentatis.

Melampyrum arvenfe. Sp. Pl. 842. Hudf. 270. With. 545. Engl. Bot. t. 53. Dickf. D)r. Pl. 74. Fl. Dan. t.9I I. Liv. Monop. Irr. t. 80.

M. purpurafcente comâ. Dill. in Rerii Sył. *2S6.

M. cxruleum. Ger. em. 90.

Triticum vaccinum. Trag. Hift. $66_{3}$. Angl. Purple Cow-wheat.

In arvis, folo glareofo.

Near Lycham, Norfolk. Sherard. In the com: mon field at Sporle in the fame county, efpecially among wheat. Rev. Mr. Edwards and Rev. Mr. Walts. At Cofiefy and Bixley near Norwich.

Annua. Nl. Julio.

Caulis bipedalis, erectus, ramofiffimus, fcaber. Folia lanccolata, acuminata, integerrima, fcabra. Spicæ terminales, laxæ, formofx, multifloræ. Bractex lancenlatæ, patentes, dentato-pinnatifidre, purpurer. Corolla claufa, flava, apice purpurafcente. Capfula ovata, con preffa. Semina laevigata, flavefcentia, Tritici fimillima, utrinque bina.

pratenge. 3. MELAMPYRUM floribus fecundis lateralibus : conjugationibus remotis, corollis claufis labio porrecto.

Melampyrum pratenfe. Sp.Pl. 843. Lightf: 324. With. 545. Engl. Bot.t. I13. Sibth. 193. Ablot: 135 .

M. fyliaticum. IIndf. zэo. Pio. Monop. Irr. t. S. f. I. Wade Dubl. 163. 
M. fylvaticum flore luteo, five Satureia lutca fylveftris. Raii Syn. *286.

Common Cow-Wheat. Pet. H. Brit. t. $3^{6}$. f. 9 . B. Melampyrum latifolium flore albo, labio inferiore duabus maculis luteis ditincto. Dill. in Raiii Syn. *286.

M. pratenfe. Hudf. 270.

Angl. Common Yellow Cow-wheat.

In nemorofis et dumetis frequens, imprimis folo argillaceo.

Anmea. Fl. Julio, Augufto.

Caulis ramofus, patens, lævis. Folia lanceolata, lævia, interdum bafi dentata. Bractere pinnatifidæe, frepiùs purpuratcentes. Flores ex axilis foliorum et bractearum, folitarii, oppofiti, per paria fecundi. Calycis lacinix lineares, elongatæ. Corolia flava, ore claufo, labio inferiore porrecto, horizontali, palato elevato, bilobo, fulvo. Capfula ovata, mucronata, obliqua. Semina utrinque bina.

Varietatem $\beta$, monente Witheringio, huc retuli.

4. MELAMPYRUM floribus fecundis latera- fylvatilibus : conjugationibus rcmotis, corollis hian- cum. tibus labio deflexo.

Melampyrum fylvaticum. Sp. Pl.843. Lighıf. 325. With. 5 6. Fl. Dan.t. I 45. Angl. Wood Cow-wheat.

In fylvis alpinis rariùs.

On the road fide going from Taymouth to the hermitage, July I 775 . Herl. Lightf. Wick Cliffs, Nir. Swayne. With. Near Middleton in Teerdale. Mr. Robfon.

Annua. Fl. Julio, Augufto.

Habitus precedentis, at fpecies diftincta. Caulis fcabriufculus. Folia parùm latiora, exficcatione minùs atra, omnia plerumque integerrima. Flores duplò minores. Calycis 
Calycis laciniæ bafi latiores. Corolla fulva, fauce hiante, labio deflexo, galeâ elevatá. Capfula reticulato. venofa. Semina utrinque bina, interdum folitaria.

\section{LATHRTEA. G.P\% 305. JuJ. IC2. Gartn. t. 52 .}

Ca7. quadrifidus. Glandula depreffia ad bafin futuræ germinis. Capf. unilocularis, receptaculss fungofis lateralibus. Semina globoia.

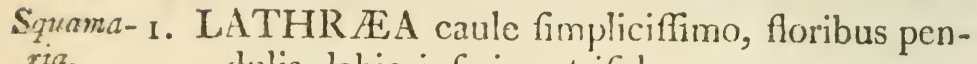
ria. dulis, labio inferiore trifido.

Latbræa Squamaria. SP. Pl. 844. Hudf. 266. With. 5+7. Engl. Bot. t. 50. Fl. Dan. t. I36. Dicks. H. Sicc. firfe. 10. I j. Abbot. 136.

Anblatum. Cord. Fift. 89.

A. Cordi, five Aphyllon. Raii Syn. ${ }^{*} 288$. Baub. Hift. $2.2 .7^{8} 3$.

Squamaria. Riv. Monsp. Irr.t.8g.f. 2.

Dentaria. Matth. Valgr. v.2.313.

D. major. Camer. Epit. 705 .

D. major Matthioli. Ger. em. 1585 .

Orobanche radice dentatâ major. Rudb. Elyj. ข. $2.230 . f \cdot 7$.

Angl. Greater Tooth-wort.

In nemoribus ficcis, frepiùs ad radices Corylorum.

In feveral places in Kent. Ray. In a fhady lane leading from Harefield town to the river, plentifully. Blackfone. In Weftmoreland. Hudf. At Exion, ncar Stamford. Earl of Gaimfborough. Newburgh woods, Yorkthire. Rew. Arcbdeacon Peirfon.

Perennis. Fl. Aprili.

Ihadix parafitica, carnofa, albida, e fquamis cordatis, dense imbricatis. Caules erecti, fimplices, fpithamæi, race6 mofi, 
mofi, carnofi, teretes, purpurei, pubefcentes, aphylli. Bracteæ ovatæ, carnofæ, albidæ. glabræ. Hlores pedicellati, fecundi, nutantes. Calyx magnus, albidus, glaber. Corolla purpurea, tubo albo; labium fuperius bifidum; inferius trifidum. Antheræ hirfutæ. Stigna emarginatum.

* Calyces quinquefidi.

283. PEDICULARIS. G. Pl. 307. Jull. 101. Gertn. t. 53 .

Cal. fubquinquefidus, ventricofus. Cor. galea emarginata, compreffa. Cap). bilocularis, mucronata, obliqua. Semina pauca, angulata, mucronata.

I. PEDICULARIS caule folitario ramofo, calyce paluftris. ovato pilofo coftato bilobo inæqualiter incifo. Pedicularis paluftris. Sp. Pl. 845 . Hudf. 270 , With. 543. Relh. 24J. Sibth. 193. Engl. Bot. t. 399 .

P. paluftris rubra clatior. Raii $S_{y} n$ * ${ }_{2} 8_{4}$. Tall Red Rattle. Pet. H. Brit. t. 36. f. 3. Angl. Marfh Loufewort.

In paludibus, et pratis humidis.

Perennis. Fl. Junio, Julin.

Radix parva, fibrofa. Caulis erectus, pedalis vel fefquipedalis, ramofus, angulatus, pilofus, foliofus. Folia fparfa, rariùs oppofita, bipinnatifida, incifa, fubreroluta, glabra. Flores axillares, folitarii, fubfeffiles, fpeciofi, purpurei. Calyx fubcompreffus, verticaliter bilobus, lobis inæqualiter crenato-incifis, fubfoliofis. Corollæ labium fuperius fornicatum, compreffum, parùm emarginatum; inferius trilobum, lobis rotundatis, ciliatis, centrali minore. Stamina bafin versùs tubi inferta. Antheræ fubtùs acutæ, nec ariftatæ. Stigma fimplex. Capfula ovata, compreffa, obliqua, acuta, bilocularis, diffepimentis e medio valvularum. Semina utrinque 5 yel 6 , vix tunicata.

2. PE- 
[ilvati$c a$.

2. PEDICUIARIS caulibus pluribus finplicibus patentibus, calyce oblongo angulato glab:o inxqualiter quinquelobo incifo.

Pedicularis fyllatica. Sp. $1 \% \delta_{45} . \quad$ Indf. 27 т. Ifill. 548. Rell. 2+1. Sillh. 194. Fingl. Bot. \% 400. Allbot. I36. 1\%. Dall. 1. 225. Pedicularis. Ger. em. $107 \mathrm{I}$. I'. pratenfis rubra vulgaris. Raii $S_{y} u_{\text {. }}{ }^{2} \delta_{+}$. Angl. Pafture Loufcivort.

In pafcuis et cricet is montofis bumidiufculis.

Percmis. F. Junio, Julio,

Radix fubfufiformis. Caules palmares, fimplices, foliofi, angulati, fubpilofi ; centralis erectus; reliqui patentes, fubinde decumbentes. Folia radicalia fimplicia, orata, crenata; caulina ferè priecedentis, at floralia minùs compofita. Flores axillares, folitarii, magni, rofei, formofi. Calyx parim inflatus, glaber, angulis alternis minoribus, margine insequaliter quinquefido, crenato. Corolla kabiuni inferius aqualiter trifido, margine glabro.

\section{ANTIRRIINUM. G. Pl. 309. Juf. I 20.} Garln. t. 53 .

Cal. quinquepartitus. Corolle bafis deorsim prominens, nectarifera. Caff. bilocularis.

* Foliis dilatatis, caulibus laxis.

C'mbalaria.
*. ANTIRRHINUM fohis cordatis quinquelobis alternis glabris, caulibus procumbentibus.

Antirrhinum Cymbalaria. Sp. Pl. $85 \mathrm{I}$. Hudf. 27x. With. 549. Relh. 242. Sibth. 194. Abbot. 137. Curt. Lond. fafc. 1. 1. 45. Engl. Bot. 1.502.

Cymbalaria. Riv. Monop. Iri. t. 86.f. z. Camer. Enit. Sto. Mlattl. Talgr. v. 2. 468.

C. italicas, 
C. italica. Ger. em. 529 .

Linaria hederacco folio glabro, feu Cymbalaria. Dill. in Raii Syn。 282 .

Umbilicus Veneris Officinarum. Lonic. Kromterb. 95 .

Angl. Iry-leaved Snapdragon.

In muris antiquis, ex Italia olim advecta.

On walls about the thores of the Thames, alfo at Oxford, Cambridge, \&ic. On the walls of Windfor Caftle. Rev. Dr. Goodenough.

Perennis. Fl. Main-Novenbri.

Ladix fibrofa. Caules proftrati, radicantes, ramofi, implexi, teretes, glabri, foliofi. Folia alterna, petiolata, cordata, quinqueloba, glabra, fubcarnofa, fubrus purpurafcentia. Flores axillares, pedunculati, folitarii. Calyx glaber. Corolla violacea, palato bilobo, elevato, flavo, pubefcente, calcari brevi, acuto. Cipfula didyma, apice utrinque lacera. Semina rugofiffima.

2. ANTIRRHINUM foliis ovatis alternis, cal-spurium. libus procumbentibus.

Antirrhinum fpurium. Sp. Pl. S $_{5}$ I. H:ktf. 272 : With. 549. Relh. 242. Sibth. 194. Alibot. 137. Curt. Lond. fafc. 3. t. 37. F\%. Dan. t. 9 I 3 .

Linaria Elatine dicta folio fubrotundo. Raii Syn. ${ }_{2} 82$.

Veronica fomina. Matib. I algr. v. 2. 55. Camer. Epit. 462. Fuchj. Hift. 167. Ger. em. 625.

Angl. Round-leaved Fluellin.

In arvis.

About London rare. Curt. In Suffolk fiequent. Hr. Woodward. In Hampthire. Sir J. Banks. At Seething, Norfolk. Mrs. Kett. 


\section{DIDYNAMIA-ANGIOSPERMIA.}

Annua. Fl. Julin-Septembri.

Radix parva. Caules demùm procumbentes, ramofi, teretes, pilofi, foliofi. Folia brevius petiolata, alterna, ovato-fubrotunda, mucronulata, integerrima, utrinque pilofa. Pedunculi axillares, folitarii, uniflori, pilofi, foliis longiores. Flores lutei, galeâ violaccâ, calcari elongato, acuto. Calycis laciniæ ovatæ, acutæ, hirtæ. Varietatem floribus regularibus, quinquefidis, invenit D. Johannes Cullum, Baronettus.

Elatime. 3. ANTIRRHINUM foliis haftatis alternis, caulibus procumbentibus.

Antirrhinum Elatine. Sp. Pl. 85 r. Hudf. 27r. With. 549. Relh. 242. Sibth. 195. Abbot. I 37. Curt. Lond. fafc. 1. t. 46. F7. Dan. t. 426 .

Linaria Elatine dicta folio acuminato. Raï Syn. ${ }_{2}{ }_{2}$.

Elatine. Camer. Epit. 754. Matth. Valgr. v. 2. 360 .

E. altera. Ger. em. 625 .

Angl. Sharp-pointed Fluellin.

\section{In arvis.}

Annua. Fl. Julio-Septembri.

Habitus præcedentis, fed parùm tenuior. Folia haftata, integerrima, pilofa; infima fubrotunda. Pedunculi capillares, glabri. Calycis laciniæ lanceolatæ, pilofie. Corolla lutea, galeâ violaceâ, calcari elongato, attenuato, pallido. Semina valde rugofa.

Variat etiam floribus regularibus.

* * Foliis angufioribus, caulibus erectis.

repens. 4. ANTIRRHINUM foliis linearibus glaucis verticillatis fparfife, caule paniculato, calyce glabro longitudine calcaris.

Antirrhinum repens. Sp.Pl.854. Hudf. 272. 


\section{IItith. 550. Sibth. 414. Dickf. Dr. Pl. 75 . H. Sice. fafe. 17.18 .}

A. monfpefiulanum. Sp. Pl. 854. With. 550 . Linaria odorata Monfpeffulana. Raii Syn. *282. Baub. Hift. $\cdot 3 \cdot 459$ ?

L. cærulea, foliis brevioribus et anguftioribus. Ruii Syn. *282.

L. angititifolia, flore cinereo ftriato. Dill. Eltb. 198. t. $163 . f$. 197 .

L. minor repens et inodora. Vaill. Par. is8. Blueith Sweet Toadflax. Pet. H. Brit. t. 35 . f. 6 .

Angl. Creeping pale-blue Toadflax.

In aggeribus, imprimis folo calcareo, fed rariùs.

In Cornwall near Penryn. Ray. F. Borone. On the chalk hill going down to Henley, Oxfordthire, plentifully.

Perennis. Fl. Julio-Septembri.

Radix repens, albida, latè extenfa. Caules numerofi, erecti, teretes, foliofi, glaberrimi, apice paniculati, bafi fubinde decumbentes. Folia lineari-lanceolata, acuta, integerrima, glaberrima, glauca, erecta, fæpiùs verticillata, quaterna vel quina, fuperiora oppofita vel alterna; interdum omnia alterna vel fparfa. Paniculæ rami alterni, fpicati, multiflori. Flores pedicellati, erecti, interdum fuareolentes. Calycis laciniæ lanceolatæ, glabræ. Corolla cinereo-albida, labio fuperiore purpureo-ftriato, calcari obtufufculo, foliolis calycinis longitudine æquali. Capfula globofa, utrinque fúlcata. Semina angulata, rugofa, nigra.

In Floribus odorem fuavem aromaticum facilè, nec tamen omnibus horis, percepi; variat ut in aliis pro cœli vel temperiei diverfitate.

Antirrhinum repens Dilleuii fide in Sp. Pl. defcripfit Linnæus, nec in herbario habuit, nifi fub nomine $\mathrm{A}$. monfpeffulani, cojus ne quidem varietas eft, fed omninò eadem planta.

Antirrhinum arvenfe nunquam in Angli.i, me fane judice, inventum 
inventum eft. Hudfonus ut videtur Dillenium in Horto Fithamenf male intellexit, qui hanc plantam in "locis" fpontaneis" fe vidiffe dicit, nee tamen in Britamnitis.

Lincrie. j. ANTIRRHINUM foliis lanceolato-linearibus confertis, caule erecto fpicato, calycibus glabris calcari brevioribus.

Antirrhinum Linaria. Sp. Pl. 858. Inudf. 273 . With. 551. Relh. 243. Silth. 195. Curt. liond. fafi. 1. t. 47. Mart. F\%. Ruft. t. 93. Dick. H. Sice. fafi. 7. I2. Fl. Dan. t. 982. Wioadv. Suppl. t. 221. Engl. But. t. 6 ;8.

Linaria. Riv. Monop. Irr. t. \$3.f. I.

L. lutea vulgaris. Raii Sym. ${ }_{2} 81$. Ger. em. 5.50.

Ofyris. Huch. Hitt. $5+5$.

E. Peloria. Linn. An. Aicul. $\%$ i. 55.t. 3. Curt. Lond. fafi. 6. t. 4r. Engl. Bot. t. 260. Angl. Common yellow Toadflix.

In fepibus et ad margines agrorum, folo ficrili.

Perennis. Wl. Junio, Julio.

Radix repens, fublignofa. Caules erecti, fubfimplices, terctes, glabri, foliofi. Folia lincari-lanceolati, integerrima, fparfa, patentia, glabra, viridia, parùm glauca. Spicx terminales, erectx, denfæ, multiflore. Flores pedicellati, magni, fpeciofi, aurei, palato fulvo, villofo, calcari fubulato, acuto, foliolis calýcinis quintupló longiore.

Var. $\beta$ gaudet corollâ regulari, quinçù efidtî, ore contracto, ut in $A$. fipurio aliifque.

minus. 6. ANTIRRHINUM foliw plerifine alternis lanccolatis obtufis pubefecutibu:, caule ramofiftimo patulo, calycibus calcari longioribus. Antirrhinum minus. Sp. Pl. 852. Indf. 272 . With. 55r. lielh. 2+3. Silth. 295. Curte 
Lond. fafc. 5. t. 4I. Dickf. H. Sicc. fafc.6.1\%. Fl. Dan. t. 502.

A. minimum repens. Ger. em. 549 .

A. tertium. Math. Valgr. v. 2.539. Camer. Epit. 922.

Linaria Antirrhinum dicta. Raii Syn. ${ }_{2} 8_{3}$.

L. arvenfis minima. Riv. Monop. Irr. t. 85. $f 2$.
Angl. Leaft Snapdragon.

In arvis arenofis.

Annua, Fl. Junio-Augufto.

Radix parva. Caulis erectus, ramofus, interdum ramo. fiffimus et diffufus, teres, pubefcens, foliofus. Folia alterna, lineari-lanceolata, obtufa, pubefcentia, vifcida ; infima fæepiùs oppofita et fubfpatulata. Pedunculi axillares, uniflori, pubefcentes, longitudine foliorum. Flores parvi. Calycis laciniæ inæquales, fpatulatæ, pilofæ. Corolla violacea, labio inferiore albo, palato flaro, calcari acuto, brevi. Capfula ovata, obtufa, compreffa, apice dehifcens.

$$
\text { *** Corollis ecaudatis. }
$$

* 7 ANTIRRHINUM corollis ecaudatis, foribus majus。 fpicatis, calycibus obtufis villofis.

Antirrhinum majus. Sp. Pl. 859. Hudf. 274. With. 552. Relh. 243. Sibth. 196. Engl. Bot. t. I 29.

Antirrhinum. Riv. Monop. Irr.t.82. f. I. A. purpureum five album. Ger. em. 549 . A. primum. Matth. Valgr.v.2.537. Angl. Great Snapdragon.

In muris antiquis et clivis cretaceis, vix indigena. Moft commos about London, in Kent and the fouthern connties, particularly on the walls of feveral old towns.

Ferennis. Fl. Julio, Augu?to.

VOL. II, 


\section{2}

DIDYNAMIA-ANGIOSPERMIA.

Radix perennis, fed frigoris acrioris impatiens. Caules erecti, fubfimplices, foliofi, teretes, fupernè pilofi. Folia lanceolata, glabra, fparfa. Spica terminalis, denfa, multiflora, bracteolata. Calycis laciniæ ovatæ, obtu$f x$, villof $x$, vifcidæ. Corolla maxima, rofea, palato luteo, calcari brevifimo, obtufo. Capfula ovata, gibba, apice obliqua.

Oronti- 8. ANTIRRHINUM corollis ecaudatis, floribus zaml. fubfpicatis, calycibus digitatis corollâ longioribus.

Antirrhinum Orontium. Sf. Pl. 860. Hudf. 274. With. 552. Curt. Lond. fafc. 4. t. 45. Dickf. H. Sice. falc. I I. 9 .

A. anguftifolium fylveftre. Raii Syn. ${ }^{*} 28_{3}$.

A. minus. Ger. em. 549 .

A. arvenfe. Riv. Monop. Trr. t. 82. f. 2.

A. quartum. Mutth. Iulgr. 2.540. Camer. Epit. 923 .

Angl. Leffer Snapdragon.

In arvis arenofis vel calcarcis.

Annua. Fl. Julio, Angufto.

Radix parva. Caulis crectus, ramofus, teres, pilofus,

Folia alterna, lanceolata, glabriufcula. Spicæ terminales, foliofi, laxi, multiflori. Flores fubfeftiles. Calycis laciniæ lineari-lanceolatæ, inæquales, pilofæ, corollam fuperantes, demùm elongatæ. Corolla carnea, labiis rofeis, palato flavo, calcari brevifimo obtufo. Capfula ovata, gibba, punctata, pilofa, bilocularis, apice nihilominùs poris tribus dehif́cens, fylo perfiftente mucronata.

Earietatem corollâ albâ labiis violaceis mifit D. Forby, Soc. Linn. Socius.

285. SCROPHULARIA. G. Pl. 3I2. Juf. I.I9. Gertn. t. 53 .

Cal. quinquefidus. Cor. fubglobofa, refupinata. Capf. bilocularis.

I. SCRO- 
t. SCROPHULARIA foliis cordatis acutis bafi nodaco trinervibus, caule acutangulo.

Scrophularia nodofa. Sp. Pl.863. Hudf.274. With. 553. Relh. 244. Sibth. 196. Abbot. I 38 .

S. major. Raii Syn. ${ }^{*}{ }_{2} 8$. Ger. em. 7 I6. Scrophularia. Riv. Monop. Irr. t. I07. f. I. Matth. Valgr. v. 2. 474. Camer. Epit. 866. Brown Figwort. Pet. H. Brit. t: 35.f. 9 . Angl. Knotty-rooted Figwort.

In nemorofis et repibus.

Perennis. Fl. Julio.

Radix tủberofa, granulata. Caulis tripedalis, crectus, fimplex, acute quadrangulus, glaber, foliofus. Folia oppofita, petiolata, cordata, acuta, ferrata, glabra, venofa, bafi ad venas laterales excifa et quafi trinervia. Racemus terminalis, erectus, pedunculis oppofitis, dichotomis, bracteolatis. Flores atro-fanguinei. Capfulæ ovatæ, acutæ.

Hujus varietas videtur S. major, caulibus foliis et floribus viridibus, Bobart in Raii Syn. $*_{2} 83$.

¿. SCROPHULARIA foliis cordatis petiolatis aquatiod. decurrentibus obtufis, caule alato.

Scrophularia aquatica. Sp.Pl. 864. Hudf.275. With. 554. Relh. 244. Sibth. 196. Curt. Lond. fafc. 5. t. 44. Fl. Dan. t. 507.

S. aquatica major. Raii Syn. $*_{2} 83$.

Betonica aquatica. Ger.em. 7 I5. Angl. Water Figwort. Water Betony.

In aquolis et ad ripas fluviorum. In Scotiâ rariffimè.

Perennis. Fl. Julio.

Radix fibrofa. Caulis tri-quinquepedalis, angulis alatis. Folia oppofita, petiolata, cordato-ovata, obtufa, ferrata, glabra, venofa, bafi in petiolur decurrentia. RaceQ2. 


\section{.654 DIDYNAMHA-ANGIOSPERMIA.}

mus terminalis, plerumque folitarius, ereetus, pedunculis ut in priore. Flores atro-fanguinci. Capfula fubrotunda, acuminata.

Scoredo- 3. SCROPHULARIA foliis cordatis duplicatonia.

$$
\text { ferratis fubtus tomentofis, racemo foliofo. }
$$

Scrophularia Scorodonia: Sp. Pl. 864. Hudf.

275. With.553. Dick.: H. Sicc. filfc. I5.9.

S. Scorodonix folio. Raii Syn.*283. Morij: fect. $5 \cdot t .35$.

Sage Figwort. Pet. H. Brit. t.35. f. I1.

Angl. Balm-leaved Figwort.

In aquolis et ad fepes rariffime.

Between the port and St. Hilary, Jerfey. Sberard. About St. Ives in Cornwall plentifully. Dill. Hudf.

Perinnis. Fl. Julio, Augufto.

Caulis quadrangulus, pilofus. Folia cordatn-oblonga, acuta, duplicato-ferrata, venofa, fubtùs molliffimè tomentofa, bafi excifo-trinervia. liacemus terninalis, foliofus, pedunculis decompofitis, fuperioribus alternis. Flores pallidiores. Calyx pubefcens. Capfula glabra, fubrotunda, acuminata.

wendis, 4. SCROPHULARIA foliis cordatis duplicatoferratis pubefcentibus, pedunculis axillaribus folitariis dichotomis foliolofis.

Scrophularia vemalis. Sp. I\%. 864. Hudf.275. With. 554. Engl. Bot. t. 567. Fl. Dan. t. $4 \mathrm{II}$.

S. flore liteo. Ger. em.717. Piv. Monop. Irr. t. Iо7.f. 2. Baub. Prodr.i I2. Ang. I I cllow Figwort.

In aquofis et ad fepes rariùs.

About Bury in Suffolk.' Sir T. C. Cullum, Bart. Near Mitcham, Surrcy. Hudf. Rev. Mr. iyfons. 
About Newburgh, Yorkmire. Rer. Archdeacon p'eirfon.

Biennis. Fl. Aprili, Maio.

Radix fibrofa. Caulis quadrangulus, interdum pentagonus, pilofus. Folia oppofita, fæpe terna, petiolata, cordata, acuta, acutè et duplicato-ferrata, venofa, fubtùs pracipuè pilofa. Pedunculi longitudine foliorum, axillares, folitarii, dichotomi, multiflori. Flores conferti. Calyx pubefcens. Corolla ventricofa, flava, ore contracto. Capfula orata, acuta.

286. DIGITALIS. G. Pl. 3І 3. JulJ. I 20. Gertn. t. 53 .

Cal. quinquepartitus. Cor. campanulata, quinquefida, ventricola. Capf. ovata, bilocularis, polyiperma.

I. DIGITALIS foliolis calycinis ovatis acutis, purpucorollis obtufis : labio fuperiore integro, foliis $r \varepsilon a$. pubefcentibus.

Digitalis purpurea. Sp. Pl. 866. Hudf. 275. With. 555. Sibth. 197. Curt. Lond. fafc. I. t. 48. Wl. Dan. t. 74. Woodv. Med. Bot. t. 24. Fuch.j. Hift. 893. Raii Syn. $2_{283}$. Ger. em. 790. Dreves. Bilderb. t. 46.

Digitalis. Riv. Monop. Irr.t. I04.

Campanula fylveftris feu Digitalis. Trag. Hift. 889.

Digitalis, berba. Pbarmac. Lond. Angl. Purple Foxglove.

In pafcuis et ad fepes, folo glareofo vel arenofo, arido,

Biennis. Fl. Junio, Julio.

Radix fibrofa. Caulis erectus, 3 vel 4-pedalis, virgatus, teretiufculus, pubefcens, foliofus. Folia alterna, petiolata, fubdecurrentia, ovata, crenata, rugofa, venofa, Q 3 fubtis 
fubtùs pracipuè pubefcentia. Spica terminalis, erects, multiflora, fpeciofa. Flores nutantes, purpurei; intù albidi, pilofi, fanguineo guttati. Capfula orata, acuta, Semina numerofa, parva.

Variat flore albo, fed rariùs

\section{LINNAEA. G. Pl. 319. JufJ. 2 II.}

Cal. duplex : fructûs diphyllus; floris quinquepartitus, fuperus. Cor. campanulata. Bacca ficca, trilocularis.

borealis. I. LINN鹿A.

Linnæa borealiș. Sp. Pl. 880. Fl. Suec. 2rg, t. I. Fl. Lapp.ed.2. 214 . t. I2.f. 4. Ait. H. Kew. v. 2. 358. Lamarck. Fl. Franc.v.3. 368. Hoffm. Fl. Germ. 221. Fl. Dan. t. 3: Ebrh. Phyt. 5. Tr. of Liml. Soc. v. 3.333. With. 556. Engl. Bot. t. 433.

Linnæa, n. 299. Hall. Hift. v. I. I 3 I.

Campanula ferpyllifolia. Baub.Prodr. 35 . Rudb. Ac7. Suec. Amno I 720, 96. t. I. Angl. Two-flowered Linnæa.

In fylvis petrofis ficcis alpinis.

In an old fir wood at Inglismaldie on the borders of Mearns-Phire. Prof. James Beattie jun.

Perennis. Fl. Maio, Junio.

Radix fibrofa. Caules proftrati, repentes, perennes, lignofi, teretes, foliofi, fubramofi, longiffimi ; juniores pilofi. Fólia oppofita, petiolata, fubrotunda vel ovata, venofa, anticè crenata; fuprà fubpilofa ; fubtùs pallịdiora, nuda. Rami floriferi erecti, palnıares, biflori, parùm foliofi. Pedicelli pilofi, vifcidi, æquales, uniflori. Bracteæ oppofitæ, lanceolatæ. Flores nutantes, albo rubroque variegati. Calyx exterior inferus, diphyllus, rariùs tetraphyllus, foliolis concavis, fubrotundis, pilofis, germen amplectentibus; interior fupefiss, pentaphyllus, foliolis lanccolatis, acutis, æquali- 
bus. Corolla campanulata, tubo gracili, limbo quinquefido, regulari. Stylus filiformi-fubclavatus, declinatus. Stigma obtufum. Bacca ficca, trilocularis. Semina folitaria, vel bina.

"Flores noete fragrantes, odore Spirææ Ulmariæ." Lim.

238. SIBTHORPIA. G. Pl. 320. Juf. 99.

$$
\text { Germ. t. } 55 \text {. }
$$

Cal. quinquepartitus. Cor. quinquefida, irregularis. Stam. per paria approximata. Caps. comprefla, obcordata, bilocularis; diffepinentis tranfverfis.

x. SIBTHORPIA foliis reniformibus fubpeltatis europes. crenatis.

Sibthorpia europæa. Sp. Pl. 880. Hudf. 276. Witb. 556. Dickf. Dr. Pl. 76. Engl. Bot. t. 649 .

S. proftrata. Salifb.Ic. I I. t. 6.

Alfine fpuria pufilla repens, foliis Saxifraga aurex. Raii Syn. 352. Pluk. Pbyt. t. 7.f.6.

Cornwall Pennywort. Pet. H. Brit. t. 6.f. I I. Angl. Cornih Moneywort. Sibthorpia.

In umbrofis humidis, et ad featurigines Cornubie et Devonix.

Plentiful in Cornwall and Devonmire. Prof. J. Sibthorp, M. D.

Perennis. Fl. Julio, Augufto.

Radix fibrofa. Caules proftrati, repentes, ramofi, longiffimi, implexi, filiformes, pilofi, foliofi. Folia alterna, petiolata, horizontalia, reniformia, latè crenata, pilofa. Pedunculi axillares, folitarii, breves, unifori, pilofi. Calyx hifpidus. Corolla luteo-purpurafcens. Stamina brevifima. Stigma peltatum. Semina pauca. 
289. LIMOSELLA. G. Pl. 320. JuJ. 96. Gartn. t. 50.

Cal. quinqucfidus. Cor. quinquefida, fubxquat lis. Stam. per paria approximata. Capfs. ovata, unilocularis, bivalvis, polyfperma.

qquatica. ז. LINIOSELLA.

Limofella aquatica. Sp. Pl. $88 \mathrm{r}$. Hudf. 276 . IVith. 557. Relh. 245. Sibth. 197. Engl. Bot.t. 357 . Fl. Dan. t. 69.

Plantaginclla palutiris. Raii Syn. 278. Rupp. Jen. ed. Hall. 23. t.6.f. 3. Morif. Seet. 15. t. 2.

Sperghula perpufilla lanceatis foliolis. Loef. Pruf. $26 \mathrm{I} .7 .8 \mathrm{r}$. Angl. Mudwort.

In inundatis limofis exficcatis.

Annua. Fl. Julio, Augufto.

Radix fibrofa, ftolonibus repentibus. Folia radicalia, Jongiùs petiolata, erecta, lanceolata, integerrima, glabra. Pedunculi radicales, uniflori, foliis breviores, demùm deflexi. Flores exigui, carnei. Calyx parùm irregularis, acutus, glaber. Corolla tubus ventricofus; limbus quinquefidus, laciniis duabus fuperioribus fæpe inflexis, infimâ anguftiore. Stamina brevia. Germen ovatum, "biloculare." Gertn. Stigna globofum, fubfeffile. Capfula ovata, femibilocularis, diffepimento ad bafin obfoleto. Semina plurima.

$$
\text { * * Calycẹs fubdipbylli. }
$$

290. OROBANCHE. G. Pl. 321. Juff. IOx. Cal. e foliolis duobus, lobatis, lateralibus. Cor. ringens. Caps. unilocularis, bivalvis, polyfperma, Glandula fub bafi germinis. 


\section{* Bracteis folitariis.}

I. OROBANCHE caule fimplici, corollâ inflatâ : major. labii laciniis acutis æqualibus, ftaminibus glabris, ftylo pubefcente.

Orobanche major. Sp. Pl. 882. Hudf. 265. With. 557. Relh. 237. Silth. 191. Curt. Lond. fafc. 4. t. 44. Engl. Bot. t. 42 I. Sutton Tr. of Linn. Soc. v. 4. 175 .

O. major Garyophyllum olens. Raii Syn. ${ }_{2} S S$. nec Bauhini. Angl. Greater Broom-rape.

In dumetis, folo fteriliorc, in Spartio vel Ulice parafitica.

Perennis. Fl. Junio, Julio.

Radix carnofa, fub-bulbofa, parafitica, fquamofa. Caulis fimpliciffimus, erectus, pedalis, carnofus, angulatus, fquamofus, pubefcens, fufcefcens. Spica terminalis, fimplex, multiflora. Bracteæ folitariæ, lanceolatæ, acutæ, fufcx, vel rubiginofx. Flores feffiles, colore trift, purpureo-rubiginofo, inodori. Calycis foliola femibifida, laciniis lanceolatis, acutis, fubæqualibus, colore bractearum. Corolla calyce duplò longior, ventricofa, dorfo carinata ; labio fuperiore integro, margine reflexo, repando; inferiore trificlo, deflexo, laciniis requalibus, acutis, undulatis, fubinde crenatis. Stamina tubo breviora, bafi dilatata, canaliculata, glaberrima, fupernè glandulofo-pubefcentia. Antheræ fubtùs acuminatæ, bilobæ, glabre. Germen fuperum, ovatum, pubefcens. Stylus pubefcens, ftaminibus vix longior. Stigma deflexum, bilobum, obtufum, divaricatum, flavum. Capfula ovata, membranacea. Semina numerofiflima.

2. OROBANCHE caule fimplici, corollâ tubu-elatior. losâ : labii laciniis acutis æuualibus, ftaminibus pubefcentibus, ftylo glabro.

Orobanche elatior. Sutton Tr. of Linn. Soc. v. 4. 178. t. I7. Engl. Bot. t. 568. Angl. Tall Broom-rape. 


\section{6jO DIDYNAMIA-ANGIOSPERMIA:}

In agris et corum marginibus, folo glareofo, haud infrequens. D. Sutlon.

Perennis. Fl. Julio, Augufto.

Habitus pracedentis, fcd elatior, magifque favefcens. Radix Trifolio pratenfi vel Centaure:e Scabiofæe plerumque adhærens. Flores numerofifimi. Calycis foliola anticè bafi connata. Corolla minùs ventricofa, limbo. fimbriato-crifpo; labio fuperiore fubinde emarginato. Stamina tubo fupra bafin inferta, intùs ad medium ufo que pubefcentia, apice glabra. Germen ftylufque glaberrimus. Stigma obcordatum, flavum.

vinor. 3. OROBANCHE caule fimplici, corollâ tubulosâ : labii laciniâ mediâ lobatâ, ftaminibus. ciliatis, ftylo glabro.

Orobanche minor. Engl. Bot. t. 422. Sutlon Tr. of Linn. Soc. v. 4. I TG.

O. flore minore. Dill. in Raii Syn. ${ }_{2} 88$.

Angl. Leffer Broom-rape.

In agris, imprimis ad radices Trifolii pratenfis.

In clover fields in Norfolk very plentifully. Found by Mr. Jacob Rayer in Kent. In clover fields near Crickhowel, Brecknocknire. Rev. Dr. Gooderiough.

Annata? F]. Julio, Augufto.

Prioribus minor, colore pallidè purpurafcens.

Caulis fubflcxuofus. Flores pauciores quam in O. elantiori. Calycis foliola plerumque inæequaliter divifa, interdum integra, bafi diftincta. Corolla minime ventricofa; labio fuperiore fubcrenato ; inferiore trifido, undulato, laciniâ mediâ majori, fæpiùs trilobầ. Stamina ciliata, nec undique pilofa. Stylus glaber. \$tignıa dilatatum, emarginatum, purpureum.

* * Bracteis ternis.

- 4utea. OROBANCHE caule fimplici, bracteis terni carollæ labio fuperiore bifido incifo. 
Orobanche cærulea. Villars. Dauph. v. 2. 406. Engl. Bot. t. 423. Sutton Tr. of Linn. Soc. v. 4.182 .

O. lævis. Lamarck. Fl. Franc. v. 2.32\%. Reicbard. Sy,t.v. $3 \cdot 183$.

O. purpurea. Jacq. Auftr. t. 276 .

O. n. 294. Hall. Hift. v. I. I29.

O. ramofa $\beta$. With. 558 .

O. purpurafcens. Gmel. Syft. 954 .

O. quarta. Lob. Ic. v. 2. 269.

O. fecunda. Cluf. Hift. v. I. 27 I.

O. flore obfoleto majore. Morif. Sect. I2. t. I6. f. 2 .

O. flore majore. Ger. em. I3I2.

Nidus avis flore et caule violaceo-purpureo colore. Goodyer. in Ger. em. 228, ex defer. nec icon.

Angl. Purple Broom-rape.

In pafcuis montofis graminofis maritimis.

At Sheringham, Beefton, and North Reps, Norfolk. Rev. Mr. Sutton. Mr. Skrim/bire.

Perennis. FI. Julio.

Caulis rectus, vix flexuofus, ferè pedalis, minùs pubefcens, fquamifque rarioribus, colore cærulefcenti. Spica pauciflora, laxa, obtufa. Bracteæ ternæ, quarum duæ interiores minores. Calycis foliola connata, bifida, laciniis attenuatis, acutis. Corolla tubulofa, calyce triplò ferè longior, cæruleo-violacea, dorfo carinata; labio fuperiore erecto, bilobo, denticulis intermediis; inferiore trilobo, laciniis acutis, æqualibus, integerrimis; palato albo pubefcente. Stamina filiformia, glabra. Germen gुlabrum. Stylus filiformis, pubefcens. Stigma capitatum, bilobum, flavefcens.

5. OROBANCHE caule ramofo, bracteis ternis, ramoja. corollâ quinquefidâ laciniis obtufis integerrimis. 


\section{7: DIDYNAMIA-ANGIOSPERMIA.}

Orobanche ramofa. Sp. Pl. 882. Hudj. 266. With. 558. Sutton Tr. of Linn. Soc. v. 4. 185. Engl. Bot. t. r 84. Dill. in Raii Syn。*288. Ger. ell. I 3 I 2.

Orobanche. Camer. Epit. $31 \mathrm{I}$. Angl. Branched Broom-rape.

In arvis, folo fertili humidiufculo, ad Cannobis radices parafitica.

In hemp fields at Brome, Norfolk, and at Mettingham, near Beccles, Suffolk. Mr. Woodwark. At Outwell, Norfolk, Rev. Mr. Sutlon. Near Wilbeach, Rev. Mr. Relhan. With. Near Beccles. Sberard.

Annua. Fl. Augufto, Septembri.

Caulis magis vel minùs ${ }^{\lambda}$ ramofus, fubpubefcens, ferè pedalis, parùm fquamofus. Spicæ acutæ, multifloræ. Flores minores quam in præcedentibus, purpureocyanei, tubo flavefcente. Bracteæ ternæ, quarum duæ interiores minores, exterior remotiufcula. Calycis foliala connata, bifida, breviora, laciniis bafi dilatatis, acutis. Corolla tubulofa, bafi demùm ventricofa; labio fuperiore erecto, bilobo, laciniis integerrimis, obtufis; inferiore trilobo, laciniis æqualibus, rotundatis; palato flavefcente, villofo. Stamina bafi fubciliata. Germen globofo-fubquadratum, glabrum. Stylus filiformis, glabriufculus. Stigma retufun, dilatatum, albiỏum. 


\section{Claffis $X V$.}

\section{TETRADYNAMIA.}

\section{Stamina 6, quorum 4 longiora.}

\section{SILICULOSA.}

\section{Pericarpium fubrotundum.}

293. DRABA. Silicula integra, valvis planiufculis, diffepimento parallelis.

292. SUBULARIA. Silic. integra, valvis ovatis, concavis, diffepimento contrariis.

29I. VELLA. Silic. diffépimento exferto, valvulis duplò longiore.

300. ISATIS. Silic. decidua, bivalvis, monofperma.

302. CRAMBE. Silic. decidua, evalvis, monofperma, coriacea.

30r. BUNIAS. Silic. decidua, evalvis, acutè quadrangula.

294. ALYSSUM. Silic fubintegra, marginata, valvulis concavis, diffepimento parallelis.

297. COCHLEARIA. Silic. fubintegra, turgida, rugofa, bivalvis, polyfperma.

298. CORONOPUS. Silic. fubintegra, compreffa, corrugata, cvalvis, difperma.

295. LEPIDIUM. Silic, emarginata, clliptica; valvulis carinatis.

296. THLASPI. Silic. emarginata, obcordata; valvulis marginato-carinatis. 


\section{(644)}

غ99. IBERIS. Silic. emarginata, obcordata. Pđ。 duo extcriora majora.

\section{SÍLIQUOSA.}

Pericarpium longiffimum, polyfpermum.

* Calyx claufus, foliolis longitudinaliter conniventibus. 3I3. RAPHANUS. Siliqua torofa, fubarticulata. 306. ERYS!MUM. Siliqua tetragona.

30\%. CHEIRANTHUS. Germen utrinque glandulâ notatum. Sem. plana.

308. HESPERIS. Glandulie intra ftamina breviora. Petala obliqua.

309. ARABIS. Gland. quatuor, reflexæ. Siliquta linearis, torulofa.

310. TURRITIS. Siliqua ftricta, fubangulata. Cor. erecta.

3 I . BRASSICA. Siliqua teretiufcula. Sem. globofa.

303. DENTARIA. Siliqua elafticè difiliens, valvulis revolutis. Stigma emarginatum.

* Calyx bians, foliolis fupernè difantibus.

304. CARDAMINE. Siliqua elafticè diffiliens, valvulis revolutis. Stigma integrum. Calo fubhians.

305. SISYMBRIUM. Siliqua dehifcens valvulis rectiufculis. Cal. patulus.

312. SINAPIS. Siliqua teretiufcula, diffepimento prominente. Cal. horizontaliter patens. 


\section{XV.TETRADYNAMIA.}

\section{SILICULOSA.}

291. VELLA. G. Pl. 33I. Juf. 24I. Gertn. $t .14$ I.

Silicula diffepimento valvulis duplò longiore, exferto, extùs ovato.

. VELLA foliis pinnatifidis, filiculis pendulis. anmus, Vella annua. Sp. Pl.895. Hudf. 278. With. $5^{64}$.

Nafturtium fylveftre, Erucæ affine. Raii Syr. 304.

N. fylveftre Valentinum. Clus. Hift. v. 2. I 30.

Baze. Hift. ข. 2. 920.

Eruca nafturtio cognata tenuifolia. Ger. em. 24.7.

Valencia Crefs. Pet. H. Brit. t. $50 . f .5$.

Angl. Annual Crefs-rocket.

In arvis arenofís rariùs.

On Salifbury Plain near Stonehenge, Mr. Lawfon. Ray.

Annza. Fl. Junio.

Radix fibrofa, parva. Cotyledones obcordatæ, glabre. Caulis ramofus, foliofus, hifpidus, fetis deflexis. Folia alterna, bipinnatifida, hifpidiufcula. Spicæ terminales, multifloræ. Flores pedicellati. Calyx tubulofus, claufus, foliolis longitudinaliter conniventibus, nitidis, purpureis. Petala obovata, integra, ochroleuca, venis violaceis, unguibus tenuiffimis. Silicula deflexa, elliptica, hif́pida, diffepimento exferto glabro, dilatato. Semina utrinque tria vel quaturor, fubrotunda. 
292. SUBULARIA. G.Pl. 332. JuIJ.240.

Siliculle integra, ovata: valvulis ovatis, concavis, diffepimento contrariis. Stylus filiculâ brevior.

a quatica. I. SUBULARIA.

Subularia aquatica. Sp. Pl. 896. Hudf. $27 \%$. With. 564. Dickf. H. Sicc. fafc. 5. 9. Ligbtf. 337. Fl. Dan. t. 35 .

S. creeta, junci foliis acutis mollibus. Raii Syn。 307 .

Graminifolia aquatica, Thlafpeos capitulis rotundis, fepto medio filiculam dirimente. Pluk. Pbyt.t. I88. f.5.

Gramen junceum Hibernicum, Thlafpeos capitulis Sherardi. Morif. Jęz. 8. t. 10. f. 29. Irith Ruh Crefs. Pet. H. Brit. t. 48. f. 8 . Angl. Awl-wort.

In lacubus alpinis immerfa, folo fabulofo.

In Lough Neagh, Ireland. Sberard. Lough Carran, Scotland; Dr. Hope. Hudf. Loch Tay, Rev. Mr. Stuart. Lightf. In feveral lakes in North Wales. Hudf. Mr. Grifjith, and Mr. Bingley.

\section{Annua. Fl. Julio.}

Herba pufilla, tota cum floribus aquâ immerfa.

Radix fibrofa, alba. Folia fubulata, glabra, radicalia. Scapi foliis duplò longiores, glabri, racemofi. Flores pedicellati, exigui, albi, petalis conniventibus. Silicula elliptica, integra, valvulis navicular:bus, vix carinatis, glabris, diffepimento contrario, pellucido. Semina parva, ovata, compreffa, utrinque fubterna. 


\section{DRABA. G.Pl.333, JufJ.240. \\ Gertn. t. I4I.}

Silicula integra, ovali-oblonga: valvulis planiufculis, diffepimento parallelis. Stylus vix ullus.

ז. DRABA fcapis nudis, petalis bipartitis, foliis werns lanceolatis fubincifis hirtis.

Draba verna. Sp. Pl. 896. Hudf. 278. With. 565. Relh. 246. Sibth. ig8. Curt. Lond. fafc. 1. t. 49. Fl. Dan. t. 983. Engl. Bot. t. 586.

Paronychia vulgaris. Raii Syn.292. Ger. em. 624.

Angl. Common Whitlow-grafs.

In muris, aggeribus, et pafcuis aridis, vulgaris.

Anmua. Fl. Martio, Aprili.

Radix fibrofa, longa. Folia omnia radicalia, lanceolata, integra vel irregulariter dentata, hirta, pilis fimplicibus vel furcatis. Scapi fubpalmares, erecti, fimplices, corymbofo-racemofi, teretes, aphylli, fubpilofi. Calyx patens. Petala alba, femibifida. Silicula elliptica, plana, glabra, polyfperma, ftigmate feffili, perfiftente.

2. DRABA fcapo fubfoliofo, petalis integris, fili-birla. culis lanceolatis, foliis fubdentatis ciliatis pilis fimplicibus.

Draba hirta. Sp. Pl. 897 .

D. ftellata. Dicks. Tr. of Linn. Soc. v. 2. 288. Crypt. fasc. 2. 29. With. 565 .

D. pyrenaica. Fl. Dan: t. I43. nec Linn. Angl. Simple-haired Whitlow-grafs.

In rupibus alpinis Scoticis.

Found on Ben Lawers by Mr. Dickfon, from whom I received a fpecimen. 
Perennis. Fl. Maio, Junio.

Radix caefpitofi. Folia omnia ferè radicalia, lanceolatã, obfoletè dentata vel repanda, ciliata, interdum fubtus pilofit, pilis fimpliciffimis, adfcendentibus. Scapus palmaris, crectus, fimplex, corymbofo-racemofus, teres, lubpilofus, bafin verfus fubmonophyllus, folio radicalibus conformi. Flores parvi, albi. Calyx paten., hirtus. Petala vix emarginata. Silicula Janceolata, pedicello parùm longior, crecta, planiufcula, ftylo breviflimo mucronata, hirta, pilis breviflimis, divaricatis, furcatis, interdum glabra.

Burfa paftoris alpina hirfuta, Baub. Prod. 51, differre videtur foliis caulinis pluribus, palmato-dentatis. Draba ftellata Jacquini plurinis notis a noftrâ ditcrepat, imprimis pilis foliormm ftellatis, filiculis ellipticis, brevibus, ftylo elongato, floribus triplò majoribus.

winana. 3. DRABA foliis caulinis numcrofis incanis, pilis implexis ftellatis, filiculis oblongis obliquis.

Draba incana. Sp.Pl. 897. Hudf. 279. With. 566. Lightf. 338 . Engl. Bot.t. 388 . Fl. Dom. t. I 30 .

Lunaria contorta major. Räi Syn.29I.

Wreathed Crefs. Pet. H. Brit. t. 48. f. 3 .

B. Paronychice fimilis fed major, perennis alpina repens. Raii Syn. 292.

Small Wreath Crers. P'et. H. Brit. t. $48 . f .4$. -1ngi. Twifted-podded Whitlow-grafs.

In rupibus calcareis alpinis.

In Wales, Weftmoreland and Scotland. On the top of Ingleborough. Mr. Woodward.

Eicrnits. Fl. Maio, Junio.

Radix longiffima, ramofa. Herba magnitudine infigniter variabilis, tota incana, pilis brevitlimis, ftellatis, implexis. Caulis fimplex vel fupernè ramofus, teres, undique foliofus. Folia ălterna, feffilia, ovata, integra vel incifo-dentata, nervofa. Flores corymbofo-racemofi, numerofi; albi. Calyx hirtus. Petala emarginata.

Silicula 
Silicula elliptico-oblonga, tortuofa, glabra, ftylo breviffimo mucronata. Pedicelli breviffimi.

4. DRABA caule ramofo, foliis cordatis dentatis maralis. hirtis, filiculis ellipticis obtufis planis.

Draba muralis. Sp. Pl. 897. Huds. 278. With. 566.

D. minima muralis difcoides. Column. Ecpbr. 274. t. 272.

Burfa paftoris major, loculo oblongo. Raii Syn. 292. Baus. Prodr. 50.

Speedwell Crefs. Pet. H. Brit. t. 48, f. 5 .

Angl. Speedwell-leaved Whitlow-grals.

In umbrofis ad latera montium.

In feveral parts of Craven, Yorkfhire. Ray. About

Malham Cove. Ricburdfon. Curt. With. At

Old Malton on walls. Rev: Arcbdeacon Peirfon.

Annua. Fl. Maio.

Radix fibrofa, parva. Caulis a bafi ramofus, foliofus, teres, fcaber, pilis ftellatis. Follia alterna, cordata, amplexicaulia, dentata, hirta, pilis fimplicibus et furcatis. Flores corymbofo-racemofi, numerofi, exigui, albi, racemo fructifero longiffimo, pedicellis patentibus, filiculâ duplò longioribus. Petala obovata, integra. Silicula plana, obovato-elliptica, glabra, ftylo brevifimo.

294. ALYSSUM. G. Pl. 335. デu/. 240. Gertn. t. I 41. Hall. Hift.v. 1. 2 I 2.

Silicula fubintegra, marginata, ftylo mucronata: valvulis concavis, diffepimento parallelis. $F_{i-}$ lamenta duo (in quibufdam) denticulo notata.

*. ALYSSUM caule herbaceo, foliis lanceolatis fativum. fagittatis, filiculis obovatis inflatis.

$\mathrm{R}_{2}$

Alyfum 
Alyfium n. 489. Hall. Hift. v. 1. 212. Alyfon regetum, folis auriculatis acutis. Tourn. $\operatorname{In} f .217$.

Myagrum. Raii Syn. 302. Ger.em.273. M. fativum. Sp. Pl. 894. Hudf. 277. Fl. Dan. t. 1038.

Møenchia fativa. Gmel. Syjt. v. 2.97r. With. 562.

Camelina fativa. Crantz. Auftr. fafc. 1. 17. Preudo-myagrum alterum. Camer. Epit. 902. Sefama. Trag. Hift. 655. Angl. Gold of Pleafure. Pet. H. Brit. t. 48: f. I I.

In agris inter Linum, quandoque et ad vias, vix indigena.

In Hezlington field near York. Sir T. Frankland. Out of St Giles's gates, Norwich, by the road fide.

Annua. Fl. Jumio.

Radix parva. Caulis erectus, fefquipedalis, teres, fubpubefcens, foliofus, apice paniculatus. Folia alterna, lanceolata, obfoletè dentata, fcabriufcula, bafi fagittata, amplexicaulia. Corymbi terminales, multiflori, demùm racemofi, longiflimi. Flores parvi, lutei. Calyx patens. Petala obtufa, integra. Filamenta fimplicia. Siliculæ erectæ, obovatæ, integræ, inflatæ, glabræ, compreffo-marginatæ, ftylo filiculâ dimidio breviore mucronatæ, utrinque polyfpermæ. Semina obovata, vix angulata, neque marginata.

Planta genere obfcura, a Myagris veris, fi quæ alia, diftincta. Cum Alyffis Linnæanis pluribus, filiculâ inflatâ, optimè convenit, quamvis filamenta denticulis non notantur, øuod aliis etiam fpeciebus accidit; neque profectó hæc naturalem præbent differentiam genericam. 
295. LEPIDIUM. G. Pl. 333. JufJ. 241. Gertn. t. I4I.

Silicula emarginata, elliptica, polyfperma : valvulis carinatis, diffepimento contrariis.

I. LEPIDIUM foliis pinnatifidis integerrimis, petratom. petalis calyce brevioribus, filiculis ellipticooblongis.

Lepidium petræum. Sp. Pl. 899. HudJ. 280. IFith.567. Engl. Bot.t. II I. Jacq. Auftr. t. I $3 \mathrm{I}$.

L. Linnæi. Crants. Auftr. fafc. I. 7. t. 2. f. 4,5 .

Nafturtiolum montanum annuum tenuifimè divifum. Raii syn. 304 .

Cardamine pufilla faxatilis montana difcoides. Column. Ecpbr. 274. t. 273 .

Fine Crefs. Pet. H. Brit. t. 50. f. 4 . Angl. Mountain Pepper-wort.

In apricis calcareis Angliæ auftralioris.

On St. Vincent's Rocks, and other places about Briftol. Sherard. Hudf. Dr. Jobn Ford. At Uphill, Somerfethire. Huds. On a limeftone wall near Pembroke. J. Adams, Efq.

Biennis. Fl. Martio, Aprili.

Radix exigua, fibrofa. Caules vix triunciales, patuli, ramofi, foliofi, terctes, fubpubefcentes. Folia alterna, impari-pinnatifida, multijuga, glabra, laciniis ellipticis vel fpatulatis, integerrinis, oppofitis. Corymbi terminales, multiflori, demùm racemofi. Flores parvi, albi, hexandri. Calycis foliola elliptica, obtufa, patula, margine fcariofa. Fetala calyce breviora, vix emarginata. Silicula elliptico-oblonga, compreffa, glabra, obfoletè emarginata, ftigmate feffili, diffepimento contrario, lanceolato. Semina utrinque bina, fubrotunda.
$\mathrm{R}_{3}$
2. IE. 
latifoli- 2. LEPIDIUM foliis ovato-lanceolatis integris zun? ferratis.

Lepidium latifolium. Sp. Pl. 899. Hudf. 279. With. 567. Raii Syn. 304. Engl. Bot. t. 182. Fl. Dan. t. 557 .

L. majus. Cord. Hift. I24.2.

Lepidium. Flbchj. Hift. 484.

Raphanus fylvettris officinarum. Ger. em. 24I. Angl. Broad-leaved Pepper-wort.

In pratis humidis fubfalfis, clivifve maritimis.

In feveral parts of Effex. Ray. Yorkthire. Richardfon. With. Sheringham Cliffs, Norfolk. Mr. Hzimpbrey.

Perennis. Fl. Julio.

Radix ramofa, longiffima. Caules tripedales, erecti, ramofi, foliofi, teretes, glabri, paniculati, multiflori. Folia alterna, ovato-lanceolata, bafi attenuata, medio præcipuè ferrata, glabra, glaucefcentia, acuta. Flores hexandri, parvi, albi. Petala calyce longiora, integra. Silicula elliptica, ftigmate feffili.

zuderale.3. LEPIDIUM floribus diandris apetalis, foliis inferioribus pinnatifidis dentatis; fuperioribus linearibus integerrimis.

Lepidium ruderalc. Sp. Pl. 900. Hudf. 279. With. 568 . Relh. 247. Hl. Dan. t. 84. Nafturtium fylveftre, Ofyridis folio. Raii Syn: 303:

Thlafpi minus. Ger. em. 262.

T. anguftifolium. Fuch. Hij.. 307.

Thlafpidii genus. Trag. Hift. 83 .

Narrow Wild Crefs. Pet. H. Brit. t. 5o.f. I. Angl. Narrow-lcaved Pepper-wort.

In ruderatis maritimis.

At Yarmouth, Cley and L.ynn, Norfolk, plentifully. At Truro, Cornwall, and Maldon, Effex. Kay. Below? 
Below Briftol. With. By the ficle of the Severn above Worcefter. Dr. Stokes.

Biennis. Fl. Junio.

Radix ramofa. Caulis pedalis, erectus, ramofus, foliofus, divaricatus, flexuofus, teres, incanus. Folia carnofa, glabra; inferiora pinnatifida, laciniis anticè dentatis ; fuperiora linearia, obtufa, integerrima, fubrevoluta. Ilores exigui, apetali, diandri. Racemi fructiferi longiffimi. Silicula elliptico-fubrotunda, emarginata, glabra. Semina fubfolitaria, pendula, obovata.

Petala nunquam inveni, nec ftamina plura quam duo; Witheringius fe flores fæepius corollatos, et ftamina interdum quatuor vidiffe memorat, qux et Gouanus \& Scopolius afirmant,

\section{THLASPI, G. Pl. 334. JuJ. 241. Gartu. t. I4I.}

Silicula emarginata, obcordata, polyfperma: valvulis navicularibus, marginato-carinatis.

3. THLASPI filiculis orbiculatis compreffis lavi-arvenfs. bus, foliis oblongis dentatis glabris.

Thlafpi arvenfe. Sp.Pl. 90 r. Hudf. 28 r. With. 568. Relh. 247. Sibth. 199. Curt. Lond. fafc. 6. t. 43. Fl. Dan. t. 793 .

T. Diofcoridis. Raii Syn. 305. Ger. cm. 262. T. fecundun. Niatth. Valgr. v. I. 5 I9. Camer. Epit. 337.

Angt. Penny Crefs. Smooth Mithridate Muftard.

In arvis folo lutofo, fubinde glareofo, rariùs.

In Eflex, Suffolk and Staffordthire. Ray. Oxfordfhire. Rer. Dr. Goodenough. On the hootingground, Norwich. Mr. Koje.

Annua. Fl. Junio, Julio.

Radix parva. Herba glabra. Caulis pedalis, fuperne ramcfus, teres, foliofus. Folia oblonga, dentata, bafi R 4 fagittata, 
fagittata, amplexicaulia. Flores albi, parvi. Petala integra. Silicula maxima, cordato-orbiculata, com» prefla, glabra, polyfperma, margine dilatato latiffimo.

ampef- 2. THLASPI filiculis fubrotundis glandulofo${ }^{A r} e_{p}$ punctatis fupernè marginatis, foliis fagittatis dentatis incanis.

Thlafpi campeftre. Sp. Pl. 902. Hudf. $28 \mathrm{I}$. With. 569. Sibth. I99. Curt. Lond. fafc. 5 . t. 45 .

T. vulgatius, Raii Syn. 305 .

Common Cow-crefs. Pet. H. Brit. t. 50. f. ๆ. B. Thlafpi Vaccariæ folio glabrum. Raï Syn. 305: T. vulgatiffimum. Ger. em. 262, ex icone. Smooth Cow-crefs. Pet. H. Brit. t.50. f. 8 , $\gamma$. Thlafpi hirtum. Hudf. $28 \mathrm{I}$.

Angl. Common Mithridate Muftard.

Inter fegetes.

B. Near Warrington. Mr. D. Turner.

Annua. Fl. Junio.

Heroa magis vel minùs pubefcens, Caulis pedalis, paniculatn-ramofus. Folia fagittata, amplexicaulia, alterna, dentata, quandoque integerrima. Flores exigui, albi. Petala fpatulata, calyce parùm longiora, integra. Silicula fubrotunda, gibba, margine apice latiffimo, emarginata, utrinque glandulofo-punctata, fæpiùs glabra, interdụm pilofa. Semina folitaria.

Birtum. †3. THLASPI filiculis elliptico-oblongis pilofis impunctatis fupernè marginatis, foliis caulinis fagittatis villofis.

Thlafpi hirtum, Sp. Pl: 901 .

T. Vaccariæ incano folio perenne. Raii $S y n_{\text {, }}$ 305. ed. 2. 175 .

T. villofum, captulis hirfutis. Bauh. Prod. 47 .

T, villofum. Matth. Bauh. 430 .

Hoary Crefs, Pot. H. Brit. t. 50. f. Io. 


\section{Angl. Hairy Mithridate Muftard.}

In montofis Cambrobritanniæ et alibi. Raius.

\section{Bicnnis? Fl. Junio.}

" Flores triplò etiam majores quam præcedentis, capfulæ longioręs et hirfutiores." Ita defcripfit Raius, quod exemplaribus in Herbario Linnæeano confervatis apprime refpondet. Hinc fummi viri auctoritatem fervare non poflum quin inter noftrates ftirpes hanc fpeciem lubens enumerem, etfi reverà Thlafpi hirtum Hudfoni nil nifi campeftris varietas fit. Planta Linnæana certo certiùs dignofcitur filiculis magis oblongis, pafìm gibbis, hirfutis, nequaqua:n glandulofo-punctatis.

4. THLASPI filiculis obcordatis, foliis caulinis perfolion fagittato-cordatis amplexicaulibus, caule ra- tum. mofo, ftylo breviffimo.

Thlafpi perfoliatum. Sp Pl.902. Hudf.ed. x. 246. With. 569. Silith. I09. Jacq. Auftr. t. 337 .

T. alpeftre. Hudf. 282. Dickf. H. Sicc. fafc. 6. 5 . T. arvenfe perfoliatum minus. Raii Syn. ed. 2. 176. Baub. Pin. Iо6.

T. arvenfe perfoliatum majus. Baub. Pin. 106. T. perfoliatum minus. Raii Syn. ed 3.305 .

T. alterum mitius rotundifolium, Buriæ pafioris fructu. Column. Ecpler. 278 t. $276 . f .2$. T. cordatum minus, flore albo, infipidum. Barrel. Ic.t. 815 .

T. tertium punilum. Chuf. Hift.v. 2. I3 1 .

T. minus Clufii. Ger. em. 268.

T. rotundifolium. Ger, em. 266. opt.

Sinall Thorow Crefs. Pet. H. Brit, t. 50.f. 12. Angl. Perfoliate Shepherd's Purfe.

In pafcuis calcareis petrofis.

Among the ftone-pits between Witney and Burford, 
ford, Oxfordhire. Bobart. Alio on Burford downs. Sibth.

Annuc. FI. Aprili, Maio.

Radix fibrofa. Caulis undique ramofus, nec niff folo fter rili fimplex, fpithamrus, patens, teretiufculus, ftriatus, glaber, foliofus. Folia glabra, glauca, obfoletè dentata; radicalia petiolata, ovata, obtufa : caulina alterna, amplexicaulia, cordata, fubfagittata, obtufiufcula. Corymbi terminales, parvi, deufi, demùm racemofi, longifimi. Calyx patens, mbicundus. Petala alba, calyce duplò longiora, obtufa, integra. Silicula glabra, obcordata, lobis ftylum breviffinum longè fuperantibus. Stigma capitatum. Scmina utrinque plurimra.

Magnitudine variat, hine duplex apud auctores exftat, ut optimè fufpicatus eft Raius. Syn.ęd.2. I 6 .

Elpeftere 5. THLASPI filiculis obovatis retufis polyfpermis, foliis caulinis fagittatis, caulibus fimplicibus, fiylo porrecto.

Thlarpi alpeftre. Sp. Pl. 903. Eng.t. Bot. t. 8 I. With. 570 .

T. montanum, Hudf.282. With. 57a. Curt. Cat. (in Fl. Lond. v. x.) n. 85.

T. folis Globulariæ. Raii Syn. ed. 2. 155. ed. 3. 305. Baub. Hift. v. 2. 926.

T. montanum fecundum. Ches. Hift. v. 2. I 3 I.

T. albi fupini varietas. Ger. em. 268. f. 2.

'T. præcox. Wulf. in Jacq. Coll. v. 2. I 24. t. 9 ? Arigl. Alpine Shepherd's Purfe.

In pafcuis montofis.

Paftures about the cbbing and flowing well near Settle, Yorkthire (where I alfo have gathered it), and between Settle and Malham. Ray. On. limetione rocks, and about the Lead mincs, at Matlock, Derbythire, growing witls Arenaria vern?, as Mr. Curtis obferved it near Settle. 
Perennis. Fl. Junio, Julio.

Radix longiffima, ramofa, multiceps. Caules plurimi, erectiufculi, fpithamæi, fimplices, vix unquam divifi, teretes, glabri, foliofi. Folia glabra, glauca, integerrima, vix dentata; radicalia numerofa, cæfpitofa, petiolata, ovata, vel obovata, obtufa; caulina alterna, feffilia, fubamplexicaulia, fagittata, acutiufcula. Corymbi ut in præcedente. Petala magnitudine varia, alba. Silicula vix obcordata, fed potiùs obovata, retufa, gibba, ftylo elongato, longè ultra, lobos prominente, mucronata. Semina utrinque plurima.

Siliculæ in Engl. Bot. nimis aliquantulum cordatæ.

6. THLASPI hirfutum, filiculis deltoideo-obcor-Burfadatis, foliis radicalibus pinnatifidis. Thlafpi Burfa-Paftoris. Sp.Pl. 903. Hudf. 283 . With. 571. Relh.248. Sibth.200. Curt. Lond. fafc. I. t. 50 .

Burfa Paftoris. Raii Syn. 306. Ger. em. 276. Matth. Valgr. v. I. 521 .

Paftoria Burfa. Fuchf. Hift. 6 I I.

Sheaperd's Purfe, Pet. H. Brit. t. 49. f. 4-7. Angl. Common Shepherd's Purfe.

In ruderatis, cultis, et ad vias paffim.

Annua. Fl. Martio, Aprili, totoque ferè anno.

Radix fibrofa. Herba hirfuto-fcabra. Caulis ramofus, teres, foliofus. Folia radicalia pinnatifida, dentata ; caulina oblonga, baf cordato-amplexicaulia. Corymbi ut in aliis. Flores albi. Siliculæ glabræ, deltoideoobcordatæ, margine non dilatato, ftylo brevi terminatæ. Semina numerofa.

Variat in folo fterili cretaceo foliis omnibus cauleque fimplicibus. Conf. Pet. $f \cdot 7$ :

\section{COCHLEARIA. G.Pl. 334. Ju/. 240.}

silicula turgida, rugofa, polyfperma: valvulis gibbis, obtufiș. 
- cfirina lis.

I. COCHILEARIA foliis radicalibus fubrctundis caulinis oblongis fublinuatis, filiculis globofis. Cochlearta officinalis. Sp. Fl. 903. Hudf. 283. Wilt. 57x. Engl. Bot. t. 55, H. Wan. t. I35. Woodv. Med. Bol. t. 29.

Cochlcaria. Raii Syn. 302. Bauß. Hifl. ซ.2. 942. Camer. Epit. 27 I.

C. rotundifolia. Ger. ell. $40 \mathrm{r}$.

Garden Scurry-grafs. Pet. H. Brit. t. 49.f. I. C. Cochlearia minor rotundifolia noftras. Ruiii Syn. 303.

\%. C. groenlandica. Wit3. 573. nec Linn.

C. rotundifolia. Dill. in Raii Syn. 302 .

Cochlearia hortenfis, berba. Pbarmac. Lond. Angl. Common Scurvy-grafs.

In littoribus maritimis cœnofss vel petrofis, interdum et in irriguis alpinis.

$\%$ Common on the mountains about Llanberris. Hudf. Mr. Bingley.

Annusa. Fl. Maio.

Herba glabra, fubcarnofa, magnitudine varia. Caulis. angulatus, corymbofo-ramofus, foliofus. Folia radicalia longiùs petiolata, reniformi-fubrotunda, fubdentata vel repanda; caulina feffilia, amplexicaulia, alterna, oblonga, angulata vel finuata. Corymbi terminales, multiflori, demùm racemofi, ebrecteati. Calyx nbtufus, patulus, concavus. Petala obovata, integra, alba. Silicula globofa, ftylo brevifimo coronata, non emarginata, parùm rugofa, obfoletè venofa. Semina utrinque 5 vel 6 .

Var. $\beta$ nondum vidi; $\gamma$ vix differt $a b \alpha$ niff magnitudine minori, ftyloque parum elorgato. Diftincta a C. groenlandica Linn.

- molica. 2. COCHLEARIA foliis radicalibus ovatis integris; caulinis lanceolatis dentatis, filiculis. ellipticis reticulato-yenofis.

Cochlearia 
Cochlearia anglica. Sp. Pl. 903. Hudj. 284. With. 574. Engl. Bot. t. 552. Fl. Dan。 t. 329 .

C. folio finuato. Raii Syn. 303 .

C. britannica. Dod.Pempt.594. Ger. em.40I. Dalech. Hift. I 320.

Sea Scurvy-grafs. Pet. H. Brit. t. 49. f. 2. Angl. Englin Scurvy-grafs.

In littoribus maritimis cœnofis.

Annua. Fl. Maio.

INerba magnitudine et foliorum formâ variabilis, glabrä, fubcarnofa. Præcedente plerumque minor. Folia radicalia longè petiolata, ovata, integra, rariùs fubdentata, vel repanda; caulina lanceolata, nec ovata, amplexicaulia, dentata, vix finuata. Flores præcedentis. Silicula duplò major, elliptica, turgida, et fubinde ferè globofa, venis numerofis, prominentibus, reticulatocorrugata, ftylo longiufculo coronata.

-3. COCHLEARIA foliis omnibus deltoideis pe-danica. tiolatis, filiculis ellipticis reticulato-venofis.

Cochlearia danica. Sp. Pl. 903. Hudf. 284. With. 573. Fl. Dan. t. I00.

C. marina, folio angulofo parvo. Raii Syn. 303 . Thlarpi hederaceum. Lob. 1c. 6:5. Ger. em.

27 I. Baub. Hifl. v. 2.933.

Ivy Scurvy-grafs. Pet. H. Brit. t. 49. $f \cdot 3$. Angl. Danilh Scurvy-grafs.

In maritimis ccenofis rariùs.

In the ifle of Walney, Lancafhire. Ray. Near Llanbadrick church, Anglefea. Mr. Lbwyd. At Wells, Norfolk. Mr. Crowe.

Annua. Fl. Maio, Junio.

Præcedentibus minor. Caules palmares, parùm ramofi. Folia omnia ferè petiolata, magnitudine æqualia, et quafi uniformia, deltoidea, triloba, quinqueloba, fubdentat2. 
dentata. Corymbi vix in racemum clongati. Fiores albi, parvi. Silicula omninò elliptiea, minùs turgida, reticulato-renofa, ftylo breviore coronata. Semina utrinque fex.

- Armora- 4. COCHLEARIA foilis radicalibus oblongis crecia. natis; caulinis lanceolatis incifis integrifve. Cochlearia Arimoracia. Sp. Pl. 904. Hudf. 284. With. 575. Relh. 249. Sibth. 200. Hoodv. Med. Bot. t. I 50 :

Ràptianus rufticanus. Räi Syn. 30r. Ger.ent. 24I:

R. fylvefiris. Flubf. Hift. 660.

R. major, feu Armoracia radix. Tras. Hift. 734. Broad Horfe-radith. P'et. H. Brit. t. 49.f. I I. B. Jagged Horfe-radioh. Pet. H. Brit. t. 49. f. I 2. Raphanus rufticanus, radix. Pbarmar. Lond. Angl. Horfe-radioh.

In aquofis, pracipuè fubalpinis.

About Alnwick, and other parts of Northumberland. Ray. Upon the banks of Skipton-beck, and cliewhere in Craven. Dr. Lifter. Common in wafte ground from the outcafts of gardens.

Percnits. Fl. Maio.

Radix alba, teres, longiffirna, vivacifima, acris. Caules

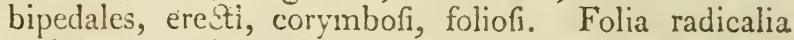
petiolata; maxima, oblonga, crenata, interdum pirinatifida, venofa; caulina fefflilia, lanceolata, incifa vel in. tegerrima. Flores albi. Silicula elliptica, ftylo breviffimo, ftigmate maximo. Fructus plerumque abortit.

\subsection{CORONOPUS. Gertn. t. I42.}

Silicula renifornis, compreflä, corriggata, loculis cvalvibus, monofpermis.

- Ruellii. 1. CORONOPUS filiculis integris criftato-muricatis, ftylo porrecto, corymbis paucifloris. 
Coronopus Ruellii. Gertn. v. I. 293. t. I4̨2. f. 5. Ger. em. 427. Dalech. Hift.670. C. n. 502. Hall. Hift. 2.1 .217$.

Cochlearia Coronopus. Sp.Pl. yo4. Hudf. 284. With. 574. Relh. 248. Sibth. 200. Fl. Dan. t. 202. Mart. Fl. Ruft. t. 92 .

Nafturtium fupinum, capfulis verrucofis. Raii Syn. 304.

PCudambrofia. Camer. Epit. 596.

Wart or Swine's-crefs. Pet. H. Brit. t. $50 . f .6$. Angl. Common Wart-crefs. Swine's Crefs.

In ruderatis et ad vias frequens.

Annua. Fl. Junio-Augufto.

Caules ramofi, omminò proftrati, depreffi, foliofi, glabri. Folia alterna, glabra, fubglaucefcentia, pinnatifida, laciniis fæpiùs anticè dentato-pectinatis. Corymbi oppofitifolii, feffiles, breves, pauciflori, demùm racemofi. Flores exigui, albi. Silicula reniformis, compreffa, corrugata, margine criftato-muricata, apice nequaquam emarginata, fed ftylo porrecto, pyramidato, brevi, mucronata; loculamenta hemifphrerica, coriacea, non dehifcentia, monofperma.

2. CORONOPUS filiculis emarginatis didymis didyma. reticulato - rugofis, ftylo obfoleto, corymbis multifloris.

Lepidium didymum. Mant. 92. Dick/. Dr. Pl. I. With. 567 . Engl. Bot. t. 248 .

L. anglicum. IHudf. 280.

Angl. Leffer Wart-crefs. Procumbent Pepperwort.

In ruderatis Angliæ occidentalis.

At Dale near Milford Haven.. J. Adams, Effq. About Exeter. Mr. Nevebery. About Truro and Penryn in Cornwall. Hudj.

Annua. Fl. Julio, 
Præcedente minor. Caules procumbentes, teretes, pilofi, ramofi, foliof. Folia pinnatifida, laciniis anticè dentatis. Corymbi fubopponitifolii, vel fubinde axillares, multiffori, demum in racenum longifimum extenfr. Flores exigui, petalis albis, minutis. Silicula didyma, utrinque emarginata, reticulato-rugofa, nec muricata, ftylo exiguo, lobis breviore, terminata. Stamina 2 vel 4 , vix plura.

\section{IBERIS: G. Pl. 335. JuJ. 240. Gortr. t. 141 .}

Cor. irregularis: petalis duobus exterioribus majoribus. Silicula polyfperma, emarginata.

mara. I. IBERIS herbacea, foliis lanceolatis acutis fubdentatis, floribus fpicatis.

lberis amara. Sp.Pl. go6. Hudf.285. Witb. 575: Sibtb. 201. Engl. Bot. t. 52 .

Thlatpi amarum. Ger.em. 263.

T. umbellatum arvenfe amarum. Bauh. Hift. v. 2. 925 .

Thlappidium foliis nafturtii. Riv. Tetrap. Irr t. 108 .

Angl. Bitter Candy-tuft.

In arvis cretaccis rariùs.

About Henley and other places in Oxfordfhire: Hitlf. About Wallingford, Berkfhire, plentifully, and undoubtedly wild.

Annua. Fl. Julio.

Herba glabra, amara. Caules diffufi, ramofi, foliofi: Folia alterna, lanceolata, fubcarnofa, fupernè dilatata, et fæpiùs dentata. Corymbi fpicati, multiflori. Flores nivei, fpeciofi. Silicula acutè emarginata, valvulis latè carinatis, diffepimento contrario.

mudicau-2. IBERIS herbacea, foliis lyrato-finuatis, caule lis. centrali nudo fimplici; lateralibus foliofis. 
Iberis nudicaulis. Sp. Il. 907. Hudf. 285. With. 575. Relh. 249. Curt. Lond. fac6. 6. t. 42. Dickf. H. Sicc. fafc. I. 10. Engl. Boto t. 327 .

Nanturtium petræum. Raï Syn.303.

Burfa paftoria minima. Ger. em. 276.

Shepherds Crefs. Pet. H. Brit. t. 50. f. 2. Angl. Naked-ftalked Candy-tuft.

In glarcofis fterilibus.

About London, Norwich and Bury. Ray and Engl. Bot. In Worcefterhirc and Cumberland. With. In old quarries on Crooks-moor ncar Sheffield. $M r$. Salt. Cornfields near Eafingwold, Yorkfhire. Rev. Arcbdeacion Peirfon.

\section{Annua. Fl. Maio.}

Caulis centralis crectus, ftrictus, fimplex, omninò aphyllus; laterales fæpiùs plures, adfcendentes, magis vel minus foliofi. Folia radicalia depreffi, tyrato-pinnatifida, margine fubinde pilofa. Corymbi capitati, demùm racemofi. Flores parvi, albi. Silicula obcordata, obtufa, emarginata, fupernè dilatato-carinata, ftylo breviffimo coronata.

Synonyma cautiùs eruenda, ob fummam ejus cum Lepidio nudicauli affinitatem.

\section{3co. ISATIS. G. Pl. 344. Juf. 242. Gartn. t. 142 .}

Silicula lanceolata, unilocularis, monofperma, decidua, bivalvis : valvulis navicularibus.

7. ISATIS foliis radicalibus crenatis, caulinis fa-tinctoria, gittatis, filiculis obtufufculis glabris.

Ifatis tinctoria. $\mathrm{Sp}_{\mathrm{p}} \mathrm{Pl}$. 936. Hudf. 299. With. 564. Relh. 259. Mart. Fl. Rujt. t. 4I. Engl. Bot. t. 97 .

VoI. II. 
I. fylieftris, Fucl.s. Irift. 333. Mattb. Valgr. v. I. 582 . Camer. Epit. 410.

Glaftum lativum. Raii Syn. 4Io. Ger.em.49I. Waidte. Schreb. Monogr. l. I-3. Angl. Woad.

In arvis et ad margines agrorum, fed rarius.

New Barnes near Ely. Relh. Near Durham. Mr. Robfon.

Biennis. Fl. Julio.

Caulis teres, glaber, foliofus, paniculatus. Folia glauca; radicalia petiolata, lanceolata, crenata; caulina alterna, amplexicaulia, fagittata. Flores aurei. Calyx coloratus. Silicula pendula, fufca, nitida, glabra, obtufuifcula, valvulis intus fubcrofis. Semen ellipticum.

301. BUNIAS. G.Pl.343. Juf.241. Gertn.t.142. Cakile. Gartn. t. I4I.

Silicula decidua, tetraëdra, angulis inæqualibus, acutis, non dchifcens.

Cakile. 1. BUNLAS filiculis ovatis ancipitibus lævibus monofpermis, foliis carnofis.

Bunias Cakile. Sp. Pl. 936 . Hudf. 298. With. 562. Engl. But. t. 23 I.

Cakile Serapionis. Germ. v. 2. 287. t. I4I. Lab. Ic. $223^{\circ}$.

C. quibufdam, aliis Eruca marina \& Raphanus: marinus. Raii Syn. 307.

Eruca marina. Ger. em. 248. Angl. Sca Rocket. Pel. H. Brit. t. 46. f. 6.

In maritimis arenofis frequens.

Annua. Fl. Junio-Septembri.

Herba levis, carnofa, fubglauca. Caulis ramofiffimus, patenti-decumbens, tortuofus, flexuofus, teres. Folia alterna, dentato-pinnatilicla." Flores dilutè purpurei, ormofi. Calyx bafi gibbofus. Silicula fubfufca, glabra. 


\section{TETRADYNANIA_SILICULOSA。 695}

302. CRAMBE. G. Pl. 344. JuJ. 242 .

Gartn. t. 142 .

Silicula coriacea, globofa, evalvis, decidua, monofperma. Filamenta quatuor longiora bifurca, altero apice antherifera.

I. CRAMBE foliis finuatis undulatis glaucis cau-maritileque glabris.

Crambe maritima. Sp. Pl. 937. Hudf. 299. With. 563. Fl. Dan. t. 3I6.

C. maritima Brafficæ folio. Raii Syn. 307 .

Braffica marina anglica. Ger. em. 315 .

B. monofpermos anglica. Bauh. Hift. v. 2.830。 Sea Grape Colewort. Pet. H. Brit. t. 48. f. I2. Angl. Sea Kalc.

In maritimis arenofis.

Perennis. Fl. Maio, Junio.

Radix multiceps. Herba lævis, glauca, fubcarnofa. Caulis bipedalis, ramofus. Folia alterna, petiolata, ellipticooblonga, vel fubrotunda, undulata, finuata, dentata. Paniculæ terminales, thyrfoidex, multifloræ. Flores albi. Silicula carnofa, globofa, læviffma. Stigma feffile, peltatum. 


\section{SILIQUOSA.}

\section{DENTARIA. G. Pl. 33\%. JiUJ.239.}

Siliqua elafticè diffiliens, valuulis revolutis, diffèpimento brevioribus. Stigma emarginatum. Cal. longitudinaliter connivens.

bullife- 1. DENTARIA foliis inferioribus pimnatis : fum$r a$. mis fimplicibus.

Dentaria bulbifcra. Sp. Pl. 912. Fudf. $2 S_{5}$. IVith. 576. Engl. Dot. t. 309. IT. Dan. t. 36 r. Ger.em.984. Lol. Lc. 687.

D. quarta baccifcra. Cluf. Hi/l. v.2. I21. Corallowits alia fpecics. Cord. Hifl. I5 1. 2. Angl. Bulbiferous Coral-wort.

In umbrofis raritis.

Near Mayfield, Suflix. Parkinfon. Old Park Wood at Harefield. Blackft. Woods between Bcconsfield and Wickham, plentifully. Hudf.

Perennis. Fl. Aprili, Maio.

Radix repens, dentata, carnnfa, albida. Caules crecti, fefquipedales, fimplices, foliofi, bafi nudi. Folia alterna, glabra, ferrata ; infcriora impari-pinnata, foliolis fubfeptenis; fuperiora fimplicia, in axillis bulbifera. Bulbi fquamofi, atropurpurei, decidui, ad novain propagandam progcnicun. Corymbus terminalis, folitarius. Flores nagnini, dilutè purpurei. Stigna capitatum, obtufum, emarginatum. Siliqua plerumque abortit.

304. CARDAMINE. G. Pl. 338. Ju/f. 239. Gertn. t. 143 .

Siliqua claftice diffitiens, valvulis revolutis, diffepimento 
pimento xqualibus. Stigma integrum. Cal. fubhians. Glandula utrinque folitaria inter ftannina breviora et calycem.

* Foliis fimplicibus.

1. CARDAMINE foliis fimplicibus ovatis inte- bplliaigerrimis petiolo triplò brevioribus.

Cardamine bellidifolia. Sp.Pl.gז3. Fl. Lapp. ed.2. 222.t.9. f. 2. Witb. 577. Fl. Dan.

t. 20. Jale. Mijc. ¿. I. I4.8. t. I 7.f. 2. Angl. Daify-leaved Ladies'-fmock.

In graminofis irriguis excelfis alpinis.

Gathered wild in Scotland by Mr. Milne. With.

Perennis. Fl. Augulto.

Radix parva, fublignofa, multiceps. Caules vix biunciales, erecti, fimplices, paucifolii, glabri. Folia ovata, integerrima, glabra; radicalia longiffimè petivlata; caulina plerumque ferè feffilia. Corymbus terminalis, pauciflorus. Petala alba, erecta, calyce dupló longiora. Siliqua linearis, obtufa, glabra.

$$
\text { * Foliis pimatis. }
$$

2. CARDAMINE foliis pinnatis: foliolis lan-impa-ccolatis incifis integrifie, ftipulis ciliatis. fulia. 
Derbyfhire, and in many parts of Weftmoreland, Cumberland, \&c.

Annua. Fl. Maio, Junio.

Radix parva. Caulis erectus, fefquipedalis, foliofus, $f x-$ piùs ramofus, fubflexuofus, angulatus, glaber. Folia alterna, impari-pinnata, multijuga ; foliolis lanceolatis, plerumque incifis, glabris, pallidis. Stipulæ amplexicaules, ciliatæ. Flores exigui, albi, interdum apetali. Racemi fructiferi longiffini, multifliquofi. Siliqua elaftice diffiliens, ad feminna latè fpargenda.

-birfutz. 3. CARDAMINE foliis pinnatis exnipulatis: foliolis rotundato-oblongis incifis petiolatis.

Cardamine hirfuta. Sp. Pl. 915. Hudf. 295. With. 578. Sibth. 205. Curt. Lond. far c. 4 . t. 48. Lightf. 348. Engl. Bot. t. 492.

C. flexuofa. With. 578 .

C. parviflora. Lighif. i 104. With.ed.2.686.

C. impatiens. Fl. Dan. t. 735 .

C. impatiens altera hirfutior. Raii Syn. 300.

Sifymbrium aquaticum alterum. Camer. Epit. 270.

IIaimy Ciefs. Pet. H. Brit. t. $47 \cdot f \cdot 4$.

Angl. Hairy Ladies'-finock.

In ruderatis et cultis, umbrofis, humidis, frequens. Anmua. Y]. Martio-Junio.

fiadix fibrofa, alba. Herba magnitudine varia, magiş vel minus hirfuta. Caulis ramolus, angulatus, foliofus: Folia impari-pinnata, foliolis petiolatis, quandoque alternis, elliptico-fabrotundis, incifis. Stipulæe nullæ. Flores albi, parri, interdum tetrandri. Siliqua angufta, pilofa.

C. parvifora Linu. noncum in Britanniâ inventa eft. Dignofcitur filiquâ latione, foliolis feffilibus, lanccolatis, integrịs, glabris. 
4. CARDAMINE foliis pinnatis: foliolis radica-pratenfis. libus fubrotundis dentatis; caulinis lanceolatis.

Cardamine pratenfis. Sp. Pl.915. Hudf. 294. With. 579. Relh. 255. Sibth. 205. Curt. Lond. fafe. 3. t. 40. Mart. Fl. Ruift. t.95. Woodr. Med. Bot.t. 3c. Fl. Dan. t. 1039.

Cardamine. Raii Syn. 299. Ger. em. 259.

Nafturtium agrefte. Fuch/. Hift. 325 .

N. pratenfe. Trag. Hift. 83 .

Hiberis. Fucles. Le. I 85 .

Cardamine, flos. Pbarmac. Lond. Angl. Meadow Ladies'-fmock. Cuckow Flower.

In pratis et pafcuis humidiufculis vulgaris.

Perennis. Fl. Aprili, Maio.

Radix tuberofa, fubdentata. Caulis erectus, ftrictus, pecialis, fimplex. Folia pinnata; radicalia longiùs petiolata, fublyrata, foliolis rotundatis, dentatis, fubhirfutis; caulina ferè feffilia, alterna, foliolis lanceolatis, glabris, canaliculatis, plerumque integerrimis. Corymbus terminalis, fpeciofus. Flores magni, purpurafcentes, frpè albi.

Folia radicalia gemmipara interdum vidi in umbrofis, unde affinitatem quandam cum Dentariis fufpicatus fum. Hanc confirmant radicis ftructura, ftylus elongatus, forumque facies et color.

5. CARDAMINE foliis pinnatis: foliolis radi-amara. calibus fubrotundis; caulinis dentato-angulatis, caule bafi radicante.

Cardamine amara. Sp. Pl. 915. Hudf. 294. With. 580. Sibth. 206. Curt. Lond. fafc.3. t. 39 .

C. flore majore clation. Pạii Syn. 299 . Bitter Cress. Pet. H. Brit. t. 47.f. r. Angl. Bitter Ladies'-fmock.

54 
In aquofis umbrofis et ad rivulos, miniss frequens.

In feveral places about London. Iiudf. On the banks of the Thames between Kew and Mortlake. Rev. Dr. Goadenough. In King-freet meadows, Norwich.

Perennis. Fl. Aprili, Maio.

Radix dentata. Caules bafi fæpiùs decumbentes et radicantes. Folia ferè glabra ; radicalia foliolis fubrotundis; caulina elliptico-oblongis, repandis, dentatis. Flores albi. Antheræ violaceæ. Siliqua, monente Curtifio, obliqua.

305. SISYMBRIUM. G.Pl. 338. Juj. 239.

Siliqua dehifcens valvulis rectiufculis. Cul. patens. Cor. patens.

Naffur- I. SISYMBRIUM filiquis declinatis, foliis pintium. natis: foliolis cordato-fubrotundis.

Sifymbrium Nafturtium. Sp. Pl.916. Hudf. 296. With. 5So. Relh. 256. Sibth. 206. Abbot. I 43 . Curt. Lond. falc. 6. t. 44. Iroodv. Mled. Bot. t. 48. Fi. Dan. t. 690.

S. Carlamine, feu Nafturtium aquaticum. Raii Syn. 300.

S. Cardamine. Fuch.j. Hijt. 723 .

Nafturtium aquaticum, five Cratevæ Sium. Ger. em. 257 .

3. N. aquaticum, foliis minoribus, præcocius. Raii Syn. 301 .

Early Water Crefs. Pet. H. Brit. t. $47 \cdot f \cdot 3 \cdot$

$\%$. Nafturtium aquaticum, pinnulis paucioribens. Dill. in Räii Syn. $30 \mathrm{r}$.

Nafurtium aquaticum, herba recens. Pharmac. Lond.

Angl. Water Crels.

In rivulis, picinis, et ad fcaturigines frequens. 
Perennis. Fl. Junio, Julio.

Radix fibrofa. Caules declinati, vel natantes, baf radicantes. Folia alterna, lyrato-pinnata, glabra, lucida, dentato-fubrepanda ; inferiora foliolis rotundioribus et ferè cordatis. Flores albi. Siliquxe breves, pedicellis patentiffimis, apice fursùm recurvæ. Stigma fubfeffile.

2. SISYMBRIUM filiquis declinatis, foliis pin-fylefefte. natis : foliolis lanceolatis incifo-ferratis. Sifymbrium fylveftre. SP. Pl. 9 I6. Hudf. 296. With. 58r. Relh. 256. Sibth. 206. Ab. bot. I 43. Curt. Lond. fufc. 3. t. $4 \mathrm{I}$.

Eruca aquatica. Raii Syn. 297. Ger. em. 248. E. fylveftris. Fuchf. Hift. 263 .

Water Rocket. Pet. H. Brit. t. 46.f. 5 . Angl. Creeping Water Rocket.

In paluftribus et ad ripas fluviorum, folo glarcofo.' In Tothill fields, and other places about the Thames. Hudf. Curt. On Bungay Common, Suffolk. Mr. Woodward. Below Leeds, Rev. Mr. Wood ; and near Worcefter, Dr. Stokes ; With. Bedfordhire frequent. Abbot.

Perennis. Fl. Junio-Septembri.

Radix valdè repens. Caules erecti, foliofi, flexuofi, an gulati, fulcati, fcabriufculi, fubpaniculati. Folia alterna, pinnata, glabra ; inferiora foliolis decurrentibus, elliptico-oblongis, dentatis; fuperiora anguftioribns, fubpetiolatis, incifo-ferratis. Petioli canaliculati. Flores aurei. Racemi denùm longiffimi, flexuofi. Stylus parùm elongatus. Siliqua brevis, plerumque abortiva.

3. SISYMBRIUM filiquis declinatis turgidis, fo-terrefte. liis pinnatifidis inæqualiter dentatis, radice fimplici, petalis calyce brevioribus.

Sifymbrium terrettre. Curt. Lond. fajc. 5. t. 49. With. 582. Sibth. 207. Abbut. 143.

S. paluftre, Pollich. थ. 230.

S. amphi- 
S. amphibium a. Hudf. 296.

Raphanus aquaticus, foliis in profundas lacinias divifis. Bant?. Prodr. 38. Dill. in Raii Syn. 301. Fl. Dan.t.931.

Small Jagged Water Radifh. Pet. H. Brit. t. $49 . f .9$.

Angl. Annual Water Rocket.

In inundatis, et ad foffarum margines.

P'entiful about London. Curt. Bungay Common. Mr. Wodward. Bedfordhire, but rare. Abbot. Oxfordhire. Sibth. On the banks of the Cam, Ine of Ely. Rev. Dr. Goodenough.

Annua. Fl. Junio-Septembri.

Radix fimplex, fufiformis, parva. Caulis fæpiùs ereêus, ramofus, pedalis, foliofus, fulcatus, glaber. Folia alterna, lyrato-pinnatifida, glabra, inæqualitèr et obtusè dentato-ferrata. Flores exigui, flavi, petalis calyce brevionibus, fubinde emarginatis. Racemi fructiferi longiffimi. Siliquæ omnes ferè fertiles, horizontaliter patentes, fubincurræ, breves, turgidæ, obtufæ, læves, polyfpermæ, ftylo brevifimo.

Hunc fpeciem, a Linnæo forfitan ignctam, cum fequente confudit Hudfonus.

amploibi-4. SISYMBRIUM filiquis declinatis pedicellatis, sim. foliis oblongis pinnatifidis ferratifve, petalis calyce longioribus.

Sifymbrium amphibium, Sp. Pl. gI \%. With. 581. Relh. 257. Siblh. 207. Albbot. 143. Fl. Dan. t. 984 .

S. amphibium B. Hudf. 296 , ct fortè $\gamma .297$. Radicula fylicftris feu paluftris. Raii Syn. 30 r. Raphanus aquaticus alter. Bauh. Prodr. $3^{3}$. R. aquaticus. Ger.em. 240.

Broad Water Radifh. Pet. H. Brit. t. 49. f. 8 , Great Jagged Water Radin, Ilid. f. Io. 
Angl. Great Water Rocket or Radirh.

In fluviis et rivis, quandoque ad ripas rarò inundatas.

Perennis. Fl. Junio-Augufto.

Radix fibrofa. Caules elongati, radicantes, fubflexuofi, foliofi, fulcati, parùm ramofi. Folia alterna, oblonga, vel ferrata, vel pinnatifida; fuperiora ferè integerrima; radicalia petiolata; et, cum extra aquas crefcunt, fubinde pubefcentia. Flores lutei, petalis calyce longioribus. Germen pedicellatem, globofum. Siliquæ breviffimæ, ftylo elongato terminatæ.

5. SISYMBRIUM filiquis erectis, foliis glabris tenuifofubintegerrimis pinnatifidis bipinnatifidifque : lium? fupremis integris.

Sifymbrium tenuifolium. Sp. Pl.917. Engl. Bot. t. 525 .

Braffica muralis. Hudf. 290. With. 592. Curt. Lind. faf c. 3.t. 38 .

B. Erucaftum. Hudf.ed. I. 253 .

Eruca fylveftris. Paii Syn. 296. Ger. en. 246. E. fativa. Fuch. Hil. 262.

E, tenuifolia perennis, flore luteo. Baub. Hijt. ข. 2. $86 \mathrm{I}$.

E. n. 46r. Hull. Hift. v. I. 200.

Angl. Wall Rocket. Pet. H. Brit. t. 46. f. 8.

In muris antiquis, et rudcribus.

About London and Weltminfter, Windior, Cher. ter, Briftol, Yarmouth, and other old towns.

Perennis. Fl. Julio ufque ad Oetobrem.

Padix fuffiformis, albida, fublignofa. Caulis ramofiffinus, fefquipedalis, foliofus, teres, levis, glaucus, interdum pilis raris confperfus. Folia fubcarnofa, lævia, glaucefcentia, jommatifida, quandoque bipinnatifida ; fumma frepius indivifa; omnia margine integerrima, id rafiffimè dentata, Flores magni, citrini, fpeciof, whe and 
acri. Calyx patens, apice plerumque hirtus. Siliqua erecta, oblonga, glabra, teres, lincé utringue elevata. Semina elliptica, compretia. Stylus breris.-Herba fapore et odore acris.

monen $\int$. 6. SISYMBRIUM filiquis erectiufulis, foliis pinnatifidis fubpilofis, caulibus finplicifimis nudiutculis glabris.

Sifymbrium monenfe. Sp. Pl. ed. r. 658 . Lightf. $353 \cdot$ t. I5. f. I. Dick. H. Silci. fajc. 17.13 .

Braffica monenfis. Hudf. 291. With. 593. Eruca monenfis laciniata lutea. Raii Syn. 297.

E. inonenfis laciniata, flore luteo majore. Dill. Elth. 135 . t. 111 . $f$. 135 .

Man Rocket. Pet. H. Brit.t. 4,6.f.7. male. Ang?. Dwarf Sea Rockct.

In arenofis maritimis rariùs.

In the ifles of Bute and Arran, and feveral parts of the weftern coant of Scotland. Lightf. In the inle of Man and in Cumberland. May. In Anglefea. Dill. Rev. H. Daries.

Perennis. Fl. Junio, Julio.

Radix lignofa, craffa. Caules plures, fpithamxi, patuli, fimpliciflimi, teretes, læves, plerumque aphylii. Folia numerofa, omnia ferè radicalia, pctiolata, fubcarnofa, glaucefcentia, pinnatifida, laciniis fubrqualibus, plerumque integris, fubinde incifo-ferratis, fetis raris acfperfis. Flores magni, citrini. Calyx apice hirtus, minus quam in præcedente patulus. Petala renofa. Siliqua erecto-patens, obloletè tetragona, lævis. Herba odore ferè precedentis.

Sifymbrium n. 8. Ger. Gallopr. 360, in Sp. Pl. ed. 2 deferiptum, venis petalorum obfoletis floribufque minoribus differre videtur,

Sopjia. 7. SISYMRRIUM foliis pinnato-Alecompofitis fubpilofis, petalis calyce minoribus. 
Sifymbrim Sophia. Sp. Pl. 920 . Ifulf. 29\%. With. 582. Reth. 258. Sibth. 208. Abbot. I43. Bíart. Fl. Rult. t. 57. Fl. Dant. t. 528 .

Eryfimum Sophia diçum. Rä̈i Syr. 298.

Sophia Chirurgorum. Ger. em. Io68.

Seriphium Abtinthium. Fuchf. Hift. 2.

Angl. Flix-weed.

In ruckatis, maccrisis, et fimetis frequens.

Annua. Fl. Julio.

Radix fufformis, parva. Caulis bipedalis, erectus, ramofus, foliofus. Folia alterna, pinnata, pinnis pinnatifidis, quandoque bipinnatifidis, laciniis decurrentibus, inrequalibus, lanceolatis, acutis, fubpilofis, Flores exigui, flaveoli. Siliquæ numerofx, erectæ, læves.

8. SISYMBRIUM foliis runcinatis dentatis nudis, Irio. caule lævi, filiquis erectis.

Sifymbrium Irio. Sp. Pl. 921. Hudf. 297. iVith. 533. Sibth. 207. Curt. Lond. fafc. 5. t. 48. Jacq. Aufir. 1.322.

Eryfimum latifolium Neapolitanum. Raii syn. 298.

E. latifolium majus glabrum. Baub. Pin. Iо Morif. Sett. $3 \cdot t \cdot 3 \cdot f \cdot 3 \cdot$

Irio lævis Apulus, Erucœ folio. Column. Eiphr. $264 . t .265$.

Broad Heige Muftard, I'et. II. Brit. t. 46. $f .4$.

Angl. London Rocket.

In ruderatis, aggeribus, et muris antiquis.

About London in various places. Ray. Curt. At Faulkbourn, Effex, and on the walls of Berwick upon Tweed. Ray.

Annua. Fl. Julio, Auguifo. 


\section{TETHADINAMIA-SILIQUOSA.}

Herba perpetuó glaberrima, acri Sinapeos fapore. Curt. Hadix fufiformis, parva. Caulis erectus, fubbipedalis; foliofus, fubflexuofus, teres, fupernè ramofus. Folia alterna, runcinato-pinnatifida, acuta, anticè imprimis dentata. Flores exigui, flavi, petalis calyce longioribus. Siliquæ numerofæ, erectæ, longiflimæ, teretiulculæ.

306. ERYSIMUM. G.Pl.339. Juf.239. Gertn. t. 143 .

Siliqua recta, columnaris, exactè tetraedra. Cal. claufus. Stigma capitaturn.

aficinab.

I. ERYSIMUM filiquis rachi adpreffis, foliis runcinatis.

Eryfimum officinale. Sp. Pl. 922. Itudf. 286. With. 583. Relh. 250. Sibth. 201. Abbot. I44. Curt. Lond. fafc. 5. t.50. Fl. Dan. t. 560. Woodv. Suppl. t. 244.

E. Diofcoridis Lobelii. Ger.em. 254.

Eruca hirfuta, filiquâ cauli apprefsâ, Eryfimum dicta. Raii Sym. 298.

Verbena recta five mas. Fuchs. Hift. 592 .

Angl. Common Hedge-muftard. P'et. H. Brit. t. $46 . f \cdot 3$.

In ruderatis et ad vias.

Annua. Fl. Junio, Julio.

Radix parva. Herba pilofa. Caulis bipedalis, ramofus, foliofus, teres, ramis patentibus. Folia lyrato-runcinata, dentata. Flores parvi, citrini. Siliquæ erectæ, pedunculo communi, valdè elongato, adpreffæ, breves; apice fubulatæ, ftyloque mucronatæ.

Barba- 2. ERYSIMUM foliis inferioribus lyratis: lubo ria. terminali rotunclato; fuperioribus obovatis dentatis.

Liryfimum Barbarea. Sp. Pl. 922. Hudf. 286. With. 
With. 584. Relh. 250. Sibtho 202. Abbot. I44. Engl. Bot. t. 443 .

Eruca lutea, feu Barbarca. Kaï Sin. 297.

Barbarea. Ger. em. 243. Bauh. Hift. v. 2. 868. Sanctæ Barbaræ herba. Fuchf. Hift. 746. Trag. Hift. Iо г.

Winter Crefs. Pet.H.Brit.t.46. f. I. Angl. Yellow Rocket. Bitter Winter Crcfs.

In ruderatis, paluftribus, vel ad fepes, vulgaris.

Perennis. Fl. Maio-Augufto.

Radix fufiformis, fublignofa. Caulis bipedalis, erectus, ftrictus, fubramofus, foliofus, angulatus, fulcatus, glaber. Folia atro-viridia, nitida, glabra, dentata; inferiora lyrata ; fuperiora fenfim fimpliciora, amplexicaulia; fumma indivifa. Flores aurei, numerofi, denfr, in hortis fæpiùs pleni. Calyx fubcoloratus. Siliquæ breves, erecto-patentes.

Herba amara, mucilaginofa, naufeofa.

3. ERYSIMUM foliis inferioribus lyratis; fupe-precon. rioribus pinnatifidis : laciniis lineari-oblongis integerrimis.

E. Barbarea G. Sp. Pl. 922?

Barbarca foliis minoribus et frequentiùs finuatis. Dill. in Raii Sym. 297.

Sifymbrium Erucæ folio glabro, minus et præcocias. Tourn. Inft. 226.

Angl. Early Winter Crefs. Pet. H. Brit. t. 4 f. f. 2 .

In herbidis irriguis, vel ad forìs.

This is inferted upon the authority of Petiver only, the Rev. Mr. Wood having aflured me the plants I found near Leeds (fee E. Bat. 443) were planted there.

Biennis, Fl. Aprili-OBtobri, 
A precedente fatis difcrepat foliis fuperioribus pinnatifidis, laciniis oppofitis, lineari-oblongis, integerrimis ; floribus pallidioribus; foliolis calycinis latioribus; filiquis triplò longioribus.

Herba in acetariis grata, guftu omninò Sifymbrï Nafturtii.

Alliaria. 4. ERYSIMUM foliis cordatis.

Eryfimum Alliaria. Sp. Pl. 922. Hudf. 286. With: 584. Relh. 25r. Sibth. 201. Alsbot. 144. Cart. Lond. fafc. 2. t. 48. Fl. Dan. t. 935. Woodv. Suppl. t. 24.5.

Hefperis Allium reảolens. Raii Syn. 293.

Alliaria. Ger. em.794. Fuch. Hift. Ic4. Camer. Epit. 589. Natth. Falgr. v. 2. 197. Angl. Garlick Hedge-muftard. Jack by the hedge. Sauce alone:

In fepibus et umbrofis vulgaris.

Biennis. Fl. Maio.

Herba lævis, nitida, odore gravi alliaceo. Caulis crectus, ftriatus, foliofus, fubfimplex. Folia petiolata, cordata, dentata. Flores albi. Siliqux longiffimre, fubulatre.

cbeiran- 5. ERYSIMUM foliis lanccolatis fubdeniticulatis, tboides. filiquis erectis, pediccllis fructiferis patentibus.

Eryfimum chciranthoides. Sp. Pl. 923. Hudf. 287. With. 585. Relb.251. Sibth. 202. Fl. Dan. t. 73 I et 923. Jacq. Aufr. t. 23. Cheiranthus eryfimoides. Ihulf. 287 .

Myagro affinis planta, filiquis longis. Raii Syn. 299. Baul. Hift. v.2.89.4.

Camelina. Ger. em. 273 .

Treacle Worm-feed. Pet. H. Brit. t. 45.f.2. Angl. Trcacle Hedge-muftard.

In arvis, falicetis, et ad repes, rarius. 
In the inle of Ely, and near Athbourne, Derbythire. Ray. Ofier holts near Godftow, Oxfordhire. Sibth. Common in turnep fields near Bungay, Suffolk, Mr. Woodward. By the road near Ipswich leading towards Norwich.

Annua. Fl. Julio.

Radix parva. Caulis fefquipedalis, erectus, frictus, denfe foliofus, angulatus, fulcatus, undique fcaber, fetis aretè adpreffis, fupernè ramofus. Folia alterna, lanceolata, bafi apiceque attenuata, integerrima, vel obfoletè denticulata, fcabra, fetis exiguis, albidis, arctè adpreffis, fæpè furcatis. Flores numerofi, aurei, calyce pallido. Racemi fructiferi longiffimi, pedicellis horizontaliter patentibus, filiquis erectis, omninò tetragonis. Stigma parvum, fubfeffile, haud emarginatum.

30\%. CHEIRANTHUS. G. Pl. 339. JuJ. 238. Gertn. t. 143 .

Germen utrinque denticulo glandulato. Cal. claufus; foliolis duobus bafi gibbis. Semina plana.

I. CHEIRANTHUS foliis lanceolatis acutis fub-fruticutùs canefcentibus, pubefcentiâ fimpliciflimâ lufus. adprefsâ, caule fruticulofo, ramis angulatis.

Cheiranthus fruticulofus. Mant. 94.

C. Cheiri. Hudf. 287. With. 586.' Relh. 252. Sibth. 202. Abbot. 144. Ait. Hort. Kew. v. 2. $395 \alpha$.

Leucojum luteum, vulgò Cheiri, flore fimplici. Ritii Syn. 29 I.

L. luteum, minus, fruticans, Barrel. Ic. t. 1228.

Viola petræa lutea. Tabern. Krauterb. 688. Angl. Wild Wall-flower.

In muris antiquis.

VoL. II,

Perennis. 
Perennis. Fl. Maio, Junio.

Caulis fruticulofus, ramofiffimus, ramis erectis, foliofis, angulatis, fubincanis, apice floriferis. Folia conferta, petiolata, lanceolata, acuta, plerumque integerrima, -viridia, fubtùs præcipuè fetis timplicifimis adpreffis tecta, et ferè canefcentia ; inferiora fubferrata. Florcs lutci, odori, calyce purpurafeente, petalis emarginatis. Siliqure crcetre, teretiufcula, cancfcentes. Stylus brevis. Stigna emarginatum. Semina non alata.

A C. Cheiri hortorum differt foliis acutioribus, fubtùs canefcentibus, floribus minoribus, luteis, nec ferrugineo-fanguincis; modò hæc fufficiant.

- Smuaius. 2. CHEIRANTHUS foliis tomentofis obtufis finuatis : rameis integris, filiquis muricatis. Cheiranthus finuatus. Sp, Pl. 926. Hudj. 288. With. 586. Engl. Bot. t. 462.

C. tricufpidatus. Hudf.ed. I. 250.

Leucojum marinum majus. Raii Syn. $29 \mathrm{I}$.

L. marinum purpureum Lobelii. Ger. em. 460 .

L. maritimum magnum latifolium. Baub. Hifl. ข. 2. 875 .

Angl. Sea Stock.

In littoribus maritimis, imprimis Cambrix.

In many parts of Wales; alfo on the coaft of Cornwall. Ray. Near Pcmbroke. J. Adams, Efq.

Biennis. Fl. Augufto.

Herba tota incana, pilis ftellatis, arcte intricatis. Caulis bipedalis, ramofus, patens; foliofus, teres. Folia alterna, oblonga, obtufa, finuata, bafi attenuata ; fuperiora plerumque integra. Flores magni, dilutè violacei, fpeciofi, vefpere odoratiffimi. Petala emarginata. Stigma parvum quadrifidum. Siliquæ longiffimæ, inca-

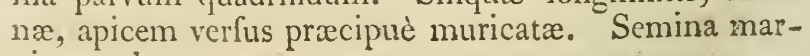
ginato-alata. 
308. HESPER!S. G. Pl. 340. Ju/. 238.

Petala obliquè flexa. Glandula intra ftamina breviora. Siliqua ftricta. Calo claufus; foliolis duobus bafi gibbis.

4. HESPERIS caule erecto, folits ovato-lanceo-irodor $\pi_{\text {. }}$ latis dentatis bafi fubhaftatis, petalis obtufis.

Hefperis inodora. Sp. Pl. 927. Hudf. 288. With. 586. Fl. Din. t. 924. Jacq. Auftr. t. 347 .

H. fylveftris inodora. Dille in Raii Syn. 293. Hall. Rupp. Jen. ; 8. t. I.

H. tertia. Chis. Hift. v. 1. 2.97.

Angl. Scentlefs Dame's-violet.

In pafcuis ad rivulos.

On the banks of the rivulets about Dale-head, Cumberland, and Graffinere, WVeftmoreland, Mr. Nicolfon. Dill. About Falmouth. With. Near the old caftle of Airly, Angus-rhire. $M r$. J. Mackay.

Perennis. Fl. Maio, Junio.

Hefperidi matronali adeò affinis ut vix dignofcenda, neque ftirpem noltram indigenam fatis examinavi ut quicquam in hoc difcrimine profim. Exemplar Linnæanum, a Jacquino miffum, gaudet foliis bafin verfus latiùs dentatis, et inde quafi haftatis. Flores inodoratos effe accepimus; quod etiam $\mathrm{H}$. matronali, nifi vefpere, convenit. Stigma in hifce fpeciebus bafi fagittatum eft, apice connivente, at non in omnibus.

309. ARABIS. G. Pl. 34I. Jüf. 238.

Glandule nectarifere quatuor, oblongæ, fquamiformes, reflexæ. Cal. claufus; foliolis duobus bafi gibbis. Stigma fimplex. Siliqua linearis, torulofa. 
- thaliana. I. ARABIS foliis pilofis fubdentatis: radicalibus petiolatis, caule ramofo, filiquis adfcendentibus.

Arabis thaliana. Sp. Pl.929. Hudf. 292. With. 587. Relh. 254. Sibth. 205. Albot. I45. Curt. Lond. fasc. 2. t. 49. Pollich. Palut. v. 2. 24.3. t. 4. Dickf. H. Sicc. fajc. I 7. I 2.

Turritis vulgaris ramofa. Raii Syn. 294. Thale Crefs. Pet. H. Brit. t. 48 . f. I.

B. Turritis minor foliofa. Raii Syn. 294.

Broad Thale Crefs. Pet. II. Brit. t. 48. f. 2. Angl. Common Wall-Crefs.

In muris, tectis, ct arenofis aridis.

Annea. Fl. Aprili.

Radix ramofa, fibrofa. Caulis crectus, ftrictus, ramofus, foliofus, teres, ftriatus, hirtus. Folia lanceolato-oblonga, dentato-ferrata, fæpe integerrima, pilofa; radicalia petiolata, depreffa ; caulina alterna, feffilia, anguftiora. Flores parvi, albi. Petala erecta. Glandulæ nectariferæ minutæ, vix exfertæ. Pedicelli fructiferi patentes. Siliqux curvato-adfcendentes, obfoletè quadrangulix.

- friala. 2. ARARIS foliis dentatis obtufis hifpidis: radicalibus fublyratis, caulibus hifpidis, petalis crectis.

Arabis firicha. Inudf. 292. With. 587. Vellev Pl. Nurit. t. 5. Engl. Bot.t.61 4. Sbiercliff, Briftol Guide, $8_{3}$, cum icone.

A. bifpida. Ait. Hort. Kerv. v. 2. 400, ncquaquam Linn.

A. n. 453. Hall. Hift. v. 1. I97. Nomencl. 42. Turritis Raii. Villars. Dauph. v. $3 \cdot 3^{26 .}$ t. 38 .

Hefperis alpina minor, flore albo, filiquis longis. Ricii Sill. 296.

Cardamine 
Cardamine pumila, bellidis folio, alpina. Raib Syn. ed. 2.372.ed.3.300?

Anjl. Britol Rock-Creis.

In rupibus Anglia temperatioris.

On St. Vincent's rocks near Briftol. Hudf. Telley.

On the fouth fide of the river, about a mile below the hot-wells, but fparingly. Mr. W. Clayfield, and Mr. Dyer.

\section{Perennis. Fl. Maio.}

Radix fibrnfa, certè perennis. Caules frepì̀s plures, cæfpitofi, erecti, fubramofi, teretes, foliofi, bafin verfus hifpidi. Folia radicalia plurima, lyrato-dentata, obtufa, hifpida, pilis plerumque finplicibus, rarius bifurcis ; caulina pauca, alterna, oblonga, obtufa, margine nervifque ciliata; omnia faturatè viridia et nitidiufcula, fubtùs rubicunda. Corymbi paucifori, erecti. Flores albidi, exficcatione ochrolevici. Calyx obtufus, glaber. Petalorum limbus crectus, obtufus, integer. Siliquæ breviùs pedicellatæ, erectæ, ftrictæ, compreffæ, vix torulofæ.

3. ARABIS foliis radicalibus runcinato-lyratis hif-bifpida. . a pidis ? caulinis lanceolatis, pilis furcatis, caulibus glabris ramofis.

Arabis hifpida. Suppl. 298. Syft. I'eg.ed. I3. $501 . e d .14 .600$.

Sifymbrium arenofum. Fl. Succ. 233? nec Sp.P.

Cardamine petræa. Kudj. 293. With. 577. Fl. Dan. t. $3^{86 .}$

C. petræa cambrica, Nafturtii facic. Dill. Elth. 70. t.6 I.f. $7 \mathrm{~s}$.

Nalturtium petræum Johnoni. Raii Syn. 3 co. Pluk. Ply.t. t. IоI. $f \cdot 3$.

Welch Rock-Crefs. Pet. H. Brit. t.50. f. 3 .

B. Cardamine baftulata. Engl. Bot. t. 469 .

$$
\mathrm{T}_{3} \text { C. petræa. }
$$


C. petræa. Lightf. 347. t. I 5.f. 2 . Angl. Alpine Kock-Crefs.

In excelfis rupibus alpinis.

In North Wales. Ray. Mr. Bingley. In Scotr land. Mr. Lindefay. Lightf.

Perennis. Fl. Junio, Julio.

Radix fublignofa, cæfpitofa. Caules plures, fpithamic, adfcendentes, ramofi, teretes, fulcati, parum foliofi, undique frepius glabri. Folia radicalia plurima, petiolata, lyrato-pinnatifida, fubruncinata, lobis acutis, hifpida, pilis omnibus furcatis divaricatis; caulina pauca, alterna, lanceolata, obtufa, fubuentata, plerumque glabra. Flores fubindè purpurei, fæpiùs albi ore purpurafcentes. Calyx obtufus, glaber. Petalorum limbus horizontalis, obtuffimus, integer. Pedicelli fructiferi divaricato-patentes. Siliquæ erectiufculæ, compreffæ, torulofæ, apice primùm dehifcentes, valvulis rectiufculis.

Cardamine haftulata noftra, collatis exemplaribus variis a D. Bingley communicatis, haud difcrepat, nifi foliis ferè glabris minúque lobakis.

Sifymbrium arenofum Linn. Fl. Suec. nec $S p$. Pl. huic quam maximè affine eft, fed radix videtur fimplex et forfitan annua, caulis ftrictus, pilofus, pilis patentibus. Defcriptionem in Syat. Veg.. al) editore, nefcio quo animo, truncatam, e mamufcriptis $\mathrm{Cl}$. Mygindi fic reftauravit amicif̣mus D. Jacquinus filius. "F Flares thalianæ majores;...calyx patulus; caulis palmaris"...

- Turrita. 4. AR ABIS foliis amplcxicaulibus, filiquis decurvis planis linearibus margine incraflatis. Arabis Turrita. Sp. Pl. 930. Hudf. 293. IVith. 588. Relb. 255. Sibth. 205. Engl. Bot. t. I 3 . Jacq. Auftr. t. I I.

Turritis major. Ger. em. 272.

Turrita major Plateau. Clus. Hif. $\bullet 2$. I26.

Braflica fylreftris albiclo flore nutante filiquâ.

Bocc. Muf. 8r.t.72. Barrel, 16.t.353. 
Great Tower Muftard. Pet. H. Brit. t. 47. f. II. Angl. Tower Wall-Crefs.

In muris antiquis.

On the walls of Trinity and St. John's Colleges, Cambridge. Dr. Martyn. On Magdalen College-walls, Oxford. Sibth.

Biennis. Fl. Maio.

Radix lignofa. Caulis pedalis vel fefquipedalis, ercetus, fubfimplex, teres, foliofus, pilofus. Folia dentatil, fcabriufcula; caulina amplexicaulia. Corymbus fimplex, terminalis. Flores ochroleuci. Siliquæ breviùs pedicellatæ, deflexæ, longiffimæ, torulofre, compreflie, margine incraffatæ.

Foliis haud acuminatis, pedicellis craffioribus et quadruplò brevioribus, filiquis denique margine incraflatis, ab A. pendulâ abunde differt.

\section{TURRITIS. G.Pl. 341. Juf. 238. Gertr. t. 143.}

Siliqua longiffima, fricta, fub-angulata. Cal. connivens, erectus. Cor. erceta.

Ов . Genus vix a præcedente diftinguendum.

I. TURRITIS foliis radicalibus dentatis hifpidis ; glabra. caulinis integerrimis amplexicaulibus.

Turritis glabra. Sp. Pl.930. Hudf. 291. With. 588. Sibth. 204. Curt. Lond. fafc. 4. t. 47. Fl. Dan. t. 809 .

Turritis. Raï Syn. 293. Ger.em. 272.

Tower Muftard. Pet. H. Brit. t. 47.f. Io. Angl. Smooth Tower-Muftard.

In aggeribus et pafcuis glareofis.

Between Norwich and Yarmouth (Ray); in many. places; alfo in the road to Coltimall. Near Charlton and Lewitham, Kent, and near ColT 4

chefter. 
chefter. Hudf. In Derbyfhire. Dr. Stokes. Near Bath, and on St. Vincent's rocks, Briftol. With. About Dauffeld near Barnfley, Yorkflire. Mr. Salt.

Annua. Fl. Maio, Junio.

Radix fufformis. Caulis virgatus, fimplex, erectus, bipedalis, teres, glaber, foliofus. Folia radicalia petiolata, lanceolata, dentata, fcabra ; caulina numerofa, alterna, fenfim minora, feffilia, amplexicaulia, fagittata, integerrima, læviffima, fubglauca. Corymbus fæpiùs folitarius, demùm in racemum longiffimum, ftrictum, productus. Flores albidi. Petala erecta, demùm patula. Siliquæ pedicellatæ, erectæ, arctè cauli approximatæ, lineares, planæ, glabræ, margine haud incraffatæ, bafi dehifcentes.

Birfuta. 2. TURRITIS foliis omnibus hifpidis, caule hirto, pilis fimplicibus patentibus, filiquâ quadirangulari.

Turritis hirfuta. Sp. Pl. 930. Hudf. 29I. With. 589. Relh. 254. Sibth. 204. Dicks. H. Sicc. fafa. 9. 8. Engl. Bot. t. $5^{8} \%$. Jacq. Coll. v. I. 70. Ic.rar. v. г. I26. Fl. Dan. t. 1040.

T. n. 456. Hall. Hift. v. r. 198.

T. muralis minor. Raii Syn. 294.

Eryfimo fimilis hirfuta alba. Bauh. Prod. 42. Barbaræa muralis. Baub. Hift.v. 2.269.

Daify Tower Muftard. Pet. H. Brit. t. 47. f. 12.

Angl. Hairy Tower-Muftard.

In faxofis, ct muris antiquis.

In the weftern and northern counties. Ray. Suffex. Doody. In Switham bottom near Croydon. Hudf. On the walls of Lakenham churchyard, near Norwich. Mr. Crowe. cot a nd. Dicks.

Perennis. 
Perennis. Fl. Maio.

Radix lignofa. Caules erecti, neta'es, ramofi, foliofi, teretes, pilofi, pilis omnibus fi. uplicibus, patulis, albis; fupernè glabri. Folia dentata, magy's vel minùs hirfuta, pilis fimplicibus furcatifve; caulina feffilia. Flores albi. Silicin: crectx, demùm nutantes, fubquadrangulæ, torulofe, glabræ, nitidæ, obtufufculæ, ftigmate fubfeffili.

Aliam fpeciem præcociorem mifit amiciffimus Davall, pilis caulinis furcatis dep. fis, fíquis omninò planis; quæe T. hirfuta, Ger. Gallop'r. 367 , eft, \& a Linnæa in herbario fưo cum noftrâ confufa, ut ex exemplaribus certæ fidei patet.

\section{II. ERASSICA. G. Pl. 342. Jil J. 238. Gertn. $t$. 433 .}

Cal. erectus, fubconnivens. Semina globofa. Siliqua teretiufcula; diffepimento prominente, fubulato. Glandula neczarifere quatuor.

I. BRASSICA foliis elliptico-cordatis obtufis am-orientaplexicaulibus glabris; radicalibus obovatis in- lis. tegris, filiquis tetragonis.

Braffica orientalis. Sp. Pl. 931. Hudf. 290. With. 589. Pollich. Palat. v. 2. 247. Jacq. Auftr. t. 282.

B. campeftris. Hudf. 290?

B. campefr ris perfoliata flore albo. Dill. in Raiz Syn. 293.

B. campeftris prima. Cluf. Hift. v. 2. 127.

Perfoliata filiquofa. Ger. èm. 536 . Baub. Hijt. v. 2.835 .

White Thorow Colewort. Pet. H. Brit. t. 45 . $f \cdot 5$.

Angl. Perfoliate Cabbage.

In arvis et clivis maritimis.

In Effex, rare, Petiver; ncal Harwich, and alfo at 
Barlfey (Bradley?) near Orford, Dale. I)ill. Ficlds near Godtione and Marfhfield, Suflex. Itudf.

Arinua. Fl. Junio.

Radix fufformis, parva. Caulis e bafi plerumq̨uc ramofus, foliofus, teres, lrevis, glaucus. Folia omnia la via, glauca, integerrima, obtufa; radicalia obovata; caulina alterna, amplexicanlia, elliptico-cordata. Flores parvi. Petala angufta, alba vel ochroleuca. Siliquie longiffimæ, graciles, erectie, tetragonæ.

B. aultriaca, Jacq. t. 283 , vix fpecic differre videtur.

2. BRASSICA radice caulcoue tenui, foliis cordatis acuminatis amplexicaulibus; infcrioribus lyratis dentatis fubhifpidis.

Brafica campefiris. Sp. N7.93I. Inudf. 290? IFith. 590? Scboll. Burl. I53. Fil. Dan. t. 550 haud benè.

B. tertia. Iuchj. Hift. 4 I 5 ?

B. rubra minor. Baub. Hijĭ. ¿.2.833? Angl. Field Cabbage.

In agris.

At Harwich, and very plentifully between Crop)redy and Norlington, Oxfordhire. Rev. Ur. Goodinough. Near Broadford, Ine of Skyc; and in fields near Forfar. Mr. Mackay. In the Phyfic-garden at Cambridge from Scotland. Mr. Dom. In ficlds below Kirkby Lonfdale, Weftmoreland, if I be not miftaken.

Attruta. Fl. Tunio.

Kadix funformis, parra. Caulis erectus, ramofus, foliofus, teres, glaber, fubghaucis. Folia caulina fuperiora alterna, amplexicaulia, cordata, acuminata, inteserrima, lievia; inferiora fubinde dentata; infima, et pracipuc radicalia, lyrata, dentata ct repanda, fubtus ad renas hifpida; omnia glaucefcentia, fubtus pallidiora. Calycis foliola vix cohærentia, patentiufcula. P'etala 
Petala lutea, quam in præcedente triplò latiora. Siliquæ erectæ, teretes, obfoletè quadrạngulæ, reticulatovenofæ, torulofæ, biunciales, roftro fubulato, bafi quadrangulo, ftriato.

A precedente omninò diftincta ; etiam diffimilis eft, nequaquam confundenda, at fynonyma utriufque apud auctores malè intelliguntur.

3. BRASSICA radice caulefeente fufformi, fo-Napus, liis lævibus: fuperioribus cordato-lanceolatis amplexicaulibus : inferioribus lyratis dentatis.

Braflica Napus. Sp. Pl. 931. Hudf. 290. With. 590. Relh. 253. Sibth. 204. Abbot. 145. Murt. Fl. Ruft. t. 103.

Napus fylveftris, Raii Syn. 295. Bumh. Hift. v. 2. 843 .

N. Bunias fylveftris. Fuchf. Fift. I77.

Bunias fylveftris Lobelii. Ger. $c m .235$. Wild Navew. Pet. H. Brit. t. 4.5.f. 9 . Angl. Rape, Navew, or Cole-feed.

Inter fegetes, et in aggeribus foffarum.

Biennis. Fl. Maio.

Radix fufformis, apice incraffata, caulefcens. Caulis erectus, ramofus, foliofus, teres, ftriatus, glaber. Folia lævia, fubtùs præcipuè glaucefcentia ; caulina fuperiora alterna, amplexicaulia, cordato-lanceolata, patentiffima, ferè integerrima; inferiora latiora, obtufiora, dentata; radicalia lyrata. Calvcis foliola patentiufcula, colorata. Petala aurea. Siliquæ demùm patentes vel deflexæ, torulofe, teretes, roftro angulato.

4. BRASSICA radice caulefcente orbiculari de-Rapa preffa carnofa, foliis radicalibus lyratis fcabris; caulinis integerrimis lavibus.

Braflica 
Braffica Rapa. Sp. Pl. 93 1. Hudf. 289. Wilh. 591. Relh. 253. Sibth.203. Abbot. 145. Mart. Fl. Ruft.t. 49, 50.

Rapa fativa rotunda. Lícii Syn. 294.

Rapum. Trag. Hift. 728, Caner. Epit. 218.

R. fativum. Fuchj. Hift. 2 I 2 ,

R. majus. Ger.em. 232 .

B. Rapa fativa oblonga, feu fomina. Raï Syn. 294.

Rapum radicc oblonga. Ger. em. 232.

R. longum. Camer. Epit. 219.

Angl. Turnep.

In arris et ad margines agrorum.

Biennis. Fl. Aprili.

Radix orbicularis vel obovata, carnofa, caulefcens. Caum lis erectus, ramofus, foliofus, teres, lievis. Folia radicalia lyrata, inæequaliter dentata, feabra, faturatè virentia; caulina cordato-lanceolata, amplexicaulia, lavia, integerrima, glaucefcentia. Flores aurei. Siliqua cylindraceæ, venofæ:

- leracea. 5. BRASSICA radice caulefcente tereti carnofa, foliis omnibus glabris glaucis repandis lobatifve.

Braffica oleracea. Sp. Pl. 9.32\%. Inudf. 289 . With. 591. Hull. 148. Freeman. Ic. t. 4a 5. Eingl. Bot. t. 637. Dickf. H. Sicc. fafc. I 7. I 4 .

B. maritima arborca, feı procecrior, ramofa. Raii Syn. 293.

Angl. Sea Cabbage.

In clivis maritimis.

On Dover cliffs and other fimilar places. Ray. On the Welch and Cornith coaft. Huitf. On the 
the fea cliffs at Staiths, Yorkfhire, abundantly. Mr. Robjon.

Biennis. Fl. Maio, Junio.

Radix caulefcens, teres, fpithamæa vel pedalis, cicatricofa. Folia glauca, glabra, repanda et finuata, formâ varia, fublyrata. Flores magni, citrini. Siliquæ torulofæ.

312. SINAPIS. G. Pl. 821. Juf. 233. Gartn. t. 143 .

Cal. patentifimus. Cor. ungues recti. Glandule nectarifere quatuor. Siliqua teretiufcula, diflepimento prominente.

I. SINAPIS filiquis multangulis torofo-turgidis arvenfs. roftro ancipiti longioribus, foliis ovatis fublyratis.

Sinapis arvenfis. Sp. Pl. 933. Hudf. 298. With.594. Relh.258. Sibth. 208. Abbot. 146. Curt. Lond. fafc. 5. t. 47. Fl. Dan. t. 753 .

Rapiftrum arvorum. Raii Syn.295. Ger. em. 233 .

Irion. Fuch. Hift. 257 . Angl. Charlock. Wild Muftard.

Inter feggetes; vitium fummum.

Annua. Fl. Maio.

Radix fuffiformis, parva, rigida. Caulis teres, ftriatus, hifpidus, fetis fubdeflexis. Folia petiolata, ovata, fcabra, in equaliter dentata; inferiora fublyrata; fumma feffilia. Flores lutei. Calycis foliola linearia, viridia. Siliquæ patentes, fuboctangulæ, torofæ, hifpidæ, quandoque glabræ, roftro enfiformi, brevi, compreffo, fulcato.

2. SINAPIS filiquis hifpidis torofis roftro ancipiti alba. brcvioribus, foliis pinnatifidis.

Sinapis 
Sinapis alba. Sf. Pl. 933. Hudf.298. H'iti.. 594. Relh. 258. Silth. 208. Abbot. 146 . Curt. Lond. faffc. 5. 1. 46. Mart. F\%. Iiufi. t. 70 .

Sinapi album, filiquâ hirfutâ, fcmine albo rel ruffo. Raiii Syn. 295.

S. album. Ger.em. 244 .

S. primum genus. Fuchl. Hift. 538 .

Angl. White Muftard. Pet. H1. Brit. t. 45. f. 10.

In arvis et ad vias.

Anmua. Fl. Junio.

Radix et caulis ferè prioris. Folia inferiora profundè pinnatifida; fuperiora fublyrata; omnia erofa, dentata, fcabra. Flores flavi. Calycis foliola linearia, viridia. Siliquæ patentes, pedunculis ferè horizontalibus, breves, fubtetrafperm $x$, torof $x$, coftatæ, hifpidæ, roftro longiffimo, enfiformi, complanato, virenti, fcabro. Semina maxima.

nigra. 3. SINAPIS filiquis glabris tetragonis racemo adpreffis, foliis fummis lincari-lanceolatis integerrimis glabris.

Sinapis nigra. Sp.Pl. 933. Hudf. 297. With. 595. Relh. 259. Sibth. 209. Abliot. 146. Woodv. Med. Bot. t. I5 I. Mart. Fl. Ruft. t. $5 \mathrm{x}$.

Sinapi fativum fecundum. RaïSyn.295. Ger. em. 244.

S. filiquà latiufculâ glabrâ femine ruffo, five vulgare. Baub. Hift. v. 2. 855 .

Sinapi, Jemen. Pharmac. Lond.

Angl. Common Muttard.

In arvis, aggeribus, et ad vias. 
Annuc. Fl. Junio.

Radix parva. Caulis ramofiffimus, patens, teres, lævis. Folia petiolata, variè lobata et dentata; radicalia feabra; caulina glabra ; fumma deflexa, integerrima, anguftata. Flores flavi, parvi. Calyx coloratus. Siliquæ erectæ, rachi adprefie, breves, quadrangulæ, parùm torulofæ, plerumque glaberrimæ, polyfpermæ, roftro brevi, quadrangulo.

Primo intuitu à congeneribus, foliis ramulorum pendulis, dignofcenda. D. Goodenough.

3I3. RAPHANUS. G. Pl. 343. Juf. 238 . Raphaniftrum. Gertn. t. 143 .

Cal. claufus. Glandule nectarifere quatuor.

Siliqua teres, torofa, fubarticulata.

I. RAPHANUS filiquis articulatis lævibus unilo- Rapbacularibus. niftrum,

Raphanus Raphaniftrum. Sp. Pl.935. Aman. Acad. v. 6. 45I. Hudf. 289. With. 596. Relh. 252. Sibth.203. Abbot. 147. Curt. Lond. fafc. 4. t. 46. Mart. Fl. Ruft. t. $7 \mathrm{I}$. Fl. Dan.t. 678 .

R. fylueftris. Ger. em. 240 .

Raphauiftrum filiquà articulatâ glabrà, majore et minore. Raii Sym. 296.

Rapifirum flore albo ftriato. Bauh. Hift. ข. 2。 851 .

White Charlock. Pet.J1. Brit. t. 46. f. 10.

B. Rapiitrum flore luteo, filiquâ glabrâ articulatâ. Raii Sy'n. 296.

$\gamma$. Raphanus maritimus, flore lateo, filiquis articulatis, fecundum longitudinem eminentèr ftriatis. Raii Syn. 296 .

Raphaniftrum filiquâ articulatâ ftriatâ maximû. Morif. 2.2.266. Ritil IIff. \%. I. 806.

Sirest 
Great White Charlock. Pet. H. Brit. t. 4 G. f. II. Angl. Wild Radih. Jointed Charlock.

Inter fegetes copiosè; $\gamma$ in maritimis. D. SioneAreet.

Annua. Fl. Junio, Julio.

Radix parva. Caulis fupernè ramofus, tcres, glancus, hifpidus, fetis porrectis. Folia lyrata, fcabra. Flores majufculi, flavi, vel ochroleuci, venis violaccis, demùm albi. Calyx linearis, claufus, hifpidus. Siliquæ moniliformes, roftro enfiformi.

Varietas $y$ nondum mihi obvia fuit. 


\section{Clafjes XVI. \\ MONADELPHIA.}

Filamenta inferne in unum corpus coalita.

\section{PENTANDRIA。 \\ Stamina 5 perfecta.}

314. ERODIUM. Monogyna. Fruchus pentacoccus, roftratus ? roftra fpiralia, introrsùm barbata.

Limum. Geranium pufillum,

\section{DECANDRIA.}

Stamina Io.

3I5. GERANIUM. Monogyna. Fruct. penta. coccus, roftratus: roftra recurva, nuda.

Oxalis. Spartium. Genifta. Antbyllis. Ulex. Ononis.

Vor. II. 


\section{$(726)$ \\ POLYANDRIA. \\ Stamina plurima.}

318. LAVATERA. Polygyna. Cal. exterior trifidus. Capf. verticillatæ, monofpermæ. 317. MALVA. Polygyna. Cal. exterior triphyllus. Capf. verticillatæ, monofpermæ.

316. ALTHAA. Polygyna. Cal. exterior novemfidus. Capf. verticillatæ, monofpermæ. 


\section{MONADELPHIA.}

\section{PENTANDRIA.}

314. ERODIUM. L'Herit. Geraniol. ined.... Ait. H. Kerv. v. 2. 414. Sibth. 211 .

Geranium. G. Pl.350. Julf. 268. Gertn。 t. 79. mofchatum.

Cal. pentaphyllus. Cor. pentapetala. Glanchile nectariferce 5. Filamenta 5 in erilia. Fructus pentácoccus, roftratus : roftra fpiralia, introrsùm barbata.

I. ERODIUM pedunculis multifforis, foliis pin-cicutanatis: foliolis feffilibus pinnatifidis incifis.

Erodium cicutarium. L'Herit. in Ait. H. Kerv. v. 2. 4I 4. Sibth. 211. Abbot. 147.

Geraniun cicutarium. Sp. Pl.951. Hudf. 300. With.609. Relh. 260. Cuit. Lond.fafs. I. t. 51. F\%. Dan. t. 986.

G. cicutæ folio inodorum. Raii Syn. 357. Ger. em. 945 .

G. primuin. Fucbs. Hif. 204.

Herba Roperti. Brunf. Herb. v. 2. 37.

ß. Geranium inodorum album, Raii Syn. $357^{\circ}$

\%. G. Pimpinellæ folio. Dill. in Raii Syn. 358 . Erodium pimpinellæfolium. Sibth. 21 I. Angl. Hemlock Stork's-bill.

In ruderatis et arenofis frequens.

Annua. Fl. Junio-Augufto.

Radix fuffiformis, albida. Caules plures, procumbentes, divaricati, longittıiine varii, frepiùs ramofi, foliofi, teretes, pilofi. Folia alterna, pinnata, pinnis plerumque alternis, feffilibus, pinnatificis, acutè incifrs, pilofis. Stipulæ ovate, acutæ, fcariofæ. Pedunculi oppofiti- 
folii, umbellati, multiflori, foliis longiores. Flores purpurei, petalis duobus vel tribus in varietate $\gamma$ bafm verfus viridi maculatis. Capfule obconic $x$, monofpermie, verticales, fursum hifpidie, fingulæe roftro longiffino, demum fjirali, intùs pilis patentibus barbato.

mofclo-

2. ERODIUM pedunculis multifloris, foliis pint.cm. natis : foliolis fubpetiolatis ellipticis inaqualiter incifis.

Erodium mofchatum, L'Fierit. in Ait. H. Kers. ข. 2. 4 I 4 .

Geranium mofchatum. Sp. Pl. 95 r. Hudf. 300. With. 609. Raii Syn. 358. Jacq. Hort. .1. t. 55. Ger. em. 941. Cavan. Dij. 227. t. 94. f. I.

Angl. Mufky Stork's-bill. Mufcory.

In pafcuis montofis.

Shotover hill near Oxford. Rev. Dr. Goodenough. Truly wild in the mountainous paftures of Yorkfhire and Weftmoreland.

Annua. Fl. Junio, Julio.

Habitus præcedentis, at foliis majoribus, odoreque ambrofiaco dignofcitur. Ilerba pilis vifcofis veftitur. Foliola pauciora, clliptica, lata, vix pinnatifida. Flores minores et pedicelli breviores quam in $\mathrm{E}$. cicutario.

mariti- 3. ERODIUM pedunculis fubtrifloris, folis cormum. datis incifis crenatis fcabris, caulibus depreffis.

Erodium maritimum. L'Herit. in Ait. H. Kerw. ข. 2. 416. Engl. Bot. t. 646.

Geranium maritimum. Sp. Pl. 95 r. Hudf. 301. H'ilh. 606. Dick.j. H. Sicc. fafc. I I. I I. Cavan. Diff. 2 I8. t. 88. f. I.

G. pufillum fupinum maritimum, Althææ aut Betonica 
Betonicx folio noftras. Raii Syn. 356. Pluk. Pbyt.t. 3I.f. 4 .

G. minimurn anglicum procumbens, Betonicæ folio. Morif. Sect. 5. t. 35 . Angl. Sea Stork's-bill.

In arenofis maritimis.

Perennis. Fl. Maio-Septembri.

Caules latè fparfi, deprefii, ramofi, foliofi, pilofi. Folia longiùs petiolata, fimplicia, cordato-ovata, incifa, crenata, hifpida. Flores exigui, carnei, fubterni, fæpe folitarii.

Stylus in omnibus fpeciebus fimplex, ftigmate quinquepartito, ut in Geranio.

\section{DECANDRIA. .}

3I5. GERANIUM. G. Pl. 350. Juf. 268. Gertn. t. 79. pratenfe.

Cal. pentaphyllus. Cor. pentapetala. Glandulde nectarifere 5. Fructus pentacoccus, roftratus: roftra recurva, nuda.

I. GERANIUM pedunculis bifloris paniculatis pboum. erectis, calyce fubariftato, capfulis carinatis: bafi hifpidis : apice corrugatis.

Geranium phæum. Sp.Pl. 953. Hudf. 30r. With. 605. Relh. Suppl. 2. 13. Abbot. 149. Engl. Bot.t. 322. Fl. Dan. t. 987.

G. montanum fufcum. Dill. in Raii Syn. 36r. U 3 G. batra- 
G. batrachioides pulio flore. Ger. en. 942. Angl. Durky Crane's-bill.

In dumetis montofis rạus.

Found by Mr. Drayton, apothecary, of Maidfone, at Tovel in the valley by the old fulling-mill. Dill. About Clapham and Ingleton, Yorkfhire. Hudf. In Lancatire, Cambridgefhire, and Bedfordinire. Engl. Bot. On a bank at Ath-Bocking Suffolk. Mrs. Cobloold. About Newburgh, Yorkilire. Rev. Arckdeacon Peirjon.

Perennis. Fl. Maio, Junio.

Radix lignnofa. Caules herbacei, erecti, bipedales, foliofi, teretes, pilofi, paniculați, multiflori. Folia palmatomultificla, incifa, pilofa, fubtùs reticulata, venis anaftomofautibus; radicalia longius petiolata; fumma fefflia, parva, trifida. Pedumculi alterni, oppofitifolii, ereeti, biflori. Bracteæ parvæ, fcariofæ, fufcæ. Calycis foliola clliptica, incana, pilofa, obfoletè ariftata. Petala atro-fanguinea, lurida, undulata, ungue albo. Stamina atro-purpurea, ferè æqualia, recurva. Antheræ flavæ, decidux, omnes fertiles Stylus fimplex, ftigmate quinquefido, ut in congeneribus. Capfulæ obovatæ, carinatæ, fufcæ; batin verfus hifpidæ, pilis albis erectis; apice tranfverfim corrugatæ, rugis repandis.

modofum.2. GERAN. U M pedunculis bifloris, foliis oppofitis trilobis ferratis, capfulis undique pilofis aqualibus.

Gerinium nodofum. Sp. Pl. 953. Hudf. 301 . With. 6oi.

G. nodofum Plateau. Raii Syn. 36 s. Cluf. Hijt. ข. 2. IOI. Ger. em. 947 .

G. magnum, folio trifido. Baub. Hift.v. 3. 478 . Angl. Knotty Crane's-bill.

In montofis Angliæ borealis, rariùs. 
In Cumberland, Mr. Archergen. Ray. Confirmed by Mr. Woodward. With.

Perennis. Fl. Maio-Augufto.

Radix tuberofa. Caules patuli, angulato-compreffi, geniculis tumidis rubicundis. Folia oppofita, petiolata, lucida, triloba, acuta, ferrata. Pedunculi laterales et terminales, folitarii, erectiufculi, biflori, longiffimi. Bracteæ lineares, acuminatæ. Flores majufculi, purpurei, fpeciofi. Calycis foliola elliptico-oblonga, incana, ariftis purpureis, obtufis. Capfulæ ellipticie, vix carinatæ, undique pilofæ, fuperficie æquali.

3. GERANIUM pedunculis bifloris fubcorymbo- fylvatifis, foliis fubfeptemlobis incifo-ferratis, capfu- cum. lis undique pilofis, ftaminibus fubulatis.

Geranium fylvaticums. Sp. Pl. 954. Hudf. 302. With. 602. Engl. Bot.t. I2 I.

G. paluftre? Roje Elem. App. 44I. t. I.

G. batrachoides montanum noftras. Raii Syn. $36 \mathrm{r}$.

G. batrachioides alterum. Ger. em. 942." fingl. Wood Crane's-bill.

In dumetis et pafcuis montofis, præfertim Angliæe borealis et Scotix.

At Spixworth, Norfolk. Mr. Humphrey. Near Lynn. Mr. Crowe. Common in the mountainous counties.

Perennis. Fl. Junio, Julio.

Radix fublignofa. Caules bi- vel tri-pedales, erecti, teretiufculi, foliofi, corymbofo-paniculati, pilofi, pilis deflexis. Folia oppofita, petiolata, quinqueloba vel feptemloba, mollia, pilofa, acuta, incifo-ferrata, venofa, fubtùs pallidiora. Pedunculi erecti, biflori. Bracteæ lanceolatæ. Calyx ariftatus. Petala purpurea, venis fanguineis, fæpiǔs emarginata, bafi pilofa. Stamina fubulata, membranaceo-alata, ultra medium ciliata. Capfulæ carinatæe, pilofre, apicem verfus utrinque $\mathrm{U} 4$

nervo 
nervo folitario fufco notatæ, nec corrugatæ. Semina punctata.

pratenfe. 4. GERANIUM pedunculis bifloris, foliis fubfeptempartitis incifo-ferratis, capfulis undique pilofis, ftaminibus bafi deltoideis.

Geranium pratenfe. Sp. Pl. 954. Hudf. 302: With.606. Hull. I53. Relh.261. Sibth. 212. Abbot. 148. Curt. Lond. fafi. 4. t. 49. Engl. Bot. t. 404. Cavan. Diff. 2 10. t. 87. f. I. Dickf. H. Sicc. fafc. 16. 18.

G. batrachoides. Raii Syn. 360. Ger. em. 942 . G. quintum. Fucb. Hift. 208. Angl. Crowfoot-leaved Crane's-bill.

In pratis, dumetis, et pafcuis humidioribus, præcipuè montofis.

Perennis. Fl. Junio, Julio.

Præcedente major. Caulis tomentofo-incanıs, pilis recurvis, fuperioribus glandulofis. Folia ufque ad bafin ferè dịvifa, lobis fubpinnatifidis, rugofis; inferiora obfoletè peltata. Flores maximi, cærulei. Stamina fetacea, glabra, bafi maximè dilatata et deltoidea. Capfulæe undique pilofæ, æquales. Semina punctata.

robertia- 5: GERANIUM pedunculis bifloris, foliis fubnum. pedatis pinnatifidis quinquangularibus, calycibus decangularibus, capfulis rugofis.

Geranium rabertianum. Sp. P\% 955. Hudf, 305. With. 608. Hull. 153. Reth. 263. Sibth. 2I5. Abbot. I49. Curt. Lond. fafc. I. t. 52. Fl. Dan. t. 694. Raii Syn. 358. Gera cn. 939. Cavan. Dif. 2 I 5. t. 86. f. I. G. quintum. Camer. Epit. 603.

G. tertium, Fuchs. Hift. 206.

B. G. lucidum faxatile, foliis Geranii robertiani, Raï Syn. 358 . 
Angl. Stinking Crane's-bill. Herb Robert.

In ruderatis, muris, et ad fepes. B. in maritimis.

Annua. Fl. Maio-Octobri.

Radix fibrofa. Caules patuli, decumbentes, fragiles, ramofi, rubicundi. Folia petiolata, ternata, fubpedata, circumfcriptione quinquangularia, foliolis pinnatifidis, fubpilofis, nitidis. Pedunculi laterales et terminales. Flores purpurei. Calyx pilofus, decangularis. Petala integra. Stamina glabra. Capfulæ tereti-oblongæ, fimpliciter carinatæ, undique reticulato-corrugatæ, interdum pubefcentes. Semina lævifima.

Herba autumno faturatè rubet. Variat petalis albis. Folia in $\beta$ maximè lucida, magifque aliquantulum carnofa.

6. GERANIUM pedunculis bifloris, foliis quin-lucidum. quelobis rotundatis, calycibus traniversè corrugatis, capfulis multicarinatis.

Geranium lucidum. Sp. Pl.955. Hudf. 304. With. 60\%. Hull. I53. Relh. 262. Sibth. 214. Abbot. 150. Engl. Bot. t. 75. Fl. Dan. t.218. Baub. Hift. v. 3. 481. Cavan. Dif. $214 . t$. So.f. 2.

G. faxatile. Raii Syn. 26r. Camer. Harcyn. 44. t. 5 . Angl. Shining Crane's-bill.

In muris, tectis, rupibufve roridis inter mufcos, præfertim in montofis.

Annua. Fl. Maio-Augufto.

Radix parva, fibrofa. Herba lucida, ferè glabra, demùm rubicunda. Caules debiles, fragiles, decumbentes, lævigati, ramofiffimi. Folia longiùs petiolata, reniformia, rotundata, quinqueloba, incifa. Flores parvi, rofei. Calyx pyramidatus, quinquangularis, tranfversè corrugatus, glaber. Petala integra, angufta. Capfulx oblongæ, compreffufculæ, utrinque reticulatæ, apice pilofe, dorfo multifulcatæ. Semina læeviffima. 
2xolle. 7. GERANIUM pedunculis bifloris alternis op. politifoliis, foliis rotundatis lobat is tomentofis, capfulis corrugat is glabris.

Gcranium molle. Sp. Pl. 955 ? Hiulf. 203. Iritb. 604. Hull. 153. Kelh. 26 r. Siliti. 213. Aibbot. 1 50. Curt. Lond. fulc. 2. t. 50. Cavan. Dilf. 203. t.83.f.3. Fl. Dan. 1.679. G. columbinun. Raii Syn. 359 .

G. alterum. Camer. Epil. 600. Angl. Dove's-foot Crane's-bill.

In pratis, pafcuis et ruderatis paffim. Annua. Fl. Aprili-Augufts.

Radix fufformis, parva, ramofi. Caules plures, patentes, hafi decumbentes, parum ramofi, teretes, pilofi, plerumque pedales. Folia petiolata, alterna, rotundatoreniformia, lobata, incifa, utrinque mollififimè pubefentit. Pedunculi folitarii, alterni, oppofitifolii; pedicelli defracti, apice adfcendentes. Flores erecti, parvi, purpurei. Calycis foliola ovata, plana, tomentofa, pilofa. Petala obcordata. Capfulæ ellipticæ, tranfversè corrugatæe, glabræ. Semina læviffina.

possgiblum. 8. GERANIUM pedunculis bifloris, foliis reniformibus palmatis incifis, capfulis æqualibus hirfutis, feminibus lævibus.

Geranium pufillum. Sp. Pl. 957. Hudf. ed. r. 266. With.ed.2. 733. Hull. 152. Relh: 262. Cavan. Diff. 202. t. 83.f. I. Dick. Dr.I'l. 78. Engl. Bot. t. 385 .

G. molle B. IIudf. $3 \circ 3$.

G. parviforum. Curt. Lond. fafc. 6. t. 46. Sibth. 2I3. Albot. I5 I.

G. malvæfolium. Witb.603. Scop. Carn. v. 2.37.

G. malvaceum $\beta$. Burm. Ger. 25 .

G. alterum. Fuchf. Hift. 205 .

G. columbinum majus, flore minore cærulco. Fail. Iar.t. I5.f. I. nec Raii. 
B. G. humile. Cavan. Diff.202.t. 83.f.2.

G. columbinum humile, flore creruleo minimo. Dill. in Raii Syn. 359. t. 16.f.2. Herb. Sherard.

G. pufillum. Burm. Ger, 27 .

Angl. Small-flowered Crane's-bill.

In ruderatis et ad fepes, imprimis folo glareofo.

Annua. Fl. Junio-Septembri.

Præcedente plerumque minor, foliis frpiùs oppofitis, profundiùfque lobatis. Flores parvi, cærulefcentes, pentandri, petalis emarginatis, calycem vix excedentibus. Calyx muticus. Capfulæ carinatæ, fuperficic æquales, nec corrugatæ, undique hirfutæ, fetis crecto-adpreffis. Semina lavifima.

Var. $\beta$ non nifi magnitudine minori differt.

9. GERANIUM pedunculis biforis, petalis calyce fyrenaiduplò longioribus, foliis reniformibus lobatis, cum. capfulis æqualibus fubpubefcentibus.

Geranium pyrenaicum. Mant. 97 et 257. Burm. Ger. 27. Hudl. 302. With.601. Hull. 152. Sibth. 212. Albot. 149. Ligbtf.367. Curt. Lond. fafc. 3. t. 42. Engl. Bot. t. 405 . Cavan. Diff. 203. t. 79.f. 2.

G. n. 12. Ger. Gallopr. 434. t. 16.f. 2.

G. columbinum perenne pyrenaicum maximum. Tourn. Inft. 268. Herb. Tournef.

Angl. Mountain Crane's-bill.

In pratis et pafcuis.

On the bank of a river between Bingley and Keighley in Yorkfhire; near Enfield ; about Brompton, Chelfea and other places in the neighbourhood of London. Hudf. In mountainous paftures and wafte places near Edinburgh; Dr. Parfons. Lightf. In a lane leading from the fouth- 
fouth-eaft part of Edinburgh to the Kingr's Park abundantly.

Percnnis. Fl. Julio.

Radix tubcrofa, perennis. Caules bi-vel tri-pedales, ereetiufculi, ramofi. Folia oppofita, reniformia, palmata, lobata, hirfuta. Flores purpurei, marni. Calyx ariftatus. Petala obcordato-biloba, calyce dupló longiora, hafi hirfuta. Staminum quinque exteriora fxpe abortiva. Capfulx carinatæ, fuperficie xquales, juniores undique pubefeentes, ætate ferè glabratæ. Semina lævia.-Variat flore albo.

A duabus precedentibus difcrepat omnium partium magnitudine duplò majori, radiceque perenni, præter characteres e petalis capfulifve defumendos. Hanc cum penultimâ olinı confudit Linnæus.

rotundi- IO. GERANIUM pedunculis bifloris, petalis intefolizm. gris, foliis reniformibus incifis tomentofis, capfulis birfutis, feminibus reticulatis.

Geranium rotundifolium. Sp. Pl. 95\%. ITuds. 303. Wilh.607. Hull. I53. Sibth. 213. Engl. Bot. t. 157. Cavan. Diff. $214 . t .93 \cdot f \cdot 2$ a G. columbinum majus, flore minore cærulco. Raii Syn. 358. nec Vaillantii.

G. colurnbinum. Ger. em. 938, ex icone:

G. malvaceum a. Burm. Ger. 24.

G. alterum. Mattb. Valyr. v, 2.208. Angl. Round-leaved Crane's-bill.

In ruderatis, aggeribus, pafcuifve fterilibus, minizs vulgaris.

About Eath, Brifol, and feveral places near London. Hudf. Allo in Northamptonfhire. Mr. E. Forflex. Common in Suffolk. Mir. Woodrard.

Annua. Fl. Junia, Julio.

Habitus trium præcedentium. Caules ramofiffimi, patuli. Herba tota mollifimè tomentofa. Folia minus profunds 
profundè lobata. Flores parvi, rofei. Petala integerrina. Capfulæ carinatæ, colore plumbeæ, undique hirfutæ, pilis patentibus. Semina pulcherrimè reticulata, nec lævia; quibus notis haud dubiè determinatur.

II. GERANIUM pedunculis bifloris, petalis emar- diffecginatis, foliis quinquepartitis laciniatis, capfulis tumb. hirfutis, feminibus reticulatis.

Geranium diffectum. Sp. Pl. 956. Hudf. 304. With. 603. Hull. 152. Relh. 263. Sibth. 214. Abbot. 150. Curt. Lond. fafc. 6. t. 45. Fl. Dan.t. 936. Cavan. Diff. 199. t. 78.f.2. G. columbinum majus, diffectis folis. Raii Syn. 359 .

G. columbinum majus, foliis imis ufque ad pedunculum divifis. Vaill. Par. t. I 5.f. 2.

F. G. columbinum maximum, foliis diffectis. Raii Syn. 360.

Angl. Jagged-leaved Crane's-bill.

In ruderatis et fterilibus glareofis, nec non arvis requictis.

Annua. Fl. Maio, Junio.

Caules ramofi, diffufi, hirfuti, pilis deflexis. Folia ad bafin ferè quinquepartita, fubhirfuta, lobis trifidis pinnatifidifve, interdum indivifis. Pedunculi breves. Calys ariftatus, tricoftatus. Petala purpurea, emarginata. Capfulæ vix carinatæ, fufcæ, fubrugofæ, undique hirfutæ, pilis patentibus. Semina pulcherrimè reticulata ut in præcedente.

2. GERANIUM pedunculis bifloris folio triplò colzmbilongioribus, foliis quinquepartitis multifidis, mum. capiulis glabris, feminibus reticulatis.

Geranium columbinum. Sp.Pl. 956. Hudf. 304. With. 603. Hull. x 52 . Sibth. 214. 
Abbot. 150. Engl. Bot.t.259. Cavan. Diff? 200. t. 82.f. I.

G. columbinum diffeetis foliis, pediculis florum longiffimis. Raii Syn. 359 .

G. diffectis foliis, pedunculis florum longiffimis. Iaill. Par. t. $15 \cdot f \cdot 4$.

Angl. Long-ftalked Cranc's-bill.

In arvis, aggeribufque, folo glareofo vel calcareo, fparfim.

Annua. Fl. Junio, Julio.

Herba gracilis, diffufa, fcabriufcula, fetis caulinis depreffis, cæteris adpreffis. Folia quinquepartita, lobis pinnatifidis, acutis. Pedunculi et pedicelli longiffimi. Flores rofei, majufculi. Calyx ariftatus, tricoftatus, pyramidatus, fcaber. Petala emarginata. Capfulæ carinatæ, læves, glaberrimæ. Semina reticulato-punctata.

fangui- 13. GERANIUM pedunculis unifloris, foliis neum. quinquepartitis trifidis rotundatis, capfulis apice fetofis.

Geranium fanguineum. Sp.Pl.958. Hudf. 305 . With. 600. Hull. I 52. Relh. 263. Engl. Bot. t. 272. Caran. Diff. 195. t.76. f. I. Dickf. H. Sicc. fafi. 16. I9.

G. hrmatodes. Riait Syn. 360 .

- G. fanguinarium. Ger. em.945.

G. fextum. Fuch. Hift. 209.

Sanguinaria radix. Trag. Hift. 348.

f. Geranium hæmatodes foliis majoribus, pallidioribus et altiùs incifis. Raii Syn. 360 .

$\gamma$. G. hæmatodes Lancaftriente, flore eleganter ftriato. Raii Syn. 360 . Dill. Elth. ${ }_{16} 6 . t .{ }_{3} 6$.

G. lancaftrienfe. With. 600. Hull. 152. G. proftratum. Cavan. Dif. 196.t. $76 . f \cdot 3$. 
Angl. Bloody Crane's-bill.

Indumetis montofis petrofis, rupibufve calcareis.

$\gamma$. On the fandy coaft of the infe of Walney, Lancafhire.

Perennis. Fl. Julio-Septembri.

Radix lignofa. Canles debiles, divaricati, geniculati, pilofi. Folia quinque-vel feptem-partita, lobis trifidis vel pinnatifidis, pilofa, circumfcriptione rotundata. Pedunculi longiffimi, pedicello folitario, unifloro. Flores maximi, fanguinei. Calycis foliola ariftata, pilofa, plerumque quinquenervia. Capfulæ carinatæ, læves, apice fetofæe, interdum difpermæ. Semina minutiffimè corrugatar

y vix differt nifi caule proftrato, ramis floriferis crectis, petalis carnèis purpureo-venofis. Huic caulem erectum IVitheringius, proft ratum Cavanilles, tribuit.

Varietatem pedunculis quandoque bifloris ex Helvetin mifit amiciffinus Davallius.

\section{POLYANDRIA.}

316. ALTH压A. G. Pl. 353. Fuf. 272.

Garln. t. I 36 .

Cal. duplex; exterior fub-novemfidus. Capf. plurimx, monofpermæ, in orbem difpofitæ.

1. ALTHEA foliis fimplicibus tomentofis fub-officinaquinquelobis.

Althæa officinalis. Sp. Pl. 966. Hudf. 306. With. 6ri. Hull. 155. Relh. 264. Engl. Bot. t. 147. Woodv. Med. Bot. t.53. Fl. Dan. t. 530 .

A. vulgaris. Raii Syn. 252.

A. Ibifcus. Ger. em. 933 .

Althar. 
Althxa. Fuchj. Hijt. 15. Matth. Valgr. ข. 2. 276 .

B. A. vulgari finilis, folio retufo brevi. Raii Synt 252.

Althea, radix, folium. Pharmar. Lond. Angl. Marn Mallow.

In paluftribus maritimis copiosè.

Pcrentis. Fl. Julio-Septembri.

Radix fufformis. Caules erecti, ferè tripedales, fimplices; teretes, viminei, foliofi. Folia alterna, petiolata, kordata, acuta, fubquinqueloba, plicata, ferrata. Paniculæ. axillares, denfæe, multifloræ, petiolis breviores. Calyx cxterior fæpè decemfidus, etiam duodecimfidus ; interior quinquefidus. Corolla et ftamina purpureo-carnea. Stigmata numerofa. ' Capfulæ compreffæ. Herba tota molliffimè pubefcens, pilis ftellatis, intertextis.

\section{I7. MALVA. G.Pl.354. Jul. 272. \\ Gertn.t. ${ }_{3} 6$.}

Cal. duplex; exterior fubtriphyllus. Capf. plurimæ, monofpermæ, in orbem difpofitæ.

I. MALVA caule erecto herbaceo, foliis feptemlobatis acutis, pedunculis petiolifque pilotis. Malva fylveftris. Sp.Pl. 969. Hudf.307. With. 613. Hull. I55. Relh. 265. Siblth. 215. Abbot. 15 1. Curt. Lond. fafc. 2.t. 5 1. Woodv。 Med. Bot. t. 54. Ger. em. 930: Engl. Bot. t. $67 \mathrm{I}$.

M. vulgaris. Raii Syn. $25 \mathrm{r}$.

M. fylveftris elatior. Fuchs. Hift. 509.

M. equina. Brunf. Herb.v. 2. $7 \mathrm{I}$.

Malva, folium, flos. Pharmac. Lond. Angl. Common Mallow.

Ad fepes et femitas, inque ruderatis ế cultis. 
Perennis. Fl. Maio-Augufto.

Radix fufiformis, ramofa, albida. Caulis plerumque erectus, ramofus, teres, pilofus, multiflorus. Folia alterna, petiolata, cordata, plicata, feptemlobata, fcabriufcula, crenata; fuperiora ferè palmata. Pedunculi aggregati, pilofi, uniflori. Flores purpurei. Petala obcordata, calyce triplò longiora. Calyx hifpidus.

2. MALVA caulibus proftratis, foliis cordato-orbi- rotundiculatis quinquelobis, pedunculis fructiferis de- folia. clinatis.

Malva rotundifolia. Sp. Pl. 969 . Hudf. 307. With.612. Hull. 155. Relh. 265. Sibth. 215. Abbot. I5 I. Curt. Lond. fafc. 3. t. 43. Fl. Dan. t. 72 r.

M. fylveftris minor. Raii Syn. $25 \mathrm{I}$.

M. fylveftris pumila. Ger. em. 930. Fuclos. Hift. 508.

Malva. Brunf. Herb. ข. 2. 70.

B.M. pufilla. Engl. Bot. t. 24I. With. 6 I 2. Hull. 155 .

M. parviflora. Hudf. $30 \%$.

M. minor, flore parvo cæruleo. Dill. in Raii Syn. 25I.

Angl. Dwarf Mallow. B. Small-flowered Mallow.

In ruderatis et ad vias,

B. Near Hithe in Kent. Sherard. Hudf.

Annua. Fl. Junio-Septembri.

Radix ramofa, albida. Caules plures, proftrati, fubfimplices. Folia minora quam in priore, quinque- vel feptem-lobata. Flores carnei.

\& vix differt nifi petalis minoribus, haud calyce longioribus.

3. MALVA foliis radicalibus reniformibus incifis ; mo chaVoL. II.

$\mathrm{X}$ caulinis ta. 
caulinis quinquepartitis pinnato-multifidis, calyce piloto.

Malva mofchata. Sp. Pl. 971. Hudf.308. With. 6 1 3. Hull. I 55. Relb. 266. Sibth. 216. Abbot. I5 I. Curt. Lond. fafc. 4. t. 50. Fl. Dan. t. 905 .

M. five Alcea montana. Column. Ecplir. 147. Alcea tenuifolia crifpa. Baub. Hift. v. 2. 1067. Dill. in Raii Syn. 25.3.

A. vulgaris. Raii Syn. 253, fynonymis omninè erroneis.

Angl. Mufk Mallow.

In agrorum marginibus ct ad vias, folo glarcofo.

Perennis. Fl. Julio, Augufto.

Radix fublignofa, tenax. Herba pilofo-fcabra, ambrofiaca.

Caules ercetiufculi, fubramofi. Folia inferiora cordatoreniformia, lobata; fuperiora quinquepartita, laciniis pinnatifidis, incifis, canaliculatis. Flores magni, fpeciofi, rofei.

A M. Alceâ Linnæi, nequaquam Britanniæ indigenâ, differt foliis laciniatis, odoratis; calyce pilofo, nec densed tornentofo, foliolis exterioribus lineari-lanceolatis, nec ovativ.

\section{LAVATERA. G.P. 35t. Juf. 272. Gertu. t. 136 :}

Cal. duplex; exterior trifidus. Capf: plurima, monofperma, in orbem difpofita.

mborea. 1. LAVATERA caule arboreo, foliis feptemangularibus tomentofis plicatis, pedunculis axillaribus confertis uniforis.

Lavatera arborea. Sp. Pl. 972. Hudf. 306. Itith. 6i4. Hull. I54. Lightf. 374 . Cavan. Diff. 86 , et 282 . t. $139 \cdot f .2$.

Malva arborea marina noftras. Raii Syn. 252. 


\section{Angl. Sea Tree-Mallow.}

In petrofis maritimis, rariùs.

On the Bafs and other iflands on the Scottinh coaft; alfo in Portland ifland, and at Hurft caftle oppofite to the ine of Wight. Ray. In Cornwall and Devonthire. Hudj. In Pembrokefhire. Mr. Adams.

Biennis. Fl. Julio-Octobri.

Caulis arborefcens, fexpedalis, teres, nudus, apice foliofus. Folia longiùs petiolata, cordata, angulato-lobata, plicata, tomentofa. Flores numerofi, axillares, fubterni, pedunculati, purpurei, ore violacei, formofi, nitidi. $\mathrm{Ca}$ lyx exterior maximus, foliaceus, trilobus; interior quinquefidus, lanatus. 



\section{Clafis XVIT. DIADELPHIA.}

Filamenta in duo corpora connexa.

\section{HEXANDRIA.}

\section{Stamina 6.}

3ig. FUMARIA. Cal. diphyllus. Cor. ringens; bafi gibbofa nectarifera. Fílám. antheris tribus.

\section{OCTANDRIA。}

Stamina 8.

320. POLYGALA. Cal. laciniæ 2 alæformes. Cor. vexillum cylindricum. Legumen obcordatum, biloculare.

\section{DECANDRIA:}

Stamina 10.

* Stamina omnia connera, feu monadelpba, tubo füpernè Sepius fiffo.

32I. SPARTIUM. Filam. germini adhærentia. Stigma adnatum, villofum. 
322. GENISTA. Piffillum deprimens carinam, vexillo reflexo.

323. ULEX. Cal. diphyllus. Legumen vix calyce longius.

325. ANTHYLLIS. Cal. turgidus, legumen includens.

324. ONONIS. Cal. quinquepartitus. Legumer rhombeum, fefile. Vexillum ftriatum.

** Stigma pubefcens. (nec priorum notr.)

327. OROBUS. Styhus linearis, terctiufculus, fupra villofus.

326. PISUM. Stylus fupra carinatus villofufque. 328. LATHYRUS. Stylus fupra planus villofufque.

329. VICIA. Stylus fub ftigmate barbatus.

330. ERVUM. Stigma capitatum, undique ptbefcens.

**** Legumen fub-biloculare. (nec priorum notæ.)

334. ASTRAGALUS. Legumen biloculare, gibbum.

***** Legunen fubmonofpermum. (nec priorum notæ.)

335. TRIFOLIUM. Legumen vix calyce longius, I five polyfpermum, non dehifcens, deciduum. Flores capitati.

***** Legumen fubaritulatum. (nec priorun not:e.)

333. HEDYSARUM. Leegumen articulis monofpermis, compreflis. "Carina obtufifima.

33r. ORNITHOPUS. Legsumen articulatum, arcuatum. 


\section{( 547$)$}

332. HIPPOCREPIS. Legumen comprefio-membranaceum, alterâ futurâ pluriès emargina. tum, curvum.

337. MEDICAGO. Legumen fpirale, compreffomembranaceum. 'Piftillum carinam deflectens.

******* Legumen uniloculare, polispermum. (nec priorum n'otæ.)

336. LOTUS. Legumen teres, farctum. Ala fursùm longitudinaliter conniventes. 


\section{DIADELPHIA.}

\section{HEXANDRIA.}

319. FUMARIA. G. Pl. 362. Juf. 237. Gartn.

t. I I 5 .

Capnoides. Gertur. t. II5.

Cal. diphyllus. Cor. ringens. Filamenta duo, mombranacea, fingula cuntheris tribus.

folida. I. FUMARIA caule fubfimplici erecto, foliis bitcrnatis, bracteis palmatis pedunculo longioribus.

Fumaria folida. Lim MJ. in Sp. Pl. Curt. Mag. t. 231 .

F. bulbofa $\gamma$. Sp. Pl. 983.

F. minor. Gmel. Syjt. 1080.

F. intermedia. With.620.t.29.

F. bulbofa, radice non cava, major. Baub. Pin. I 44 .

Angl. Solid Bulbous Fumitory.

In nemorofis.

About Kendal and in other parts of Weftmoreland; alfo at Perry Hall near Birmingham. Witb.

Perennis. Fl. Aprili, Maio.

Radix bulbofa, folida. Caulis erectus, fpithamæus, plerumque fimplex, rariùs bifidus, teretiufculus, foliofus, glaber. Folia alterna, pauca, petiolata, biternata, lievia; foliolis fubcuneatis, apice incifis. Spica terminalis, folitaria, fimplex. Bractere palmato-quinquefidæe, pedunculis lnngiores. Flores bafi pallidi, apice purpurei. Calcar pedunculo æquale, cylindraceum, obtufiufculum. Siliqua brevis, bivalvis, polyfperma, bafi dehifcens. 
2. FUMARIA filiquis teretiufculis pedunculo bre- luted. vioribus, caulibus angulatis, bracteis minutis, calcari breviffimo rotundato.

Fumaria lutea. Niant. 2. 258. Bauh. Pin. I43. Mill. Ic. t. г 36. f. I. Mill. Mlluftr. t.60. Gmel. Sy/t. I080. Ait. H. Kew. v. 3.2. Engl. Bot. t. 588. Ger. em. 1088.

F. capnoides. With. 620.

F. corydalis. Matth. Falgr. v.2.503. Camer. Epit. 892.

F. lutea montana. Dalech. Hift. r 293 .

F. tingitana, radice fibrosâ, percnnis, flore ex albo flavefcente, filiquis curtis. Pluk. Phyt。 t. go.f. 2.

Capnoides lutca. Gertn. v. 2. $16_{3}$.

Pfeudo-Fumaria flore lutco. Riv. Tetrap. Ir\% t. $75 . f_{\text {. } \mathrm{I} .}$

Angl. Yellow Fumitory.

In muris antiquis.

On old walls near Caftleton, Derbyfhire, far from any garden: Mr. Robfon. With. Near Fountain's Hall, by Fountain's Abbey. Mr. Wr. Brunton, jun.

\section{Perennis. Fl. Maio.}

Radix fibrofa. Caules ferè pedales, erecti, fubramofi, trigoni, glabri, rubicundi, foliofi. Folia triternata; foliolis latè cuneatis, trifidis, glaberrimis, glaucefcentibus. Spica terminalis. Bracteæ minutæ, ovatæ, acutæ, ferratæ. Flores flavi, apice fulvo. Calcar breviffimum, rotundato-incurvum. Siliqua teretiufcula, pedunculo brevior.

A F. capnoide Linn. differt radice perenni, florum colore faturatiori, calcari breviffimo rotundato, nec fubulato, filiquis duplò brevioribus, teretiufculis, nec triquetris. 
effisina- 3. FUMARIA fpicis laxis, filiquis monofpermis lis. globofis cmarginatis, caule diffufo, foliolorum laciniis dilatatis.

Fumaria officinalis. Sp. Pl. 984. Hudf. $30 g, \alpha$ : With. 620. Relh. 267, a. Sibth. 217. Albont. 152. Curt. Lond. faff. 2. t. 52. Mart. H\% Ruft.t.68. Woodv. Med. Bot. t.88. Engl. Bot.t.589. Fl.Dan. t.940. Dreves. Bil. derb. t. 16 .

F. vulgaris. Raii Syn. 204.

F. purpurea. Ger. em. 1088.

Fumaria. Riv. Tetrap. Irr.t. I.

Fumus terræ. Brunf. Herb. v. I. 99.

Angl. Common Fumitory.

In arvis, hortis, et ad repes vulgaris.

Annua. Fl. Maio-Augufto.

Radix parva, fufformis. Herba glauca, lævis. Caulis ramofifinus, diffufus, angulatus, foliofus. Folia bipinnata; foliolis cuneatis, lobatis, dilatatis. Spicæ oppofitifoliæ, folitariæ, laxæ, multifloræ. Bracteæ exiguæ. Flores rofei, apice fanguinei, petalorum carinâ viridi. Calcar breve, obtufum. Siliqua ferè globofa, lævis, apice retufa et fcrobiculata. Semen folitarium, globofum.

parviflo 4. FUMARIA fpicis laxis, filiquis monofpermis ra. globofis acuminatis, caule diffufo, foliolorum laciniis linearibus canaliculati .

Fumaria parviflora. Lamarck. Encycl. v. 2.56\%. Engl. Bot. t. 590.

F. Ipicata ß. Syft. Veg.ed. I 4. 637 .

F. tenuifolia. Sym. Syn. 200. Synonymis omnibus, ni fallor, erroneis.

F. foliis tenuiffimis, floribus albis, circa Monfpelium nafcens. Vaill. Par. 56. 6. Iо. f. 5 . 
Anzl. Small-flowered Fumitory.

In arvis Anglix auftralioris.

In the corn-fields about Woldham, near Rochefter. Mr. Jacob Rayer. Near Epfom. Mr. T. $F$. Forfter jun.

Annua. Fl. Angufto, Septembri.

Habitus præcedentis, fed foliorum lacinix anguftifimx, lineares, canaliculatr, fubtùs convexæ, nequaquam dilatatæ vel cuneatæ; flores cluplò ferè minores, pallidiores. Siliqua fubglobofa, acuminata, nec fcrobiculato-emarginata.

F. fpicata Linnæi dignofcitur filiquâ ellipticâ, comprefsá, utrinque excarato-punctatà, margine incruffatâ.

5. FUMARIA fpicis laxis, filiquis monofpermis capresglobofis, caule petiolis contortis fandente, latu. foliolis cuncatis lubatis.

Fumaria capreolata. Sp. Pl. 985. With.621.

t. 30. Sibth. 21\%. Curt. Lond. fafc. 6. t. $4 \%$

Dicks. H. Sicc. fue. 9.9. lightf. 380.

F. officinalis B. Elull. 309 . Relh. 267.

- F. major fcaudens, flcre pallidiore. Raik sin. 204.

Angl. Ramping Fumitory.

In arvis, imprimis Anglix aufralioris.

Rarely about London; more plentiful abont Barnftaple, Devonfhire, and eliewhere. Curt.

\section{Annua. Fl. Junio-Septembri.}

Caulis ramofiffimus, fæpe tripedalis, fcandens petiolis cirrhorum modo contortis. Folia bipinnata, foliolis latioribus quam in F. officinali, minufque glancis. Spicx laxæ, panciforæ. Flores dilutè carnei, apice atrofanguinei, formofi, majores. Siliqua fubolobofa, nitida, apice retufo bifcrobiculato. 

6luvicu- 6. FUMARIA filiquis lanceolatis lacvibus fubtri=
lata. fpermis, caule fcandente, petiolis cirrhofis. Fumaria claviculata. $S_{p} . P$ Pl. $^{85}$. Hudf. 30g. With. 621. Engl. Bot. t. 103. Fl. Dar. t. 340 .

F. aiba latifolia. Raï Syn. 335. claviculata. Ger. em. Io88.

Capnos alba latifolia. Lob. Ic. 758. Dalech. Hift. 1295.

Angl. White Climbing Fumitory.

In dumetis roridis, folo glareofo vel petrofo.

Annua. Fl. Junio, Julio.

Radix parva, fibrofa. Herba lævis, tenerrima, fúccofa.

Caulis ramofus, foliofus, rubicundus, hinc complanatus. Folia pinnata, cirrhifera, foliolis ternatis vel pedatis, ellipticis, acutis, integerrimis, fubtùs præcipuè glaucis. Spicæ paucifloræ. Flores albidi. Siliqua lanceolata, acuta, lævis. Semina duo vel tria, reniformia.

\section{OCTANDRIA.}

320. POLYGALA. G. Pl. 364. Jul. 99 :

Gertn. t. 62.

Cal. pentaphyllus : foliolis duobus maximis, aleformibus, coloratis. Legumen obcordatum; biloculare.

vislgaris. 1. POLYGALA floribus criftatis racemofis, eaulibus 
libus herbaceis fimplicibus procumbentibus, foliis lineari-lanceolatis.

Polygala valgaris Sp. Pl. 986. Huds. 3 ro. With. 622. Hull. 158. Relh. 268. Sibth。 218. Abbot. 153. Engl. Bot. t. 76. Fl. Dan. t. 5 16. Dick. H. Sicc. fafc. I6. 17.

Polygala. Raii Syn.*287. Ger. em. 563.f. 3, 4, et $564, f \cdot 5$.

Polygalon. Trag. Hift. 57 I.

Angl. Milkwort.

In pafcuis et apricis glareofis.

Perennis, Fl. Junio, Julio.

Radix lignofa. Herba glabra. Caules decumbentes. Folia lanceolata, integerrima, latitudine et longitudine varia. Flores fæpiùs cyanei, interdum albi, incarnati, vel violacei. Calyx corollæ concolor, demùm virefcens.

\section{DECANDRIA}

321. SPARTIUM. G. Pl. 368. Gertn.t. 153 . Genifta. Juf. 353 .

Stigma longitudinale, fupra villofum. Filamento monadelpha, germini adhærentia. Cal. deorsùm productus.

7. SPARTIUM foliis ternatis folitariifque, ramis $\int c o p a r i-$ inermibus angulatis.

Spartium fcoparium. Sp. Pl. 996. Hudf. zio. With. 623. Hull. I58. Relh. 268. Sibth. 2 I 8. 
218. Abtor. 153. Curt. Lond. fafi. 5. t. 52. Wonde. Med. Bot. t. 89. H. Dan. t. 313. Dreves. Bilderb. $t .48$.

Genitia. Ger. em. I311. Camer. Epit. 950. I'uch. Itift. 28.

C. angulora trifolia. Raii Syn. 474 .

Genifta, cacumen, femen. Pbamac. Lond. Angl. Common Broum.

In campis et dumetis ficcioribus.

Frutex. Fl. Maio, Junio.

Rami numerofi, ftricti, angulati, fempervirentes, glabrị, fo linfi. Folia ternata, parva, glabra ; fuperiora frequentiùs fimplicia. Flores axillares, folitarii, pedunculati, nutantes, magni, fpeciofi, papilionacei, aurei, interdum extùs fulvi, rariffimè toti citrini. Calyx fubcampanulatus, bilabiatus, hians, lævis, purpurafcens, apice quinquedenticulatus. Stamina omnia bafi in tubum comnexa. Germen villofum. Stylus demùm intortus. Legumen compreffum, fufcum, ciliatum, polyfpermum. Semina compreffi, nitida.

Hoc genus fequenfque in unum coegerunt Lamarckius ct Juffieus, nec forfitan immeritò.

322. GENISTA. G. Pl. 368. Ju/. 353 .

$$
\text { Gertn. t. I5 } 1 \text {. }
$$

Cal. bilabiatus; labio fupcriore bidentato, inferiore tridentato. Texillum oblongum, a piftillo ftaminibufque deorsim reflexum.

sincloria. I. GENISTA foliis lanceolat is glabris, ramis teretibus ftriatis erecis inermibus.

Genifta inctoria. Sp. Pl. 998. Mhudf. $3 \mathrm{II}$. IVith. 624. Hull. 159 Relh. 269. Sibth. 219. Abbot. 153. Eingl. Bot. t. 44. Dicks. H. Sicc. fafc. 3. 1 1. H. Dan. $1.5=6$.

Geniftella tinctoria. Puii Syn. 474. Ger. ema I 316.

Tinctorius 
Tinctorius flos. Fuchf. Hift. 808.

Angl. Dyer's Green-weed. Wood-waxen.

In pafcuis, dumetis, et ad margines agrorum.

Frutex. Fl. Julio, Augufto.

Radix lignola. Rami crecti, vel adfcendentes, rarius procumbentes, ftricti, coarctati, angulato-teretes, fulcati, glabri, folinfi. Eolia alterna, fefilia, fimplicia, lanceolata, glabra, interdum fubtùs margineque pilofiufcula. Flores axillares, folitarii, fubfeffiles, aurei. Calyx angulatus, dentibus lanceolatis, acutis. Legunnen teretiufculum, polyfpermum.

2. GENISTA foliis obovato-lanccolatis obtufis pilofa fubtìs pilofis, caule tuberculato decumbente inermi.

Genifta pilofa. Sp. Pl.999. Hudf. 3 I I. With. 625. Hull. r 59. Eingl. Bot. t. 208. DickJ. II. Sicc. fajc. 16. i 6. Jacq. Auftr. 1. 208, ex ipfius herbario.

Chamægenifta prima. Clus. Pann. 50, Hijl. ข. 1. 103 .

C. pannonica. Ger.cm. I3 3 3. Angl. Hairy Green-weed.

In ericetis campifie arenofis elatioribiss.

On high fandy ground about Bury, Suffo!k. Mr. Dickfon. At the foot of Cader Idris, North Wales; Mr. Griffith. With. On foap rocks near the Lizard point. Sir 'T. G. Cullum, Bart.

Frutex. Fl. Maio.

Radix lignofa. Caules proftrati, ramofi, ftriati, tubcrculati. Folia fafciculata, fimplicia nec (ut apud $\mathrm{Engl}$. Bot. ex crrore memoravi) ternata, petiolata, magis vel minis angufè lanceolata, obtufiffma; fuprà glabra; fubtus fericea. Flores folitarii, axillares, pedunculati, 6 flavi, 
flavi, extùs fericei. Calyx fericeus, Legunen hirtum, compreffum, fubdifpermum.

anglica.

3. GENISTA fpinis fimplicibus, ramis florifẹris inermibus, foliis ovato-lanceolatis.

Genifta anglica. Sp. Pl. 999. Hudf. 3 1 1. With. 625. Hull. 159. Kelh. 269. Sibth. 2 19. Abbot. I54. Engl. Bot. t. I32. Dickf. H. Sicc.fafc.3.12. Fl. Dan. t. 619.

G. minor afpalathoides, five Genilta fpinofa anglica. Raii Sin. 475 .

G. aculeata. Ger. em. I 320.

Angl. Needle Green-weed. Petty Whin.

In ericetis humidis, folo fpongiofo.

Frutex. Fl. Maio, Junio.

Radix lignofa. Caules erectiufculi, ramofi, fpinofi, fpinis fimplicibus, patentibus, fubulatis, valdè pungentibus, junioribus bafi foliolofis. Rami floriferi inernes. Fclia alterna, ovata, acuta, glabra. Flores axillares, folitarii, breviùs pedunculati, citrini, vexillo aureo. Calyx glaber. Legumen glabrum, turgidum, polyfper mum.

323. ULEX. G. Pl. 379. Jll J.352. Gartn. t. I5I.

Cal. diphyllus. Legumen vix calyce longius, Stam. omnia connexa.

eureper- 1. ULEX dentibus calycinis obfoletis conniventibus, bracteis ovatis laxis, ramulis erectis.

Ulex curopaus. ip. Pl. 1045. Hudf. $3=2$. Forft. in Sym. Syn. 160. With. 626. 1. tiull. 159. Relh. 269. Sibth. 220. Abbot. 154. H' Dan. 1. 608 .

U. grandiflorus. Pourr. Al. Iolof. v.3.333. 
Genifta fpinofa vulgaris. Raii Syn. 475. Ger. em. I3Ig.

Geniftellæ fpinofæ affinis, Nepa quibufdam. Baub. Hift. v. I. p. 2. 400.

Scorpius primus. Cluf. Hitt. v. I. 106.

Angl. Common Furze, Whin or Gorfe.

In fabulofis ferilibus, et cricetis, vulgaris.

Frutex. Fl. Maio-totoque ferè anno.

Rami denfiffimi, fulcati, hirfuti, fpinofiffimi. Spinæ porrectæ, compofitæ, angulatæ, maximè pungentes, glabræ, fempervirentes, foliolofæ, fæpe floriferæ. Folia ad bafin fpinarum et fpinularum, folitaria, fubulata, pungentia, fcabriufcula, fæpe hirfuta, decidua. Pedunculi axillares, folitarii vel binati, uniflori, villofi. Bracteæ calyci approximatæ, laxæ, rec adpreffæ, fubinde patentes, ovatæ, concavæ, tomentofæ, calyce quintuplò ferè breviores. Calyx tomentofus, foliolo fuperiori apice bidentato, inferiore tridentato, dentibus exiguis, obtufis, conniventibus. Corolla calyce fefquilongior, aurea, odore mellino. Stamina monadelpha, tubo fupernè fiffo. Legumen oblongum, pubefcens, fubtetrafpermum.

2. ULEX dentibus calycinis lanccolatis diftanti-nanus bus, bracteis minutis adpreffis, ramulis decum. bentibus.

Ulex nanus. Forfe. in Sym. Syn. I6o.

U. curopæus B.SP. Pl. 10+5. Hudf. 3 I 2. Relh. 270. With. 626.2. Hull. I59.2.

Genifta fpinofa minor. Raii Syn. 475 . fingl. Divarf Furze.

In ericetis elatioribus.

Frutex. Fl. Augufto-Octobri.

Præcedente longè humilior, ramis decumbentibus, fpinis brevioribus, floribus minoribus. Bracteæ exiguæ, fæpe vix manifefæ, calyci adpreffæ, monente amiciffimo $D$. YOL. II, 
Stackhoufio. Calyx fericeus, minufque tomentefus, dentibus maximè confpicuis, altè incifis, ac diffantibus. Corolla calyce parum longior, colore minus quam in priore fulgenti. Legumen hirtum.

\section{ONONIS. G. Il.370. Jilf. 354. \\ Gartn. t. I54.}

Cal. quinquepartitus; laciniis lincaribus. Vexillum tiriatum. Legumen turgidum, rhombeum, feffile. Filamenta monadelpha abfque fiffurà.

arvenfis. i. ONONIS caule villofo, ramulis demùm fpinefcentibus, floribus fubfolitariis, foliis fubfimplicibus pofticè integerrimis.

Ononis arvenfis. Lightf. 386. Relh. 2\%0. Engl. Bot. 1.682.

s. O. inermis $\alpha$. Hudf. 3 โ2.

O. arvenfis. With. 627. Hull. 160. Sibth. 220. Abbot. 155 .

Anonis non fpinofa, purpurea. Raii Syn. $33^{2}$.

3. Ononis Ipinofa $\beta$. Sp. Pl. 1006.

O. fpinola. Syjt. Veg.ed. I 4. 65I. ILudf.3 Iz. Itith. 627. Hill. 160. Sibib. 220. Ablot. 55. Retz. Prod. I69. Olg. Bot. falfe.2. 2 I. Fl. Dan.t. $78_{3}$. Hort. II. Ruft. t. I 29.

O. antiquorum. Sp. $Y$ l. I006, vix differt. Anonis. Fuchs. Hijt. 60.

A. fpinofa, flore purpureo. Raii Syn. 332.

A. five Refta bovis. Ger. em. I 322 .

$\%$ Ononis repens. Sp. Pl. 1006. Syf. I'eg. ed. I 4 65 . Lighif. $3^{8 \%}$.

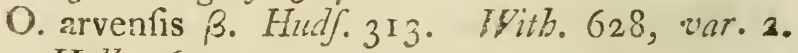
Inill. 160 .

Anonis procumbens maritima noftras, foliis hirfutie pubercentibus. Raii Syn. 332 . 
A. maritima procumbens, foliis hirfutie pubercentibus. Dill. Elth. 29. t. 25 . Angl. Reft-harrow. Cammock.

In pafcuis fterilioribus agrorumque marginibue, ê ad vias, $y$ in maritimis arenofis,

Perennis. Fl. Junio-Augufto.

Radix lignofa, multiceps, nigricans. Caules erectiufcult vel procumbentes, annui, teretes, lignofi, ramofi, foliofi, pilofi, ramulis in ftirpe annofiori, præcipuè folo fterili, fpinefcentibus. Folia alterna, petiolata, cuneato-elliptica, lineata, fcabriufcula, bafi integerrima, apicem verfus denticulato-ferrata, inferiora fæpè ternata. Stipulæ maximæ, connatæ, ovatæ, amplexicaules, dentatæ. Flores axillares, folitarii, pedunculati, rofei. Calyx pilofus, dentibus lineari-lanceolatis, acutis, adfcendentibus, maturefcente fructu dilatatis, perfiftentibus. Vexillum alis carinâque duplò longius. Legumen calycem vix excedens, pilofum. Semina tiberculato-punctata.

Var. a præcipuè hircun olet.

Folia in $\beta$ minora, floribus breviora; in $\alpha$, longiora funt. Ramuli in $y$ etiam frequentèr fpinefcunt.

Diverfa fpecies videtur O. hircina, Jacq. Hort. v. I. t. 93. Syft. Veg.ed. I+. 651. Ait. Hort. Kewv. is. 3. 21, cui folia omninò elliptica funt, frepiùs ternata, undique ferè ferrata, caules erecti, altiores, flores frequentiùs binati. Hæc eft vera Ononis fpinofa mitis, Sp. Pl. Ioo6, O. arvenfis, Retz. Obf. fafc. 2. 21. Prodr. I69, Anonis mitior prima, Cluf. Hift. ข. 1. 99, A. non fpinofa purpurea, Ger. em. 1322; necdum, quantum ccio, in Britanniâ inventa fuit.

\section{ANTHYLLIS. G.Pl. 37т. Juf. 355. Gartn. t. 145 .}

Cal. ventricofus. Legumen fubrotundum, calyce tectum. Stamina monadelpha.

1. ANTHYLLIS herbacea, foliis pinnatis inæ-oulnera qiualibus, capitulo duplicato. rik.

$$
\mathrm{Y}_{2} \quad \text { Anthyllis }
$$


Anthyllis vulncraria. Sp. Pl. Iо I2. Hudf. 313. II ill. 629. Hull. 159. Relh.271. Sibih. 221. Abbot. I55. Dick. H. Sicc. farfc.3. 10. Engl. Bot. t. I 04. 1\%. Wan. t. 988.

A. leguminofa. Ger. cm. I 240.

Vulneraria rultica. Raii Syn. 325. Bauh. Hift. ข. 2.362 .

B. V. fupina, flore coccineo. Dill. in Raii Syn. 325 . H. Elth. 43 I. t. 320.

Angl. Kidncy-vetch. Ladies'-finger.

In pafcuis cretaceis ct arenofis.

B. In Pembrokenhire. Mi. Lbreyd.

Perennis. Fl. Junio-Augufto.

Radix lignofa. Caules decumbentes, parùm ramofi, foliofi, teretes, hirti, pilis adpreffis. Folia lyrato-pinnata, integerrima, glaucefcentia, fubtùs pilofa; inferiora latiora. Capitula terminalia, gemina, multiflora, bracteata, bracteis palmatis. Flores aurei; in $\beta$ punicei. Calyx membranaceus, albidus, pilofus.

\section{PISUM. G. Pl. 374. JuJ. 360. Garm. t. I52.}

Stylus triangulus, fupra carinatus pubefcens. Calycis lacinix fupcriores duæ breviores.

maritimucm.

I. PISUM petiolis fupra planiufculis, caule angulato, flipulis fagittatis, pedunculis multifloris. Pifum maritimum. Sp. Pl. roz7. Hull. 3 I 3. With. 629. Hull. 160. Sin. Spicil. 8. t. 9. Fl. Dan. t. $33^{8}$.

P. marinum. Raï Syn. 3 I 9.

P. fpontaneum perenne repens humile. Morif. feit. 2. t. I. f. 5 :

Pifa fponte nafcentia. Caï Opufc. lib.2.29.2. Ger. em. I 250. 


\section{Angl. Sea Pea.}

In maritimis petrofis.

On the pebbly beach near Orford, Suffolk, abundantly, and near Haftings, Suffex. Ray. On the weft fide of Denge-nefs, near Lyd in Kent. Cambden. In Lincolnfhire. With. On the tharp ridge running from Portland ifland to Bridport. Mr. Stackboufe.

Perennis. Fl. Julio.

Radix repens, ramofa, longiffimè defcendens. Caules procumbentes, fimplices, foliofi, quadranguli, fubcompreffi, flexuofi, glabri, rubicundi. Folia abrupte pinnata, cirrhofa, foliolis fuboctonis, alternis, ellipticis, integerrimis, glabris, reticulato-venofis. Petioli communes fupra complanati. Stipulæ reflexæ, fagittatæ, bafin verfus dentatæ. Racemi axillares, folitarii, pedunculati, multiflori. Flores pedicellati, cernui, fpeciofi. Calyx glaber. Vexillum magnum, emarginatum, purp:reum, venis dorfoque fanguineis. Alæ et carina cæruleo-incarnatæ. Stamina diadelpha. Stigma adfcendens. Legumen compreffum, læve, polyfpermum.

\section{OROBUS. G. Pl. 374. Juff. 360. Gertn. 1. I5 I.}

Stylus linearis, teretiufculus, fupra villofus. Cal. bafi obtufus; laciniis fuperioribus profundioribus, brevioribus.

I. OROBUS foliis pinnatis elliptico-lanceolatis, tuberoftipulis femifagittatis bafi dentatis, caule fim- fus. plici.

Orobus tuberofus. Sp.Pl. 1028. Hudf. 314. With.631. Hull. 160. Sibth. 221. Abbot. 155. Lightf. 388 . Curt. Lond. fafc. 1. t. 53. Dick. H. Sicc.fafc. I. I . Fl. Dan. t. $78 \mathrm{I}$. O. fylvaticus, foliis oblongis glabris. Räi Syn. 324. 
Aftragalus fylvaticus. Ger. em. 1237. Sibb. Scot.t. I. Camer. Harcyn. 7. t. I. Aingl. Common Orobus. Heath Pea.

In pafcuis, dumetis et nemorofis, precipuè montanis.

Perennis. Fl. Maio, Junio.

Radix tuberofa, extùs nigra. Caules pedales, erecti, fime plices, foliofi, angulati, ftriati, glabri. Folia alterna, bi- vel tri-juga, petiolo communi complanato, cirrho deftituta; foliola feffilia, oppofita, elliptico-lanceolata, mucronulata, nervofa, atroviridia, glabra. Stipulæ utrinque acutæ, contra infertionem dentatæ. Racemi 2 vel 3 , caulis apicem verfus axillares, folitarii, pauciflori. Flores magni, cernui, amœni, purpurco fanguineoque varii, demùm cxrulefcentes. Calyx atropurpureus, glaber. Legumen pendulum, teretiufcullun, nigrum, polyfpermum. Stylus anticè canaliculatus, perfiftens.

Sylvatisus.

2. OROBUS caulibus decumbentibus hirfutis ramofis, foliolis numerofis.

Orobus fylvaticus. Sp. Pl. ro29. Hudf. 3 I4. With. 630. Lightf. 390. t. I6. Hull. 160. Engl. Bot. t. 5 I ठै. Dickf. IT. Sicc. fafc. I. 12. O. fylvaticus noftras. Raii Syn. 324 . Vicia caflubica. Fl. Dan. t. 98. nec Linn. Angl. Wood Orobus or Bitter-Veich.

In fylvis et dumetis montofis.

In feveral parts of Wales, and the lowlands of Scotland; alfo at Gamblerby, Cumberland, where Ray obferved it. Engl. Bot.

Perennis. Fl. Malo, Junio.

Pradix fublignofa. Caules plurimi, patentes et fæpiùs decumbentes, angulati, ftriati, flexuofi, pilofi, foliofi, denùm ex axillis ramofi. Folia alterna, impari-pinnata, nsultijiga, cirrho terminali, abortivo; foliola o:atoJanceolata, 
lanceolata, mucronulata, fubtus pilofa. Stipulæ femitagittatx, pilofre, utrinque acutre, extus denticulo folitario notatæ. Racemi axillares, multiflori, longius pedunculati, fecundi. Flores ochrolecuci, purpureo lineati. Calyx pilofus. Legumen ovatum, compreffum, glabrum, pallidè fufcum, fubtrifpermum.

\section{LATHYRUS. G. Pl. 375. Ju/J.359.}

Garm. t. I52.

Stylus planus, fupra villofus, fupcrnè latior. $C_{a l}$. laciniæ fuperiores duæ breviores.

* Pedunculis unifloris.

I. LATHYRUS pedunculis unifloris, cirrhis Aphaca. aphyllis, ftipulis fagittato-cordatis.

Lathyrus Aphaca. Sp. Pl. 1029. Hudf. 3 I5. With. 632. Hull. 160. Relh. 271. Sibth. 222. Curt. Lond. fafc. 5. t. 5 I.

Aphaca. Raii Syn. 320. Ger. em. I 250. Angl. Yellow Lathyrus or Vetchling.

In arvis arenofis vel glareofis, haud frequens.

In Cambridgethire. Relh. Near Oxford. Sibth. About Tottenham and Enfield. Curt. About a gravel-pit in the road to Brooke, Norfolk. Mrs. Kett.

Anzua. Fl. Junio-Augufto.

Radix exigua. Caulis fubfefquipedalis, bafi ramofus, cirrhis fcandens, foliofus, angulatus. Folia nulla, nifi in plantâ nuperrimè enatâ, eaque ftatim emarcida. Cirrhi alterni, fimplices, nudi. Stipulæ maximæ, folia referentes, feffiles, oppofitæ, cordato-faggittatæ, integerrimæ, nervofæ, glaucefcentes. Pedunculi axillares, folitarii, nniflori, apicem verfus bracteolati, fubpilofi. Flores parvi, citrini, cernui. Dentes calycini lanceolati, acuti, corollam ferè æquantes. Legumen comprefitum, glabrum.

$$
\mathrm{Y}_{4} \quad \text { 2. LATHY }
$$


Nefolia. 2. LATHYRUS pedunculis fubunifloris, folis fimplicibus, Atipulis fubulatis.

Lathyrus Niflolia. Sp. Pl. 1029. Hudf. 315. Wilh. 632. Hull. 160. Relh.271. Sibth.222. Abbot. 156. Curt. Lond. fafc. 6. t. 51. Engl, Bot.t. II2.

Niffolia parva, flore purpureo. Buxb. Cent. 3. t. $45 \cdot f$. I.

Catananche leguminofa quorundam. Raii Syn, 325. Baub. Hift. v. 2. 309 .

Ervum fylveftre. Ger. em. I 249.

Angl. Crimfon Lathyrus or Grafs-vetch.

In agrorum marginibus, et inter vepres.

Annua. Fl. Maio.

Radix parva. Herba glabra, graminea. Caulis erectus, bipedalis, ftriatus. Folia alterna, fefflia, fimplicia, lineari-lanceolata, acuta, nervofa. Stipulæ binæ, fubulatæ, exiguæ. Pedunculi axillares, folio breviores, uni-. flori, rarius biffori. Flores pulcherrimi, vexillo fanguinco, alis carinâque albidis, purpureo variegatis. $\mathrm{Ca}-$ lyx gläber. Legumen pendulum, lineare, teretiufcu. lum, slabrum.

* Pedunculis biforis.

Zirfutus: 3. LATHYRUS pedunculis bifloris, cirrhis diphy!lis: foliolis lineari-lanccolatis, lçguminibus hirfutis, feminibus fcabris.

Lathyrus hirfutus. Sp. Pl. I032. IHudf. 3 I5. With. 633. Hull. 160.

L. filiquâ hirfutâ. Raii Syn. 320. Bauh. Hifl. v. 2. 305. Rivin. Irr. Tetrap. t. 42. Angl. Rough-podded Lathyrus.

In arvis rariùs.

In feveral parts of Effex. Ray. Dale. Between Bath and Briftol, Mr. Swayne. With.

Annua 
Annua. Fl. Julio.

Caules fcandentes, alati, pilofi. Folia pctiolata, binata; cirrho trifido ; foliolis lincari-lanceolatis, glabris. Stipulæ femifagittatæ, lineari-lanceolatæ, acutæ, pilofæ. Pedunculi foliis triplò longiores, fæpiùs biflori, interdum uni- ant tri-flori. Flores purpurei, cernui, pedicellis calyceque pilofis. Legumen compreffum, hirfutum, fcabrum. Stigma perfittens, obtufifimum.

\section{*** Pedunculis multifloris.}

4. LATHYRUS pedunculis multifloris, cirrhis pratenfes. diphylis fubfumplicibus: foliolis lanceolatis.

Iathyrus pratenfis. Sp. Pl. 1033. Hudf. 317. With. 633. Hull. 161. Relh. 273. Sibth. 223. Abbot.157. Curt. Lond. fafc. 3.t. 44 . Mart. Fl. Rust.t.52. Fl. Dan.t.527. Engl. Bot.t. 670 .

L. luteus fylveftris dumetorum. Raii Syn. 320. Bank. Hift. .2 .304$.

L. fyleftris flore luteo. Ger. em. I231.

Angl. Yellow Lathyrus. Meadow Vetchling,

In pratiş, pafcuis, et dumetis, vulgaris.

Perennis. Fl. Julio, Augufto.

Padix repens, tuberculofa. Caules ramofi, debiles, cirrhis fcandentes, tripedales, foliofi, glabri, acutanguli, vix alati. Folia petiolata, binata; cirrho plerumque fimpliciffimo; foliolis elliptico-lanceolatis, acutis, glabris. Stipulæ inxqualiter fagittatæ. Pedunculi longiffimi, apice multiflori. Flores aurei. Calyx pilofus, dentibus fetaceoacuminatis, Legumen erectiufculum, nigrum, glabrum.

3. LATHYRUS pedunculis multifloris, cirrhis $\int_{y}$ lveftris. diphyllis: foliolis enfiformibus, caule alato. Lathyrus fylveftris. Sp.Pl. 1033. Hudf. 3 I6. IVith. 634. Hull. 161. Relh. 272. Sibth. 
222. Abbot. 156. Cur\%. Lond. fusca. 6. t. 52. Cluf. Hift. v. 2. I 29.

Lathyri majoris fpecics, fore rubente et albido minore, dunctorum. Raii Syil 319. Buub. Hift. $.2 .3 ว 2$.

Ervom fativum (rectius fylvefire). Fuchf. Hift. 572.

Angl. Narrow-leaved Lathyrus or Everlafting Pea.

In nemorofis et fepibus fubhumidis.

Between Caftle-Campes and Bartlow, Cambridgefhire. Dale. In a copfe under Shotover hill, Oxfordihire. Sibth. Common in Bedfordhire. Abbot. In feveral parts of Kent. Curt. Between Bath and Briftol abundantly, and near Conway in Wales. Hudf. On the fouth of Brundle church, Norfolk. Mr. Humpbrey. In inoift hedges between King's Wefton and the New Paffage plentifully.

Perennis. Fl. Julio, Augufto.

Radix ramofa. Caules fexpedales, cirrhis fcandentes, ramofi, quadranguli, glabri, internodiis latè alatis. Folia petiolata, binata; cirrho plerumque trifido; foliolis enfiformibus, acutis, nervofis, glabris. Stipulæ femifagittatæ, utrinque lineari-lanceolatæ, acutæ, anguftiffimæ, integerrimæ. Pedunculi foliis longiores, 4-10flori. Flores cernui, purpurei, alis violaceis, carinâ virenti. Calyx glaber, dentibus fetaceis. Legumen declinatum, glabrum, xerampelinum.

Iatifo- 6. LATHYRUS pedunculis multifloris, cirrhis dilizis. phyllis : foliolis ellipticis, caule alato. Lathy rus latifolius. Sp. Pl. 1038. Hudf. 3 I6. Wil'. 634. Hull. 161. Relh. 272. Abbot. 156. Mart. Fl. Ruft. t. 8. MH). Mlluftr. t. 62. Garid. Prov. 271.t. I08. 
L. Fl. Dan. $t .785$, fynonymis erroneis.

L. major latifolius. Raii Sy'n. 3 Ig.

L. major latifolius, flore majore, purpureo, fpeciofior. Bauh. Hift. v. 2. 303 .

Clymenum. Matth. Vulgr. v. 2. 320. Ed. Bauh. 69o. Camer. Epit. 7 I 2.

Angl. Broad-leaved Lathyrus or Everlafting Pea.

In fylvis et nemorofis rariùs.

In Madingley and other woods in Cambridgefhire. Ray. Mart. On the rocks by Red Neefe, near Whitchaven; Mr. Lawfon. Ray. In Severn Stoke copfe, Worcetterfhire; Mr. Ballard. With. Bedfordthire, rare. Abbot.

Perennis. Fl. Julio, Augufto.

Radix ramofa. Habitu precedentis, fed major. Foliola latè elliptiç, multinervia. Cirrhi fæpiùs quinquefidi. Stipulæ fupernè ovatx, caule lațioreses. Flores numerofi, maximi, formofi, rofei,

7. LATHYRUS pedunculis multifloris, cirrhis paluftris. polyphyllis, ftipulis lanccolatis acuminatis.

Lathyrus paluftris. Sp. Pl. I034. Hudf. 317 . With. 635. Hull. 161. Relh. 273. Eng\% Bot.t. 169. Fl. Dan. t. 399. Dickf. H. Sice. fafc. 16. I 5 .

L. vicixformis, feu Vicia Lathyroides noftras. Raii syn. 320. Pluk. Plsyt. t. 71.f. 2. Angl. Marh Lathyrus or Everlanting Pea.

In pratis et dumetis humidis.

In Peckham fields; T. Willifel. Ray. In a wood near Abinggdon, Berkfhire. Blackfone. In Leicefterfhire. Dr. Pulteney. In fome parts of Lancahire and Yorkfhire. Hudf. Near Ranaugh, Norfolk. Mr. Humplrey. At Burgh, near Yarmouth. Mr. D. Furner.

Perennis 
Perennis. Fl. Julio, Augufto.

Caules cirrhis fcandentes, quadripedales, alati, parum ramofr. Folia petiolata; foliolis bijugis vel trijugis, elliptico-lanccolatis, venofis ; cirrhis bifidis. Stipula femifagittatæ, lineari-lanceolatæ, fetaceo-acuminatæ. Pedunculi foliis duplò longiores, 3-6-flori. Flores cernui, cæruleo-violacei. Legumen pendulum, glabrum.

329. VICIA. G. Pl. 376. Juf. 360.

$$
\text { Gertn. t. I5 I. }
$$

Stigma latere inferiori tranfversè barbatum.

$$
\text { * Pechunculis elongatis, multifloris. }
$$

fylvati- I. VICIA pedunculis multifloris, foliolis ellipticis, 64. ftipulis lunatis dentatis.

Vicia fylvatica. Sp. Pl. 1035. Hudf. 3 18. With. 635. Hull. I61. Lighif. 393. Relb. Suppl. 3. 5. Sibth. 223. Abbot. I 57. Engl. Bot. t. 79. Dickf. H. Sicc.faje. 6. I4. Fl. Dan. t. $27 \%$.

V. fylvatica multiflora maxima. Raii Syn. 322 . V. n. 426. Hall. Hift. v. I. I85.t. I2.f. 2 . V. multiflora maxima perennis, tetro odore, floribus albentibus, lineis cæruleis ftriatis. Pluk, Pbyt. .7 I.f. I. Aingl. Wood Vetch.

In fylvis et fepibus, præcipuè montofis.

In feveral woods and thickets in Wefmoreland, Cumberland, Worcefterfhire, and the north of Yorkfhire, as well as in Wales and Scotland. On hedges behind Matlock bath. In a wood near Newmarket, found by the Rev. Mr. Hemfted.

Perennis. Fl. Julio, Augufto.

Planta formofa. Radix ramofa, multiceps. Caules ramofiffimi, 
mofifimi, cirrhis altè fcandentes, foliofi, fulcati, glabri. Folia multijuga, cirrho ramofo, foliolis ellipticis, mucronulatis, glabris. Stipulæ lunatæ, crebrò profunde et acutè dentatæ. Pedunculi axillares, erecti, multiflori, foliis longiores, quadranguli, fulcati. Flores fparfi, cernui, pediceliati, albidi, purpureo vel caruleo venofi ac variegati. Legumen lanceolatum, glabrum, pallide fufcum, fubtetrafpermum.

2. VICIA pedunculis multifloris, floribus imbri-Cracca. catis, foliolis lanceolatis pubefeentibus, ftipulis femifagittatis fubintegris.

Vicia Cracca. Sp. Pl. 1035. Hudf. 317 . With. 636. Hull. 161. Relh. 274. Sibth. 223. Abbot. 157. Curt. Lond. fufc.5. t. 54. Mart. Fl. Kuft.t.117. H'. Dan.t. 804.

Cracca. Raii Syn. 322. Riv. Tetrap. Irr. t. 50. Angl. Tufted Vetch.

In dumctis, nemorofis, fepibus, pratifve.

Perennis. Fl. Julio, Augufto.

Radix repens. Caules debiles, cirrhis fcandentes, bi- feu tri-pedales, foliofi, fulcati, fubpubefcentes. Folia multijuga, utrinque fericeo-villofa, cirrho ramofo, foliolis lanceolatis, mucronulatis. Stipulæ femifagittatæ, villof $x$, fxpius integerrimx, interdum fubdentatx. Pedunculi longitudine foliorum, angulati, pilofi. Flores

- numerofiffimi, areté imbricati, deflexi, fecundi, dilutè violacei. Calyx fubcoloratus, nudiufculus. Legumen glabrum, fufcum.

Stylus undique pilofus. Curt.

** Floribus axillaribus, fubfefribus.

3. VICIA leguminibus fefilibus fubbinatis erecti-fativa. ufculis, foliis inferioribus retufis, ftipulis dentatis notatis, feminibus lævibus.

Vicia fativa. Sp.Pl. 1037. Hudf.318. With. 636. Hull. I6r. Relh. 274. Silth. 224. 
Albot. 147. Engl. Bot. 1. 334. Mart. Fi. Ruft.t. I 6 . Fi. Dan.t. 522 .

Vicia. Raiii Syn.320. Riv. Telrap. Irr. t.55. Ger. ell. 1227. Lob. 1c. 2.2 .75 . Cumer. Epit. 320.

V. vulgaris fativa. Baub. Ilift. 2.2 .310$.

ß.V. fylveftris, five Cracca major. Raiii Syn. 32 I. Ger. em. 1227.

V. lathyroides. Itudf. 3 I8, a. Dicks. H. Sict. faf $c .4 .12$.

V. anguftifolia. Riv. Tetrap. Irr. t. 56?

V. vulgaris fylveftris, femine parvo et nigro, frugum. Bauh. Hift. v. 2. 312.

Aracus, Araca ct Cracca major. Lob. Ic. v. 2. 75. $\%$. Vicia fylvefiris hore ruberrimo, filiquâ longâ ni. grâ. Raï Syn. 32 I.

V. angुuftifolia. Sillth. 224. Ab6ot. I5S.

V. folio anguftiore, flore rubro. Dill. Gisf. App. 47.

Angl. Common Vetch.

In agris et inter fegetes. $\beta$ In fepibus dumetis et graninofis, folo fterili, arenofo. $\gamma$ In cretaceis et glarcofis, minùs frequens.

$y$ On Shotover hill. Bolmar. At Weymouth. Sir T. G. Cullum. Anong thort grals in Richmond garciens.

Annua. Fl. Maio, Junio.

Caules magnitudine varii, fcandentes vel proftrati. Herba magis vel minus pubefcens. Folia tri-multijuga, cirrho elongato, bifido rel trifido, foliolis oppofitis al. ternifve, mucronulatis, fæpius retufis, latitudine variis. Stipulze femifagitiatre, magis vel minus dentatæ, maculâ imprefsà nigrâ, pallidave, extùs notatix. Flores axillares, folitari vel binati, fubfeffiles, purpureo varii. Lecumen compreffufculum, fufcum, fcabrum. Semina plurima, paululum compreffa, levifima. 
- gaudct flore aliquantulùm majore, fpeciofiore, fanguineo, leguminibus longioribus, nigris.

4. VICIA leguminibus feffilibus folitariis glabris, latbyfoliis fubtrijugis: inferioribus retufis, ftipulis roides, integris, feminibus tuberculatis.

Vicia lathyroides. Sp. Pl. 10.37. Jacq. Mifc. Auftr. v. 2. 299. to r8. Fl. Dan.t. 58 . Engl. Bot.t.30. Lighif. 396 . With. 638. Hull. г6г. Alibot. I58. Thulf. 3 I9, $\gamma$.

V. minima pracox Parifienfium. Dill. in Raï Syn. 32r. Toum. Infl. 397. Herl. Tournef. V. minima. Riv. Tetrap. $1 r$. t. 56 .

V. pratenfis verna five præcos, fernine hexaciro. Morif. Sect. 2.t.3.f. I 4. peffima.

Ervum folonienfe,"Sp.Pl. Iс40. Hritf.el. I. 279.

Angl. Spring Vetch.

In arvis requictis, folo glareofo, campifque cretaceis.

About Norwich; and in the Ling's Park, Edinburgh.

Annua. Fl. Aprili, Maio.

Caules procumbentes, divaricati. Tlerba pulbefcens. Folia bijuga vel trijuga, cirrho fimplici, frepiùs breviffimo et fere abortivo, foliolis oppofitis, obcordatis, caulis apicem versùs quandoque lanccolatis et angufatis. Stipulæ femifagittatæ, plerumque integerrimæ, impunctatæ. Flores fubfeffiles, folitarii, parvi, cærulefcentes. Legumen erectum, glaberrimum, polyfpermum. Semina cubica, tuberculato-fcabra.

$\checkmark$ ariat flore albo.

$\mathrm{Ab}$ omibus præcedentis varietatibus dignofcitur leguminibus lævibus, feminibus tuberculato-fcabris, ne dicam cirrhis nunquam ramofis, nec foliolis pluribus quam fex. 
Zutea. 5. VICIA leguminibus feffilibus folitariis reflexis pilofis, caulibus diffulis, fitipulis coloratic, rexillo glabro.

Vicia lutea. Sp. Il. 1037. Hudf.319. With. 639. Hull. 161. Engl. Bot. t. $48 \mathrm{I}$. Angl. Roughth-podded Yellow Vetch.

In petrofis maritimis.

At Orford, Suffolk. Mr. Humphrey. At Aldborough. Rev. Mr. Burroughes. At Weymouth. Hudf. Mearns-fhire, North Britain. Profeffor Beatlie. Certainly found in a chalk-pit on the fide of Glattenbury Tor-hill, by Mr. D. Turner in 1799 .

Perennis. Fl. Augufto.

Radix repens, multiceps. Caules diffufi, parùm ramofi, glabri, angulati, ftriati, fubfexuofi, foliofi, longitudine varii. Folia multijuga, cirrho ramofo, foliolis ellipticolanceolatis, quandoque retufis, fubtùs pilofis. Stipulæ parvæ, deltoideæ, fubfagittatæ, plerumque atro-fanguineæ. Flores folitarii, ferè feffiles, fulphurei, cinereo lineati, interdim toti cinerafcentes, quandoque albi. Calyx tubulofus. Vexillum omninò glabrum. Legumen reflexum, latum, compreffum, undique pilofo-hif́pidum. Semina 5 vel 6, fubrotunda, glabra.

bybrida. 6. VICIA leguminibus fefflibus folitariis reflexis pilofis, vexillo villoro, foliolis emarginatis. Vicia hybrida. Sp. Pl. 1037. Jacq. Hort. t. 146. Engl. Bot. t. 482. Hull. I62.

V. luteo flore fylveftris. Raii Syn. 32 I ? Angl. Hairy-flowered Yellow Vetch.

In dumetis, at rarifimè.

On Glaftenbury Tor-bill. Ar. Sole, and A. B. Lambert, Efq. It could not be found there by Mr. D. Turner in 1799.

Perennise 
Perennis. Fl. Junio.

Facies precedentis, fed caulis erectior et altior. Foliols plerumque obtufiora, magifque emarginata. Flores citrini, fæe purpureo-lineati, vexillo extùs pilofo, bafi rubicundo, Stipulæ virides, nec fanguineæ. Legumen pilofo-hípidum, pentafpermum.

7. VICIA leguminibus feffilibus folitariis reflexis leviga glabris, caulibus erectiufculis, foliis glaberri- $t a$. mis.

Vicia lævigata. Engl. Bot. t. 483. Hull. 162. V. hybrida. Hudf. 319 . With. 639. Angl. Smooth-podded Sea Vetch.

In petrofis maritimis.

At Weymouth. Rev. Mr. Baker.

Perennis. Fl. Julio, Augufto.

Habitus V. luteæ, fed caules breviores et ferè erecti, ramofi. Tota planta glaberrima. Foliola elliptico-lanceolata, mucronulata, vix unquam retufa. Stipulæ virides, vel fubfufcæ. Dentes calycini fubæquales. Flores cinereo-flavefcentes, interdùm dilutè purpurei. Legumen pentafpernum, fufcum, undique læve atque glaberrimum.

8. VICIA legumiribus pedicellatis fubquaternisfepium crectis glabris, foliolis ovatis obtufis : exterioribus minoribus.

Vicia fepiurn. Sp.Pl. 1038. Hudf.320. With. 637. Hull. 161. Reih. 275. Sibth. 224. Ab. bot. 158. Fl. Dan.t. 699. Riv. Tetrap. Irr. t. 57 .

V. fepium perennis. Raii Syn: 320. Baub. Hifi. ข. 2. 3 i3.

V. maxima dumetorum. Ger. em.1227. A phace. Fuchj. Hift. 110.

B. Vicia folio fubrotundo, brevi, obtusè mucronato, VoL. II. 
pediculo brevi infidente flore Vicia repium

ficu dumetorum vulgaris. Raii Syn. 32 I. Angl. Bufh Vetch.

In dumetis et fepibus vulgaris.

Perennis. Fl. Maio, Junio.

Caules cirrhis fcandentes, bipedales, fulcati, parùm ramofi. Folia multijuga, cirrhis ramofis, foliolis ovatis, obtufis, quandoque emarginatis, fubpilofis, exterioribus fenfim minoribus. Stipulæ lunatæ, acutè dentatæ. Flores axillares, fepiùs quaterni, breviùs pedicellati, $\mathrm{fe}-$ cundi, purpuro-cyanei. Calyx pilofus. Legumen erectiufculum, fufcum, punctatum, glabrum. Semina globofa, lævia.

Variat flore albo. Raii $S_{y} n .478$.

bitbyni- 9. VICIA leğtuminibus pedunculatis folitariis erecca. tis fcabris, foliolis bijugis elliptico-lanceolatis, fiipulis dentatis.

Vicia bithynica. Sp. Pl. 1038. Hudf. 320. Wilh. 639 . Hull. 162. Jacq. Hort. t. 147. Allion. Ped. v. I. $325 \cdot$. 26.26 .2$.

Cracca floribus albis, foliis circa caulem denticulatis. Burb. Cent. 3.25.t. 45.f. 2 . Angl. Rough-podded Purple Vetch.

In arvis glareofis et ad fepes.

Near Doncafter. Mr. Tofield; upon the authority of his herharium, now in the hands of Dr. Iounge of Shefficld. In woods near Clifton upon Teme, Worcefterhire. Dr. Stokes. In a field half way between W eymouth and Portland ferry, near the fea. A.B. Lambert, Efq.

Ferennis. Fl. Julio, Augufto.

Radix ramofa. Caules plures, cirrhis fcandentes, ramofi, angulati, fulcati, glabri. Folia bijuga, cirrhis elongatis, ramofis, foliolis magnis, elliptico-lanceolatis, acutis, fubtus pilofuffculis. Stipulæ magnæe, femifagittatæ, inæqualiter dentatæ, dentibus divaricatis, acutis. Flores axillares, 
svillares, folitarii, pedunculati, pedunculis longitudine variis, rariffimè bifloris. Calycis dentes ciliati. Vexillum magnum, purpureo-plumbeum. Alæ carinaque albida. Legumen erectum, badium, pilofo-fcabrum. Semina 5 vel 6 , globofa, glabra, nigro cinereoque variegata.

\section{ERVUM. G. Pl. $376 . J u \int \cdot 360$.}

Stigma capitatum, undique pubefcens.

I. ERVUM pedunculis biforis, leguminibus gla-tetrajperbris polyfpermis.

Ervum tetrafpermum. Sp. Pl. 1039. Hudf.320. With. 639. Hull. 166. Relb. 275. Sibth. 225. Abbot. 159. Curt. Lond. fafc. I. t. 55. F\%. Dan.t. 95 .

Cracca minor, filiquis fingularibus, flofculis cærulefcentıbus. Raii Syn. 322.

C. minor, filiquis gemellis. Riv. Tetrap. Irr. t. 54 .

Vicia minor fegetum, filiquis pancis glabris. Morif. Sect. 2. t. 4. f. 16. Angl. Sinooth Tare.

In arvis, fepibus et dumetis, præcipuè humidiufculis.

Annua. Fl. Junio.

Radix fibrofa. Caules debiles, cirrhis feandentes, ramofi, angulati, pilofi. Foliola plurima, alterna, lineari-lanceolata, obtufa, fubtùs pilofa. Cirrhi bifidi. Stipulæ femihaftatæ. Pedunculi filiformes, longitudine foliorum, pubefcentes, fæpiùs biflori. Flores pallidè purpurei, vexillo ftriato. Calyx pilofus, corollâ duplò brevior. Stylus filiformis, glaber, inflexus. Stignıa parvum, capitatum, undique tomentofum. Legumina plerumque binata, pendula, compreffa, glabra, parùm torulofa. Semina quatuor, rariùs plura.

Varietatem foribus parùm majoribus, feminibus 5 ad 7 , in folo glareofo ficco invenit D. Woodward.

$$
\mathrm{Z}_{2} \text { 2. ER- }
$$


2. ERVUM pedunculis multifloris, leguminibus birfutis difpermis.

Ervum hirfutun. Sp. Pl. 1039: Itudf. $32 \mathrm{I}$. I'tib. 6н0. Hull. 166. Relh. 275. Sibth. 225. Alibot. 159. Curt. Lond. faf c. I. t. 54 . Dicks. H. siace fafe. 8. 13. Fl. Dan. t. 639. Cracca minor. Raili Syn. 322 . Riv. Tetrap. Irr. t. $5+$.

Vicia fyluctiris, feu Cracca, minima. Ger. em. 1228 .

V. minor fegetum, filiquis pluribus hirfutis. Morif. let. 2. t. 4.f. 15 . Angl. Hairy Tare.

In arvis, fepibus, et pratis; fegetum peftis.

Annua. Fl. Junio.

ILabitus pracedentis, fed caules glabriufculi, foliola parùm latiora, magifque retufa. Stipula femihaftatee, fape dentatre. Pedunculi multiflori. Flores purpureoalbidi. Calyx pauló longior, dentibus anguftioribus quim in priore, nequaquam tamen corollie æaqualis, Stylus brevior, ftigmate præcedentis. Legumina $5-7$, pindula, brevia, torulofa, hirfuta. Semina bina.

Er:i gerus apud Linnæum confufum admodum atque obfcurum eft, charactere erroneo, qui non nifi prime fpeciei convenit, defignatum. At hæc prima fpecies, Ervum Lens, omnibus notis, et imprimis calyce, Cicer nuncupands eft, et revera ftigmate imberbi gaudet. $\mathrm{E}$. folonienfe jamjam ad Viciam lathyroidem, haud dubitandâ inductus auctoritate, revocavi. E. monanth is et Ervilia, e ftylo fuperne villofo, Orobi vel Lathyri tpecies mihi videntur.

\section{I. ORNTHOPUS. G. Pl. $38 \mathrm{I} . J 4 / \cdot 36 \mathrm{I}$. Gertn.t. 155 .}

Legunen articulatum, teres, arcuatum. 
I. ORNITHOPUS foliis pinnatis, leguminibus in-terpuficurvis.

Ornithopus perpufillus. Sp. Pl. ro49. Hhalf. 321 . IIth. 640. Hull. 165. Relh. 276. Silth. 225. Abbot. 159. Curt. Lond. fulc. 6. t. 53. Eingl. Bot. t. 369 . Dick. H. Sicc. faji. I6. I4.

Ornithoporlium radice nodosâ. Raii Sỵn. $3: 6$.

O. minus. Ger. em. I2+1.

Angl. Common Bird's-foot.

In pafcuis arenofis et glareofis.

Annue. Fl. Maio.

Radix fibrofa, interdum tuberculis carnofis propagata.

Caules proftrati, ramofinimi, longitudine varii, fulcati, pubefcentes. Folia impari-pinnata, foliolis numerofis, oppofitis, ellipticis, pilofis, fubcarnofis. Capitula pedunculata, axillaria, foliofi, pauciflora. Flores exigui, vexillo alifque albo rubroque pulcherrime variegatis, carinâ virente. Legumen moniliforme, fubconipre:fum, pilofum, polyfpermum, mucronulatum.

\section{HIPPOCREPIS. G.Pl. $38 \mathrm{r} . J_{4 \pi} \cdot 3^{6 \mathrm{r}}$}

Legzunen articulatum, compretiom, alterî̀ futurâ pluries cmarginatum, curvum.

I. HIPPOCREPIS leguminibus pedunculatis con-comnfa.

fertis arcuatis margine exteriore repandis.

Hippocrepis comola. Sp. Pl. 1050. Hudf. $32 \mathrm{r}$. IVith. 6+1. Hull. 165. Relh.276. Sibth. 226. Abbot. 159. Dick. H. Sicc.fafc. 8. 14. Engl. Bot. t. $3 \mathrm{I}$.

Ferrum equinum Germanicum, filiquis in fummitate. Raii Syn. 325 .

F. equinum capitatum. Column. Ecphr. $30 \mathrm{x}$. Morij. fect. 2. t. 10. f. 3 . Angl. Tutted Horfe-thoe Vetch. 
In collibus cretaccis, interdum in montibus calcareis.

Plentiful in Kent, Cambridgefhire, at Marbam in Norfolk, and moft chalky countries.

Perennis. Fl. Main-Augufto.

Radix lignofa. Herba glabra. Caules proftrati, fulcati, ramofi. Folia impari-pinnata, foliolis numerofis, obovatis, emarginatis. Stipulæ lanccolatæ. Pedunculi axillares, Jongiffimi, umbellati, nultiffori. Pcdicelli breves, hirfuti. Calyx campanulatus, glaber. Corolla lutea. Legumina recurva, glandulofo-fcabra, articulis feminibufque reniformibus.

333. HEDYSARUM. G.Pl. 382. Ju/. 362 . Gartn.t. I 55 .

Lezumen articulis monofpermis. Cor. carina tranfversè obłufa.

Onobry- I. HEDYSARUM foliis pinnatis, leguminibus cbis. monofpermis aculeatis, corollarum alis longitudine calycis, caule elongato.

Hedy farum Onobrychis. Sp. $1 \%$ 1059. Hudf. 322. With. 642. Hull. 165. Relh. 277. Sibth. 226. Abbot. 160. Mart. Fl. Ruft.t. 47. Dicks. H. Sicc. fafc. 7. 9. Engl. Bot.t. 96́.

Onobrychis, feu Caput gallinaceum. Raii Sym. 327. Ger. em. 1243.

Onobrychis. Riv.Telrap. Irr. t.2.

Polygalon Gefneri. Baub. Hift. v, 2. 335 . Angl. Saint-foin.

In collibus pafcuifve cretaccis,

Perennis. Fl. Junio, Julio.

Caules decumbentes, bi-vel tri-pedales, teretes, fulcati, ranofi. Folia impari-pinnata, multijuga, foliolis ellipticis, glabriufcilis, æqualibus. Stipulæ ovatæ, acuminatie, fcariofe. Pedunculi axillares, adfcendentes, longiflimi? 
longiffimi, fpicati, multiflori, pilofi. Flores imbricati, bracteolati. Calycis dentes fubulati. Corolla faturatè rofea, ftriata. Legumen criftatum, reticulatum, pilofum, coriaceum, non dehifcens. Semen reniforme, glabrum.

\section{AStragalus. G. Pl. $3^{8} 5 . J u l \cdot .358$. \\ Gertn. t. I54.}

Legumen biloculare, gibbum.

ז. ASTRAGALUS caulefcens proftratus, legumi-glycynibus fubtriquetris arcuatis, ivliis pedunculo pbyllos. longioribus; foliulis ovatis. Aftragalus glycyphyllos. Sp.Pl. 106\%. IHudf. 322. With. 643. Hull. 162. Relh. $27 \%$. Sibth. 227. Abbot. 160. Dicks. H. Sicc. fiejc. 7. I I. Engl. Bot. t. 203.

A. luteus perennis procumbens, vulgaris five fylveftris. Raii Syn. 326.

Hedyfarum glycyrrhizatum. Ger. em. I 233 . Fænogracum fylueftre. Trag. Hift. 599. Angl. Sweet Milk-vetch. Wild Liquorice.

In dumelis ad latera montium, marginibuique agrorum, et ad vias, imprimis folo calcareo.

Perennis. Fl. Junio.

Radix ramofa, longa. Canles proftrati, flexuofi, teretes, fulcati, pilofiufculi. Folia impari-pinnata, multijuga, læetè viridia, glabra; foliolis ovatis feu ellipticis. Stipulæ ovatæ, magnæ, fubdentatæ. Pedunculi foliis breviores, fpicati, multiflori. Calyx campanulatus, obliquus, glaber, dentibus fuperioribus breviffimis. Corolla fulphurea. Legumen incursum, triquetro-cylindricum, glabrum, polyfpermum.

2. ASTRAGALUS caulefcens proftratus, foribus bypoglotcapitatis, leguminibus ovatis dorfo canalicula- tis. tis pilofis : apice aduncis.

$$
\mathrm{Z}_{4} \quad \text { Aftragalus }
$$


Aftragalus hypoglottis. Mant. 2.274. Sibtb. 227. Engl. Bot. t. 274. With. 643. Hull, 162 .

A. arenarius. Hudf. 323, Relh. 278, Fl. Dan. t. 614 .

A. Danicus, Retz. Obf. fafic 3. 4I.

A. epiglottis. Dicks. H. Sicc. fajc. 1. I 3 . fed perperàm.

A. incanus parvus purpurcus noftras. Raii $S y n$. 326.t. I 2.f. 3 .

Angl. Purple Mountain Milk-vetch,

In campis elatis cretaceis, vel arenofis.

On Newmarket heath and Gogmagog hills, alfo about Doncafter. Ray. Richardfon. Swaffham heath, Norfolk. Mr. Crowe and Mr. Wood . ward. On feveral parts of the fea coatt in Scotland. With. On the thore beyond New-Haven ncar Edinburgh.

Perennis. Fl. Junio, Julio.

2adix repens, fublignofa, ramofa. Caules flexuofi, parùn ramofi, proftrati, longitudine varii, plerumque vix biunciales. Folia impari-pinnata, foliolis numerofis, parvis, ovatis, fubtùs pilofis. Pedunculi vix foliịs longiores, capitati. Bracteæ calyce triplò breviores. Flores purpureo alboque varii. Calyx tubulofus, hirtus, pilis atris, cum paucis albis immixtis. Legumen ovatum, turgidum, pilofum, dorfo canaliculatum, apice acuminatum, aduncum. Variat corollâ albâ.

tralengjo 3. ASTRAGALUS acaulis, fapo crecto foliis longiore, leguminibus oblongis inflatis villofis crectis.

Aftraralus uralenfis. Sp. Pl. 1071. Hudf. 323 . Lightf. 401.t. 17. Wilh.644. Engl. Bot. t. 466.

A. n. 410. Eall. Hijt. v. 1. I79. t. I4.f. 3 . 
Angl. Hairy Mountain Milk-vetch.

In alpibus fcoticis, folo arenofo.

Perennis. Fl. Julio.

3adix lignofa. Folia radicalia, multijuga, fericea, petiolo communi perfiltente, indurato, denudato. Stipulæ fcariofæ. Scapi foliis longiores, erecti, capitati, demùm fpicati. Bractex longitudine calycis, lineari-lanceolatie. Calyx tubulofus, hirtus, pilis nigris albifre. Corolla violacea. Legumen ercetum, cylindraceo-oblongum, zurgidum, nigrum, pilofum, pilis adpreffis.

\section{TRIFOLIUM. G.Pl. $387 . \quad J_{11}$ J. $355^{\circ}$ G.ertn. t. I53.}

Flores fubcapitati. Legumen vix calyce longius, non dehifcens, deciduum.

* Meliloti. Leguminitus nudis, poly/permis.

1. TRIFOLIUM leguminibus racemofis nudisofficinals difpermis rugofis acutis, caule crecto.

Trifolium Melilotus-officinalis. Sp. Pl. 1078. Hudf. 323. With. 645. Hull. I62. Reib. 278. Sibth. 227. Albot. 161. Mart. Fl. Ruft.t.72. Fl. Dum. t. 934 .

T. odoratum, five Melilotus vulgaris, flore luteo. Bauh. Hift. v. 2. 370.

Melilotus vulgaris. Raii Syn. $33 \mathrm{I}$.

Melilotus. Riv. Tetrap. Irr. t.6.

Saxifraga lutea. Fuch. Hijt. 749. Angl. Common Meilot.

In dumetis et fepibus, interdum et inter fegetes.

Annua. Fl Junio, Julio.

Caulis erectus, bipedalis, ramofus, fulcatus. Folia, ut in toto genere, ternata. Foliola lanceolato-obovata, ferrata, glabra. Spicæ axillares, pedunculatæ, denfix, multitopa. Flores parvi, cernui, aurei. Calyx campanuJatus, 
Jatus, pilofus. Stigma capitatum. Legumen pendulum, ellipticum, utrinque acutum, tranfiersè rugofum, pilofum.

Herba cxficcata odore fuavi gaudet, Anthoxanthi quodammodò finili.

-rnitbo- 2. TRIFOLIUM leguminibus nudis octofpermis podioides. fubternis calyce duplò longioribus, caulibus declinatis.

Trifolium Melilotus-ornithopodioides. Sp. Pl. 1078. Hudf. 324. With.645. Hull. 162. Curt. Lond. fafc. 2. t. 53. Fl. Dan.t. 368.

T. filiquofum Loto affinc, filiquis Ornithopodii. Pluk. Phyt. t. 68.f. I.

Fœnugræcun humile repens, Ornithopodii filiquis brevibus ereetis. Raii Sym.331. t. 14. $f$. I.

Aingl. Bird's-foot Trefoil.

In herbidis glarcofis fierilioribus.

On feveral heaths about London. Curt. In Oxfordthire, and on fandy banks by the fea fide in Effex. Ray. On Mufhold licath near Norwich. Mi. Pitchfort.

Annua. Il. Junio, Julio,

Caules proftrati, breves, divaricati, vix ramofi, glabri. Foliola obcordata, ferrata, glabra. Stipulæ lanceolatre, acuminatæ, connatie. Pedunculi axillares, petiolis breviores, fæpius breviffmi, triflori, umbellati. Dentes calycini fetacci. Flores graciles, rubicundi. Legumen calyce longius, obtufum, tranfversè rugofum, pilofum, fuboctofpermum.

Folia in Herb. Limn. obfoletiùs ferrata.

* Lotoidea. Leguminibus tectis, polypermis.

mens, 3. TRIFOLIUM capitulis umbellaribus, leguminịbus tetrafuermis, caule repente.

Trifolium 
Trifolium repens. Sp. Pl. 1080. Hudf. 324 . With. 646. Hull. 163. Relh. 279. Sibth. 228. Abbot. 161. Curt. Lond. falc. 3, t. 46. Mart. Fl. Kuft.t. 34. Fl. Dan. t. 990. Riv. Tetrap. Irr. t. I $4 . f .2$.

T. pratenfe. Ger. em. II 85 , ic. nec defor.

T. pratenfe album. Raii Syn. 327.

Trifoliaftrum. Mich. Gen. t. 25.f. 3, 4.

Melilotus Parifienfis humifurus, foliis erratis giabris. Vaill. Par. t.22.f. I.

Angl. White Trefoil. Dutch Clover.

In pratis et pafcuis vulgaris.

\section{Perennis. Fl. Maio-Septembri.}

Radix fibrofa. Caules proftrati, repentes, hatè extenfi, bafi ramofi, foliofi, glabri. Folia longius petiolata. Foliola obcordata, denticulata, glabra, læe fufco al= boque maculata. Pedunculi adfcendentes vel erecti, longiffimi, nultiflori, umbellati. Flores albi, interdum
carnei, erecti, poft anthefin penduli. Calyx decemnervis, glaber. Corolla perfiftens. Legumen corollâ tectum, oblongum, glabrum, tri- vel tetra-fpermum.

Variat in folo fertiliori humido caule ereetiufculo, ramofiore, attamen a T. hybrido Linnæi femper diftinctillimum.

\section{*** Lagopoda. Calycibus Sepiùs villofis.}

4. TRIFOLIUM capitulis villofis fubquadrifloris, fubterstyinvolucro centrali reflexo rigicio ftellato fruc- ncum. tum obvolvente.

Trifolium fubterraneum. Sp. Pl. 1080. Hudf. 328. With. 647. Hull. 163. Relh. 279. sibth. 228. Abbot. 161. Curt. Lond. fafc. 2. t. 54. Kin. Tetrap. Irr.t. I 4. f. x.

T. pumilum fupinum, flofeulis longis albis. Raii Syn. $327 \cdot t \cdot 13 \cdot f .2$.

T. fub. 
T. fubterraneum tricoccum Gaftonium. Morif: Sect. 2. $t$. $x_{4} \cdot f \cdot 5$.

T. pratenfe fupinuin $x \alpha \dot{u}^{\prime} b \lambda \mathrm{s} \psi$, feu capite humi merfo. Barel. Ic. t. $88 \mathrm{I}$. Angl. Subterraneous Trefoil.

In pafcuis et ericetis fterilioribus glareofis.

Annua. Fl. Maio.

Radix fibrofa. Caules proftrati, deprefli, divaricati, teretes, pilofi. Foliola obcordata, utrinque pilofa. Pedunculi tri- aut quadri-flori, floriferi erecti, fructiferi in terram deflexi. Calyx tubulofus, glaber, purpurafcens, dentibus capillaribus, pilofis. Corolla gracilis, nivea. Legumen calyce tectum, monofpermmm, involucro centrali, ramentaceo, ftellato, comofo, reflexo, albo, demùm indurato, obvolutum.

aibroleu- 5. TRIFOLIUM capitulo villofo, caule erecto cum. pubefcente, foliolis infimis obcordatis, dente calycino infimo longifimo.

Trifolium ochroleucum. Syft. Nat.ed. 12. v. 3 . 23.3. Syjt. Veg. ed. 14. 689. Hudf. 325. With. 653. Hull. 164. Relh.281. Abbot. 162. Curt. Lond. fafs. 6. t. 49. Mart. Fl. Inuft.t. 35. Dickf. H. Sicc. fajc. 3. 9. Af zel. in Tr. of Linn. Soc. v. 1. 229. Jacq. Auftr. t. 40.

T. pratenfe hirfutum majus, flore albo-fulphureo. Raii Syn. 328.

T. pratenfe album. Fuchs. Hift. 818. benc̀. Ic. 472 .

Angl. Sulphur-coloured Trefoil.

In pafcuis et dumetis ficcioribus glareofis rcl calcarcis.

Perennis. Fl. Junio, Julio.

Kadix ramofa. Caules erecti, pedales rel fefquipedales, parùm ramofi, teretes, pilofi. Folia diftantia ; fumma 
oppoitta, foliolis lineari-oblongis; infima foliolis brêvibus, obcordatis; omnia integerrima, pilofa. Stipulæ lineares, connatæe, amplexicaules, nervofæ, nervis fimplicibus, villof $x$, apice fubulatæ. Capitulum terminale, pedunculatum, folitarium, erectum, multiflorum. $\mathrm{Ca}-$ lyx gracilis, fulcatus, pilofus, dentibus fetaceis, infimo reliquis triplò ferè longiore. Corolla ochroleuca, monopetala, vexillo elongato, recto. Legumen membranaceum, monofpermum, calyce tectun.

6. TRIFOLIUM fpicis denfis, caulibus adfcen-pratenfe. dentibus, corollis inæqualibus, dentibus calycinis quatuor æqualibus, ftipulis ariftatis. Af $\approx$ el.

Trifolium pratenfe. Sp. Pl. I082. Hudf. 325 . With. 651. Hull. 163. Relh.280. Silth. 228. Abbot. 162. Afzel. in Tr. of Limn. Soc.v. 1. 240. Matth. Valgr.v.2.189. Trag. Hift. $5^{86 .}$

T. pratenfe purpureum. Raii Syn.328. Fuclof. Hift. 8 I 7.

Trifolium. Riv. Tetrap. Irr.t. I I. f. I.

R.T. pratenfe. Fl. Dan. t.939. Mart. Fl. Rult, t. 3 .

T. purpureum majus fativum, pratenfi fimiles Raii Syn. 328.

$\gamma$. flore albo. Af $\approx$ el. loc. cit. 243. With. 652 .

$\delta$. Trifolium pratenfe purpureum minus, foliis cordatis. Dill. in Raiii Syn. 328.t.13.f. $\mathrm{r}$. Angl. Common Purple Trefoil, or Clover. Ho.. neyfuckle Trefoil.

In pratis et pafcuis vulgaris.

Perennis. Fl. Maio-Septembri.

Radix ramofa. Caules adfcendentes, pedales et ultra, fubramofi, tupernè fubvillofi. Foliola elliptica, plerumque integerrima, glabriufcula. Folia fuperiora frequentiùs oppofita. Stipulæ latè ovatæ, connatæx, brevins 
brevius arifatx, pallidx, nervofa, nervis purpureia, marginen versus ramofis, anaftomofantibus. Spicze terminales, feffiles, folitarix, ovatæ, obtufx, denfx, nultiflore, odoratæ. Calyx pilofus, decemmervis, dentibus fubulatis, infimo reliquis :equalibus duplò longiore. Corolla purpurea, monopetala, vexillo alis longiore.

mediun. $\%$. TRIFOLIUM fpicis laxis, caulibus flexuofis ramofis, corollis fubxqualibus, litipulis fubulato-linearibus.

Trifolium medium. Faun. Suec. ed. 2. $55^{8}$. Hudf. ed. I. 284. Afsel. in Tr. of Limn. Soc. v. 1. 237. Engl. Bot. t. 190. Witb. 650. Hull. 163. Sibih. 229. Dickf. H. Sicc. fafí. 4. 10.

T. flexuofum. Jacq. Aufir. t. 386. Retz. Prodr. I 74 .

T. alpeftre. Hudf. 326 . Relh. $28 \mathrm{I}$.

T. purpureum majus, foliis longioribus et angufitoribus, Horibus faturatioribus. Raii Syn. 328 . Angl. Zigzag Trefoil.

In pafcuis clatis calcareis, vel glareofis argillâ fubfiratis.

Perennis. Fl. Julio.

A precedente differt caule ramofiori, flexuofo, ftipulis longioribus, linearibus, dentibus calycinis duobus fuperioribus brevioribus, fpicâ laxiore. Foliola elliptica, fubtùs glaucefcentia, margine pilofa.

A T. alpeftri abunde differt. Confer Afzcl. loc. cit. ct Jacq. Auftr. t. 433 .

mariti- 8. TRIFOLIUM fpicis pilofis globofis, dentibus mum. calycinis foliaceis demùm patentibus, fipulis lanceolatis, foliolis obovatis.

Trifolium maritimum. Hudf.ed. 1.284. Engl. Bot.t. 220. Dicks. H. Sicc.fajc. 7. 8. Wilt. 633. Hull. 164.

T. ftel- 
T. ftellatum. Hudf. 326 .

T. ftellatum glabrum. Raii Syn. 329. Ger. em. I 208. Pluk. Phyt. t. II j.f. 4 .

T. Spicatum minus, flore minore dilutè purpureo. Morif. Sect. 2. t. I4.

Angl. Teafel-headed Trcfoil.

In paluftribus cœnofis, præcipuè maritimis.

In Norfolk, Eflex, Kent, Dorfethire, Somcrfetthire, in various parts of the coaft.

Anmua. Fl. Junio, Julio.

Caules plures, patentes, fæpè decumbentes, plerumqu ferè pedales, ramofi, teretes, ftriati, pilofuffuli. Folia fumma oppofita. Foliola obovata, fubintegerrima, faturatè viridia, pilofa. Stipulæ lineares, anguftæ, apice fubulato, elongato, pilofo. Spica terminalis, folitaria, fæpiùs pedunculata, parva, denfa, brevis, obtufa, multiflora. Calyx tubulofus, apice tubi precipuè pilofus, dentibus poft anthefin elongatis, foliaceis, trinervibus, demùm patentibus, perfiftentibus. Corolla pallidè purpurea, fubæqualis. Legumen turbinatum, monofpermum.

9. TRIFOLIUM fpicis villofifimis fubcylindra-arvanfe. ceis, dentibus calycinis fetaceis corollà longioribus, foliolis obovato-linearibus.

Trifolium arvenfe. Sp. Pl. 1083. Hudf. 326. . With.649. Hull. 163. Relh. 28 1. Sibth. 229. Abbot. I62. Curt. Lond. fafc. 6. t. 50. Dicks. H. Sicc.fafc. 3. 8. Fl. Dan. t. 724 .

T. arvenfe humile fpicatum, feu Lagopus. Raii Syn. 330.

Lagopus. Fuch. Hift. 494. Riv. Tetrap. Ir. t. 16. Camer. Epit. 724.

Lagopodium, Pes leporis. Ger. em. I 193.

B. Lagopus perpufillus fupinus perelegans maritimus. Dill. in Raii Syn. $330 . t$. x $5 \cdot f .2$. 
Angl. Hare's-foot Trefoil.

In arvis pratifque arenofis.

Anmer. 'Fl. Julio, Augufto.

Radix parva. Caulis erectiufculus, rmofifimus, teres, villofus. Foliola angufta, obovato-linearia, pilofa, ir maritimis fericea. Stipulæ linearcs, connatæ, apice fubulatr. Spica terminales, cylindraceer, obtufa, longitudine varix, denfa, multiflor:e, villofifima, canefcentes. Calycis dentes fubulati, xquales. Corolla calyce brevior, allba vel incarnata. Legumen exiguum, tenue, monofpermum.

foubrum. 10. TRIFOLIUM capitulis feffilibus lateralibus ovatis, dentibus calycinis inaqualibus perfiftentibus rigidis recurvis.

Trifolium fcabrum. Sp. Pl. 1084. Hudf.327. With. 648. Hull. 163. Relh. 282 . Sibth. 229. Ablot. 162. Curt. Lond. fafc. 6. t. 48.

T. flofculis albis, in glomerulis oblongis afperis cauliculis proxime adnatis. Raii Syn. 329 . Faill. Par. $t \cdot 33 \cdot f$. r.

T. minus, capite fubrotundo parvo albo ct cechinato. Barrel. Ic.t. 870 .

Angl. Rough Trefoil.

In campis cretaccis vel arcnofis.

On Newmarket heath. Ray. Between Northfleet and Gravefend. Isill. About Croydon. Cunt. Nicar Bungay. Mr. Mondrard. On Caifier common near Norwich. Mr. Cronee. Wick cliffs; Mr. Swayne. With. On Cromer cliffs, Norfolk.

Annua. Fl. Maio, Junio.

Fadix fibrofi. Caules proftrati, rigidi, terełes, fcabsi. Foliola obovata vel obcordata, denticulata, pilofa. Stipula fcarinfre, lanceslatx, commatx, pilofie. Capitula axillaria, folitiria, fcitilia, ovata, mulkifora, denfa, pilota. 
pilofa. Calyx fulcatus, dentibus poft florefcentiam recurvato-patentibus, rigidis, pungentibus. Corolla alba, calyce longior. Legumen membranaceum, albidum. Semen folitarium, ellipticum, nitidum, flatefcens.

in. TRIFOLIUM capitulis hemifphæricis feffili-glomera? bus lateralibus glabris, dentibus calycinis cor- $t u m$. datis reflexis venofis.

Trifolium glomeratum. Sp. Pl. 1084. Hudf. 327. With. 648. Hull. 163: Curt. Lond. fafc. 4 . t. $5 \mathrm{x}$.

T. cum glomerulis ad caulium nodos rotundis. Raii Syn. 329. Pluk. Plyyt.t.113.f. 5 .

T. arvenfe fupinum verticillatum. Barrel. $I c$. t. 882 .

Angl. Round-headed Trefoil.

In pratis et pafcuis glarcofis, minùs frequens. About Saxmundham, Suffolk, and about London. Ray. In the ifle of Shcpey. Hudf. On Kew Green, and Hanwell heath, Middlefex. Rev. Dr. Goodenough. On the Bath hills near Bungay, Suffolk. Mr. Woodward. In a pafture adjoining to Mackerel's tower, Norwich.

Annita. Fl. Junio.

Planta glaberrima. Radix fibrofa, parva. Caules proItrati, longitudine varii, parùm ramofi, ftriati. Folia remota. Foliola obovata, denticulata. Stipulæ fcariof $x$, latè ovatæ, conniatæe, acuminatæ. Capitula axillaria, folitaria, feffilia, hemifphærica, multiflora, omninò glabra. Calyx campanulatus, fulcatus, pallidus, dentibus cordatis, foliaceis, viridibus, ariftatis, reticulato-venofis, reflexis, tubo duplò brevioribus. Corolla rofea, recta, calyce duplò longior. Legumen exiguum, fubrotundum, monofpermum.

TOL. II. 
ftriatum. 12. TRIFOIIUM capitulis feffilibus lateralibus terminalibufque ovatis, calycibus ellipticis hirfutis fulcatis : dentibus retaccis.

Trifolium titiatum. Sp. I'l. 1085 . Hudf. 327. I'il. 649. Hull. I63. Relh. 282. Sibl\%. 230. Abbot. 163 .

T. parvum hirfutum, floribus parvis dilutè purpurcis, in glomerulis mollioribus et oblongis, feminc magno. Raii Syn. 329. 1.13. f.3. Fiill. Par. t. 33.f. 2.

Angl. Soft knotted Trefoil.

In pralis et pafeuis ficeioribus, fterilioribus.

Amura. Fl. Junio.

Caules procumbentes, ramofi, teretes, villofi. Foliola obovata, vel obcordata, pilofa. Stipulæ latè ovatre, acuminatre, nervofre, fcariofæ. Capitula plerumque terminalia, o:ata. Calyx ellipticus, fubventricofus, decemfulcatus, villofus, dentibus fubulatis, viridibus, demùm clongatis, patentibus, ciliatis. Corolla vix longitudine calycis, purpurafcens. Legumen membranaceum. Semen ellipticum comprefím, præcedente triplò majus.

futfora- I $_{3}$. TRIFOLIUM capitulis feffilibus lateralibus thrm. fubrotundis glabriufculis, dentibus calycinis lanceolatis acutis recurvis corollâ longioribus.

Trifolium fuffocatum. Mant.2.276. Tr. of Linill. Soc. v. 2. 357. With. 656. Inull. s 64. Jacq. Hort. Vind. t. 60.

T. minimum fupinum, flofeulorun et feminum globulis plurimis confertim ad radiecm nafeenibus. Raii Hijn. v. 5. 942.

Angl. Suffocated Trefoil.

In arenofs maritimis.

In the loofe fand on the beach at Yarmouth. MIr 
Wigg. At Loweftoft. Mifs Temple. Plentiful about Landguard fort. Sir'T. G. Cullum, Burt.

Annua. Fl. Junio, Julio.

Radix fibrofa. Caules breves, tortuofi, glabri, fubterran nei. Folia longiffimè petiolata, foliolis obovatis, obtufis, denticulatis, glabris. Stipulæ membranaceæ, latiffimæ, mucronibus divaricatis. Flores glomerati, feffilcs, axillares, arenà mobili immerfi et futfocati. Calyx tubulofus, fulcatus, fubvillofus, dentibus lanceolatis, acutis, recurvis, immutatis. Corolla parva, albida, calyce brevior. Legumen oblongum difpermum. Semina lenticularia, margine fcabra.

T. fuffocatum ad hanc fectionem proculclubiò pertinet, inter T. glomeratum et uniflorum inferendum, nec uilo modo lupulinis affociandum.

*****aforia. Calycibus ingatis, sentricofis.

I4. TRIFOLIUM capitulis fubrotundis, calycibus fragifeinflatis bidentatis reflexis, caulibus repentibus. rum.

Trifolium fragifcrum. Sp. Pl. 1086. Hudf. 328. With.654. Flull. 164. Relh.283. Sibth. 230. Abbot. 163. Catt. Lond. fafc. 2. t. 55. Dickf. H. Sicc. fafi. 4. I I. Fl. Dan. t. 104.2. Raii Syn. 329. Ger. ein. 1208.

T. fragiferum folio oblongo. Vaill. Par. $t: 22$. $f .2$. Angl. Strawberry-headed Trefoil.

In pratis et pafcuis humidis.

Peremis. Fl. Julio, Angufto.

Habitus ferè $T$. repentis. Caules proftrati, radicantes. Petioli ut et pedunculi longifimi. Foliola obovata, denticulata, glabra. Capitula globofa, multiflora. Corolla incarnata, gracilis, calyec longior. Calyx demùm hinc maximé ventricofus, fcariofus, reticulato-venofus, rubicundus, pilofus, apice bidentatus, defexus. Legumen in fundo calycis, difpermum.

$$
\text { A a } 2 \text { ****** Labir- }
$$


****** Lapulina. Texillis corolla reflexis, demintr forriofis.

procum:cons.

I5. TRIFOLIUM fipicis ovalibus imbricatis, vexillis deflexis perfftentibus fulcatis, caulibus procumbentibus, foliolis obovatis.

Trifolium procunbens. Sp. Pl. 1088. Will. 654. Hull. 164. Silith. 230. Albot. I6 3. li. D.m.t. $79^{\text {h. }}$

T. agranium. Hulf. 328. Relh. 283. Curt. Lont. fack 3. t. 45. Mart. Fl. Rilft.t. I 2 I.

T. pratente luteum, capitulo Lupuli, vel agrarium. Raï Syn. 330.

'T. Iupulinum. Riv. Tetrap. Irr. /. Iо. f. I.

Ncilotus, qui Trifolium pratene lutcum, capitulo Lupuli, vel agrarium. Laill. I'ar. t. 22. $f \cdot 3$.

Angl. Hop Trefoil.

In pratis et pafcuis glarcofis, ficcioribus.

Annua. Fl. Junio, Julio.

Radix crafliufcula, brevis, fibrofa. Caules procumbenter, latè diffufi, parùm ramofi, pilofi, apice adfendentes. Foliola obovata, denticulata, fub-glaucefcentia, glabra, Stipula femiovatæ, integerrima, nervofe, ciliate. Spicre axillares, folitarix, pedunculata, folium requantes, interdùm fuperantes, oviales feu cllipticre, obtufie, denfie, multifora: Pedunculi imprimis apicc villofi. Dentes calycini fubulati, inæquales, pilofi. Corolla aurea. Flores imbricati, denùm deflexi, corollâ perfiftente, fcariosà, fufcefcente, vexillo longitudinalitet fulcato, inflexo, dilatato, ferè obcordato. Legumen ellipticum, utrinque acutum, monofpermum.

fliforme. 16. TRIFOLIUM fpicis capitatis hemifphericis, vexillis deflexis perfiftentibus levibus, caulibus procumbentibus, foliolis obcordatis. 
Trifolinn filiforme. Sp. Pl. го88. Hudf. 329. With. 655. Hull. 164. lielh. 284. Sibth. 231. Abbot. I64.

'T. lupulinum minimum. Dill. in Raii Syn. 33 r. t. I f. f. 4 .

B. T. procumbens. Hud]. 328. Rell. 283. Curt. Lond. faf c. 5.t. 53 .

'T. dubium. Sibth. 23 I. Ablot. I63.

T. lupulinum alterum minus. Raii Syn. 330 .

t. I $4 \cdot f \cdot 3$.

T. luteum minimum. Ger. em. I 86.

Angl. Lefler Yellow Trefoil.

In pafcuis arenofis vel glareofis fubhumicis. $\beta$ in folo fertiliore, vulgaris.

Annea. Fl, Junio-Augulto.

Radix parva, fibrofa. Caules proftrati, filiformes, fubpilofi. Foliola obcordata, dentata, ftriata. Stipule fubovatæ, nervofæ, ciliatæ. Pedunculi axillares, capillares, pilofi; in a vix quadriflori, in $\beta$ multiflori, floribus ercetis, fubcapitatis, pedicellatis, flavis, demùm deflexis. Calyx glaber, dentibus inæqualibus. Corolla perfiftens, fcariofa, fufcefcens, rexillo carinato, quam in precedente anguftiori, nec inflexo, neque fulcato. Legumen ellipticum, pedicellatum, monofpermum.

\section{LOTUS. G. Pl. $3^{88 . ~ J l i f l} \cdot 356$. Gertn. t. I 53 .}

Legumen cylindricum, ftrictum. Ai.e fursum longitudinaliter conniventes. Cal. tubulofus.

3. LOTUS capitulis depreffis multifloris, caulibus cornicudecumbentibus, leguminibus teretibus paten- latus. tibus.

Lotus corniculatus. Sp. Pl. 1092. Hudf. 329 . IVith. 656. Hull. 166. Rell. 284. silbth. 231. Albot. 164. Curt. Lond. fafe. 2. t. 56. A a 3 Mart. 
Mutrt. F\%. Ruft. t. 53. Fl. Dan. 1. 99 1. Dicks. H. Sice. fafti. $17 \cdot 7$.

L. corniculata glabra minor. Raii Syn. 334 .

Trifolium filiquofum minus. Ger. cm. I I 90.

Melilotus germanica. Luch. Hift. 527 .

B. Lotus pentaphyllos ininor, anguftioribus foliis, fruticofior. Raii Syn. 334 .

$\%$ Loti comiculatæ major fpecies. Raii Syn. 334 . Bautb. Hift. $\because 2.355$.

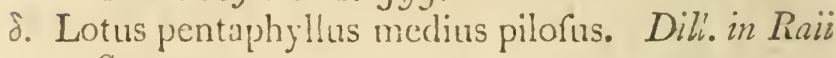
Syn. 334.

s. L. corniculata minor, foliis fubtùs incanis. Dill. in Raii Syn. 334 .

fingl. Common Bird's-foot Trefoil.

In pratis, pafcuis, et cricetis, vulgaris. $\gamma$ et $\delta$ in pratis et fepibus humidis, vel falicetis. $\varepsilon$ in clivis cretaceis.

Perennis. Fl. Junio-Augufto.

Herba polymorpha. Radix lignofa. Caules decumbentes, ramofi. Folia alterna, ternata, breviùs petiolata, foliolis acutis integerrimis, fubtùs glaucis, fæpè ciliatis, exterioribus obliquis. Stipulæ magnæ, ovatæ, foliaceæ. Pedunculi axillares, folitarii, folia longiffimè fiuperantes, capitati, nuultiflori, bracteâ ternatâ, foliaceâ. Ilores depreffo-patentes, fubpedicellati, aurei, vexillo fulvo, calyce glabro, interdùm dentibus pilofis. Legumina patentia, cylindracea, læria, xqualia, fufca, nitida, polyfperma, intùs cellulofa. Semina reniformia.

Varietates $\gamma$ et $\delta$ magnitudine majori, caule vepribus fuffulto erectiufculo, floribus faturatè fulvis dignofcuntur, at charsctere fpecifico diffincto vix gaudent.

diffirfus. 2. LOTUS pedunculis fubunifloris, caule ramofiffimo decumbente, foliis calyceque pilofis, leguminibus teretibus ftrictis gracillimis. Iotus diffufus. Soland. in Herb. Banks. L. pentaphyllos minor hirfutus, filiquâ anguftiffimà. 
Iimâ. Baub. Pin. 332. Saurages. in Herb. Linn.

Trifolium corniculatum minus, pilofum. Banh. Prod. I 44. Defer. opt. Angl. Slender Bird's-foot Trefoil.

In rupibus maritimis anfralioribus. Amongft the rocks near Haftings. Mr. Dickfon. At Kingfteington and Bifhopfteington, Devonthire. Rer. Mr. Beeke.

Perennis? Fl. Maio, Junio.

Irrcedente minor. Caules procumbentes, rufefcentes, pilofi. Foliola utrinque pilofa. Pedunculi uniflori, rarius biflori, longitudine varii. Flores aurei. Calyx pilofiffimus. Legumen compreffo-teres, anguftiffimum, calyce fextuplò longius, fufcum, glabrum, polyfpermum, intùs cellulofum. Semina orbicularia.

Diftinctus a Loto anguftifino Linnæi, Baub. Hi/f. v. 2 . 356 . $f .2$. filiquis longioribus duplòque tenuioribus, foliis pilofis, floribus colore faturatioribus.

\section{MEDICAGO. G. Pl. 389. Ju/f. $35^{6}$. Gertn. t. I 55 .}

Legumen comprefum, cochlcatum, carinam corollx a vexillo deflectens.

* I. MEDICAGO pedunculis racemofis, legumi-fativa. nibus contortis, caule crecto glabro. Medicago fativa. S. SP. 1095 . Hudf. 330. With. 658. Hull. 165. Abbot. 164. Mart. F. Ruft.t. 48 .

Medica falcata fativa, filiquâ cornutâ magìs tortili, flore violaceo. Morif. Sect. 2. t. 16.f.2. M. legitima. Cluf. Hift. v. 2. 242.

Trifolium Burgundiacum. Ger. em. I 89 . Angl. Lucerne. Purple Medick.

In pratis, pafcuis, et ad fepes, haud indigena.

$$
\text { A a } 4 \text { Perennis. }
$$


Perenutis. Fl. Junin, Julin.

Radix fublignofa. Caules ereetiufculi, bipedales, ramofi, angulato-teretes, glabri. Folia alterna, petiolata, ternata, foliolis cuneato-oblongis, apice fcrratis, nucronulatis, fubtus pilofis. Stipulæ femiovatæ, longiùs acuuınat , nervofie, rariùs fubdentatæ. Racenii pedunculati, axillares, multiflori, erecti. Flores pedicellati, bracteâ folitariá fetaceâ ad bafin pedicelli, violacei. Calyx pilofus, dentibus fubulatis. Legumen fpirale, anfractibus duobus, tribus, pluribufve, remotis, polyfpermum, glabrum.

Anne fequentis varietas?

falcata. 2. MEDICAGO pedunculis racemofis, leguminibus lunatis, caule procumbente. Medicago falcata. Sp. Pl. 1096. Hudf. 330. IVith. 658. Hull. 165. Relh. 285. Mart. Fl. Ruft. .85 et 87 . Fi. Dan. t. 233.

Mcdica fylveftris. Raili Syz. 333 .

M. flavo flore. Clus. Hift. 2.2 .243 .

Trifolium lutcum, filiquâ cornutâ. Ger. $\mathrm{em}$. I 9 I.

Angl. Yellow Medick.

In verfuris agrorum, aggeribus, murifie antiquis.

Between Watford and Bufhy-hill, by the foot-way. Doody. Common about Norwich in dry grarelly ficlds, and on the city walis in many places; alfo at Bury.

Perennis. Fl. Julio.

Habitus præcedentis, fed caules onninò decumbentes, fubpilofi. Folia anguttiora. Flores plerumque lutei, frè violacei, vel, e colore violaceo cun flavo conjuncto, virentes. Imprimis difcrepat leguminibus recurvatofalcatis, pilofis, minimè cochleatis. Semina 4-8. Stylus conipreffus, figniate capitato, ut in priore.

iztulina. 3. MEDICAGO fpicis ovatis, leguminibus reniformibus 
formibus venofo-corrugatis monofpermis, caule procumbente.

Medicagolupulina. Sp.Pl. 1097. Irudf. 330. With.659. Hull. 165. Kelh. 286. Sibth. 2.32. Abbot. 165. Curt. Lond. fafc. 2. t. $5 \%$. IIIart. Fl. Ruft. t. т 9. Fl. Dan. t. 992.

Trifoliun luteum lupulinum. Raii Syn. 33I. Ger. enl. I I 86.

T. pratenfe luteum. Fucler. Hift. 8 ig.

Melilotus minima. Riv. Tetrap. Irr.t. 8.

B. Medica polycarpos, fructu minore compreflo fcabro. Raaii Syn. 333 .

Aingl. Black Medick or Nonefuch.

In arvis, pratis, et pafcuis, frequens.

Anmua. Fl. Maio-Augufto.

Radix fibrofa. Caules proftrati, longitudine varii, angulati. Foliola obovata, fubinde rhombea, glabriufcula, apice dentata. Stipulæ dentatre. Spicæ longiùs pedunculate, ovatæ. Flores parvi, aurei. Racemi fructiferi cylindrici. Legumen cochleato-reniforme, monofpermum, reticulato-venofun et corrugatum, nigrum, interdùm pilufiufculum.

Var. $\beta$ non ipfe vidi. Icon apud MTorif. Sect. 2. z. 15. $f . I_{4}$, vix huic fpeciei refpondet.

4. MEDICAGO leguminibus cochleatis, ftipulis polymorfubdentatis, caule diffuro.

a. Medicago polymorpha arabica. Sp.Pl. Iog8, $\eta$. Hudf. 33 I. Relb. 386. Curt. Lond. fafs. 3 . t. 47. Mart. Fl. Ruft. t. 76.

M. arabica. With.660. Sym. Syn. I67. Hull. 165.

M. maculata. Sibth. 232.

Medica arabica. Camer. Hort. 97.t.2\%. Trifolium cochleatum, folio cordato maculato. Raiii Syn. 333. 
T. cordatum. Ger.em. 1190.

B. minima. Sf. Pl. $1099, \mu$. F\%. Dam. t. 211 .

Medicago minima. IIth. 660. Hall. I65.

- Medica echinata minima. Raii Sym. 333. Buzb. Hift. .2 .386$.

$\%$ muricata. Sp. Pl. $1098, \zeta$.

Medicago muricata. With. 66:. Hull. 165.

Trifolium cochleatum, modiolis fpinofis. Raii Sym. 333. Pluk. Pbyt.t. II 3. f. 6.

d. Medica marina fupina noftras, foliis viridibus, ad fummos ramulos villofis. Dill. in Raii Syn. 4ingl. Heart Medick, or Claver.

In pafcuis glarcofis vel arcnofis, imprimis maritiinis.

3. At Narburgh, Norfolk. Mr. Woodrvard. $\gamma$. On the fea bank at Orford, Suffolk. Ray.

Anmua. Fl. Maio, Junio.

Radix fibrofa, tuberculofa. Caules proftrati. Foliola dentata. Stipulæ in omnibus varietatibus magis vel minùs dentatæe, etiam in $\beta$. Pcdunculi axillares, fubtrifori. - Tlores flavi. Legumen fubrotundum, anfractibus nurnerofis, extùs fpinofis, polyfpermum. Scmina reniformia, compreffa, læviffima.

a dignofcitur foliolis obcordatis, glabris, maculâ nigrâ in medio, fpinis leguminum undique patentibus, rectiufculis; $\beta$ foliolis obovatis, fericeis, fpinis fruetus aduncis; $\gamma$ foliolis obovatis, pilofis, fpinis fructûs breviffimis, deprefis, radiantibus.

Var. $y$ et $\delta$ nondum fpontancas vidi. 


\section{Clafis XVIII. \\ POLYADELPHIA.}

Filamenta in tria, vel plura, corpora connexa.

\section{POLYANDRIA. \\ Stamina numerofa.}

338. HYPERICUM. Cal. quinquepartitus, inferus. Petala 5. Filamenta in 3 vel 5 phalanges bafi connata. Capjula polyiperma. 


\section{POLYADELPHIA.}

\section{POLYANDRIA.}

338. HYPERICUM. G. Pl. 392. Juf. 253 .

Garln. t. 62.

Cal. quinquepartitus, inferus. Petala 5. Filamenta multa, in 3 vel 5 phalanges bafi connata. Capfula polyfperma.

Andro- I. HYPERICUM floribus trigynis, capfulis bacfambm. catis, caule fruticofo ancipiti.

Hypericuin Androfixmum. Sp.Pl. I 102. Hudf.

332. With. 663. Sibth.233. Curt. Lond. fialc. $3 . t .48$.

H. maximum, Androfxmum vulgare dictum. Raii Syn. 343 .

Clymenon Italorum. Ger. em. 543. Lob. Ic. 632.

Angl. Tutfan. Park lcaves.

In fylvis et nemorofis humidiufculis, haud vulgaris.

About North Waltham, Norfolk. Rev. Mr. Hepworth. At Field Dalling, Norfolk, and very plentifully at Afheridge, Herffordhire. Mr. Moodward.

Perennis. Fl. Julio, Augufto.

Radix lignofa. Caules fuffruticofi, erecti, ramofi, fubdichotomi, foliofi, teretiufculi, ancipites, glabri. Folia oppofita, feffilia, patentiffima, ovata, integerrima, venofa, glabra, exftipulata. Cymæ terminales, erectx, pedicellis teretibus. Flores aurei. Calyx inæqualis, perfiftens, deflexus, demùm coloratus. P'ctala obliqua. Stamina parùm connexa. Styli apice recurji, bafr perfiftentes. 
perfiftentes. Capfula baccata, clliptica, nigra, trilocularis.

2. HYPERICUM floribus trigynis, caule qua-quadran drangulo herbaceo, foliis pellucido-punctatis, guhum. 'foliolis calycinis lanceolatis.

Hypericum quadrangulum. Sp.Pl. i 104. Hudf. 334. Thith.663. Relh. 289. Curt. Lond. falc. 4. t. 52. Engl. Bot. t. 370. Fl. Dan. t. 640 .

H. quadrangulare. Syyt. Teg. ed. I4. 701. Sibth. 235 .

H. Afcyron dictum, caule quadrangulo. Raii Syn. 344 .

Afcyron. Ger. em. 542. Camer. Epit. 6;6. Matth. Falgr. v. 2.28\%.

Angl. Square St. John's Wort. St. Peter's iWort.

In pratis et dumetis humidis, et ad fluviorum ripas, vulgaris.

Perennis. Fl. Julio, Augufto.

Radix fublignofa, repens. Caules erecti, ftricti, ramofi, foliofi, acutè quadranguli, lieves. Folia oppofita, per paria decuffata, clliptica vel ovata, integerrima, nervofa, glabra, punctis numeroiss, pellucidis, fparfis, margine nigris. Flores terminales, fubpaniculati, oppofiti, lutci. Calycis foliola lanceolata, acuta. Petala obliqua, rariùs purpureo maculata.

3. HIYPERICUM floribus trigynis, caule anci-perforapiti, foliis obtufis pellucido-punctatis, foliolis tum. calycinis lanceolatis.

Hypericum perforatum. Sp. Pl. I 105. Hudf. 333. With. 664. Reth. 288. Sibth. 234. Curt. Lond. fafe. I. t. 57. Woodv. Med. Bot. t. 10. Engl. Bot. t. 295. Fl. D.n. t. 1043.

Hypericum, 
Hypericum. Raii Syn. 342. Ger. em. 539. Matth. Falgr. v. 2. 286. Fuch. Hil. $83 \mathrm{I}$. Hypericum, flos. Pharmac. Lond. Angl. Perforated St. John's Wort.

In dumetis et nemorofis, et ad fepes, vulgaris.

Perennis. Fl. Julio, Augunto.

Radix repens. Caules erecti, bipedales, foliofi, teretes, obfoletè ancipites. Folia elliptico-oblonga, obtufiufcula, nervofa, glabra, punctis pellucidis, fparfis, numerofis, margine nigris. Panicula terminalis, brachiata, foliofa. Flores aurei. Calycis foliola anguftè lanceolata, acuta. Petala purpureo maculata et lineata, hine crenata. Antheræ glanculliferæ. Stigmata albida.

dubium. 4. HYPERICUM foribus trigynis, caule obfoletè quadrangulo, foliis obtufis epunctatis, foliolis calycinis ellipticis.

Hypericum dubium. Leers. I65. Engl. Bot. t. 296. With. 664. Abbot. 167. Listh. W\% Germ.v.2.p.2. 230.

Angl. Imperforate St. John's Wort.

In dumetis et nemorofis fubmontofis.

About Sapey, near Worcefter. Dr. I. Seward. Found at Luton, Bedfordhire, by Mr. Vaux. Abbot. At Downton Cafte ncar Ludlow, and at Hafod, Card enithe, plentifully.

Perennis. Fl. Julio, Augufto.

Statura præcedentis, at differt turionibus vividè coccineis; caule fupernè quadrangulo ; foliis vel cmninò impunctatis, vel margine tantum puncto uno five altero notatis; pracipuè veró ioliolis calycims quadruplio lationibus, ellipticis, obtufis. Diftinctiflima fpecies eft, a nemine ante Leerfium detceta.

bumifu- 5. HYPERICUM floribus trigynis fubcymofis, fum. caule ancipiti protrato, folis ellipticis glabris. Hypericum 
Iypericum humifufum. Sp. Pl. I105. Hudf. 332. With. 665. Relh. 287. Sibth. 233. Curt. Lond. fafc. 3.t.50. Fl. Dan. t. I4I.

H. minus fupinum. Raii Syn. 343 .

H. fupinum glabrum. Ger.em. $54 \mathrm{I}$.

H. exiguum. Trag. Hift. 72 .

Angl. Trailing St. John's Wort.

In pratis pafcuis et nemorofis.

Perennis. Fl. Julio.

Radix fibrofa. Caules plures, proftrati, filiformes, obfoletè ancipites, foliofi, glabri. Folia elliptica, obtufa, margine nigro punctata. Panicula dichotoma, dein racemofa, foliofa. Flores pedicellati, aurei, quam in præcedentibus minores. Calycis foliola magna, petalis plerumque longiora, foliis conformia.

6. HYPERICUMI floribus trigynis, calycibus fer-monta rato-glandulofis, caule erecto tereti glabro, num. foliis ovatis nudis.

Hypericum montanum. Sp.Pl. I 105. Hudf. 333. With. 666. Sibth. 235. Engl. Bot. t. 37 I. Fl. Dan. t. I 73 .

H. elegantiffimum non ramofum, folio lato. Raii Sy. 343. Bauh. Hift. v. 3.p.2. 383. Androfæmum campoclarenfe. Column. Eicpibr. 73. t. 74.f. I. Angl. Mountain St. John's Wort.

In dumetis montofis.

Ferennis. Fl. Julio.

Radix fubrepens. Caules bipedales, erecti, frieti, fimplices, teretes, glabri, foliofi. Folia ovata, glabra, nervofa, punctis pellucidis fparfis, margine nigris. Panicula terminalis, dichotoma, coaretata. Calycis foliola lanceolata, acuta, glandulis refinofis, nigris, pedicellatis, ciliata, uri bractex. Petala lanceolata, citrina. 
birfutum. 7. HYPERICUM floribus trigynis, calycibus ferrato-glandulofis, caule erecto tereti, foliis ovatis pubefcentibus.

Hypericum hirfutum. Sp. Pl. I105. Hulf. 333 . With. 666. Relh. 288. Sibth. 234. Curt. Lond. falc. 3.t. 49. Fi. Dan. t. 802 .

H. Androfamum dictum. Raiii Syn. 343. Baub. Hift. $\because .3 . p .2 .382$.

Androfemum alterum hirfutum. Column. Ecplar. 75. t. 74.f. 2 .

Angl. Hairy St. John's Wort.

In dumetis et fepibus, imprimis folo calcarco.

Perennis. Fl. Junio, Julio.

Caules bipedales, erecti, ftricti, fubramofi, teretes, densid hirfuti, foliofi. Folia quam in prixcedente minora, ovata, nervofa, fubtùs præcipuè hirfuta. Panicula thyrfoidea, multiflora, foliofa, hirfuta. Calyx et bracteæ ferrato-glandulofæ. Flores aurei, foribus H. montani duplò minores.

pulcbrum. 8. HYPERICUM floribus trigynis, calycibus ferrato-glandulofis, caule tercti, foliis amplexicaulibus cordatis glabris.

Hypericuin pulchrum. Sp. Pl. 1 106. Hudf. 332. With. 667. Relh. 287. Sibth. 234. Curt. Lond. fafc. t. t. 56 . Fl. Dan. t. 75. Trag. Hift. 74. Dicks. H1. Sicc. fafc. I6. I3.

H. pulchrum 'T'ragi. Raii Syn. 342 . Angl. Small Upright St. John's Wort.

In fylvis et dumctis fiequens, folo argillaceo.

Perennis. Fl. Julio.

Caules erecti, ftricti, fefquipedales, teretes, glaberrimi, rubicundi, foliofi, ramis oppofitis, axillaribus, fterilibus. Folia amplexicaulia, cordata, glabra, punctata, fubtùs glauca. Panicula ftrigofa, ramis fubtriforis. Calycis foliola 


\section{POLYADELPHIA-POLYANDRIA. 805}

foliola elliptica, obtufa, ferrato-glandulofa. Flores aurei, extús rubri.

9. HYPERICUM flo: repente foliifque villofis fubrotundis, paniculâ pauciflorâ.

Hypericum elotes. Sp. Pl. i 106. Hudf. 334. With. 665. Rell. 289. Dickf. H. Sicc. fafc. 2. I . Eingl. Rot. i. I09.

H. tomentolum. Lol. Ic. 400 . Ger. em. 540.

Afcyron fupinum villofum paluftre. Raii Syn. 344 .

Angl. Marh St. John's Wort.

In paludibus fpongiofis fulmontofis.

Perennis. Fl. Julio, Augufto.

Radix fibrofa. Caules procumbentes, radicantes, teretes, foliofi, fpongiofi, fupernè præcipuè villofi. Folia ovatofubrotunda, obtufa, nervofa, nervis omnibus e bafi ortis, utrinque villofa. Panicula terminalis, demùm lateralis, dichotoma, pauciflora, pubefcens. Calycis foliola bafi connata, ovata, nervofa, glabra, ciliata. Petalä citrina, nervis virefcentibus. Glandulæ nectariferæe zres inter ftaminum phalanges infertæ. 



\section{Clafis XIX. \\ SYNGENESIA.}

Antheræ in tubum connatæ. Flores compofiti.

\section{POLYGAMIA ÆQUALIS.}

Flofculi omnes hermaphroditici, fertiles.

*'Semifofculof Tournefortii; corollulis ligulatis omnibus.

349. HYPOCH ÆRIS. Receptaculum paleaceum. Pappus plumofus. Cal. fubimbricatus.

35 I. CICHORIUM. Recept. fubpaleaceum. Pappus paleaceus, femine brevior. Cal. calyculatus.

347. CREPIS. Recept. hifpidiufculum. Pappus fimplex, fubftipatitus. Cal. calyculatus, fquamis deciduis, demùm torulofus.

346. HIERACIUM. Recept. nudiufculum, punctatum. Pappus fimplex, feffilis. Cal. im. bricatus, ovatus.

345. HEDYPNOIS. Recept. nudum, punctatum. Pappus plumofus, feffilis, inæqualis. Cal. imbricatus, calyculatus.

$\mathrm{B} \mathrm{b}_{2}$ 340. PICRIS. 


\section{( 808$)$}

340. PICRIS. Recept. nudum. Pappus plumofus. Semina tranfverfim fulcata. Cal. duplicatus; interior equalis; exterior laxus.

339. TRAGOPOGON. Recept. nudum. Pappus ftipitatus, plumofus. Cal. fimplex, polyphyllus.

344. LEONTODON. Recept. nudum. Pappus ftipitatus, fimplex. Cal. imbricatus, fquamis laxiufculis.

342. LACTUCA. Recept. nudum. Pappus fitpitatus, fimplex. Cal. imbricatus, cylin4. draceus, margine membranaceo.

343. PRENANTHES. Recept. nudum. Pappus fubfeflilis, fimplex. Cal. calyculatus. Flofculi fimplici ferie.

341. SONCHUS. Recept. nudum. Pappzes feffilis, fimplex. Cal. imbricatus, ventricofus.

348. HYOSERIS. Recept. nudum. Pappus fimplex rel obfoletus. Cal. fubæcialialis.

350. LAPSANA. Recept. nudum. Pappus nullus. Cal. calyculatus; foliolis interioribus æqualibus, canaliculatis.

*** Capitati. Corollule omnes tubuloge, apice divaricato-patula.

356. CARLINA. Cal. ventricofus; fquamis exterioribus fpinefis; interioribus coloratis fcariofis radiantibus. Recept. paleaceum. Pappus plumofus.

352. ARCTIUM. Cal. globofus; fquamis apice hamatis, inflexis.

354. CARDUUS. Cal. ventricofus, imbricatus; fquamis fpinofis. Recept. pilofum. Pappus. deciduus.

355. ONOPORDUM. Cal. ventricofus; fquamis 


\section{$(809)$}

mis patentibus, fpinofis. Recept. favofum, fubpaleaceum.

353. SERRATULA. Cal. fubcylindricus, imbricatus; fquamis inermibus. Pappus perfiftens.

Centaurea nigra.

*** Difcoidei. Corollule omnes tubulofe, erectoparalleli, apice planiufculi, denfi.

358. EUPATORIUM. Recept. nudum. Pappus fcaber. Cal. imbricatus, oblongus. Stylus femibifidus, exfertus.

357. BIDENS. Recept. paleaceum. Pappus retrorsùm feaber. Cal. polyphyllus. Cor. fubindè radiata.

359. SANTOLINA. Recept. paleaceum. Pappus nullus. Cal. imbricatus, hemifphæricus.

Tanacetum. Senecio vulgaris. After Tripolium. Antbemis nobilis.

\section{POLYGAMIA SUPERFLUA.}

\section{Flofculi difci hermaphroditici; radii fominei; omnes fertiles.}

* Difcoidei. Corollule radii obfolete.

360. TANACETUM. Recept. nudum. Sem. coronata. Cal. imbricatus, hemifphæricus. Flofc. radii trifidi, obfoleti, interdùm nulli.

363. CONYZi. Rerept. nudum. Pappus faber. Cal. imbricatus, fubrotundus. Flofc. radii trifidi.

$$
\mathrm{Bb}_{3} \quad 362 \text {. GNA }
$$


362. GNAPHAliUm. Recepi. nudum. Papfis icaber aut plumofus. Cul. imbricatus, fquamis feariofis coloratis. Flofe radii fubulati.

36r. ARTEMISIA. Recept. nudum, aut villofum. Pappus nullus. Cal. imbricatus, fquarmis rotundatis, conniventibus. Flojc. radi fubulati, integerrimi.

Tuffilago bybrida et Petafites.

* Pauliuti. Corollula radii ligulata.

372. BELLIS. Recept. nudum, conicum. Pappus, nullus. Cal. hemifphæricus, fquamis æqualibus. Sem. obovata.

375. MATRICARIA. Recept nudum, cylindra. cco-conicum. Pappus nullus. Cal. planiufculus, imbricatus, fquamis margine fca. riofis.

373. CHRYSANTHEMUM. Recept. nudum, Pappus nullus. Cal. hemifphæricus, ime bricatus, fquamis margine dilatatis, mem. branaceis.

374. PYRETHRUM. Recept. nudum. Pcippus marginatus. Cal. hemifpharicus, imbricis tus, fquamis acutiufculis, margine feariofis.

371. DORONICUM. Recipt. nudum. Pappus fimplex. Sem. radii mutica. Cal. fquam duplici ordine, æquales, difco longiores.

369. INULA. Recept. nudum. Pappus fimplex. Cal. imbricatus. Cor. radii numcrofiffima, lineares. Anthere bafi bifet $x$.

364. ERIGERON. Recept. nudum. Pappus fim. plex. Cal. imbricatus. Cor. radil lineares, anguftiflimæ, numerof $x$.

SOLIDAGO. Recept. nudum, ferobiculatum. Pappus fimplex. Cal. imbricatis, fquamix. 


\section{(8II)}

fipamis conniventibus. Flosce radii circiter 5 .

367. ASTER. Recept. nudum. Pappus fimplex. Cal. imbricatus, fquamis inferioribus patulis. Flofe. radii plures guam 10.

366. SENECIO. Recept. nudum Pappus fimplex. Cal. cylindricus, polyphy!lus, æqualis, calyculatus, fquamis apice fphacelatis.

365. TUSSILAGO. Recept. nudum. Pappus fimplex. Cal. fimplex, polyphyllus, æqualis, fubmembranacens, bafi ventricofus.

370. CINERARIA. Recept. nudum. Pappus fimplex. Cial. fimplex, polyphyllus, æqualis, cylindraceus.

376. AN I'HEMIS. Rerept. palcaceum. Pappus fubmarginatus. Call. hemifphæricus, fquamis fubequalibus. Flofc. radii plures quam 5 , oblongi.

377. ACHILLEA. Recept: paleaccum. Pappis nuilus. Cal ovatus, imbricatus, inæqualis. Flofc radii 5 ad 10 , obcordato-fubrotundi. Bidens cernua.

\section{POLYGAMIA FRUSTRANEA:}

Flofculi difci hermaphroditici; radii neutri, fteriles.

378. CENTAUREa. Recept. Retofum. Pappus fimplex. Cor. radii infundibuliformes, longiores, irregulares. 


\section{SYNGENESIA.}

\section{POLYGAMIA EQQUALIS.}

* SEMIFLOSCULOSI. Flofculi ligulati.

339. TRAgopogon. G. Pl. 398. Juf. I үa. Germ. t. I 59.

Receptaculum nudum. Cal. fimplex, polyphyllus. Pappus fipitatus, plumofus.

pratenfis. I. TRAGOPOGON calycibus corollarum radium fubrquantibus, foliis integris carinatis acuminatis; bafi dilatatis, pedunculo tereti.

Tragopogon pratenfis. Engl. Bot. t. 434. Ifull. I 72 .

T. pratenfe. Sp. Pl. I rog. Hudf. 335. With. 672. Relb. 290. Sibth. 236. Ab6or. 168. Fl. Dan. t. 906.

T. luteum. Raii Syn. I 7. Ger. em. 735.

Tragopogon. Fuchj. Hijt. 821. Matth. Falgr. \%. I. 490.

Barbula Hirci. Trag. Hift. 280.

Hirci Barba. Cord. Hift. $\mathrm{I}_{5} 6$.

Narrow and Common Goat's-beard. Pet. H. Brit.t. I $5 \cdot f \cdot 6,7$.

Angl. Ycllow Goat's-beard.

In pratis et pafcuis graminofis.

Biennis. Fl. Junio.

Radix fufformis, lactefcens, dulcis. Herba glabra, lisviffima. Caules ramofi, foliofi, teretes, fetquipediales, frepè purpurafcentes. Folia alterna, amplexicaulia, ca.rinata, acuminata, indivifa, integerrima ; bafi dilatata, ventricofa, et fubundulata; apice flaccida. Pedunculi terminales, folitarii, uniflori, exactè cylindracci. Flores magni, aurei, matutini, nec ultra meridiem, nifi fub nebulot. 
nebulofo et caliginofo coelo, expanfi. Foliola calycina lanccolata, acuminata, plana, duplici ferie digefta, rqualia. Flofculi quinquedentati, exteriores maximi, longitudine varii, at plerumque calyci æquales vel longiores. Antheræ fufcefcentes. Germen apice penicillatum. Receptaculum punctatum. Senina curvata, fulcata, fcabra. Pappus radiatus, plumofus, fitpite fubulato.

2. TRAGOPOGON calycibus corollarum radio porrifofefquilongioribus, foliis integris ftrictis, pedun- lius. culo fupernè incraffato.

Tragopogon porrifolius. Jacq. Coll. v. I. 99. $l i$. rar. v. I. t. I 59. Engl. Bot.t. $63^{8}$.

T. porrifolium. Sp. Pl. I I I o. Itudf. 335 . Will. 672. Hiull. I 72 . F\%. Dan. t. 797 .

T. purpurcum. Raii Syn. г7 I. Ger. ent. 735 .

T. alterum. Matth. Valgr. v. I. 491.

Angl. Purple Goat's-beard. Pet. H. Brit. t. I $5 . f .8$.

In pratis humidiufculis.

On the banks of the Chalder near Whalley, Lancathire. Gerarde. In many parts of Cornwall; Dr. Gunthorp. Merret. Fields about Carlint: and Rofe Caftic, Cumberland; Mr. Nicholfon. Dill. Marfhes below Woolwich, and near Edmonton;. Blackftone. Hudf. Meadows below St. Vincent's rocks, Briftol. Mr. Sozerby and Mr. D. Turner.

Biennis. Fl. Maio, Junio.

Radix fufformi-teres, lactefcens, dulcis. Herba glabra, glauca, quadripedalis. Folia vix undulata, apice rectiufcula. Pedunculus apice incraffatus. Foliola calycina lineari-lanceolata, flofculis dupló ferè longiora. Corolla fufco-violacea. Antheræ nigræ. 


\section{I4 STNGENESIA-POLYGAMIA EQUALIS.}

340. PICR IS. G.Pl. 399. Ji/f. 170. Gartn.l. I59. Helmintia. Ju/f: s 70. Gicrtn. t. 159.

Recept. nudum. Cal. duplicatus; interior xqua. lis; cxterior laxus. l'apprus plumofus. Semina tranfverfin fulcata.

eckioides. 1. PICRIS calyce exteriori pentaphyllo maximo aculeato, pappo ftipitato, foliis repandis.

Picris cchioides. Sp. Pl. I I I 4. Hudl. 342. Witb: 673. Hull. 172. Relb. 297. Sibtb. 240. Abloot. 168. Ciut. Lond. fact. 3.t. 51 .

Helmintia echioides. Gortn. v. 2. 368 .

Hieracium echioides, capitulis Cardui benedicti. Laiii Syn. 166. Bauh. Hijt. v. 2. 1029.

Bugloftum luteum. Ger. ell. 798.

Ox-tongue Hawkweed. Pet. H. Brit. t. 12. f. 12.

Angl. Brifily Ox-tongue.

In agrorum marginibus, aggeribufve, imprimis folo argillaceo.

Annua. Fl. Junio, Julio.

Radix ranıfa. Herba finulis pungentibus, porrectis, undique horrida. Caulis bipedalis, ercetus, ramofus, foliofus, fulcatus, teres. Folia repanda, lætè virentia, lucida: radicalia obovata; caulina acuta, bafi cordata, amplexicaulia, patentifinia. Peclunculi fubpaniculati, uniflori, apice demùm incraffati. Flores aurei. Calyx exterior pentaphyllus, maximus, laxus, folliolis cordatis ; interior fuboctophyllus, folliolis lanceolatis, æqualibus, conniventibus, nec imbricatis, ariftâ pinnatâ, parùm infra apicem infertâ, purpureâ. Flofculi calyce longiores. Semina terctiufcula, tranfverfim pulcherrinie corrugata. Pappus plumofus, ftipite filiformi, ipfo fenine parùm longiori.

bieraci- 2. PICRIS calyce extcriori polyphyllo abbreviato, oides. 
pappo feffili, foliis undulatis; radicalibus dentatis.

Picris hieracioides. Sp. Pl. II5. With. 673. Ilull. 172. Relh.297. Sibtb. 240. Abbot. 168. Eingl. Bot. t. 195.

Hedypnois hieracioides. Hudf. 342.

Hicracium afperum, majori flore, in agrorum limitibus. Raii Syn. 167. Banh. Hijt. \&.2. IO29.

H. alperum. Ger. em. 298.

Angl. Hawkweed Ox-tongue.

Ad agrorum viarumque margines, folo glareofo ve) calcareo.

Biennis. Fl. Julio, Augufto.

Herba fcabra ramofifima, bipedalis. Folia undulata, margine præcipuè aculeata; radicalia lanceolata, inzequalitir dentata; caulina amplexicaulia, recurva, acuta. Panicula fubcorymbofa, foliolofa. Pedunculi parùn incrallati, fubfquamati. Flores flavi. Calyx exterior $e$ foliolis plurimis, lanceolatis, laxè patentibus, inaqualibus, abbreviatis, fcabris ; interior polyphyllus, foliolis triplò longioribus, lanceolatis, xqualibus, conniventibus, nequaquam imbricatis, villofis, fcabris, muticis. Flofculi calyce duplò longiores. Semina fulcata, tranfverfim rugofa. Pappus plimolus, fefilis, xqualis.

341. SONCHUS. G. Pl. 400. Jiff. I6g. Gertin. t. 158 .

Respt. nudum. Cal. imbricatus, ventricofus. Pappus fimplex, feffilis.

I. SONCHUS pedunculis calycibufque hifpidisceruleus, racemolis, foliis fublyratis : loboterminali deltoideo maximo.

Sonchus caruleus. Camer. Epit. 281. S. canadenfis. Sp. Pl. I I j. With.674. Hill. 177.

S. alpinus. 


\section{E16 SYNGENESIA-POLYGAMIA RQUALIS.}

S. alpinus. Hual. 336. Fl. Dan.t. i 82.

S. n. 20. Hull. Hifl. v. I. 9 .

S. carulens latifolius. Bauh. Hift.v. 2. 1005.

S. flore caruleo. Ger.em. 294.

Ang\%. Blue Sow-thiftle.

In pafeuis montofis et alpinis.

On the borders of corn - fields about Willington and Howden-pans, Northumberland; Wallis. Hudj:

Percnnis. Fl. Julio, Augufto.

Radix carnofa, ramofa, cæefpitofa. Caules erecti, tripeciales, fimplices, foliofi. Folia alterna, amplexicaulia, runcinato-lyrata, denticulata, lævia, fubtùs glauca, lobis acutis, terminali maximo, deltoideo : fuperiora linearia, ciliata. Racemus terminalis, folitarius, erectus, hifpidus, pilis porrectis, rubris, glandulofo-vifcidis. Bracteæ lineares. Calyx hifpidus, rubicundus. Corolla purpuro-cærulea, calyce duplò longior. Antheræ rubræ. Semina compreffa. Pappus fcaber, nec plumofus. Exemplaria indigena nondum mihi obvia fuere.

Nomen S. canadenfts huic plantæ, Alpium omnium Enropæarum incolæx, minimè convenit; antiquifimum proindè reftitui. A S. alpino Linnxi quam maximè difcrepat. Confer Pl. Ic. cx Herb. Linn.t.2I.

palufris. 2. SONCHUS pedunculis calycibufque hifpiclis fubumbellatis, foliis runcinatis bafi fagittatis margine fcabris.

Sonchus paluftris. Sp. Pl. iा 6. Hudf. 337. Witb.674. Hull. I 77. Relb. 292. Curt. Lond. fafc. 5. t.59. Fl. Dan. t. 606 .

S. tricubitalis, folic cufpidato. Raii Syn. 163.

S. arborcfcens alter. Ger. em. 294. Angl. Tall Marh Sow-thifle. Pet. H. Brit. t. I 4. $f .7$.

In paluftribus ad ripas fluviorum. 
About Greenwich and Blackwall. Ray. Curtis. Near Streatham ferry, inle of Ely. Relh.

Perennis. Fl. Julin, Angufto.

Radix ramofa, "minime repens." Curt. Caules erecti, 6-8 pedales, fubfimplices, foliofi, angulati, fiftulofi. Folia rneinata, acuta, glabra; bafi fagittat?, amplexicaulia; margine denticulato-feabra. Panicula rerminalis, fuhumbellata vel cymofa, multitlora, hifpida, pilis denfis, glandulofis, atris, uti calyx. Cornlla flava, calyce duplö longior. Semina fulcata. Pappus lavis.

3. SONCHUS pernncuils calycihufque hifpidis arvenfis. fubumbelatis, foliis runcinatis denticulatis bafi cordatis, radice repente.

Sonchus arvenfiэ. Sp. Pl. I I I6. IRudl, 337. With.674. Hull. 177. Relh.29I. Sibth. 237. Abbot. 169. Curt. Lond. fasc. 4. t. 53. Eingl. Bot.t. 674 .

S. repens, multis Hieracium majus, Räai Syn. 163 .

S. arborefcens. Ger.em. 294.

Hieracium mains. Fuchs. Hift. 3 I 9.

Angl. Corn Św-tliftie. Pet. H. Brit. t. I4. f. 6 .

In arvis et ad tepes, folo argillacco.

Perennis. Fl. Augufto.

Radix repens, carnofa, lactefcens. Caulis 3-4 pedalis, erectus, fubfimplex, teretiufculus, foliofus, fiftulofus. Folia runcinata, acutiufcula, glabra ; bafi cordata, amplexicaulia; margine denticulato-fpinulofe. Panicula terminalis, pauciflora, fubcymofa, hifpida, pilis glandulofis, fufcis. Calyx etiam hifpidus. Corolla maxima, aurea. Semina fulcata. Pappus lævis.

4. SONCHUS pedunculis tomentofis, calycibusoleraceus. lævibus, foliis runcinatis dentatis.

Sonchus 
Sonchus oleraccuss. Sp. I'. I1 16. Hullf. 336 . With.675. Hill. 177 . Rill.291. Sibib. 237. Albot. 169. Curt. Lond. falc. 2. t. 58 .

S. lævis, Raii sin. 162. Ger.em.292. Camer. Epit. 279. Mutth. Valyr. v. I. 452.

Smooth jagged Sowthifile. Pet. H. Brit. t. I4. f. 9 et io.

G. Sonchus oleraceus. Fl. Dant. t.682.

S. Iævis minor, paucioribus laciniis. Raii Syr. 163.

S. lavis latifolius. Ger. em. 292.

Smooth broad Sowthiftle. Pet. H. Brit. t. I4. f. 8 .

\%. Sonchus afper laciniatus. Raii Syn. I63.

S. afperior. Ger.em.29r.

Prickly jagged Sowthifile. Pet. II. Brit.t. I4. $f \cdot 5$.

d. Sonchus afper non laciniatus. Raii $S_{y} n$. I63.

S. afper. Ger.em.291.

Broal Sowthifile. Pct. H. Brit. t. I 4.f. 2.

Prickle-dented Sowthiftle. Jlid. $f .4$.

๕. Sonchus fubrotundo folio notùras. Dill. in Raia Syn. 163. Pluk. Phyt. t. 6r.f. 5.

Round-leaved Sowthifle. Pet. H. Brit. t. 14. f. 1 .

$\zeta$ Sonchus aphyllocaulis angunto ct oblongo folio noftras. Dill. in Raii Sym. 163. Pluk. Jbyt. t. 62. f. 4 .

Narrow Sowthiftle, Pet. H. Brit. t. I4.f: 3 . Angl. Common Sowthitile.

In cultis et ruderatis nimis frequens,

Annua. Fl. Julio-Septembri.

Radix fuffiformis. Herba polymorpha. Caulis ramofus, teres, glaber, fragilis, foliofus. Folia lævia, runcinata, lobis acutis, magis minưfve dentatis vel fpinofis. Pedunculi 
axillares et terminales, fubcynofi, lanugine albâ, nolliffimâ, (ftatim deciduâ) toment , fi, deinde gla! : lyx glaber. Corolla lutea. Semina angulata, fulcata, crenulata. Pappus lævis.

\section{LACTÜCA. G. Pl. 400. Juf. I69. Gertn.t. I 58.}

Recopt. nudum. Call. imbricatus, cylindraceus, margine membranaceo. P'appus fimplex, itipitatus.

๖. LACTUCA foliis horizontalibus denticulatis virofa. carinâ aculeatis.

Lactuca virofa. Sp. Pl. I I 9. Hudf. 337. With. 677. Hull. 175. Kelh. 292. Sibth. 237. Ligbtf. 429. Woodv. Suppl.t. 250.

L. Sylveltris major, odore opii. Räi Syn. 16 I. Ger, em. jog.

L. fylveftris hirfuta, odore virofo opii finili. Morif. Sect. $7 \cdot t \cdot 2 \cdot f .16$.

Cut Lettuce. Pet. H. Brit. t. 15.f. 2.

3. Lactuca fylveftris, folio non laciniato. Raii Syn. I62.

Broad Lettucc. Pet. H. Brit.t. I 5.f. 2. Angl. Strong-fcented Lettuce.

Ad fepcs, muros, et agrorum margines, folo calcareo.

About Norwich in many places. Common in all chalk countries. Dr. Goodenough has obferved it on dry banks in the neighbourhood of London, as at Acton, Ealing, Brentford, \& $x$.

Biennis. Fl. Augufto, Septembri.

Herba lactefcens, fucco virofo, acri, fomnifero. Caulis erectus, virgatus, teres, paniculatus, purum foliofus. Folia glabriufcula, denticulata; radicalia plurima, obovatą, indivifa; caulina minora, fæpè lobata, amplexicaulia, 
caulia, coftâ pectinato-fpinosâ. Bractcie cordatre, acutæ. Pedunculi fquanati. Calyx glaber, paucifinrus. Corolla fulphurea, vix calyce lonenr. Sen na clliptica, comprefia, ftriata, nigra. Pappus fipitatas, fcaber.

Scariola. 2. LACTUCA foliis verticalibus finuatis denticullatis carinâ aculcatis.

Lactuca Scariola. Sp. Pl. I I I9. Hudf. 338 . itith. 677. Hull. 175. Relb. 293. Engl. Eot.t. 268.

I. fylveftris, cofta fpinora. Raiisyn. I6r.

L. fylvefiris, foliis diffectis. Ger. em. 309.

L. fylveftris. Fuch. Hif. 30 I. Mattb. Valgr. v. I. 476. Comer. Epit. 300.

Angl. Prickly Lettuce.

In ruderatis et ad agrorum margines petrofos. In the ifle of Ely. Relb. Hemfled.

Biennis. Fl. Augufto.

Herba glauca, lactefcens, minus virofa. Caulis erectus, foliofus, apice paniculatus. Folia pinnatifida, verticalia, nec horizontalia, variè derticulata, coftâ pectinato-fpinosâ. Bractcæ cordatæ, amplexicaules, acutæ, integerrimæ. Pedunculi bre ves, fquamati. Calyx glaber. Corolla parva, citrina. Semina elliptica, fulcata, pallida. Pappus ftipitatus, faber.

faligne. 3. LACTUCA foliis haftato-linearibus pinnatifidifque feffilibus carinâ aculeatis.

Lactuca faligna. Sp. Pl. Irig. Hudf. 338. With. 678. Hull. I75. Relh. 293. Jacq. Anftr. t. 250. Dickf. H. Sicc. fafc. 17. 16.

I. fylvefiris minima. Raï Syn. I62.

L. fylveftris altera, angufto faligno folio, coft $\hat{\mathbf{a}}$ albicante. Tupp. Ten. ed. Hall. 207. t. 4. Small Iagged Leituce. Pet. H. Brit.t. I5.f. 4. Ang? 


\section{Angl. Leaft Lettuce.}

In aggeribus et ruderatis, folo calcareo.

About Pancras. Ray. Sir J. Banks. In thady lanes in Doriethire, but rare. Dr. Pulteney.

Biennis. Fl. Augufto.

Herba viminea, glauca. Caulis ramofus, foliofus. Folia feffilia, linearia, integerrima; bafi haftata ; quandoque pinnatifida. Flores fubracemofi. Bracteæ fagittatæ.

Calyx lævis. Corolla luteola, calyce longior. Pap. pus articulato-fcaber.

Variat foliorum coftâ aculeatâ et inerni.

343. PRENANTHES. G. Pl. 401. Juf. 168. Gartn. t. I 58 .

Recept. nudum. Cal. calyculatus. Pappus fimplex, fubfefilis. Flofculi fimplici ferie.

I. PRENANTHES flofculis quinis, foliis runci-muralis. natis.

Prenanthes muralis. Sp.Pl. II21. Hudf. $33^{8}$. With. 678. Hull. 174. Relh. 293. Sibth. 238. Curt. Lond. fafc. 5. t. 58. Eingl. Bot. t. 457. Fl. Dan. t. 509.

Lastuca fylveftris murorum flore luteo. Raii Syn. 162. Baub. Hift. v. 2. 1004. Sonchus lævis muralis. Ger. em. 293. Angl. Ivy-leaved Lettuce.

In nemorofis folo cretaceo, vel ad muros.

Perennis. Fl. Julio.

Radix fublignofa. Herba gracilis, lævis, fragilis, lactefcens. Caulis teres, foliofus, erectus. Folia runcinata, amplexicaulia, rubicunda; radicalia petiolata. Panicula divaricata, flexuofa, bracteolata. Calyx gracilis, lævis, purpurafcens. Flofculi quini, citrini, patuli, You. II. $\quad \mathrm{C} \mathrm{c}$ calyce 
calyce longiores. Pappus parùm e femine elevatus. articulato-feabriufculus.

Variat foliis fuperioribus indivifis.

344. LEONTODON. G. Pl. 402. Gartn. t. I5S. Taraxacum. Ju/J. I69.

Recept. nudum. Cal. imbricatus, fquamis laxiufculis. Pafpus fimplex, ftipitatus.

Taraxa- I. LEONTODON fquamis calycinis exterioribus cum. reflexis, foliis runcinatis dentatis glabris. Leontodon Taraxacum. Sp. Pl. ir22. Hullf. 339. Relb. 294. Abliot. 169. Curt. Lond. fafc. r. t. 58. Woodv. Med. Bot. t. 3. Engl. Bot. t. 510. Mill. Illuftr. t.66. Fl. Dum. t. 574. Dieves Bilderb. t. 4 .

L. officinalis. With. 679. Hull. 173.

Taraxacum officinale. Sibth. 239 .

Dens leonis. Raii Syn. I 7o. Ger. em. 290. Hedypnois. Fucls. Hift. 680 .

Common Dandelion. Pet. H. Brit. t. I I. f. 7 . B. Dens leonis anguftioribus foliis. Raii Syn. I 7 . Narrow Dandelion. Pet.H. Brit.t. I I. f. 8. Taraxacum, radix, berba. Pbarmac. Lond. Angl. Common Dandelion.

In pratis, pafcuis, ruderatis, et cultis ubique.

Perennis. Fl. Aprili-Julio.

Radix fuffiformis, nigra. Folia radicalia, runcinata, dentata, lætè viridia, glabra. Scapi erecti, fuliis altiores, fimplices, nudi, glaberrimi, teretes, fiftulofi, fragiles. lactefcentes, uniflori. Flos terminalis, magnus, an-reus, vefpere claufus. Calyx glaber, fquamis exterioribus (parùm brcvioribus) laxè reflexis. Flofculi numerofiffimi. Receptaculum fphæroideum, excavatopunctatum. Semina obovata, fulcata, fufcefcentia. Pappus radiatus, fcabriufculus, longiffimè ftipitatus. 


\section{SYNGENESIA-POLYGAMIA \&QUALIS. 823}

2. LEONTODON fquamis calycinis exterioribus paluftre;

brevioribus erectis ovatis, foliis finuatis dentatis glabriufculis.

Leontodon paluitre. Lyonts. Fafc. 48. Engl. Bot.t. 553 .

L. Taraxacon. Wiib. 679. Hull. 173. Hudf.

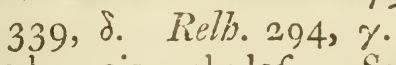

Hedypnois paludofa. Siop. Cam. ซ. 2. 100.

t. 48 .

Angl. Marh Dandelion.

In pratis humidis, ex paludibus.

On Hinton Moor, Cambridgenire. Relb. On the luwer common at Heydon, Norfolk. Rev. Mr. Bryant.

Perennis. Fl. Junio, Julio.

Radix fufiformis. Folia minùs runcinata, quandoque fub. pubefcentia. Scapi longitudine foliorum vel breviores, interdum decumbentes. Calyx undique imbricatus, fquamis exterioribus fenfim minoribus, ovatis, acutis, omnibus erectis. Flofculi aurei, exteriores dorfo purpurei. Semina et pappus ferè prioris.

\section{HEDYPNOIS. Hudf. 340.}

Leontodon. Juf. I 70.

Virea. Gertn.t. I59.

Recept. nudum, punctatum. Cal. imbricatus, calyculatus. Pappus plumofus, feffilis, inæqualis.

1. HEDYPNOIS fcapis unifloris, foliis dentatis, bip̧ida, fcabris, flofculis ore pilofis apice glandu. lofis.

Hedypnois hifpidum. Hudf. 340. Engl. Bot.

t. 554 .

Leontodon hifpidum. Sp. Pl. I 24. With. 68 s. $\mathrm{C} \mathrm{C}_{2}$ Hull. 
Hull. 174. Relh. 295. Silib. 239. Abliot. 170. Curl. Lond. fafc. 5. t. 56 . Fl. Dan. t. 862 .

Dens leonis hirfutus leptocaulis, Hicracium dictus. Raii Syn. I 7 I.

Hicracium dentis lconis folio hirfutum. Ger. em. 303 .

Angl. Rough Hedypnois.

In pafcuis, praccipuè folo calcareo vel cretacco.

Perennis. Fl. Julio.

Radix fufiformis, gracilis, tortuofa, fufca. Folia radicalia, oblonga, varie dentata vel fubpinnatifida, hifpida, pilis plerumque furcatis, quandoque trifidis. Scapi erecti, fimplices, uniflori, teretes, hifpidi. Flos ante expanfionem cernuus, dein erectus, flavus five aureus. Squamæ calycinæ erectæ, inæquales, irregulares, hifpidæ. Flofculi ore pilofi, pilis longis erectis flavis; apice quinquedentati, dentibus fubtùs fafciculo glandularum fufcefcentium notatis, monente amiciffimo Sowerbæo. Semina uniformia, gracilia. Pappus feffilis, plumofus, inæqualis.

birta. 2. HEDYPNOIS fcapis unifloris, foliis dentatis fcabris, calyce glabriufculo, feminibus exterioribus pappo deftitutis.

Hedypnois hirtum. Engl. Bot.t. 555 .

H. hifpidum, B. Hudf. 340 .

Leontodon hirtum. Sp. Pl. I 123. With. 682. Hull. 174. Sibth. 238. Abbot. I70. Curt. Lond. fafc. 6. t. 59 .

Hieracium pumilum faxatile afperum, præmorfầ radice. Raii Syn. 167.

H. dentis leonis folio, hirfutie afperum, minus. Baub. Procl. 63.

Angl. Deficient Hedypnois.

In paicuis et cricetis glarcofis.

Perennis. 
Perennis. Fl. Julio, Augufto.

Radix præmorfa. Folia lanceolato-oblonga, dentata, quandogue integra, pilis fimplicibus vel furcatis, etiam tricufpidatis, ut in priore. Scapi foliis duplò altiores, hifpidi. Flos præcedente duplo minor, ante explicationem cernuus, dein erectus, flavus five aureus, extùs fanguineus. Calyx ferè glaber. Flofculi ore imberbes, apiceque eglandulofi. Semina oblonga, fulcata, pappo plunofo ; exteriora imberbia, fquamis brevibus, erofis, quafi abortivis, coronata, monente D. Dawfon apud Curt. Fl. Lond.

3. HEDYPNOIS fcapis fubunifloris, foliis runci-Taraxici. nato dentatis, glabris, calyce pilofo.

Hedypnois Taraxici. Villars. Dauph. v. 3.80. t. 26.

H. autumnale s. Hudf. 341 .

Hieracium Taraxici. Sp, Pl. I 125. Wilh. 683. Hull. I 75. Lightf. 435. Retz.Olj. fafc. 4. t. 2. Dicks. H. Sicc. fafc. 17 . I 5 .

Picris Taraxici. Allion. Ped. v. I. 2 I I. 1.31. $f . \mathbf{I}$.

P. n. 27. Hall. Hift. v. I. 12.

Lcontodon pyrenaicum. Gouan. Oly. 55.t.22. f. $\mathrm{s}, 2$.

Angl. Alpine Hedypnois.

In locis irriguis alpinis.

In the inle of Skye, Lightf. On many Highland mountains. Mr. Mackay. In Wales as well as Scotland. Huds.

Perennis. Fl. Augufto.

Planta polymorpha. Radix præmorfa, fibris longis, fimplicibus, rectis. Folia glabra, fæpiùs lanceolata, runcinata; interdum ferè linearia, dentata. Scapus adfcendens, foliis longior, plerumque uniflorus, rariùs biflorus; medium versùs bracteolatus, bracteâ fubulatâ; apice incraffatus, pubefcens, uti calyx, pilis paten$\mathrm{C}$ c 3 tibus, 


\section{SYNGENESIA-POLYGAMIA EQUALIS.}

tibus, atris. Corolla calyce duplò longior, aureą. Pappus feffilis, plumofus.

Diftincta fpecies proculdubio eft, nec hybrida. Calyce quodammodò cum Hieracio alpino convenit, at pappa plumofo abundè differt.

cutum- 4. HEDYPNOIS fcapo ramoro, pedicellis fquazalis. mofis, foliis lanceolatis dentato-pinnatifidis glabriufculis,

Hedypnois autumnale. Hudf. $34 \mathrm{I}$.

Leontodon autumnale. Sp. Pl. I I23. With. 680. Hull. 173. Relh. 295. Sibth. 238. Abbot. I 7c.

Hieracium minus præmorsâ radice. Rại $S_{y} n_{\text {. }}$ I 64. Bauh. Hift. v. 2. Iо31.

H. minus. Fucbf. Hift. 320.

H. minus five leporinum. Ger. em. 296.

Common Hawkbit. Pet. H. Brit. t. I2. f. I.

B. Hieracium præmorfum laciniatum. Dill. in Raii Syn. I64.

Jagged Hawkbit. Pet.H. Brit. t. I2. f. 2.

$\gamma$. Hieracium folio acuto minus. Dill. in Raï Syn. I 64.

Small jagged Hawkbit. Pet. H. Brit. t. I2, $f \cdot 3$.

3. Hieracium folio obtufo minus. Dill. in Raii Syn. I 64.

Dandelion Hawkbit. Pet. H. Brit. t. I 2. f. 4. Angl. Autumnal Hedypnois.

In pratis et pafcuis vulgaris.

Perennis. Fl. Augufto.

Padix præmorfa, fibris longiffimis. Folia omnia fere radicalia, lanceolata, dentata vel pinnatifida, plerumque glabra, interdum fcabra vel hifpidiufcula. Scapus rainofus, patens, fulcatus, fcabriufculus, quandoque bafin versùs fubfoliofus. Pedunculi arcuato-adfcendentes, elongati, 
elongati, fquamofi, fquamis fparfis, fubulatis, apice incraffati, fubvillofi. Calyx pubefcens. Flofculi aurei, extùs apiceque rubicundi. Semina gracillima, fulcata. Pappus feffilis, plumofus.

Varietaten foribus e receptaculo proliferis invenit amiciffimus D. H. Bryant.

346. HIERACIUM. G. Pl. 402. JufJ. I69. Gertn. t. 158 .

Recepl. nudiufculum, punctatum. Cal. imbricatus, ovatus. Pappus fimplex, feffilis.

* Scapo nudo unifloro.

r. HIERACIUM foliis oblongis integris dentatis, alpinum. fcapo nudiufenlo unifloro, calyce pilofo. Hieracium alpinum. Sp.Pl. I 24. Hudf. 343. With. 683 . Ligbtf. 434. t. 18. Hull. 175 . H. villofum alpinum, flore magno fingulari, caule nudo. Dill. in Raii Syn. 169. t. 6. f. 2 .

H. alterum pumilum. Column. Ecpbr. v. 2. 29. t.30. f. 2 .

Welfh Moufe-ear. Pet.H.Brit.t. I I.f. 2 ? Angl. Alpine fingle-flowered Hawkweed.

In petrofis alpinis Cambricis et Scoticis.

On the mountains about Llanberris, North Wales. Hudf. On many mountains in the Highlands. Lightf.

Perennis. Fl. Julio.

Radix fublignofa. Herba undique pilofa, pilis canis bafi fulvis. Folia radicalia, obovato-lanceolata, indivifa, fæpiùs denticulata. Scapus folitarius, palmaris, erectus, fimplex, uniflorus, teres, fupernè nigricans, medium versùs foliolo folitario, lanceolato, integerrimo. Flos erectus, magnus, aureus. Calyx undique imbricatus, niger, villofiffimus, pilis canefcentibus. Semina $\mathrm{C} \mathrm{C}_{4}$ caftanea, 
caftanea, angulata, punctulata. Pappus fimplex, feffilis, faber.

Pilofel- 2. HIERACIUM foliis ellipticis integerrimis fubtùs tomentofis, ftolonibus repentibus, fcapo unifloro nudo.

Hicraciun Pilofella. Sp. Pl. I I 25. Hudf.343. With. 682. Hull. 175. Relb. 298. Sibib. 241. Albout. I7o. Curt. Lond. fafc. 4. t. 54. Dreves. Bilderb. t. I7. Fl. Dan. t. I I го.

Pilofella repens. Raii Syn. I jo. Ger.em. 638 . P. major. Fuchs. Hift. 605 .

fingl. Moufe-ear Hawkweed.

In pafcuis ficcioribus vulgaris.

Perennis. Fl. Maio--Julio.

Radix fibrofa. Stolones foliofi, pilofi, repentes. Folia elliptica, obtufa, integerrima, bafi anguftata; fuprà lætè viridia, hifpida, fetis rigidulis, fparfis ; fubtùs tomentofo-nivea atque pilofa. Scapus folitarius, palmaris, erectus, fimplex, uniflorus, tomentofus, aphyllus. Calyx hirfutus, pilis albis nigrifque. Corolla citrina, flofculis exterioribus fubtùs purpureo elegantèr vittatis. Semina fufca, friata. Pappus f́caber.

** Scapo mudo multifloro.

dubium. 3. HIERACIUM foliis elliptico-lanceolatis fubintegerrimis pilofis, ftolonibus repentibus, fcapo multifloro.

Hieracium dubium. Sp. Pl. I I 25 ? Hudf. 344. With. 684. Hull. I76.

H. Auricula. Fl. Dan. t. I I I .

H. n. 53. Hall. Hifl. v. I. 22, ex defcr. Angl. Branching Moufe-ear Hawkwced.

In montofis hemidiufculis. Hudf.

On Fairfield mountain, near Rydall, Wcfimoreland. 
land. Hudf. North of England. Mir. Woodwarl.

Perennis. Fl. Julio, Augufto.

Radix fibrofa. Caules et tolones procumbentes, repentes, foliofi. Folia elliptico-lanceolata, obtufiufcula, plerumque integerrima, rariùs obfoletè dentata, utrinque hifpida, fetis fparfis, fubtùs lanata. Scapi $2-6$ flori, pedicellis alternis, tomentofis, glandulofis. Calyx tomentofus, fcaber, fetis brevibus, glandulofis, nigricantibus. Corolla utrin ue citrina. Pappus fcaber.

Ad exemplarium à D. Woodwardio benevolè cormmunicatum defcriptionem elaboravi. In herbario Linnæano defideratur.

†4. HIERACIUM foliis lanceolatis integerrimis, Auricuftolonibus repentibus, fcapo nudiufcuio inal- la. tiforo umbellato.

Hieracium Auricula. sp. P!. I I26. Huclf. 344 . With. 684. Hull. $7^{6}$.

H. dubium. Fl. Dan.t. : 044 .

Angl. Umbelled Moufe-ear Hawkweed.

In montofis. Hudls.

On Dalehead, not far from Graffinere, Weftmoreland, but fparingly. Hudf.

Perennis. Fl. Julio, Augufto.

"Radix præmorfa, radiculis numcrofis, fimplicibus. Stolones repentes, foliofi. Scapus erectus, nudus, fubpilofus, pilis raris, vix femipedalis. Folia lanceolata, fubintegerrima, acuta, nuda. Flores paniculati, a tri, bus ad fex, lutei. Calycis foliola linearia, pilofa." Hudf.

Stirpem ab Hudfono elefcriptam nondum vidi.

H. Auricula (Herb. Linn.) e monte Cenifio, gaudet foliis lanceolatis, acutis, vix dentatis, magis minúfve fetof - hifpidis; fcapo erecto, tomentofo, fubinue pilofo, medium versùs foliolum folitarium plerumque gerente; umbellâ pauciflorâ; calyce nigro, pilofo; coroilâ au- 
rễ: pappo fcabro. IIuic omminò pertinet H. dubiun. F\%. Dan, t. 1044.

\section{*** Caule foliofo.}

murcrum. 5. HIER ACIUM caule paniculato, foliis radictlibus ovatis dentatis majoribus.

Hicracium murorum. Sp. Pl. I I 28 . Hudf. 344. With. 686. Hall. 176. Rell. 298. Sibth. 241. Abbot. I7I.

H. murorum, folio pilofifimo. Raii Syn. г68. Pulmonaria gallica five aurea latifolia. Ger. em. 304.

Pilofella major quibufdam, aliis Pulmonaria flore lutco. Bauh. Hift. v. 2. 1033.

Corchorus. Dalech. Hijt. 5 ńs.

French Hawk-lung. Pet. H. Brit. t. 13. f. 4. f. Hicracium macrocaulon hirfutum folio rotundiore. Raii Syn. I69.

Round Hawk-lung. Pet. H. Brit. t. 13. f. 2. $\%$ Hieracium leptocaulon hirfutum folio longiore. Raii Syn. 169.

H. fylvaticum. Fl. Dan.t. II I 3 .

Angl. Wall Hawkweed. Golden Lungwort.

In fylvis, muris antiquis, et aggeribus agrorum. \%. In Weftmoreland. Ray. Nit. Crowe.

Perennis. Fl. Julio.

Radix fibrofa. Herba pilofo-fcabra. Caulis erectus, altitudine varius, paniculatus, bafi præcipuè foliofus. Folia inferiora petiolata, ovata, vel ovato-lanceolata, dentata, bafin versùs fimlata, vel fubpinnatifida ; fuperiora pauciora, minora, ierè feffilia ; omnia maculis atro-purpurcis fubinde contaminata. P'etioli hirfuti. Pedunculi incani. Bracteæ fubulatæ. Flores aurei. Calycis foliola linearia, acuta, dorfo glandulofo-hifpida, corollâ duplò breviora. Semina angulata, fulcata. Pappus fcaber. 
SYNGENESIA-POLYGAMIA EQUALIS. 83 r

Variat caule aphyllo, quandoque unifloro.

Varietas $\gamma$ gaudet foliis frequentiùs maculatis, longioribus, caule tripedali, foliofo, nec (ut Raius e memoriâ fcripfit) aphyllo. Hanc vix refert icon apud Petiv. H. Brit. t. I3. $f \cdot 3$. e J. Bauhino mutuata.

6. HiERACIUM caule paniculato foliofo, foliis fylvatiradicalibus ovatis utrinque acutis fubdenta- cun. tis.

Hieracium fylvaticum. Gouan. Obf.56. With. 687. Hull. п76.

H. inurorum. Allion. Ped. v. I. 2 I 5. t. 28. f. I. Hudf. 345, B (nec Linn.) eliam $\varepsilon$.

H. Pulmonaria dictum anguftifolium. Räi Syn. 168.

Pulmonaria Gallica, five atirea, anguftifolia. Ger. em. 304.

Pilofellæ majoris, five Pulmonaria luteæ fpecies anguftifolia. Baub. Hift. v. 2. I034.

Narrow Hawk-lung. Pet. H. Brit. t. 13.f. 5 . Angl. Wood Hawkweed.

In dumetis et montofis fubalpinis.

In a Roman camp at Sidmonton, near Newberry ; Mr. William Coote. Ger. em. In Walcs. Ricbardfon. On Dudley Caftle hill. With.

Perennis. Fl. Augufto.

Præcedente major, cauleque magis foliofo. Folia radicalia bafi attenuata, et per petiolos quafi decurrentia, obfoletè dentata, nunquam pinnatifido-laciniata ; caulina feffilia, ovata. Flores aurei. Calyx incanus. Gouan. With. Hanc fpeciem nondum ipfe vidi.

7. HIERACIUM caule paniculato filtulofo, foliis paludocordato-amplexicaulibus dentatis glabris, ca- fum. lycibus hifpidis.

Hieracium paludofum. Sp. Pl. I I 29. Hudf. 345 . 
With.686. Hull. 176. Lightf. 4i8. H. Dan.

1.928. Allion. Pid. $v$. 1. 216. t. 28. f. 2 .

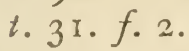

H. montanum Cichorci folio nofiras, Raii Syn。 166.

H. montanum latifolium minus. Ger. em. 300 .

H. latifolium glabrum. Baub. Hift. v. 2. 1033. H. Britannicum. Cluf. P'ann. 643, ex defer. Angl. Succory-leaved Mountain Hawkweed.

In umbrofis irriguis alpinis.

In the alpine parts of Yorkfhire. Ricbardfon. Not unfrequent in Weftmoreland, as at Kirkby Lonfdale juft below the bridge, and between that town and the lakes; alfo in marhy places near Moffit, and other parts of the lowlands of Scotland.

Perennis. Fl. Julio.

Radix fibrofa, certè perennis. Herba glabra, intensè amara. Caulis erectus, bi - vel tri-pedalis, angulatus, fulcatus, foliofus, apice paniculatus, intùs cavus. Folia ovata, acuminata, dentata, bafi cordata amplexicaulia; infima quandoque fublyrata. Flores fubcorymbofi, faturatè citrini. Bractex ciliatæ. Calyx hifpidus, pilis nigris. Semen pallidè fufcum, fulcatum. Pappus feaber.

molle. 8. HIERACIUM caule paniculato fiftulofo, foliis lanceolatis obfoletè dentatis pilofis amplexicaulibus; inferioribus petiolatis.

Hieracium molle. Jasq. Aufl. t. I 19 . (Herb. Linn.) Dickf. Tr. of Limm. Soc. v. 2. 288. H. Sicc. fáfc. I1. 13. With.688. Hubll. 176. Angl. Soft-leaved Hawkweed.

In fylvis.

Woods in the fouth of Scotland. Dickfon.

Perinnis. Fl. Julio, Augufto.

Radix 
Radix fibrofa. Herba pilofiufcula, pilis brevibus, fparfis.

Caulis fefquipedalis, erectus, angulatus, foliofus, apice paniculatus, intùs cavus. Folia lanceolata, obtufiufcula, obfoletè denticulata ; inferiora petiolata ; fuperiora feffilia, bafi cordata et femiamplexicaulia. Pedunculi glandulofo-pubefcentes. Flores faturatè aurei. Calyx pilofus et fubtomentofus. Semen flavefcens, ftriatum. Pappus fcaber.

9. HIERACIUM caule foliofo fubramofo, foliis villofum. hirtis repandis dentatifque : radicalibus lanceolatis; caulinis ovatis amplexicaulibus.

Hieracium villofum. Sp. Pl. I i3o. With.687. Hull. I76. Dicks. Tr. of Lim. Soc. v. 2. 288. Jacq. Austr. t. 87.

H. n. 44. Hull. Hift. v. I. I8. Enum. rar. 54. n. $97 \mathrm{I}$.

II. quintum villofum. Chef. Hift. $v$. 2. I12. Pann.644. Ger. em.301. Baub. Hift.v. 2. $1027 \cdot f \cdot 2$.

Pet. H. Brit.t. I $3 \cdot f .6$, nomine erroneo. Angl. Shaggy alpine Hawkweed.

In rupibus humidis alpinis.

Ben Nevis. Mr. Dickfon. Near Mcer Gill at the foot of Ingleborough, Yorkfhire; Mr. Caley. With.

Perennis. Fl. Augufto.

Radix fublignofa, fibrofa. Caulis erectus, foliofus, pilofo-fcaber, fæpiùs fpithamæus, fimplex, uniflorus; quandoque bipedalis, ramofus, multiflorus. Folia radicalia lanceolata; caulina alterna, amplexicaulia, cordato-ovata ; omnia repanda five dentata, fubglaucefcentia, utrinque villofiffima, pilis rigidulis, flavefcentibus, bafi bulbofis. Flos terminalis, magnus, citrinus. Calyx nigricans, pilis albidìs, corollâ duplò brevior. Pappus bafi imprimis fcaberrimus. 


\section{SYNGENESIA-POLYGAMIA AQUALIS.}

faban- Io. HIERACIUM caule erecto multifloro, foliis dum. ovato-lanccolatis dentato-ferratis fubamplexicaulibus fubtìs fcabris.

Hicracium fibandum. Sp. Pl. I г 3 I. Fl. Suec. 274. Itud. 345. With.685. Haill. г76. Relb. 293. Sibth.24r. Abbot.17r. Engl. Bot. t. 349. Fl. Dan. t. 872 . Baut. Hift. v. 2. 1030 , varietas fesunda.

H. n. 35. Hall. Hift. v. 1. 15.

H. fruticofum latifolium hirfutum. Raii $S_{y n \text {. }}$ 167.

Broad hairy Hawklung. Pet. H. Brit. t. I3. $f \cdot \%$.

R. Hieracium fruticofum latifolium glabrum. Raii Syn. 168.

Broad fmooth Hawklung. Pet. H. Brit. t. I3. f. 9 .

$\gamma$. Hieracei feu Pilofellæ majoris fpecies humilis, foliis longioribus rariùs dentatis plurimis fimul, flore fingulari noftras. Raii $S_{y} n$. I 70. Pluk. Plyyt.t. $37 \cdot f \cdot 3$.

Plukenet's Moufe-ear. Pet. H. Brit. t. II. f. 6 .

Angl. Shrubby broad-leaved Hawkwced.

In dumetis et nemorofis.

B. Near Ulfwater lake, Weftmoreland. Ray.

Perennis. Fl. Augufto, Septembri.

Caulis ereetus, ftrictus, tripedalis, foliofus, teres, fulcatus, fcaber, intùs fpongiofus, vix fiftulofus, apice paniculatus, multiflorus. Folia fparfa, numerofa, fubfeffilia et ferè amplexicaulia, ovata, acuminata, dentata, plerumque hirfuta, fubtùs præcipuè fcabra et pallidiora; radicalia lanceolata, longiora. Panicula ramofa, pilnfa. Bracteæ integerrimæ. Calyx fufco-virens, pilofus, fquamis infinis laxis. Corolla aurea. Semer angulatum, 
angulatum, caftaneum, fcabriufculum. Pappus fcaber. Receptaculum farofum, fubhifpidum.

I. HIERACIUM caule ereêto multifloro, foliis prenanelliptico-lanceolatis denticulatis læviufculis thoides. ciliatis amplexicaulibus fubtùs glaucis.

Hieracium prenanthoides. Villars. Dauph. v. 3 . 108. With. 685. Sym. Syn. 173. Hull. 176. H. ipicatum. Allion. Ped. v. I. 218 . t. 27. f. 1 et 3. Dickf. Tr. of Linn. Soc.v.2. 288.

H. Kalmii. Sym. Syn. 173. Hull. 176.

H. n. 43. Hall. Hift. ข. I. I 8.

H. montanum Mali cottoneæ folio. Bocc. Muj. t. 53 .

Angl. Glaucous-leaved Hawkweed.

In fylvis montofis Scotix.

In woods in the fouth of Scotland. Mr. Dickfon and Mr. Donn. In Rannach, Perthihire. Mr. Jobn MIackay.

Perennis. Fl. Augufto, Septembri.

Caulis erectus, tripedalis, foliofus, teres, ftriatus, fubpilofus, intùs fpongiofus, fubfitulofus, apice paniculatus, multiflorus. Folia numerofa, alterna, plerumque amplexicaulià, latè elliptico-lanceolata, acuta, rarè denticulata, tenuia, læviufcula; fubtùs glauca et fubpilofa; margine ciliata, pilis brevibus, æqualibus. Panicula ramofa, patens, pilofa, fubvifcida. Bractex integerrimx, parve. Calyx fufco-virens, pilofo-muricatus, tomentofus, fubvifcidus. Corolla aurea. Semen angulatum, fufcum, lavifimum. Pappus fcaber.

I2. HIER A CIUM caule erecto fubumbellato, fo- umbellaliis linearibus fubdentatis fparfis.

tum.

Hieracium umbellatum. $s p . P l$. I1 31 . Hudf. 346. With. 688. Hull. 177. Relh. 299. Sibtb. 242. Abbot. I 7. Curt. Lond. fafc. 6. t. 58. Fl. Dan. t. 680 . 
H. fruticofum angultifolium majus. Raï Syn. I 68.

H. intybaceum. Ger.em. 298 .

H. rectum rigidum, quibudam Sabaudum. Baub. Hift. v. 2. 1030.

Long hairy Hawklung. Pet. H. Brit. t. I3. f. 8. and Narrow hairy Hawklung. Ibid. f. 10.

ß. Pulmonaria angufiffolia glabra. Dill. in Rair Syn. 168.

Narrow fmooth Hawklung، Pet. H. Brit. t. I3. f. II.

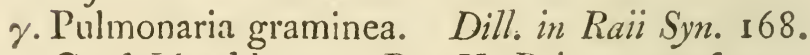
Grafs Hawklung. Pet. H. Brit. t. I3.f. 12. Angl. Narrow-leaved Hawkweed.

In nemorofis et dumetis petrofis.

Perennis. Fl. Augufto, Septembri.

Caulis erectus, bi- vel tri-pedalis, foliofus, teres, obfoletè ftriatus, apice paniculatus, fubumbellatus. Folia numerofa, feffilia, fparfa, linearia, feu lineari-lanceolata, obfoletè dentata, vel denticulata, utrinque viridia. Pedunculi apice aliquantulùm incraffati, fquamati, pubefcentes, erecti. Calyx atro-virens, fæpiùs glaber. Corolla aurea, majufcula. Semen angulatum, caftaneum, oculo armato punctulatum. Pappus fcaber. Receptaculum fubhifpidum.

Variat foliis et caule fcabris, vel omninò lavibus. Folia in $y$ anguftiffima, integerrima. Panicula vix, nifi pre infectorum injuriâ, umbellata eft.

\section{CREPIS. G.Pl. 403. JuJ. 169. Gertn. t. 158.}

Recept. hifpidiufculum. Cal. calyculatus, fquamis deciduis, demùn torulofus. Pappus fimplex, fubftipitatus.

1. CREPIS 
2. CREPIS foliis runcinato-pinnatifidis hirtis, pe-fetids. tiolis dentatis, caule pilolo, calyce tomentoro.

Crepis fotida. Sp.Pl. I I 33. Hul]. 339. With. 689. Hull. 174. Relh. 296. Engl. Bot.t. 4.06. Hicracium Caftorei odore Montpclienfum. Raii Syn. 165 .

H. flore externè croceo, amygdalas amaras olens. Morif. Sect. 7. t. 4.f. 4 .

Caftor Hawkweed. Pet. H. Brit. t. i 2.f. 8. Angl. Stinking Hawk's-beard.

In pafcuis ficcis cretaceis, fed rariùs.

In Cambridgefhire. Ray. Relb. In Chariton chalkpits, Kent. Petiver. At Barton, Norfolk. Rev. Mr. Porly, and Mr. Pitchford.

Biennis. Fl. Junio, Julio.

Radix parva. Caules diffufi, ramofi, foliofi, teretes, pilofi; centralis erectus. Folia runcinato-pinnatifida, dentata, pilofa, lobo terminali maximo, fubdeltoideo. Pecimculi terminales, elongati, fursùm incraffati, fubfquiamofi, uniflori. Calyx pilofus vel tomentofus, foilicis fụbæqualibus, carinatis, femina marginalia denuùn smplectentibus, fquamis fubulatis, laxis, brevibus, do dafin. Corolla citrina, dorfo rubicunda. Receptaculım favofum, fcrobiculis margine ciliatis. Senina gracilia, flavefcentia, fulcata, fcabriufcula. Pappus ftinitatus, fcaber nec plumofus, ftipite afpero; in fenunibus marginalibus fubfeffilis. Herba odore Opii.

2. CREPIS foliis radicalibus runcinatis; caulinis tectorum. amplexicaulibus lanceolatis dentatis, caule glabro.

Crepis tectorum. Sp. Pl. I I35. With. 689. Hull. I74. Relh. 295. Sibth.240. Abbot. I72. Curt. Lond. fafc. 5. t. 55. Fl. Dan. t. 501.

Hedypnois tectorum. Hudf. $34 \mathrm{I}$. VOL. II. D d

Hieracium 
33 SYNGENESIA-POLYGAMIA EQUALIS.

Hicracium lutcum glabrum, five minùs hirfutum. Raii Sym. 165.

H. aphacoicles. Ger. em. 297.

H. fecundum. Tabern. Kreuterl. 491 .

Hawkbeard. P'et. H. Brit. I. I 2. f. 5, 6, 7 . Angl. Sinooth Hawk's-beard. Smooth SuccoryHawkweed.

In pratis et pafcuis ficcioribus, muris, tcetifve, vulgaris.

Annaa. Fl. Junio-Septembri.

Ylanta polymorpha. Radix fufiformis. Caulis erectus, ramofus, fulcatus, glaber, purpurafcens; rariùs fubpilofus. Folia glabriufcula, frepius glaberrima, læetè viridia; radicalia runcinata; caulina lanceolata, dentata vel fubpimatifida, bafi fagittata, amplexicaulia. Panicula terninalis, fubcorvmbofa, foliolofa, fcabriufcula. Flores parvi, lutci. Calyx muricato-fcaber. Receptaculum farofum. Semina fulcata, crenulata, fufca. l'appus omninò feffilis, fcaber.

Eiennis. 3. CREPIS follis runcinato-pinnatifidis fcabris: lobis anticè dentatis, calyce muricato fubtomentofo.

Crepis biennis. Sp.Pl.1136. With.69o. Hull. I74. Reih. 296. Engl. Bot. t. I 49.

C. ก. zo. Hull. Hift. v. I. I3. Davall.

Hedypnois biennis. Hudf. $34^{2}$.

Hicracium maximum, Chondrillæ folio, afperum. Racii syn. 166.

H. erucafolium hirfutum. Bazh. Hift. v. 2 . 1025.

Tall Succory Hawkweed. Pet. H. Brit. t: 12. f. Iо.

P. Hicracium Cichorei folio minus. Dill. in Raii s.11. I65: 
Small Succory Hawkweed. Pet. H. Brit. t. i2. $f \cdot 9$.

Angl. Rough Hawk's-beard.

In pafcuis cretaceis.

Plentiful in feveral parts of Kent. Ray. Hudf. Nea: Bury. Mr. Matbew.

Biennis. Fl. Junio, Julio.

Radix fufformis. Caulis erectus, 3-vel 4-pedalis, foliofus, fulcatus, muricato-fcaber, bafi purpurafcens. Folia radicalia et caulina inferiora petiolata, runcinato-pinnatifida, lobis antice dentatis; fuperiora lanceolata, bafi pinnatifida, amplexicaulias f fumma integra; omnia fcabra, nervis fulcatis pilofis. Flores corymbofi, magni, lutei. Foliola calycina, ut et fquamæ, dorfo plus minùs muricata, fubtomentofa. Receptaculum favofum, fcrobiculis ciliatis. Semina fufca, fulcata, crenulata, apice fubulata. Pappus feffilis, fcaber.

348. HYOSERIS. G. Pl. 405. Juf. 169. Arnoferis. Gertn. t. I 57 .

Recept. nudum. Cal. fubæqualis. Pappus fim. plex, vel obfoletus.

I. HYOSERIS caule divifo aphyllo, pedunculisminima, incraffatis ventricofis.

Hyoferis minima. Sp. Pl. 11 38 . Hudf. 346. With. 690. Hull. I98. Relh. 300. Albot. I 72. Engl. Bot.t. 95. Fl. Dan. t. 20 I.

H. mafcula. Ger. em. 288.

Arnoferis pufilla. Gertn. v. 2.355. t. I57.f. 3 . Hicracium minimum Clufii, Hyoferis Tabernamontani et Gerardi. Raï Syn. I 73.

Small Swine's Succory. Pet. H. Brit. t. I5. f. 9 .

Angl. Swine's Succory.

In arvis glareofis ftcrilioribus.

D) $\mathrm{d}_{2}$ 


\section{SYNGENESIA-POLYGAMIA EQUALIS.}

About Hampton court. Doody. Walthamftow. Sir W. Watfon and Mr. E. Forfter jun. In Dorfethire. Dr. Pulteney. Near Armingthall wood, Norwich.

Annua. Fl. Junio.

Raddix parva, fuffiformis. Folia onmia radicalia, depreffa, oblonga, dentata, fubindè integerrima, margine praxcipuè feabra. Caules erecti, vix fpithamæi, aphylli, fimplices vel ramofi, teretes, glabri, bafi rubicundi. Pedunculi adfcendentes, bafi atteruati, purpurafcentes, attque bracteati, fupernè incraflati, cavi, uniflori. Calyx grabriufculus, vix calyculatus; foliola sequalia, acuta, acutè carinata. Corolla parva, citrina. Receptaculum punctatum, nudum. Semina coftato-angulata, margine obfoleto coronata, pappo deftituta.

\section{HYPOCHARIS. G. P\%. 405. Ju/. 170. Gertn. \%. 160.}

Recept. palcaccum. Cal. fubimbricatus. Pappus plumofus.

macula- 1. HYYOCHERIS catule folitario nudiufculo tat. fubfinplici, foliis ovato.oblongis integris dentatis.

II pochæris maculata. Sp. Pl. I 140 . Hudf. 346. HFith. 691. Hull. I72. Rell.300. Engl. Bot. t. 225 . Fi. Dan. t. I 49 .

Hicraciun primun latifolium. Raii syn. 167. Ger. em. zor. Angl. Spotted Cat's-car.

In pafcuis montofis calcarcis.

On Newmarket heath and Gogmagog hills. Ray. Rethan. On Bernuk heath, Northamptonthire. Ray. On Ompherhead by Cartmel Wells, Lancathire, very plentifully; Mr. Hall; and near Settle, Yorkthire; Mr. Galcy. Witb.

Perennis. 
Perennis. Fl. Julio.

Radix teres, craffa. Folia omnia radicalia, patentia, feffilia, elliptico-oblonga, dentata, fcabra, fæpiùs purpureo maculata. Caulis vel fcapus folitarius, erectus, ftriatus, hirtus, plermmque uniflorus. Bracteæ 2 vel 3 , fparfæ, parvæ, lanceolatæ, adprefiæ. Flos terminalis, magnus, aureus. Calyx muricatus, pilofus. Pappus plumofus.

2. HYPOCHARIS glabriufcula, calycibus ob-glabra. longis imbricatis, caulibus ramofis fubfoliofis, foliis dentato-finuatis.

Hypochæris glabra. Sp. Pl. I 40 . Hudf. 347 . With. 692. Hull. 172. Albot. 173. Curt. Lond. fajc. 3. t. 53. Engl. Bot. i. 575. Fl. Dan. t. 424 .

Hieracium parvum in arenofis nafcens, feminum pappis denfiùs radiatis. Raii Sm. 166 . Angl. Smooth Cat's-ear.

In ericetis et campis glareofis; interdim et in cultis, folo arenofo.

On the gravelly grounds near Middleton, Warwick hire. Ruy. Bedfordhire. Aubot. Cawfton heath, Norfolk. Rev. Mr.Bryant. Turnep-fields about Norwich. Mr. Crowe. Under Greenwich Park wall on Blackheath. Curtis.

Anmua. Fl. Junio-Augufto.

Herba undique ferè glabra, magnitudine varia. Radix fufiformis. Caules plurimi, erecto-patentes, ramofi, teretes, parùm foliofi ; primordialis fimpliciffimus, ftrictus, uniflorus, nudus. Folia radicalia plurima, fublingulata, dentato-finuata, nitida, rariùs ciliata et fubpilofa ; caulina alterna, feffilia. Flores terminales, folitarii, erecti, parvi, citrini, matutini. Calvx gracilis, imbricatus, lævis, glaucus, foliolis planis, apice purpurafcentibus. Receptaculum paleaceum, paleis lanceolatis, acutis, deciduis, longitudine calycis. Se- 


\section{SYNGENESIA-POLYGAMIA \&EUALIS.}

mina fulcata, fcabra. Pappus ftipitatus, fcaber, plumofus; in feminibus marginalibus feffilis.

radicata. 3. HYPOCIIERIS foliis runcinatis obtufis feabris, caulibus ramofis nudis lavibus, pedunculis fquamofis.

Hypochæris radicata. Sp. Pl. I I 40. Hudf. 347. Wilh. 692. Hull. 172. Relh. 301. Sibih. 242. Abtrot. 172. Curt. Lond. fafc. 3. t. 52. Fl. Dan. 1.150.

Hieracium longiùs radicatum. Raii Syn. I65. Ger. em. 298.

Rough Branched Dandelion. Pet. H. Birt.t. Ir. f. I I.

Angl. Long-rooted Cat's-ear.

In pratis et pafcuis ubique.

Perennis. Fl. Junio-Augufto.

Radix fufformis, longiffimè defcendens. Caules plurimi, divaricato-patentes, ramofi, teretes, glabri, glaucefcentes, fupernè flores versùs fquamati. Folia omnia radicalia, depreffa, oblonga, obtufa, runcinata, dentata, pilofo-hifpida. Flores terminales, folitarii, magni, aurei. Calyx imbricatus, foliolis carinâ muricatis. Receptaculum paleaceum, paleis lanceolatis. Semina fulcata, granulata. Yappus ftipitatus, fcaber, plumofus.

350. LAPSANA. G. Pl. 405. Gartn. t. I57. Lampfana. JufJ. 68 .

Recept. nudum. Cal. calyculatus; foliolis interioribus æqualibus, canaliculatis. Semina mutica.

commu- 1. LAPSANA ca'ycibus fruchûs angulatis, caule nis. paniculato, pedunculis filiformibus. Lapfana communis, Sp. Pl. II4I. Hudf. 347 . 
With.693. Hull. x78. Relh.301. Sibth. 242. Abbot. I 73. Curt. Lond. fafc. r. t. 59. Wicks. H. Sicc. fafc. II. I2. Fl. Datn. t. 500.

Lampfana. Raii Syn. I 73. Ger.em. 255. Angl. Nipple-wort. Pet. H. Brit. t. It.f. I2.

In ruderatis et cultis frequens.

Annua. Fl. Junio, Julio.

Radix ramofa, fibrofa. Caulis erectus, tripedalis, foliofus, paniculato-ramofus, teretiufculus, fulcatus, glabriufculus. Folia dentata, molliufcula, fubpilofa ; radicalia lyrata ; caulina ovati, acuta, alterna. Pecunculi alterni, teretes, tenues, glabri, bafi bracteati. Bractexe lineari-lanceolatre, acute. Flores parvi, lutci. Calyx glaber. Semina rectiufcula, angulata, omninò mutica.

\section{I. CICHORIUM. G. Pl. 406. Juf. I 7 I. Garin. t. $15 \%$.}

- Recept. fubpaleaccum. Cal. calyculatus. Pappus paleaccus, femine brevior.

1. CICHORIUM floribus geminis fefilibus, foliis Intybus. runcinatis.

Cichorium Intybus. Sp. Pl. I I 42 . Hudf. 348 . With.693. Hull. I72. Relh. 302. Silth. 243. Abliot. 17. Curl. Lond. fafc. 4. t. 56 . Wart. Fl. Ruf.t. 144. IV oode. Suppl.t. 248. Engl. Bot.t 539. Fl. Dan.t. 907 .

C. fylueftre. Raii Syz. 172. Ger. em. 284.

Intubum fylveftre. Fuchj. Hijt. 679 . Arigl. Wild Succory.

Ad agrorum margines ct vias, imprimis folo glareofo vel calcarco, frequens.

Perennis. Fl. Julio, Augufto.

Radir fufformis, carnota, alba. Caulis ferè tripedalis, erectus, ftrictus, tenax, fupernè angulatus, fcaber, foD d 4 liofus, 


\section{SYNGENESIA-POLYGAMIA EQUALIS.}

liofus, ramofus, ramis divaricatis, multifloris. Folìa fcabriufcula ; radicalia runcinata ; caulina cordata, amplexicaulia, acuninata. Flores gemini, feffiles, axillares, per paria alterni, magni, fpeciofi, cyanei, quandoque albi. Foliola calycina dorfo muricata, demùm reflexa. Receptaculum punctatum, fubpilofum. Semina angulata, pappo paleaceco, brevi, duplici ferie coronata.

** CAPITATI, Flofeuli tubulofi, apice divaricatapatuli.

352. ARCTIUM. G. Pl. 407 .

Lappa. Ju/J. I 73. Gertn, t. 162.

Cal. globofus; fquamis apicc hamatis inflexis.

Lappa. I. ARCTIUM foliis cordatis inermibus petiolatis. Arctium Lappa. Sp. Pl. I 143 . Hudf. 348. With. 694. Hull. 178. Relh. 302. Sibth. 243. Abbat. 174. Curt. Land. fafc. 4. t. 55. Woodv. Med. Bot.t. 15. Fl. Dan. t. 642 . Lappa n. 1-6. Raii Syn. 196, 197. Brunf. Herb. v. 2. 6I.

Burdock. Pet. H. Brit. t. 23.f. 1-6.

Bardana major. Ger. em. 809 .

Perfonatia, Fuckf. Hifl. 72. Ic. 4I.

Perfonata. Camer. Epit. 887. Mattl. Valgr. 497 et 498.

Bardana, radix. Pharmac. Lond. Angl. Burdock. Clat-bur.

In ruderatis et ad vias.

Biennis. Fl. Julio, Augufto.

Radix fufiformis. Caulis fubquadripedalis, erectus, ramofus, ramis patentiffimis, foliofus, teres, fulcatus, fcabriufculus. Folia alterna, petiolata, cordata, ampla, margine undulata, fubdenticulata, fcabriufcula. Flores paniculati, terminales, globofi, demùm decidui, veftibus, 
bus, feu animalium relleri, fquamis uncinatis calycuna arctè adhærentes, vel fibi invicem conglomerati. Corolla purpurea, flofculis omnibus uniformibus, tubulofis, quinquefidis, regularibus, fertilibus. Receptaculum punctatum, multifetofum. Semina quadrangularia. Pappus fetofus, fcaber.

Variat floribus (feu capitulis) majoribus vel minoribus, calyce glabro vel fquamis lanâ bombycinâ intertextis. Hinc tot fpecies et varietates apud auctores.

\section{SERRATULA. G. Pl. 408. JufJ. I74. \\ Gortn. t. 162.}

Cal. fubcylindricus, imbricatus ; fquamis incrmibus. Pappus fcaber vel plumofus, perfiftens.

I. SERRATULA foliis ferratis fubciliatis lyrato- tincoria. pinnatifidis : lobo terminali maximo, flofculis uniformibus, pappo feabriufculo.

Serratula tinctoria. Sp. Pl. I I 44. Hudf. 349. With. 695. Hull. 180. Rell. 303. Sibth. 243. Abbot. 174. Engl. Bot. t. 38. Fl. Dan. t. $28 \mathrm{I}$.

Serratula. Raii Syn. 196. Baub. Hif. v.3. 23. Ger.em.713. Matth. Valgr.v.2. 295. Camer. Epit. 682.

Angl. Common Saw-wort.

In nemorofis, dumetis et fepibus.

Perennis. Fl. Julio, Augufto.

Radix fublignofa. Caulis erectus, ftrictus, bipedalis, fo-liofus, angulatus, glaber. Folia alterna, lyrata, feu variè pinnatifida, quandoque (monente amiciffimo D. Wood) indivifa; radicalia fæpiùs integra; omnia acutè ferrata, et minutè ciliata, rigida, utrinque glabra. Flores corymbofi, purpureo-fanguinei, interdùm albi. Calycis fquamæ fufco-purpureæ, fubinde villofæ, exteriores fensim minores. Receptaculum fetofum. Semina ftriata. Pappus inæqualis, flavus, hinc fcaber, apice rẹcurvus.

2. SER - 


\section{SYNGENESIA-POLYGAMIIA NQUALIS.}

apina. 2. SERRATULA calycibus fubpilofis ovatis, foliis indivifis fubtùs lanatis, pappo plumofo.

Serratula alpina. Sp. I'. I I 45 . Hudf. 349. With. 696. Inull. 180. Lighif. 448.t. ig. Engl. Bot.t. 599 .

Cirfum humile montanum, Cynoglofi folio, polyanthemum. Raii Syn. 193. Dill. Elth. 82. $t .70$.

C. n. I79. Hall. Hif. v. 1. 77.t. 6.

Carduo-Cirfun minus Cambrobritannicum, floribus plurimis fummo caule congeftis. Pluk. Pbyt. t. : 54.f. 3 .

Carduus mollis, foliis Lapathi. Ger. em. I 184.

B. Serratula alpina. Fl. lian. t. 37 .

Cirfium montanum polyanthemum, Salicis folio angufto denticulato. Ruiii Syn. 193. Angl. Alpine Saw-wort.

In fifturis rupium alpinarum.

On Snowdon and other high mountains in North Wales. Ray. In feveral parts of the highlands of Scotland. Lightfoot.

Perennis. Fl. Julio, Augufto.

Radix lignofa, extus nigra. Caules fimplices, erecti, foliofi, teretes, ftriati, lanati, altitudime varii. Folia fparfa; radicalia et caulina inferiora petiolata, fuperiora feffilia; onnia ianceulata vel ovata, (in $\beta$ lineari-lanceolata, clongat?, denticulata, fupra nudiufcula, fubtùs tomentolo-alba. Flores corynibofi, terminales, erecti, purpurei, antheris cerulefcentibus, formofi. Calycis fquanæe obtufæe, fufco-purpureæ, pilis albis fericer. Pappus xqualis, eleganter plumofus.

Ab hâc Cirfum alpinum Boni Henrici folio 'Tournefortii malè diftinsit Dillenius. 


\section{SYNGENESIA-POLYGAMIA RQUALIS. 847}

354.CARDUUS.G.Pl.408.Juf.173 Gertn.t.162. Silybum. Gertn.t. 163 .

Cal. ventricofus, imbricatus; fquamis fpinofis. Recept. pilofum. Pappus deciduns.

\section{* Foliis decurrentibus.}

1. CARDUUS foliis decurrentibus pinnatifidis hif-lanseola* pidis: laciniis divaricatis, calycibus ovatis vil- tus. lofis, caule pilofo.

Carduus lanceolatus. Sp. Pl. i i 49. Hirdj.350. With. 699. Hull. 179. Relh. 3с4. Sibth. 244. Abbot. 175. Mart.Fl. Rufl. t. І31. Engl. Bot.t.107. Fl Dan t. 1173

C. lanceatus. Raii Syn. I95. Ger. em. II 74 .

C. lanceo'atus five fylveturis Dodonai. Baub. $H_{i f t}$ ข. $3 \cdot 5^{8}$.

B. C. lanceatus, Hore et capitc minoribus. Merr. Pin. 2'. Dill. in Rulin Sin. : 5.5.

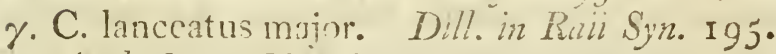
Angl. Spear Thiltle.

In ruderatis, aggeribus, et ad vias, vulgaris.

Biennis. Fl. Junio-Septembri.

Radix ramofa. Caulis quadriperlalis, erectus, validus, ramofus, folcfus, fulcatus, pilofus, foliis decurrentibus alatus, multiflorus. Folia alterna, pinnatifida, hifpida, fubtùs lanata, lobis pinnatificlis, vel bafi palnatis, laciniis alternatim divaricatis, mucronato-fpinofis, fpinis flavis, nitidis. Flores terninales, erecti, magni. Calyx ovatus, fquamis acutè fpinofis, adfcendentibus, villo albo intertextis. Flofculi uniformes, purpurei, antheris flavis. Receptaculum piinfum. Semina obovata, nitida. Pappis plumofus, denium e fenine deciduus.

Varietates, a Dillenio memoratre, nondum mihi obviæ fuere. 
sytans. 2. CARDUUS foliis interrupti decurrentibus fpinofis, floribus cernuis, fquamis calycinis lanceolatis tupernè patentibus.

Carduus nutans. Sp. Pl. 1150. Hulls. 350. With. 699. Hull. 179. Relh. 304. Siblh. 244. Albbot. 175. Hl. Dan. t.675. Raii Syn. 173. Baub. Hift. v. 3. 56.

C. mufcatus. Ger.em. II 74 , defer. nec icon, Angl. Murk Thiftle. Pet. H. Brit. t. 2 I. f. 1,

In ruderatis et arvis requietis, pracipuè folo glareoro vel calcareo.

Anmua. Fl. Julio, Augufto.

Radix fufformis. Caulis bi- vel tri-pedalis, quandoque pedalis tantùm, erectus, fubramofus, friatus, glabriufculus, foliis decurrentibus interruptè alatus. Folia finuata, lobis fpinofis, utrinque viridia, fubpilofa, nequaquàm hif́pida. Flores terminales, folitarii, pedunculati, nutantes, purpurei, mofchati, pedunculo lanato. Calyx ovatus, fquamis lanceolatis, fubfoliaceis, patentibus, acutè fpinofis, fublanatis. Semina nitida, punctulato-ftriata, compreffa. Pappus deciduus, pilofus, fcaber, nec plumofus.

ecantoai- 3 . CARDUUS foliis decurrentibus finuatis fpinofis, des. calycibus globofis fubpedunculatis ; fquamis linearibus recurvatis.

Carduus acanthoides. Sp.Pl. i i5o. Will. 698. Hull. I 79. Sym. Syn. I 7 . Kéelh. 304. Jacq. Auftr. t. 249 .

C. crifus. Iludf. 350 . Lightf. 452 .

C. polyacanthos. Curt. Lond. fafi. 6. t. 54a Sibth. 275. Abbot. 175 .

C. caule crifpo. Raii Syn. 194. Bauh. Hifl. v. 3. 59 .

Polyacanthos. Ger. em. II73. Dalech. Hifl. 1473. 
Gray Thifte. Pet. H. Brit.t.2 I.f. 3 . Angl. Curled or Welted Thifle.

In ruderatis et ad fepes.

Annua. Fl. Junio, Julio.

Radix fufiformis, albida. Herba virens. Caulis tripedalis et ultra, erectus, ramofus, fulcatus, parùm pilofus, foliis decurrentibus fubinterrupte alatus ; ramis elongatis, patulis. Folia quam in præcedentibus minora, finuata, fpinofa, utrinque viridia et glabriufcula. Flores terminales, plerumque pedunculati, erectiufculi, faturatè purpurei. Calyx globofus, fquamis linearibus, apice recurvatis, tenuè fipinofis, parùm lanatis. Semina ferè prrecedentis. Pappus deciduus, pilofus, ficaber.

4. CARDUUS foliis decurrentibus finuatis fpino- tenuifiofis tomentofis, calycibus fubcylindricis aggre- rus. gatis feffilibus: fquamis lanceolatis erectiufculis.

- Carduus tenuifiorus. Curt. Lond. fafc. 6. t.55. With. 698. Sym. Sym. 176. Hull. 179. Sibth. 244. Abbot. 175. Engh Bot.1.412. Pulten. Dorjet. 80.

C. acanthoides. Hull. 351 . Lightf. 45 I. With. ed. 2. 871. Baub. Hift.v.3.56.

C. fpinofifimus capitulis minoribus. Räii Syr. I 94.

Welted Thiftle. Pet.H. Brit.t. 2 I.f. 2. Angl. Slender-flowered Thiftle.

In aggeribus et ad vias, minus frequens.

Common about London. Curtis. Near the feafide frequent. Rev. Dr. Goodenough. Dr. Pril. teney. Betwcen Edinburgh and Leith.

Armua. Fl. Junio, Julio.

Radix fufiformis, parva. Herba tomentofo-albida. Caulis quadri- 


\section{SYNGENESIA-POLYGAMIA RQUALIS.}

quadripedalis, erectus, ftrictus, nuinùs ramofus, fulcatus, foliis decurrentibus latè alatus. Folia finuata, fpinofa, fubtis prarcipué lanata. Flores terminales, congefti, fefliles, pallidè purpurci. Calyx ferè cylindricus; gracilis, pallidus, vix lanatus, fquamis lancenlatis, planis, levibus, crectiufculis, fubenervibus, acutè fpinofis. Pappus deciduus, pilofus, feaber.

Diftinetiflimus a C. crifpo Linnæi, cujus iconem apud Loefelium, $t .5$, videas.

paluftris. 5. CARDUUS foliis decurrentibus pinnatifidis dentatis fpinofis fabris, calycibus ovatis aggregat is pinulofia, pappo plumofo.

Carcluns paluftis. Sp. 13\% 115 I. Hudf. $35=$ Iith. 697. Inull. 179. Relh.305. Silith. 245. Abbot. 176 . Curt. Lond. fajc. 6. t. 56. Raii Syn. 194.

ß. C. paluftris mitior, Bardanæ capitulo fummo caule fingulari. Pluk. Alm.82. Dill. in Raii Syn. 194. nondum vidi. Angl. Marth Thiltle. Pet. H. Brit. t. $21 . f .4$.

In pratis et parcuis humidis vulgaris.

Biennis. Fl. Julio, Augufto.

Radix ramofa. Caulis erectus, ftrictus, tri- vel fex-pedalis, ramofus, angulatus, foliis interruptè decurrentibus undigne alatus; ransi patentes. Folia pinnatifida, faturate viridia, fcabra, lobis finuatis, dentatis, fpinofis. Flores terminales, aggregati, plerumque fciriles, faturatè purpurei, fapè albi. Calyx oratụs, vel ferè globofus, fquanuis lanceolatis, adprefîs, brevifimè mucronato-fpinofis, parum lanatis. Scmina levifima, cxftriata. Pappus deciduus, plumofus.

\section{** Foliis Sefilibus.}

arenfis. 6. CARDUUS foliis feffilibus pinnatifidis fpirofis, caule paniculato, calycibus ovatis fpinulofis, pappo plumofo.

Carduns 
SYNGENESIA-POLYGAMIA EQUALIS. 857

Carduus arvenfis. Curt. Lond. fafe. 6. t. 57. Sibth. 245.

C. vulgatiflimus viarum. Raï Syn. 194. Ger. en. I I 73 .

Serratula arvenfis. Sp. Pl. I I 49. Ihudf. 349. With. 696. Hull. 180. Relh. 303. Abbot. 174 . Mart. Fl. Rult. t. 132.

Ceanothos Theophraiti. Column. Espbr. v. I. 46. Common Thiftle. Pet. H. Brit. t.2 I. f. 5 . Angl. Creeping Thiftle.

In arvis et ad vias vulgatiffimus.

Perennis. Fl. Julio.

Radix repens, flagelliformis, ramofa, profundè defcendens, vivacifima, et difficillimè exftirpanda. Caules erecti, tripedales, foliofi, teretes, læves, fupernè paniculati, multiflori. Folia feffilia, vix ac ne vix decurrentia, alterna, pinnatifida, glabriufcula, lobis inæqualibus, ciliatis et fpinofis. Flores tcrminales, fubpedunculati, purpurei, rariùs albi. Calyx ovatus, fquamis latè lanceolatis, adpreffis, margine lanatis, brevifimè mucronato-fpinofis, fpinis patentibus. P'appus plumofus, deciduus.

Hujus generis proculdubiò cft, et ftructurâ fructificationis C. paluftri proximus, optimè monente Curtifio.

7. CARDUUS foliis amplexicaulibus repandis fpi-maria. - nofis; radicalibus pinnatifidis, fqumis calyci- nus. nis foliaceis refractis margine aculeatis.

Carduus marianus. Sp. Pl. I153. Hzudf. 353 . With. 7co. Hull. 179. Relh. 306. Sibth. 246. Abbot. I75. Curt. Lond. fafc. 3. t. 54.

C. Mariæ. Ruii Syn. 195. Ger. em. II50. Trag. Hift. 850 .

C. lacteus. Nlatth. Valgr. v. 2. 38. Camer. Epit. 445 .

Silybum marianum. Gertn. $v \cdot 2 \cdot 37^{8}$.

S. n. I81. Hall. Hijf. ข. s. 78 . 


\section{SYNGENESIA-POLYGAMIA RQUALIS.}

Spina alba hortenfis. Fucbl. Hifl. $5^{6}$.

B. Carduus Maria hirfutus non maculatus. Raiz Syn. 195.

Angl. Milk Thiftle. Pet.H. Brit. t.2r.f. 9.

In aggeribus foffarum et ruderatis.

B. A bout London, but not common.

Anmea. Fl. Augufto.

Radix fufformis. Caulis crectus, ramofus, 4-6-pedalis, foliofus, teres, fulcatus, glaber. Folia radicalia pinnatifida; caulina alterna, recurva, oblonga, acuta, repanda, bafi cordato-amplexicaulia; omnia faturatè vi ridia, nitida, venis albis anaftomofantibus pulcherrimè picta, plerumque glabra, margine fpinis inæqualibus ciliata. Flores terminales, folitarii, magni, purpurei, pedunculo nudo. Calyx ovatus, glaber, fquamis bafi orbiculatis, ciliato-fpinzfis, arctè adpreffis, apice appendiculatis, foliaceis, refractis, lanceolatis, canaliculatis, fpinâ validâ flavefcente pungentibus. Semina nigricantia, nitida. Pappus fcaber, deciduus.

Folia in $\beta$ unicolora, nee albo variegata.

eriopiso- 8. CARDUUS foliis fefflibus bifariàm pinnatifidis fpinofis fabris: laciniis alternis erećtis, calycibus giobofis villofis.

Carduus criophorns. Sp.Pl. ir 53. Hudf. 354 . With. 700. Hiili. 179. Relh. 307. Silth. 246. Abbot. 176. Engl. Bot. 1.386. MLill. Ic. 1.293. Jacq. Aifir. t. 171 .

C. tomentofus, corona fratrum dielus. Raii Syn. 195.

C. eriocephalus. Ger.em. II 52 .

Fryar's Thiftle. Pet. H. Brit.t. 21.f. 8. Angl. Woolly-headed Thinle.

In ruderatis montofis, et ad vias, folo calcareo.

In Worcefterfhire, Huntingdonthire, Oxfordhire, Warwickntire, Berkfhire, Somerfethire, and

Cornwall!. 
Cornwall. With. in a gravel-pit at North Pickenham, Norfolk. Rev. Mr. Watts. Between Stamford and Grantham plentifully, alio at Matlock-bath about the zigzag walk.

Piennis. Fl. Augufto.

Radix fufiformis. Caulis erectus, tripedalis, ramofiffimus, ramis patentibus, foliofus, teres, fulcatus, glabriufculus, multiflorus. Folia patentia, alterna, pinnatifida, feu bipinnatificla, laciniis bifariàm divaricatis, apice margineque fpinofis, fuprà fcabris, fubtùs ianatis. Flores terminales, folitarii, erecti, maximi, purpurei, pedunculo foliofo. Calyx globofus, demùm depreffus, arachnoideo-lanatus, pulcherrimus, fquamis linearibus, patentibus, apice foliaceis, coloratis, ciliatis, glabratis, mucronato-fpinofis. Pappus plumofus, deciduus.

9. CARDUUS foliis amplexicaulibus lanceolatis beterociliatis integris laciniatifque fubtùs tomentofis, fbyllus. fiore fub-folitario pedunculato.

Cardus heterophyllus. Sp. Pl. I I54. Fl. Dan. t. 109. Engl. Bot.t. 675 .

C. helenioides. Hudf. 352. Lightf. 457. With. 702. Hull. 179.

Cirfium n. I80. Hall. Hiff. $\%$. . 77. t. 7 .

C. anglicum fecundum. Chif. Hift. v. 2. 148. Ger.em. I i 83 , icon Pennei.

C. Britannicum Clufii repens. Raii Syn. 193. Bauh. Hift. v. 3. 46. Mill.Ic.t.94.

Northern Iniftle. Pet.H. Brit.t.22.f.2. Angl. Melancholy Thifte.

In pafcuis alpinis humidioribus.

In the mountainous parts of York fhire and Weftmoreland; alfo about Snowdon, Trales. Ray. In all parts of the inland highlands of Scotland not unfrequent. Ligbtf. A little way up Ben Lomond.
VoL. II.
E. e
Perennis. 


\section{\$ 34 SYNGENESIA-IOLYGAMIA KQUALIS.}

Perennis. Fl. Julio, Augulio.

Radix repens, nodofa, nigra. Caulis tripedalis, creetus, fubimplex, uni-aut bi-florus, folicilus, teres, fulcatus, lanatus. Folia lancenlata, acuta, fuprà levia, glaberrima, fubtus tomentofo-nirea, margine fpinulis dupli(ate)-ciliata, interdum pinsuatifida; radicalia petiolata ; citulina numerofit, alterna, bafi cordato-amplexicaulia. Flos terminalis, nutans, demum ercétus, magnus, pur. pureus, pedunculo elongato, tnmentofo, nudo, vel ad apicim tantim, ful fore, foliolum gerente. Calyx o'atus, minutè pubefens, fquamis lanceolatis, ercetis, apice denudatis, carinatis, fulcefcentibus, fpinulâ brevi ant obfoletâ teminatis. Antbcrae albidæe. Stigma lincare, exfertun, pupureun, cmarginatum. Pappus fominum marginalium feaber, interiorum plumofus.

C. heleninides Linnai abunde diferepat, caute cluplò altiori, folic numerofioribus, omninò indivifis, floribus in fummo caule foffilibus, quatuor pluribufre, duplòque minoribus. Hanc fpeciem nondum in Britanniâ neque frontancam neque cultam vidi.

fratenfis. 10. CARDUUS folits feffilibus lanceolat is fubdentatis ciliatis fibtis lanatis, caule nudiufculo unitloro, caljec villoro.

Carduus pratentis. Hudli 353. With. 7o1. Hull. i 79. Silth. 246. Engl. Bot. t. 177 , exclufo jyonyino Jarquini. Pulten. Dorfet. 80.

C. difiectus. Hhadf. ed. 1. 307. nec Linn.

C. heteropluyllus. Relh. 306. Liglnf. 456 .

Cirtiun Acglicum. Räii Syn. 193. Jab. lc. 583 . oly. 3 i. t. 4. Dalecb. Hift. 58 4.

C. montanum Anglicum. Ger. $e m$. I I $8_{3}$.

C. pannonicum primum pratenfe. Chif. Hifl. ?. 2. 148.

C anglicum, radice I Iclicbori nigri modo fibrosâ, fulio longo. Laub. Hijt. ¿' 3. 45. Peckban Thifle. Ret. H. Brit.t. 22 f. r. Angl. Meadow Thifilc. 
In pratis et pafcuis humidioribus, imprimis nemorofis.

\section{Perennis. Fl. Junio.}

Radix fibrofa, fibris fimplicibus, carnofis. Caulis erectus, pedalis aut fefquipedalis, fimplex, uniflorus, rariùs biflorus, teres, fulcatus, lanatus, paucifolius. Folia lanceolata, inæqualiter dentata, quandoque finuata, ciliatofpinofa, fcabriufcula, fubtùs arachnoideo-lanata, nec tomentofo-nivea; radicalia tria vel quatuor, petiolata; caulina duo vel tria, minora, remota, cordato-amplexicaulia. Flos terminalis, folitarius, nutans, demùm erectus, pallidè purpureus, præcedente parùm minor, pedunculo apice aliquantulùm incraffato, niveo. $\mathrm{Ca}$ lyx ovatus, arachnoideo-lanatus, fquamis lanceolatis, erectis, mucronulato-pungentibus. Pappus ut in præcedente. Diftincta fpecies Linnæo ignota.

I I. CARDUUS acaulis, calyce glabro.

Carduns acaulis. Sp. Pl. 1156 . Hudf. 354. Wilh. 703. Hull. 180. Relh. 307. Sibth. 247. Abiot.176. Engl. Bot.t.161. Jacq.1c. rar. v.3.t.579. Fl. Dan.t. 1114.

Carlina acaulis minore purpurco flore. Raii $S y n$. 195.

C. acaulos ininor flore purpureo. Ger. em. 1158. Chamæleon exiguus. Trag. Hift. 852. Bauh. Hif. v. 3.p. . 62. Angl. Divarf Thintle. Pet. H. Brit. t.21.f.6.

In pratis et pafcuis folo glareofo vel calcareo. But too common in many fields and upland grounds in Doriethire. Dr. Pulteney. Very firequent on commons in Norfolk and other counties.

Perennis. Fl. Julio, Augufto,

Radix lignofa, nigricans. Caulis nullus. Folia depreffa, radiato-patentia, numerofa, petiolata, glabra, pinnatifida, lacinitis fubpalmatis, fpinofis. Flos magnus, frE e 2 


\section{SYNGENESIA-POLYGAMIA AQUALIS.}

pius folitarius, ferè feffilis, puppureus. Calyx ovatus, claber, fquamis lanceolatis, vix carinatis, apice fubcilittis, mucronulato-pungentibus. Stsli longiùs exferti. Pappis plumofus.

Planta in hortis culta forman demùm alicnam induit, floribus tribus vel quatuor in caule palmari; quod aliis fyngenctiis acaulibus paritèr accidit.

\section{ONOPORDUM. G. Pl. 409. JisJ. I73. G.erln. \%. I6I.}

Cul. ventricofis; fyuamis patentibus, fpinofis. Recept. favofum, fubpalcaccum.

Acantbi-I. ONOPORDUN calycibus fquarrofis: fpinis $u m$. fubulatis, foliis ovato-oblongis finuatis utrinque lanatis.

Onopordum Acanthium. Sp. Pl. 1 i 58. Hudf: 354. With. 704. Hull. 180 . Titll. 307. Sibth. 247. Abbot. I 77. Cart. Lont. falfic. 5 . t. 57 . Fl. Dan.t. gog.

Carluus tomentofins, Acanthium dictus, vulgaris. Raii Syn. 196.

C. mufichatus. Ger. $\mathrm{em} .1174$, icon, nec defer. Acanthium. Matth. Tulgr. 2.2.34.

A. album, Ger. en. I 149 .

Spina alba filvedtris. Fuch. Hift. 57 . ingl. Cotton Thifte. I'et. H. Brit.t. 2 I. f. Io.

In ruderatis et ad vias, folo glareofo, frequens.

biennis. Fl. Julio.

Biadix fulformis. Herba tomento niveo facilè abradendo undique reftita. Caulis erectus, quinquepedalis, ramofus, foliis decurrentibus alatus. Folia ovato-oblonga, finuata, fpinofa. Flores terminales, folitarii, erecti, purpurci. Calyx globofus, demùm depreffus, fquamis fubulatis, undique divaricato-patentibus, tomento albo intertextis, apice denudatis, fpinâ flavâ fimplici terminatis. Receptaculum favofum, diffepimentis in paleas acutas 
acutas elevatis. Semina obovata, nitida. Pappus inæqualis, fcaber, cleciduus, rubicundus.

\section{CARLINA. G. Pl. 4io. JuJ. I 72.}

$$
\text { G.ertn.t. } \mathrm{I}_{3} \text {. }
$$

Cal. ventricofus; fquamis exterioribus finofis ; interioribus coloratis, feariofis, radiantibus. Recept. paleaccum. Pappus plumofus.

r. CARLINA caule multifloro corymbofo, flori- vulgaris. bus terminalibus, fquamis calycinis exterioribus pinnatifidis; interioribus albidis.

Carlina vulgaris. Sp. Pl. I 6 1. Hudf. 355. With. 704. Hull. I78. Relh. 308. Sibth. 247. Abbot. 177.

C. fylveftris quibufdam, aliis Atractylis. Raii Syn. 175. Baub. Hift. v. 3. 8i.

C. fylveftris. Ger. em. 1159 .

Carduus. Brunf. Herb. v. 2.65.

C. vulgaris. Matih. Valgr.v.2.32.

Atractylis mitior. Fucbl. Hift. $12 \mathrm{I}$.

Angl. Common Carline. P'et. H. Brit. t. Ij. f. Iо.

In pratis ct pafcuis aridis fabulofis.

Biennis. Fl. Junio.

Radix fufformis. Caulis rigens, erectus, pedaiis, foliofus, fulcatus, lanatus, corymbofus. Folia alterna, oblonga, finuata, fubtùs præcipuè lanata, fubinde glaberrima, margine fpinofa, fpinis divaricatis, fla vefcentibus. Flores terminales, folitarii. Calyx extùs fipinofiffimus, fufcus; fquamis interioribus duplò longioribus, linearibus, incrmibus, patentibus, feariofis, luteo-albidis. Corolla purpureo-albida. Paleæ receptaculi canaliculatæ, apice laciniatæ. Semina fericea. Pappus plumofus, deciduus. Herla tota, perfectis feminibus, dealbata, exfucca, per hyemem fæè perfiftit. 


\section{$\S_{j} \delta$ SYNGENESIA-POLYGAMIA EQUALIS.}

*** DISCOIDEI. Flofuculi tubulose, erecto-paralleli, apice planinesculi.

357. BIDENS. G. Pl. 412. Ju/f. 188.

Gartn. t. 167 .

Recept. paleaccum. Pappus ariftis retrorsùm fcabris. Cal. polyphyllus. Cor. fubinde radiata.

triparti- I. BIDENS foliis trifidis, calycibus bafi foliofis, fe$t a$. minum ariftis erectis fubternis.

Bidens tripartita. Sp. I'l. I165. Ifudf. 35.5. With. 706. Hull. 18 1. Relh. 308. Sibth. 248. Abbot. 177. Curt. Lond. faje. 4. t. 57 .

Verbefina feu Cannabina aquatica, fore minùs pulchro, clatior et magis frequens. Raii $S y n$. 187 .

Eupatorium Cannabinum fomina. Ger. ein. iI 1 .

Angl. Trifid Bur Marygold. P'et. H. Brit.t. 20. f. 7 .

In inundatis, et ad foffarum margines, frequens.

Annua. Fl. Augufto, Septembri.

Radix fufiformis. Caulis erectus, bi- vel tri-pedalis, ramofus, patens, foliofus, obtusè quadrangularis, fulcatus, glaber. Folia oppofita, glabra, incifo-ferrata, trifida feu pinnatifida. Flores terminales, folitarii, erectiufculi, foliis indivifis patentibus obvallati. Calycis foliola fubæqualia, plana, levia, fufco ftriata. Flofculi uniformes, tubulofi, flavi. Semina compreffa, bi- feu tri-angulata, angulis retrorsùm fcabris, ariftis binis terniffe, terminalibus, erectiufculis, fulvis, triquetris, retrorsim aculeatis. Palere receptaculi foliolis calycinis conformes, fed anguftiores.

cernua. 2. BIDENS foliis lanceolatis ferratis, floribus cernuis bafi foliofis, feminum ariftis creetis fubquaternis.

Bidens cernua. Sp. Pl. I165. Irudf. 3j6. With. 
705. Hull. I8 I. Relh. 309. Sibth. 2.48. Aboot. 177. Curt. Lond. fifc.3. t.55. Fl. Dan.t. 84 I.

Verbefina pulchrinre flore luteo. Raiis Syn. $18 \%$. Buub. Iiift. v. 2. $10 \div 4$.

Bur Marygold. Pet. H. Brit.t. 20. f. 6.

G. Coreopfis Bidens. Sp. Pl. $128 \mathrm{I}$.

Chryfanthemun cannabinum bidens, foliis integris. Morif. fect. 6. $t \cdot 5 \cdot f \cdot 22$.

Eupatorium cannabinum chryfanthemum. Barrel. Ic. t. I 209 .

Conyza palutris, foliis ferratis. Loef. Pruff. 54 . t. II.

$\gamma$. Bidens minima. Sp. Pl. I16.5. Hud/. ed. I. 310. Fl. Dan.t. 312 . A66ot. 178.

B. Iripartita $\beta$. Hludf. 3.55:

Verbefina minima. Dill in Raii Sym. 198. 1.7. f. 2. Giff. 167. app. 66.

Angl. Nodding Bur Marygold.

In foflis et fiagnis. $\gamma$ in paludibus exficentis. $\beta$ frequent in Ireland. Shorcurd. Cheihire. IHudf. Norfolk, but not common. Mr. Woodwart. In Thorpe meaklows, Norwich.

Annua, Fl. Septembri.

Radix ramofa. Canlis erectus, teretiufculus, fcabriufculus, foliofus, ramofus, bipedalis ; in $\gamma$ fimplex, palmaris. Folia amplexicaulia, fimplicia, lanceolata, acuminata, ferrata. Flores terminales, folitarii, foliolis involucrati, cemmi, aurei, interdùm radiati, unde Coreopfis evadit. Seminum anguli rarè et inæequalitèr fpinulofi ; ariftæ frepiùs quaterin.

\section{EUPATORIUM. G. Pl. 4I3. JU: 179. Gartn. t. I 65.}

Recept. nudum. Pappus faber. Cal. imbricatus, oblungus. Shylus femibifidus, exfertus.
E e 4
I. EU. 
cannabi- I. EUPATORIUM foliis diritatis.

num. Eupatorium cannabinum. Sp. P\%. \&173. Hudf. 356. With. 706. Tith. İi. Rilh. 309. Sibth. 249. Ailot. 178. Käil Syn. I79. Engl. Bot.'t. 428. F\% Dan.t. 745 .

E. cannabinum mas. Ger. en. 7 II.

E. adulterinum. Fuche. Hit. 265 .

B. E. cannabinum folio integro, feu non digitato. Dill. in Raii Syn. I 80. Angl. Hemp-agrimony.

In aquofis fpongiofis.

Perennis. Fl. Julio, Augufto.

Caules tripedales, erecti, ramofi, foliofi, teretes, fulcati, fcabri. Folia oppofita, tri- vel quinque-partita, ferrata, fcabra, fubtùs pallidiora; fuperiora in $\beta$ fimplicia. Corymbus terninalis, multiflorus, pubefcens, dilutè purpureus. Caljcis foliola oblonga, obtufa; exteriora parra. Flofculi 5 vel 6 , uniformes, regulares, tubulofi. Stigmata exferta, linearia, divaricata, pubefcentia. Receptaculum convexum, nudum. Semina angulata, gracilia. Pappus fcaber, haud plumofus.

359. SANTOLINA. G. Pl. 4I6. Juf. 185 . Gartn. t. 165 .

Gnaphalium. Garin. t. 165 .

Recept. palcaceum. Pappus nullus. Cal. imbricatus, hemifphæricus.

marii. I. SANTOLINA pedunculis corymbofis, foliis $m a$. oblongis obtufis crenatis densè lanatis.

Santolina maritima. Linn. MSs. in Sp.Pl. I 182. Hudf. 356. With. 707. Hull. ז81. Dickf. H. Sicc. fafc. 6. I 1. Engl. Bot. t. I 4 I. Pul:. ten. Dorfet. 80.

Athanafia maritima. Sp.Pl. I182. Mant.2. 464. Hull. $18 \mathrm{I}$.

Filago 


\section{SYNGENESIA-POLYGAMIA ÆQUALIS. 86r}

Jilago maritima. Sp. Pl. ed. 1.927. Mill. Ic. t. 135 .

Gnaphalium. Camer. Epit. 605.

G. maritimum. Raii Syn. 1 8o. Bauh. Hif. v. 3 . p. 1. 157 .

G. legitimum. Gertn. v. 2.39I.

G. marinum. Ger. em. 640. Lob. Ic. 480 . Angl. Sea Cotton-weed.

In arenofis maritimis rariùs.

In Anglefea and in Cornivall. Ray. In DorfetPhire and the inle of Shepey. Hudf. Pulteney. On the beach juft above ligh-water mark, one mile north of Landguard fort, Suffolk.

Perennis. Fl. Augufto, Septembri.

Radix longiffimè defcendens, ramofa. Herba tomento niveo, denfo, undique veftita. Caules decumbentes, fragiles, teretes, ramofi, foliofi, ramis erectis. Folia numerofa, alterna, patentia, oblonga, obtuia, plana, crenulata, enervia. Flores terminales, corymbofi, flofculofi, aurei. Calyx imbricatus, multiflorus, extùs tomento obductus, foliolis intùs concavis, nitidis. Corollulæ regulares, bafi utrinque productæ ad latus germinis, compreffie. Stigmata exferta, retufa. Recep. taculi paleæ apice lanatæ. Semina mutica. 


\section{I. POLYGAMIA SUPERFLUA.}

\section{* DISCOIDEI.}

360. TANACETUM. G. I'l.4I\%. Jlif. I $8_{4}$. G.ertn. t. I 65 .

Recept. nudum. Sem. coronata. Cal. imbricatus, hemifphericus. 1\%ofouli radii trifidi, obfoleti, interdùm nulli.

sulgare. I. TANACETUM foliis bipinnatifidis incifoferratis nudis.

Tanacetum vulgare. Sp. Pl. I I 84. Hudf. 357. With. 708. Hull. I82. Relh. 310. Sibth. 249. Abbot. I79. Wodv. Med. Bot. t. II5. Fl. Dan. t. 87 I.

Taracetum. Raii Syn. 188. Ger. ell. 650 . Matth. Valgr. v.2.259. Camer. Epit. 650. Brunf. Lerb. ข. 1. $250 . v, 2.87$.

Artemifia monoclonos. Fuch.j. Hift. 46 .

6. Tanacetum foliis crifpis. Dill. in Kaii Syn. 188. T. crifpun anglicum. Ger. em. $6_{50}$. Angl. Common Tanfy.

In montolis, ad vias, et agrorum margines.

Perennis. Fl. Julio, Augufto.

Radix repens. Herba anıara, odore gravi, aromatico.Caules erecti, bipedales, foliofi, teretes, ftriati, vix pilofi. Folia alterna, bipinnatifida, acutè incifa, glabra, vel fubtus fubpilofa, bafi auriculata, amplexicaulia. Flores corymbofi, terminales, aurei, planiufculi. $\mathrm{Ca}-$ lycis foliola obtufa, margine fcariofa. Flofculi numerofiffimi, plerumque quinquefidi; marginales tantum faminei, trifidi. Semina uniformia, coronâ membrañaceâ, pentagnnâ, aquuali. 
361. ARTEMISIA. G. Pl. 4I8. J4f. 184. Gartn.t. Í́4.

Abfinthium. G.ertn. t. 164.

Resept. undum, aut villofum. Senn mutica. Cal. imbricatus, fquamis rotundatis, conniventibus. Flof $\mathcal{F}_{\text {c }}$ radii fubulati, integerrimi.

3. ARTEMISIA foliis multifidis linearibus, cau-campeslibus procumbentibus virgatis.

Artemifia campeftris. Sp. Pl. I 85 . Hudf. 357 . Witb. 709. Hull. 182. Engl. B3,t.t.333.

A. tenuifolia, five leptophylios, aliis Abrotonum fylveftre. Baub. Hijt. थ. 3. p. . . 194.

Abrotanum campettre. Raii Sym. 190. Ger. em. I 106.

A. inodorum Lobelii. Dalech. Hift. 939.

Wild Sonthernwood. Pet. H. Brit.t. 20. f. 4 : Angl. Field Southernwood.

In ericetis aridis fabulofis, ad vias, rariùs.

About Barton Mills and Elden, Suffolk; T. WTit- lifel. Ruy. About a mile north of Thetford, Norfolk. Mr. Crowe. On Icklingham heath near Bury, Suffolk. Sir 'T. G. Cullum.

Perennis. Fl. Augufto.

Radix fuffiformis. Herba omninò ferè incdora. Caules proftrati, dẹmùm erecti, bipedales, virgati, paniculati, angulati, glabri, rubicundi, foliofi. Folia irregulariter bipinnatifida, fubcarnofa, linearia, fubtùs fubpilofa; radicalia depreffa, longiùs petiolata; caulina alterna, minufque compofita. Flores numerofi, racemofi, cernui, parvi, fufco-virides. Calycis foliola carinata, margine fcariofa. Flofculi difci circiter quindecim, quinquefidi, flavi, apice purpurei; radii paucigrmi, (2 vel 3, ) tenuiffimi, fubulati, claufi, integerrimi. Receptaculum convexum, nudum, rugofum. Semina parva, mutica.

2. ARTE. 
meriti- 2. ARTEMISIA foliis multipartitis tomentofis, na. racconis cernuis, receptaculo nudo, flolculis fomincis ternis.

Artemifia maritima. Sp.Pl. i s86. Hulf. 358 . IIith. 709. Hull. 182. Relh. Suppl. 2. I4. Hoode. Med. Bot. t. I 22.

Abfinthium marinum album. Raii Syn. ed. 2. 94. ed. 3. 188. Ger. em. 1099. Camer. Efit. 455 .

A. maritimum noftras. Dill. in Raii Syn. 189. Raii Hiff. v. 3. 231, cx defer.

B. A. maritimum, Seriphio belgico fimile, latiore folio, odoris grati. Raii Syz. ecl. 2. 94. ed. 3 . I 88 .

A. maritimi fpecies latiore folio D. Dale. Raii Syn.ed. 2. 94. ed. 3. I89.

$\%$ A. feriphium tenuifolium marinum Narbonenfe. Dill. in Raii Syn. 189. Baub. Hift.v.3.p. I. I 77 .

Abfinthium maritimum, cacuinen. Phamac. Lond. Angl. Sea Wormwood.

In maritimis.

Pereninis. Fl. Augufto.

Fiadix futhignofa. Herba tomentofo-alba, aromatica, amara. Canles paniculati, erecti vel clecumbentes, foliofi, fulcati. Folia inferiora pinnata, pinnis tripartitis; fuperiora variè divifa; fumma fimplicia; onmia margine integerrima, utrinque nirea. Racemi plùs minùs nutantes. Flores ovati, cernui. Calyx extùs lanatus, margine fcariofus. Receptaculum nudum. Flofculì radii pauciffimi.

foliola latitudine variant.

Ab/2n- 3. ARTEMISIA foliis multipartitis fericco-incathisum. nis, 
nis, foribus hemifphæricis pendulis, receptaculo pilofo.

Artemifia Abfinthium. Sp. Pl. I I89. Hudf. $35^{\circ}$. Wilb. 7 10. Hull. 182. Relb. 3 10. Sibth. 250. Abbot. 179. Woodv. Med. Bot.t. I 20. Abfinthium. Camer. Epit. 452. Trag. Hifi. 335. Mattb. Valgr. v. 2. 47. A. vulgare. Raii Syn. 188. Dalech. Hifl. 943. A. latifolium five Ponticum. Ger. enl. 1 og6. Abfinthium vulgare, berba. Pbarmac. Lond. Angl. Coinmon Wormwood. Pet. H. Brit. t. 20. $f . \mathrm{I}$.

In ruderatis et ad pagos frequens.

Ferennis. Fl. Augufto.

Radix fublignofa, ramofa. Herba fericeo-incana, intensè amara, aromatica. Caules erectiufculi, ramofi, angulati, fulcati, apice paniculati. Folia inferiora bipinnatifida ; fuperiora pinnatifida, vel digitata ; laciniis elliptico-nblongis, obtufis, integerrimis. Racemi erecti. Flores pedicellati, nutantes, flavefcentes, hemifphærici. Flof́culi difci numerofi; radii pauci. Receptaculum pilofifimum.

4. ARTEMISIA foliis pinnatifidis planis incifis: vulgaris. fubtùs tomentofis, racemis fimplicibus, floribus ovatis, receptaculo nudo.

A rtemifia vulgaris. Sp. Pl. I I 88. Hudf. 359. With. 7 10. Hull. I82. Relh. 311. Sibth. 250. Abbot. I 79. Woodv. Med. Bot.t. I 21. Raii Syn. I90. Baub. Hift. v. 3. p. I. I84. Artemifia. Matth. Valgr. v. 2. 202 . Brinf. Herb. v. 2.83 (4I).

A. mater herbarum. Ger. em. IIO3.

A. latifolia. Huibf. Hift. 44 . Angl. Mugwort. Pet. H. Brit. t. 20.f.5. 


\subsection{SYNGENESIA-POLYGAM. SUPERFLUA.}

In ruderatis et all fepes vulgaris.

Perennis. Fl. Augufto.

Radix lignofi. Caules quadripedales, crecti, ranof, paniculati, fulcati, glabrati, foliofi, purpurafcentes. Folia alterna, petiolata, pinnatifida, incifa; fuprà glabra, atro-viridia; fubtùs tomentofa, nivea. Raceni erectiufculi, finıplices, foliofi. Flores feffiles, crecti, ovati, lanati. Receptaculum nudum. Hofculi radii, recté notante Linnæo, quini.

cerulef- t5. ARTEMISIA foliis incanis: cam!inis lanceolarins. tis integris; inferioribus multifidis, floribus cylindricis, receptacu!o nudo.

Artemifia cærulefcens. 9f. Pl. I i 39 . I7idj. 359. With. 7x I Inll. i82.

A. marina. Ger. em. 1104.

Abfinthium mariumm. Matb. Falgr. v. 2. 49. A. maritimum Lavendula folio. Ssauh. l'ir. 139. IIorif. Jikt. 6. t. i.f. 5. Dubum. 1rlt. ช. 1. 24. .5 .

Abrothium latifolim, Artemina folio. Cobmmo Ecptor. v. 2.76. Angl. Blueith Ningwort.

In maritimis. IJudf. Civis dubia.

Near Bofton in Lincolnthire; Mr. Totichl. Itwo Not found there by any one elic.

Perennis. Fl. Augufto.

Radix fibrofa. Caules ereftiufeuli, teretes, fulcati, pubefcentes, glaucefcentes, foliofi, paniculati. Folia alterna, petiolata, utrinque incana; fuperiora lanceolata, integra ; inferiora varie lobata, quandoque pinnatifida. Racemi erecti, fimplices. Flores erefi, ovatocylindracei, parvi, lanati. Receptaculum mulrm, exjeruum. Flofculi radii (ex Limmo) terni. Deferiptionem plantæ hortenfis accipe. 
362. GNAPHALIUM. G.Pl.4I 9. JuJ. I 79.

Elichryfum. Gertn. t. 166.

Antennaria. Gerin. 1.167.

Filago. G. Pl. 450 . Juf. 179. Garm.

t. 166 .

Recept. nudum. Pappus feaber, aut plumofus. Cal. imbricatus, fquamis feariofis coloratis. Flo $\int c$. radii fubulati. Flofculi aliquot dirci rubindè abortivi.

* Chryfocoma.

i. GNAPHALIUM herbaceum, foliis femiam-luteo-atplexicaulibus enfiformibus repandis utrinque $6 r \mathrm{~m}$. tomentofis : inferioribus obtufis, floribus conglomeratis.

Gnaphalium luteo-album. Sp. Pl. I i 96. Thuts. 359. With. 712. Hull. 183. Dicks. H. Sicc. fafc. $5 \cdot 13$.

G. ald Stœchadem citrinam accedens. Bauk. Hift. $\bullet \cdot 3 \cdot p$. . I. I60.

G. Plateau iecundum. Clıf. Hift. v. I. 329.

G. majus, lato oblongo foliv. Pluk. Pbyt.t. $3 \mathrm{t}$. f. 6 .

G. oblongo folio. Ger. en. 643.

Elichryfum filveftre latifolium capitulis conglobatis. Tiaii Syn. i 82 .

Jerfey Live-long. Pet. II. Bril.t. 18.f. 5 . Angl. Jerfey Cud-weed.

In muris et aridis arenofis fub coelo mitiore.

On dry banks and walls in Jerfey very common. Sberard. Mr. Goffeline.

Annua. Fl. Julio, Angyufto.

Radix parva. Herba undique tomentofo-alba. Caules bafi diffufi, dein erecti, fimplices, foliofi, teretes, apice corymbofi, multiflori. Folia alterna, integerrima, erecto. 
crecto-patentia ; inferiora apice dilatata, obtufa. Flores terminales, conglomerati. bafi densè lanati. Calycis foliola acutiufcula, fonriofa, glabra, nitida, pallidé citrina. Illofeuli hemaphroditici pauci, centrales, infunclibuliformes, quinquefidi, flavefcentes; foeminei numcrofimini, gracillini, fubulati, figmate exferto, bifido, fanguineo. Receptaculum papillofo-tuberculatum, gyabrum. Semina umnia fertilia, parra. P’appus tcuuifimus, fcaber.

\section{* Argurocoma.}

margari-2. GNAPHALIUM herbaceum, foliis linearitaceum. lanceolatis acuminatis altornis, caule fuperni ramolo, corymbis faftigiatis.

Gnaphalium margaritaccum. Sp. P!. I I g8. Hudf. 360. With.; I2. Ilit!. Isj. Dichl. H. Sicc. fiifc. 3. 15.

G. americanum. Raiis Syn. 182. Ger. en. 64r. Baub. Hift.v. 3.p. 1. 162.

American Live.long. P'et. H. Brit. l. I 3.f. 3 . Angl. American Cudwecol. Peany Lverlaftinge.

In pratis humidis.

Fear Bocking, Effex, but foarcely wild. Ray. On the banks of Rymny river (North Wrales?') for at leaft twelve miles; Mr. Llwyd. Dillenius.

Perennis. Fl. Augufto.

Radix fubrepens. Caules bipedales, creat, foliofi, teretes, lanati, apice corymbofo-ramof, multiflori. Foliz alterna, lineari-lanceolata, acuminata, parúm reroluta ; fuprà virentia, tomento deciduo; fubius denfiffimè lanata, alba. Flores corynbofi, conglonerati, globofi. Calycis fquame conniventcs, concave, nivere, opaca nec nitidx. Flofculi hermaphoditici numeroif, quinquefidi, lutefontes; foninei panifini, marginales, fubligulati. Receptaculum papillotum. Semina uniformia, fapè abortiva. Pappus obtufus, tcaber. Ex exemplario hortenfi. 
3. GNAPHALIUM farmentis procumbentibus, dioicum. caule fimplicifimo, corymbo fimplici terminali, floribus dioicis.

Gnaphalium dioicum. Sp. Pl. I199. Hudf. 360. With. 7I2 Hull. 183. Relh. 3II. Sibth. 250. Engl. Bot. t.267. Ligbif. 470. t.20. f. 1 .

G. montanum album. Raii Syn. I8 I. et G. longiore folio et flore. Dil. in Raii Syn. I8z.

G. montanum purpureum ct album. Ger. crit. 640.

Antennaria dioica. G.ertn.v.2.410.t.16\%.

Cat's foot. Pet. H. Brit. t. Is.f. 4. Angl. Mountain Cudwecr.

In pafcuis montofis aricis.

On Newmarket heath; and on Stratton Strawlefs heath near Norwich. Frequent in the mountainous counties.

Perennis. Fl. Junio, Julio.

Radix repens. Sarmenta procumbentia, foliofa, radicantìa, lanata. Caules folitarii, fimplices, erecti, palmares, foliofi, lanati. Folia fuprà nudiufcula ; fubîus dengè tonientofa; radicalia fpatulata; caulina larceolata; omnia verò formá et latitudine varia. Corymbus fimplex, terminalis. Flores dioici. Squamse calycinæ nitidæ, in mafculinis plerumque albæ, in fomineis rofer, magifque elongatæ. Pappus in mafculinis apice incraffatus, plumofus, niveus; in fomineis fimplex, fcaber. Receptaculum fcrobiculatum.

Varietatem majorem ex infula Skye mifit D. Joharines Mackay, foliis latioribus, utrinque lanatis; at in hâc lana paginam fuperiorem tandem deficit. $\mathrm{H} æ \mathrm{c}$ ad G. plantaginifolium Linnæi quodammodò accedit, fed diftincta videtur.

*** Filaginoidea.

4. GNAPHALIUM caule fimplici erecto, fori-fyluatiVoL. 11.

F f bus cum. 
bus fpicatis, foliis lanccolatis bafi anguftatis utrinque lanatis.

Gnaphalium fylvaticum. Sp. Pl. I 200. Lightf. 472 , varictas. With. 7 13. IIull. 183 .

Gnaphalium. Fl. Dan. t. 254.

G. norvegicum. Rets. Prodr. 193.

Angl. Highland Cudweed.

In pafcuis vel dumetis alpinis.

On mountains to the north of Blair in Athol, abore Loch Erruch, and Ben Wyvis in Rofs-thire, but not in woods. Mr. J. Mackay.

Perennis. Fl. Augufto.

Radix e fibris fimplicibus, nigris. Caulis folitarius, fimplex, palmaris, vix fpithamæus, tomentofus, foliofus. Folia alterna, lanccolata, acuta, utrinque lanata, bafi elongata et attenuata. Spica terminalis, parùm ramofa, denfa, foliclofa, multiflora. Flores cylindracci. Squamæ calycinæ nitidæ, coarelatæ, apice nigricantes, obtufiufculæ. Flofculi hermaphroditici pauci, quinquefidi; fominei numerofi, fubulati, gracillimi; omnes fertiles. Pappus fcaber. Receptaculum fubfavofum.

Caulis inter vepres altior evadit, et in hortis paniculatoramulofus.

reziun. 5. GNAPHALIUM caule erecto paniculato multifloro, foliis lineari-lanceolatis fuprà denudatis.

Gnaphalium rectum. Bauh. Hiff. vo 3. p.'I。 160. Engl. Bot. t. 124. With. 7 13. Hull. 183. Sibth. 251. Ábot. I79.

G. fylvaticum. Hudf. 360 . Lightf. 472 . Rell. 312. Retz. Prod. 193.

G. anglicum. Raii Syn. 180. Ger. em 639. Englifh Live-long. Pet. H. Brit.t. I8. f. 6 . Angl. Upright Wood Cudweed. 
In nemorofis, dumetis et pafcuis, folo arenofo, interdùm et inter fegetes.

Perennis. Fl. Augufto.

Radix fublignofa, fibris fimplicibus, nigricantibus. Caulis erectus, bipedalis, teres, tomentofus, foliofus, pani. culato-multiflorus. Folia fuperiora linearia, angufta $;$ inferiora lineari-lanceolata, parùmque latiora; omnia fubtùs tomentofo-alba ; fuprà deriudata, viridia. Panicula ftricta, foliofa, compofita, plerumque pedalis. Squamæ calycinæ incarnato-fufcæ, minùfque nigricantes. Flofculi et pappus ut in præcedente, eui reveres nimis affinis eft.

6. GNAFHALIUM caule decumbente fimplicif- fapinum: fimo racemofo paucifloro, foliis lineary-lanceolatis utrinque fubtomentofis.

Gnaphalium fupinum. Syt. Nat.ed. 12, v. 3. 234. Hudf. 361. With. 714. Hull. 183. Dickf. H. Sicc. fafc. 2. I 7 .

G. alpinum. Ligbtf. 470.t. 20.f. 2. Fl. Dari。 t. 332 .

G. fưfum. Scop. Carn. v. 2. I52.t. 57.

G. alpinum nanum, feu pumilum. Bocc. Sic。 40. $t .20 . f .1$.

Elichryfum alpinum minimum, capillaceo folio. Tournef. Inf. 454 . Herb. Tourn. Angl. Dwarf Cudweed.

In alpibus Scoticis, folo micaceo.

Near the top of Ben Lomond in abundance.

Perennis. Fl. Julio.

Radix repens, nigra. Caules palmares, decumbentes vel erectiufculi, fimpliciffimi, filiformes, lanati, foliof, racemofi, pauciftori ; interdùm vix biunciales, uniflori. Folia alterna, lineari-lanceolata, anguftiflima, utrinque magis vel minùs tomentofa. Flores erecti, alterni; fuperiores feffiles; inferiores pedicellati. Squanæe calycinze fufcæ, fere unicolores, acutiufculæe, patentiufFis 2 culæ. 


\section{SYNGENESIA-POLYGAM. SUPERFLUA。}

culie. Flofeuli hermaphroditici pauciores, infundibuliformes, quinqueficli ; foeminei magis numerofi, etiam infundibuliformes, fed gracillimi, quinguedentati ; onines fertiles. Semina obovata, comprefla, nitida. Pappus fcabriufculus. Receptaculum parvum, fcrobiculattim.

Diftuctiffima fpecics a præcedentibus.

aligino- 7. GNAPHALIUM caule ramofifimo diffufo, jum. floribus confertis terminalibus.

Gnaphalium aliginofum. Sp.Pl. I200. Hudf. 3hr. With. 715. Hull. 183. Kelb. 312. Sibth. 25 I. Abbot. 180. Dickf. H. Sicc. faji. 2. I8. Fl. Dan. t. 859 .

G. longifolium humile ramofum. Raï Syn. I8I. G. vulgare. Ger.em. $\sigma_{39}$.

Long Cudweed. Pet. H. Brit. t. 18.f. 7 . Angl. Marth Cudweed.

In arenofis uliginofis, ubi per hyemem aqua ftagnaverint.

Armua. Fl. Augufto.

Radix ramofa. Caulis fpithamæus, e bafi ramofiffimut', undique diffufus, tomentofo-niveus. Folia alterna, 1ineari-lanceolata, bafi attenuata, utrinque lanata. $\mathrm{Co}-$ rymbi terminales, denfi. Squamæ calycinæ lanceoJatæ, acutæ, fufco-citrinæ. Flofculi hermaphroditíc: pauci; fueminei plurimi, filiformes; omnes fertiles. Pappus fcaber. lieceptaculum fcrobiculatum.

gallizum. 8. GNAPHALIUM 'caule crecto ramoro, foliis linearibus revolutis acutis, floribus fubulatis confertis axillaribus.

Gnaphalium gallicum. Hudf. $36 \mathrm{r}$. With. 7 I 5 . Hull. I8 3. Dickf. H. Sirc. fafc. I1. 10.

G. parvum ramofitinum, folis anguftiffimis, poiyfeämon. Raï Syn. I8r. Pluk. Pbyt. t. $298 . f \cdot 2$.

Filag 


\section{SYNGENESIA-POLYGAM. SUPERFLUA. 873}

Filago gallica. $S p . P l$. I 32.

Grafs Cudweed. Pet.H. Brit.t. I8.f. I2. Angl. Narrow-leaved Cudweed.

In arvis glareofis, fed rariùs.

Among corn in fandy rounds about CaAte-Heveningham, Efex. Dale.

Annua. Fl. Julio, Augufto.

Radix attenuata. parva. Caulis erectus, fpithamærus, teres, lanatus, foliofus; bafi ftrictus et fimplex; fupernè ramofiffimus, patentiufculus. Folia fparfa, lineari-fubulata, acuta, revoluta, utrinque plùs minùs lanata. Flores axillares, fefiles, plerumque aggregati, fubulati, bafi gibbi, extus lanati. Squamæ calycinæ fubulatæ, carinate, dorlo viricles, apice fcariofe. Flofculi hermaphroditici circiter tres, tubulof, apíce fufci; foeminei plures, fubulati, tenuithmi. Gemina omnia, ut mihi videtur, fertilia. Pappus oculo armato fcabrufculus. Receptaculum convexum, parvum, tuberculatum.

9. GNAPHALIUM caule ereelo ramoro, folisminimum. lancenlatis acutis planis, floribus conicis $1 \mathrm{t} b$ confertis lateralibus terminalibufque.

Gnaphalium minimum. Lob. Ic. 48I. Bant. Hift. v.3.p. I. 59 . Kail Svn. I 8 I.

G. montanum. Hudf: 352 . With. 75 . Till. I 83 .

G. minimum erectum. Morif. fect. 7 . t. I I. f. 3 . Filago montana. Relh. 327. Silith. 262. Alm bot. I89. nee Linn.

F. minor. Ger. em. 641. Angl. Leaft Cudweed. Pet. H. Brit.t. 18. f. Is.

In arenofis et glareofis frequens.

Annua. Fl, Julio.

Iiadix parva. Caulis erectus, palmaris vel fpithamaus, variè ramofus, teres, fublanatus, foliofus. Folia al $\mathrm{Ff}_{3}$

terns, 


\section{SYNGENESIA-POLYGAM. SUPERFLUA.}

terna, erecto-adpreffa, lanceolata, vel ovato-lanceolata, acuta, brevia, plana, utrinque lanata. Flores conferti rel folitarii, feffiles, axillares et terminales, pyramidatoconici, minores quam in præcedente, extus lanati. Squamæ calycinæ fubulatæ, carinat $x$, intus fufcæ, $\mathrm{ex}$ tùs lanatæ, apice fcariofæ. Flofculi hermaphroditici circiter quituor; tominei plures, fubulati, tenuifini ; omnes, ut optimè cicfcripfit Stokefius, fertiles. Pappus fcaber. Reccptaculum tuberculofum.

Filago montana vera Linnæi difcrepat magnitudine, imprimis foliorum et florum, duplò majori ; totâque herbâ, at præcipuè fquamis calycinis, longè magis lanatâ; floribus omnibus confertis, nunguam folitariis.

F. arvenfis Linnæi nobis extranea omninò eft.

germani-IO. GNAPHALIUM caule erecto dichotomo, cum. foliis lancculatis, capitulis globofis multifloris lateralibus terminalibufque.

Gnaphalium germanicum. Hudf. 362. With. 716. Hull. 184. Bauh. Hift. v. 3.p. 1. I 58.

G. mirus, feu Herba impia. Raii Syn. I80.

G. vulgare. Matth. Falgr.v.2.214. Camer, Efit. 006.

Filago germanica. Sp. Pl. I3I I. Relb. 327. Sibtb. 262. Abbot. 189. Fl. Dan. t. 997. Leers. 186.

F. fivc herba impia. Ger.em. 642.

Childing Cudweed, Pet. H. Brit. t. r8. f. 9, , o, Angl. Common Cudiveed.

In pafcuis, arvis, et ad vias, folo glareofo fterili, vulgaris.

Annua. Fl. Julio, Augufto.

Radix parva, ramola. Caulis pedalis aut fefquipedalis, erectus, demum patulus, dichotomus, feu prolifer, foliofus, teres, fublanatus. Folia alterna, femi-amplexicaulia, erecta, lanceolata, acuta, fubrepanda, utrinque lanata. Capitula terminalia, folitaria, demum axillaria feu lateralia, globofa, multiflora. Flores undique patentes 
patentes, cylindrici, fufco-nitidi. Squamæ calycinæ lanceolatæ, acuninatæ, planæ, fcariofæ, carinâ medio viridi, glabre. Flofculi hermaphroditici duo vel tres; fominei plurimi, tenuifinimi ; omnes fertiles. Pappus fcaber. Receptaculum parvum, tuberculatum.

Obf. In plurimis fpeciebus fcmina extima, inter fquamas calycinas fita, pappo orbata funt. In omnibus germina centralia quandoque, neque infrequenter, abortiunt, rariùs quæ difci marginen occupant.

\section{CONYZA. G. Pl. 4.22. JuJ. I80.}

\section{Gartn.t. I66.}

Recept. nudum. Pappus fcaber. Cal. imbricatus, fubrotundus. Flofc. radii trifidi.

x. CONYZA foliis ovato-lanceolatis pubefcenti- fquarre-

bus, caule herbaceo corymbolo, fquamis caly- ja.

cinis fquarrofis foliaceis.

Convza fquarrofa. Sp. Pl. I 205. Hudf. 363. With. 717. Hull. 183. Relh. 312. Sibth. 251. Abbot. 180. Fl. Dan. t.622.

C. major. Matth. Valgr. v. 2. 222. Camer. Epit. 612. Baub. Hift. v. 2.1051.

Baccharis monfpelienfium. Raii Syn. I79. Ger. em. 792.

Angl. Plowman's Spikenard.

In pafcuis montofis et ad vias, folo calcareo.

Common in chalky or limeftone countries, and in woods in Norfolk on a marly foil. Plentiful about St. Vincent's rocks, Briftol.

Biennis. Fl. Julio, Augufto.

Radix ramofa, magna. Herba undique molliter pubefcens, amara, fubaromatica. Caulis bi- vel tri-pedalis, erectus, angulatus, foliofus, parùm ramofus, apice corymbofus, multiflorus. Folia lanceolata, alorna, integerrima vel fubcrenata; radicalia majora, ovata, petiolata, crenata. Flores congefti, ovati, flavefcentes. $\mathrm{Ff}_{4}$

Sqquamæ 
Squamæ calycinæ exteriores apice recurvato-patentes, foliacere - intericres recta, ciliatæ. Flofculi difci numerofi, quinquefidi; margunales trifidi, fubligulati, fœminei. Semina angulata, fulcata. Pappus fealber. Reeeptaculum tuberculatum.

$$
\text { * } R A D T A T I \text {. }
$$

364. ERIGERON. G. Pl. 422. Juj. I80. G.ertn. t'í 70 .

Revept. nudum. Pappus fimplex. Cor. radii lineares, angufiflimie, numerofa. Cal. imbricatus.

canadenfe* I. ERIGERON caule hirto floribufque paniculatis, foliis lanceolatis : inferioribus dentatis.

Erigeron canadente. Sp. I'. I 2 I o. Hudf. 363 . With. 718 . Hull. 185 . Dickf. H. Sicc. fafe. 10. I6.

Conyza canadenfis annua, acris, alba, Linarix foliis. Ruii Syn. 175. Bocc. Sic. 86. t. 46. C. annua acris alba, Linaria folio. Murif. Sect. 7 . t. $20 . f .20$.

White Goidén Rod. Pet. H. Brit. t. I6. f. I2. ángl. Canada Ylea-bane.

In cultis et ruderatis, fed non indigena. Raius.

About London frequent. Ray. Hudf. On St. Vincent's rocks, Britiol. With.

Annua. Fl. Augufto, Septembri.

Caulis erectus, virgatus, paniculato-ramofus, foliofus, fulcatus, pilofus, pecialis aut bipedalis, poultiflorus. Folia fparfa, acuta, margine præcipuè fcabra; fuperiora lineari-lanccolata, integerrima; inferiora lanceolata, apicem verfus dentata. Floreș paniculati, parvi, lutenli, Calycis fquamæ lineari-lanccolatæ, acutæ, glabriufculæ, demùm patentes. Flofculi marginales erecti, vix calyce longiores, albidi, tenuiffimi. Semina obovatiag 
ovata, angulata, fubfericea, allida. Pappus fcaber. Receptaculum convexum, fcrobiculatum, fcabriufculum.

2. ERIGERON caule racemofo, peilunculis fub-acrs. unifloris, foliis lanceolato-lingulatis feffilibus.

Erigeron acre. Sp.Pl. $12 \mathrm{I}$. Hudf. $36_{3}$. With. 718. Hull. 185. Relh. 313. Sibth. 252. Abbot. 181. Curt. Lond. fafc. 1. t.60. Dreves. Bilderb. t. 27 .

After arvenfis cæerulcus acris. Rüii Syn. I75. Conyza cxulea acris. Ger. em. 484. Amellus montanus. Columr. Ecpbr. v. 2. 26. f. 2 .

Angl. Blue Flea-bane. Pet. H. Brit. t. :6. $f^{2}: 4$.

In pafcuis glareofis vel calcareis aridis.

Biennis. Fl. Julio, Augufto; quandoque primo vere. Radix fublignofa, ramofa. Caulis erectus, ftrictus, pedalis vel bipedalis, foliofus, teres, ftriatus, fcaber, rubirindus, pilofus, racemofus, multifiorus. Folia fparia, feffilia, oblongo-lanceolata, fcabriufcula, plerunque integerrima; radicalia petiolata, obovata, ferrata. Pedunculi alterni, f piùs uniflori, erecti, foliolofi. Calyx hirfutus. Flofculi radii cærulei, erecti, difcum fuperantes. Semina fufca, pilofa. Pappus icaber, rufus. Receptaculum fcrobiculatum, et fubfarofum.

3. ERIGERON caulibus fubunifloris, calyce fub-alpinun: hirfuto, radio atenic.

Erige on aipinum. Sp. Pl. raII. Dickf. ir Tr. of Limn Soc.v. 2.288. T7ith. 7 I Hull. 185. Engl. Bot. t. 46. F. Tl. Dan. t. 292. Afteri montano purpurco fimilis, ve: Globulariac. Bauh. H.jt. v. 2. 1047. Angt. Alpine Flea-bane.

In rupibus iviguis alpinis Scoțix. 
On Ben Lawers. Mr. Dickfon and Mr. Mackay.

T'erennis. Fl. Julio.

Radix fibrofa. Caules plures, palmares, erecti, angulati, foliofi, plerunuite fimplices, uniflori, rariùs tri- aut quadri-fori, fücrnè imprimis pilofi. Folia alterna, tefilia, lanceolatz, obtufa, nervofa, ciliata; radicalia majora. Flores folitarii, terminales, crecti. Calyx fubhirfutus, nec, ut in E uniloro, lanatus. Flofculi radii numcrofi, purpurei, patentes, diffo duplò longiores. Semina fetofa. Pappus rufus, fcaber.

\section{TUSSILAGO. G. Pl. 423. Jilg. I 8 r. Gartn. เ. I70. \\ Petafites. Gertn.t. I66.}

Recept.nudum. Pappus fimplex. Cal. fimplex, polyphyllus, æqualis, fubmembraraceus, bafi ventricofus.

Farfara. I. TUSSILAGO fcapo uniforo fquamofo, foliis cordatis angulatis denticulatis.

Tuffilago Farfara. Sp.Pl. 1214. Hudf. 364. With. 719. Hull. 187. Reth. 3:4. Sibth. 261. Abbot. I81. Curt. Lond. fufc.2. t. 60. Dreves. Bilderb. t. 49. Fl. Din. t. 595. Woodv. Med. Bot. t. I3. Engl. Bot. t. 429. Tuffilago. Ruiii Syn. I 73. Ger.em. 8 I I. Matth. Valgr. \%. 2. 198. Camer. Epit. 590, 59I. Fuchs. Hift. I 40.

Ungula caballina. Trag. Hift. 418. Tuffilago, berba. Pbarmac. Lond. Angl. Colt's-foot,

In umbrofis humidis calcareis.

Perennis. Fl. Martio, Aprili.

Radix longè latèque repens. Scapi aphylli, crecti, pal. mares, fimplices, unifori, tomentofi, bracteis fparfis, adpreffis, glabris, fquamati. Ilos inapertus nutans, demùm 
demủm erectus, aureus. Squamæ calycinæ, lineares, trinerves, planæ, glabræ, purpurafcentes, longitudine difci, æquales, uniformes, demùm reflexæ. Flofculi radii numerofi, patentes, lineares, difco duplò longiores, 1tigmate tenuiori. Semina glabra, fæpiùs abortiva, imprimis in difco. Pappus omninò feffilis, fcaber, albus, nitens. Receptaculum fcrobiculatum, demùm convexum. Folia poft florem oriuntur, radicalia, petiolata, erecta, cordata, angulata, dentata; fuprà lævia ; fubtùs lanato-alba, venofa,

2. TUSSILAGO thyrfo oblongo, flofculis foemi-bybrida. neis plurimis; hermaphroditicis paucifimis, antheris diferetis,

Tuffilago bybrida. Sp. Pl. I2 I4. IHudf. 364 . With. 72 . Intl. 188. Engl. Bat. 1. 430 . Petafites major, floribus pediculis longis intidentibus. Dill. in Raii Syn. I79. Hort. Elth. 309. t. 230.

$\mathrm{P}$, major et vulgaris prima. Rupp. Jen. ed. I. I 80. 2 d. Hall. I 90 .

Angl. Longer-ftalked Butter-bur.

In pratis humidis cum fequenti, fed longê minùs frequentèr.

In feveral parts of Leicefterhire ; alfo about Manchefter. With. and Engl. Bot. Oxfordthire. Dill. and Mr. Woodward.

Perennis. Fl. Aprili,

Radix craffa, carnofa, repens. Scapus erectus, fefquipedalis, multiflorus, teres, lanatus, bracteis fparfis, lanccolatis, apice frepè foliaceis. Thyrfus terminalis, erectus, ovatus, elongatus, demùn cylindricus, pedicellis uni- aut bi-floris, fubindè tri-floris, bracteolatis. Flores carnei, radio orbati. Calyx glabriufculus, apice purpurafcens. Flofculi numerofiffimi, omnes tubulofi; fentrales 2 vol 3 hermaphroditici, rubri, antheris vel omninò 
omninò difinet is, vel leviffimé connexis, ftigmate obtufo, clavato, cmarginato, germine femper abortivo; cæteri fominei, corollâ graciliore, allbilá, figmate bipartito, acuto, germinc naturalitier fertili, fiepè verò, ob radices prester modum propagatas, abortivo. Semen obovatum. Pappus fcalier, argenteo-albus Receptaculum fcrobiculatum. Folia indicalia, petiolata, corrdata, acuta, inæqualiter dentata, venofa; fubtùs lanata; bafi ad venas cxcifa; denum maxima. P'etioli erecti, carnofi, teretes, fuprà canaliculati.

An vera fequentis foemina?

Patafites. 3. TUSSILAGO thyrfo ovato, flofculis omnibus ferè hermaphroditicis fyngenenis.

Tuffilago Petafites. Sp. 1\%. I215. Hudf. 364. With. 720. Irull. 187. Kelh. 314. Sibl\%. 261. Aibot. 181. Curt. Lond. fufe. 2. t. 59. Engl. Bot.t. 43 r. Hi. Dan. t. 842 .

Petafites. Raii Syn. 179. Ger. em.814. Fucbs. Hift. 644 .

Tuffilago major. Natth. Valgr.v. 2. 199. Ca+ mer. Epit. $59^{2}$.

Butter-bur. Pet. H. Brit.t. I5.f. II, I2. Angl. Common Butter-bur.

In pratis humiclis fpongiofis, et ad fluviorum mar gines, vulgaris.

Perennis. Fl. Aprili.

Radix et folia præcedentis. Scapus vix pedalis, thyrfo poft florefcentiam minus elongato. Flores majores; calyce duplò longiori. Flofcuili omnes plerumque hermaphroditici, uniformes, tubulofi, antheris coalitis, ftigmate incraffato, cmarginato, germine omninò abortivo. Hinc mas rrecedentis mihi videtur. Flofculos foemineos dnos vel tres aliquando invenerunt Linnæus filius, atque Hallerus, fed vix alịus. 
366. SENECIO. G.Pl. 424. Juf. I8I. Gertn.t. 166.

Jacobra. Gertn.t. I 70.

Recept. nudum. Pappus fimplex. Cal. cylindricus, polyphyllus, æqualis, calyculatus, fquamis apice fphacelatis.

\section{* Floribus flojculojis.}

I. SENECIO floribus radio deftitutis fparfis, foliis vulgaris, pinnato-finuatis amplexicaulibus deniatis. Senecio valgaris. Sp. Pl. 1216 . Hudf. 365 . With. 721. Hull. 186. Relh.315. Sibth. 252. Abbot. 182. Curt. Lond. fajc. 1. t. 6r.: Fl. Dan.t.5I3. Dreves. Bilderb.t.26. Raii Syn. 178.

Senecio. Muth, Fulgr. v. 2.476. Fuclig. Hift. 276.

Erigerum. Ger. $\mathrm{cm} .278$.

Verbena fornina. Brunf. Herb. v. I. I 20, opt. Angl. Common Groundfel. Simfon.

In cultis et ruderatis ubiqué.

Anmua. Fl. toto ferè anno.

Radix fibrofa. Caulis erectus, ramofus, foliofus, fubpaniculatıs, angulato-teres, glabriufculus. Folia alterna, pinnatifudo-finuata, obtufa, dentata, vel omninò glabra, vel fubtùs laxè lanata; radicalia petiolata; caulina alterna, fefilia, auriculato-amplexicaulia. Flores terminales, fparti, vel fubpaniculati, aurei, pedunculis ftriatis, parum bracteolatis. Calyx conico-cylindraceus, glaber; fquamis linearibus, acutis, rqualibus, conniventibus, apice fphacelato-nigris; bafi calyculatus fquamulis plurimis, brevibus, lanceolatis, adpreffis, apice etiam nigris. Flofculi numerof, omnes uniformes, hermaphroditici, aınue fertiles, corollulà tubulosâ, quinquefidâ, lorgitudine calycis. Stigma bipartitum, demin exfertum. Semina fulcata, pubefcentia. Pappus 


\section{SYNGENESIA-POLYGAM. SUPERFLUA.}

pus feffilis, fcaber. Receptaculum torulofum, punctae tum, glabrum.

\section{** Floribus radiatis, radio flatim revoluto.}

yifcofus. z. SENECIO radio revoluto, foliis pinnatifidis vifcidis, calyculis laxis perianthio fubær ualibus, caule ramofiffimo patulo.

Senecio vifcofus. Sp.Pl. 1217. Hudf. ${ }_{3} 65, \alpha_{0}$ With. 722. Hull. 186. Relh. 315. Sibth. 253. Lighlf. 479. Engl. Bot.t.32.

S. hirfutus vifcidus major odoratus. Raii Syn. 178. Bauh. Hift. v. 2. 1042.

S. hirfutus vifcidus graveolens. Dill. Hort. Elth。 $347 \cdot t .258 \cdot f \cdot 33^{6}$. Angl. Stinking Groundrel.

In ruderatis folo calcareo vel arenofo.

On the fen banks in the Ifle of Ely. Ray. A t Gamlingay, Mepole and Chatteris, Cambridgethire. Relh. Near Baldon, Oxfordhire. Sibth. By the fea fide at New Haven, in the King's Park Edinburgh, and about the chalkpits at Dartford, Kent.

Annua. Fl. Julio-Octobri.

Herba pilofo-vifcida, foetens. Caulis pedalis, ramofifimus, patulus, fulcatus, foliofus. Folia alterna, feffilia, vix amplexicaulia, pinnatifida, erofa, fubdentata. Pedunculi uniflores, terminales, fubfolitarii. Flores aurei, majores quam in præcedente, radiati. Calyx hirfutus, vifcidus, fquamis ad bafin paucis, linearibus, laxis, hirfutis, longitudine ferè perianthii vel duplò brevioribus. Flolculi difci numerofi, tubulofi; radii pauciores, ligulati, lineares, quinquedentati, ftatim revoluti: connes fertiles. Pappus oculo armato fcabriufculus.

fyluasi- 3. SENECIO radio revoluto, foliis pinnatifidis locus. batis 
SYNGENESIA-POLYGAM. SUPERFLUA. 88

batis denticulatis, calyculo brevifimo, caule erecto ftricto corymbofo.

Senecio fylvaticus. Sp. Pl. I21\%. With. 722. Hull. 186. Sibth.253. Abbot. 182. Ligbtf。 480.

S. vifcofus $\beta$. Hudf. ${ }_{3}^{6} 5$.

S. minor, latiore folio, five montanus. Dill. in Raii Syn. 178. Hort. Elth. 347. t. 258. f. 337 .

Jacobæa Senecionis folio incano perennis. Rupp. Jen. ed. Hall. I $77 . t . \hat{3}$. Angl. Mountain Groundfel.

In fylvis cæduis et cricetis, folo glareofo vel arenofo.

Annua. Fl. Juilio.

Caulis tripedalis, erectus, ftrictus, foliofus, fulcatus, fubpilofus, apice corymbofus, multiflorus. Folia numerofa, fparfa, lyrato-pinnatifida, lobata, denticulata, fubpilofa, ingratè odora, fed parùm vifcida. Flores duplò minores quam in præecedente, flavefcentes. Calyx gracilis, fubpubefcens, fquamis ad bafin parvis, brevibus, adpreflis. Corollulæ radii parvi, revoluti ; difci gracillimi, filiformes. Pappus oculo armato fcaber. Keceptaculum parvum.

Omninò a præcedente diftincta.

*** Floribus radiatis, radio patente; folits pirnatifidis.

4. SENECIO radio patente : fofculis ellipticis in- fqualitegerrimis, foliis pinnatifidis: lacinis fubli- dus. nearibus diftantibus.

Senecio fqualidus. Sp.Pl. I2IS. Engl. Bot. t. 600 .

S. n. 3. Linn. Hort. Up. 260 . Angl. Inelegant Ragwort. 


\section{SYNGENESIA-POLYGAM. SUPERFLUA:}

In muris Oxonix.

Very plentiful on almoft every wall in and about Oxford.

Annua. H. Junio-Oetobri.

Caulis ercetus, ramofus, patentiufculus, glaber vel fubindè pilofus. Folia feffilia vel auriculato-amplexicaulia, pirofundè pinnatifiela, laciniis anguftis, fer linearibus, acutis, remotis, denticulatis, planis, glabriufculis, lævibus, fubtus frepè violaccis. Corymbus terminalis, laxus, pauciforus, bracteolatus. Flores aurei. Calyx feré hemifphæricus, glaber, fquamis ad bafin paucis, laxis, parvis. Flofculi difei numerofiffimi ; radii plures, patentes, elliptici, lati, apice integerrimi, demùm fubrevoluti. Semina tomentofa. Pappus f́caber.

tenuifo- 5. SENECIO radio patente, folis pinnatifidis fublius. revolutis : fubtus pallidioribus pubefcentibus, caule erecto villofo.

Senecio tenuifolius. Jacq. Aufir. t. 278. (Herb. Jacq.) With. 723. Sim.Syn. 18 . Hull. 187. Sibib. 253. Engl. Bot. t. 574 .

S. erucifolius. IHudf. 366. Relh.316. Abbot. 182. Curt. Lond. falc. 5. t. 64.

Jacobaa Senccionis folio incano, perennis. Raii Syn. 177 .

Groundfel Pagwort. Pet. H. Brit.t. i $7 \cdot f \cdot 3$. Angl. Hoary Raguort.

In fjlvis, fepibus, et ad vias, imprimis folo calcarco.

Pirennis. Fl. Julio, Angufto.

Radix fubrepens. Caulis ercetus, ftrictus, fulcatus, foliofus, lanatus, apice corymbofus. Folia numerofa, alterna, amplexicaulia, pinnatifida, hinc indè dentata, fubrevoluta, magis vel minis lanata, præcipuè ad paginam inferiorcm, qua fæpè tomentofo-nivea eft. Corymbus terminalis, bracteclatus. Flores aurei. Calycis fquamæ dilatatæ, fubpubefcentcs, margine membranaceæ ;

calyculo 


\section{SYNGENESIA-POLYGAM. SUPERFLUA. $88 \xi$}

calyculo exiguo, laxo. Flofculi radii patentes, linearioblongi, obtufi, tridentati, demum revoluti. Semina pilofa. Pappus fcaber.

6. SENECIO radio patente, foliis lyrato-bipinnati-Jacobcri fidis divaricatis dentatis glabris, caule crecto.

Senecio Jacobra. Sp. Pl. : 219. Hudf. 365. With. 724. Hull. 187. Relh. 316: Sibth. 254. Abbot. I82. Mart. Fl. Ruft. t. $8_{5}$.

S. major, five Flos Sancti Jacobi. Mattb. Valgr. ข. 2. $47 \%$.

Jacobæa. Ger. ein. 280.

J. vulgaris. Räi Syn. 177. Baub. Hij.. ข.2. 1057.

Sancti Jacobi herba: Fucbj. Hift.742. Brunf: Herb. ข. 2. 56 .

Angl. Common Ragwort.

In pafcuis, ruderatis, et ad vias paffim:

Perennis. Fl. Julio, Augufto.

Radix fibrofa. Caulis erectus, ramofus, ftriatus, glabriufculus, foliofus, corymbofus, multiflorus. Folia lyratobipinnatifida, plerumque glabra, atro-viridia, laciniis fubcuneatis, divaricatis, dentatis, planis; bafi amplexicaulia, multifida. Corymbi terminales, multiflori, bracteolati, glabri. Flores aurei. Calyx glaber, fulcatus, cylindricus, brevis; fquamis ad bafin paucis, laxis, fubulatis. Flofculi radii patentes, lineari-oblongi, tridentati, demùm revoluti. Serinina pilofa. Pappus fcaber.

Variat floribus radio deftitutis in arenofis. Sherard.

7. SENECIO radio patente: fofculis ellipticis, aguatio foliis lyratis ferratis; inferioribus obovatis in- cus. - tegris, feminibus glabris.

Senecio aquaticus. Hudf. 366. With. 725 Hull. I.97. Relh. 3 r6. Sibth. 254. Abbot. I 82. Fl. Dan. t. 784 . Vol. II. 


\section{SYNGENESIA-POLYGAM. SUPERFLUA.}

Jacobra latifolia. Buth. Miff. $\because 2.1057$. fingl. Marth Ragwort. 1'el.H. Brit.t. I $7 \cdot f .2$.

In paludofis et aquofis ubique.

Perennis. Fl. Julio, Augufto.

Herba plerumque glaberrima; in locis exficcatis guandoque fublanata. Caulis crectus, ramofus, foliofus, bañ frepè purpurafecns, ut in priori ; etiam corymbofus, fed floribus majoribus ct longè paucioribus. Folia lietè, nee atro, virentia; inferiora petiolata, obovata feu elliptica, indivifa, et ferè integerrima; fuperiora feffilia, vel amplexicaulia, lyrato-pinnatifida, ferrata, apice integerrima. Flores aurei, fpeciofi. Calyx brevis, ct ferè hemifpharicus, glaber, vix calyculatus. Flofculi radii patentes, elliptici, tri- vel guadri-clentati, latitudine varii, demum revoluti; difci plurimi. Semina gliberrima, quá notà certò certiùs a $\mathrm{S}$. Jacobxâ dif. crepat. P’appus fcaber.

Variat floribus radio orbatis. D. Woodward.

****** Floribus radiatis; foliis indivifis.

aludo- 8. SENECIO radio patente, floribus corymbofis, jus. foliis enfiformibus acutè ferratis fubtùs fubvillofis, caule ftricto.

Senecio paludofus. Sp. Pl. 1220. Hudf. 366. With. 725. Hull. 187. Relh. 357. Engl. Bot.t. 650. Fl. Dan.t.385.

Virgæ aurea, five Solidagini anguftifoliæ, affinis, Lingua avis Dalcchampii. Raii Syn. 176. Licuh. Hij»v. 2. 1063 .

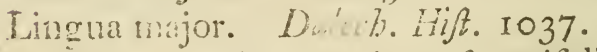

Conyza aquatica maxima ferratifolia. Camer. Itargy. 2 I. t. 3 .

C. palutiris fermtifolin Cer. em. $4^{8} 3$. Marn Golden-rod. Pet. H. Brit.t. 16.f.8. Angl. Marh Groundiel. Bird's tongue.

In fontis et palidofis rarifime. 
Near Streatham ferry in the ifle of Ely. Ray. In Lakenheath fen near Wangford, Suffolk. Rev. $M r$. Hemfied. On the banks of ditches near Braford water, half a mile from Lincoln. Rev. $M r$. Woollafton.

Perennis. Fl. Junio, Julio.

Radix fibrofa, fubrepens. Caules erecti, fricti, tri-fex. pedales, fimplices, 'foliofi, teretes, ftriati, fiftulofi, tomento laxo, deciduo, veftiti. Folia numerofa, fparfa, feflilia, lanceolata, acuta, acute ferrata, bafi anguftata et integerrima; fuprà glabra ; fubtùs pallidiora, et plerumque pubefcentia. Corymbus terminalis, pauciflorus, pedunculis inferioribus axillaribus. Bractex fubulatæ. Flores aurei, magni. Calyx glabriufculus, fquamis ad bafin linearibus. Flofculi radii patentes, lineares, longi, apice quinquedentati. Semina pilofa. Pappus minutè fcaber. Receptaculum pilofiufculum.

9. SENECIO radio patente, floribus corymbofis, faraceriz foliis lanceolatis ferratis glabriufculis.

Senecio faracenicus. Sp.Pl. I 22 I. Hudf. 367. With. 726. Hull. i 87. Jacq. Auftr. t. I 86.

Virga aurea maxima, radice repente. Raï Syn. I 77 .

$\mathrm{V}$. aurea anguftifolia ferrata, five Solidago farracenica. Bauh. Hijt. v. 2. 1063 .

Solidago farracenica. Fuch. Hif. 728. Trag. Hift. 487 .

Angl. Broad-leaved Groundfel.

In pratis et parcuis fubhumidis.

Plentifully by the fide of a fmall river between Wells and Glaftenbury. Bobart. Near Halifax; Mr. Newton. Dill. Very common at Salkeld, Cumberland; Mr. Nicholfon. Ray. In a moift lane near Prefton hall, between Kirkby Lonfdale and Kendal, Weftmoreland, 1732 ; alfo in

$$
\text { G } g_{2}
$$

the 


\section{SSS SYNGENESIA-POLYGAM. SUPERFLUA.}

the King's Park, Edinburgh, but probably planted in the place laft mentioned.

Perennis. Fl. Julio, Augufto.

Radix repens. Caules crećti, ftricti, tripedales, fubinde quinquepedales, angulati, foliofi, glabri, apice corymbofi. Folia alterna, feffilia, lanceolata, acuta, ferrata vel denticulato-ferrata, læviufcula, vel minutè pubefcentula, fuperiora fensim minora. Corvmbus multiflorus. Bractex lineari-lanccolatx, acuminatx. Pedicelli angulati, pubefcentes. Flores lutei. Calyx fublanatus, fquamis ad bafin lanceolatis. Flofculi radii patentes, elliptici, longius unguiculati, apice vix dentati. Semina glabra. Pappus minutè fcaber.

\section{ASTER. G. Pl. 424. Juf. $18 \mathrm{I}$. Gertn.t. 170.}

Recept. nudum. Pappus fimplex. Cal. imbricatus, fquamis inferioribus patulis. Flofculi radii plures quam decem.

Tripo- I. ASTER herbaceus corymbofus, foliis lanccolalí $i m$. tis integerrimis carnofis glabris fubtrinervibus, fquamis calycinis fubmembranaceis obtufis.

After Tripolium. Sp. Pl. I 226. Hudf. 368. Wilb. 726. Hull. 188. Relb. 318. Engl. Bot.t.87. Fl.Dan. t.615.

- A. maritimus caruleus, Tripolium dictus. Raii Syn. 175 .

Tripolium vulgare majus et minus. Ger. em。 413. Baub. Hift. v. 2. 1064 .

Great and fmall Sea Star-wort. Pet. H. Brit. t. I7.f. IO, II. Angl. Sea Star-wort.

In maritimis uliginofis, et paludibus falfis, copiosè.

Perennis. Fl. Augufto, Septembri.

Herba lævis, fubglauca, magnitudine infigniter varians. 
Radix fibrofa. Caulis teres, cavus, ftriatus, foliofus, corymbofus; plerumque erectus, multiflorus. Folia carnofa, lanceolata, integerrima, alterna ; inferiora petiolata. Flores fpeciofi, difco luteo vel aurantiaco, radio cæruleo, interdùm albo. Squamæ calycinæ ovatæ, obtufæ, planæ, fubmembranaceæ, obfoletè ciliatæ. Flofculi radii numerofi, patentes, elliptico-lineares, nunquam revoluti, apice dentati. Semina compreffa, margine fetis erectis ciliata. Pappus fcabriufculus, rubicundus.

Variat floribus radio deftitutis.

\section{SOLIDAGO. G. Pl. 425. Juf. I $8 \mathrm{I}$. \\ Gertn.t. 170 .}

Recept. fcrobiculatum, nudum. Pappus fimplex. Cal. imbricatus, fquamis conniventibus. Hlofculi radii circitèr quinque.

1. SOLIDAGO caule fubflexùofo angulato, race-Virgaumis paniculatis erectis confertis.

Solidago Virgaurea. Sp.Pl. 1 235. Hudf. 367. With. 727. Hull. 186. Relh. 317. Sibth. 254. Abbot. 183. Engl. Bot. t.301. Fl. Dan. $t .66_{3}$.

Virga aurea. Raï Syn. 176. Ger. em. 430. Matth. Kalgr. v. 2. 354. Camer. Epit. 748 et 749 .

V. aurea vulgaris latifolia. Baub. Hifl. v. 2. 1062.

Common Golden Rod. Pet. H. Brit. t. 16. $f$. Io.

B. Virga aurea, vulgari humilior. Raii Syn. I76. Dill. Hort. Elth. 4I4. Exemplar Sherardianum nonclum examinavi.

$\gamma$. Solidago cambrica. Hudf: 367 . With. 728 . Hull. 186.

Virga aurea montana, folio angufto fubincano, flofculis conglobatis. Raii Syn. I77.

G 33 rea. 


\section{\$gO SYNGENESIA-POLYGAM. SUPERFLUA.}

V. aurea cambrica, floribus conglobatis. Dill. Hort. Elih. 4. 3. t. 306.f. 393.

๖. V. aurea montana biuncialis pumila, foliis acuminatis. Pluk. Phyt.t.235.f. 7 , et fol. obtufis. f. 8. Conf. Dill. H. Elth. 4 ז 3 . Angl. Common Golden-rod.

In nemorofis, dumetis, ericetis, et montofis.

Perennis. Fl. Julio - Septembri.

Radix e fibris longis, fimplicibus. Caulis altitudine valde̊ varius, fæpiùs ramofo-paniculatus, magis minùfve flexuofus, nunquam omninò ftrictus, foliofus, angulatus, pubefcens; bafi teres ac frè purpureus. Folia elliptico-lanceolata, fcabriufcula, rigidula ; radicalia latiora, longiùs petiolata, latiùfque ferrata ; caulina plerumque obfoletè crenato-ferrata, fubinde fere integerrima, magnitudine varia, fæpe recurva; fumma in bracteas fensim dininuta: omnia fubhirfuta, imprimis in varietate $\gamma$. Danicula terminalis, multiflora, foliolofa, pubefcens, ramulis racemofis, vel fubcorymbofis; in folo fterili vel in montofis brevior, denfiner, minùfque compofita. Flores aurei. Foliola calycina demùm patula, fed onnia reeta, imbricata, lanceolata, ciliata, quandoque dorfo fcabra, margine membranacea. Flofculi radii 5 ad 9 vel Io, patentes, elliptico-oblongi, apice dentati. Scmina pubefcentia. Pappus fcaber.

Petiveri icon t. I6. $f$. I I e Camerario mutuata, nullius

: auctoritatis eft ad Cambria ftirpem defignandam.

Collatis exemplaribus Cambro-britannicis et Eboracenfi-

- bus, in folo natali decerptis, cum Solidagine vulgari, ne minimam differentiam fpecificam inveni. S. lapponica Witheringii ad eandem fpeciem pertinere mihi etiam videtur.

\section{INULA. G.Pl. 426. Juf. I8I. Garts.t. I 70 .}

Recept. nudum. Pappus finplex. Cal. imbricatus. Cor. radii numeroliffimæ, lineares. Anthere bafi bifetze.': 
I. INULA foliis amplexicaulibus ovatis rugofis Helemifubtùs tomentofis, calycum fquamis ovatis.

Inula Helenium. Sp. Pl. I236. Hudf. 368. With. 730. Hull. 185. Kelh. 318. Siblh. 255. Abbot. 183. Woodv. Med. But. t. 108. Fi. Dan. t. 728 .

Helenium. Ruii Syn. п76. Ger.em. 793. Matth. Valgr.v. 1. 65. Camer. Epit. 35 .

Enula campana, radix. Pburmac. Lond.

Angl. Elccampane. P'et. H. Brit. t. 16:f. I.

In pratis et pafcuis humidis, haud vulgaris.

Frequent in Eflex; about St. Ives in Cornwall, and Bugden, Hertfordhire; alfo between Denbigh and St. Afaph. Hudf. In feveral parts of Norfolk and Suffolk. Mr. Woodward. Near Dalton, Lancahire. Mr. Alkinfon. Between Worcefier and Ludlow, and between Bifhop's Caftle and New Town, I795.

Perennis. Fl. Julio, Augu?to.

Radix craffa, ramofa, intus mucilaginofa, aromatica et amara. Caulis erectus, tripedalis, foliofus, teres, fulcatus ; fupernè ramofus et pubefcens. Folia svata, ferrata, renofa, fubtùs tomentofo-alba ; radicalia petiolata; raulina alterna, amplexicaulia. Flores terminales, folitarii, magni, aurei. Calycis fquamæ interiores anguftæ, lineares, æquales, fcariofæ; exteriores imisicatie, ovatæ, magnæe, extus tomentofre. Flofculi radii numerofi, patentes, calyce duplò longiores, linear - apice tridentati. Antheræ bafi in fetas cluas produce. Semina quadrangularia, glabra. Pappus oculo armato fcabriufculus. Receptaculum reticulatum, papillofum.

2. INULA foliis amplexicaulibus cordato-ob'ongis dyfentetomentofis, caule villofo paniculato, fquamis rica. calycinis fetaceis hirtis.

Inula dyfenterica. SP. Pl. I237. Hudf. 368. 
With. 731. Hull. 185. Relh. 319. Silth. 256. Abbot. 184. Curt. Lond. fafc. 3.t. 56 \% Fl. Dan. t. 4 Io.

Conyza media. Raii Syn. I 74 . Ger.em. 48z: Mattb. Valgr. v. 2.224.

C. tertia. Camer. Epit.6I4.

Calaminthæ tertium genus. Fuch. Hift. 436 . Angl. Common Fleabane. Pєt. H. Brit. t. 16. f. 2 .

In aquofis et ad rivos vulgaris.

Perennis. Fl. Anigufto.

Radix repens. Caulis erectus, pedalis aut fefquipedalis, ramofus, corymbofus, foliofus, angulatus, fulcatus, lanatus. Folia alterna, amplexicaulia, patentia, oblonga, zepanda, denticulata, fubtùs præcipuè tomentofo-albida. Flores numerofi, terminales, folitarii, ąrei. Calycis fquamæ omnes fubæquales, numerofe, linearifetaceæ, pilis longis albidis hirfutæ. Flofculi radii numerofiffimi, patentes, calyce duplò longiores, lineares, appice tridentati, demùm revoluti. Antheræ bafi longiùs bifetæ. Semina hifpida. Pappus fcaber. Re= ceptaculum fubfavofum.

Herba fubvifcida, odore acidulo, aromatico, forti, malo perfico haud abfimili, fed ingratiore.

pritica- 3. INULA foliis amplexicaulibus undulatis, caule ria. ramofiffimo pilofo, floribus hemifphæricis: radio breviffimo.

Inula pulicaria. Sp. Pl. I 238. ITudf. 369. Relh. 319. Abbot. 184. Curt. Lond. fafc. 3.'t. 57. Dick. H. Sicc. fafc. 7. 13. Leers. I80. F\%. Dan.t.6I3.

I. uliginofa. Sibth. 256 .

I. cylindrica. With.731. Hull.185. Sym. Syn. 183.

Alter n. 80. Hall. Hift. v. I. 33 .

Conyza minor. Raii Syn. 174. Mattb. Valgr. ข. 2 . 
v. 2. 223. Camer. Epit. 6r3. Trag. Hift. 166, sum icone.

C. minina. Dod. Pempt. 52. Ger.em. 482.

C. medix minor fpecies, flore vix radiato. Bauls. Hift. v. 2. 1050, defer. nec icon.

Angl. Sinall Fleabane. Pet. H, Brit.t. I6.f. 3 。

In pratis vel ericetis arenofis, hyeme inundatis.

Annua. Fl. Septembri.

Radix fufiformis, tortuofa, ramofa. Caulis ramofiffimus, fubfiesuofus, foliofus, multiflorus, angulatus, pilofus, frepiùs erectus, quandoque diffufus. Folia fparfa, fubanplexicaulia, lanceolato-oblonga, undulata, recurva, utrinque pilofa, margine rariùs denticulata. Flores folitarii, terminales, demùn laterales, hemifphærici, triftè luteoli. Calycis fquamæ omnes ferè æquales, numerofæ, lineari-fetacex, hirfut». Flofculi radii fæpiùs numerofi, patentes, recurvi, breviffrmi, tridentati. Antheræ bafi bifetæ. Semina hifpidula. Pappus e radiis fex vel feptem, acutis, fcabriufculis, femine haud longioribus. Receptaculum papillofum.

Variat radio paucifloro, vel omninò nullo.

Specimen Linnæanum cum pluribus in Angliâ lectis fedulò contuli, nec ullam differentiam inveni. Florum forma in omnibus eadem eft, ac tota facies. Caulis apud nos quandoque etiam decumbit.

4. INULA foliis linearibus carnofis fubtricufpida- crithaso tis, calyce glabro.

Inula crithmoides. Sp. Pl. I240. Hudf. 369. With. 732. Engl. Bot. t. 68. Pulten. Dorfet: 8 I.

1. crithmifolia. Hull. 185 ,

After maritimus flavus, Crithmum chryfanthemum dictus. Raii Syn. 174.

Crithmum chryfanthemum. Ger. em. 533 .

C. tertium. Mattb. Valgr.v. 1. 446.

Golden Sampire. Pet. H. Brit.t. I 7.f. 9 .

9 Angl. 


\section{SYNGENESIA-POLYGAM. SUPERTLUA.}

Angl. Samphire-leaved Flcabane.

In maritimis cœnofis.

In a marth near Hurft caftle over againft the ifle of Wight plentifully; at Llandivyn in Anglefea; and on the bank of the river juft above Fulbridge at Maldon, Eflex. Ray. In Shepey inland; J. Sherard. Dill. Portland ifland. Rev. Mr. Baker.

Perennis. 'Fl. Augufto.

Radix repens. Caules ereeti vel decumbentes, fubfimplices, densè foliofi, glabri, ap̣ice corymbofi. Folia conferta, carnofa, glabra, linearia, apice vel integra, vel trifida. Pedunculi corymbofi, terminales, fquamati, uniffori. Flores magni, ippeciofi, difco fulvo, radio patenti, aureo, calyce longiori. Calyx imbricatus, fquamis exterioribus laxis, ut in Aftere. Antherre vix bifetxe. Semina pilofa. Pappus fcaber, rubicundus. Receptaculun fcrobiculatum.

Taleis facilè propagatur. D. Goodenougb.

370. CINERARIA. G.Pl. 426. JufJ. I8I. Gurtn. t. I†

Recept. nudum. Pappus fimplex. Cal. fimplex, polyphyllus, æequalis, cylindraceus.

paluftris. т. CINERARIA floribus corymbofis, foliis latolanceolatis dentatis finuatifie, caule villofo foliofo.

Cineraria paluttris. Sp. Pl. I243. Hudf. 369 . With. 729. Hull. 186. Relh. 320. Engl. Bot.t. I5 r. Fl. Dan. t. 573 .

Soliclage n. I3I. Gmel. Siv. J.2. 3j8.t. 72. Conyza foliis lacinatis. Rail syn. I 74. Ger.em. 483.

Marfh Fleabane. Pet. H. Brit. t. I6.f. 5 ; and Jagged Fle abane. Ibid. f. 6 . 


\section{Angl. Marh Flea-wort.}

In foflis et paludofis.

In the Ine of Ely, Lancanire and Wales. Ray. Near Acle, Norfolk. Sherard. Near Haddifcoe, and on St. Faith's Newton bogs. E. Bot. In Skoulton meer near Hingham, Norfolk. $M r$. Crowe.

Perennis. Fl. Junio, Julio.

Piadix fibrofa. Caules tripedales, erecti, fimplices, foliofi, crafi, fiftulofi, angulati, villofi. Folia alterna, lanceolata, nervofa, pallida, pilofa, dentata, fæpè pinnatifidolaciniata et undulata. Flores corymbofi, terminales, aurei, numerofi. Pedunculi villofi. Calyx cylindraceus, villofus, lutefcens, nunquam bafi ventricofus; fquamis margine membranaceis. Flofculi radii fquamis calycinis numero circit̀̀r æquales, parùmque longiores, fubelliptici, apice dentati, patentes; difci numerofi, fulvi ; omnes fertiles. Semina fulcata, glabra. Pappus fcaber. Receptaculum fcrobiculatum, nudum. Pubefcentia ornnis pellucida et articulata.

2. CINERARIA foliis oblongis obfoletè denticu-integrilatis villofis, umbellâ fimplici involucratâ. folia.

Cineraria integrifolia. With. 729. Hull. I86. Sibth. 255. Engl. Bot. t. 152.

C. integrifolia $\beta$, pratenfis. Sy t. Veg. ed. I $4_{\text {* }}$ 764. Jacq. Anifr. t. 180. Herb. Linn.

C. alpina. Sp.P! $1243, \gamma$. Hudl.370. Relh. 320.t. 4 .

Jacobæa Pannonica, folio non laciniato. Raii Syn. 178. Bauh. Hitt. v. 2. 1056.

J. anguftifolia. Ger.em. 280.

Cambridge Ragwort. Pet. H. Brit.t. I\%.f. 4 .

B. Cineraria alpina. Allion. Ped.v. I. 203.t. 38 . f. 2.

Angl. Mountain Flea-wort. 
In pafcuis cretaceis editioribus, vel clivis calcareis. On Goginagog hills, Newmarket heath, and other like places. Ray. Relh. Near Bafngftoke and Andover. Hhadf.

$\beta$ on cliffs near Holy-head, Anglefea. Rev. H. Davies.

Perennis. Fl. Maio, Julio.

Radix fibrofa. Herba tomento albo, deciduo, veftita. Caulis fimpliciffimus, fpithamæus, fulcatus. Folia elliptico-oblonga, fubrevoluta, rariùs et obfoletè denticulata; radicalia depreffa, majora, et fæpiùs obtufiora; caulina alterna, erecta, anguftiora. Umbella terminalis, pauciflora, pedunculis fingulis bracteâ lanceolatâ, brevi, ad bafin. Flores aurei. Calyx cylindracco-hemifphæricus, glabratus, bafi lanatus, fquamis margine membranaceis. Flofculi radii plures, calyce duplò longiores, elliptico-oblongi, apice tridentati, patentes. Semina fericeo-villofa. Pappus fcaber.

Caulis in $\beta$ pedalis, folis omnibus (at præcipuè caulinis) majoribus, fuprà magis denụdatis, radicalibus quandoque latè dentatis.

\section{DORONICUM. G. Pl. 427. Ju/f. I 82. Gartn. t. I73.}

Recept. nudum. Pappus fimplex. Calycis fquamæo duplici ordine, æquales, difco longiores. Sem. radii mutica.

Pordali- $\bar{z}$. DORONICUM foliis cordatis denticulatis: enches. raclicalibus petiolatis; caulinis amplexicaulibus.

Doronicum Pardalianches. Sp. Pl. I247. Ligbrf. 485. Hudf.650. With. 732. Hull.185. Engl, But. t. 630. Scop. Carn. v. 2. I74. Jaiq. Auftr. t. 350. Mill. Ic. t. 128.

D. majus officinarum. Ger. ein. 759 .

D. Iatifolium. Chif. Hift. v. 2. I6.

D. tertii 
D. tertii varietas. Lob. Ic. 649 . Angl. Great Leopard's-bane.

In pratis et pafcuis montofis.

Gathered in the cold mountains of Northumberland, by Dr. Penny. Gerarde. In feveral places in the lowlands of Scotland, but always near houfes. Lightf. On the banks of the Severn. below Bridgnorth. Witb. By the road fide neak Saling hall, Effex. T. Walford, Efq.

\section{Perennis. Fl. Maio.}

Radix tuberofa, repens, apice lanata. Caulis erectus, bivel tri-pedalis, ramofus, foliofus, teres, fulcatus, pilofofeaber, fupernè fubvifcidus. Folia cordata, dentatorepanda, pilofa, molliufcula; radicalia magna, pctiolata; caulina alterna, amplexicaulia, minora; fumma lanceolata. Flores terminales, folitarii, magni, aurei. Calycis fquamæ lineares, acutæ, pilofæ, dif́co duplò longiores. flofculi radii numerofiffimi, lineares, patentes, calyce longiores, apice quinquedentati. Semina fulcata; radii glabra, pappo deftituta ; difci pilofa, pappo fcabro coronata. Receptaculum convexum, fcrobiculatum.

\section{BELLIS. G.Pl. 429. JufJ. 183 . Gartn. t. I68.}

Recept. nudum, conicum. Pappus nullus. Cai. hemifphæricus, fquamis æqualibus. Sem. obovata.

I. BELLIS fcapo nudo, radice repente. Bellis perennis. Sp. Pl. I 248. Hudf. 370 . With. 733. Hull. I 84. Relh. 320. Sibth. 256. Abbot. 184. Curt. Lond. fafc. I. t. 62. Engl. Bot. t. 424. Fl. Dan.t. 503 .

B. fylveftris minor. Räii Syn. 184, Ger. em. $\sigma_{3} 6$. Fuch.j. Hift. 147.

B. minor. Matth. L'algr. ข. 2. 263. 
Primula veris. Trag. Hifl. $16 \mathrm{I}$. Angl. Common Daify.

In pratis et pafcuis ubique.

Perennis. Fl, toto ferè anno.

Radix repens, ramofa, fibris longis. Folia radicalia, depreffa, obovata, crenata, pilofa. Scapi erecti, fimplices, uniflori, teretes, nudi. Flos pulchellus, dif́co conico, aureo, radio albo vel frepius rubicundo. Flofculi radii lineari-obovati, plani, emarginati, numerofifimi, patentes. Semina compreffa, pilofa. Receptaculum conicum, acutum, punctatum, concavum:

373. CHRYSANTHEMUM. G. Pl. 432. JufJ. 183. Gocrtn。 t. 168.

Recept. nudum. Pappus nullus. Cal. hemifphæricus, imbricatus, fquamis margine dila: tatis, membranaceis.

* Radio albo.

Leucan- I. CHRYSANTHEMUM foliis amplexicaulibus tbemum. oblongis obtufis incifis bafi pinnatifidis; radicalibus obovatis petiolatis.

Chryfanthemum Leucanthemum. Sp. Pl. I25 I. Hudf. 371. With. 733. Hull. 184. Relh. 321. Sibth.257. Abbot. 185. Curt. Lond. fafc. 5.t.62. Mart. Fl. Ruft.t. 109. Engl. Bjot. t. 601. Fl. Dan.t. 994.

Leucanthemum vulgare. Raii Syn. I 84. Bellis major. Ger. em. 634. Matth. Valgr. v. 2. 261. Camer. Epit. 653: Fuchf. Hift: I 48 .

Buphthalmon. Brunf. Herb. v. I. 258 . Angl. Great White Ox-eye.

In pafcuis, arvis, et ad vias, vulgaris. 


\section{Perennis. Fl. Junio, Julio.}

Radix fublignofa, fibrofa. Caules erecti, bipedales, fubramofi, fulcato-angulati, angulis rubris, pilofiufculi, foliofi. Folia faturatè viridia, nitida, glabriufcula, incifa: infima petiolata ; fuperiora alterna, amplexicaulia, bafi pinnatifida. Flores folitarii, terminales, magni, formofi, difco aureo, radio albo. Calyx hemifphæricodepreffus, glaber, fquamis numerofis, imbricatis, margine fcariofis, interioribus præcipuè apice dilatatomembranaceis. Flofculi radii calyce triplò longiores, numerofi, patentes, elliptico-oblongi, nitidi, apice erofi, dentati. Semina cylindracea, omninò mutica, fulcata, nigra, coftis albis. Receptaculum convexum.

\section{** Radio luteo.}

2. CHRYSANTHEMUM foliis amplexicaulibus Segctum. glaucis fupernè laciniatis bafi dentatis.

Chryfanthemum fegetum. Sp. Pl. I254. Hudf. 371. With 735 . Hull. 185 . Relh.321. Sibth. 257. Abbot. i 85 . Dickf. H. Sicc. fafc. 6. 13. Curt. Lond. fafc. 6. t. 6o. Mart. Fl. Rujt. t. 110. Enyl. Bot. t. 540. Raï Syn. 182. Ger. em. 743. Fl. Dan.t. 995.

Corn Marygold. Pet. H. Brit.t. ig.f.6.

B. Chryfanthemum fegctum noftras, folio glauco multifciffo majus, flore minore. Raï Syn. I 83 . Angl. Yellow Ox-eye. Corn Marigold.

Inter fegetes vulgaris, præcipuè folo fabulofo.

Anmue. Fl. Junio-Augufto.

Radix fufformis, parva. Herba glauca, lævis. Caulis pedalis-bipedalis, ramofus, angulatus, foliofus. Folia amplexicaulia, oblonga, variè dentata aut pimnatifilolaciniata, rariùs integra. Flores terminales, folitarii, toti aurei, fpeciofi, magnin; in $\&$ minores. Calycis fquamæ undique latè membranaceæ. Flofculi radii breviores quam in precedente, obcordati, patentes. 


\section{SYNGENESIA-POLYGAM. SUPERFLUA:}

Scmina fulcata, mutica; ex errore apud Engl. Bot. cós ronata defcripfi.

Variat ftigmate trifido in flofculis radii. With.

\section{PYRETHRUM. Garin. t. i6g. Haller. v. I. 40.}

Recept. nidum. Pappus marginatus. Cal. hemifphæricus, imbricatus, fquamis acutiufculis, margine fcariofis.

Partbe- I. PYRETHRUM foliis petiolatis compofitis planizum. nis: foliolis ovatis incifis, pedunculis ramofis corymbofis, caule erecto.

Matricaria Parthenium. Sp. Pl. 1255. Ihudl: 37 I. With. 335. Hull. I84. Relh. 322. Sibth. 258. Abbot. 185. Woodv: Suppl: t. 249. Tl. Dan. t. 674.

Matricaria. Raii Syn. 187. Ger.em. 652. Parthenium feu Matricaria: Mattb. Valgr. v. 2. 258. Camer. Epit. 649.

Angl. Common Feverfew. Pet. H. Brit. t. I9: $f \cdot 5$.

In ruderatis et ad fepes.

Perennis. Fl. Junio, Julio.

Radix fibrofa, ramofa. Herba amara, aromatica. Caules erecti, bi- vel tri-pedales, ramofi, fulcati. Folia petiolata, pinnata vel bipinnata, foliolis dilatatis, incifis; fubincanis. Pedunculi terminales, ramofi, corymbofis, fulcati, pubefcentes. Flores albi, radio brevi, fubdeflexo, quandoque nullo. Calyx pubefcens, hemifphæricus, fquamis apice fcariofis, laceris. Semina fulcata, margine membranace proculdubiò coronata. Receptaculum planum, nudum.

inodo- 2. PYRETHRUM foliis ferfilibus pinnatis capilrasme. laceo: 
laceo-multifidis, caule ramofo patulo, coronâ feminum integrâ.

Pyrethrum inodorum. Engl. Bot.t. 676 .

Chryfanthernum inodorum. Sp.Pl. I 253. With. 734. Hull. I 84. Rell. Suppl. I. I 4. Sibtb. 257. Abbot. 185 . Fl. Dan. t. 696.

Matricaria inodora. Hudf. 372 .

Chamæmelum inodorum annuum humilius, foliis obfcurè virentibus. Dill. in Raii syn. 186.

C. inodorum, live Cotula non fatidu. Bums. Hift. $\% 3 \cdot 120$.

Buphthalmum. Fuchs. Hift. I 4 f.

May-weed. Pet. H. Brit. t. I9.f. I 2.

Angl. Corn Feverfew. Scentlefs May-weed.

In arvis et ad vias, imprimis folo glarcofo.

Annua. Fl. Augufto, Septembri.

Radix fufiformis. Herba ferè inodora. Caulis ramofus, diffufo-patulus, foliofus, angulatus, glaber. Folia feffilia, lyrato-pinnata, foliolis lineari-multifidis, anguftiffimis, fubrevolutis, mucronulatis, glabris. Flores terminales, folitarii, majufculi, pedunculis nudis. Difcus luteus, convexus. Flofculi radii patentes; albi, ellipticooblongi, obtufi, tridentati. Calycis fquama glabra, margine tenui, nigricante, fubmembranaceo, æquali, undique cinctre. Semina apicc margine membranaceo, integro, coronata. Receptaculum conicum, obtufum, omninó nudum.

Variat radio multiplicato. D. Crowe.

Chamæmelum majus, folio tenuifimo, canle rubente, Dill. in Räi Syn. 186, nondum vidi, nec e defcriptione ad hanc vel aliam fpeciem referre aufus fum. Annè fequentis varietas?

3. PYRETHRUM folis bipinnatis carnofis mu-maniti. ticis : fuprà convexis : fubtìs carinatis, coronà $m u m$. feminum lobatâ. Vot.II. 
Niatricaria maritima. Sp. Pl. 1256. Lightf. 491 . With 736. Mull. 184. M. inodora \%. Iludf. 373 .

Chamamclum maritinum percnne humilius, foliis brevibus craffis, obfeurè vircntibus. Dill. in Raï Syn. 186. . . . f. 1. fingl. Sea Feverfew.

In maritimis arcnofis vel petrofis.

On the Sufiex coaft at Cockbun, 7 miles from Chichefter, in plenty. Dill. At Weymouth. Rev. Archdeacon Gooch. At Whitburn, Durham. Mr. Rolyon. In the ifle of Bute, and on. the weftern fide of Cantire. Lightf. On the rocks at Doun near Bamff.

Perennis. Fl. Julio.

Radix lignofa. Caules cæépitofi, decumbentes, palmares vel fpithamæi, parùm ramofi, foliofi, glabri, fufcopurpurafcentes, nitidi. Folia feffilia, lyrato-bipinnata, laciniis brevibus, obtufiufculis, muticis, glabris, craffis et carnofis, nitidis, fubtùs carinatis. Flores terminales, folitarii, magnitudine ferè præcedentis. Calyx glaber, fquamis margine tenuifimo, nigricante, cinctis. Difcus aureus, duplò latior quam in P. inodoro, convexus. Flofculi radii patentes, albi, ol,usè tridentati, nec (ut ex defcriptione Dillenianâ intelligitur) integri. Semina margine membranaceo trifido aut quadrifido coronata. Species toto cœlo a præcedente diftincta.

\section{MATRICARIA. G.Pl. 432. Juf. I83.} Gartn.t. I68.

Recept. nudum, cylindracco-conicum. Pappus nullus. Cal. planiufculus, imbricatus, fquamis margine feariofis.

Chamo- I. MATRICARIA folis glabris pinnatis : foliolis milla.

lincaribus 
tinearibus integris laciniatifque, radio patente, fquamis calycinis dilatatis.

Matricaria Chamomilla. Sp. Pl. 1256. Hudf.

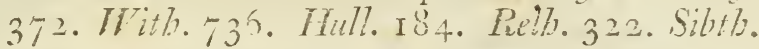
253. Abbot. 185. Curt. Lond. firfa. 5. t. 63 . Murt. Fl. Pujt. t. 74 .

Chamomilla vulgaris. Trag. Hift. I 48 .

Chamæmelum. Räi, Syn. I $8_{4}$. Ger. en. 754. C. leucanthemon. Ficky. Hijt. 25 .

Anthemis five Chamamilla. Hatul. Vulgr. v. 2 . 25.5 .

Bitter Camomilc. Pet. II. Brit. t. I g. f. 9 . Angl. Wild Chamomile.

In arvis et ad vias, vel in fimetis.

Very common about London; rare in Norfolk.

Annua. Fl. Maio-Julio.

Radix fibrofa. Caulis pedalis, erectus, ramofiffimus, foliofus, ftriatus, glaber. Folia feffilia, lyrato-bipinnata, faturatè viridia, glabra, laciniis linearibus, obtufis, mucronulatis. Flores numerofi, terminales, folitarii, magnitudine Anthemidis nobilis, quâcum etiam odore quodammodò conveniunt. Calyx planiufculus, glaber, fquamis extits dilatatis, fcariofe, albidis. Difcus lutcus, conicus, Flofculi radii patentes, albi, retufi, tridentati, noctu deflexi. Scmina angulata, obliqua, glabra, omninò mutica. Receptaculum conico-cylindraceum, acutum, punctulatum, glabrum.

Matricaria fuaveolens Linnæi diftincta fpecies eft, nunquam in Britanniâ inventa, cui flores duplò minores funt quam M. Chanomilla.

376. ANTHEMIS. G. Pl. 434. JuS. I 85.

Gertn.t. 169.

Recept. paleaceum. l'appus fubmarginatus. Cal. hemifpharicus, fquamis fubrqualibus. Flofculi radii plures quam quinque, oblongi.

$$
\text { II h } 2 \text { * Ralin }
$$




\section{STNGENESIA-POLYGAM. SUPERLLUA. \\ * Radio difcolore, five allo.}

43.ritima. I. ANTHEMIS foliis bipinnatifich acutis carnofis fubpiiofis, caule proftrato, calycibus fubtomentofis.

Anthemis maritima. Sp.Pl. 1259. Hulf. 374. With. 740. Hull. I\$8.

A. maritima annua odorata præcox, flore albo, caule purpurafcente. Mich. Gen. 33 .

Chamæmelum inaritimum latifolium ramofiflmum, flore albo. Dill. in Raii Syn. IS6.

C. maritimum odoratum precox, flore albo, caule purpurafcente. Till. Pij. 39. t. I 9. $f \cdot 3$.

C. maritimum. Dalech. Hift. I 394 .

C. marinum. Buah. Hift. v. 3. 122 . Angl. Sea Chamomile.

In maritimis petrofis. At Sunderland, Durham. Mr. Robfon.

Annua. Fl. Julio.

Caules proftrati, fpithamæi, foliofi, angulati, pilofo-incani, multifori. Folia feffilia, bipinnatifida, carnofa, fuibtùs pracinuè pilofa ; laciniis acuninatis, fuprà planis, fubtùs convexis. Flores folitarii, terminales, pedunculis nudis, apice incrafatis, villofis. Calyx hemifphrericus, arachnoidco-pilofus, fquamis lanceolatis, apice plumofo-laciniatis. Difcus aureus, planus. Flofculi radii albi, patentes, elliptico-oblongi, apice fubdontati. Semina margine membranacco, integro, coronata. Receptaculum planum, paleaceum; paleæ flofculis difci duplò lingiores, bafi lanceolatx, carinatæ. membranaceæ, fufcefcentes, apice fubclavat $x$, acuminatæ, flavæ.

Flores Tanacetum, folia Artemifiam rulgarcm redolent.

nobilis, 2. ANTHEAIS folis pinnato-rlccompofitis filiformibus acutis fubpilofis, paleis receptaculi fearions vix longitudine forculorum. Anthemis nobilis. SP. Il. 1260. HInlf. $27 \%$ It 
SYNGENESIA-POLYGAM. SUPERFLUA.90马

IVith. 739. Hull. 188. Sibth. 258. Woodv. Med. Bot. t. 103.

Chamæmelum odoratifinum repens flore fimplici. Rä̈ Syn. I 85 . Banto. Hift. v. 3. I I8.

C. romanum. Ger. em. 755 .

Sweet Camomile. Pet. H. Brit. t. 19.f. 10. Chamxinelum, flos fimplex. Pbarmac. Lond. Angl. Common Chamomile.

In pafcuis apricis glareofis.

In Cornwall very plentiful. Ruy. At Oatlands, Surrey. Mr. Woodward. Staffordhire; Mr. Pitt. With. On Hounflow heath in abundance, and in feveral parts of Norfolk.

Perennis. Fl. Augufto, Septembri.

Radix lignofa. Caules proftrati, fpithamæi, fubramofi, foliofi, villofi. Folia bipinnata, pilofa, foliolis filiformibus, acutis, integris, laciniatifve. Pedunculi terminales, folitarii, elongati, uniflori, nudi, ftriati, pubefcerites. Calyx pilofis, fquamis margine membranaceis. Difcus luteus, convexus, demùm conicus. Flofculi radii albi, patentes, clliptico-oblongi, tridentati, demùm defexi. Semina cbfoletè coronata. Receptaculum conico-convexum; paleæ lanceolatæ, fcariof muticæ, flofculos haud fuperantes.

Herba intensè amara, gratè aromatica. Variat radio multiplicato, pleno; interdùn verò radius planè deêt, monente Bobartio.

3. A N'THEMIS receptaculo conico; paleis lan-arvenfs. ceolatis acutis carinatis exfertis, foliis bipinnatifidis pilofis.

Anthemis arvenfis. Sp. Pl. 1261 . Hulls. 373. With. 737. Hull. 188. Relh. 323. Sibth. 259. Abbot. 186. Engl. Bot.t. 602. Chamxmclum inodorum. Dill. in Raii Syn. 385. White Ox-eye. Pet. H. Brit.t. 19.f. S. 


\section{Singl. Com Chamonile.}

In arvis et ruderatis, imprimis folo glarcofo. Abont London. B)ill. Walchamfiow. Mr. R. M. Forfler. In varions parts of Norfolk occationally. Mr. Cronse.

Anma, vil Bimmis. Fl. Junio, Julio.

Radix parva, tortuofa. Caulis ranufirtimus, erectus, firliofus, multiflorus, pilofo-incanus. Folia bipinnatifica, plana, pilofa, cinereo-virentia. P'edunculi nudi, clongati, terminales, uniflori, tomentofi. Calyx pilofus, fquamis apice fcariofis, nitidis, fufcis. Difcus lutens, convexus. Flofculi radii numerofi, alli, patentes, demim defexi, apice tridentati. Semina coronato-marginata. Receptaculum conicum ; palere flofculis lonriores, lanccolatæ, membranaccæ, carinatæ.

Hërba ferè inodura; flores fuavcolentes.

Colula. 4. ANTHEMIS receptaculo conico; palcis fetaceis, fominibus muticis, foliis bipinnatifidis glabriufculis.

Anthemis Cotula. Sp. Pl. I261. Ihudf. 373. Wilh.738. Full. I89. Relh.323. Sibih. 259. Abbot. I85. Curt. Lond. fafic. 5. t.6I.

Chanæmelum foutidum. Raii Syn. 18 j.

C. foctidum, five Cotula fotida. Bant. Eifl. ข. 3. 120.

Cotula fortida. Bmanf. Herb.v. 1. 255. Gir. em. 757 .

Stinking Camomile. Pet. H. Brit. t. 19. f. Is. Angl. Stinking Maywced or Chamomile.

In arvis vulgaris.

Annua. Fl. Junio, Julio.

Radix tortuofa. Caulis ramofiflinus, crectus, foliofus, multiforus, glaber. Folia bipinnatifida, plana, incifa, læxtè viridia, vix pilofa. Calyx pilofus, minùs fcariofus. Difcus 
Difcus aurens, convexus. Flofculi radii albi, tridentati, patentes, noctu deflexi. Semina obovata, fulcata, omninò mutica, interdùm tuberculato-fcabra. Receptaculum cylindraceo-conicum; paleæ omninò fetaceæ, flofculis breviores.

Herba, et pracipuè flores, ingrati odoris. Variat flore pleno. Dill.

* Radio concolore, five luteo.

5. ANTHEMIS foliis bipinnatifidis ferratis fubtùs tinatora. tomentofis, caule corymbofo erecto.

Anthemis tincloria. Sp. Pl. I 263 . Hutf. 374. Itith. 740. Hull. 189. Dickf. H. Sicc.fafc.

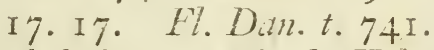

Buphthalmum. Mattb. Falgr.v. 2.260. Camer. Epii. 651. Trag. Tijt. $15^{2}$.

B. vulgare. Raï \$yn. IS 3 . Ger. em. 747.

Chamanelum chryfanthemon. Fuch. Hif. 26. Yellow Ox-eye. Pet. H. Brit.t. 19.f. 7 . Angl. Ox-eye Chamomile.

In petrofis et aprieis montolis, rariùs.

On a bank ncar the river Tees not far from Sogburn, Durham. Ray. Not now to be found there; Mr. Roufon. With. In Effex. Dickf. I1. Sici.

Perennis. Fl. Julio, Angufto.

Caulis ereetus, fefquipedalis, corymbofo-ramofus, foliofus, angulatus, tomentofus. Folia bipinnatifida, ferrato-incifia, plana, fubtus tomentofa, laciniismucronatis. Pedunculi terminales, folitarii, elongati, uniffori, lanati. Calyx ferè A. maritimxe. Flores omninò anrei, fpeciofi. Difcus hemifphericus. Flofculi radii mumerofi, patentes, apice integri, bifidi vel trifidi. Semina tetragona, coronâ membranacci, integrâ. Receptaculum convexiufculum; palex longitudine fiofculorum, bafi lato-lanccolatx, carinate, margine fcariofe, apice fubulatæ, flavefcentes. 
377. ACHILLEA. G. P\% 435. Jilf. 186. Garth.t. 168.

Recept. paleaccum. P'appus nullus. Cal. ovatus, imbricatus, inaqualis. Flofculi radii quinque ad decem, obcordato-fubrotundi.

Ptarmica. I. ACHILLEA foliis lanceolatis acuminatis argutè ferratis.

Achillea Ptarmica. Sp. Pl. I266. Hudf. 375. With. 741. Hull. 189. Relh. 324. Sibth. 260. Allbot. 187. Curt. Lond. fafc. 5. t. 60. F\% Dan.t.643:

Ptarmica. Raii Syn.183. Ger. em. 606. Matth. Valgr. v. 1. 535. Camer. Efit. 354. Snecz-wort. Pet. H. Brit. t. 19.f. 3 . Angl. Sneeze-wort Yarrow. Goofe-tongue.

In nemorofis et ad fepes humidas.

Perennis. Fl. Julio, Augufto.

Radix maximc̀ repens. Caules erecti, bipedales, foliofi, glabri, apice ccrymbofi. Folia fimplicia, lanceolatolincaria, acuta, argutè et concinnè ferrata, utrinque glabra. Flores pedunculati, terminales, albi. Calyx fubhemifphæricus, pilofus, imbricatus. Difcus planus. Flofculi radii 8 vel io, latè obcordati, plani, ap,ice trifidi. Semina mutica, compreffo-alata. Receptaculum planum; palex longitudine flofculorum, lineari-lanceolatæ, obtufæ, apice villofie.

Variat flore pleno.

Millefo-2. ACTILLEA folis bipinnatificlis pilofis: lacilium. nis linearibus dentatis mucronatis, caulibus fulcatis.

Achillca Millefolium. Sp. Jl. 1267. Hudf. 374. Ifith. 742. Hhill. 189. Relh. 324. Sibth. 259. Aliot. i 86. Curt. Loml. fafe.6. t. 6r. Mart. Fl. Rufl. 
Fl. Ruft. t. I23. Wosdv. Med. Bot. t. 64. Fl. Dan. t. 737 .

Millefolium vulgare. Raii Syn. is 3 .

M. terreftre vulgare. Ger.em. 1072.

Stratiotes millefolia. Fuch. Hif. 727 .

Yarrow or Nofe-bleed. Pet. H. Brit.t. 19.f. 4: Angl. Common Yarrow. Milfoil.

Pn pratis et pafcuis vulgaris.

Perennis. Fl. Junio-Augufto.

Radix repens, farmentofa. Caules pedales, erecti, angulati, fulcati, pilofi, foliofi, corymbofi, multiflori. Folia bipinnatifida, laciniis cuneato-linearibus, numerofiffinis, incifis, mucronatis, fubtùs magìs minùfve pilofis. Flores congefti, albi vel rubicundi, parvi. Calyx ovatus, fquamis apice pilofis. Difcus convexus. Flofculi radii circitèr quinque, rotundati, tridentati. Semina mutica, undique fubalata. Receptaculum pla. num; palex foliolis calycinis conformes.

\section{POLYGAMIA FRUSTRANEA.}

378. CENTAUREA. G. Pl. 442 .

Jacea. Juff. 173 .

Cyanus. Juer. 174. Gortn.t.16r. Seridia. Juff. I 73 .

Calcitrapa. JuJf: I73. Gertn. t. 163.

Recept. fetofum. Pappus fimplex. Cor. radii infundibuliformes, longiores, irregulares. 


\section{SYNGENESIA-POLYGAM. FRUSTRANEA.}

\section{* Cal. Syuamis apice ciliatis.}

x. CENTAUREA fouamis calycinis oratis : cilis capillaribua crectis, foliis inferioribus lyratoangulatis; funerioribus ovatis.

Centaurcat nigra. Sp. P\%. I 28S. Ihudf. 375. With. i+3. Hull. is9. Pelh. 325. Silih. 260. Althot. 187. Engl. Bot.t.278. Niart. H\%. Ruft.t. I 30. H\%. Dan. t. 996.

Jacea 11. I84. Hall. Hift. v. I. 80.

J. nigra. haii Syn. Ig8. Ger.em.727?

J. cum fquamis cilii inftar pilofis. Baut. Itift. ข. $3 \cdot 23$.

Common and Jagged Knapweed. Pet. II. Brit. t. $22 . f .8,9$.

6. Floribus radiatis. Raï Syn. i99. ITudf. 376. var. y. Wil. 744. var. 2. Sibth. $26 \mathrm{r}$.

\%. Jacea nigra minor tomentofa laciniata. Dill. in Raaii Syr. 199. Nondum vidi. Angl. Black, or leffer, Knapweed.

In pafeuis et ad rias ubique.

B. Common in the went of England. Ray. With. Near Oxford. Dill. Sibth. $\gamma$. Four miles on this fide Malton in the road to York, in ftony ground near a rirulct. Dr. Richardfon.

Perennis. Fl. Junio-Augufto.

Radix lignofa, fubrepens. Herba rigida, dura, fcabra. Caulis ramofus, angulatus. Folia inferiora pracipuè lyrato-angulata vel dentata; fuperiora ovata, frepius integra. Hlores terminales, folitarii, feffiles, purpurei. Calyx globofus; fquame nigræ, ovatæ, ciliis erectis, fetaceis, fufcis, interiores unguculatæ. Flofculi onmes plerumque aquales, regulares, hermaphroditici ct fertiles; radii interdim, quandoque etiam omnes difci, monente Raio, radiantes, ampliati, fteriles. Semina pilufa. Pappus brevis, multifquamofus. 
2. CENTAUREA fquamis calycinis ferratis, fo-Cyanus. lis linearibus in tatis.

Contaurea Cyanus. Sp.Pl. I289. Hudf.375. Tribl. 7\%2. Ihull. 189. Relh. 325. Sibih. 260. Alblot. I87. Curt. Lond. fafc. 6. t. 62. Mart. Fl. Rujt. t. II I. Ringl. Bot. t. 2\%t. Fl. Dan. t. 993 .

Cyanus. Raii S:n. I98. Baub. Hif.v. 3.2 I.

C. vulgaris. Ger. en. 732 .

C. minor. Matth. Talgr. v. I. 463. Camer. Epit. 289 .

Papaver Heracleum. Column. Pbytob. 92. Angl. Coin Blue-bottle.

Inter fegetes vulgaris.

Anmua. Fl. Julio, Augunto.

Radix fibrofa, nigra. Caulis erectus, ramofinimus, foliofus, fublanatus, multifiorus. Folia lineari-lanceolata, acuminata, fublanata; inferiora pinnatilida ant dentata; fuperiora integerrima. Flores terminales, folitarii, pedunculati, flofculis difci purpurafcentibus, regularibus, antheris nigris; radii infundibuliformibus, cyaneis, neutris. Calyx ovatus, fquamis lanceolatis, ferratis. Semina lævia, pappo polyphyllo, inæquali, fcabro, rubicundo.

3. CEINTAUREA fquamis calycinis ciliatis ova-Scabiofa. tis, folis pionatifidis : laciniis lanceolatis fubdentatis pilofufculis.

Contanea feabiola. Sp. Pl. I29I. Hudf. 3\%6. With. 744. Hu7l. I8g. Relh. 326. Sihth. 25x. Abbot. 188 . Engl. Bot. t. 56 .

Jacea major. Raï Syn. Ig8. Ger. em.72\%.

Matfollon. 'Pet. H. Brit. t. 2a.f. $\%$. Angl. Greater Knapweed.

In arvis, marginiburve agrorum, et ad vias. 


\section{SWNGENESIA-POLYGAN.FRUSTRANEA.}

Perennis. Fl. Julio, Augunto.

Cantis bi- rel tri-pedalis, erectus, ramofus, fulcatus. Folia pimnatificla, utrinque fubpilofa, fiturati viridia, lacinis lanceolatis, fepius dentatis. Flores terminales, folitarii, pedunculati, nagni, fpeciofi, purpurei, flofculis radii clongatis, lacinis linearibus, anguftis. Pappus iniequalis, fcabriufculus.

\section{* Cal. Squamis palmato-jpirojis.}

Ifnardi. 4. CENTAUREA fquamis calycinis palmato-rpinofis, foliis ly rato-dentatis fcabriufculis fubamplexicaulibus, floribus fefflibus terminalibus.

Centaurca Ifnardi. Sp. Pl. I 295. Dickf. H. Sic. fac $\therefore$ I6. IO.

Calcitrapoides procumbens, Cichorii folio, flore purpurafcente. Ifuard. in Aa. Paris. ann. i7 I9. ed. gemman. 378 . t. Ig.

Angl. Jerfey Star-thiftle.

In pratis auftralioribus.

In Jerfey. DickJ. H. Sicc.

Perennis. Fl. Julio, Augufto.

Caules procumbentes, ramofi, foliofi, anguiati, fulcati, glabriufculi. Folia lyrato-pinnatifida, margine imprimis fabra, lobis fpinulofis; fuperiora fæpiùs integra, fublentata. Flores terminales, folitarii, feftiles, dilutì purpurei, raciantes. Calyx ovatus, glaber, fquanis apice palmato-quinquefidis, patentibus, Ipinofis.

Toto ccelo a C. pullatâ diftincta eft.

*** Spinis calycinis compofitis.

calcitrapa.5. CENTAUREA floribus feffilibus, calycibus iuplicato-fpinofis, foliis pinnatifidis dentatis, canle divaricato-patente pilofo.

Contaurea Calcitrapa. Sp. Pl. I297. Hudf. 376. 
With.745. Hull. 189. Relh.326. Ablot. I88. Engl. Bot. t. I 25.

Carduus fiellatus. Raii Syn. I 96 . Ger.em. I 166. C. ftellatus, five Calcitrapa. Baub. Hift.c.3.89. Hippophaftum. Column. Plytob. 107. Polyacantba. Cord. Hift. 91. 2. Star-thiftle. Pet.H. Brit.t.27.f. II. Angl. Common Star-thiftle.

In ruderatis glarcofis, vel arenofis maritimis.

Annua. Fl. Julio, Augufto.

Caulis humilis, ramofiffimus, divaricato-patens, foliofus, fulcatus, pilofus. Folia fparfa, inæqualitèr pinnatifida, dentata, latitudine varia, denubus fpinulofis, fub floribus aggregata. Flores laterales, feffiles, folitarii, rofei. Calyx ovatus, fquamarum fpinis divaricatis, flavefcentibus, glabratis, ipfo calyce triplò longioribus, bafi palmato-fpinulofis. Flofculi radii difco vix longiores, fubregulares. Semina obovata, variegata, nitida, mutica.

6. CENTAUREA floribus folitariis terminalibus, folfitialis, calycibus duplicato-fpinofis, foliis decurrentibus inermibus lanceolatis; radicalibus lyratis.

Centaurca folftitialis. Sp. Pl. 1 297. Hudf. 377.

With. 745. Hull. 189. Tr. of Limn. Soc. v. 2. 236. Engl. Bot. t. 243.

Carduus ftcllatus luteus, foliis Cyani. Raii Syn. r 96.

C. folftitialis. Ger. em. I 66 .

Spina folftitialis. Bauh. Hift. v. 3. 9r.

S. folftitialis mitior apula. Column. Ecpler. v. I. 3 I.

Yellow Thifte. Pet. H. Brit. t. 2 I.f. 12. Angl. St. Barnaby's Star-thittle.

In arvis st ad fepes rariùs. 
By the hedges not far from Cirencefter, Glousefferthire, Bobart. Near Northflect, Kent. Hudf. At Arminghall near Norwich. Mi. Croves.

Annza. FI. Julio, Augufto.

Herba lanato-incana, fubvifcida, inteusè amara. Caulis ferè bipedalis, ramofus, alatus, foliofus, multiforus. Folia radicalia lyrato-pinnatifida, acuta, denticulata; caulina lancenlata, integerrima, acuminata, decurrentia. Flores terminales, folitarii, aurei, vix radiati. Calyx ovatus; fquamis interioribus apice fcariofis; mediis fpinofis, fpinis flavis, fubulatis, divaricatis, calyce duplò longioribus, bafi palınato-fpinulofis; extcrioribus palmato-fpinulofis, fpinis fubæqualibus.

END OF THE SECOND VOLUME.

Printed by J. Davis, Chancery Lase. 


\section{$I N D E X \quad G E N E R U M$ \\ VOL. I. ET II.}

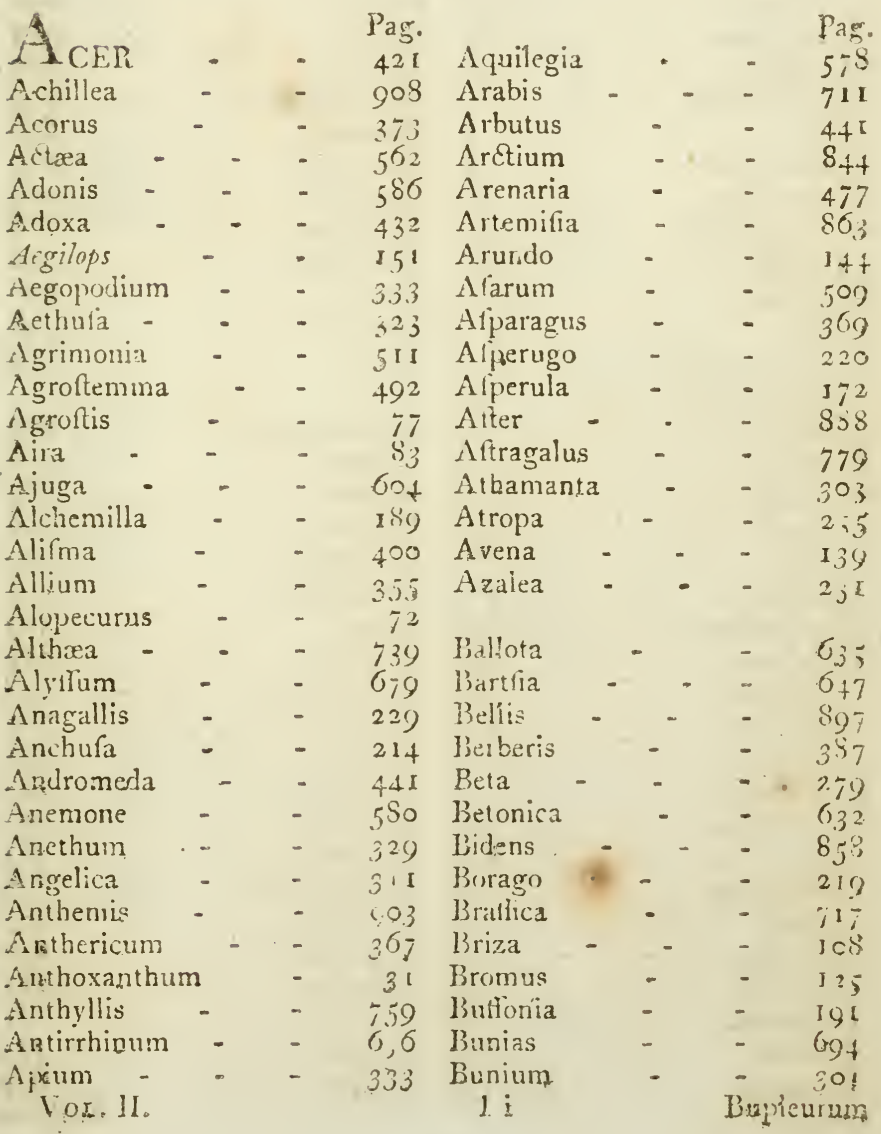


INDEX GENERUM VOL. I. ET II.

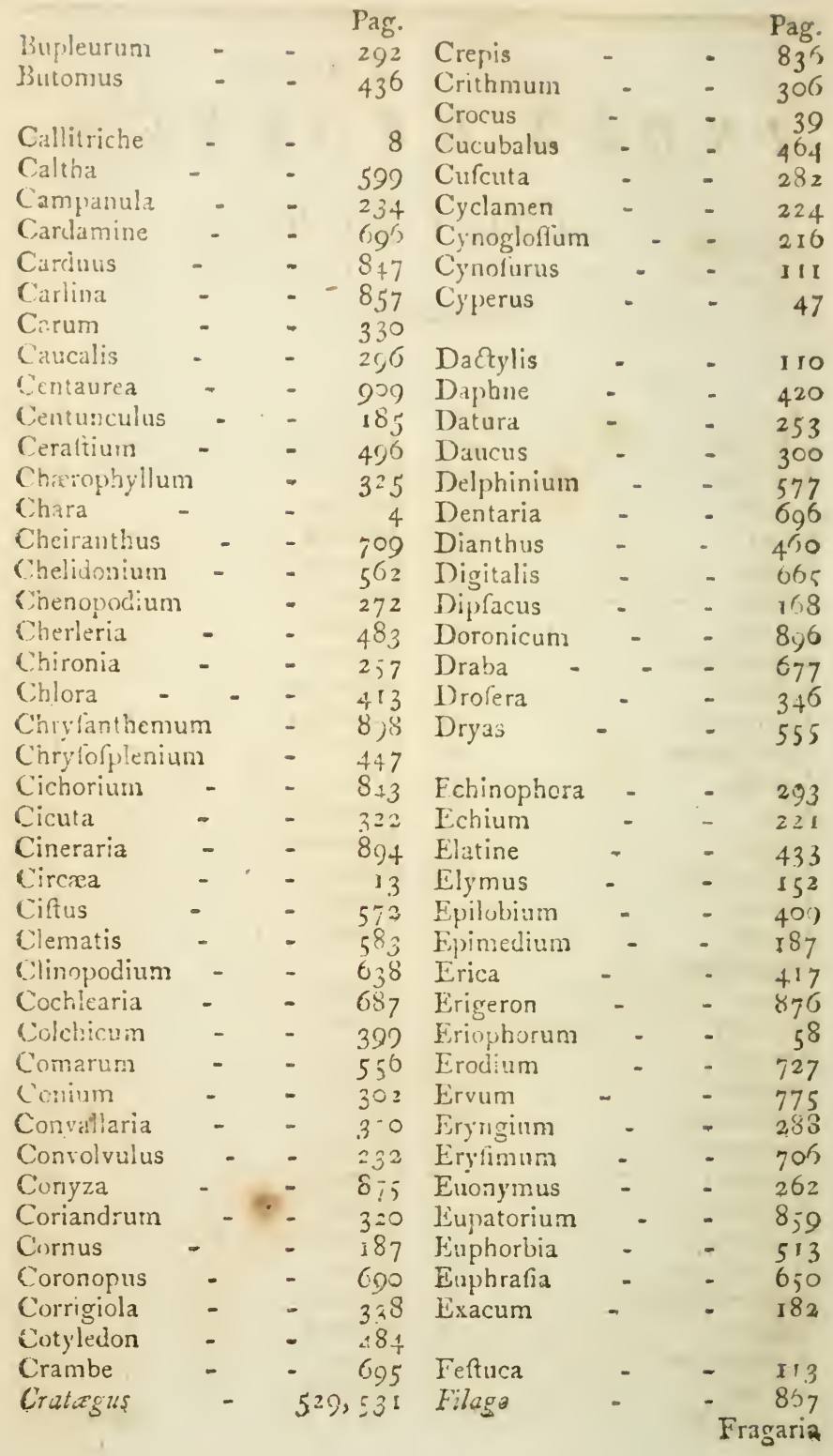


INDEX GENERUM VOL. I. ET II.

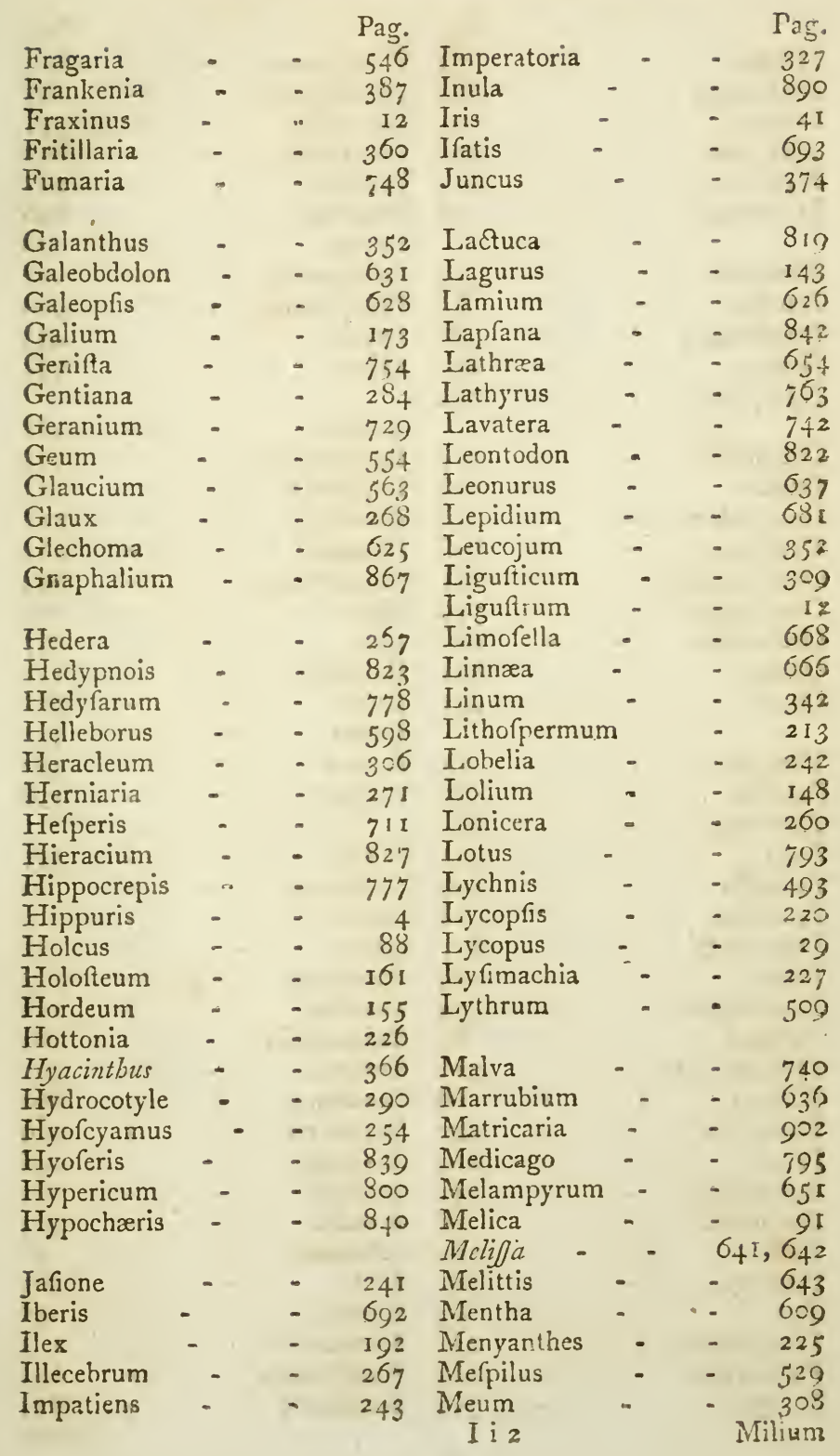


INDEX GENERUM VOL. I. ET II.

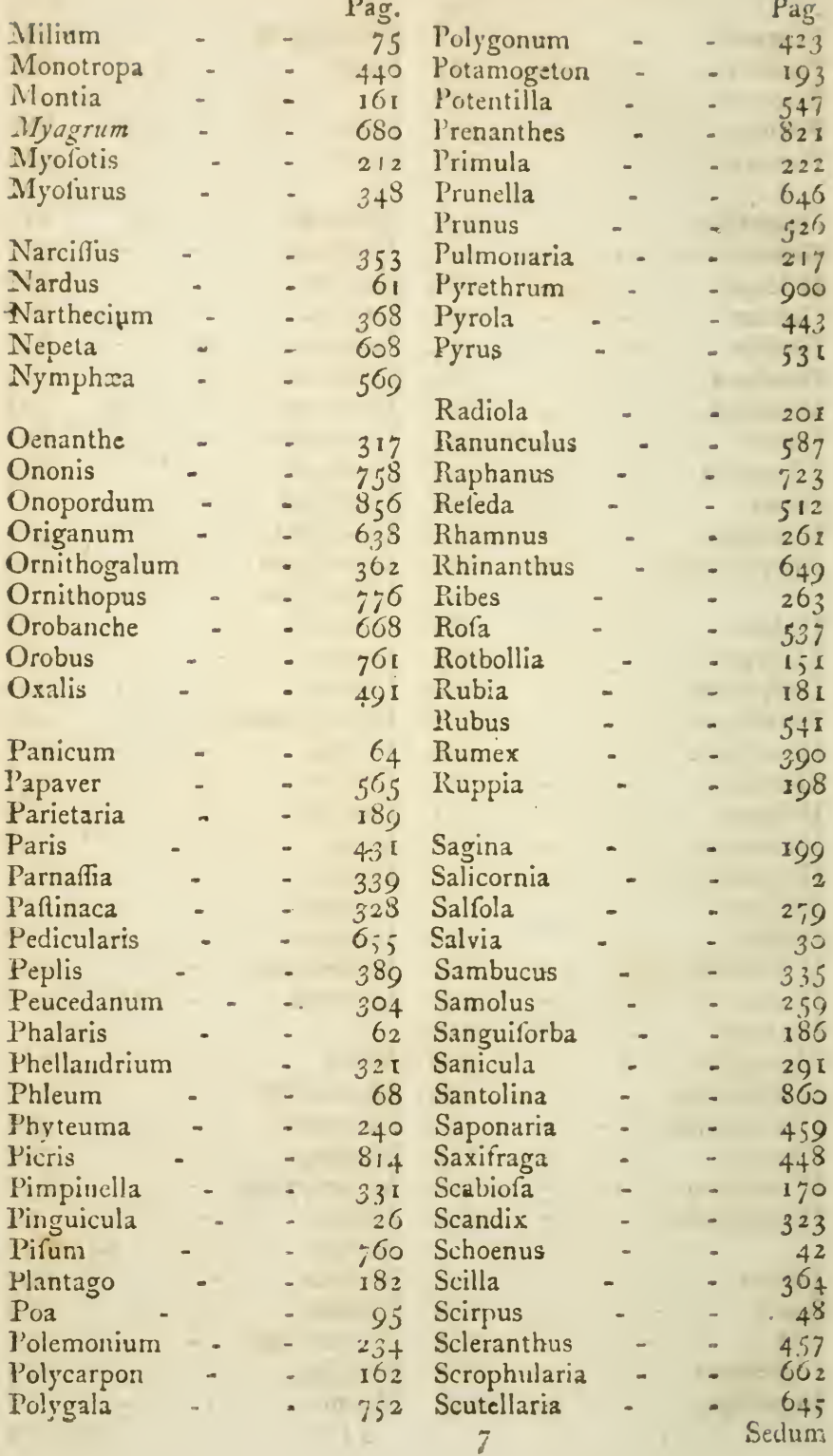


INDEX GENERUM YOL. I. LT II.

\begin{tabular}{|c|c|c|c|c|c|c|c|}
\hline Sedum & - & - & Pag. & Thalictrum & - & - & Pag. \\
\hline Selinum & - & - & $\begin{array}{l}407 \\
303\end{array}$ & Thefiurn & . & - & 26 \\
\hline Sempervivum & - & - & 522 & Thlafpi & - & - & 583 \\
\hline Senecio & - & - & 83 I & Thymus & - & - & 639 \\
\hline Serratula & - & - & $8+5$ & Tilia & - & - & 578 \\
\hline Sefleria & - & - & 93 & Tillaa & - & - & $2<1$ \\
\hline Sherardia & - & - & 171 & Totieldia & - & - & 397 \\
\hline Sibbaldia & - & - & $3 \div 5$ & Tordylium & - & - & $29 \div$ \\
\hline Sibthorpia & - & - & 667 & Tormentilla & - & - & 352 \\
\hline Silene & - & - & 463 & T'ragopogos & - & - & 812 \\
\hline Sinapis & - & - & 721 & Trientalis & - & - & 406 \\
\hline Sifon & - & - & 315 & Trifolium & - & - & $78:$ \\
\hline Sifymbriun & - & - & 700 & Triglochin & - & - & 398 \\
\hline Sium & - & - & $3: 2$ & Triticum & - & - & 157 \\
\hline Smyrnium & - & - & 328 & Trollius & - & - & $50 \%$ \\
\hline Sulanum & - & - & 256 & Tulipa & - & - & 3 \\
\hline Solidago & - & - & 889 & Turritis & - & - & $\because 15$ \\
\hline Sonchus & - & - & 815 & Tutilago & - & - & $8-8$ \\
\hline Surbus & - & - & 534 & & & & \\
\hline Spartium & - & - & 753 & Ulex & - & $\therefore$ & -350 \\
\hline Spergula & - & - & $5=2$ & Ulmus & - & :- & $\mathrm{S}_{1}$ \\
\hline Spirza & - & - & 535 & Utricularia & - & - & 28 \\
\hline Stachys & - & - & 632 & & & & \\
\hline Staphylea & - & - & 337 & Vaccinium & - & - & $I_{4}$ \\
\hline Statice & - & - & 340 & Valeriana & - & - & 37 \\
\hline Stellaria & - & - & $4: 2$ & Vella & - & - & $6-5$ \\
\hline Stipa & - & - & 138 & Verbafcum & - & - & 249 \\
\hline Stratiotes & - & - & 579 & Verbena & - & - & 508 \\
\hline Subularia & - & - & $6 ; 6$ & Veronica & - & - & 15 \\
\hline Swertia & - & - & 284 & V'iburnum & - & - & 3.34 \\
\hline \multirow[t]{2}{*}{ Symphytum } & - & - & 218 & Vicia & - & - & \\
\hline & & & & Vinca & - & - & $0 y$ \\
\hline Tamarix & - & - & 338 & Viola & - & - & \\
\hline Tanacetum & - & - & S02 & & & & \\
\hline Teucrium & - & - & 606 & Zoftera & $=$ & - & $\because$ \\
\hline
\end{tabular}




\section{ERRATA Eq CORRIGENDA.}

Pug. I 1 , ad calcem inferatur Bromus diandrus.

13 , lin. 22 , cedens, lege cedentia.

1.5, $-27,274$ lege 282 .

33 , ad calcem inferatur $\mathcal{F u n c u s ~ c o n g l o m e r a t u s . ~}$

34 , lin, ult. dele apetalo.

I66, lin. ult. adde Cufcute.

350 , lin. ult. adde Polygona.

392 , lin. 7 , lege Surlingham.

455 , - 8, fucculens lege fuccofa.

$574,-4$, exitipulatus lege ftipulatus.

$809,-8$, lege parallela, apice planiufiula; den $\int \alpha_{0}$

810, lin. penult prefigatur num. 363.

I'rinted by J. Davis, Chancery-Lane. 

mith, James Edward/Flora britannica

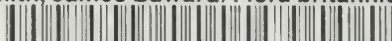


Y 100

(1) 5

10.02010

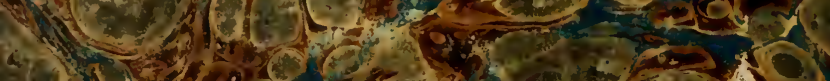

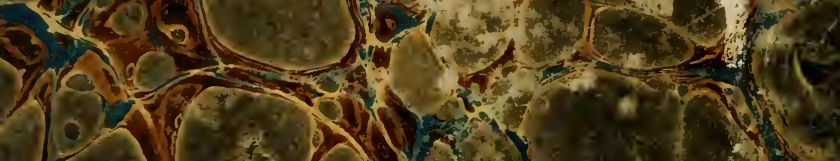

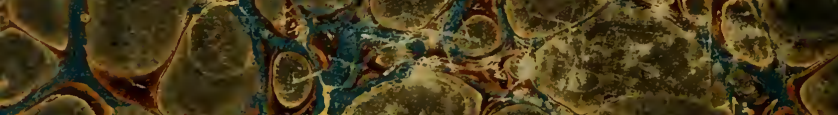

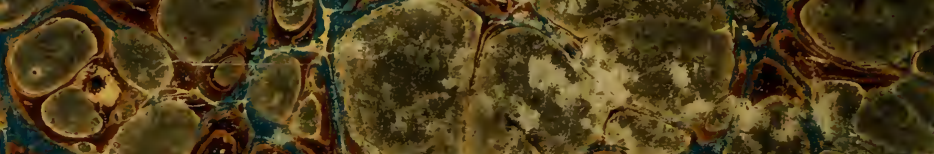

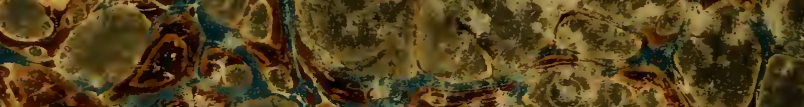

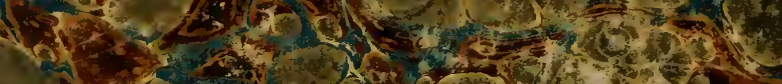

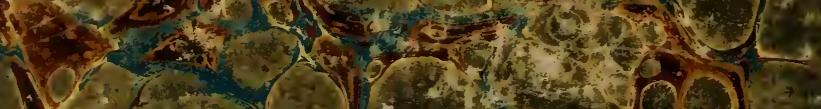

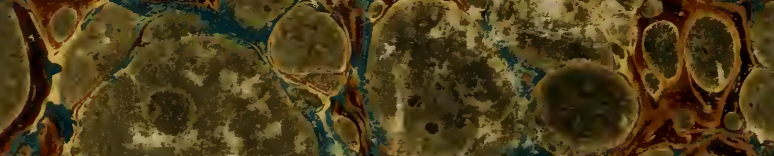

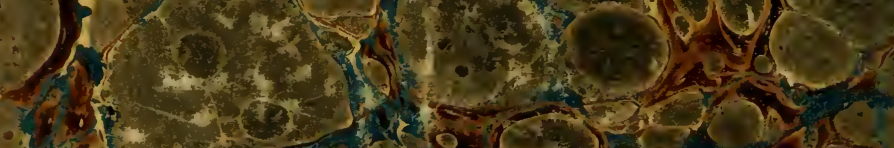

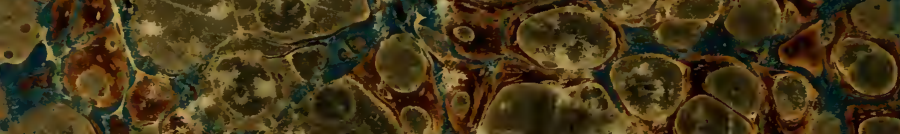

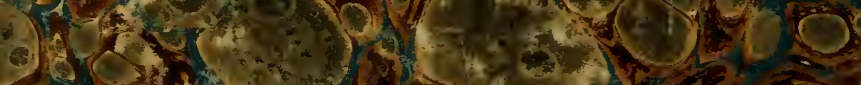

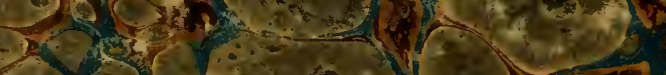

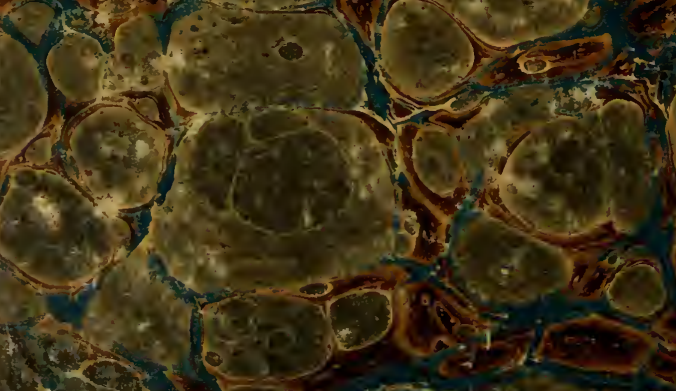

